
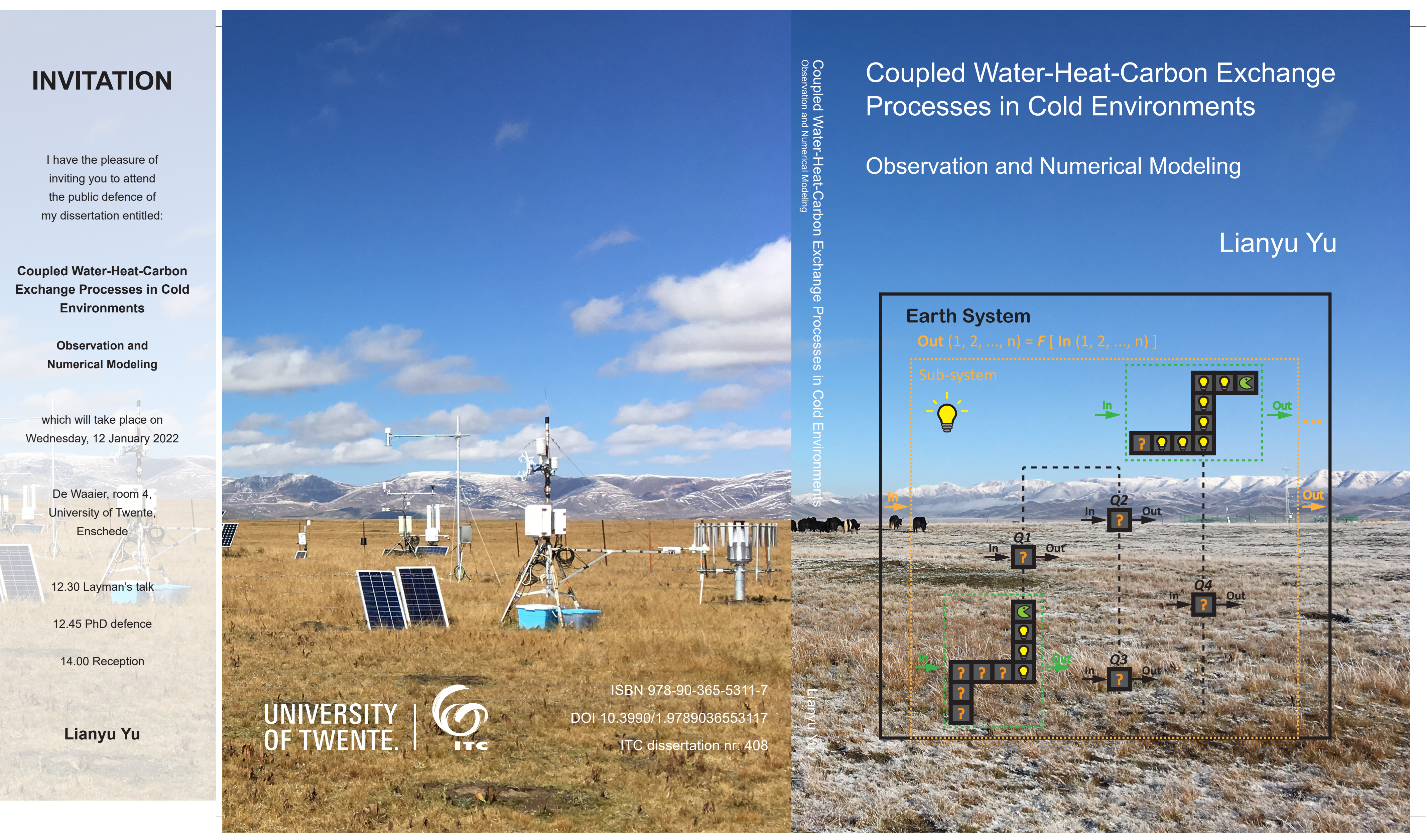
COUPLED WATER-HEAT-CARBON EXCHANGE PROCESSES IN COLD ENVIRONMENTS:

OBSERVATION AND NUMERICAL MODELING

Lianyu Yu 



\title{
COUPLED WATER-HEAT-CARBON EXCHANGE PROCESSES IN COLD ENVIRONMENTS: OBSERVATION AND NUMERICAL MODELING
}

\author{
DISSERTATION
}

to obtain

the degree of doctor at the University of Twente, on the authority of the rector magnificus, prof.dr.ir. A. Veldkamp

on account of the decision of the Doctorate Board, to be publicly defended

on Wednesday 12 January 2022 at 12.45 hrs

By

Lianyu Yu

born on 8 February 1988

in Hebei, China 
This thesis has been approved by:

Prof. dr. Z. Su, supervisor

Dr. Y. Zeng, co-supervisor

ITC dissertation number 408

ITC, P.O. Box 217, 7500 AE Enschede, The Netherlands

ISBN 978-90-365-5311-7

DOI $10.3990 / 1.9789036553117$

Cover designed by Lianyu Yu and J ob Duim

Printed by CTRL-P Hengelo

Copyright (C) 2022 by Lianyu Yu

All rights reserved. No parts of this thesis may be reproduced, stored in a retrieval system or transmitted in any form or by any means without permission of the author. Alle rechten voorbehouden. Niets uit deze uitgave mag worden vermenigvuldigd, in enige vorm of op enige wijze, zonder voorafgaande schriftelijke toestemming van de auteur.

\section{UNIVERSITY OF TWENTE.}

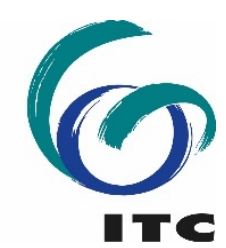


Graduation committee:

\section{Chairman/ Secretary}

Prof.dr. F.D. van der Meer

\section{Supervisor}

Prof.dr. Z. Su

University of Twente

\section{Co-supervisor}

Dr. Y. Zeng

University of Twente

\section{Members}

Dr. M.W. Lubczynski

Dr.ir. C.M.M. Mannaerts

Prof.dr.ir. A. Veldkamp

Prof.dr. H. Cai

Prof.dr. S. Kollet

University of Twente

University of Twente

University of Twente

Northwest A\&F University

Forschungszentrum J uelich \&

University of Bonn

Prof.dr. D. Chen

University of Gothenburg 

To my family 



\section{Acknowledgments}

I would like to take the 'Marathon' as the metaphor to describe my $\mathrm{PhD}$ journey. I'd say the experience 'on the road' is valuable and unforgettable to me. People might say that the starting point, which way you will select to go and where you start, is very important. Yes, I definitely agree. However, I want to leave most of my words to the running process here. Trial and error, making adjustments and modifications, pains and gains are all the necessary and beautiful (complex mood to say this word) scenery along the journey. You have to experience and learn how to enjoy and overcome them. Luckily, I am not lonely. Many people are to be appreciated here.

First and foremost, I would like to express my sincere thanks to my promoter Prof. Dr. Bob $\mathrm{Su}$, who initializes this running project and provides me with the message "there is a very interesting research topic I would like you to contribute something!". Your critical thinking, rich experience, continuous support and warming encouraging words, “Enjoy the journey! Cherish the person! Good health!”, like the lighthouse, inspire me to keep on track and stand up from the failures and then move forward.

I am deeply grateful to my daily supervisor Dr. Yijian Zeng. He is enthusiastic and full of passion in research and cheers me up when I am depressed. I felt revived with full energy after discussions with Yijian. He can always point out the key points of my problems and keep me along with the research line. There are lots of valuable memory, e.g., good and joyful fieldwork experience, and many pleasant life episodes shared with Yijian and his lovely family Rong and Gaoqi. Pains are relieved and gains are achieved here from Dr. Yijian. He provided me with many good chances and opportunities and encouraged me to be more confident. I really appreciate and cherish Yijian's supervision and moreover the friendship.

I am also indebted to Prof. Huanjie Cai, my domestic advisor, who initialized my very starting research journey. His modesty, rigidity and passion on research affect me most and help to form the base of my research attitude.

I would like to thank Prof. Bob Su and Chris for the support during the 'special period', which largely eased my financial pressure.

I would like to thank our secretarial support from Tina, Anke, Lindy, Ceciel, who made my studying in ITC easy and happy.

I am grateful to our ITC colleagues, Maciek for hosting the groundwater modelling course, Christiaan van der Tol for organizing the SCOPE course, Rogier for teaching me how to operate the Lab equipment and helpful discussions. I learned a lot from your detailed and dedicated presentation and illustration. 
I would like to thank our former colleague of ITC when it was located in Delft, Jean Roy, for contributing lots of dedicated effort and valuable suggestions and comments in terms of my field and lab experiment. We together also had the chance to listen to the sound of the Yellow River (Mother River of China), cycle along the Yellow River, and walk at the Yantan Park in LanZhou city. Big thanks, Jean, you made my PhD journey colorful and enjoyable.

I would like to thank our fieldwork and laboratory supportive staffs, Prof. Wen Jun, Wang Xin, Wang Zuoliang, Murat, Caroline, Sip Jan, Rindert, UTwente group, drivers from NIEER and ITP, Mr. Fan and Mr. Xue. I much appreciate your dedicated effort and work in helping to provide and produce the fieldwork and lab related technique and facilities. My fieldwork and lab experiment cannot be so smooth without your generous help. Specially, I would like to thank Prof. Wen Jun, Wang Xin, Wang Zuoliang, and $\mathrm{Xu}$ Min, who helped to arrange my accommodation and the delicious meals during my stay in LanZhou city.

I would like to thank Mr. Ji, Li, Chen, and Mrs. Tian from the Gan Su company, who helped to drill the groundwater monitoring well in Maqu. And a thank you to the Tibetan herder, who agreed to let us drill such a groundwater well in his grassland, which is usually seen as the golden land by the Tibetan herders and cannot be destructed. The help from the driver Mr. Fang, and other friendly people is also appreciated.

My sincere thanks also go to Prof. Bob Su, Yijian Zeng, Qian Hui, Mengna Li, Zhenyu $\mathrm{Li}$, and his Groundwater Exploration group, for coordinating and conducting the ERT and MRS field monitoring work in Maqu, which is the first time over this area. I would like to thank all the kind and friendly people we met in Maqu. They made this field campaign not only for the science but also for enjoying another fresh and interesting living mode.

I would like to thank my ITC colleagues and friends, Xuelong, Donghai, Qiang Wang, Shaoning, Binbin, Peiqi and Jing Liu, Xiaolong and Yuan Xu, Junping, Zhao Hong and Bai Wen, Chengliang, Ruosha, Zhang Pei, Mengna, Jinbang, Yunfei, Samuel, Chandra, Jan, Harm-Jan, Egor, Sammy, Donald, Bas, Kingsley, Megan, Novi, Cesar, Bagher and Arabi. Thank you very much for sharing your experience and knowledge in the personal contacts, coffee break talks and WPW workshops, you made the working place warm and pleasant.

My thanks also go to the visiting scholars, Profs. and Drs. Jianrong Wang, Min Xu, Yongming Du, Kunrong Lai, Jing Zhang, Dan Meng, Feng Zhao, Guowang Jin, Yongmin Yang, Yam Dhital. Many activities and joy were shared with you. I felt lucky and grateful to meet you guys in ITC, which is such a lovely studying environment. 
I would like to thank my Chinese friends, Shihao, Junjie, Yihua, Wenchao, who contacted me regularly and provided me with their selfless help.

Last but not least, my special thanks go to my beloved family (my parents, my dear La, my brother and sister and their family). Nothing can be accomplished without your support. Great thanks for your accompany when I felt frustrated and stressed. Most of my pains were relaxed by your encouraging words and your consistent support. I would like to thank my dear La Zhuo, for your continuous encouragement and support. I thought the right time the right place to say the right words is important. Now I find you are the most important.

Given all the help and all the 'beautiful scenery' along my $\mathrm{PhD}$ journey, I am finally reaching the point and ready to tell the important message, which we want to convey to you.

Lianyu Yu

September 2021

Enschede, the Netherlands 


\section{Table of Contents}

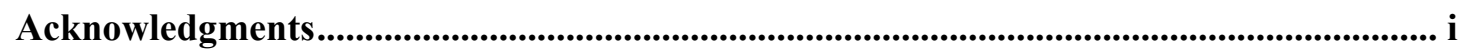

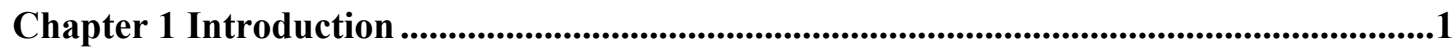

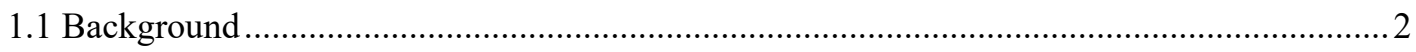

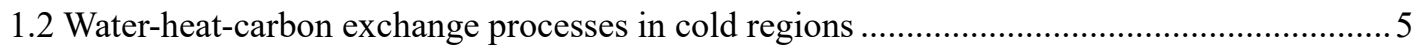

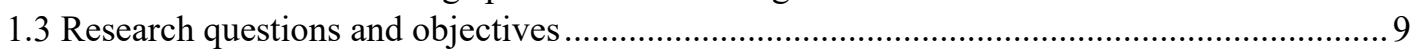

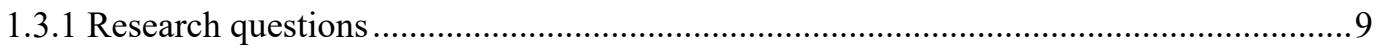

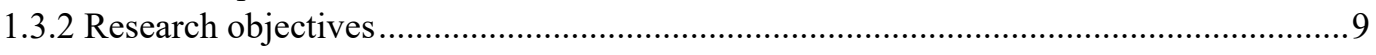

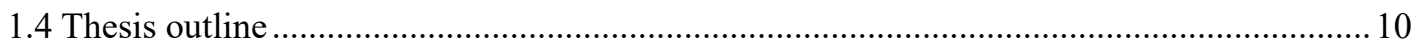

Chapter 2 Maqu observatory and in situ measurements................................................13

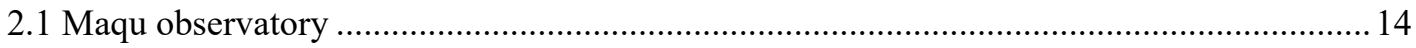

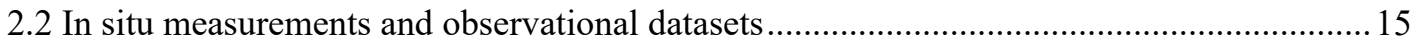

2.2.1 Hydro-meteorological variables and hydro-geological \& hydro-geophysical survey....15

2.2.2 Vegetation and land surface carbon fluxes ................................................................ 18

Chapter 3 Liquid-Vapor-Air Flow in the Frozen soil . . ...........................................................21

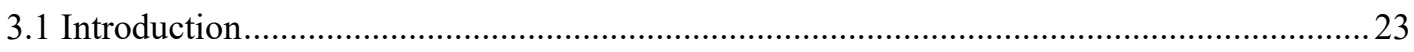

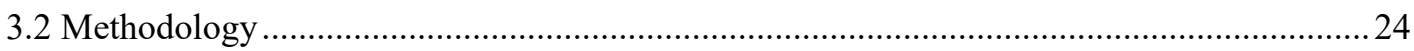

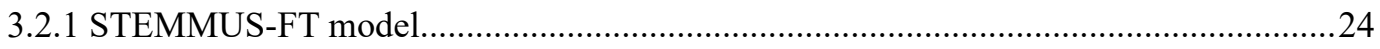

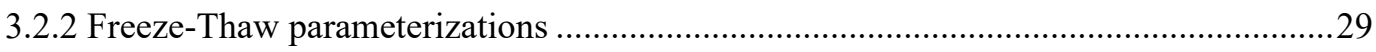

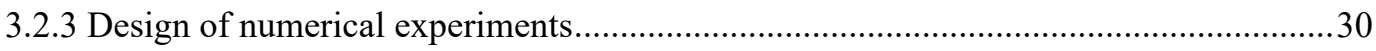

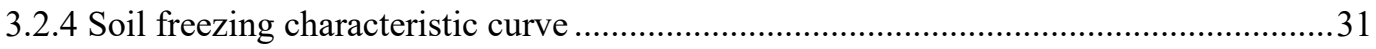

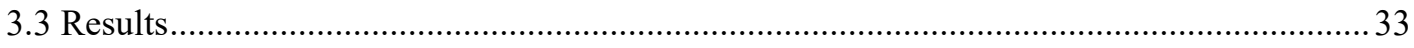

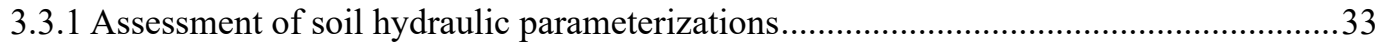

3.3.2 Assessment of parameterizations of soil thermal conductivity ………….........................37

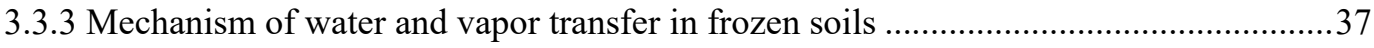

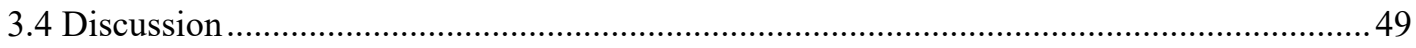

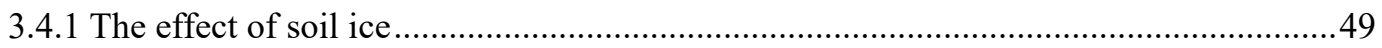

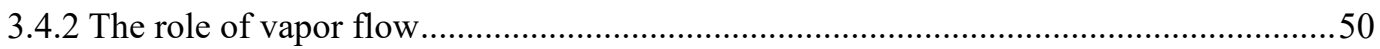

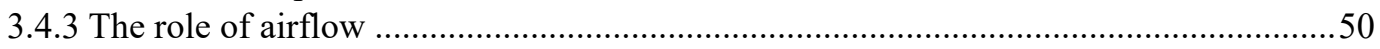

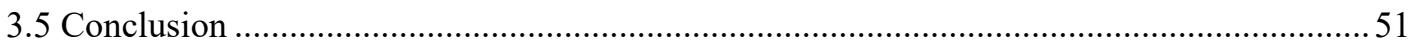

Chapter 4 Understanding the mass, momentum, and energy transfer in frozen soils . ..53

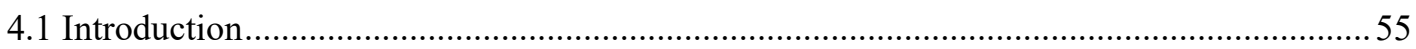

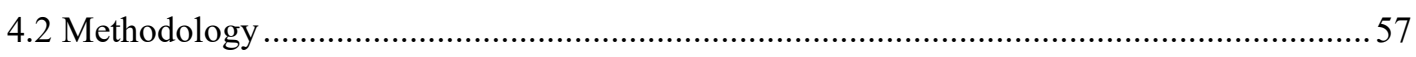

4.2.1 Mass and energy transport in unsaturated soils .......................................................5

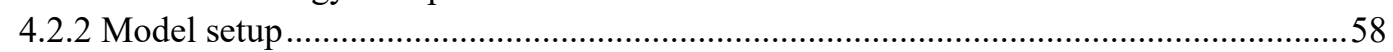

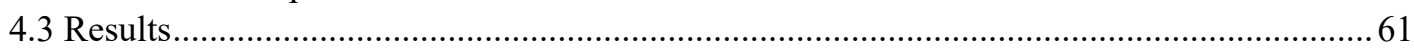

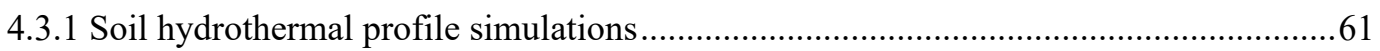

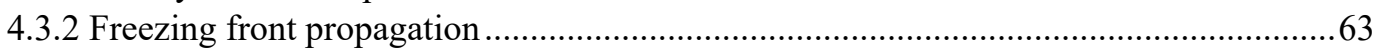

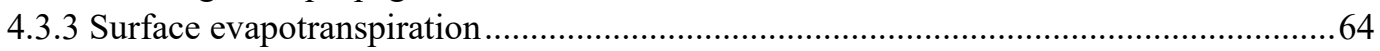

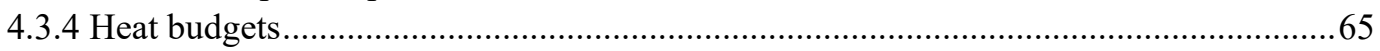

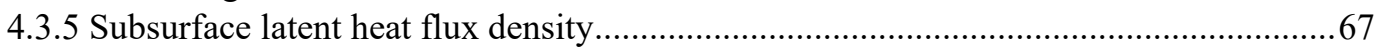

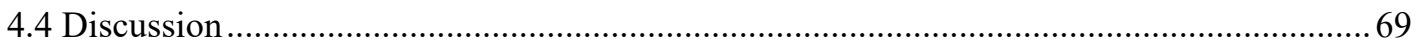

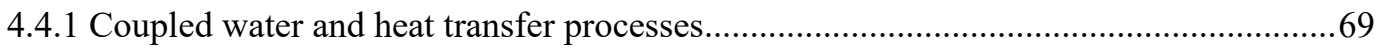

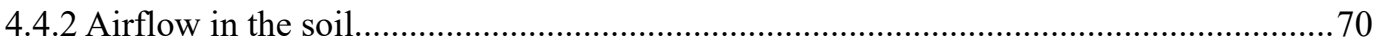

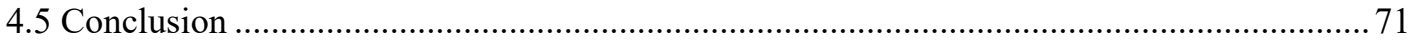


Chapter 5 STEMMUS-UEB v1.0.0: integrated modeling of snowpack and soil water and energy transfer with three complexity levels of soil physical processes. . ..........................73

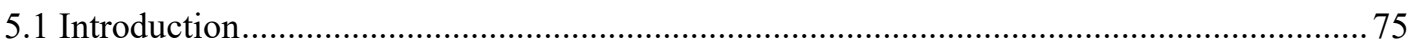

5.2 Description of coupled soil-snow modeling framework and model setup ..........................79

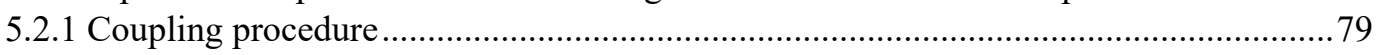

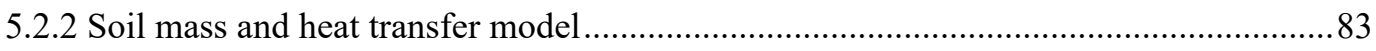

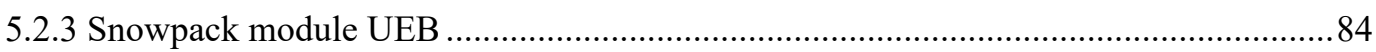

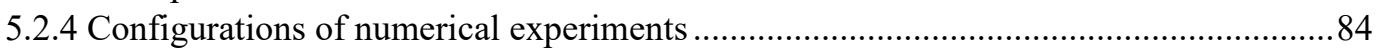

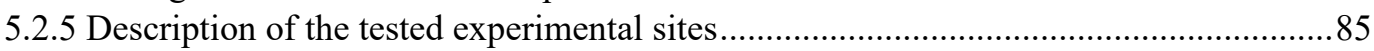

5.3. Results: comparison of simulation results of surface variables with/without snowpack effect

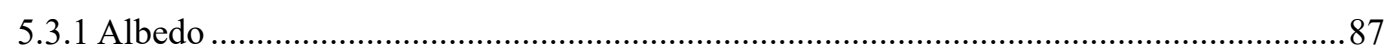

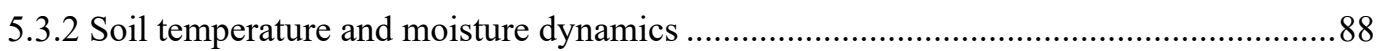

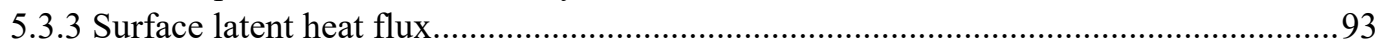

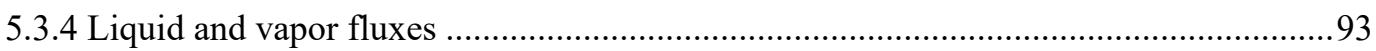

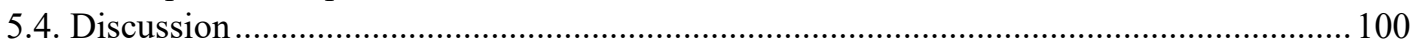

5.4.1 Uncertainties in simulations of surface albedo and limitations....................................100

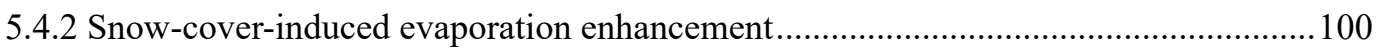

5.4.3 Snow cover impacts with different soil model complexities............................................ 101

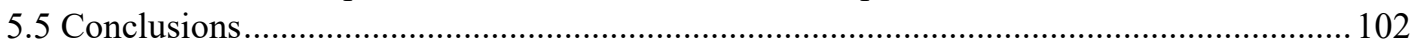

Chapter 6 Integrating soil water and groundwater flow processes ....................................105

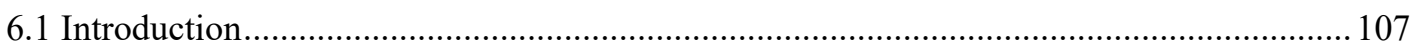

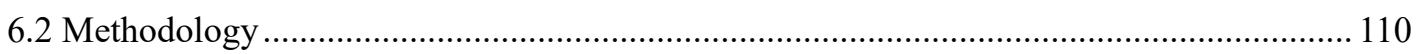

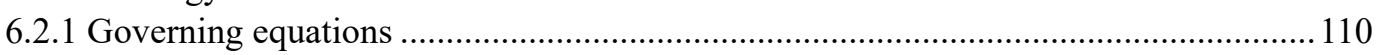

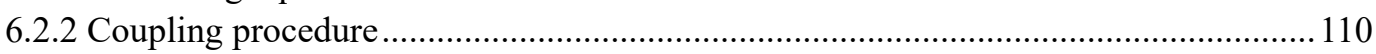

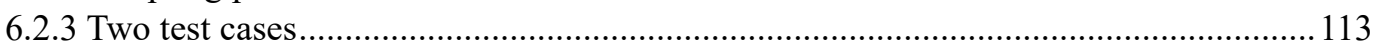

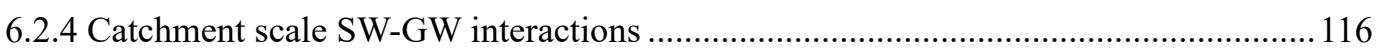

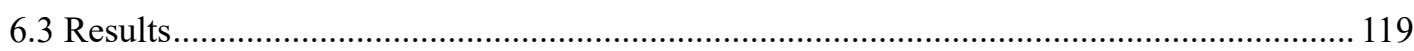

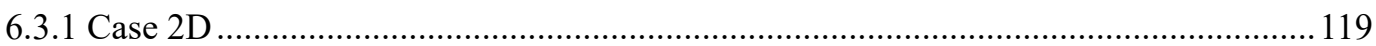

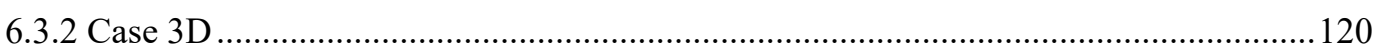

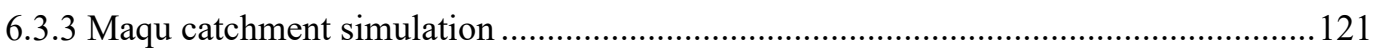

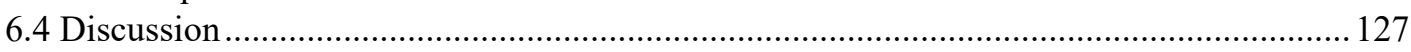

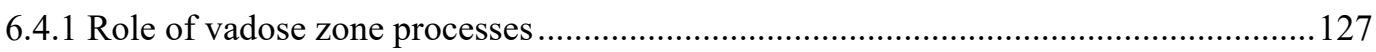

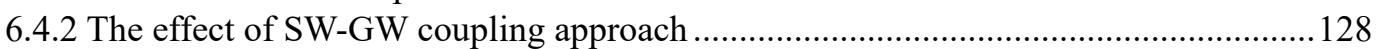

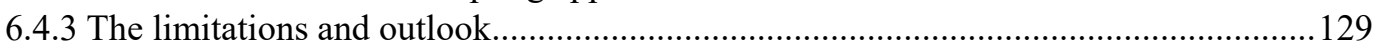

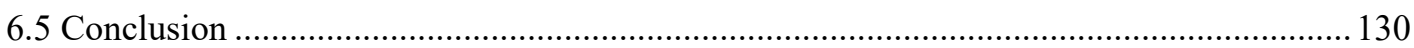

Chapter 7 Effect of vadose zone physics on ecosystem functioning . .............................131

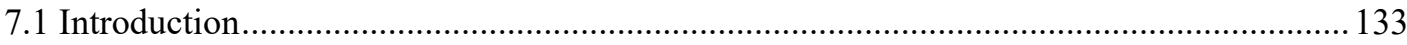

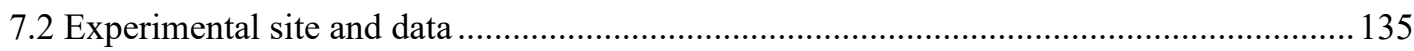

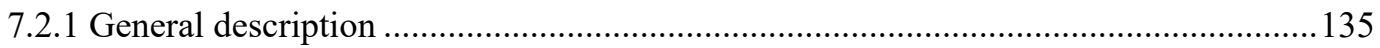

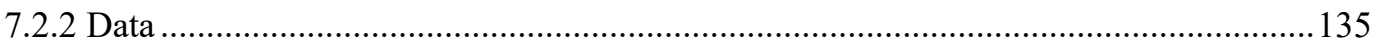

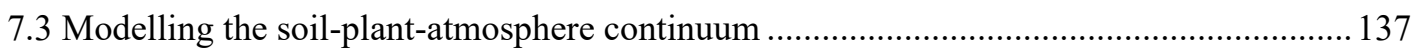

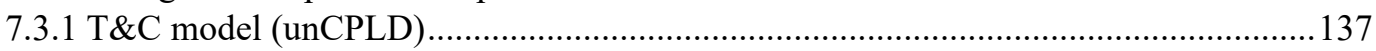

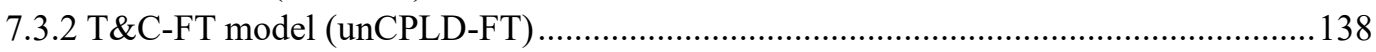

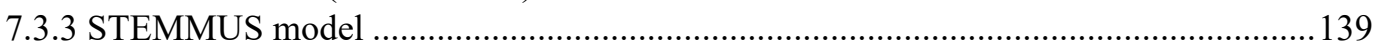

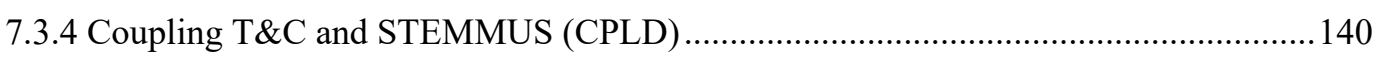

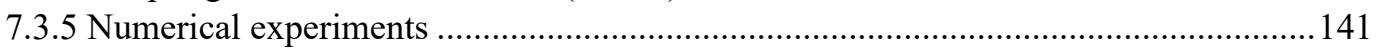

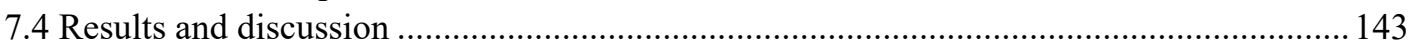

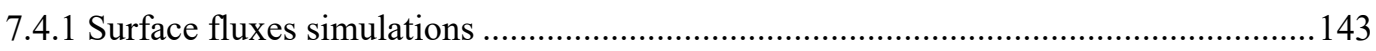

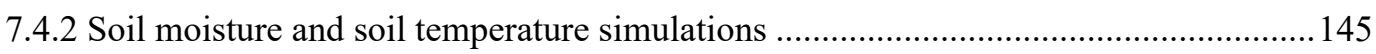

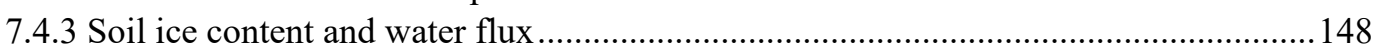




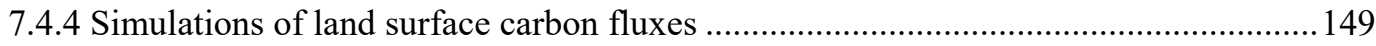

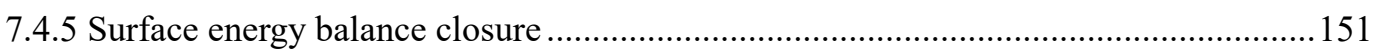

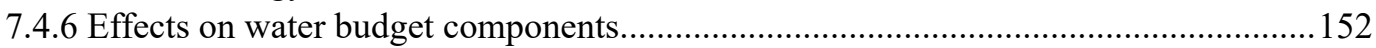

7.4.7 The influence of different mass/heat transfer processes ................................................154

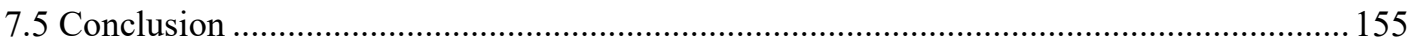

Chapter 8 Synthesis ....................................................................................................................157

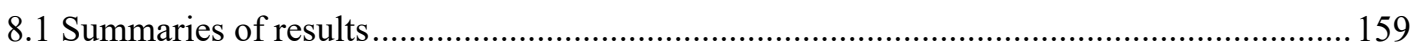

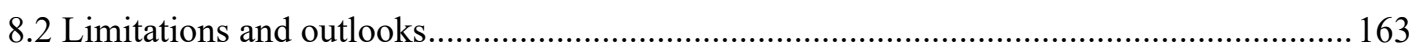

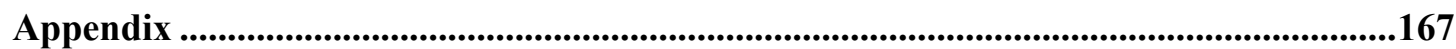

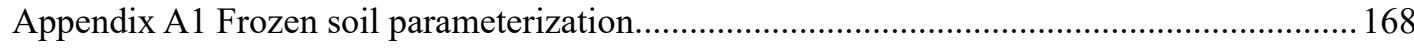

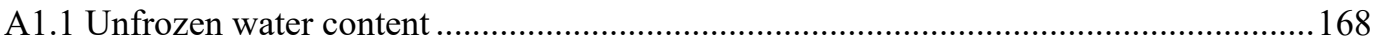

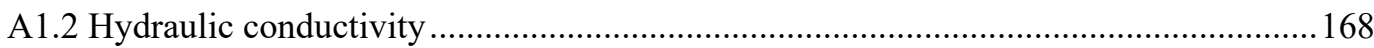

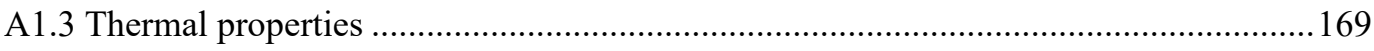

A1.4 Temperature dependence of matric potential and hydraulic conductivity .....................171

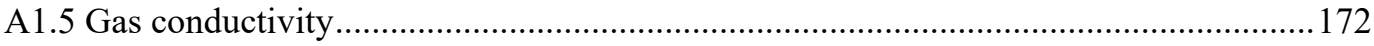

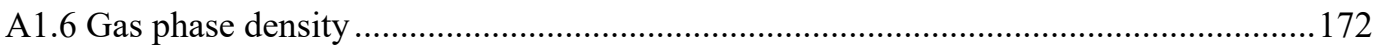

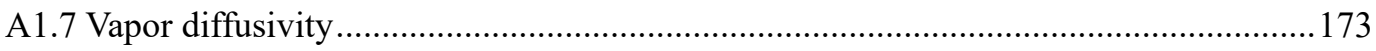

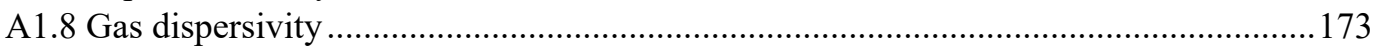

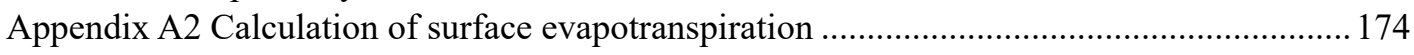

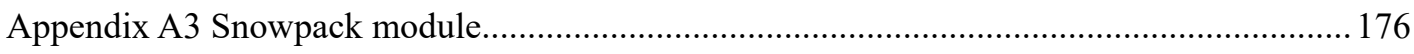

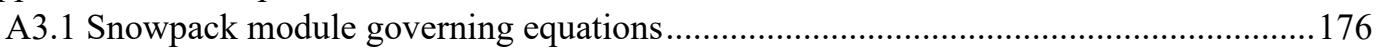

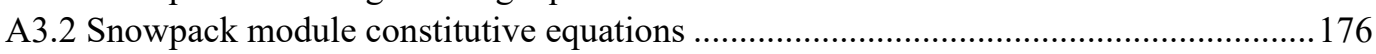

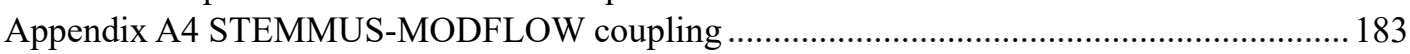

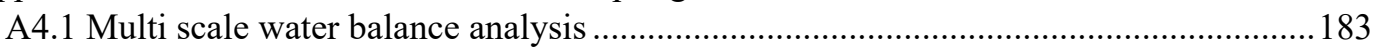

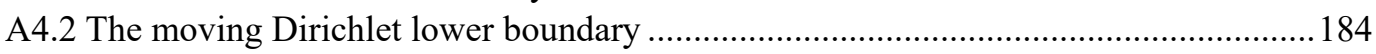

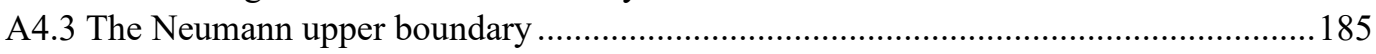

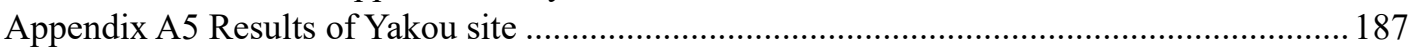

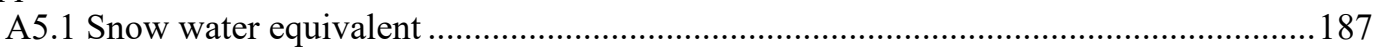

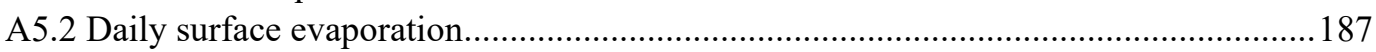

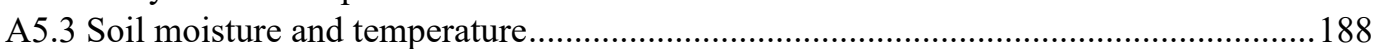

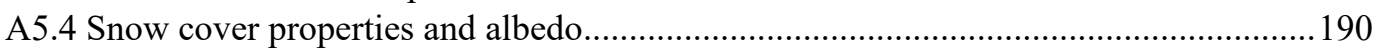

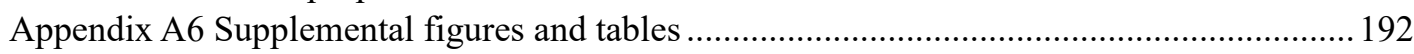

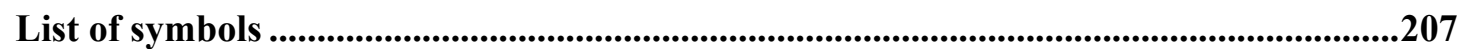

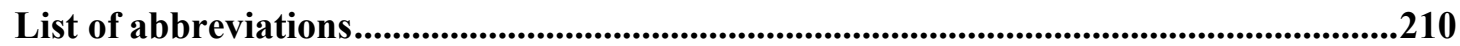

Bibliography.................................................................................................................212

Summary .....................................................................................................................232

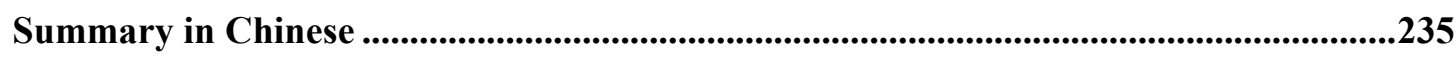

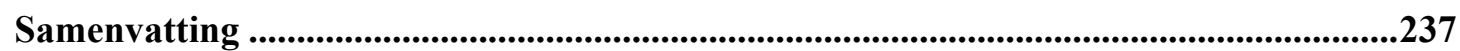




Chapter 1 Introduction 


\subsection{Background}

Earth system science (ESS) extends from the climate research and has been developing rapidly in recent decades (see Figure 1.1 for the timeline of the ESS development, Steffen et al., 2020). Understanding the mass, energy, and carbon transfer across the land-atmosphere interfaces under the current and future climate conditions is the key research content of ESS. Land surface process, due to its intense interaction and sensitivity to the external environmental changes, has drawn much attention of Earth system science researchers. Earth system observation (ESO) and modelling (ESM) are two legs of the ESS. Many projects and initiatives were initiated and lots of Earth system observations for specific purposes were built up (see the reviews by Fu et al., 2010; Bojinski et al., 2014; Brantley et al., 2017; Baatz et al., 2018; Mirtl et al., 2018; Paganini et al., 2018; Su et al., 2018; Li \& Vereecken, 2020). ESOs from point, field, catchment scale, with long term observation are of great importance to reveal the true nature of the specific systems. Observation is also needed to validate and evaluate the developed relationships, models, and theory and can also help to identify the drawbacks of current models thus drive the development of Earth system models. Despite the fact that ESOs can give clues of the underlying physics for the tested area with the specific land surface and local climate conditions, due to the heterogeneous nature of the Earth system, no ESOs can be representative for the full picture of the Earth system. ESMs are necessary to extend what we learned from the current ESOs to that at various temporal and spatial scales (from local to global scale, from year to multi-year and further long-term predictions).

Our way to interpret the Earth system observation are mainly two-fold. One way is to use the data assimilation to integrate the observation with the modelling and thus have the updated analysis approaching the observations, while acknowledging the fact that both the model and observation are not perfect. This way is of importance as it can provide the reliable (currently best) interpretation and projections of the Earth system development by assimilating the available relevant observations (remote sensing products, ESOs). Data assimilation systems, e.g., IFS of ECMWF, ECMWF-LDAS, GLDAS, NLDAS, and CLDAS, greatly improve our capabilities in obtaining reliable large-scale simulations of the state and flux variables of land, ocean and atmosphere. Nevertheless, the performance of such data assimilation system is much more affected by the choice of land surface models (or Earth system models, ESMs) than the data assimilation methods (Zhang et al., 2017). 


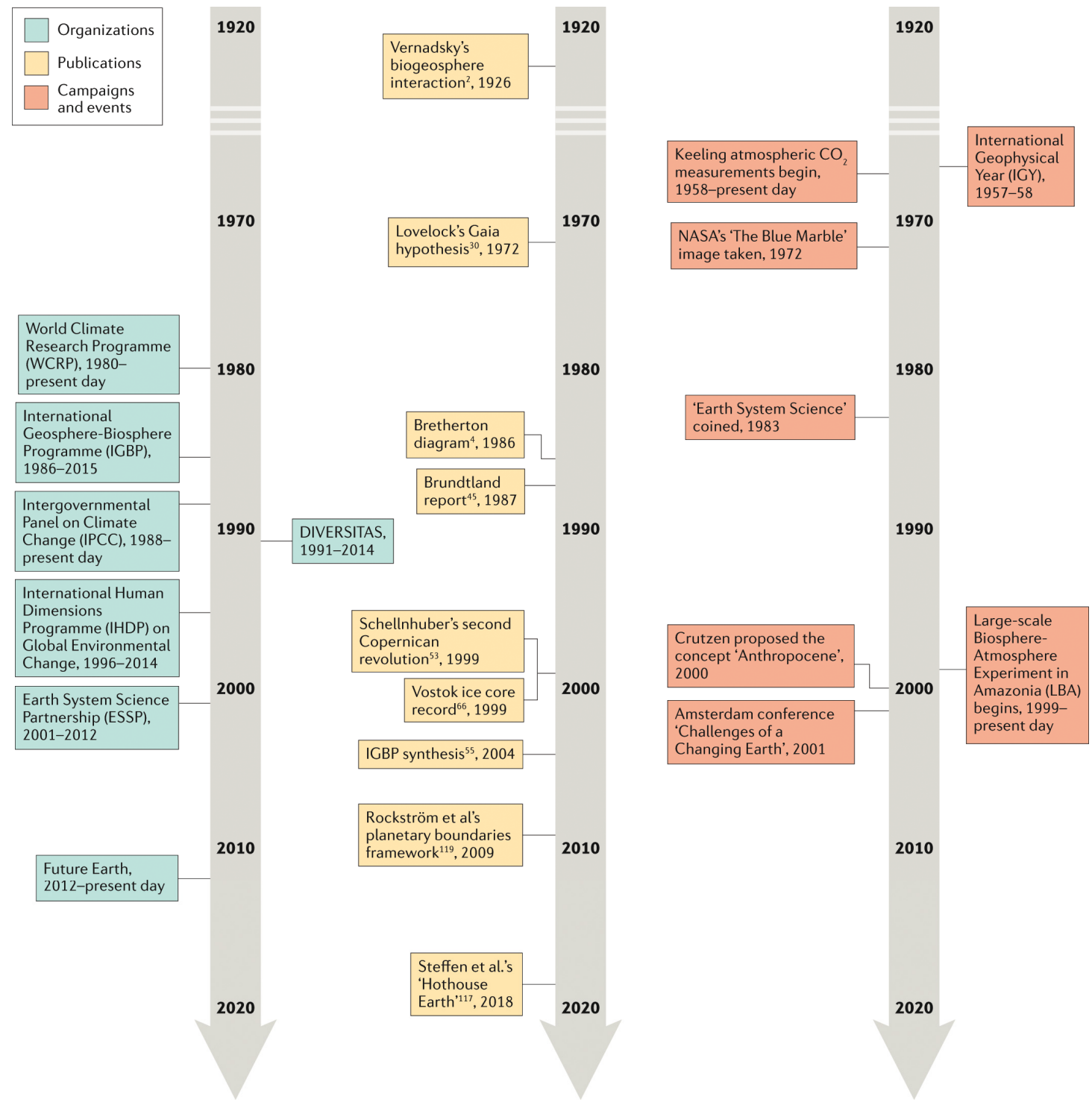

Figure 1.1. Timeline illustrating the development of Earth System Science from the mid-20th century. The figure shows the key organizations, events and concepts that have helped to define and develop Earth System Science (from Steffen et al., 2020).

The other way of interpreting the observation is to improve the land surface models (and ESMs), based on the discrepancy identified by the model-observation deviation, in terms of more physical representation of the overlooked/oversimplified physical processes (e.g., freezing and thawing, coupled transfer of liquid, vapor, dry air and heat) or physiographical properties (e.g., terrain, aspect, spatial heterogeneity, etc.). Although this approach requires more dedicated efforts and sometimes constrained by the computing cost, it deserves more attentions and is the sustainable research goal from the long-term perspective. More and more progress has been made to enrich the underlying physics of land surface models, hydrological and ecohydrological models, and global vegetation models. For example, the first-generation traditional bucket model had been updated by the physical Richards equation in land surface models (LSMs) for simulating soil water flow, which is further enhanced by considering two- 
big-leaf model, photosynthesis-transpiration coupled concept, plant hydraulics, frozen soil representation, etc. (Dai et al., 2001; Niu et al., 2011; Yang et al., 2011; Wang et al., 2017b; Gou et al., 2018; Kennedy et al., 2019; Lawrence et al., 2019; Bonan et al., 2021; Li et al., 2021).

ESOs and ESMs for the temperate climate conditions have been widely reported. While most of the ESMs are developed with their focus on the normal conditions, there is an insufficient description of land surface processes under water stressed conditions, induced by either the lack of water availability or soil freezing (Boone et al., 2000; Chadburn et al., 2015; Harper et al., 2021; Lawrence et al., 2019; Luo et al., 2003; Mu et al., 2021).

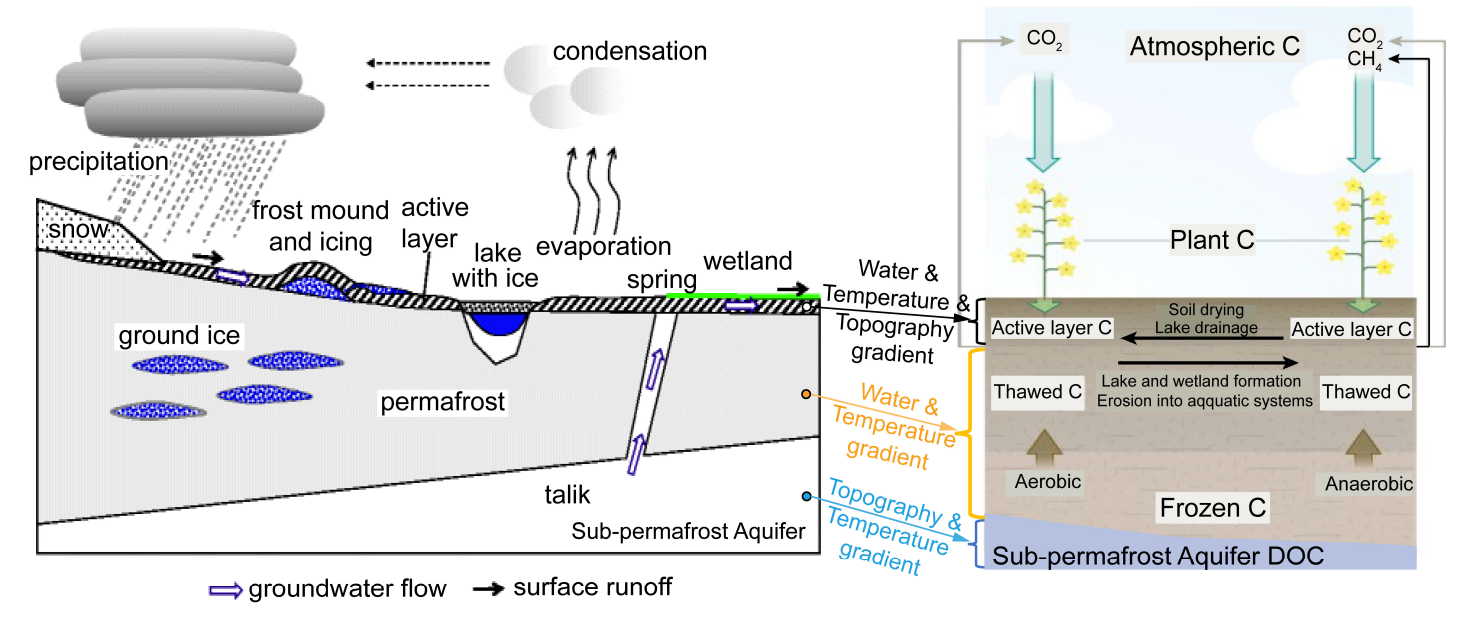

a) Permafrost hydrology

b) Permafrost carbon feedback

Figure 1.2. Conceptualization of (a) the water cycle in permafrost regions (adapted from Woo, 2012) and (b) the permafrost carbon feedback to climate change (adapted from Schuur et al., 2015). DOC, dissolved organic carbon.

In particular, the physical process of water, heat and carbon transfer in cold regions are considerably different and more complex (Figure 1.2). The presence of snowpack or soil ice, and their timing and amount, can alter the water and energy budget of surface and subsurface soil layers as well as their unique hydrothermal properties. Adding to the complexities, groundwater discharge, if it occurs in winter, freezes above ground or within the active layer. Otherwise, it probably emerges as springs or feeds the streams, wetlands, lakes and the sea (Woo, 2012). In cold regions, permafrost controls the water and heat exchange between groundwater and surface water. As the permafrost thaws, ice in soil pores melts, which relaxes the impedance effect on the hydraulic permeability. The aquifers may be activated and hence increase the baseflow to surface water (Bense et al., 2012; Kurylyk et al., 2014a). 
From the perspective of carbon cycle, the decomposition and distribution of soil organic carbon are strongly linked with active layer thickness, soil moisture, and thermokarst terrains ( $\mathrm{Mu}$ et al., 2020). The non-growing season was found exerting a strong influence on the vegetation cover, phenology, and growth (Zhuang et al., 2001; Wania et al., 2009; Lyu \& Zhuang, 2018; Zhang et al., 2018). Under climate warming, organic carbon originally stored in frozen soils (permafrost) will be decomposed into greenhouse gases $\left(\mathrm{CO}_{2}\right.$ or $\left.\mathrm{CH}_{4}\right)$, which enters the ecosystem and further releases to the atmosphere thus accelerates the climate change (Schuur et al., 2015). The water saturation status, affected by permafrost thaw, determines which microbial decomposition process is predominant (aerobic for dry or anaerobic for wetter conditions). This is the so-called permafrost carbon feedback to climate change (Figure $1.2 \mathrm{~b}$ ). The cryosphere components and their interactions together make the cold region ecosystem complex and highly climate vulnerable.

In view of the foregoing, the detailed investigation of coupled water, energy, and carbon exchange processes in cold environments is imperative to enhance our mechanism understanding of the land-atmosphere interaction and its impacts on future environmental and climatic changes in cold regions.

\subsection{Water-heat-carbon exchange processes in cold regions}

The Tibetan Plateau is recognized as one of the cold regions most sensitive to climate change (Liu \& Chen, 2000; Cheng \& Wu, 2007; Yao et al., 2019). Various field campaigns have been made since $1990 \mathrm{~s}$, including the $1^{\text {st }}$ and $2^{\text {nd }}$ Tibetan scientific exploration, GAME/Tibet, CAMP-Tibet, and GEWEX CEOP. In particular, numerous long-term regional scale hydrological and ecohydrological monitoring networks have been built up with the aims to validate and understand the modeling and remote sensing products (Ma et al., 2008; Su et al., 2011; Yao et al., 2012; Yang et al., 2013; Wang et al., 2021a). Consequently, several datasets have been recently published covering the soil moisture/temperature, ecohydrological, and integrated monitoring dataset (Zhao et al., 2018; He et al., 2020; Li et al., 2020; Ma et al., 2020; Su et al., 2020a; Zhang et al., 2021). All the relevant work and datasets, linked with the remote sensing data and reanalysis products, inevitably help to facilitate our understanding of the coupled waterheat-carbon exchange processes that occur in this unique cold environment, termed the Third Pole Environment.

Taking the benefit from these observation efforts, land surface models have been developed, validated, and enhanced in terms of its capability in modelling and representing water-heat-carbon exchange processes on the Tibetan Plateau.

\section{1) Understanding freeze-thaw process}

Water and heat flow are tightly coupled in frozen soils. When soil experiences the 
freeze/thaw process, there is a dynamic thermal equilibrium system of ice, liquid water, water vapor and dry air in soil pores. Coupled water and heat physics, describing the concurrent flow of liquid, vapor as well as heat flow, was first proposed by Philip \& De Vries (1957) (hereafter termed PdV57), considering the enhanced vapor transport. The PdV57 theory has been widely applied for a detailed understanding of soil evaporation during the drying process (De Vries, 1958; Milly, 1982; De Vries, 1987; Saito et al., 2006; Novak, 2010). As both the drying and freezing soils lose liquid water from larger pores to micro-ones, it is assumed that the freezing process is, to some extent, similar to the drying process (Koopmans \& Miller, 1966; Hansson et al., 2004; Dall'Amico, 2010). Since 1970s, researchers developed a hierarchy of frozen soil models, from the simple ones to the models with coupled water and heat physics, to help to understand and represent the water and heat transfer processes (e.g., Harlan, 1973; Guymon \& Luthin, 1974; Li et al., 2010; Bao et al., 2016; Wang et al., 2017b); Some well-known models include SHAW (Flerchinger \& Saxton, 1989); HYDRUS1D (Hansson et al., 2004); MarsFlo and its successor Advanced Terrestrial Simulator (Painter, 2011; Painter et al., 2016). The role of vapor flow, which links the soil water and heat transfer, however, is not well understood in frozen soils.

Airflow has been reported important to the soil water and heat transfer process under certain conditions (Touma \& Vauclin, 1986; Prunty \& Bell, 2007). Recently, numerical tools have been developed to study the role of air convection regarding the soil water and heat transport (e.g., enhanced soil evaporation, Zeng et al., 2011a, b; enlarged temperature difference between the upper and the lower part of a permafrost talus, Wicky \& Hauck, 2017; interactive effect of soil airflow and ice, Yu et al., 2018). The abovementioned studies demonstrate that the explicit consideration of airflow has the potential to affect the soil hydrothermal regime. However, to what extent and under what condition airflow plays significant roles in the subsurface water and heat transfer has not been detailed.

On the other hand, current LSMs and ESMs usually adopted a simplified frozen soil physics with relative coarse vertical discretization (Koren et al., 1999; Viterbo et al., 1999; Niu et al., 2011; Swenson et al., 2012). In their parameterizations, soil water and heat interactions can only be indirectly activated by the phase change processes, the mutual dependence of liquid water, water vapor, ice and dry air in soil pores is absent. This mostly leads to oversimplifications of physical representations of hydrothermal and ecohydrological dynamics in cold regions (Novak, 2010; Su et al., 2013; Wang et al., 2017b; Cuntz \& Haverd, 2018; Grenier et al., 2018; Wang \& Yang, 2018; Qi et al., 2019). Specifically, Su et al. (2013) evaluated the European Centre for Medium-Range Weather Forecasts (ECMWF) soil moisture analyses over the Tibetan Plateau and found that HTESSEL cannot capture phase transitions of soil moisture (i.e., underestimation during the frozen period while overestimation during the thawing 
period). There are continuous efforts in improving parameterizations and representations of land surface processes in cold regions, including frozen ground (Boone et al., 2000; Luo et al., 2003), vapor diffusion (Karra et al., 2014), thermal diffusion (Bao et al., 2016), coupling water and heat transfer (Wang \& Yang, 2018), and three-layer snow physics (Wang et al., 2017b; Qi et al., 2019). While to our knowledge, few studies have investigated the role of increasing complexities of soil physical processes (from the basic coupled to the advanced coupled water and heat transfer processes, and then the explicit consideration of airflow) in simulating the thermo-hydrological states in cold regions. How and to what extent does the complex mutual dependent physical processes affect the soil mass and energy transfer in frozen soils? Is it necessary to consider a fully coupled physical process in LSMs or ESMs?

\section{2) Snow cover influence on the subsurface soil hydrothermal regime}

In permafrost regions, the snow has a profound effect on the hydrology and surface energy through its modification of the surface albedo, roughness and insulating properties. Different from the rains, precipitation water enters the soil significantly lagged in time due to the storage by the snow cover. However, a large and sudden outflow or runoff may be produced as a result of snowmelt. The heat insulating effect of snow cover also provides a buffer layer to reduce the magnitude of the underlying subsurface temperature variation and thus markedly affects the thickness of active layer in cold regions.

Often, snowpack dynamics was expressed as a simple empirical function of temperature in hydrological models. But these empirical relations have limited applications in complex climate conditions (Pimentel et al., 2015). Many physically based models for the mass and energy balance in the snowpack have been developed to couple with hydrological models or atmospheric models. Boone \& Etchevers (2001) divided these snow models into three main categories: (i) simple force-restore with composite snowsoil (SURFEX 1-layer ISBA) or single explicit snow layer (e.g., ECMWF/HTESSEL, HIRLAM/RCA, UEB); (ii) detailed internal snow process schemes with multiple layers of fine vertical resolution (e.g., SNOWPACK, Crocus, SNTHERM); and (iii) intermediate-complexity schemes with physics from the detailed schemes but with a limited number of layers, which is intended for NWP/Climate models (e.g., SURFEX 3-layer). Their intercomparison results at an alpine site indicated that all three types of schemes are capable of representing the basic features of the snow cover with similar errors averaged over the 2-yr period but behaved differently on shorter timescales. Later on, the Snow Model Intercomparison Project (SnowMIP) at two mountainous alpine sites revealed that the albedo parameterization was the major factor influencing the simulation of net shortwave radiation, which was independent of model complexity (Etchevers et al., 2004). SnowMIP2 evaluated 33 snowpack models across a wide range of hydrometeorological and forest canopy conditions and revealed the shortcomings of 
different snow models and highlighted the necessity of studying separately the contribution of individual components to the snow mass and energy balance (Rutter et al., 2009).

\section{3) Hydrothermal interactions between groundwater and frozen soil}

During the last two decades, a series of modeling tools have emerged and facilitated researchers to investigate the hydrothermal interactions between groundwater flow, subsurface process, and climate change in hydrogeologically complex environments (Lemieux et al., 2008; Bense et al., 2009). Further research was conducted to study the effects of permafrost degradation on hydrogeological regime of sub-permafrost aquifer systems in various permafrost environments (Bense \& Person, 2008; Ge et al., 2011; Bense et al., 2012; Evans et al., 2015; Johansson et al., 2015).

From the perspective of thermal state, numerical models, analytical solution, and inversed heat conduction method were used to reproduce the dynamics of surface/subsurface temperature and ice distribution (Isaksen et al., 2000; McKenzie et al., 2007; Kurylyk \& Macquarrie, 2014; Kurylyk et al., 2015). The heat budget components play different roles in determining the thermal state of groundwater and frozen soil under various hydro-geophysical conditions (Rowland et al., 2011; Kurylyk et al., 2016; Sjöberg et al., 2016). In addition to the heat conduction, the advective heat transport (vertical and lateral heat transport) has been demonstrated important, which highlights the necessity of coupling thermal and hydrologic processes to understand the groundwater and permafrost dynamics.

Current modeling of the climate-driven evolution of groundwater flow in permafrost regions (taliks) are more or less ideal, mainly due to the limited measurement accuracy, changing boundary conditions, and the strong water and heat coupling between the saturated aquifer with the overlying unsaturated zone (Troch et al., 2013). This underscores the need for improved characterization of permafrost and other hydrogeologic information via geophysical techniques, remote sensing, and groundbased observations (Walvoord et al., 2012).

Although measurements can provide us with useful information of groundwater, e.g., initial water and heat regime. The accurate description of boundary conditions may be out of these measurements' league, especially at catchment scale. Many researchers often prescribe a specified head or flux boundary conditions (Boano et al., 2009; Ge et al., 2011; Kurylyk et al., 2014b). In fact, the heads and flux can change considerably both in time and in space, due to the temporal and spatial variation of surface melting, precipitation and hydrogeologic conditions.

Most of the studies have represented the permafrost-groundwater systems as one-way coupling, i.e., either investigate the influence of permafrost thaw on groundwater flow or vice versa. However, permafrost is strongly coupled with groundwater. Permafrost 
thaw will increase the groundwater recharge and this advective heat transfer then will accelerate the permafrost thawing. The two-way coupling mechanism should be well described to better mimic the subsurface conditions in the context of current and future climate change.

\subsection{Research questions and objectives}

\subsubsection{Research questions}

Given by the current state-of-the-arts and knowledge gaps regarding the coupled water-heat-carbon exchange processes in cold regions, we proposed five research questions as below.

Q1: How to physically understand and interpret the coupled liquid, vapor, dry air, and heat transfer in response to soil freeze-thaw cycles?

Q2: How do different representations of soil physical processes (i.e., from the basic coupled to the advanced coupled water and heat transfer processes, and then the explicit consideration of airflow) affect the simulation of soil hydrothermal dynamics in frozen soils?

Q3: How does the snowpack impact subsurface soil water-heat dynamics considering different representations of soil physical processes?

Q4: How do the soil water-groundwater interactions affect the soil water dynamics?

Q5: What is the importance of vadose zone physics in understanding the ecosystem functioning (water, energy, and carbon exchanges) in cold regions?

\subsubsection{Research objectives}

Driven by the aforementioned five research questions, the corresponding research tasks and objectives are as follows:

OBJ 1. Understand the coupled liquid, vapor, dry air and heat transfer processes during soil freezing and thawing periods.

OBJ 1.1 Develop the soil freeze-thaw model considering the coupled liquidvapor-air flow (STEMMUS-FT).

OBJ 1.2 Investigate the coupled physical processes and mechanisms in frozen soils.

OBJ 2. Understand the effect of snowpack on underlying soil water and heat dynamics.

OBJ 3. Explore the impact of integrating soil water-groundwater modelling on soil water dynamics.

OBJ 4. Explore the impact of soil physical model complexities on the coupled waterenergy-carbon exchange processes. 


\subsection{Thesis outline}

To answer the proposed research questions and achieve the designed objectives, we conducted the laboratory and field experiments, developed the process-based modeling framework and further conducted the numerical simulations. The thesis outline is as follows (Figure 1.3 and 1.4).

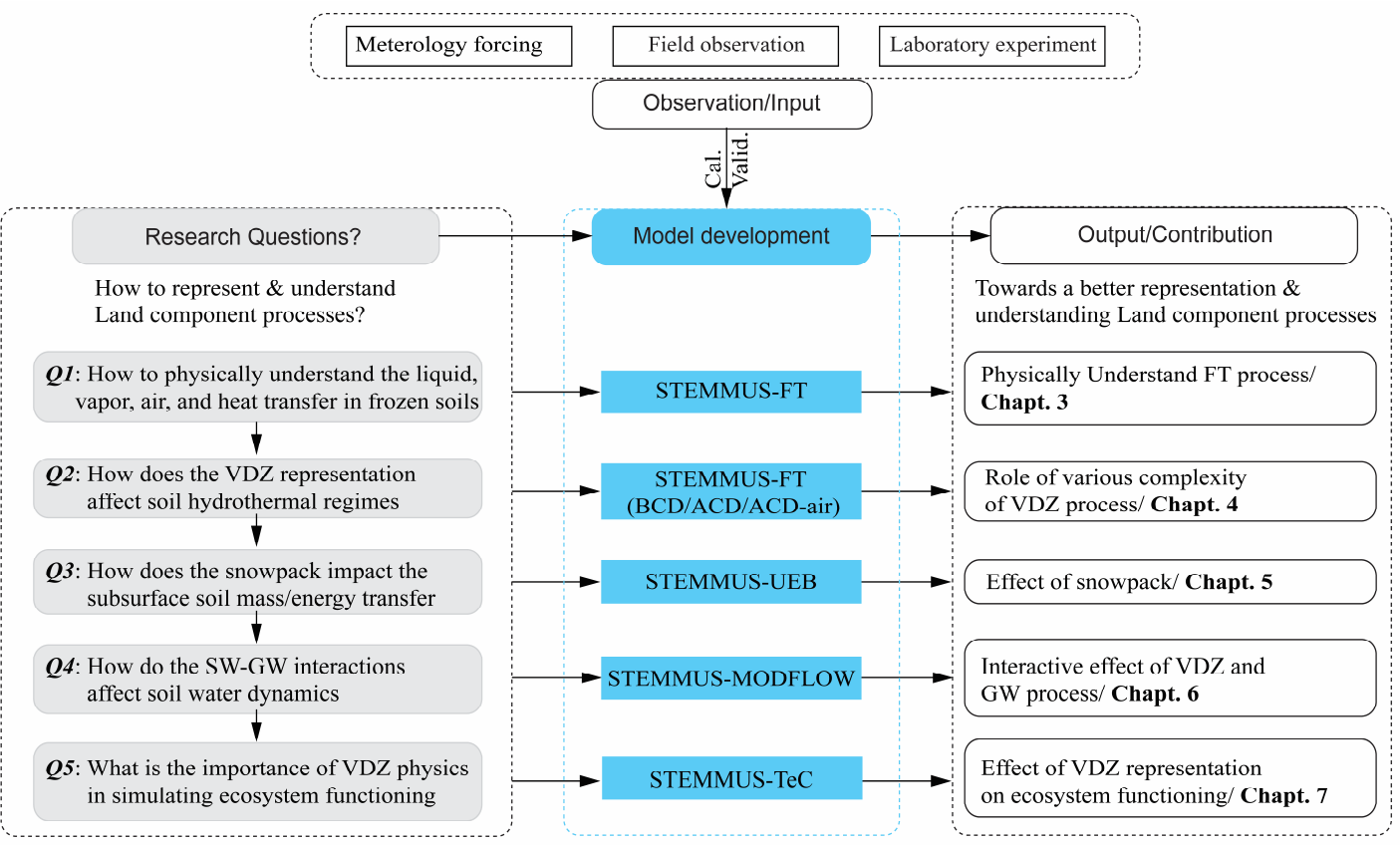

Figure 1.3. Schematic of the thesis structure. Gray filled boxes are the research questions, white boxes are input variables, blue filled boxes represent developed models, white rounded rectangle boxes are model outputs corresponding to research questions. FT, freeze and thaw. VDZ, vadose zone. SW-GW, soil water-groundwater.
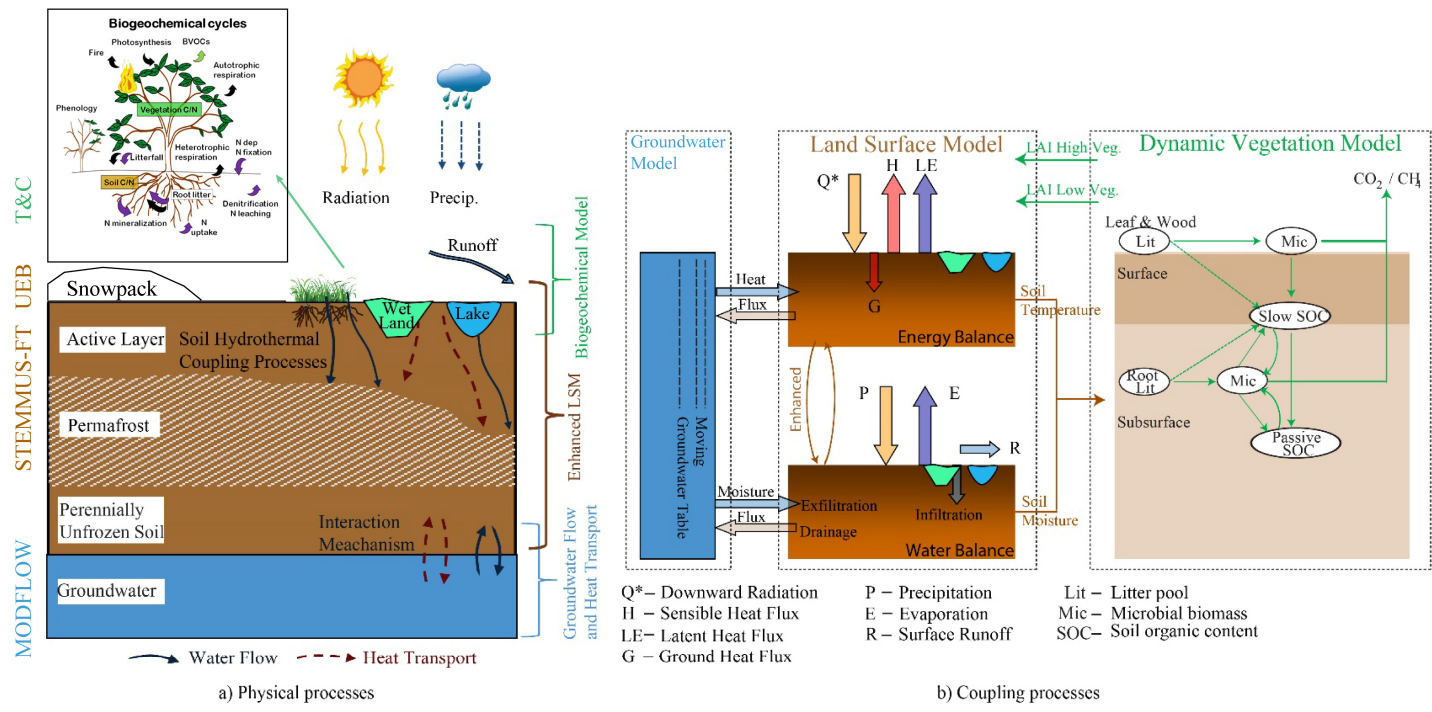

Figure 1.4. The thesis structure is backboned by the integrated modelling framework (physical processes and coupling processes). Adapted from Zeng and $\mathrm{Su}$ (2016). 
The original STEMMUS model (Zeng et al., 2011b; a; Zeng \& Su, 2013) will be firstly extended by considering soil freeze-thaw process (STEMMUS-FT, tested in a cold region, Chapter 3), corresponds to $Q 1$. Furthermore, on the basis of STEMMUS-FT model, three levels of soil physical complexity were taken into account to understand the mass and energy transfer in frozen soils and explain how the soil physical processes affect the model-interpreted soil hydrothermal regimes (Chapter 4). The role of different vadose zone physics in representing the water, heat, carbon exchanges of a cold region ecosystem was further investigated by incorporating STEMMUS-FT model into the biogeochemical model T\&C (Chapter 7). Furthermore, Chapter 5 explored the effect of snowpack on the underlying soil water and heat transfer with different soil physical processes. The interactive effect of soil water and groundwater flow was taken into account by coupling STEMMUS with MODFLOW (Chapter 6). Input dataset, meteorology forcing, field observation and laboratory experiment data will be deployed to fully calibrate and validate the mentioned models for the current climate conditions (Chapter 2). The schematic drawing of the logic of the thesis structure, i.e., QuestionMethodology-Output/Contribution Research Loop, can be seen as Figure 1.3. Figure 1.4 illustrates in detail the modelling and process perspective of this thesis. 

Chapter 2 Maqu observatory and in situ measurements 


\subsection{Maqu observatory}

The Maqu soil moisture and soil temperature (SMST) monitoring network ( $\mathrm{Su}$ et al., 2011; Dente et al., 2012; Zeng et al., 2016) is located on the north-eastern fringe of the Tibetan Plateau $\left(33^{\circ} 30^{\prime}-34^{\circ} 15^{\prime} \mathrm{N}, 101^{\circ} 38^{\prime}-102^{\circ} 45^{\prime} \mathrm{E}\right.$, Figure 2.1$)$. The monitoring network spans an area of approximately $40 \mathrm{~km} \times 80 \mathrm{~km}$ and the elevation ranges from $3200 \mathrm{~m}$ to $4200 \mathrm{~m}$ a.s.1. Referring to the updated Köppen-Geiger climate classification system, it can be characterized as a wet and cold climate, with dry winters and rainy summers. Precipitation in Maqu is uneven over the year with most of the precipitation events occurring from May to October and little precipitation or snowfall during the wintertime. The precipitation event is characterized as high frequency with relatively low intensity. The annual mean precipitation is about $620 \mathrm{~mm}$ and the annual average potential evaporation is about $1353.4 \mathrm{~mm}$. The mean annual air temperature is $1.2{ }^{\circ} \mathrm{C}$, and the mean air temperatures of the coldest month (January) and warmest month (July) are about $-10.0^{\circ} \mathrm{C}$ and $11.7^{\circ} \mathrm{C}$, respectively. Land cover in this region is dominated by alpine meadows with heights varying from $5 \mathrm{~cm}$ to $15 \mathrm{~cm}$ throughout the growing season. The general soil types are sandy loam, silt loam and organic soil with on average $39.7 \%$ sand, $8.0 \%$ clay and a maximum of $18.3 \%$ organic matter ( $\mathrm{Su}$ et al., 2011; Dente et al., 2012; Zheng et al., 2015a; Zhao et al., 2018).

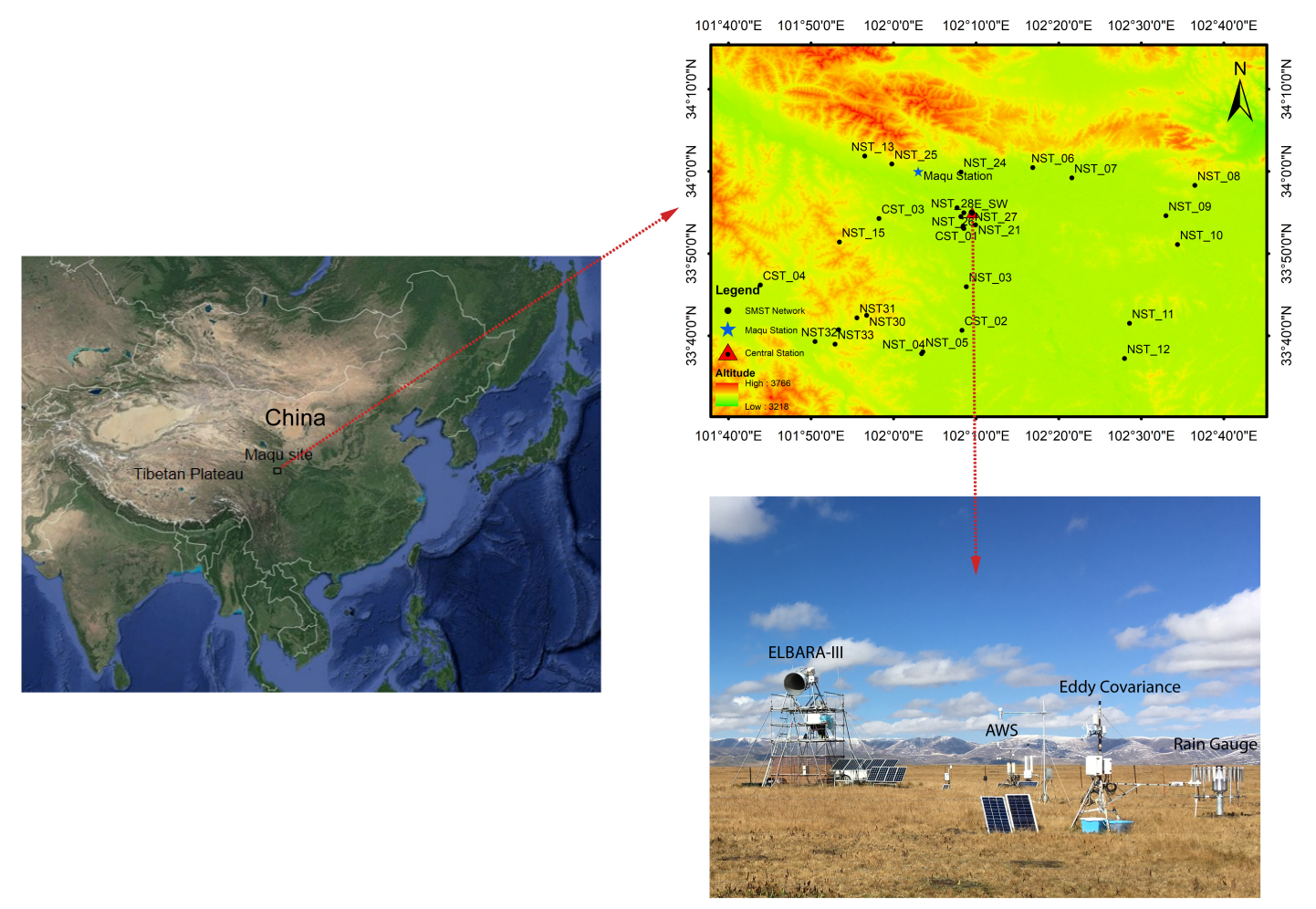

Figure 2.1. Location of Maqu observatory and soil moisture and soil temperature (SMST) monitoring network. The bottom right figure is the micro-meteorological site. ELBARA-III is the ELABARA-III microwave radiometer. AWS is the automatic weather station. 
Maqu observatory was setup primarily for the calibration and validation of satellitebased soil moisture products (Su et al., 2011; Dente et al., 2012; Lv et al., 2014; Wang et al., 2018). Further efforts contribute to enhance its multifunctionality, including the understanding of land surface processes (Zheng et al., 2014; Zheng et al., 2015a; Zheng et al., 2015b; Yu et al., 2018; Yu et al., 2020b), soil-water-plant-energy interactions (Yu et al., 2020a), surface water-groundwater interactions ( $\mathrm{Li}$ et al., 2021), microwave observations of land surface processes (Su et al., 2020a; Hofste et al., 2021), synergy between the model and observations via forward observation simulator and data assimilation (Mwangi et al., 2020; Zhao et al., 2021), multi-scale and multi-sensor earth observations of the ecohydrological dynamics (Zeng et al., 2016; Su et al., 2020b; Zhuang et al., 2020).

\subsection{In situ measurements and observational datasets}

\subsubsection{Hydro-meteorological variables and hydro-geological \& hydro-geophysical survey}

\section{1) Hydro-meteorological variables}

At Maqu site, SMST profiles are automatically measured at a 15-min interval by 5 TM $\mathrm{ECH}_{2} \mathrm{O}$ probes (METER Group, Inc., USA) installed at the following depths: $5 \mathrm{~cm}, 10$ $\mathrm{cm}, 20 \mathrm{~cm}, 40 \mathrm{~cm}, 80 \mathrm{~cm}$. The micro-meteorological observing system includes an automatic weather station (AWS) providing wind speed and direction, atmospheric humidity and temperature measurements at $2 \mathrm{~m}$ above ground, and an eddy covariance (EC) system installed for measuring the turbulent heat fluxes and carbon fluxes. Instrumentations for measuring four radiation components (i.e., upward and downward shortwave and longwave radiation), atmospheric pressure and liquid precipitation are also deployed. Table 2.1 summarizes the measured hydro-meteorological variables and the relevant equipment in Maqu observatory.

\section{2) Hydro-geological and hydro-geophysical survey}

The landscape in Maqu observatory is made up of low mountains, hills, river valley, terrace, gully, marsh land and flood plain. The mountain region is a composite of feldspathic quartzose sandstone and sandy slate with soil covered at the top. The sediments of the low land area are mainly alluvial deposits with intercalated eolian units. Groundwater is mostly the phreatic aquifer stored in the Quaternary loosen stratum. The phreatic water level for the swamps is usually less than $1 \mathrm{~m}$ below the ground. For the gullies, there are large areas with ponding during the monsoon. Groundwater in mountain regions comes out as springs, which directly or indirectly recharge the swamp wetlands.

To enhance our knowledge on the regional groundwater system, hydro-geological and hydro-geophysical survey were conducted in Maqu recently. Groundwater monitoring well was drilled in 2017, which equipped with the groundwater level measurement 
sensors, TD-Diver and Baro-Diver. The borehole core lithology analysis and aquifer pumping test were conducted for the hydro-geophysical parameters. In 2018 and 2019, the regional groundwater level survey was conducted, measurements from 34 boreholes were collected to generalize the regional groundwater piezometric map. To obtain the spatial variation of the aquifer hydraulic conductivity, aquifer tests (including two pumping tests and eight slug tests) were conducted in 2019.

Electrical resistivity tomography (ERT) survey at seven locations was carried out for the subsurface resistivity, which can be used to infer the subsurface soil water content and lithology. Along with the magnetic susceptibility measurements, we performed the magnetic resonance sounding (MRS) survey at 18 locations using the instrument Numis Poly. All these hydro-geophysical measurements can contribute a better interpretation of subsurface soil hydraulic conductivity, water content and aquifer geometry. Table 2.1 summarizes the relevant equipment used for the hydro-geological and hydrogeophysical survey. Additional information on the hydro-geological and hydrogeophysical survey procedures and datasets can be found in Li et al. (2021).

Table 2.1. Description of the hydro-meteorological variables and hydro-geological and hydro-geophysical measurements in Maqu observatory.

\begin{tabular}{|c|c|c|c|}
\hline $\begin{array}{l}\text { Monitoring } \\
\text { System/Campaign }\end{array}$ & Items & $\begin{array}{l}\text { Mounting } \\
\text { Height/Depth (m) }\end{array}$ & Sensors/Equipment \\
\hline $\begin{array}{l}\text { Soil moisture and soil } \\
\text { temperature monitoring } \\
\text { network (SMST) }\end{array}$ & $\begin{array}{l}\text { Soil moisture, soil } \\
\text { temperature }\end{array}$ & $\begin{array}{l}-0.05,-0.1,-0.2 \\
-0.4,-0.8,-1.6\end{array}$ & $\begin{array}{l}\mathrm{EC}-\mathrm{TM} \mathrm{ECH}_{2} \mathrm{O} \\
\text { probe }\end{array}$ \\
\hline \multirow{5}{*}{ Eddy-covariance system } & Wind fluctuation & \multirow{5}{*}{2.5} & $\begin{array}{l}\text { CSAT3 3D sonic } \\
\text { anemometer }\end{array}$ \\
\hline & Land carbon flux & & \\
\hline & Sensible heat flux & & \\
\hline & Latent heat flux & & Campbell EC150 \\
\hline & Atmospheric pressure & & \\
\hline \multirow{5}{*}{ Automatic weather stations } & $\begin{array}{l}\text { Wind speed, wind } \\
\text { direction }\end{array}$ & & Gill WindSonic 2D \\
\hline & Air temperature & 2 & $\begin{array}{l}\text { Campbell } \\
\text { HMP155A, 109-L }\end{array}$ \\
\hline & Relative humidity & & Campbell HMP155A \\
\hline & Radiation flux & 1.6 & Hukseflux NR01-L \\
\hline & Precipitation & 1.5 & Geonor T200B \\
\hline \multirow{3}{*}{$\begin{array}{l}\text { Groundwater monitoring } \\
\text { system }\end{array}$} & Groundwater level & & \\
\hline & $\begin{array}{l}\text { Groundwater } \\
\text { temperature }\end{array}$ & -14 & TD-Diver \\
\hline & $\begin{array}{l}\text { Atmospheric pressure } \\
\text { Ambient temperature }\end{array}$ & -0.25 & Baro-Diver \\
\hline
\end{tabular}


Table 2.1. Continued.

\begin{tabular}{|c|c|c|c|c|}
\hline \multicolumn{2}{|c|}{$\begin{array}{l}\text { Monitoring } \\
\text { System/Campaign }\end{array}$} & Items & $\begin{array}{l}\text { Mounting } \\
\text { Height/Depth (m) }\end{array}$ & Sensors/Equipment \\
\hline \multirow{8}{*}{$\begin{array}{l}\text { Hydro- } \\
\text { geological } \\
\text { survey }\end{array}$} & \multirow{6}{*}{$\begin{array}{l}\text { Vadose } \\
\text { zone }\end{array}$} & $\begin{array}{l}\text { Soil saturated } \\
\text { hydraulic conductivity }\end{array}$ & & $\begin{array}{l}\text { Aardvark } \\
\text { permeameter }\end{array}$ \\
\hline & & $\begin{array}{l}\text { Soil thermal } \\
\text { conductivity }\end{array}$ & & $\begin{array}{l}\text { KD2Pro thermal } \\
\text { property analyzer }\end{array}$ \\
\hline & & Soil texture & $-0.05,-0.1,-0.2$ & $\begin{array}{l}\text { Malvern Mastersizer } \\
2000 \text { particle size } \\
\text { analyzer }\end{array}$ \\
\hline & & Soil organic content & $-0.4,-0.0$ & $\begin{array}{l}\text { Total Organic } \\
\text { Content analytical } \\
\text { instrument of Multi } \\
\text { N/C } 3100\end{array}$ \\
\hline & & $\begin{array}{l}\text { Soil water retention } \\
\text { curve }\end{array}$ & & $\begin{array}{l}15 \text { BAR CERAMIC } \\
\text { PLATE } \\
\text { EXTRACTOR }\end{array}$ \\
\hline & & Soil thickness & $-0.2 \sim-1.2$ & Clinometer \\
\hline & \multirow[t]{2}{*}{$\begin{array}{l}\text { Subsurface } \\
\text { soil }\end{array}$} & $\begin{array}{l}\text { Borehole core } \\
\text { lithology }\end{array}$ & $\begin{array}{l}-0.8,-1.9,-4,-6,-8, \\
-10,-12,-14,-16, \\
-18,-20,-22,-24, \\
-26,-28,-30,-32\end{array}$ & Sieve \\
\hline & & $\begin{array}{l}\text { Hydraulic } \\
\text { conductivity }\end{array}$ & / & $\begin{array}{l}\text { TD-Diver, pump, } \\
\text { slug test }\end{array}$ \\
\hline \multirow{3}{*}{\multicolumn{2}{|c|}{ Hydro-geophysical survey }} & $\begin{array}{l}\text { Magnetic } \\
\text { susceptibility }\end{array}$ & Land surface & SM-20 \\
\hline & & Subsurface resistivity & Land surface & $\begin{array}{l}\text { WGMD-9, TEM- } \\
\text { FAST-48 }\end{array}$ \\
\hline & & $\begin{array}{l}\text { Water content, } \\
\text { transmissivity }\end{array}$ & Land surface & Numis Poly \\
\hline
\end{tabular}

Table 2.2. Measured soil properties in Maqu observatory

\begin{tabular}{|c|c|c|c|c|c|c|}
\hline Soil depth $(\mathrm{cm})$ & & $5 \mathrm{~cm}$ & $10 \mathrm{~cm}$ & $20 \mathrm{~cm}$ & $40 \mathrm{~cm}$ & $80 \mathrm{~cm}$ \\
\hline \multirow{3}{*}{ Sand $(\%)$} & $\min$ & 14.45 & 14.44 & 17.00 & 17.81 & 19.06 \\
\hline & mean & 26.95 & 29.03 & 29.20 & 31.60 & 34.83 \\
\hline & $\max$ & 41.37 & 47.59 & 45.34 & 53.11 & 63.31 \\
\hline \multirow{3}{*}{ Clay (\%) } & $\min$ & 8.66 & 8.40 & 9.42 & 9.01 & 5.47 \\
\hline & mean & 9.86 & 9.95 & 10.15 & 10.43 & 9.35 \\
\hline & $\max$ & 11.03 & 11.25 & 10.90 & 11.55 & 13.87 \\
\hline \multirow{3}{*}{ Silt (\%) } & $\min$ & 49.70 & 44.01 & 44.30 & 37.88 & 31.22 \\
\hline & mean & 63.19 & 61.02 & 60.65 & 57.97 & 55.82 \\
\hline & $\max$ & 75.02 & 74.31 & 72.81 & 70.86 & 69.46 \\
\hline \multirow{3}{*}{$\begin{array}{l}\text { Soil organic } \\
\text { content }(\%)\end{array}$} & $\min$ & 9.44 & 5.34 & 4.40 & 0.94 & 0.54 \\
\hline & mean & 17.88 & 12.16 & 8.05 & 4.13 & 2.87 \\
\hline & $\max$ & 39.01 & 22.36 & 20.11 & 10.89 & 9.58 \\
\hline \multirow{3}{*}{$\begin{array}{l}\text { Saturated hydraulic } \\
\text { conductivity Ks } \\
\left(\mathrm{m} \mathrm{s}^{-1}\right)\end{array}$} & $\min$ & / & $1.14 \mathrm{E}-06$ & 7.44E-07 & $1.57 \mathrm{E}-07$ & $2.67 \mathrm{E}-07$ \\
\hline & mean & l & $3.87 \mathrm{E}-06$ & $3.85 \mathrm{E}-06$ & $3.64 \mathrm{E}-07$ & $8.76 \mathrm{E}-06$ \\
\hline & $\max$ & I & 8.53E-06 & $6.27 \mathrm{E}-06$ & $7.33 \mathrm{E}-07$ & $2.63 \mathrm{E}-05$ \\
\hline
\end{tabular}

Data source: Zhao et al. (2018) 


\section{3) Topsoil properties dataset}

For enriching the soil property database, soil samples from eight stations were collected recently in 2016 (three sampling points were located around the central station, and the rest five were in the southeast corner of the Maqu observatory). Meanwhile, the measurement of saturated hydraulic conductivity Ks was conducted in four stations using the Aardvark permeameter (of which, three located near the central station while one located in the southeast corner). Soil samples, taken at soil depth of 0.05, 0.1, 0.2, 0.4 , and $0.8 \mathrm{~m}$, were transported to the laboratory for further analysis. Malvern Mastersizer 2000 particle size analyzer was employed to provide the precise measurement of the soil texture (percentages of sand, clay, and silt). Soil organic content (SOC) was determined with the total organic content analytical instrument, Multi N/C 3100. The undisturbed soil samples, collected by the standard sample rings, were used for the laboratory analysis of the porosity, bulk density, soil heat capacity and thermal conductivity, and soil water retention curve. The relevant equipment was listed in Table 2.1 and the average and minimum/maximum value of the soil properties was presented in Table 2.2. Additional information on the field experiment, laboratory processing procedure, quality assessment for the topsoil hydrothermal properties can be found in Zhao et al. (2018).

\subsubsection{Vegetation and land surface carbon fluxes}

We downloaded MOD15A2H (Myneni et al., 2015) and MOD17A2H (Running et al., 2015 ) products as representative of remotely sensed vegetation dynamics data from the Oak Ridge National Laboratory Distributed Active Archive Center (ORNL DAAC) website. MOD15A2H provides estimates of $8 \mathrm{~d}$ composites of LAI and FPAR, while MOD17A2H an $8 \mathrm{~d}$ composite of gross primary production (GPP). Both MODIS products are at a resolution of $500 \mathrm{~m}$.

The meteorological and $\mathrm{CO}_{2}$ density data from the eddy covariance system and automatic weather station were processed to obtain the reliable land surface carbon fluxes (net ecosystem exchange $N E E$, gross primary production $G P P$, and ecosystem respiration $R_{\text {eco }}$ ). Starting from the raw $N E E$ and ancillary meteorological data (friction velocity $u_{*}$, global radiation $R_{g}$, soil temperature $T_{\text {soil }}$, air temperature $T_{\text {air }}$, and vapor pressure deficit $V P D$ ), we employed the REddyProc package (Reichstein et al., 2005; Wutzler et al., 2018) post-processing tool to obtain the time series of NEE, GPP and $R_{\text {eco }}$ dynamics. Three different techniques, $u_{*}$ filtering, gap filling, and flux partitioning, were adopted in REddyProc package. The period with low turbulent mixing is firstly determined and filtered for quality control $\left(u_{*}\right.$ filtering, Papale et al., 2006). Then, the marginal distribution sampling (MDS) algorithm was used as the gap filling method to replace the missing data (Reichstein et al., 2005). Finally, $N E E$ was 
separated into GPP and $R_{\text {eco }}$ by nighttime based and daytime based approaches (Lasslop et al., 2010). 

Chapter 3 Liquid-Vapor-Air Flow in the Frozen soil*

${ }^{*}$ This chapter is based on the paper: Yu, L., Zeng, Y., Wen, J., \& Su, Z. (2018). Liquid-Vapor-Air Flow in the Frozen Soil. Journal of Geophysical Research: Atmospheres, 123(14), 7393-7415. doi:10.1029/2018JD028502 


\begin{abstract}
Accurate representing freeze-thaw (FT) process is of great importance in cold region hydrology and climate studies. With the STEMMUS-FT model (Simultaneous Transfer of Energy, Mass and Momentum in Unsaturated Soil), we investigated the coupled water and heat transfer in the variably saturated frozen soil and the mechanisms of water phase change along with both evaporation and FT process, at a typical meadow ecosystem on the Tibetan Plateau. The STEMMUS-FT showed its capability of depicting the simultaneous movement of soil moisture and heat flow in frozen soil. The comparison of different parameterizations of soil thermal conductivity indicated that the de Vries parameterization performed better than others in reproducing the hydrothermal dynamics of frozen soils. The analysis of water/vapor fluxes indicated that both the liquid water and vapor fluxes move upward to the freezing front and highlighted the crucial role of vapor flow during soil FT cycles as it connects the water/vapor transfer beneath the freezing front and above the evaporation front. The liquid/vapor advective fluxes make a negligible contribution to the total mass transfer. Nevertheless, the interactive effect of soil ice and air can be found on the spatial and temporal variations of advective fluxes in frozen soils.
\end{abstract}




\subsection{Introduction}

Cold region hydrology is of significant importance to global climate change studies (Hinzman et al., 2005; Cheng \& Wu, 2007; Yang et al., 2014; Ding et al., 2017). For instance, soil freeze-thaw (hereafter as FT) will sharply disturb the thermodynamic equilibrium system and release/absorb large amount of latent heat (Boike et al., 1998; Li \& Koike, 2003). This will further mediate the exchange of water and energy flux between the surface and atmosphere (Viterbo et al., 1999). Moreover, the degradation of permafrost will release carbon stored in the frozen soils and generate the positive feedback on the global warming (Burke et al., 2013; Schaefer et al., 2014). Thus, understanding and representing the underlying physics of FT process are of great interest among scientists.

Large modelling efforts have been made to understand the FT process in cold region as reviewed by Kurylyk \& Watanabe (2013). Most of these FT models, however, differed not only in the physics representing the FT process, but also in many other ways: e.g., numerical discretizations, diagnostic variables, and application in different regions ( $\mathrm{Li}$ \& Koike, 2003; Wang et al., 2010; Zhang et al., 2010; Su et al., 2013; Zhang et al., 2013b; Bao et al., 2016; Wang et al., 2017b). These factors render the intercomparison results difficult to be interpreted and hard to identify the underlying difference among the various FT parameterizations.

Moreover, soil ice, liquid water and water vapor dynamically coexist in the frozen soil pores, the phase change of soil water usually happens along with large amount of latent heat flux (Boike et al., 1998; Li \& Koike, 2003). Soil water and heat transfer are strongly coupled during FT process, neglecting this coupling process in most of the current models limited their capability of accurate description of soil FT physics (Zhang et al., 2007; Endrizzi et al., 2014; Zheng et al., 2017).

The water vapor flow, which has been proved to be of great importance in water and heat transfer of dry soils (Bittelli et al., 2008; Zeng et al., 2009a; Zeng et al., 2009b; Yu et al., 2016), recently have been taken into account by land surface models (LSMs) (Garcia Gonzalez et al., 2012). Similar to the drying soils, vapor flow also plays an important role in frozen soils. Experimental evidence has demonstrated that vapor flow is essential in ice formation and frost heave (Eigenbrod \& Kennepohl, 1996; Zhang et al., 2016b). Dandar et al. (2017) found that the vapor diffusion process can affect not only the water balance but also the energy balance component. The relative contributions of different fluxes and underlying mechanism of water and vapor transfer in drying soils have been widely reported (Scanlon \& Milly, 1994; Boulet et al., 1997; Grifoll et al., 2005; Saito et al., 2006), while little attention has been devoted to such kind of research in terms of frozen soils. Dry air is also one independent component in soil pores. It can significantly retard the infiltration (Touma \& Vauclin, 1986; Prunty 
\& Bell, 2007), enhance the evaporation after irrigation (Zeng et al., 2011b; a; Zeng \& $\mathrm{Su}, 2013$ ), and cause the convective heat transfer (Wicky \& Hauck, 2017). However, how and to what extent the air component affects the soil water and vapor transfer in frozen soils remain unclear.

In this chapter, we conducted an intercomparison of different FT parameterizations based on a common fully coupled water and heat modeling framework (STEMMUSFT, Simultaneous Transfer of Energy, Mass and Momentum in Unsaturated Soil with Freeze-Thaw). On the basis of STEMMUS-FT with the reliable hydrothermal parameterization, we concentrated our research on the investigation of the mechanism of water, vapor and air flow of FT processes. Section 3.2 introduces the STEMMUSFT governing equations and underlying physics, the design of numerical experiments for intercomparing different FT parameterizations, and the soil freezing curves as deployed. Section 3.3 presents the intercomparison results of different FT parameterizations, which identified the best representative schemes for the Tibetan site under investigation. Different mechanisms of water and vapor transfer in frozen soils were analyzed. Section 3.4 discusses the effect of soil ice and the role of vapor and air flow in the frozen soil. The study was concluded in Section 3.5.

\subsection{Methodology}

\subsubsection{STEMMUS-FT model}

The STEMMUS (Simultaneous Transfer of Energy, Mass and Momentum in Unsaturated Soil), detailed in Zeng et al. (2011a; b) and Zeng \& Su (2013), taking into account the soil Freeze-Thaw process (STEMMUS-FT) was developed. The details of governing equations are given below.

\subsubsection{Soil water transfer}

$$
\begin{gathered}
\frac{\partial}{\partial t}\left(\rho_{L} \theta_{L}+\rho_{V} \theta_{V}+\rho_{i} \theta_{i}\right)=-\frac{\partial}{\partial z}\left(q_{L h}+q_{L T}+q_{L a}+q_{V h}+q_{V T}+q_{V a}\right)-S \\
=\rho_{L} \frac{\partial}{\partial z}\left[K\left(\frac{\partial h}{\partial z}+1\right)+D_{T D} \frac{\partial T}{\partial z}+\frac{K}{\gamma_{w}} \frac{\partial P_{g}}{\partial z}\right] \\
+\frac{\partial}{\partial z}\left[D_{V h} \frac{\partial h}{\partial z}+D_{V T} \frac{\partial T}{\partial z}+D_{V a} \frac{\partial P_{g}}{\partial z}\right]-S
\end{gathered}
$$

where $\rho_{L}, \rho_{V}$ and $\rho_{i}\left(\mathrm{~kg} \mathrm{~m}^{-3}\right)$ are the density of liquid water, water vapor and ice, respectively; $\theta_{L}, \theta_{V}$ and $\theta_{i}\left(\mathrm{~m}^{3} \mathrm{~m}^{-3}\right)$ are the volumetric water content (liquid, vapor and ice, respectively); $z(\mathrm{~m})$ is the vertical space coordinate (positive upwards); $S\left(\mathrm{~s}^{-1}\right)$ is the sink term for the root water extraction. $K\left(\mathrm{~m} \mathrm{~s}^{-1}\right)$ is hydraulic conductivity; $h(\mathrm{~m})$ is the pressure head; $T\left({ }^{\circ} \mathrm{C}\right)$ is the soil temperature; and $P_{g}(\mathrm{~Pa})$ is the mixed pore-air pressure. $\gamma_{W}\left(\mathrm{~kg} \mathrm{~m}^{-2} \mathrm{~s}^{-2}\right)$ is the specific weight of water. $D_{T D}\left(\mathrm{~kg} \mathrm{~m}^{-1} \mathrm{~s}^{-1}{ }^{\circ} \mathrm{C}^{-1}\right)$ is the 
transport coefficient for adsorbed liquid flow due to temperature gradient; $D_{V h}\left(\mathrm{~kg} \mathrm{~m}^{-2}\right.$ $\left.\mathrm{s}^{-1}\right)$ is the isothermal vapor conductivity; and $D_{V T}\left(\mathrm{~kg} \mathrm{~m}^{-1} \mathrm{~s}^{-1}{ }^{\circ} \mathrm{C}^{-1}\right)$ is the thermal vapor diffusion coefficient. $D_{V a}$ is the advective vapor transfer coefficient (Zeng et al., 2011a, b). $q_{L h}, q_{L T}$, and $q_{L a}\left(\mathrm{~kg} \mathrm{~m}^{-2} \mathrm{~s}^{-1}\right)$ are the liquid water fluxes driven by the gradient of matric potential $\frac{\partial h}{\partial z}$, temperature $\frac{\partial T}{\partial z}$, and air pressure $\frac{\partial P_{g}}{\partial z}$, respectively. $q_{V h}, q_{V T}$, and $q_{V a}\left(\mathrm{~kg} \mathrm{~m}^{-2} \mathrm{~s}^{-1}\right)$ are the water vapor fluxes driven by the gradient of matric potential $\frac{\partial h}{\partial z}$, temperature $\frac{\partial T}{\partial z}$, and air pressure $\frac{\partial P_{g}}{\partial z}$, respectively.

3.2.1.2 Dry air transfer

$$
\begin{aligned}
\frac{\partial}{\partial t}\left[\varepsilon \rho _ { d a } \left(S_{a}+\right.\right. & \left.\left.H_{c} S_{L}\right)\right] \\
& =\frac{\partial}{\partial z}\left[D_{e} \frac{\partial \rho_{d a}}{\partial z}+\rho_{d a} \frac{S_{a} K_{g}}{\mu_{a}} \frac{\partial P_{g}}{\partial z}-H_{c} \rho_{d a} \frac{q_{L}}{\rho_{L}}+\left(\theta_{a} D_{V g}\right) \frac{\partial \rho_{d a}}{\partial z}\right]
\end{aligned}
$$

where $\varepsilon$ is the porosity; $\rho_{d a}\left(\mathrm{~kg} \mathrm{~m}^{-3}\right)$ is the density of dry air; $S_{a}\left(=1-S_{L}\right)$ is the degree of air saturation in the soil; $S_{L}\left(=\theta_{L} / \mathcal{E}\right)$ is the degree of saturation in the soil; $H_{c}$ is Henry's constant; $D_{e}\left(\mathrm{~m}^{2} \mathrm{~s}^{-1}\right)$ is the molecular diffusivity of water vapor in soil; $K_{g}\left(\mathrm{~m}^{2}\right)$ is the intrinsic air permeability; $\mu_{a}\left(\mathrm{~kg} \mathrm{~m}^{-2} \mathrm{~s}^{-1}\right)$ is the air viscosity; $q_{L}\left(\mathrm{~kg} \mathrm{~m}^{-2} \mathrm{~s}^{-1}\right)$ is the liquid water flux; $\theta_{a}(=\theta)$ is the volumetric fraction of dry air in the soil; and $D_{V g}\left(\mathrm{~m}^{2} \mathrm{~s}^{-1}\right)$ is the gas phase longitudinal dispersion coefficient (Zeng et al., 2011a; b).

\subsubsection{Energy transfer}

$$
\begin{gathered}
\frac{\partial}{\partial t}\left[\left(\rho_{s} \theta_{S} C_{s}+\rho_{L} \theta_{L} C_{L}+\rho_{V} \theta_{V} C_{V}+\rho_{d a} \theta_{a} C_{a}+\rho_{i} \theta_{i} C_{i}\right)\left(T-T_{r}\right)+\rho_{V} \theta_{V} L_{0}-\right. \\
\left.\rho_{i} \theta_{i} L_{f}\right]-\rho_{L} W \frac{\partial \theta_{L}}{\partial t} \\
=\frac{\partial}{\partial z}\left(\lambda_{e f f} \frac{\partial T}{\partial z}\right)-\frac{\partial}{\partial z}\left[q_{L} C_{L}\left(T-T_{r}\right)+q_{V}\left(L_{0}+C_{V}\left(T-T_{r}\right)\right)\right. \\
\left.\quad+q_{a} C_{a}\left(T-T_{r}\right)\right]-C_{L} S\left(T-T_{r}\right)
\end{gathered}
$$

where $C_{s}, C_{L}, C_{V}, C_{a}$ and $C_{i}\left(\mathrm{~J} \mathrm{~kg}^{-1}{ }^{\circ} \mathrm{C}^{-1}\right)$ are the specific heat capacities of solids, liquid, water vapor, dry air and ice, respectively; $\rho_{s}\left(\mathrm{~kg} \mathrm{~m}^{-3}\right)$ is the density of solids; $\theta_{s}$ is the volumetric fraction of solids in the soil; $T_{r}\left({ }^{\circ} \mathrm{C}\right)$ is the reference temperature; $L_{0}\left(\mathrm{~J} \mathrm{~kg}^{-1}\right)$ is the latent heat of vaporization of water at temperature $T_{r} ; L_{f}\left(\mathrm{~J} \mathrm{~kg}^{-1}\right)$ is the latent heat of fusion; $W\left(\mathrm{~J} \mathrm{~kg}^{-1}\right)$ is the differential heat of wetting (the amount of heat released when a small amount of free water is added to the soil matrix); and $\lambda_{\text {eff }}\left(\mathrm{W} \mathrm{m}^{-1}{ }^{\circ} \mathrm{C}^{-1}\right)$ is the effective thermal conductivity of the soil; $q_{L}, q_{V}$, and $q_{a}\left(\mathrm{~kg} \mathrm{~m}^{-2} \mathrm{~s}^{-1}\right)$ are the liquid, vapor water flux and dry air flux. 


\subsubsection{Underlying physics and calculation procedure of STEMMUS-FT}

\section{1) Underlying physics of STEMMUS-FT}

When soil water starts freezing, soil liquid water, ice, vapor, and gas coexist in soil pores. A new thermodynamic equilibrium system will be reached and can be described by the Clausius Clapeyron equation (Fig. 3.1). In combination with soil freezing characteristic curve (SFCC), the storage variation of soil water can be partitioned into the variation of liquid water content $\theta_{L}$ and ice content $\theta_{i}$, and then vapor content $\theta_{V}$.

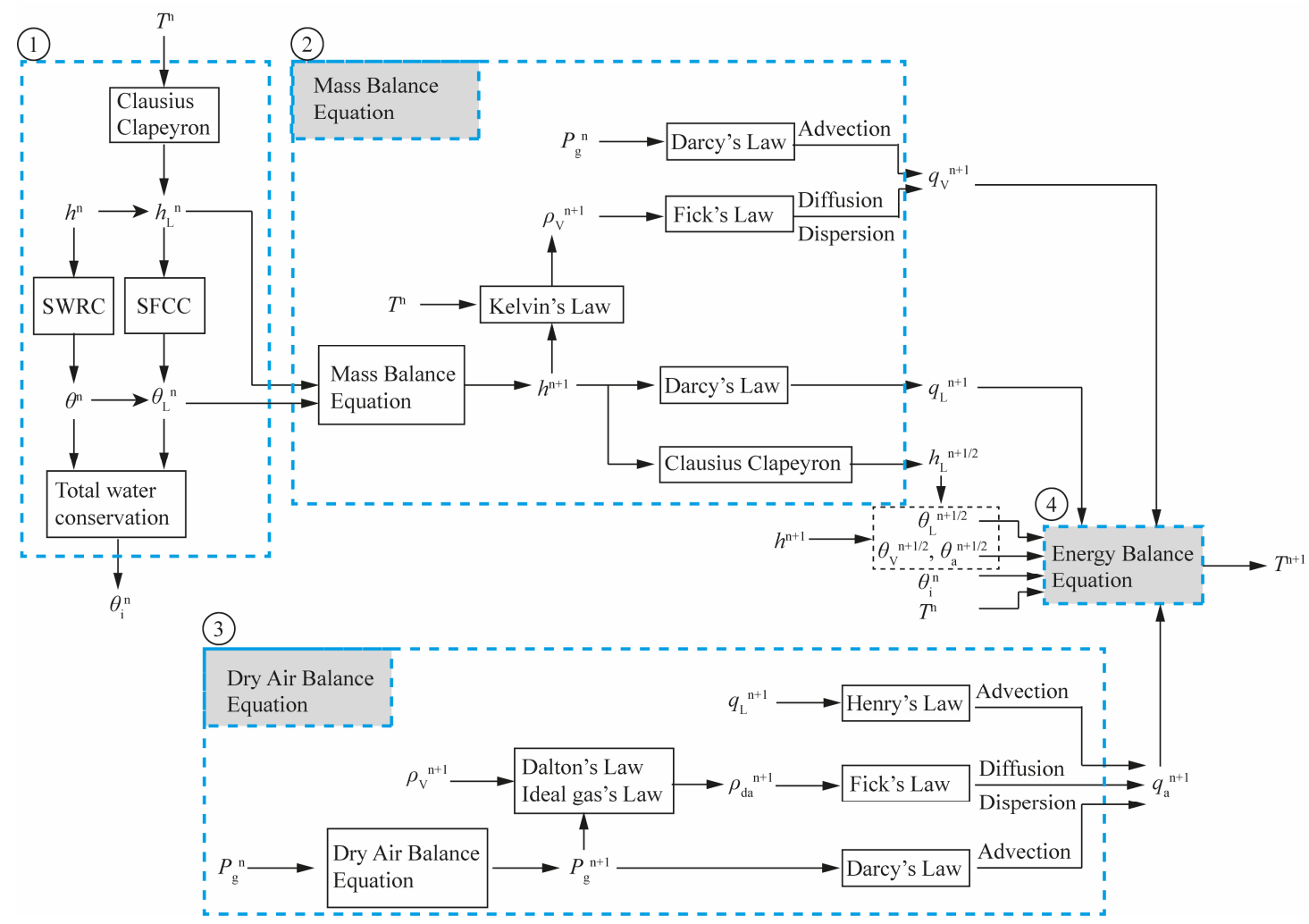

Figure 3.1. The underlying physics and calculation procedure of STEMMUS-FT expressed within one time step. $n$ is the time at the beginning of the time step, $n+1$ is the time at the end. The variables with the superscript $(n+1 / 2)$ are the intermediate values.

With regard to a unit volume of soil, the change of water mass storage with time can be attributed to the change of liquid/vapor fluxes and the root water uptake $S$ (Eq. 3.1). The fluxes, in the right-hand side of Eq. 3.1, can be generalized as the sum of liquid and vapor fluxes. The liquid water transfer is expressed by a general form of Darcy's flow $\left(-\rho_{L} K \frac{\partial\left(h+\frac{P g}{\gamma_{w}}+z\right)}{\partial z}\right)$. According to Gronenevelt \& Kay (1974), the other source of liquid flow is induced by the effect of the heat of wetting on the pressure field $\left(-\rho_{L} D_{T D} \frac{\partial T}{\partial z}\right)$. 
The vapor flow is assumed to be induced in three ways: i) the diffusive transfer (Fick's law), driven by a vapor pressure gradient $\left(-D_{V} \frac{\partial \rho_{V}}{\partial z}\right)$, ii) the dispersive transfer due to the longitudinal dispersivity (Fick's law, $-\theta_{V} D_{V g} \frac{\partial \rho_{V}}{\partial z}$ ), iii) the advective transfer, as part of the bulk flow of air $\left(\rho_{V} \frac{q_{a}}{\rho_{d a}}\right)$. As the vapor density is a function of temperature $T$ and matric potential $h$ (Kelvin's law, Appendix Eq. A1.29), the diffusive and dispersive vapor flux can be further partitioned into isothermal vapor flux, driven by the matric potential gradient $\left(D_{V h} \frac{\partial h}{\partial z}\right)$, and the thermal vapor flux, driven by the temperature gradient $\left(D_{V T} \frac{\partial T}{\partial z}\right)$. The advective vapor flux, driven by the air pressure gradient, can be expressed as $\left(D_{V a} \frac{\partial P_{g}}{\partial z}\right)$ in Equation 3.1.

Dry air transfer in soil includes four components (Eq. 3.2): 1) the diffusive flux (Fick's law) $D_{e} \frac{\partial \rho_{d a}}{\partial z}$, driven by dry air density gradient, 2) the advective flux (Darcy's law, $\rho_{d a} \frac{S_{a} K_{g}}{\mu_{a}} \frac{\partial P_{g}}{\partial z}$ ), driven by the air pressure gradient, 3) the dispersive flux (Fick's law, $\left.\left(\theta_{a} D_{V g}\right) \frac{\partial \rho_{d a}}{\partial z}\right)$, and 4) the advective flux due to the dissolved air (Henry's law, $\left.H_{c} \rho_{d a} \frac{q_{L}}{\rho_{L}}\right)$. According to Dalton's law of partial pressure, the mix soil air pressure $P_{g}$ is the sum of the dry air pressure and water vapor pressure. Considering dry air as an ideal gas, the dry air density $\rho_{d a}$, can be expressed as the function of air pressure $P_{g}$, water vapor density $\rho_{V}$, thus the function of three state variables $\left(h, T, P_{g}\right)$ (see Appendix Eqs. A1.30 \&A1.31).

Heat transfer in soils includes conduction and convection. The conductive heat transfer contains contributions from liquid, solid, gas and ice $\left(\lambda_{e f f} \frac{\partial T}{\partial z}\right)$. The convective heat is transferred by liquid flux $-C_{L} q_{L}\left(T-T_{r}\right),-C_{L} S\left(T-T_{r}\right)$, vapor flux $-\left[L_{0} q_{V}+\right.$ $\left.C_{V} q_{V}\left(T-T_{r}\right)\right]$ and airflow $q_{a} C_{a}\left(T-T_{r}\right)$. The heat storage in soil, the left hand side of Equation 3, includes the bulk volumetric heat content $\left(\rho_{s} \theta_{S} C_{s}+\rho_{L} \theta_{L} C_{L}+\rho_{V} \theta_{V} C_{V}+\right.$ $\left.\rho_{i} \theta_{i} C_{i}\right)\left(T-T_{r}\right)$, the latent heat of vaporization $\left(\rho_{V} \theta_{V} L_{0}\right)$, the latent heat of freezing/thawing $\left(-\rho_{i} \theta_{i} L_{f}\right)$ and a source term associated with the exothermic process of wetting of a porous medium (integral heat of wetting) $\left(-\rho_{L} W \frac{\partial \theta_{L}}{\partial t}\right)$.

\section{2) Calculation procedure of STEMMUS-FT}

The mutual dependence of soil temperature and water content makes frozen soils a complicated thermodynamic equilibrium system. The freezing effect explicitly considered in STEMMUS-FT includes three parts: i) the blocking effect on conductivities (see Appendix A1.2), ii) thermal effect on soil thermal capacity/conductivity (see Appendix A1.3), iii) the release/absorption of latent heat flux 
during water phase change. The calculation procedure of STEMMUS-FT can be summarized as below (Fig. 3.1).

Step 1. Partition of the soil mass storage

First, applying the Clausius Clapeyron equation, soil temperature $T$ at time step $n$ was utilized to achieve the initial soil freezing water potential. Given the pre-freezing water matric potential $h$ and liquid water matric potential $h_{L}$, the SFCC and SWRC are applied to obtain pre-freezing water content $\theta$ and liquid water content $\theta_{L}$. Then the soil ice content $\theta_{i}$ can be derived via total water conservation equation considering the difference in the density between liquid and ice water. The volumetric fraction of soil vapor $\theta_{V}$ in soil pores is the difference of soil porosity and the total water content.

Step 2. Solving the mass balance equation

Taking the soil mass storage variables and matric potentials as inputs, we can solve the mass balance equation successfully. Then a new matric potential can be achieved. Applying Darcy's law with consideration of the blocking effect of soil ice on the hydraulic conductivity, we can get liquid water flux $q_{L}$. The liquid water matric potential can be updated by applying Clausius Clapeyron equation. Applying the Kelvin's law (Appendix Eq. A1.29), we can update the vapor density $\rho_{V}$ at the end of time step. Then the dispersive and diffusive vapor fluxes are possible to be calculated according to Fick's law. Another component of vapor flux is considered as part of the bulk flow of air, which is driven by the air pressure according to Darcy's law.

Step 3. Solving the dry air balance equation

When considering soil dry air as an independent component in soil pores, the dry air balance equation is utilized, whose solution provides the new air pressure $P_{g}^{n+1}$. Applying Dalton's law, air pressure can be partitioned into vapor pressure and dry air pressure. Given the updated vapor density, the dry air density can be expressed as the function of air pressure, and vapor density (Appendix Eqs. A1.30 \&A1.31). Applying Fick's law, we can calculate the diffusive and dispersive components of dry air flux. Applying Darcy's law, the advective flux is derived from the air pressure. To maintain the mechanical and chemical equilibrium, a certain amount of air will dissolve into liquid, such effect is described by Henry's law. Finally, we can achieve the dry air flux $q_{a}$ by the sum of the aforementioned effects.

Step 4. Solving the energy balance equation

Given the inputs, updated values of liquid water flux $q_{L}^{n+1}$, water vapor flux $q_{V}^{n+1}$, soil liquid water content $\theta_{L}^{n+1 / 2}$, vapor content $\theta_{V}^{n+1 / 2}$, ice content $\theta_{i}^{n+1 / 2}$, and dry air flux $q_{a}^{n+1}$, we can update the thermal parameters, calculate the latent heat of water phase 
change, then solve the energy balance equation. A successful estimate of soil temperature will be obtained, which can be used as input for the next time step.

Note that the effect of snow accumulation and ablation was not considered in the current version of STEMMUS-FT model. In our further development of the model, we will incorporate such effect in a more realistic and physical way (e.g., Tarboton \& Luce, 1996; Koren et al., 1999; Boone \& Etchevers, 2001; Ding et al., 2017; Wang et al., 2017b).

\subsubsection{Freeze-Thaw parameterizations}

The water and heat flow during FT processes can be generally characterized by three main sets of parameters: unfrozen water content, hydraulic conductivity and heat capacity/conductivity. Among the commonly used models, two categories of method to estimate unfrozen water content were employed: i) water change as from water to ice is calculated by the available heat energy for such a phase change process (Jansson, 2012). The fixed freezing point is assumed in these schemes and thus it simplifies the physical process of FT; ii) soil freezing depression theory and soil water retention curve are combined to derive the soil freezing characteristic curve (SFCC), which is a function of soil temperature to estimate the unfrozen water content (Flerchinger \& Saxton, 1989; Hansson et al., 2004). Due to the high sensitivity to the calibration of related soil parameters, the empirical equations-based frozen soil parameterizations (e.g., Li \& Koike, 2003; Wang et al., 2009; Wang et al., 2010) were not considered in this study.

The effect of ice presence in soil pores on the hydraulic conductivity is generally characterized by a correction coefficient, which is a function of ice content (Taylor \& Luthin, 1978; Hansson et al., 2004). The calculation of heat conductivity can be divided into three categories: empirical Campbell method (Hansson et al., 2004), Johansen method (Johansen, 1975) and de Vires method (De Vries, 1963). Due to the necessity in the calibration of parameters, the empirical Campbell method is complicated and rarely employed in LSMs and thus not discussed in the current context. While other variations of Johansen method and de Vries method, in which the parameters are based on soil texture information, i.e., Farouki method (Farouki, 1981) and simplified de Vries method (Tian et al., 2016), were further incorporated into STEMMUS-FT. A brief review of the different parameterizations for frozen soil employed in current models is given by Table 3.1 .

The above FT parameterizations are used as constitutive equations for STEMMUS-FT, and are detailed in Appendix A1 and further designed as different numerical experiments in section 3.2.3. 
Table 3.1. Different model parameterizations for frozen soil.

\begin{tabular}{|c|c|c|c|c|c|}
\hline Model & $\begin{array}{l}\text { Unfrozen water } \\
\text { content }\end{array}$ & Hydraulic conductivity $K$ & $\begin{array}{l}\text { Heat } \\
\text { conductivity }\end{array}$ & $\begin{array}{l}\text { Soil water } \\
\text { and heat } \\
\text { transfer }\end{array}$ & Reference \\
\hline Noah-MP & $\begin{array}{l}\text { SFCC (Clapeyron }+ \\
\text { Clapp and } \\
\text { Hornberger) }^{\mathrm{a}}\end{array}$ & $\begin{array}{l}\text { Clapp and Hornberger }+ \text { ice } \\
\text { correction coefficient }\end{array}$ & $\begin{array}{l}\text { Johansen } \\
\text { method }\end{array}$ & uncoupled & $\begin{array}{l}\text { (Yang et al., } \\
2011 \text { ) }\end{array}$ \\
\hline CLM 4.5 & $\begin{array}{l}\text { SFCC (Clapeyron }+ \\
\text { Clapp and } \\
\text { Hornberger) }\end{array}$ & $\begin{array}{l}\text { Clapp and Hornberger }+ \text { ice } \\
\text { correction coefficient }\end{array}$ & $\begin{array}{l}\text { Johansen } \\
\text { method }\end{array}$ & uncoupled & $\begin{array}{l}\text { (Oleson et al., } \\
\text { 2013) }\end{array}$ \\
\hline SHAW & $\begin{array}{l}\text { SFCC (Clapeyron + } \\
\text { Brooks-Corey) }\end{array}$ & $\begin{array}{l}\text { Clapp and Hornberger, reduced } \\
\text { linearly with ice content }\end{array}$ & $\begin{array}{l}\text { de Vires } \\
\text { method }\end{array}$ & coupled & $\begin{array}{l}\text { (Flerchinger \& } \\
\text { Saxton, 1989) }\end{array}$ \\
\hline COUP & $\begin{array}{l}\text { Available energy for } \\
\text { phase change }\end{array}$ & $\begin{array}{l}\text { Van Genuchten + impedance } \\
\text { factor }\end{array}$ & $\begin{array}{l}\text { Kersten } \\
\text { method }\end{array}$ & coupled & (Jansson, 2012) \\
\hline CLASS & $\begin{array}{l}\text { Available energy for } \\
\text { phase change }\end{array}$ & $\begin{array}{l}\text { Clapp and Hornberger }+ \text { ice } \\
\text { correction coefficient }\end{array}$ & $\begin{array}{l}\text { Johansen } \\
\text { method }\end{array}$ & coupled & $\begin{array}{l}\text { (Verseghy, } \\
\text { 2009) }\end{array}$ \\
\hline HTESSEL & $\begin{array}{l}\text { SFCC (empirical } \\
\text { function of soil } \\
\text { temperature) }\end{array}$ & $\begin{array}{l}\text { Weighted values between } \\
\text { unfrozen and frozen hydraulic } \\
\text { conductivity }\end{array}$ & $\begin{array}{l}\text { Johansen } \\
\text { method }\end{array}$ & uncoupled & $\begin{array}{l}\text { (Viterbo et al., } \\
\text { 1999) }\end{array}$ \\
\hline HYDRUS & $\begin{array}{l}\text { SFCC (Clapeyron }+ \\
\text { Van Genuchten) }\end{array}$ & $\begin{array}{l}\text { Van Genuchten + impedance } \\
\text { factor }\end{array}$ & $\begin{array}{l}\text { Modified } \\
\text { Campbell } \\
\text { method }\end{array}$ & coupled & $\begin{array}{l}\text { (Hansson et al., } \\
\text { 2004) }\end{array}$ \\
\hline CoLM & $\begin{array}{l}\text { SFCC (Clapeyron }+ \\
\text { Clapp and } \\
\text { Hornberger) }\end{array}$ & $\begin{array}{l}\text { Clapp and Hornberger }+ \text { ice } \\
\text { correction }\end{array}$ & $\begin{array}{l}\text { Johansen } \\
\text { method }\end{array}$ & uncoupled & $\begin{array}{l}\text { (Dai et al., } \\
\text { 2001) }\end{array}$ \\
\hline
\end{tabular}

\subsubsection{Design of numerical experiments}

To assess the effect of different hydraulic parameterizations on the performance of STEMMUS-FT model, two control experiments (Ctrl1 and Ctrl2) were designed, in which Van Genuchten and Clapp and Hornberger hydraulic schemes were employed respectively, with De Vries method for the heat conductivity (Table 3.2). On the basis of two control experiments, the performance of STEMMUS-FT with three other thermal parameterizations was further investigated (i.e., EXP1, for Farouki method, EXP2, for Simplified De Vries method, and EXP3, for Johansen method).

A dataset collected from 1 Dec. 2015 to 15 Mar. 2016 at Maqu SMST site was employed to run and evaluate all the numerical experiments. Soil moisture and temperature at various depths are utilized to initialize and to validate STEMMUS-FT model. Land surface latent heat flux is employed to investigate the model performance and further to testify the underlying physics of soil water, vapor and air transfer in the frozen soil. The average feature of soil properties is listed in Table 3.3. The type of vegetation is grassland, which will be in low activity during frozen periods. Thus, the assumption that there is no transpiration when soil temperature drops below $0^{\circ} \mathrm{C}$ was adopted (Kroes et al., 2008). Refer to Zheng et al. (2015a, b) for further details of the vegetation and soil parameters. 
Table 3.2. Numerical experiment designs to assess the different FT parameterizations.

\begin{tabular}{|c|c|c|c|c|c|c|c|c|c|}
\hline \multirow{2}{*}{\multicolumn{2}{|c|}{ Experiment }} & \multicolumn{2}{|c|}{ Unfrozen Water Content } & \multicolumn{2}{|c|}{ Hydraulic Conductivity } & \multicolumn{4}{|c|}{ Heat Conductivity } \\
\hline & & \multirow{2}{*}{$\begin{array}{l}\text { Clapeyron + } \\
\text { VG }\end{array}$} & \multirow{2}{*}{$\begin{array}{l}\text { Clapeyron + } \\
\mathrm{CH}\end{array}$} & \multirow[b]{2}{*}{ VG } & \multirow[b]{2}{*}{$\mathrm{CH}$} & \multirow[b]{2}{*}{ D63 } & \multirow[b]{2}{*}{ F81 } & \multirow[b]{2}{*}{ T16 } & \multirow[b]{2}{*}{ J75 } \\
\hline & & & & & & & & & \\
\hline Ctrl1 & & $\mathrm{V}$ & & $v$ & & $\mathrm{~V}$ & & & \\
\hline $\mathrm{Ctrl} 2$ & & & $\mathrm{v}$ & & $\mathrm{v}$ & $v$ & & & \\
\hline & EXP1 & $v$ & & V & & & V & & \\
\hline \multirow[t]{3}{*}{ Ctrl1 } & EXP2 & $\mathrm{v}$ & & $v$ & & & & $\mathrm{v}$ & \\
\hline & EXP3 & V & & $v$ & & & & & $v$ \\
\hline & EXP1 & & V & & v & & V & & \\
\hline \multirow[t]{2}{*}{$\mathrm{Ctr} 12$} & EXP2 & & V & & $v$ & & & $v$ & \\
\hline & EXP3 & & $\mathrm{v}$ & & $\mathrm{v}$ & & & & $\mathrm{v}$ \\
\hline
\end{tabular}

Note: VG, Van Genuchten (van Genuchten, 1980, Appendix Eqs. A1.1-A1.4); CH, Clapp and Hornberger (Clapp \& Hornberger, 1978, Appendix Eq. A1.5); Heat conductivity: J75, Johansen thermal conductivity method (Johansen, 1975, Appendix Eqs. A1.10-A1.15); F81, Farouki method (Farouki, 1981, Appendix Eq. A1.16); D63, de Vries method (De Vries, 1963, Appendix Eqs. A1.17-A1.19); T16, Simplified De Vries method (Tian et al., 2016, Appendix Eqs. A1.20-A1.22).

Table 3.3. The average values of soil texture and hydraulic properties at different depths.

\begin{tabular}{llllllllll}
\hline Soil depth (cm) & $\begin{array}{l}\text { Clay } \\
(\%)\end{array}$ & $\begin{array}{l}\text { Sand } \\
(\%)\end{array}$ & $\begin{array}{l}K_{\mathrm{s}} \\
\left(10^{-6}\right. \\
\left.\mathrm{m} \mathrm{s}^{-1}\right)\end{array}$ & $\begin{array}{l}\theta_{\mathrm{s}} \\
\left(\mathrm{cm}^{3}\right)\end{array}$ & $\begin{array}{l}\text { CH model } \\
\left.\mathrm{cm}^{-3}\right)\end{array}$ & $\begin{array}{l}\psi_{\mathrm{s}}(\mathrm{m}) \\
b\end{array}$ & $\begin{array}{l}\theta_{\mathrm{r}} \\
\left(\mathrm{cm}^{3} \mathrm{~cm}^{-3}\right)\end{array}$ & $\alpha\left(\mathrm{m}^{-1}\right)$ & $n$ \\
\hline $5-10$ & 9 & 44.13 & 1.45 & 0.5 & 0.17 & 4.178 & 0.035 & 0.04139 & 1.332 \\
$10-40$ & 10.12 & 44.27 & 0.94 & 0.45 & 0.17 & 4.3 & 0.039 & 0.04139 & 1.3618 \\
$40-80$ & 5.59 & 65.55 & 0.68 & 0.41 & 0.1 & 3.4 & 0.045 & 0.075 & 1.59 \\
\hline
\end{tabular}

Note: VG, Van Genuchten (van Genuchten, 1980); CH, Clapp and Hornberger (Clapp \& Hornberger, 1978).

\subsubsection{Soil freezing characteristic curve}

In order to obtain unfrozen water content, the potential-freezing point depression theory (Koopmans \& Miller, 1966; Dall'Amico, 2010) and the reversion of two water retention equations were combined to characterize SFCC, that is, the relation between unfrozen water content and subfreezing temperature. In-situ measurements of the liquid water contents for the subzero temperatures at soil depths of $5,10,20,40$, and $80 \mathrm{~cm}$ were used to fit the SFCCs.

Figure 3.2 shows the measured and estimated unfrozen water content with two SFCC parameterizations (Appendix Eqs. A1.2 \& A1.5). Both method can capture the dependence of unfrozen water content on soil temperature at different soil depths. Due to the multiple freezing/thawing cycles, the relationship of unfrozen water content and 
soil temperature are not constrained along with one single SFCC but with certain range (e.g., see observation data in Figure 3.2a, b \& c), which indicates the hysteresis effect. It can also be found in Fig. 3.2e that when liquid water content approaches the residual water content (c.a. $0.05 \mathrm{~cm}^{3} \mathrm{~cm}^{-3}$ ), both types of SFCCs fail to capture the relationships between liquid water content and soil temperature.
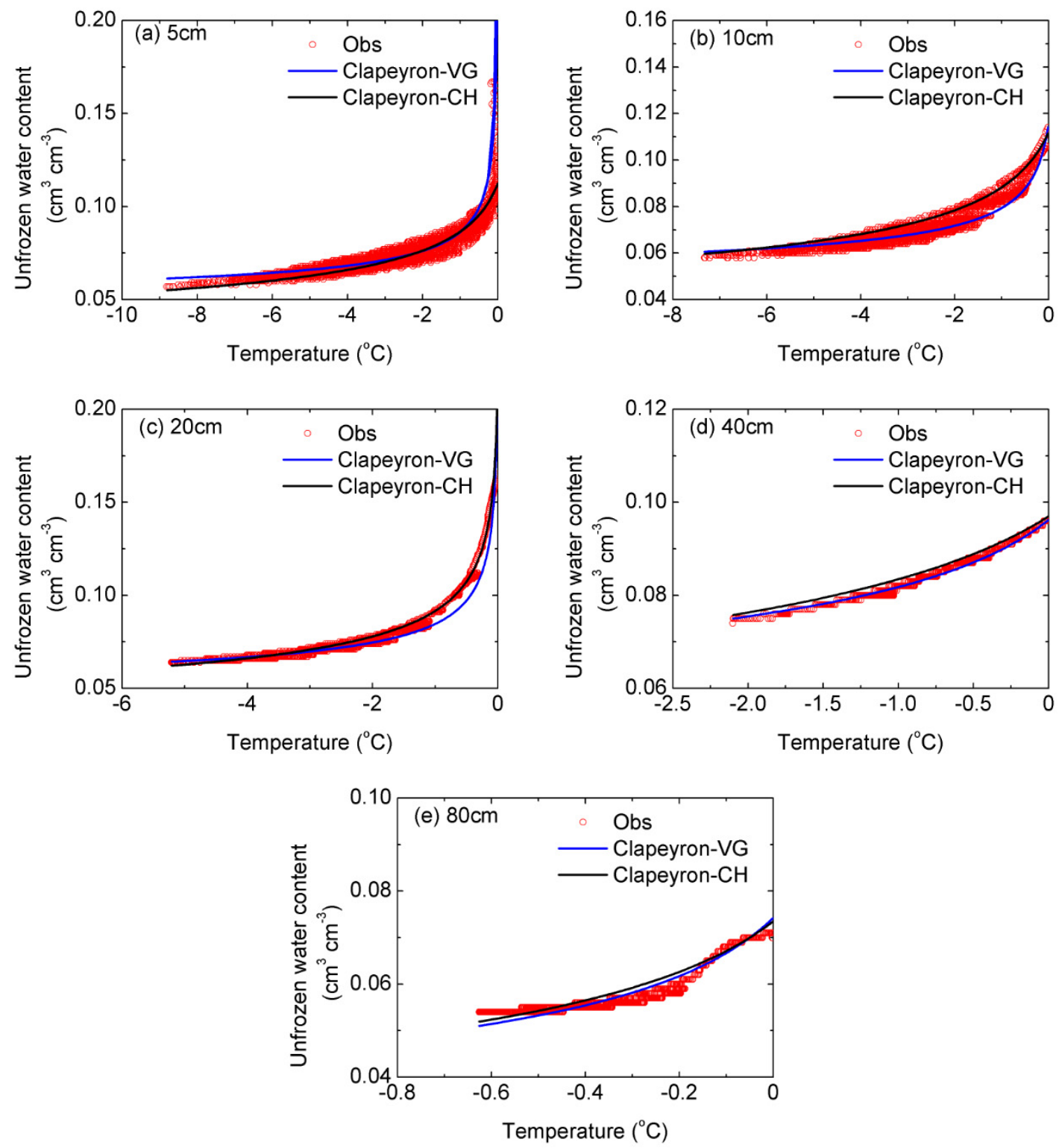

Figure 3.2. Observed and simulated unfrozen water content under subfreezing soil temperature using two SFCC parameterizations at different soil layers $(5,10,20,40$, and $80 \mathrm{~cm})$. Clapeyron-VG and Clapeyron-CH represent the SFCC using Van Genuchten (Van Genuchten, 1980) and Clapp and Hornberger (Clapp \& Hornberger, 1978) method, respectively. 


\subsection{Results}

\subsubsection{Assessment of soil hydraulic parameterizations}

Figure 3.3 shows the comparison of soil temperature simulated using two hydraulic schemes (Ctrl 1 and Ctrl 2, with D63 for heat conductivity, see Table 3.2) and observed values at different soil depths. As indicated by Fig. 3.3, FT processes can be separated into three periods: i) freezing period. Despite of the daily fluctuation of soil temperature, the trend of soil temperature keeps falling down, and the freezing front extends downward rapidly. ii) transition period. The soil temperature is getting warmer and finally stabilized just below the freezing temperature (melting soil ice requires much more energy). The propagation rate of freezing front slows down and keeps stable. iii) thawing period. The soil temperature increase above the freezing temperature as enough energy is absorbed at topsoil. Thawing front initializes from topsoil. Following the Fourier heat transfer theory, the trend of soil temperature propagated downward, while the daily variation damped and time lag increased with the increasing soil depths. STEMMUS-FT with both hydraulic schemes can capture very well the diurnal and seasonal variations of soil temperature during the freezing, transition and thawing period at upper soil layers. At soil depth of $40 \mathrm{~cm}$, the soil temperature was significantly underestimated by STEMMUS-FT model. This may be attributed to the sharply changed soil texture (see Table 3.3), which has a significant effect on the soil thermal properties. In addition, the observed sharp decrease of soil temperature at $40 \mathrm{~cm}$ soil depth around 25 December is abnormal. Whether this observed sharp decrease phenomenon ranged from 2 to $0{ }^{\circ} \mathrm{C}$ is an observation error or the misinterpretation of the underlying physics requires further investigation. 


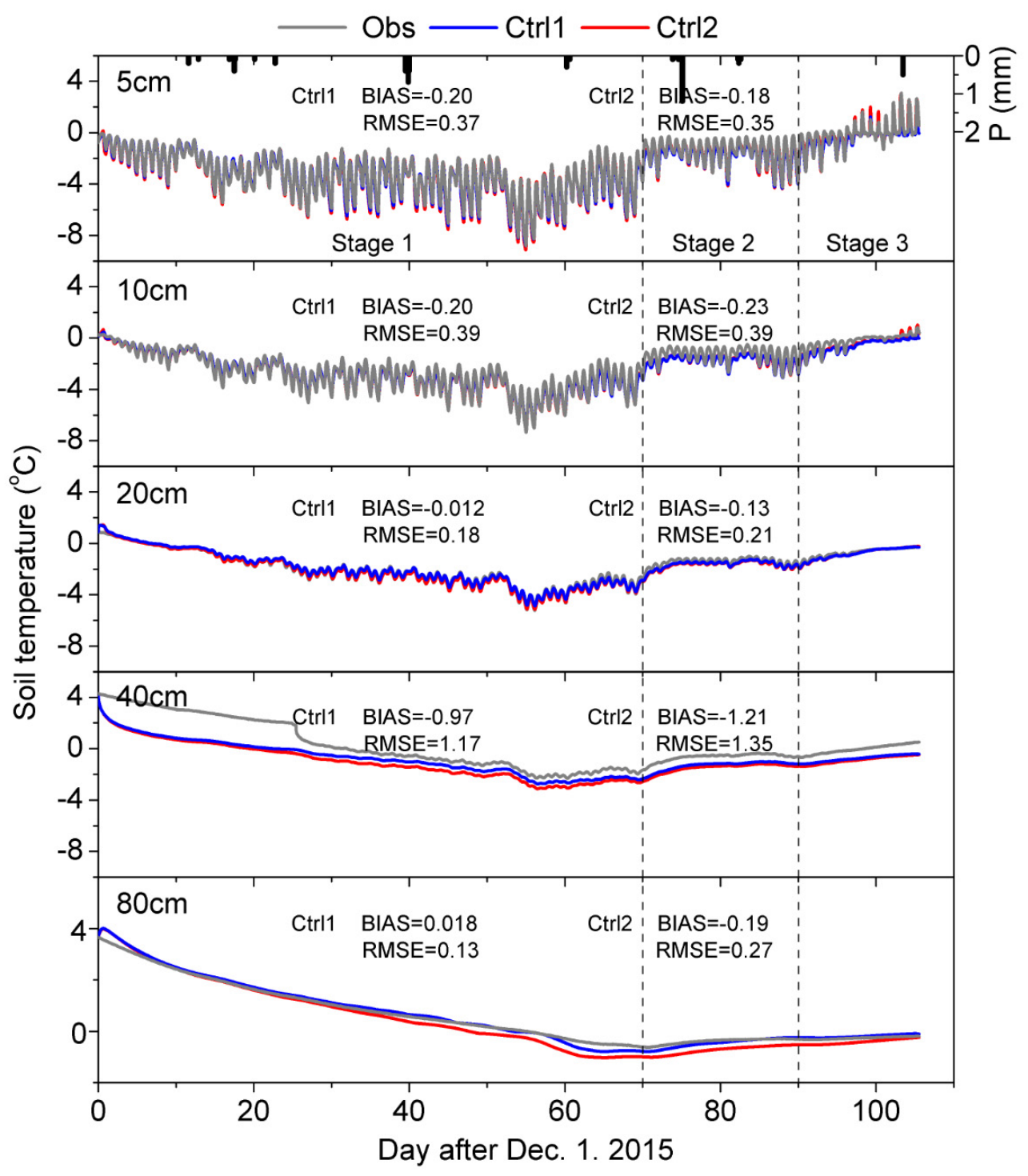

Figure 3.3. Comparison of observed and simulated soil temperature at different soil layers using different parameterizations of unfrozen water content and hydraulic conductivity (Ctrl1-Ctrl2). 


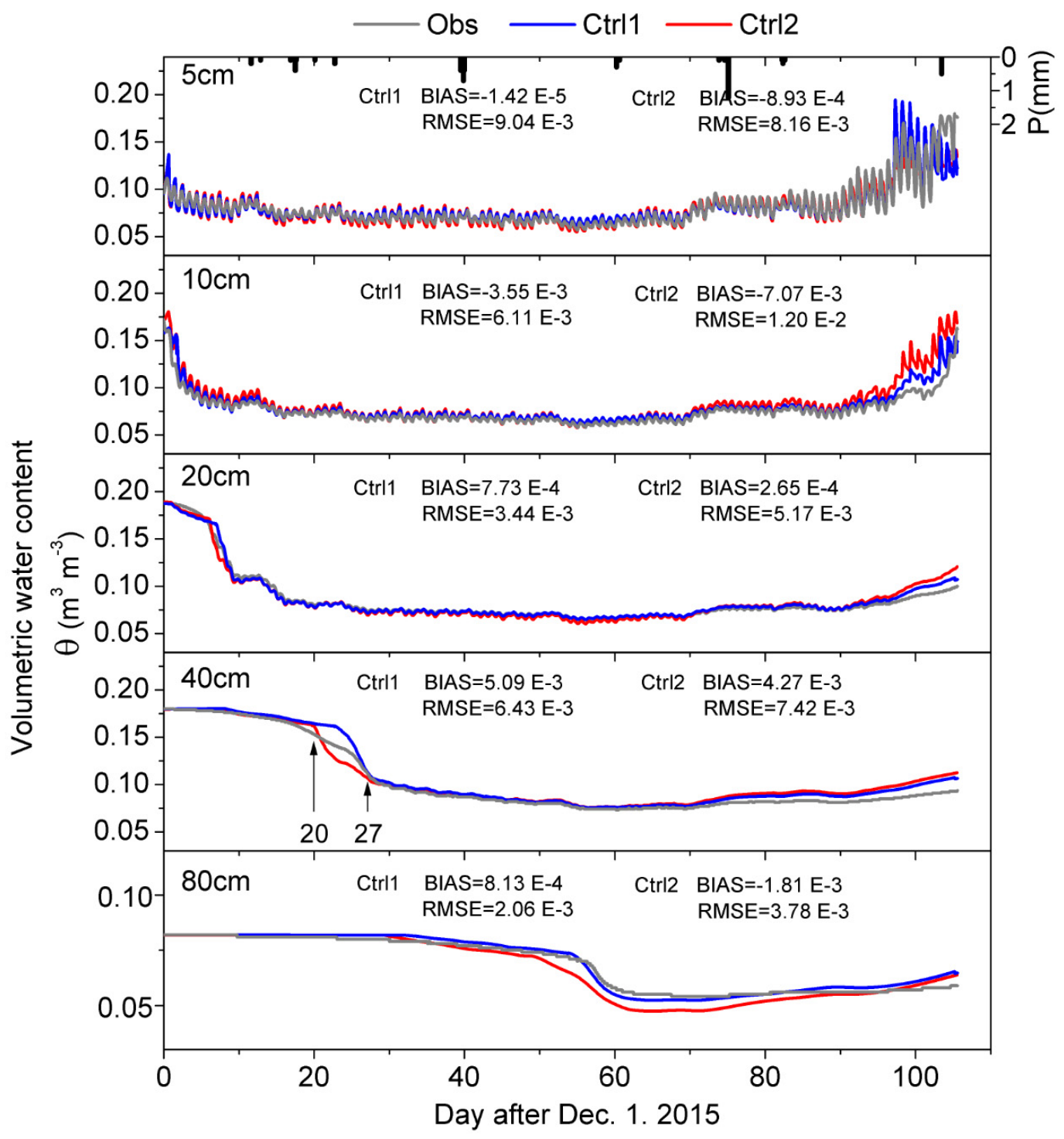

Figure 3.4. Same as Figure 3.3, but for volumetric water content.

Observed soil liquid water content at five soil depths were employed to assess the model performance of STEMMUS-FT with two different hydraulic schemes (Fig. 3.4). For the upper soil layers $(5-20 \mathrm{~cm})$, soil liquid water contents were well simulated at freezing period and transition period, while little overestimation was given at the thawing period at soil depth of $10 \mathrm{~cm}$ and $20 \mathrm{~cm}$. During the freezing/thawing transition period, soil suffers from frequent freeze/thaw cycles and the heat exchange (release/absorb latent heat during freezing/thawing process) is significant. The soil hydraulic properties can change observably due to the freeze/thaw cycles (i.e., after the freeze/thaw cycle, the soil hydraulic parameters are not the same as the former ones) (Qi et al., 2006; Ishikawa et al., 2016). These make it more difficult to mimic the water 
and heat transfer during transition periods, especially when the current existing FT models/theories do not consider comprehensively all these effects.

At the soil depth of $40 \mathrm{~cm}$, STEMMUS-FT estimated unfrozen water content agreed well with the measured values except for the rapid freezing period (20-27 December). Soil liquid water content was overestimated and underestimated by the experiment Ctrl1 and Ctrl2, respectively. It can be due to both the soil temperature drop at $40 \mathrm{~cm}$ (see Fig. 3.3) and the uncertainties in SFCC models (Fig. 3.2d). The underestimation of soil temperature results in the underestimation of soil liquid water content at $80 \mathrm{~cm}$. While the underestimation of liquid water content for the numerical experiment Ctrl1 is acceptable, such underestimation for the numerical experiment $\mathrm{Ctrl} 2$ is obvious from $45^{\text {th }}$ to $80^{\text {th }}$ days after 1 December 2015. The divergence between the two hydraulic schemes enlarged at the rapid freezing period (e.g., $40 \mathrm{~cm}$ ) and thawing period (e.g., 10 $\mathrm{cm}$ ), which implicated that the divergence of different hydraulic schemes was highly sensitive to the rapid freezing/thawing process.

Frost depth, derived from the zero-thermal line, was usually employed to characterize the evolution of FT process. As shown in Fig. 3.5, soil water begins to freeze at a relatively high rate, then slows down until 20 December 2015 (i.e., observation in Fig. $3.5)$, which may be due to the snow insulating effect. The freezing process continues with a high speed and levels off from the $70^{\text {th }}$ days after 1 December 2015. STEMMUSFT well predicts the dynamic of freezing depth as observed. However, the slowing down of freezing rate during 10-27 December was not fully captured mainly due to (i) the inaccurate "observation" values of frost depth due to the linear interpolation between two soil temperature measurements and (ii) STEMMUS-FT that lacks a detailed representation of snow process on land surface.

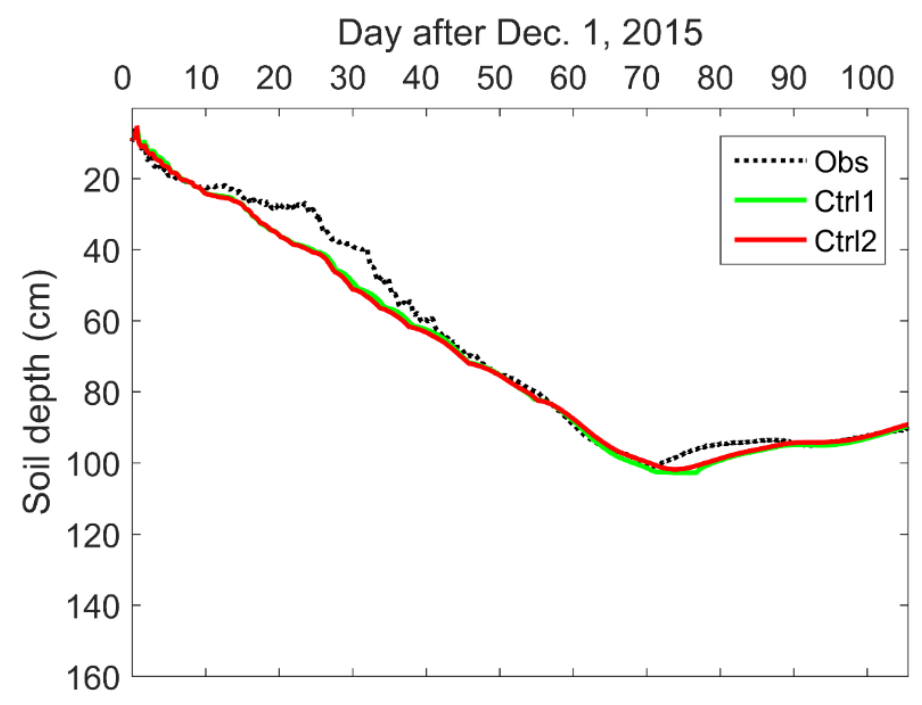

Figure 3.5. Comparison of observed and simulated soil freezing front using different parameterizations of unfrozen water content and hydraulic conductivity (Ctrl1-Ctrl2). 


\subsubsection{Assessment of parameterizations of soil thermal conductivity}

To understand the effect of multiparameterizations of soil thermal conductivity on modeling the FT process, we investigated the observed and simulated soil freezing front using different thermal schemes (see Table 3.2). It is to note that the thermal schemes under investigation are all based on the soil texture information for the inputs. As such, all the input parameters (Table 3.3) are the same for the designed numerical experiments showed in Table 3.2. Figure 3.6 shows that F81 generated the fastest freezing rate than other methods, indicating the highest thermal diffusivity predicted. The J75 and T16 perform better than F81 method; however, a deeper frost depth than the observed values was predicted. D63 method gives the best performance.
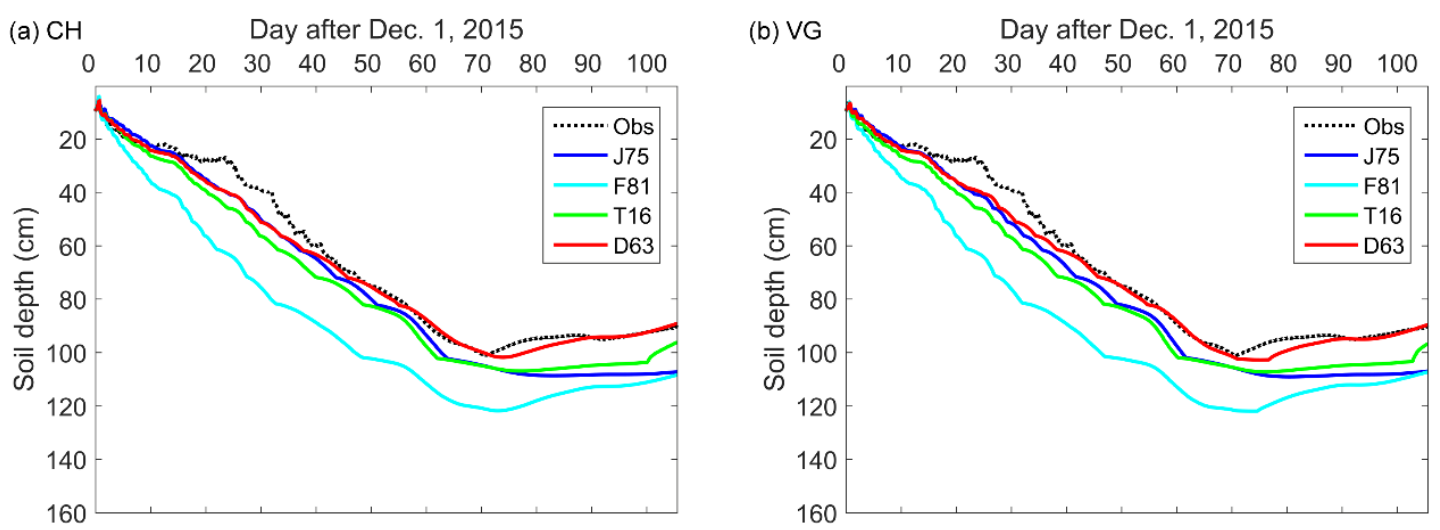

Figure 3.6. Comparison of observed and simulated soil freezing front using different parameterizations of thermal conductivity (see Table 3.2) with (a) Clapp and Hornberger $(\mathrm{CH})$ and (b) van Genuchten (VG) hydraulic schemes.

\subsubsection{Mechanism of water and vapor transfer in frozen soils}

After validating the performance of STEMMUS-FT model with different hydrothermal parameterizations, the simulation results of numerical experiment Ctrll were utilized to further investigate the underlying mechanism of water and vapor transfer during FT process.

\subsubsection{Freezing period}

Diurnal dynamics of latent heat flux during the rapid freezing period, from eighth to twelfth days after 1 December 2015, is shown as Fig. 3.7a. Although the values are not large, the diurnal variations of latent heat flux were obvious and captured well by the proposed model, with the root-mean-square error, bias, and $R^{2}$ values of $1.55 \mathrm{E}-7$, $5.04 \mathrm{E}-8 \mathrm{~g} \mathrm{~cm}^{-2} \mathrm{~s}^{-1}$, and 0.80 , respectively. To understand the relative contribution of liquid, vapor and air flow to the total mass flux, the surface latent heat was partitioned into different components as Fig. 3.7b \& c. According to Equation (3.1), total mass transfer can be separated into liquid water flux driven by temperature $q_{L T}$, matric 
potential $q_{L h}$ and air pressure $q_{L a}$, water vapor flux driven by temperature $q_{V T}$, matric potential $q_{V h}$ and air pressure $q_{V a}$.

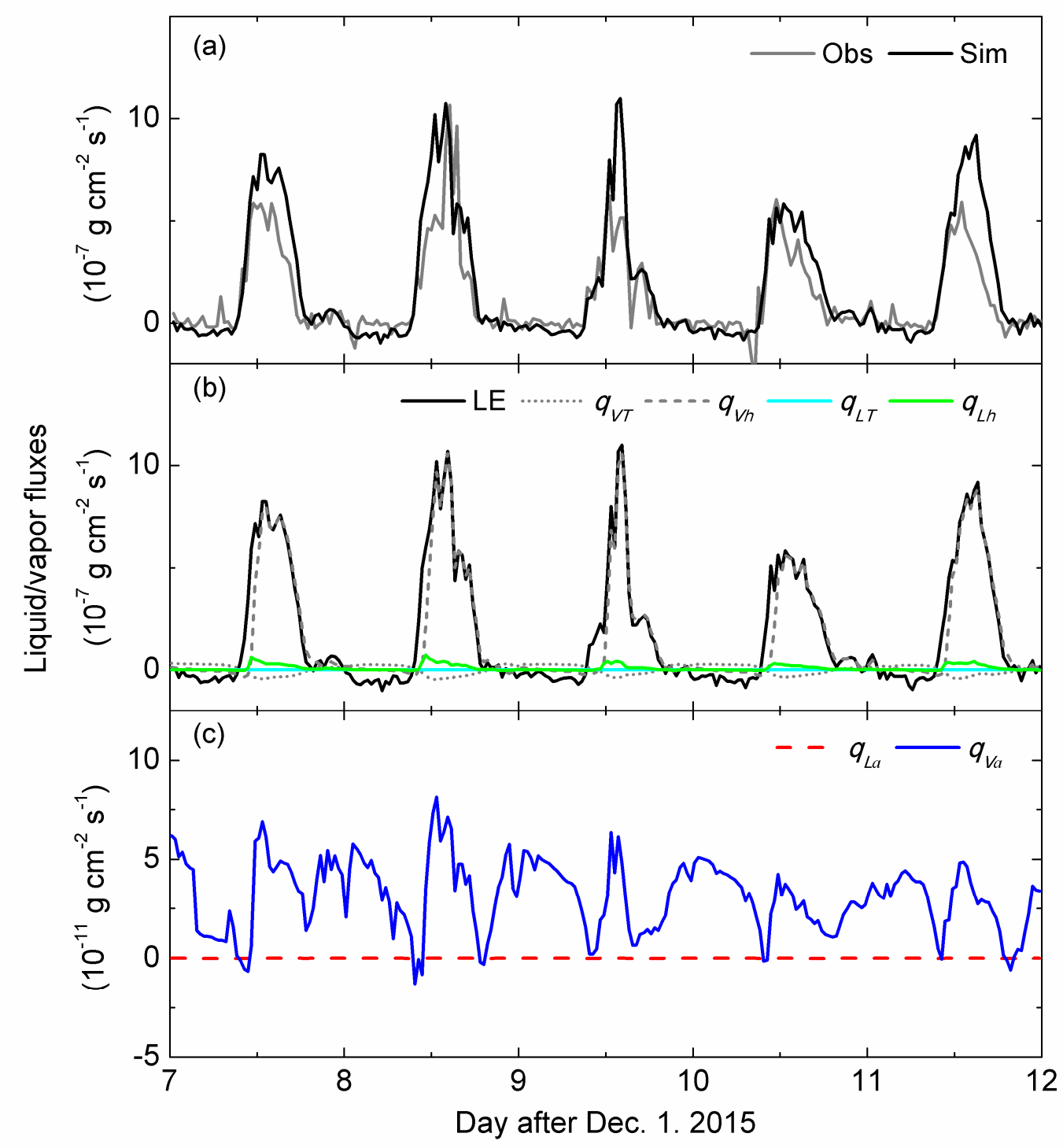

Figure 3.7. Observed latent heat flux and simulated (a) latent heat flux and (b) surface soil $(0.1 \mathrm{~cm})$ thermal and isothermal liquid water and vapor fluxes (LE, $q_{V T}, q_{V h}, q_{L T}$, $\left.q_{L h}\right)(\mathrm{c})$ surface soil $(0.1 \mathrm{~cm})$ advective liquid water and vapor fluxes $\left(q_{L a}, q_{V a}\right)$ of a typical five-day freezing period (from eighth to twelfth days after 1 December 2015). LE is the latent heat flux, $q_{V T}, q_{V h}$ are the water vapor fluxes driven by temperature and matric potential gradients, $q_{L T}, q_{L h}$ are the liquid water fluxes driven by temperature and matric potential gradients, $q_{L a}, q_{V a}$ are the liquid and vapor water fluxes driven by air pressure gradients. Positive/negative values indicate upward/downward fluxes. 
While the downward thermal vapor flux driven by a downward temperature gradient occurred during daytime, there was a comparable amount of upward liquid water flux due to an upward matric potential gradient. The isothermal vapor flux played a dominant role in the total mass flux at topsoil layers when soil is freezing, which is similar to the drying process (Saito et al., 2006). The source for such an upward water vapor flux, however, was not only the isothermal liquid water flux $q_{L h}$, but also the vapor directly from ice sublimation. Other components, liquid water flux driven by temperature gradient, liquid/vapor water flux driven by air pressure gradient, appeared negligible to the total mass flux during day/nighttime.

Figure 3.8 shows the vertical flux profiles during the rapid freezing period, which can be classified into different zones as follows. Compared to the thermal/isothermal liquid/vapor fluxes, the air pressure induced liquid/vapor fluxes are relatively small. Thus, we separately presented the vertical variations of liquid/vapor advective fluxes $\left(q_{L a}, q_{V a}\right)$ in Fig. 3.9.

\section{1) Zone 1 (region at and below the freezing front)}

Observably, an upward transport of liquid water flux $q_{L h}$ occurred at the freezing front, that is, the soil depth of $22 \mathrm{~cm}$ in the eleventh December, where soil ice diminished (Fig. 3.8a). This movement of liquid water is primarily due to a large upward moisture gradient around the freezing front, with the soil moisture decreased by about $36 \%$ (from $0.175 \mathrm{~cm}^{3} \mathrm{~cm}^{-3}$ at soil depth of $24 \mathrm{~cm}$ to $0.112 \mathrm{~cm}^{3} \mathrm{~cm}^{-3}$ at soil depth of $20 \mathrm{~cm}$ ). There was also an observable amount of upward thermal vapor flux $q_{V T}$, which takes up about $13 \%$ of total water flux $\left(q_{L h}+q_{V T}\right)$ toward the freezing front. In the region below the freezing front, where the variation of soil moisture was nearly uniform, the isothermal liquid water flux moved downward mainly due to the gravity flow. Note that only the soil depth upper than $30 \mathrm{~cm}$ was presented in Fig. 3.8 to concentrate our analysis on the FT process. During the selected typical freezing period, there was no significant effects of FT process on the transport of the water/vapor fluxes in the region below the depth of $30 \mathrm{~cm}$. The water/vapor transfer behavior of this region is similar to the drying process, as reported by Boulet et al. (1997) and Grifoll et al. (2005).

In this region, there was no significant difference in the transfer patterns of soil temperature and moisture gradient induced liquid/vapor fluxes between the daytime and nighttime (Fig. 3.8a and 3.8b). 
(a) Mid-day Temperature $T\left({ }^{\circ} \mathrm{C}\right)$

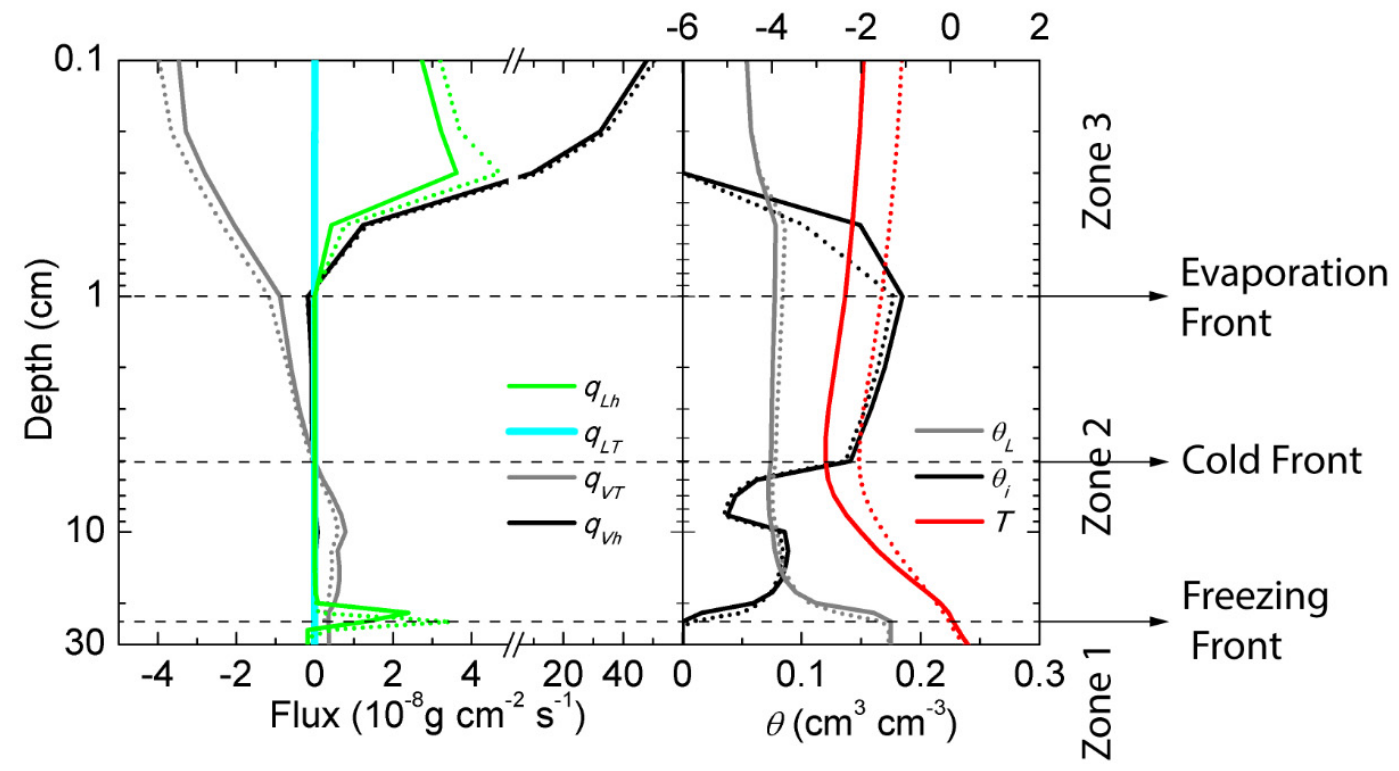

(b) Mid-night

Temperature $T\left({ }^{\circ} \mathrm{C}\right)$

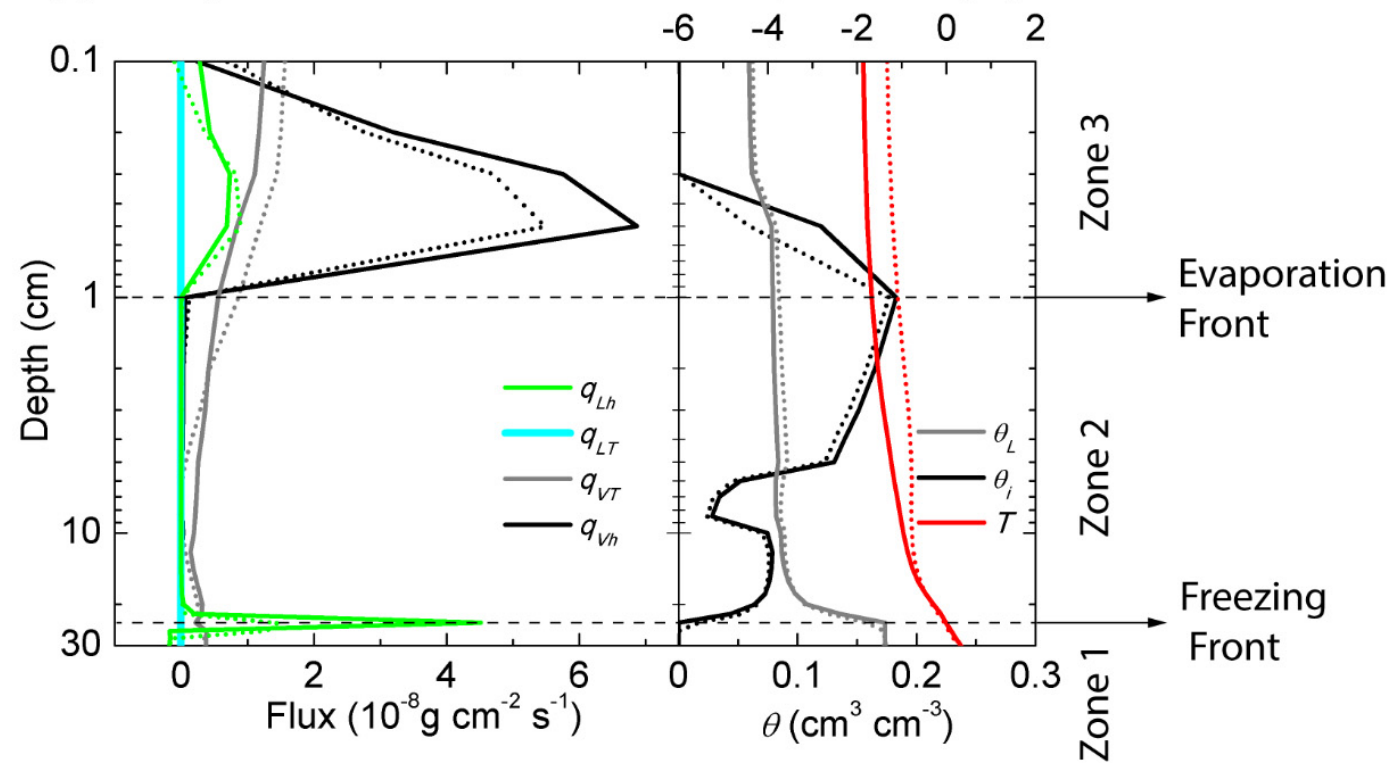

Figure 3.8. Simulated vertical profiles of the thermal and isothermal liquid water and vapor fluxes, soil ice content at 1200 and $0000 \mathrm{~h}$ of a typical freezing period during eleventh and twelfth days after 1 December 2015. Positive/negative values indicate upward/downward fluxes. The solid lines and dotted lines represent the fluxes and soil moisture, temperature and ice content profile on the eleventh and twelfth days after 1 December 2015, respectively.

\section{Zone 2 (frozen region)}

Although soil moisture decreased from $0.112 \mathrm{~cm}^{3} \mathrm{~cm}^{-3}$ at soil depth of $20 \mathrm{~cm}$ to 0.074 $\mathrm{cm}^{3} \mathrm{~cm}^{-3}$ at soil depth of $5 \mathrm{~cm}$, such a moisture gradient was still not able to overcome the blocking effect of soil ice on the conductivities. Thus, all moisture gradient driven fluxes ( $q_{L h}$ and $q_{V h}$ ) were negligible in this zone. On the other hand, the variation of temperature was significant. Starting from the freezing temperature at the freezing front 
(c.a. $22 \mathrm{~cm}$ in this occasion), soil temperature dropped below $-2{ }^{\circ} \mathrm{C}$ at a depth of about $5 \mathrm{~cm}$, and the soil depth where the lowest temperature occurred is defined as the cold front. Below the cold front, the thermal vapor flux moved upward due to an upward temperature gradient. Above the cold front, there was a progressive increase of soil temperature with the depth extending to the soil surface, which induced a downward thermal vapor flux during the daytime.

During the nighttime, soil temperature decreased progressively from the freezing front to the soil surface (Fig. 3.8b). Driven by the upward temperature gradient, the thermal vapor flux kept moving upward to the soil surface.

\section{3) Zone 3 (surface evaporation region)}

In the top surface region, depth from $1 \mathrm{~cm}$ to $0.1 \mathrm{~cm}$, soil ice began decreasing due to the melting/sublimation effect and was completely diminished at the depth of $0.3 \mathrm{~cm}$. On the other hand, liquid water content varied uniformly from a depth of $1 \mathrm{~cm}$ to 0.5 $\mathrm{cm}$ and rapidly decreased by about $31 \%$ (from 0.078 to $0.054 \mathrm{~cm}^{3} \mathrm{~cm}^{-3}$ ) till near the soil surface. Thus, the upward isothermal liquid/vapor fluxes starting from $1 \mathrm{~cm}$ can be mainly attributed to the melting/sublimation of soil ice. Once the soil moisture began to decrease, the upward moisture gradient significantly enhanced the transport of liquid and water vapor upward to the soil surface. As partly transformed into vapor flux, there was a noticeable decrease of isothermal liquid flux $q_{L h}$ near the surface. The source for the evaporation into atmosphere was mainly from the isothermal vapor flux $q_{V h}$ (see also Fig. 3.7b).

During the night, most of the fluxes near the surface moved upward with relatively low values. Nevertheless, the amount of upward fluxes was larger than the latent heat flux evaporated into the atmosphere. As such, a part of the isothermal liquid and vapor fluxes accumulated around the evaporation front (the depth where the isothermal vapor flux starts dominating the total water flux), resulting in an increase of soil moisture. Such a behavior is similar to the drying process reported by Saito et al. (2006).

The diurnal patterns of water and vapor transport of the latter day were similar to that of the previous day aforementioned. Nevertheless, it is worth to be mentioned that the freezing front was deeper on the twelfth day (Fig. 3.8a). As the freezing front propagated, the peak value of upward liquid water flux $q_{L h}$ moved downward to a depth of $24 \mathrm{~cm}$. The amount of such water flux, influenced by moisture gradient, was comparable to that of the eleventh day. The contribution of temperature gradient induced thermal vapor flux $q_{V T}$ to total water flux was a bit lower than the previous day with a value of $6.7 \%$. 
(a) Mid-day

Soil air pressure gradient $\left(\mathrm{Pa} \mathrm{cm}{ }^{-1}\right)$ Temperature $T\left({ }^{\circ} \mathrm{C}\right)$

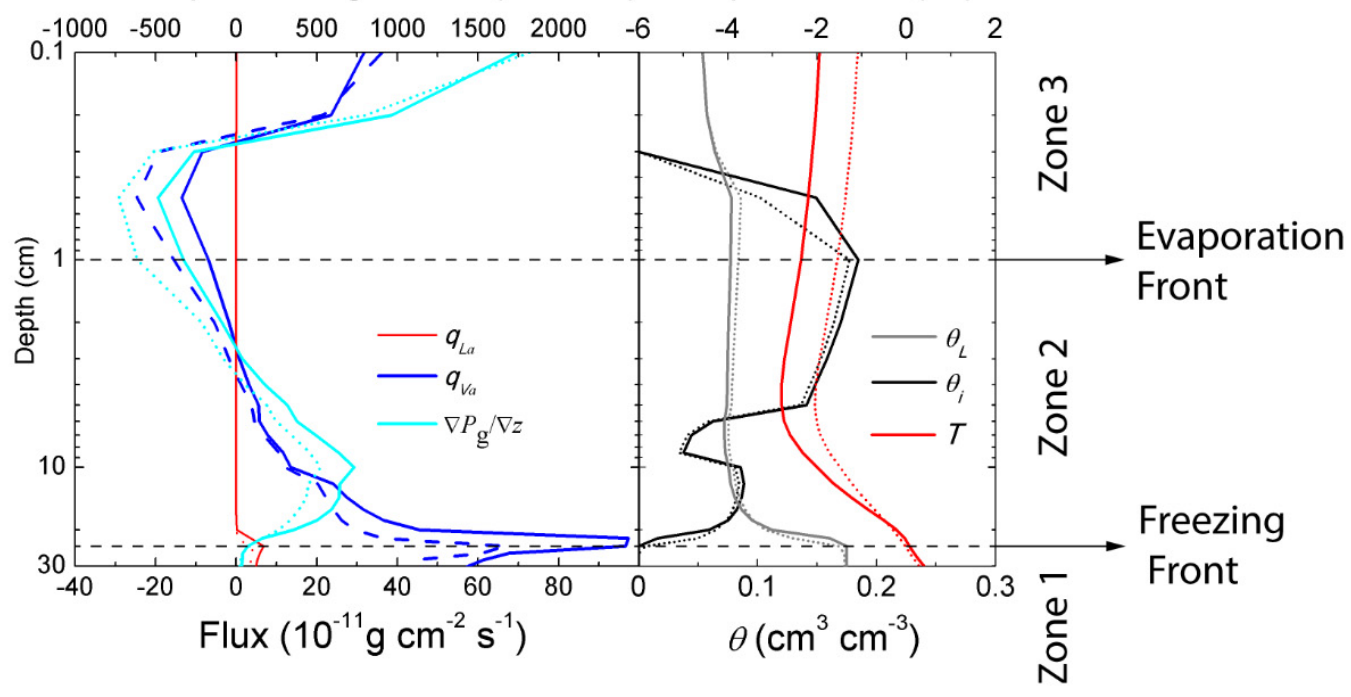

(b) Mid-night

Soil air pressure gradient $\left(\mathrm{Pa} \mathrm{cm}^{-1}\right)$ Temperature $T\left({ }^{\circ} \mathrm{C}\right)$

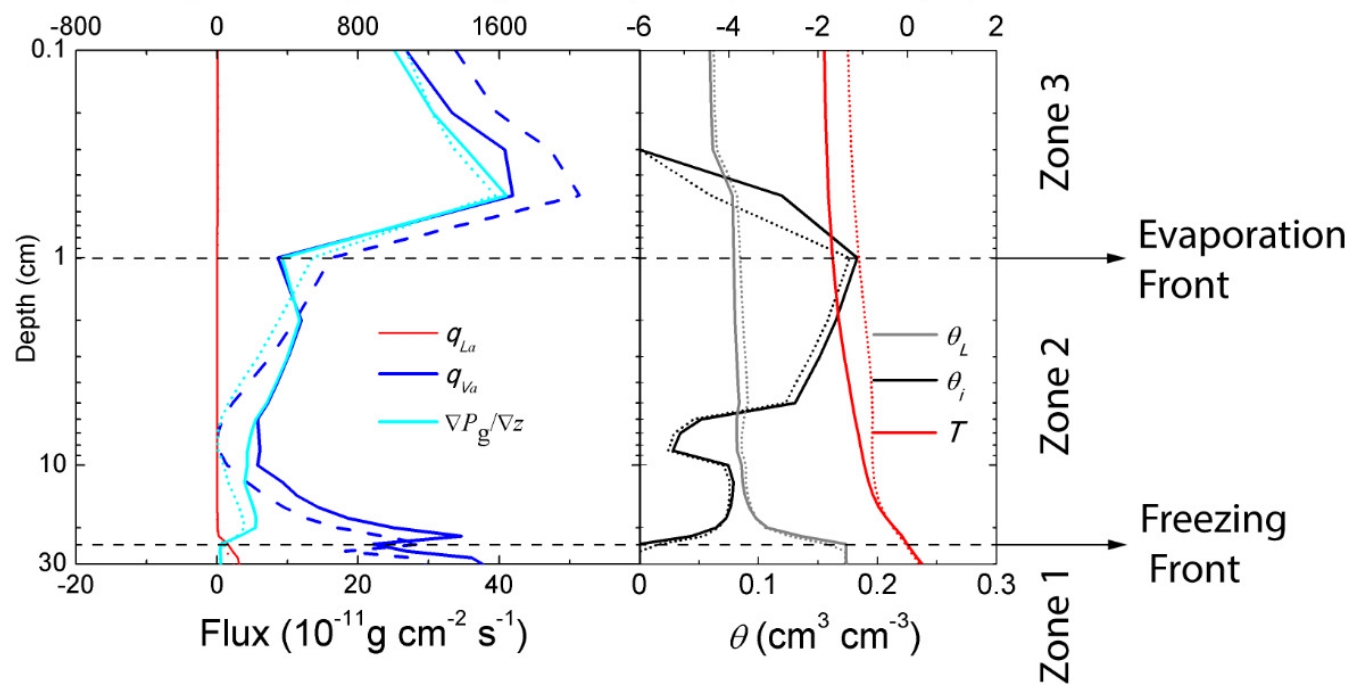

Figure 3.9. Simulated vertical profiles of the air pressure induced liquid water and vapor fluxes, soil air pressure gradient, soil ice content, liquid water content and soil temperature at 1200 and $0000 \mathrm{~h}$ of a typical freezing period during eleventh and twelfth days after 1 December 2015. Positive/negative values indicate upward/downward fluxes. The solid lines and dotted lines represent the fluxes and soil moisture, temperature and ice content profile on the eleventh and twelfth days after 1 December 2015 , respectively.

Figure 3.9 shows the vertical variations of advective liquid/vapor water fluxes of a typical freezing period. Similar to the isothermal liquid/vapor water flux, there was also a certain amount of air pressure gradient induced liquid/vapor flow accumulating to the freezing front, mainly due to the interactive effect of ice and air pressure. At the upper soil layers, the air pressure gradient induced liquid water flux was largely decreased as the impendence effect of ice on the soil permeability. At soil surface, in order to 
equilibrate with the atmospheric pressure, there was an upward gradient of soil air pressure during the daytime. In the frozen region, the gradient of soil air pressure was significantly reduced, mainly due to the increasing surface contact between solid particles and air. Note that there was a negative soil air pressure gradient at soil depth between $0.2 \mathrm{~cm}$ and $3 \mathrm{~cm}$. The vapor flux driven by air pressure gradient diverged at $0.2 \mathrm{~cm}$, while accumulated at $3 \mathrm{~cm}$. The vertical variations of vapor flux at soil layers above the freezing front were of the same to the variations of air pressure gradient.

During the nighttime, soil air pressure gradients were relatively small in the frozen zone, while increased significantly in the evaporation zone. The variation of liquid/vapor advective fluxes changed synchronously with that of soil air pressure gradients along the vertical profile, except for the soil depth around the freezing front. A certain amount of liquid and vapor advective fluxes moved upward to the freezing front, although soil air pressure gradients are negligible. There is an air pressure induced diurnal vapor circulation at soil depth between $0.2 \mathrm{~cm}$ and $3 \mathrm{~cm}$.

Figure 3.10 and 3.11 show the spatial and temporal distribution of matric potential, temperature, and air pressure gradients and the gradient-induced water/vapor fluxes of a typical freezing period. Note that the variations of soil matric potential gradient at shallow soil layers $(0.1-2 \mathrm{~cm})$ differ significantly with that at the deeper soil layers (2$30 \mathrm{~cm}$ ), with about 3 orders difference in the magnitude (Fig. 3.10b). In order to clearly illustrate what happens below the soil depth of $2 \mathrm{~cm}$, surface soil layers (top $2 \mathrm{~cm}$ ) and deeper soil layers $(2-30 \mathrm{~cm})$ are separately presented to have a detailed illustration of gradient fields and fluxes.
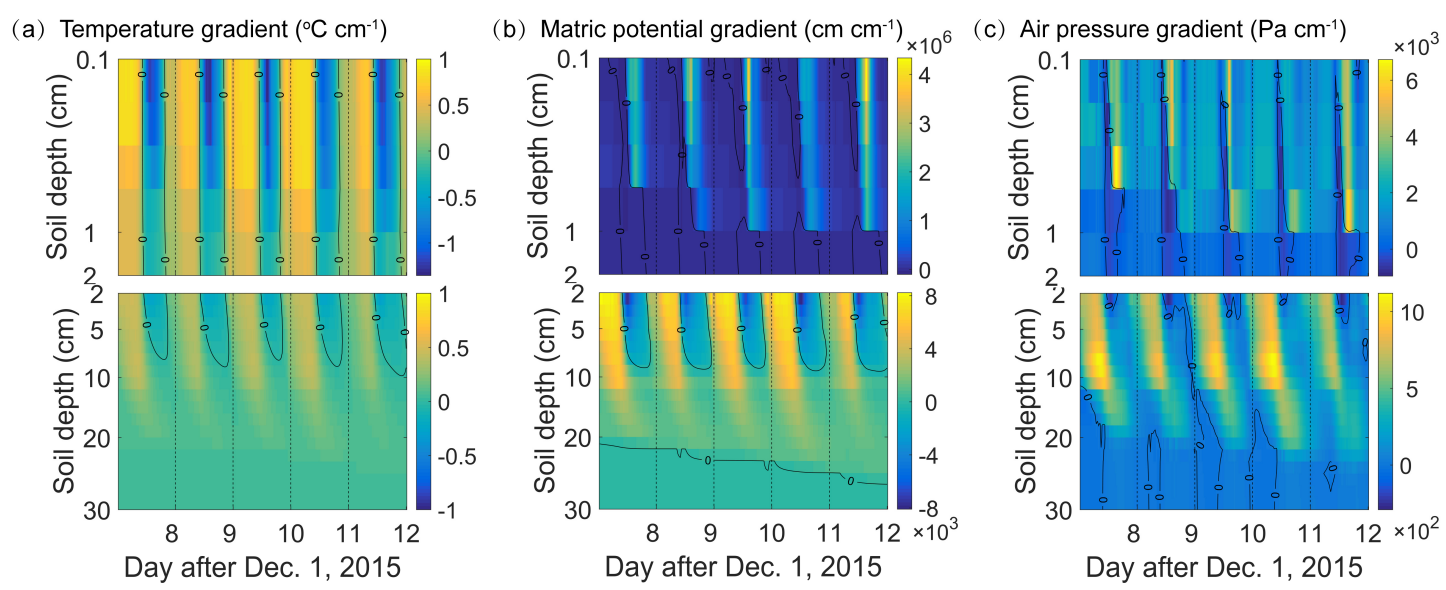

Figure 3.10. Spatial and temporal variations of (a) temperature gradient, (b) matric potential gradient and (c) air pressure gradient at surface soil layers (top $2 \mathrm{~cm}$, upper figure) and deeper soil layers (2-30 cm, bottom figure), respectively, of a typical freezing period during eighth and twelfth days after 1 December 2015. 

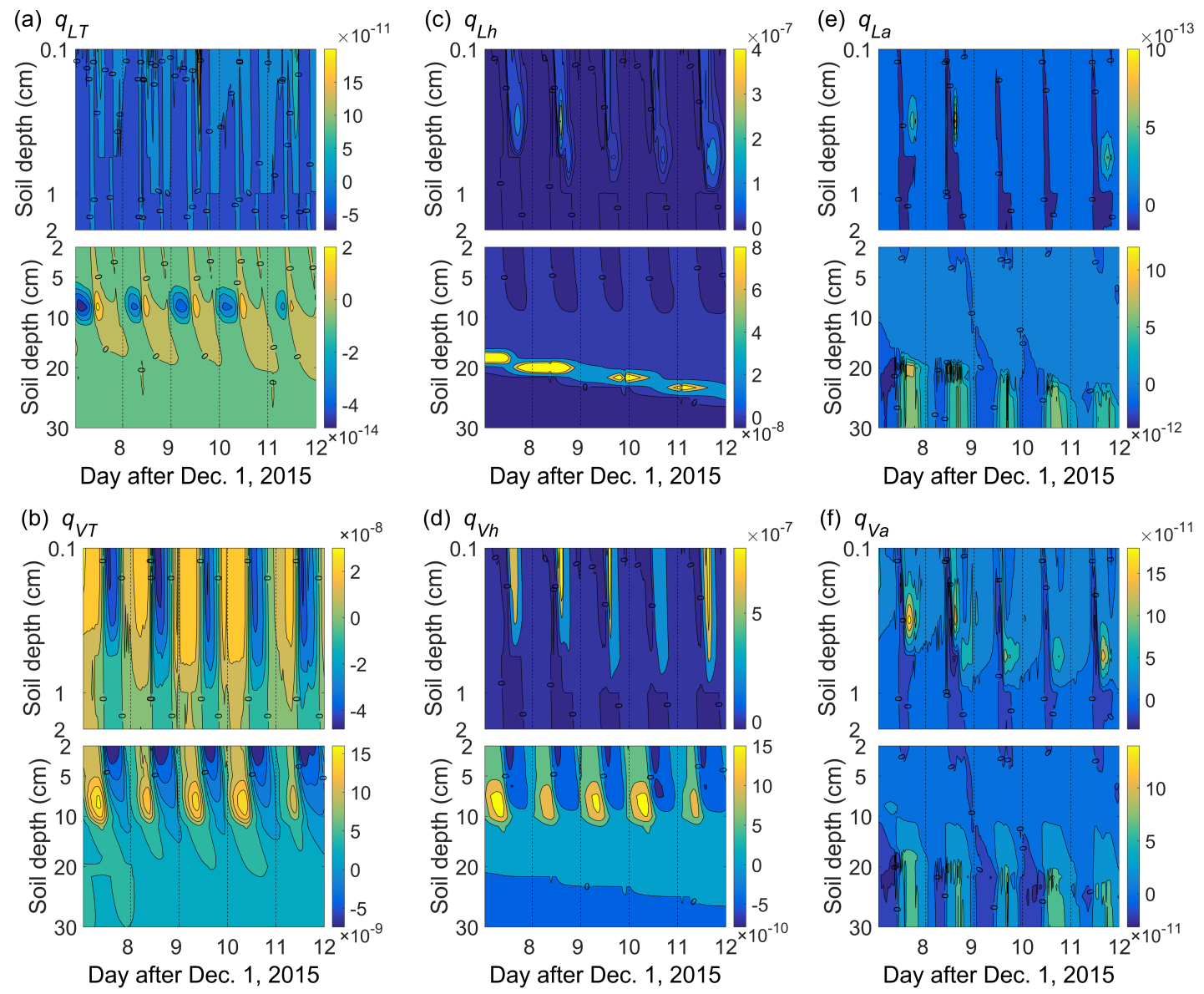

Figure 3.11. The spatial and temporal distributions of ( $a$, and $b$ ) thermal liquid water, and vapor fluxes, (c, and d) isothermal liquid water, and vapor fluxes, (e and f) advective liquid water, and vapor fluxes, at surface soil layers (top $2 \mathrm{~cm}$, upper figure) and deeper soil layers $(2-30 \mathrm{~cm}$, bottom figure), respectively, of a typical freezing period during eighth and twelfth days after 1 December 2015. Note that the unit for the fluxes is $\mathrm{g} \mathrm{cm}^{-2} \mathrm{~s}^{-1}$.

Figure 3.10a shows soil temperature gradient experiences a diurnal variation in the subsurface layers (from the surface to the freezing front, about 22-24 cm), with a downward gradient during the daytime (from 10:00 to 20:00) and an upward gradient during the night (from 20:00 to 10:00). This diurnal pattern agrees well with the results of the drying soils (Zeng et al., 2011a). Two points are worth to be mentioned: (i) the difference in the emergence time of downward gradient (10:00 versus 7:30 in Zeng et al., 2011a) is mainly due to the different time zone of two experimental sites, (ii) the region where the diurnal fluctuation of soil temperature gradient, driven by the atmosphere forcing, can be observed as constrained by the freezing front. It implicitly indicates that the influence of the future climate change on the subsurface in cold regions can reach the freezing front. The freezing front, indicating the thickness of active layer, thus can be identified as an important indicator for climate change in cold regions (GCOS, 2015). There were five zero-gradient lines, on which the exchange of heat flux was 0 . The gradient was negative above the zero-gradient line while positive 
below the zero-gradient line, which indicated that the fluxes driven by temperature gradient accumulated around the zero-gradient lines (see Fig. 3.11b). These zerogradient lines can also indicate the position of cold front. At soil depth below the freezing front, the variations of soil temperature were largely reduced, the soil temperature gradient was less than $0.1{ }^{\circ} \mathrm{C} \mathrm{cm}^{-1}$.

The diurnal patterns of soil matric potential gradient can be recognized from soil surface to the freezing front, and the gradient was positive during the night and negative/less positive during the daytime. The variations of soil matric potential at shallow soil layers $(0.1-1 \mathrm{~cm})$ were significantly larger than that at the deeper soil layers $(1-24 \mathrm{~cm})$, with about 3 orders difference in the magnitude. Two kinds of zero-gradient lines were identified in Fig. 3.10b:

i) The first kind of zero-gradient lines initialized from the surface and extended vertically to the depth of $8 \mathrm{~cm}$. The soil matric potential gradient was positive outside the zero-gradient lines while negative inside the zerogradient lines, implying that the fluxes driven by the soil matric potential gradient moved toward and accumulated around the zero-gradient lines at a depth of $8 \mathrm{~cm}$ (sink, Fig. 3.11c \&d). Interestingly, staring from the tenth day after 1 December, the zero-gradient lines were interrupted by a relatively wet soil layer occurred at around $1 \mathrm{~cm}$, which can be attributed to the downward total water fluxes (the sum of water fluxes is negative around the soil depth of $1 \mathrm{~cm}$, see Figure 3.8a, Zone 3). The isothermal liquid/vapor fluxes accumulated at the upper part (sink) while diffused at the lower part (source) of this wetter soil layer. The wetter soil layer broke the isothermal liquid/vapor fluxes continuity between the top surface and subsurface soil layers and enhanced the upward transport of isothermal fluxes around $1 \mathrm{~cm}$ in the following days (Figure 3.11c and 3.11d).

ii) The other kind of zero-gradient line lay below the freezing front and propagated downward with time. This kind of zero-gradient line formed the source of water fluxes. The matric potential gradient was upward above this zero-gradient line while downward below it. Note that the isothermal liquid fluxes $q_{L h}$ are determined not only by the gradient (the directions) but also by the conductivities (the magnitude). Thus, when the isothermal liquid fluxes pass through the freezing front, the presence of soil ice significantly reduces the conductivities and further the amount of fluxes are sharply decreased. Therefore, the fluxes move into the freezing front are remarkably larger than the fluxes move out of the freezing front. Then the isothermal liquid fluxes $q_{L h}$ appear accumulating around the freezing front (Figure $3.11 \mathrm{c})$. The gradient of soil matric potential was downward and at a magnitude of $10 \mathrm{~cm} \mathrm{~cm}^{-1}$ at the soil layers below the freezing front. 
Due to the active water phase change at top surface soil layers (above $1 \mathrm{~cm}$ ), the diurnal variations of soil air pressure gradient are disturbed (Zeng et al. 2011b). At soil depth below $1 \mathrm{~cm}$, the gradient varied diurnally, positive during the daytime and negative or less positive during the night (Figure 3.10c). The time delay and reduced amplitude were perceived for deeper soil layers. The zero-gradient lines grew isolated at shallow soil layers (roughly $1-3 \mathrm{~cm}$ ) during the daytime and at deeper soil layers (roughly below $10 \mathrm{~cm}$ ) during the night. At shallow soil layers $(1-2 \mathrm{~cm})$, the fluxes diffused at the upper part of zero-gradient lines and accumulated at the lower part of zero-gradient lines during the daytime (see Figure 3.11e and 3.11f). And the fluxes diffused along with the zero-gradient lines at deeper soil layers (below $12 \mathrm{~cm}$ ) during the night.

The overall patterns of soil water/vapor transfer in frozen soils, based on our analysis, can be generalized as follows. A continuous isothermal liquid water $q_{L h}$, accompanied with a nonnegligible amount of thermal vapor $q_{V T}$, moves upward to the freezing front (e.g., Figure 3.8a). Above the freezing front, where soil ice dominated (Zone 2), soil ice blocks most of the water fluxes except for the thermal vapor flux qVT. This temperature gradient driven vapor flux transfers, from both the top and bottom soil layers, toward the cold front during the daytime while moves upward to the soil surface during the night.

Liquid/vapor fluxes become active until up to the evaporation front (Zone 3) as the diminishing effect of soil ice. During the daytime, liquid water transfers upward by the isothermal liquid water flux $q_{L h}$ from both the ice and liquid water phase, partly transforms into water vapor, finally moves toward the surface (Figure 3.8a). Water vapor directly sublimates from soil ice surface by the isothermal vapor flux $q v h$ (Figure 3.8a, Zone 3) and evaporates into the atmosphere as the major flux component. While during the night, thermal vapor flux $q_{V T}$ serves as a continuous source of evaporation (Figure 3.8b). This diurnal behavior of thermal vapor flux results in the daily cycle of soil moisture in the zone between the evaporation front and cold front. Around the freezing front, water phase experiences a change from liquid/vapor to ice, while at the topsoil layers, the water phase change from ice to liquid/vapor happens due to soil ice melting/sublimation process.

\subsubsection{Thawing period}

Figure 3.12 presents the model performance in simulating latent heat flux during a fiveday thawing period. Although the diurnal variations of latent heat flux can be well reproduced by the proposed model, a noticeable underestimation can be observed during the daytime, with the bias of $-4.78 \mathrm{E}-8 \mathrm{~g} \mathrm{~cm}^{-2} \mathrm{~s}^{-1}$. Such an underestimation of latent heat flux can be attributed to two possible reasons. (i) The soil water retention curve/SFCC is of large uncertainty when soil moisture is low. (ii) There was little precipitation (mainly in the form of snow as the air temperature was lower than $0{ }^{\circ} \mathrm{C}$ ) 
occurred on the 85th day after 1 December 2015. Thus, the underestimation might be due to the lag effect of snow melting/sublimation, which was simplified in the STEMMUS-FT.

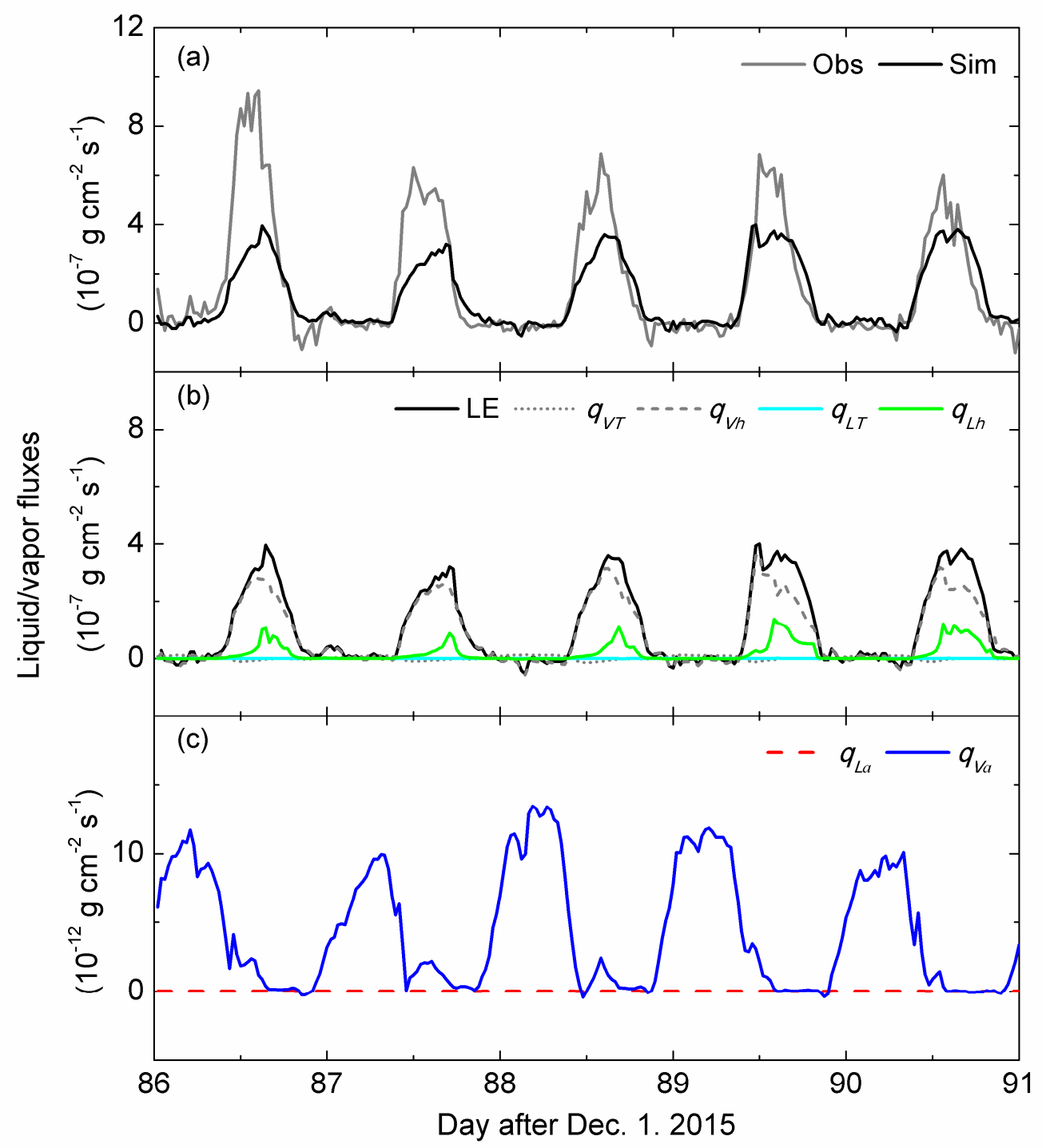

Figure 3.12. Same as Figure 3.7 but for a typical five-day thawing period (from 87 th to 91 st days after 1 December 2015). 


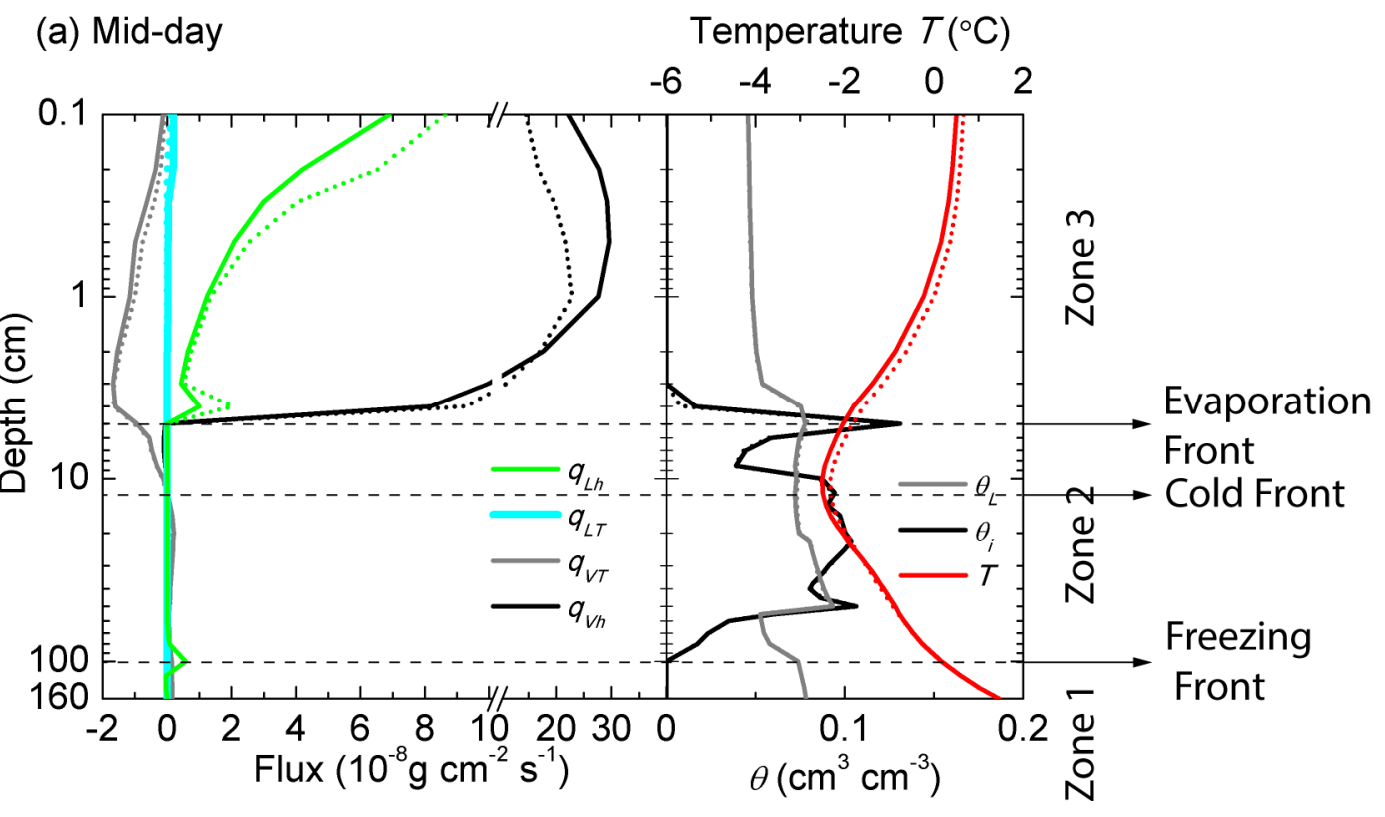

(b) Mid-night

Temperature $T\left({ }^{\circ} \mathrm{C}\right)$

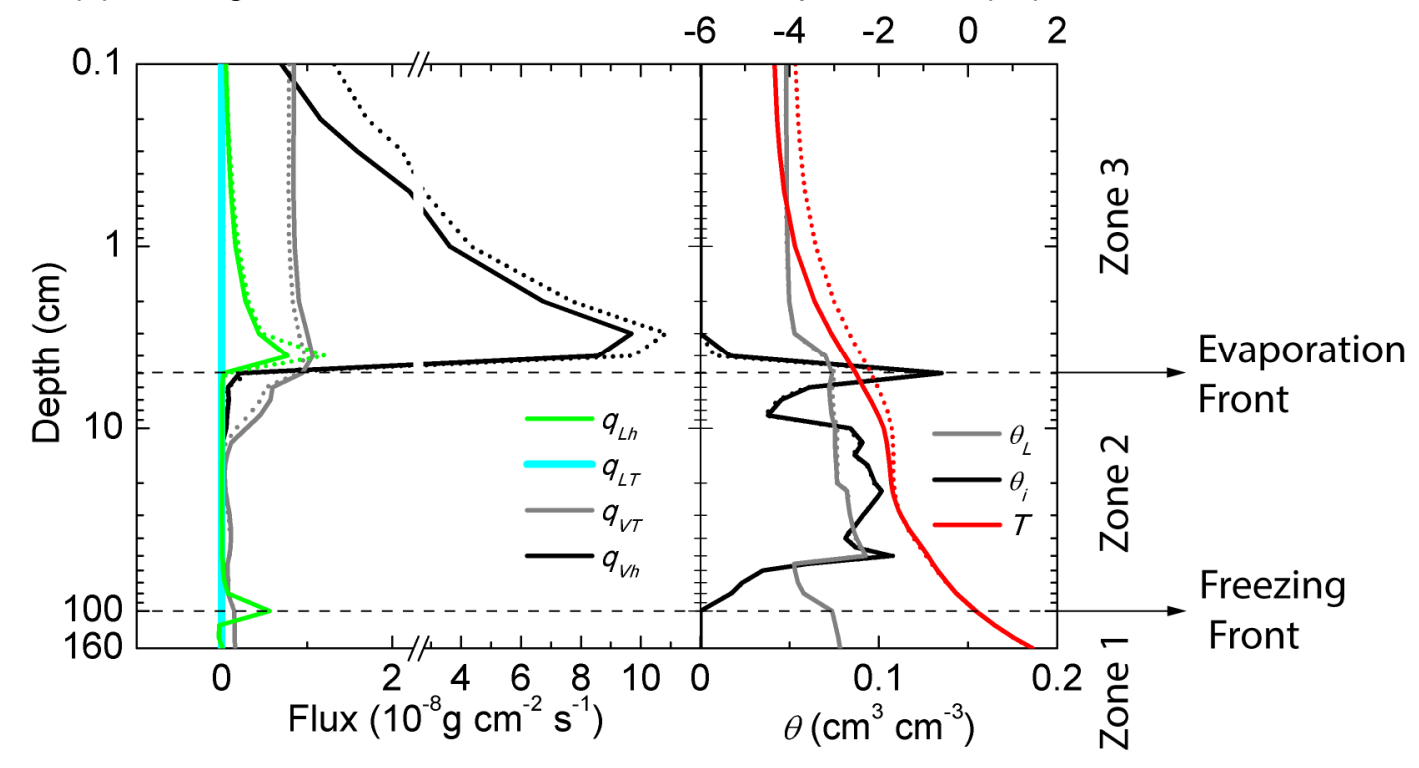

Figure 3.13. Simulated vertical profiles of the thermal and isothermal liquid water and vapor fluxes, soil ice content at 1200 and $0000 \mathrm{~h}$ of a typical freezing period during 90th and 91st days after 1 December 2015. Positive/negative values indicate upward/downward fluxes. The solid lines and dotted lines represent the fluxes and soil moisture, temperature and ice content profile on the 90th and 91st days after 1 December 2015, respectively.

The contribution of flux components to the surface evaporation was similar to the freezing process. The isothermal vapor flux contributed most to the total mass during the daytime, followed by the isothermal liquid flux. Liquid water transferred by the downward thermal vapor flux near the surface was reduced, which is the result of the decrease of the temperature gradient in the top surface layers. The thermal liquid flux, which was small enough to be neglected during the freezing days, was observed upward 
near the surface when soil began thawing. This behavior was also reported by Saito et al. (2006, Figure 12) when the drying soil experienced the irrigation. The values of air pressure induced liquid/vapor fluxes are relatively small and the vertical variations of advective liquid/vapor fluxes are similar to that of freezing periods (results not shown).

Compared to the freezing periods, similar diurnal patterns of water and vapor transport were simulated during the thawing periods (Figure 3.13). The depth where the upward liquid water occurred was much deeper than the freezing periods. Due to the coarse resolution of vertical profile, there is no difference in the depth of the freezing front between two sequential days. Zone 3 was also extended from about $1 \mathrm{~cm}$ in freezing periods to $5 \mathrm{~cm}$ in thawing periods as the depletion of soil ice content.

\subsection{Discussion}

\subsubsection{The effect of soil ice}

When soil experiences the FT process, there is a dynamic coexistence of ice, liquid water, water vapor and dry air in soil pores. As unfrozen water has been observed not only on the surface of soil aggregates but also among soil ice crystals, the matric potential will be affected by soil ice (Farouki, 1986; Zhang et al., 2007). Thus the liquid water flow can be not only driven by the moisture gradient but also by the gradient of soil ice content (Zhang et al., 2007), which can be clearly seen in our simulations (e.g., Figure 3.8 Zone 3). In addition to liquid water, soil ice (sublimation) also serves as the source for the evaporation into atmosphere.

Both experimental and modeling effort have demonstrated that the blocking effect of soil ice exists on the liquid flow passing through a porous medium (Harlan, 1973; Taylor \& Luthin, 1978). This effect can be attributed to the ice induced soil porosity reduction, and the increasing surface contact between solid particles and water. Although an impedance factor was widely employed in models to account for such effect, some researches pointed out its limitations: i) not physically based (Newman \& Wilson, 1997); (ii) nondifferentiable when soil ice begins to form (Kurylyk \& Watanabe, 2013); (iii) constant with varied matric potentials, which has been demonstrated not realistic (Watanabe, 2008; Zhao et al., 2013); iv) unable to explicitly take into account the increasing surface contact factor (Koren et al., 2014). Thus, alternative methods to take into account the blocking effect require further research (Watanabe \& Wake, 2008; Azmatch et al., 2012; Kurylyk \& Watanabe, 2013). In the STEMMUS-FT, the potential-freezing point depression theory and the reversion of water retention equations were combined to derive the SFCC, the parameters of which were further applied in the Mualem hydraulic conductivity scheme to account for the soil ice effect, together with the impedance factor (see Appendix A1.1 \& A1.2). 
A certain amount of heat can be released/absorbed during FT process. This amount of heat will result in the change of temperature gradient, transformed into thermodynamic moisture potential and then the water pressure gradient (Romanovsky \& Osterkamp, 2000; Luo et al., 2003). Then the liquid water flow and vapor flow accumulate toward the freezing front (and diverge around the evaporation front) under the temperature and water pressure gradients. According to the foregoing (Figure 3.8 \& Figure 3.13), the presence of soil ice constrains the evaporation zone to the depth of $1-5 \mathrm{~cm}$, which is much shallower than that of the drying process (Boulet et al., 1997; Grifoll et al., 2005; Saito et al., 2006). Nevertheless, soil ice serves as the source for evaporation at very top surface layers, and the sink for the liquid/vapor water fluxes at the freezing front.

\subsubsection{The role of vapor flow}

As both the drying and freezing soils lose liquid water from larger pores to micro-ones, it is assumed that the freezing process is, to some extent, similar to the drying process (Koopmans \& Miller, 1966; Hansson et al., 2004; Dall'Amico, 2010). At soil surface, isothermal vapor flow indeed contributes most to the total mass flux. Due to the day/night behavior of thermal vapor flow, there is a diurnal variation of moisture content at topsoil layers (Figure 3.4). Such kind of behavior is similar to that of the drying process reported by Boulet et al. (1997) and Saito et al. (2006). While the difference is that this vapor circulation can only be restricted in the zone between the soil surface and the cold front during FT process. Vapor flow move upward to the freezing front and contribute about $6 \%-13 \%$ to the total water flux for the ice formation, which agrees well with the results of Teng et al. (2015) and Zhang et al. (2016b). The variations in the percentage of vapor flux in the total water flux can be attributed to the interactive effect of moisture gradient field and temperature gradient field (Zhang et al., $2016 \mathrm{~b}$ ). The results deduced from our simulations indicate that it is mainly the vapor flow that connect the water/vapor transfer beneath the freezing front (sink) and above the evaporation front (source).

\subsubsection{The role of airflow}

Since the natural field experiment is normally considered as an open boundary condition, the variation of air pressure due to the volumetric expansion of ice is smaller than the lab experiment with bounded boundary conditions. The contribution of air pressure induced liquid/vapor fluxes to the total water mass, based on our simulations, is negligible. Nevertheless, the interactive effect of soil ice and air pressure on the vertical variations of advective liquid/vapor fluxes in frozen soils can still be recognized (see Fig. 3.9, taking the freezing period as an example). Furthermore, the diurnal behavior of air pressure resulted in the vapor circulation mainly in the surface region. According to Wicky \& Hauck (2017), the air circulation with atmosphere can result in a significant temperature difference between the lower and the upper part of a 
permafrost talus slope via the convective heat flux and thus have a remarkable effect on the thermal regime in a talus slope. Zeng et al. (2011a) concludes that the air pressure-induced advective fluxes inject the moisture into the topsoil layers and increase the hydraulic conductivity, then further enhance the soil evaporation after precipitation events. These studies clearly prove that the airflow has the potential to affect the hydrothermal regime of subsurface soils. Here we concentrate only on the interactive effect of soil ice and air on the vertical variations of advective fluxes in frozen soils. Further research studies are necessary to explicitly explain the role of airflow in cold regions from the perspective of hydrological, thermal and ecological effects.

\subsection{Conclusion}

We can conclude, from the intercomparison results of different hydrothermal parameterizations, that there is little difference in simulating soil water content, temperature and freezing depth between two different hydraulic schemes. The simulation results with different thermal schemes, however, are significantly different. de Vries parameterization performed better than others in simulating the soil thermal regime. The simplified de Vries method has the potential to be employed over the Tibetan plateau.

The analysis of water and vapor fluxes during FT process indicates that both the liquid and vapor fluxes transfer upward to the freezing front. Due to the blocking effect of ice presence in soil pores, the vapor flow rather than the liquid flow contributes most to the total mass flux in frozen soil region. The diurnal cycle of soil moisture in the zone between the evaporation front and cold front was found mainly due to the diurnal behavior of thermal vapor flux. The isothermal vapor and liquid water fluxes are the major source for the evaporation into atmosphere. The air pressure-induced liquid/vapor fluxes play a negligible role in the total mass transfer. Nevertheless, the interactive effect of soil ice and air can be found on the spatial and temporal variations of water/vapor transfer. Further studies are still essential to investigate the role of dry airflow in cold regions from the multidisciplinary perspective of hydrological, thermal and ecological effects. 

Chapter 4 Understanding the mass, momentum, and energy transfer in frozen soils*

* This chapter is based on: Yu, L., Zeng, Y., \& Su, Z. (2020). Understanding the mass, momentum, and energy transfer in the frozen soil with three levels of model complexities. Hydrology and Earth System Sciences, 24(10), 4813-4830. doi:10.5194/hess-24-4813-2020 


\begin{abstract}
Frozen ground covers a vast area of the Earth's surface and it has important ecohydrological implications for cold regions under changing climate. However, it is challenging to characterize the simultaneous transfer of mass and energy in frozen soils. Within the modeling framework of Simultaneous Transfer of Mass, Momentum, and Energy in Unsaturated Soil (STEMMUS), the complexity of the soil heat and mass transfer model varies from the basic coupled model (termed BCM) to the advanced coupled heat and mass transfer model (ACM), and, furthermore, to the explicit consideration of airflow (ACM-AIR). The impact of different model complexities on understanding the mass, momentum, and energy transfer in frozen soil was investigated. The model performance in simulating water and heat transfer and surface latent heat flux was evaluated over a typical Tibetan plateau meadow site. Results indicate that the ACM considerably improved the simulation of soil moisture, temperature, and latent heat flux. The analysis of the heat budget reveals that the improvement of soil temperature simulations by ACM is attributed to its physical consideration of vapor flow and the thermal effect on water flow, with the former mainly functioning above the evaporative front and the latter dominating below the evaporative front. The contribution of airflow-induced water and heat transport (driven by the air pressure gradient) to the total mass and energy fluxes is negligible. Nevertheless, given the explicit consideration of airflow, vapor flow and its effects on heat transfer were enhanced during the freezing-thawing transition period.
\end{abstract}




\subsection{Introduction}

Frozen soils have been reported to undergo significant changes under climate warming (Cheng \& Wu, 2007; Hinzman et al., 2013; Biskaborn et al., 2019; Zhao et al., 2019). Changes in the freezing and thawing process can alter soil hydrothermal regimes and water flow pathways, and thus affect vegetation development (Walvoord \& Kurylyk, 2016). Such changes will further considerably affect the spatial pattern, the seasonal to interannual variability and long term trends in land surface water, energy and carbon budgets and then the land surface-atmosphere interactions (Subin et al., 2013; Iijima et al., 2014; Schuur et al., 2015; Walvoord \& Kurylyk, 2016). Understanding the soil freeze/thaw processes appears to be the necessary path for a better water resources management and ecosystem protection in cold regions.

When soil experiences the freezing and thawing process, there is a dynamic thermal equilibrium system of ice, liquid water, water vapor and dry air in soil pores. Water and heat flow are tightly coupled in frozen soils. Coupled water and heat physics, describing the concurrent flow of liquid, vapor as well as heat flow, was first proposed by Philip and De Vries (1957) (hereafter termed as PdV57), considering the enhanced vapor transport. The PdV57 theory has been widely applied for a detailed understanding of soil evaporation during the drying process (De Vries, 1958; Milly, 1982; De Vries, 1987; Saito et al., 2006; Novak, 2010). The attempts to simulate the coupled water and heat transport in frozen soils started in 1970s (e.g., Harlan, 1973; Guymon \& Luthin, 1974). Since then, numerical tools for simulating one-dimensional frozen soil were gradually developed. Flerchinger and Saxton (1989) developed the SHAW model with the capacity of simulating the coupled water and heat transport process. Hansson et al. (2004) accounted for the phase changes in HYDRUS-1D model and verified its numerical stability with rapidly changing boundary conditions. Considering the two components (water and gas) and three water phases (liquid, vapor, and solid), Painter (2011) developed a fully coupled water and heat transport model MarsFlo. Aiming to efficiently deal with the water phase change between liquid and ice, the enthalpy-based frozen soil model (using enthalpy and total water mass instead of temperature and liquid water content as the prognostic variables) was developed and demonstrated its capability to stably and efficiently simulate soil freeze/thaw process (Li et al., 2010; Bao et al., 2016; Wang et al., 2017b). These works together with other modifications, simplifications, generate a hierarchy of frozen soil models, see the detailed review by Li et al. (2010) and Kurylyk and Watanabe (2013).

Airflow has been reported as being important to the soil water and heat transfer process under certain conditions (Touma \& Vauclin, 1986; Prunty \& Bell, 2007). Zeng et al. (2011a, b) found that soil evaporation is enhanced after precipitation events by considering airflow and demonstrated that the air-pressure-induced advective fluxes inject the moisture into the surface soil layers and increase the hydraulic conductivity 
at the top layer. The diurnal variations in air pressure resulted in the vapor circulation between the atmosphere and the land surface. Wicky and Hauck (2017) reported that the temperature difference between the upper and the lower part of a permafrost talus slope was significant and attributed it to the airflow induced convective heat flux. $\mathrm{Yu}$ et al. (2018) analyzed the spatial and temporal dynamics of air-pressure-induced fluxes and found an interactive effect in the presence of soil ice. The abovementioned studies demonstrate that the explicit consideration of airflow has the potential to affect the soil hydrothermal regime. However, to what extent and under what conditions airflow plays significant roles in the subsurface heat budgets have not been detailed.

Current land surface models (hereafter LSMs), however, usually adopted simplified frozen soil physics with relatively coarse vertical discretization (Koren et al., 1999; Viterbo et al., 1999; Niu et al., 2011; Swenson et al., 2012). In their parameterizations, soil water and heat interactions can only be indirectly activated by the phase change processes, the mutual dependence of liquid water, water vapor, ice and dry air in soil pores is absent. This mostly leads to oversimplifications of physical representations of hydrothermal and ecohydrological dynamics in cold regions (Novak, 2010; Su et al., 2013; Wang et al., 2017b; Cuntz \& Haverd, 2018; Grenier et al., 2018; Wang \& Yang, 2018; Qi et al., 2019). Specifically, Su et al. (2013) evaluated the European Centre for Medium-Range Weather Forecasts (ECMWF) soil moisture analyses over the Tibetan Plateau, and found that HTESSEL cannot capture phase transitions of soil moisture (i.e., underestimation during the frozen period while overestimation during thawing). There are continuous efforts to improve parameterizations and representations of cold region dynamics, including frozen ground (Boone et al., 2000; Luo et al., 2003), vapor diffusion (Karra et al., 2014), thermal diffusion (Bao et al., 2016), coupling water and heat transfer (Wang \& Yang, 2018), and three-layer snow physics (Wang et al., 2017b; Qi et al., 2019). While, to our knowledge, few studies have investigated the role of increasing complexities in soil physical processes (from the basic coupled to the advanced coupled water and heat transfer processes and, then, to the explicit consideration of airflow) in simulating the thermo-hydrological states in cold regions. How, and to what extent, do the complex mutual dependent physics affect the soil mass and energy transfer in frozen soils? Is it necessary to consider a fully coupled physical process in the LSMs? These two questions frame the scope of this work.

In this chapter, we incorporated the various complexities of soil water and heat transport mechanisms into a common modeling framework (namely, the simultaneous transfer of energy, momentum, and mass in unsaturated soils with freeze-thaw - STEMMUSFT). With the aid of in situ measurements collected from a typical Tibetan meadow site, the pros and cons of different model complexities were investigated. Subsurface energy budgets and latent heat flux density analyses were further carried out to illustrate the underlying mechanisms of different coupled soil water-heat physics. Section 4.2 
describes three different complexities of subsurface physics within the STEMMUS framework. The performance of different models is presented in Section 4.3 together with the subsurface heat budgets and latent heat flux density analyses. Section 4.4 discusses the effects of considering coupled soil water-heat transfer and airflow in frozen soils. The conclusion is drawn in Section 4.5.

\subsection{Methodology}

\subsubsection{Mass and energy transport in unsaturated soils}

On the basis of the STEMMUS modeling framework, the increasing complexity of vadose zone physics in frozen soils was implemented as three alternative models (Table 4.1). First, STEMMUS enabled isothermal water and heat transfer physics (Eqs. 4.1 and 4.2). The 1D Richards equation was utilized to solve the isothermal water transport in variably saturated soils. The heat conservation equation took into account the freezing and thawing process and the latent heat due to water phase change. The effect of soil ice on soil hydraulic and thermal properties was considered. This is termed the basic coupled water and heat transfer model (BCM).

Second, the fully coupled water and heat physics, i.e., water vapor flow and thermal effect on water flow, was explicitly considered in STEMMUS and termed the advanced coupled model (ACM). For the ACM physics, the extended version of Richards (Richards, 1931) equation, with modifications made by Milly (1982), was used as the water conservation equation (Eq. 4.3). Water flow can be expressed as liquid and vapor fluxes driven by both temperature gradients and matric potential gradients. The heat transport in frozen soils mainly includes: heat conduction (CHF; $\left.\lambda_{e f f} \frac{\partial T}{\partial z}\right)$, convective heat transferred by liquid flux (HFL; $-C_{L} q_{L}\left(T-T_{r}\right),-C_{L} S\left(T-T_{r}\right)$ ), vapor flux (HFV; $-C_{V} q_{V}\left(T-T_{r}\right)$ ), the latent heat of vaporization (LHF; $-q_{V} L_{0}$ ), the latent heat of freezing or thawing $\left(-\rho_{i} \theta_{i} L_{f}\right)$ and a source term associated with the exothermic process of the wetting of a porous medium (integral heat of wetting) $\left(-\rho_{L} W \frac{\partial \theta_{L}}{\partial t}\right)$. It can be expressed as Eq. 4.4 (De Vries, 1958; Hansson et al., 2004).

Lastly, STEMMUS expressed the freezing soil porous medium as the mutually dependent system of liquid water, water vapor, ice water, dry air and soil grains, in which, other than airflow, all other components are kept the same as in ACM (termed the ACM-AIR model) (Eqs. 4.5, 4.6, \&4.7, Zeng et al., 2011a, b; Zeng and Su, 2013). The effect of airflow on soil water and heat transfer can be two-fold. First, the airflowinduced water and vapor fluxes $\left(q_{L a}, q_{V a}\right)$ and the corresponding convective heat flow $\left(\mathrm{HFa} ;-q_{a} C_{a}\left(T-T_{r}\right)\right)$ were considered. Second, the presence of airflow alters the vapor transfer processes, which can considerably affect the water and heat transfer in an indirect manner. 
Table 4.1. Governing equations for different complexity of water and heat coupling physics (see List of symbols for notations)

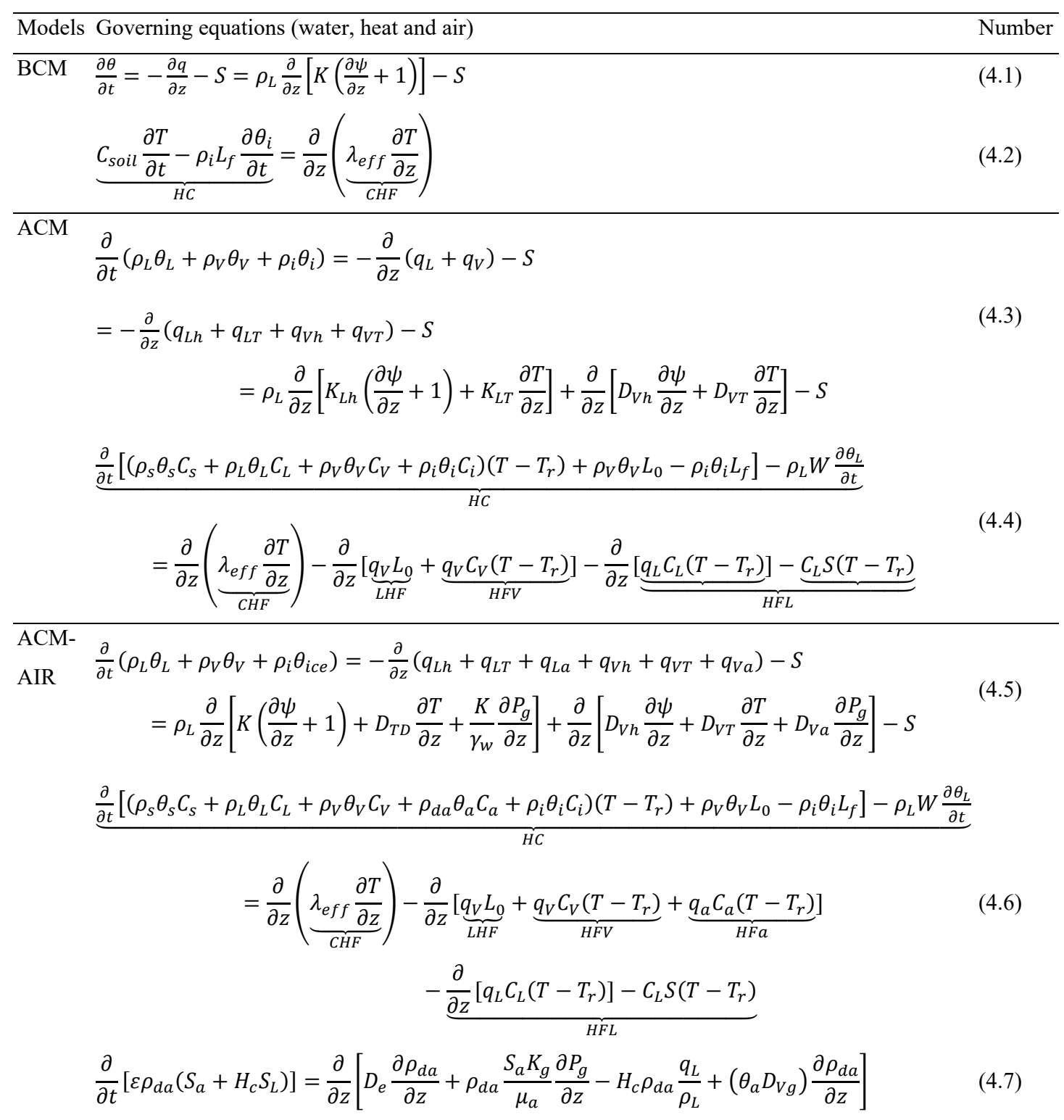

\subsubsection{Model setup}

STEMMUS utilized the adaptive time-step strategy, with maximum time steps ranging from 1 to $1800 \mathrm{~s}$ (e.g., with 1800s as the time step under stable conditions). The maximum desirable change in soil moisture and soil temperature within one time step was set as $0.02 \mathrm{~cm}^{3} \mathrm{~cm}^{-3}$ and $2{ }^{\circ} \mathrm{C}$, respectively, to prevent too large a change in state variables that may cause numerical instabilities. If the changes between two adjacent soil moisture and temperature states are less than the maximum desirable change, STEMMUS continues without changing the length of current time step (e.g., $1800 \mathrm{~s}$ ). Otherwise, STEMMUS will adjust the time step with a deduction factor, which is proportional to the difference between the changes that are too large and the maximum that are desirable in state variables. Within one single time step, the Picard iteration was 
used to solve the numerical problem, and the numerical convergence criteria is set as 0.001 for both soil matric potential (in centimeters) and soil temperature (in degrees Celsius).

To accommodate the specific conditions of a Tibetan meadow, the total depth of the soil column was set as $1.6 \mathrm{~m}$ (Figure 4.1). The vertical soil discretization was designed to be finer for the upper soil layers $(0.1-2.5 \mathrm{~cm}$ for $0-40 \mathrm{~cm} ; 27$ layers) than for the lower soil layers (5-20 cm for 40-160 cm; 10 layers). The surface boundary for the water transport was set as the flux-type boundary controlled by the atmospheric forcing (i.e., evaporation and precipitation), while the specific soil temperature was assigned as the surface boundary of the energy conservation equation. The free drainage (zero matric potential gradient) and measured soil temperature were set as the bottom boundary conditions for the water transport and heat transport, respectively. For the airflow, the surface boundary was set as the atmospheric pressure and soil air was allowed to escape from the bottom of the soil column. Surface evapotranspiration was calculated using the Penman-Monteith method. Soil evaporation and transpiration can be separately estimated. The available radiation energy is partitioned into the canopy and soil component via the leaf area index (LAI); the canopy minimum surface resistance and soil surface resistance are then utilized to calculate the potential transpiration and soil evaporation. Actual transpiration is calculated as the function of potential transpiration and the root-length-density-weighted available soil liquid water (which is assumed to be zero if soil temperature falls below $0{ }^{\circ} \mathrm{C}$; Kroes et al., 2008; Orgogozo et al., 2019). For our simulation period, grassland stepped into the dormancy period as the soil froze. The accumulative positive temperature during the thawing period was not enough to break the dormancy of the vegetation. The contribution of plant transpiration to the land surface heat flux is negligible during the dormancy period. The effect of soil moisture on the actual soil evaporation is taken into account via the soil surface resistance (Eq. A6). All three aforementioned models adopted the same adaptive time step strategy and numerical solution and the same soil discretization, soil parameters (shown as Table 4.2), and boundary conditions. It indicated that the truncation errors, due to numerical solution, among three models were comparable. The differences among the models were mainly restricted to the various representations of soil physical processes (e.g., the inclusion of vapor flow and airflow or not).

Table 4.2. The adopted average values of soil texture and hydraulic properties at different depths (see the List of symbols for the notations)

\begin{tabular}{llllllll}
\hline $\begin{array}{l}\text { Soil depth } \\
(\mathrm{cm})\end{array}$ & Clay (\%) & Sand $(\%)$ & $\begin{array}{l}K_{\mathrm{s}} \\
\left(10^{-6} \mathrm{~m} \mathrm{~s}^{-1}\right)\end{array}$ & $\begin{array}{l}\theta_{\text {sat }} \\
\left(\mathrm{m}^{3} \mathrm{~m}^{-3}\right)\end{array}$ & $\begin{array}{l}\theta_{\mathrm{r}} \\
\left(\mathrm{m}^{3} \mathrm{~m}^{-3}\right)\end{array}$ & $\alpha\left(\mathrm{m}^{-1}\right)$ & $n$ \\
\hline $5-10$ & 9.00 & 44.13 & 1.45 & 0.50 & 0.035 & 0.041 & 1.332 \\
$10-40$ & 10.12 & 44.27 & 0.94 & 0.45 & 0.039 & 0.041 & 1.362 \\
$40-160$ & 5.59 & 65.55 & 0.68 & 0.41 & 0.045 & 0.075 & 1.590 \\
\hline
\end{tabular}


(a) Model setup

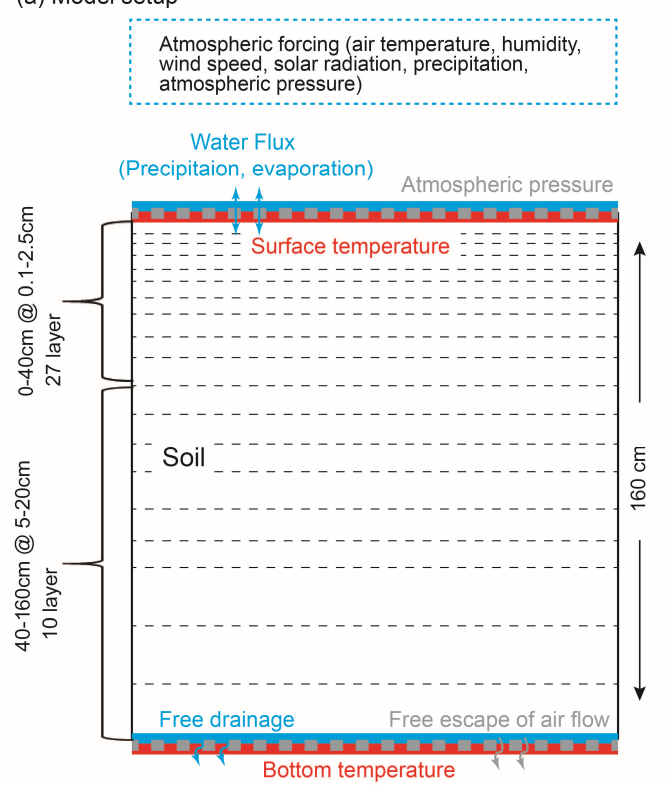

(b) Meteorological Forcing
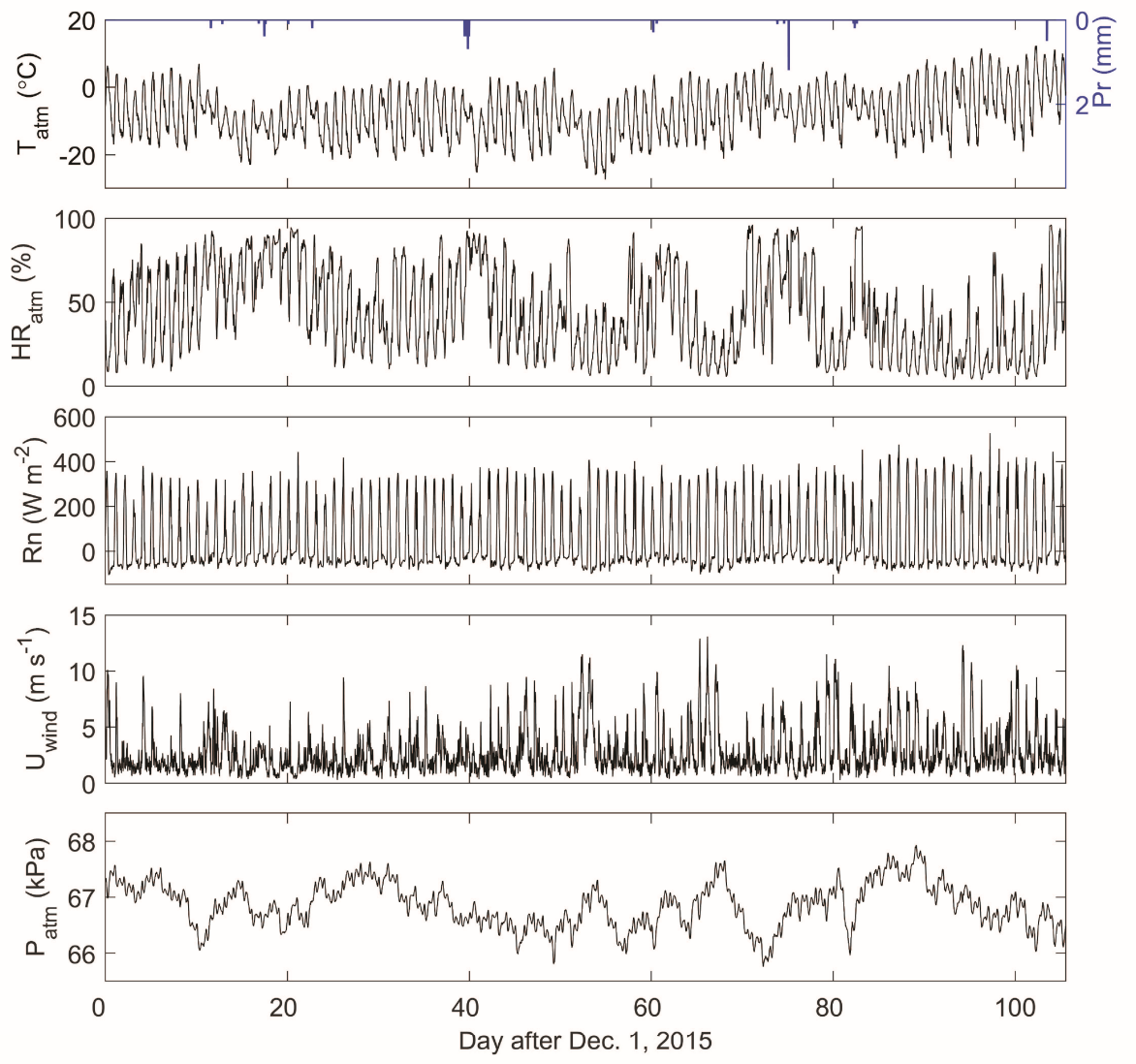

Figure 4.1. (a) Conceptual illustration of the model setup, the surface and bottom boundary conditions, driving forces, and vertical discretization. (b) Half-hourly measurements of meteorological forcing, including air temperature $\left(\mathrm{T}_{\mathrm{atm}},{ }^{\circ} \mathrm{C}\right)$, relative humidity $\left(\mathrm{HR}_{\mathrm{atm}}, \%\right)$, net radiation $\left(\mathrm{Rn}, \mathrm{W} \mathrm{m} \mathrm{m}^{-2}\right.$ ), wind speed $\left(\mathrm{U}_{\text {wind }}, \mathrm{m} \mathrm{s}^{-1}\right)$, and atmospheric pressure $\left(\mathrm{P}_{\mathrm{atm}}, \mathrm{kPa}\right)$, during the simulation period. Note that dimensions are not drawn to scale, models were run at a $1 \mathrm{D}$ scale. 


\subsection{Results}

Given the same atmospheric forcing and the same set of parameters, the performance of models with varying complexities of soil water and heat physics was illustrated in Sect. 4.3.1, 4.3.2 \& 4.3.3. Sect. 4.3.4 \& 4.3.5 further analyzed the variations in heat budgets and subsurface latent heat flux density, illustrating differences in the underlying mechanisms among various models.

\subsubsection{Soil hydrothermal profile simulations}

The performance of the model, with various soil physics, in simulating the soil thermal profile information is illustrated in Figure 4.2. Both ACM and ACM-AIR reproduced the time series of the soil temperature at different soil depths well, except at $40 \mathrm{~cm}$ which is most probably due to the inappropriate measurements (e.g., improper placement of sensors). However, there are significant discrepancies in soil temperature simulated by the BCM. Compared to the observations, a stronger diurnal behavior of soil temperature in response to the fluctuating atmospheric forcing, was found, and an earlier stepping in and stepping out of the frozen period was simulated by the BCM. Such differences enlarged at deeper soil layers, with large bias and root mean square error (RMSE) values (Table 4.3).

Table 4.3. Comparative statistics values of observed and simulated soil temperature and moisture with three models, with the bold font indicating the best statistical performance

\begin{tabular}{llllllllllll}
\hline \multirow{2}{*}{ Experiment } & \multirow{2}{*}{ Statistics } & \multicolumn{4}{c}{ Soil temperature $\left({ }^{\circ} \mathrm{C}\right)$} & \multicolumn{5}{c}{ Soil moisture $\left(\mathrm{m}^{3} \mathrm{~m}^{-3}\right)$} \\
\cline { 3 - 11 } & & $5 \mathrm{~cm}$ & $10 \mathrm{~cm}$ & $20 \mathrm{~cm}$ & $40 \mathrm{~cm}$ & $80 \mathrm{~cm}$ & $5 \mathrm{~cm}$ & $10 \mathrm{~cm}$ & $20 \mathrm{~cm}$ & $40 \mathrm{~cm}$ & $80 \mathrm{~cm}$ \\
\hline \multirow{2}{*}{ BCM } & Bias & $\mathbf{- 0 . 0 3 9}$ & 0.177 & -0.022 & -1.103 & -0.140 & 0.009 & 0.009 & 0.005 & $\mathbf{0 . 0 0 4}$ & 0.002 \\
& RMSE & 0.381 & 0.407 & 0.521 & 1.524 & 0.526 & 0.025 & 0.022 & 0.031 & 0.032 & 0.012 \\
& Bias & -0.183 & 0.093 & $\mathbf{0 . 0 0 1}$ & -0.956 & $\mathbf{0 . 0 2 7}$ & $\mathbf{0 . 0 0 0}$ & 0.004 & 0.001 & 0.005 & $\mathbf{0 . 0 0 1}$ \\
ACM & RMSE & 0.365 & $\mathbf{0 . 3 1 4}$ & 0.186 & 1.168 & 0.128 & $\mathbf{0 . 0 0 8}$ & 0.007 & 0.003 & 0.007 & $\mathbf{0 . 0 0 2}$ \\
& Bias & -0.187 & $\mathbf{0 . 0 9 3}$ & 0.005 & $\mathbf{- 0 . 9 5 3}$ & 0.029 & -0.001 & $\mathbf{0 . 0 0 4}$ & $\mathbf{0 . 0 0 1}$ & 0.005 & 0.001 \\
\multirow{2}{*}{ ACM-AIR } & RMSE & $\mathbf{0 . 3 6 2}$ & 0.316 & $\mathbf{0 . 1 8 0}$ & $\mathbf{1 . 1 6 8}$ & $\mathbf{0 . 1 2 6}$ & 0.011 & $\mathbf{0 . 0 0 6}$ & $\mathbf{0 . 0 0 3}$ & $\mathbf{0 . 0 0 7}$ & 0.002 \\
\hline
\end{tabular}

Note: Bias $=\frac{\sum_{i=1}^{n}\left(y_{i}-\widehat{y_{l}}\right)}{n}, R M S E=\sqrt{\frac{\sum_{i=1}^{n}\left(y_{i}-\widehat{y}_{l}\right)^{2}}{n}}$, where $y_{i}, \widehat{y}_{l}$ are the measured and model simulated soil temperature or moisture, and $\mathrm{n}$ is the number of data points. 


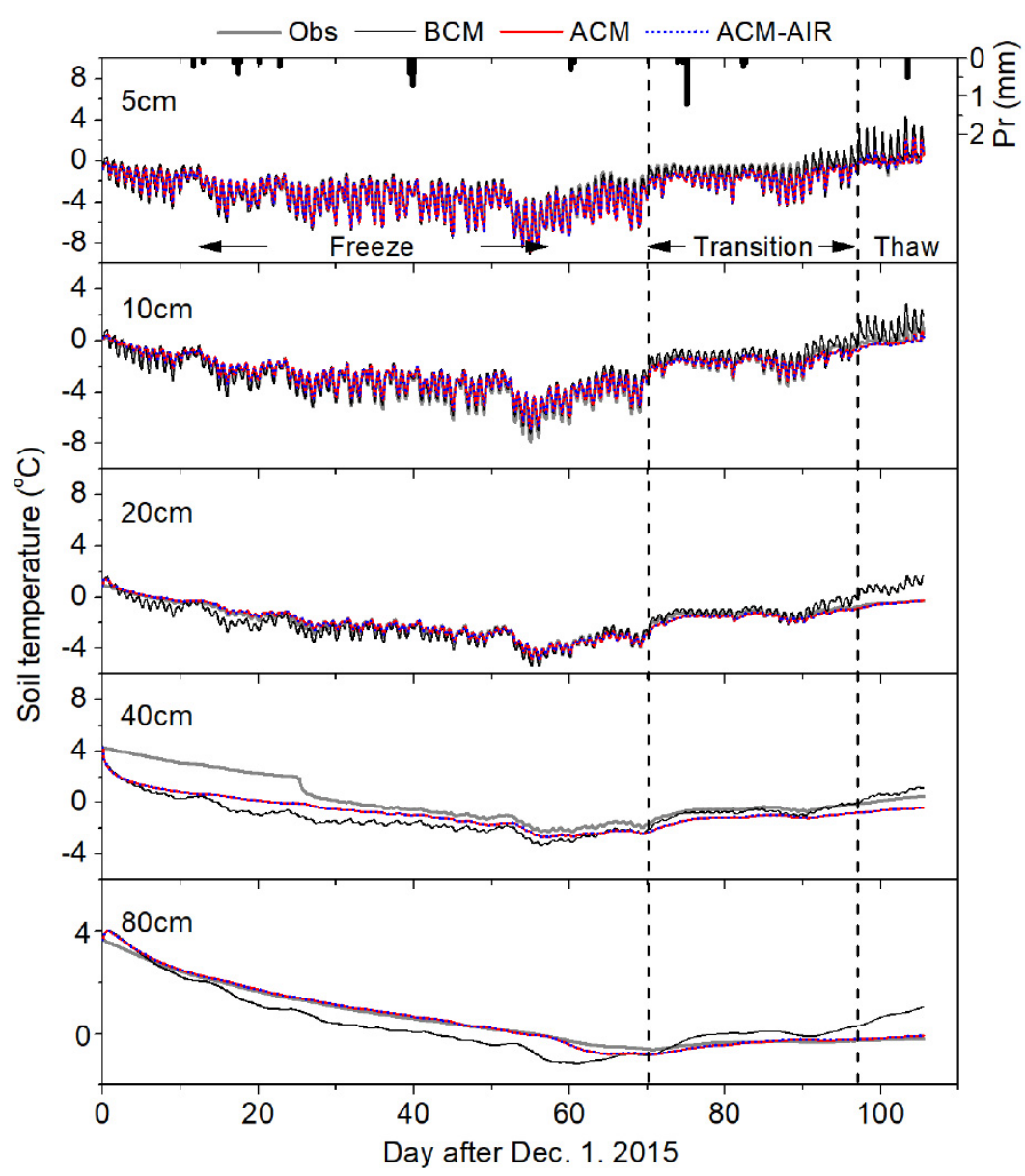

Figure 4.2. Comparison of measured (Obs) and model-simulated time series of soil temperature at various soil layers using the basic coupled model (BCM), advanced coupled model (ACM), and advanced coupled model with airflow (ACM-AIR).

Figure 4.3 presents the time series of observed and simulated soil liquid water content at five soil layers. During the rapid freezing period, a noticeable overestimation of the diurnal fluctuations and an early and fast decrease in soil liquid water content was simulated by BCM. Moreover, stronger diurnal fluctuations and an early increase in liquid water content were also found during the thawing period. The early thawing of soil water even led to an unrealistic refreezing process at $80 \mathrm{~cm}$ (from the 88th to $92 \mathrm{nd}$ day after December 2015), which is due to the simulated early warming of soil by BCM (Figure 4.2). Such discrepancies were significantly ameliorated by ACM and ACMAIR simulations. Nevertheless, all three models can capture the diurnal variations and magnitude of liquid water content during the frozen period well. Note that there is an observable difference between ACM- and ACM-AIR-simulated soil liquid water content at shallower soil layers during the thawing process (e.g., Figure $4.3 ; 5 \mathrm{~cm}$ ). 


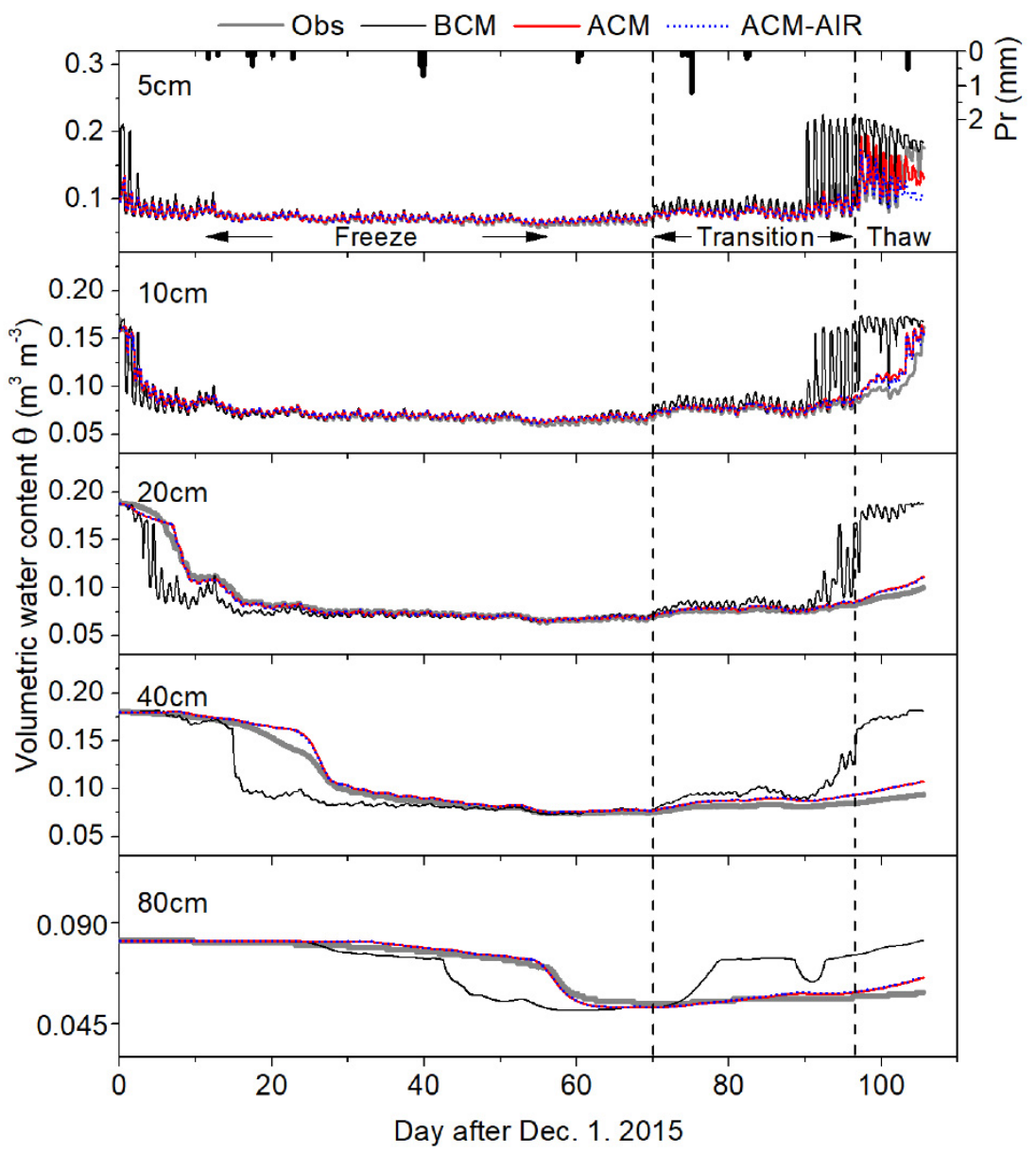

Figure 4.3. Comparison of measured (Obs) and model simulated time series of soil moisture at various soil layers using basic coupled model (BCM), advanced coupled model (ACM) and advanced coupled model with airflow (ACM-AIR).

\subsubsection{Freezing front propagation}

The time series of freezing front propagation derived from the measured and simulated soil temperature was reproduced in Figure 4.4. Initialized from the soil surface, the freezing front quickly develops downwards until the maximum freezing depth is reached. The thawing process starts from both the top and bottom and is mainly driven by the atmospheric heat and bottom soil temperature, respectively. Such characteristics were captured well by both the ACM and ACM-AIR models in terms of freezing rate, maximum freezing depth, and surface thawing process, while the $\mathrm{BCM}$ tended to present a more fluctuating and rapidly freezing front propagation and a deeper maximum freezing depth that was reached early. The effect of atmospheric heat sources on the soil was overestimated by the BCM, as shown by the stronger diurnal early onset of the thawing process. 


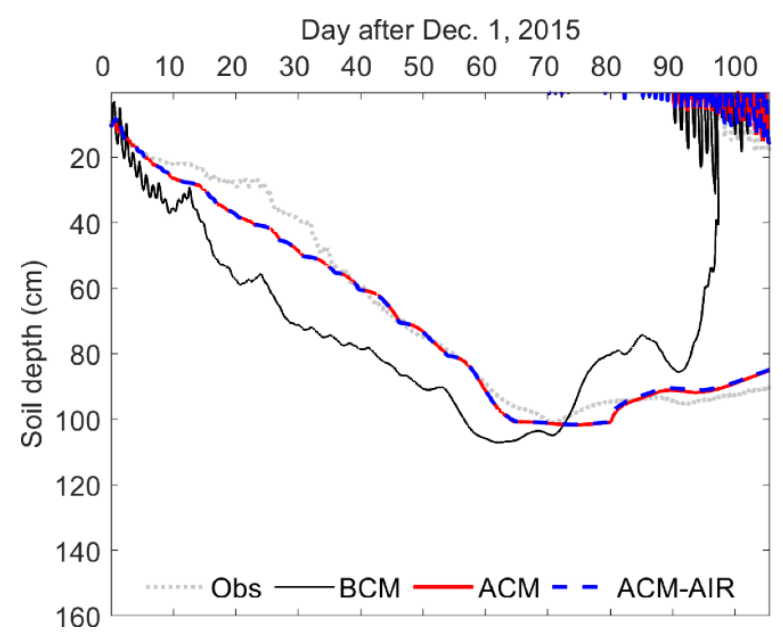

Figure 4.4. Comparison of measured (Obs) and model-simulated freezing front propagation (FFP) using basic coupled model (BCM), advanced coupled model (ACM), and advanced coupled model with airflow (ACM-AIR). Note that the measured FFP was seen as the development of zero-degree isothermal lines from the measured soil temperature field.

\subsubsection{Surface evapotranspiration}

The performance of the model with different soil physics in reproducing the latent heat flux dynamics is shown in Figure 4.5. Compared to the observed LE, there is a significant overestimation of the half-hourly latent heat flux, which significantly degraded the overall performance when using BCM. The occurrence of such an overestimation was notably reduced when using ACM and ACM-AIR. The general underestimation of the latent heat flux by the ACM and ACM-AIR was found mostly during the freezing-thawing transition period (Figure 4.6b) when the soil hydrothermal states are not well captured (Figure $4.2 \& 4.3$ ).
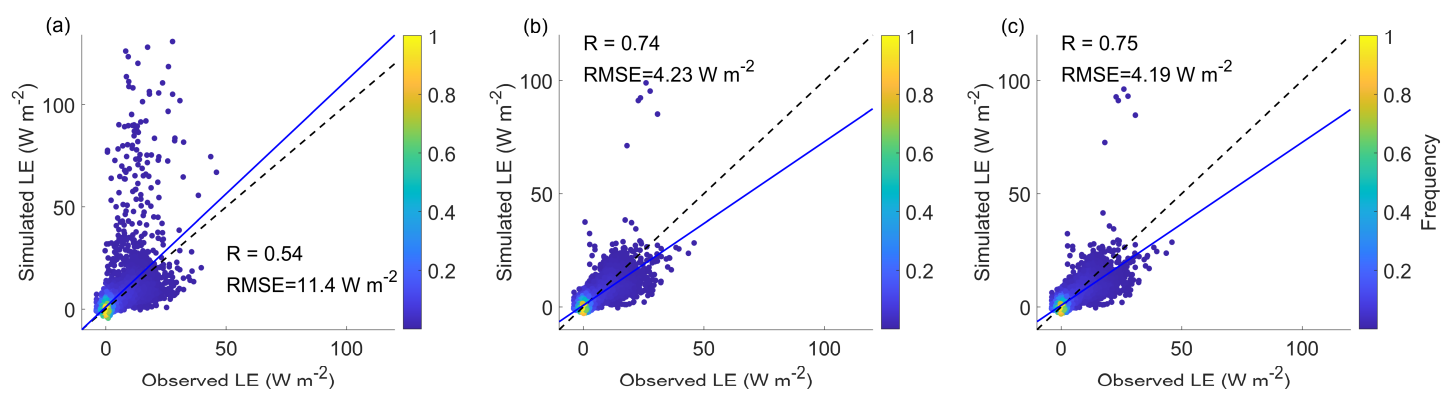

Figure 4.5. Scatter plot of observed and model estimated half-hourly latent heat flux using (a) basic coupled model (BCM), (b) advanced coupled model (ACM), and (c) advanced coupled model with airflow (ACM-AIR). The color indicates the data composite of surface latent heat flux. 

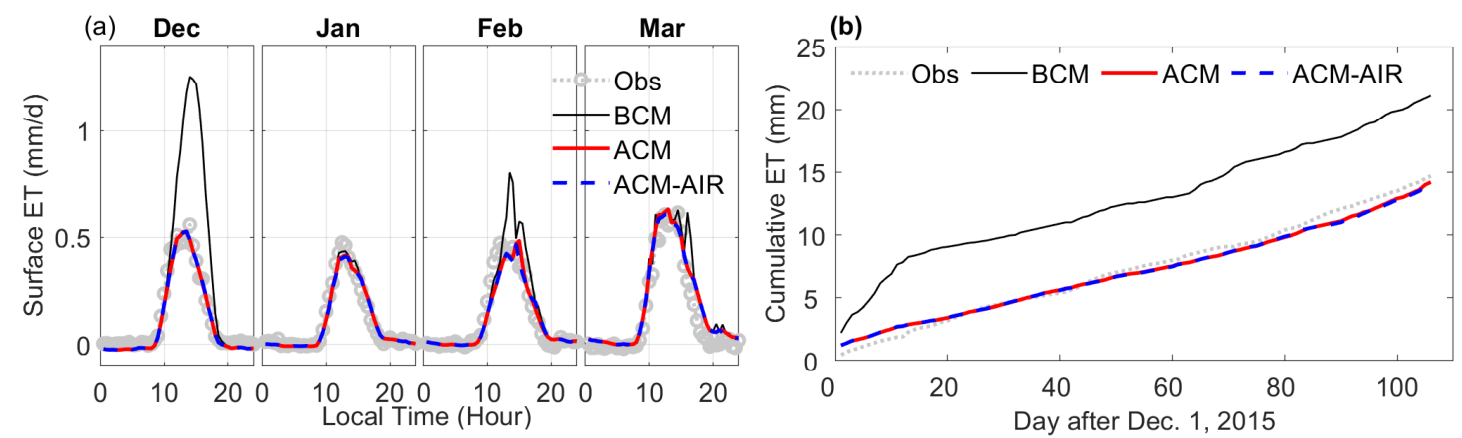

Figure 4.6. Comparison of observed and model simulated (a) mean diurnal variations in surface evapotranspiration and (b) cumulative evapotranspiration (ET) by the basic coupled model (BCM), advanced coupled model (ACM), and advanced coupled model with airflow (ACM-AIR).

The overestimation of surface evapotranspiration by BCM was significant during the initial freezing and transition period (Figure 4.6a; December and February). During the rapid freezing period (January), BCM presented a good match in the diurnal variation as compared to the observations. The monthly average diurnal variations were found to be well captured by ACM and ACM-AIR. Figure 4.6b shows the comparison of observed and simulated cumulative surface evapotranspiration. The overall overestimation of surface evapotranspiration by BCM can be clearly seen in Figure 4.6b. Days in the initial freezing periods, with high liquid water content simulations, accounted for more than $90 \%$ of the overestimation. The initial stage overestimation of surface evapotranspiration was significantly reduced by ACM and ACM-AIR. A slight underestimation of cumulative surface evapotranspiration was simulated by ACM and ACM-AIR, with values of $3.98 \%$ and $4.78 \%$, respectively.

\subsubsection{Heat budgets}

Figure 4.7 shows the time series of simulated energy budget components at $5 \mathrm{~cm}$ using BCM, ACM and ACM-AIR during the freezing period (5th-11th day after 1 December) and the freezing-thawing transition period (83rd-89th day after 1 December). For the $\mathrm{BCM}$, only the change rate of heat content $(\mathrm{HC})$ and conductive heat flux divergence (CHF) are considered in the left-hand side (LHS) and right-hand side (RHS) of Eq. 4.2; see Table 4.1. Three additional terms, namely convective heat flux divergence of liquid flow (HFL) and vapor flow (HFV) and latent heat flux divergence, were included for the ACM, while for the ACM-AIR the convective heat flux divergence of airflow (HFa) was also added. 


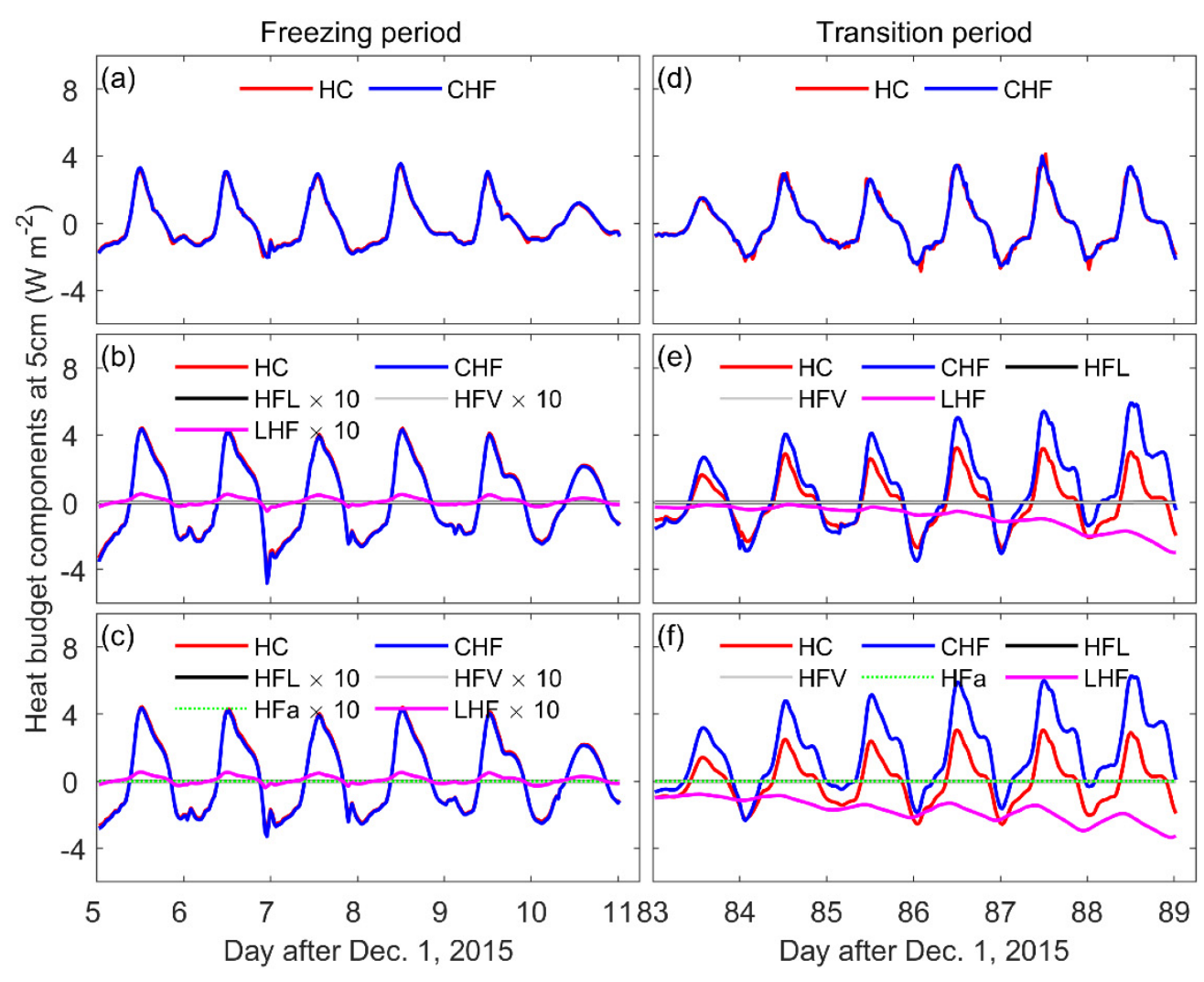

Figure 4.7. Time series of model-simulated heat budget components at the soil depth of $5 \mathrm{~cm}$ using (a \&d) basic coupled model (BCM), (b \&e) advanced coupled model (ACM), and (c \&f) advanced coupled model with airflow (ACM-AIR) simulations during the typical $6 \mathrm{~d}$ freezing $(\mathrm{a}-\mathrm{c})$ and freezing-thawing transition $(\mathrm{d}-\mathrm{f})$ periods. $\mathrm{HC}$ - change rate of heat content; CHF - conductive heat flux divergence; HFL convective heat flux divergence due to liquid water flow; HFV - convective heat flux divergence due to water vapor flow; $\mathrm{HFa}$ - convective heat flux divergence due to airflow; LHF - latent heat flux divergence. Note that, for graphical purposes, HFL, $\mathrm{HFV}, \mathrm{HFa}$, and LHF were enhanced by a factor of 10 during the freezing period.

There is a strong diurnal variation of heat budget components (HC, CHF \& LHF, Table 4.1 ), corresponding to the diurnal fluctuation in soil temperature. For the BCM, the change rate of heat content was almost completely balanced by the conductive heat flux divergence (CHF; Figure 4.7a). Compared to the BCM, a stronger diurnal fluctuation of $\mathrm{HC}$ and $\mathrm{CHF}$ was found in ACM results. As inferred from the results in Figure 4.2, the time series of soil temperature change $(\partial T / \partial t)$ simulated by $\mathrm{BCM}$ was larger than that simulated by ACM. This indicates BCM produced less fluctuation in apparent heat capacity $\left(C_{a p p}=C_{\text {soil }}+\rho_{i} \frac{L_{f}^{2}}{g T} \frac{d \theta_{L}}{d \psi}\right)$ than ACM. During the freezing period, the latent heat flux divergence (LHF) was lower than conductive heat flux divergence (CHF) by 1-2 orders of magnitude (Figure 4.7b). The positive value of the LHF term during the daytime indicates that condensation happens at $5 \mathrm{~cm}$ as the water vapor moves downward. The convective heat fluxes of liquid flow and vapor flow were even smaller 
compared to conductive heat flux (Figure 4.7b). There is no significant difference in heat budget components between ACM and ACM-AIR in terms of diurnal variation and magnitude. The convective heat flux divergence of airflow played a negligible role in the change in the thermal state (HC) (Figure 4.7c).

The dynamics of heat balance components at the $5 \mathrm{~cm}$ soil layer were simulated for the freezing-thawing transition period (Figure $4.7 \mathrm{~d}-\mathrm{f}$ ). Both $\mathrm{HC}$ and $\mathrm{CHF}$ underwent strong diurnal variations with increasing fluctuation magnitude, indicating soil warming at 5 $\mathrm{cm}$. For the ACM, CHF outnumbered HC during daytime and the difference increased with time. Negative values were found for LHF and developed further over time. The sum of CHF and LHF nearly balanced the HC term. Such behavior was similarly reproduced by ACM-AIR, with a slightly larger difference between the $\mathrm{HC}$ and $\mathrm{CHF}$ terms. This means a larger amount of water vapor was evaporated from $5 \mathrm{~cm}$ soil layer (with a more negative LHF term) from ACM-AIR simulations than that from ACM simulations, which explains the lower liquid water content for ACM-AIR (Figure 4.3; $5 \mathrm{~cm})$.

\subsubsection{Subsurface latent heat flux density}

To give more context to the results, the spatial and temporal distributions of the simulated latent heat flux density $\left(\mathrm{S}_{\mathrm{h}}\right)$, namely $-\rho_{w} L \partial q_{v} / \partial z$, during the freezing and freezing-thawing transition period are shown in Figure 4.8. For the BCM, the latent heat flux density $\left(\mathrm{S}_{\mathrm{h}}\right)$ is not available as it neglects the vapor flow. 

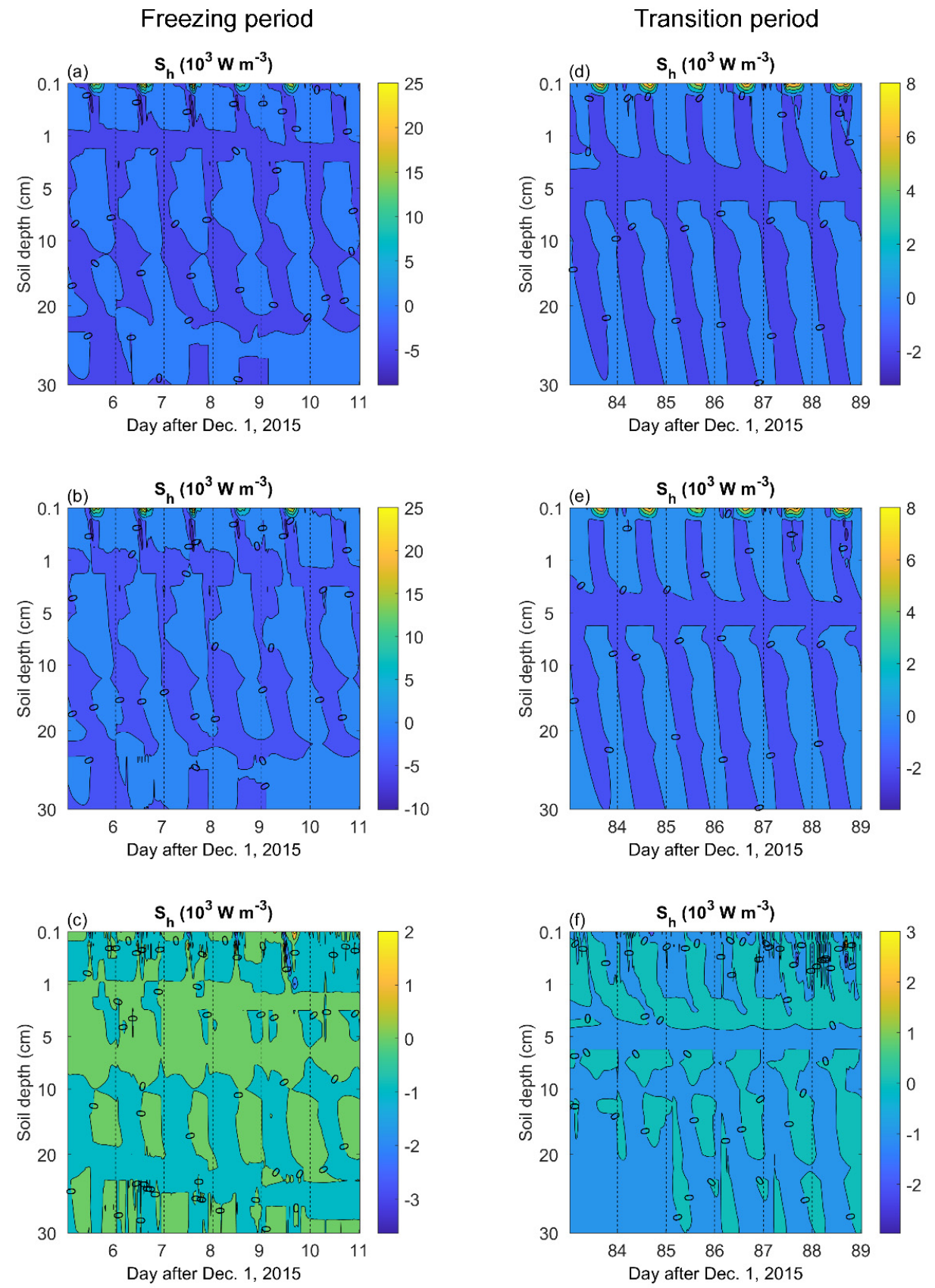

Figure 4.8. The spatial and temporal distributions of model estimated soil latent heat flux density using (a \&d) advanced coupled model (ACM), (b \&e) advanced coupled model with airflow (ACM-AIR) and (c \&f) the difference between ACM and ACMAIR simulations $\left(S_{h, A C M-A I R}-S_{h, A C M}\right)$ during the typical $6 \mathrm{~d}$ freezing and freezingthawing transition periods. The left $(\mathrm{a}-\mathrm{c})$ and right $(\mathrm{d}-\mathrm{f})$ columns are for the freezing and freezing-thawing transition periods, respectively. Note that figures for the basic coupled model (BCM) are absent as the model can not simulate the subsurface soil latent heat flux density.

Figure $4.8 \mathrm{a}$ shows that there is a strong diurnal variation of $\mathrm{S}_{\mathrm{h}}$ in the upper $0.1 \mathrm{~cm}$ soil layers. Such diurnal behavior along the soil profile was interrupted at $1 \mathrm{~cm}$, at which point the water vapor consistently moved upwards as an evaporation source (termed the 
evaporative front). The path of this upward water vapor was disrupted at $20 \mathrm{~cm}$ from the 6 December onward when the freezing front developed. Compared to the upper 0.1 $\mathrm{cm}$ soil, a weaker diurnal fluctuation of $\mathrm{S}_{\mathrm{h}}$ was found at lower soil layers. For ACMAIR, the vapor transfer patterns were similar to those of ACM (Figure 4.8b). There were isolated connections of condensed water vapor between the upper $1 \mathrm{~cm}$ of soil and the lower soil layers ( $\mathrm{S}_{\mathrm{h}}>0$; e.g., 6, 7, 9, and 10 December), possibly associated with the downward airflow (see Figure 12 in Yu et al., 2018). The large difference in magnitude of latent heat flux density between ACM and ACM-AIR appeared to be mainly isolated in the upper soil layers (Figure 4.8c). At soil layers between 1 and 20 $\mathrm{cm}$, ACM-AIR simulated less in condensation vapor area $\left(\mathrm{S}_{\mathrm{h}}>0\right)$ and more in the evaporation area $\left(S_{h}<0\right)$, indicating that $A C M-A I R$ produced an additional amount of condensation and evaporation water vapor compared with ACM (Figure 4.8c).

Similar to that during the freezing period, the $\mathrm{S}_{\mathrm{h}}$ during the transition period can be characterized as: strong diurnal variations at upper soil layers, interruptiing diurnal patterns with the constant upward evaporation of intermediate soil layers, and having weak diurnal variations at lower soil layers (Figure $4.8 \mathrm{~d}$ and e). While the maximum evaporation rate was less than that during the freezing period, the consistent evaporation zone developed to a depth of $5 \mathrm{~cm}$. The path for the upward-moving water vapor tended to develop deeper than $30 \mathrm{~cm}$ with the absence of soil ice. The simulation by ACMAIR produced more condensation and less evaporative water vapor than that of ACM (Figure 4.8f). In addition, steadily more evaporative water vapor from $5 \mathrm{~cm}$ was simulated by ACM-AIR compared to ACM. This confirms the aforementioned point that during the freezing-thawing transition period, large LHF values were simulated by ACM-AIR (Figure 4.7).

\subsection{Discussion}

\subsubsection{Coupled water and heat transfer processes}

Vapor flow, which is dependent on soil matric potential and temperature, links soil water and heat transfer processes. The mutual dependence of soil water in different phases (liquid, water vapor, and ice) and heat transport on vapor flow enables the facilitation of our better understanding of the complex soil physical processes (e.g., Figure 4.7-4.8). Specifically, the interdependence of soil moisture and soil temperature (SMST) profiles simulated by ACM was closer to the observation than that by B. In addition, a significant enhancement in portrayal of the monthly average diurnal variations in surface evapotranspiration and cumulative evapotranspiration can be found in ACM simulations which constrain the hydrothermal regimes, especially during the freezing-thawing transition periods (Figure 4.2, 4.3 and 4.6).

During the freezing period, liquid water in the soil freezes, which is analogous to the soil drying process, and water vapor fluxes instead of liquid fluxes dominate the mass 
transfer process (Zhang et al., 2016a). Neglecting such an important water flux component unavoidably results in different or unrealistic simulations of surface evapotranspiration and SMST profiles (Li et al., 2010; Karra et al., 2014; Wang \& Yang, 2018). Li et al. (2010) reported that vapor fluxes were comparable to the liquid water fluxes and affected the freezing and melting processes. On the basis of long term 1D soil column simulations, Karra et al. (2014) reported that the inclusion of the vapor diffusion effect significantly increased the thickness of the ice layer as explained by the positive vapor cold trapping-thermal conductivity feedback mechanism. From the energy budget perspective, latent heat fluxes contribute more, due to the vapor phase change (LHF), to the heat balance budget at soil layers above the evaporative front than that below it (see LHF in Figure 4.7e vs. Figure 4.7b; corresponding evaporative front shown in Figure 4.8d vs. Figure 4.8a). This is consistent with findings by Zhang et al. (2016), who concluded that the latent heat of vapor, due to phase change, is 2 orders of magnitude less than the heat fluxes due to conduction during wintertime. This corresponds to our results of Figure $4.7 \mathrm{~b}$ and c during the freezing period, while our results further showed that the latent heat fluxes due to vapor phase change can be considerable during the transition period (Figure 4.7e and $\mathrm{f}$ ). The downward latent heat flux from ACM makes the subsurface soil warmer, which reduces the temperature gradient $(\partial T / \partial z)$ (Wang and Yang, 2018). This further results in the weaker diurnal fluctuations of the HC term in ACM than that in BCM (see HC in Figure 4.7e vs. Figure 4.7d). At the soil layers below the evaporative front, the heat flux source from the vapor transfer process (LHF) is negligible (e.g., Figure 4.7b). The thermal retard effect occurs as the presence of soil ice, expressed as the apparent heat capacity term $\left(\mathrm{C}_{\mathrm{app}}\right)$, dominates the heat transfer process in frozen soils. By considering the thermal effect on water flow, ACM usually has a larger water capacity value $\partial \theta / \partial \psi$ than $\mathrm{BCM}$ does. As such, the intense thermal impedance effect leads to the result that ACM produced a weaker diurnal fluctuation of soil temperature than BCM at subsurface soil layers (e.g., Figure $4.2 ; 20 \mathrm{~cm})$.

\subsubsection{Airflow in the soil}

Since soil pores are filled with liquid water, vapor and dry air, taking dry air as an independent state variable can facilitate a better understanding of the relative contribution of each component to the mass and heat transfer in soils. The results show that the dry-air-induced water and heat flow is negligible in relation to the total mass and energy transfer (Zeng et al., 2011b; Yu et al., 2018). Nevertheless, dry air can affect soil hydrothermal regimes significantly under certain circumstances. Wicky and Hauck (2017) reported that the airflow-induced convective heat transfer resulted in a considerable temperature difference between the upper and lower part of a permafrost talus slope and thus had a remarkable effect on the thermal regime of the talus slope. Zeng et al. (2011b) demonstrated the airflow-induced surface evaporation enhanced 
after precipitation events, since the hydraulic conductivity of topsoil layers increased tremendously due to the increased topsoil moisture by the injected airflow from the moist atmosphere. In this study, we found that the explicit consideration of airflow introduced an additional amount of subsurface condensation and evaporative water vapor in the condensation region and evaporation region, respectively (Figure 4.8c and f). The effect of latent heat flux on heat transfer was enhanced by airflow during the freezing-thawing transition period (Figure 4.7), which further affected the subsurface hydrothermal simulations (e.g., Figure 4.3).

\subsection{Conclusion}

On the basis of the STMMUS modeling framework with various representations of water and heat transfer physics (BCM, ACM and ACM-AIR), the performance of each model in simulating water and heat transfer and surface evapotranspiration was evaluated over a typical Tibetan meadow ecosystem. Results indicated that compared to in situ observations, the BCM tended to present earlier freezing and thawing dates with a stronger diurnal variation in soil temperature and liquid water in response to the atmospheric forcing. Such discrepancies were considerably reduced by the model with the advanced coupled water-heat physics. Surface evapotranspiration was overestimated by BCM, mainly due to the mismatches during the initial freezing and freezing-thawing transition period. ACM models, with the coupled constraints from the perspective of water and energy conservation, significantly improve the model performance in mimicking the surface evapotranspiration dynamics during the frozen period. The analysis of the heat budget components and latent heat flux density revealed that the improvement in soil temperature simulations by ACM is ascribed to its physical consideration of vapor flow and thermal effect on water flow, with the former mainly functioning at regions above the evaporative front, and the latter dominating below the evaporative front. The nonconductive heat process (liquid or vapor or air-induced heat convection flux) contributed very minimally to the total energy fluxes during the frozen period, except for the latent heat flux divergence at the topsoil layers. The contribution of airflow-induced water and heat flow to the total mass and energy fluxes is negligible. However, given the explicit consideration of airflow, the latent heat flux and its effect on heat transfer were enhanced during the freezing-thawing transition period. This work highlighted the role of considering the vapor flow and the thermal effect on water flow and airflow in portraying the subsurface soil hydrothermal dynamics, especially during freezing-thawing transition periods. To sum up, this study can contribute to a better understanding of the freeze-thaw mechanisms of frozen soils, which will subsequently contribute to the quantification of permafrost carbon feedback (Burke et al., 2013; Kevin et al., 2014; Schuur et al., 2015), if the STEMMUS-FT model is to be coupled with a biogeochemical model, as lately implemented (Yu et al., 2020a). 

Chapter 5 STEMMUS-UEB v1.0.0: integrated modeling of snowpack and soil water and energy transfer with three complexity levels of soil physical processes*

* This chapter is based on: Yu, L., Zeng, Y., \& Su, Z. (2021). STEMMUS-UEB v1.0.0: integrated modeling of snowpack and soil water and energy transfer with three complexity levels of soil physical processes. Geoscientific Model Development, 14(12), 7345-7376. doi:10.5194/gmd-14-7345-2021 


\section{Abstract}

A snowpack has a profound effect on the hydrology and surface energy conditions of an area through its effects on surface albedo and roughness and its insulating property. The modeling of a snowpack, soil water dynamics, and the coupling of the snowpack and underlying soil layer has been widely reported. However, the coupled liquid-vaporairflow mechanisms considering the snowpack effect have not been investigated in detail. In this study, we incorporated the snowpack effect (Utah energy balance snowpack model, UEB) into a common modeling framework (Simultaneous Transfer of Energy, Mass, and Momentum in Unsaturated Soils with Freeze-Thaw, STEMMUSFT), i.e., STEMMUS-UEB. It considers soil water and energy transfer physics with three complexity levels (basic coupled, advanced coupled water and heat transfer, and finally explicit consideration of airflow, termed BCD, ACD, and ACD-air, respectively). We then utilized in situ observations and numerical experiments to investigate the effect of snowpack on soil moisture and heat transfer with the abovementioned model complexities. Results indicated that the proposed model with snowpack can reproduce the abrupt increase of surface albedo after precipitation events while this was not the case for the model without snowpack. The BCD model tended to overestimate the land surface latent heat flux (LE). Such overestimations were largely reduced by the ACD and ACD-air models. Compared with the simulations considering snowpack, there is less LE from no-snow simulations due to the neglect of snow sublimation. The enhancement of LE was found after winter precipitation events, which is sourced from the surface ice sublimation, snow sublimation, and increased surface soil moisture. The relative role of the mentioned three sources depends on the timing and magnitude of precipitation and the pre-precipitation soil hydrothermal regimes. The simple BCD model cannot provide a realistic partition of mass transfer flux. The ACD model, with its physical consideration of vapor flow, thermal effect on water flow, and snowpack, can identify the relative contributions of different components (e.g., thermal or isothermal liquid and vapor flow) to the total mass transfer fluxes. With the ACDair model, the relative contribution of each component (mainly the isothermal liquid and vapor flows) to the mass transfer was significantly altered during the soil thawing period. It was found that the snowpack affects not only the soil surface moisture conditions (surface ice and soil water content in the liquid phase) and energy-related states (albedo, LE) but also the transfer patterns of subsurface soil liquid and vapor flow. 


\subsection{Introduction}

In cold regions, the snowpack has a profound effect on hydrology and surface energy through its change of surface albedo, roughness, and insulating property (Zhang, 2005; Boone et al., 2017). In contrast to rainfall, the melted snowfall enters the soil with a significant lag in time, and a large and sudden outflow or runoff may be produced because of the snowmelt effect. The heat-insulating property of snow cover also provides a buffer layer to reduce the magnitude of the underlying subsurface temperature variations and thus markedly affects the thickness of the active layer in cold regions. The effect of snow cover on the subsurface soils has been studied and reviewed (e.g., Zhang, 2005; Hrbáček et al., 2016). For instance, snow cover can act as an insulator between atmosphere and soil with its low thermal conductivity (Zhang, 2005; Hrbáček et al., 2016). The snowmelt functions as the energy sink via the absorption of heat due to phase change (Zhang, 2005). Yi et al. (2015) investigated the seasonal snow cover effect on the soil freezing and thawing process and its related carbon implications. Such studies mainly focus on the thermal effect of snowpack on the frozen soils. However, the effect of snowpack on the soil water and vapor transfer process is rarely reported (Hagedorn et al., 2007; Iwata et al., 2010; Domine et al., 2019).

A great amount of effort has been made to better reproduce the snowpack characteristic and its effects in models. Initially, snowpack dynamics were expressed as a simple function of temperature. Nevertheless, these empirical relations have limited applications in complex climate conditions (Pimentel et al., 2015). Many physically based models for the mass and energy balance in the snowpack have been developed for their coupling with hydrological models or atmospheric models. Boone and Etchevers (2001) divided these snow models into three main categories: (i) simple force-restore schemes with the snow modeled as the composite snow-soil layer (Pitman et al., 1991; Douville et al., 1995; Yang et al., 1997) or a single explicit snow layer (Verseghy, 1991; Tarboton \& Luce, 1996; Slater et al., 1998; Sud \& Mocko, 1999; Dutra et al., 2010); (ii) detailed internal snow process schemes with multiple snow layers of fine vertical resolution (Jordan, 1991; Lehning et al., 1999; Vionnet et al., 2012; Leroux \& Pomeroy, 2017); and (iii) intermediate-complexity schemes with physics from the detailed schemes but with a limited number of layers, which are intended for coupling with atmospheric models (e.g., Sun et al., 1999; Boone \& Etchevers, 2001). The intercomparison results of the abovementioned snow models at an alpine site indicated that all three types of schemes are capable of representing the basic features of the snow cover over the 2-year period but behaved differently on shorter timescales. Furthermore, the Snow Model Intercomparison Project (SnowMIP) at two mountainous alpine sites revealed that the albedo parameterization was the major factor influencing the simulation of net shortwave radiation. Though this 
parameterization is independent of model complexity (Etchevers et al., 2004) it directly affects the snow simulation. SnowMIP2 evaluated 33 snowpack models across a wide range of hydrometeorological and forest canopy conditions. It identified the shortcomings of different snow models and highlighted the necessity of studying the separate contribution of individual components to the mass and energy balance of snowpack (Rutter et al., 2009). With the majority of research focused on the intercomparison of the snowpack models with various physical complexities, little attention has been paid to the treatment of the underlying soil physical processes (see the brief overview of current soil-snow modeling efforts in Table 5.1).

In current soil-snow modeling research, soil water and heat transfer are usually not fully coupled, and moreover the vapor flow and airflow are absent (Koren et al., 1999; Niu et al., 2011; Swenson et al., 2012). This may lead to the unrealistic interpretation of the underlying soil physical processes and the snowpack energy budgets ( $\mathrm{Su}$ et al., 2013; Wang et al., 2017). Researchers have emphasized the need to consider the coupled soil water and heat transfer mechanisms (Scanlon and Milly, 1994; Bittelli et al., 2008; Zeng et al., 2009a; Zeng et al., 2009b; Yu et al., 2018). As a consequence, dedicated efforts have been made to implement it in the recent updated models (e.g., Painter et al., 2016; Wang et al., 2017; Cuntz and Haverd 2018). On the other hand, the role of the airflow has been reported as being important in many relevant studies, including retarding soil water infiltration (Touma and Vauclin, 1986; Prunty and Bell, 2007), enhancing surface evaporation after precipitation (Zeng et al., 2011a, b), enlarging the temperature difference between the upper and lower part of a permafrost talus slope (Wicky and Hauck, 2017), interacting with soil ice and vapor components and enhancing the vapor transfer in frozen soils ( $\mathrm{Yu}$ et al., 2018; $\mathrm{Yu}$ et al., 2020). However, to our knowledge, few soil-snow models have taken into account the soil dry-air transfer processes and moreover the multi-parameterization of the soil physical processes (from the basic coupled to the advanced coupled water and heat transfer processes and then to the explicit consideration of airflow), resulting in the lack of understanding on how and to what extent the complex soil physics affect the model interpretation of the snowpack effects.

In this chapter, one of the widely used snowpack models (Utah energy balance snowpack model, UEB, Tarboton and Luce, 1996) was incorporated into a common soil modeling framework (Simultaneous Transfer of Energy, Mass and Momentum in Unsaturated Soils with Freeze-Thaw, STEMMUS-FT, Zeng et al., 2011a, b; Zeng and $\mathrm{Su}, 2013$; $\mathrm{Yu}$ et al., 2018). The new model is named STEMMUS-UEB and is configured with three levels of model complexity in terms of mass and energy transport physics. We utilized in situ observations and numerical experiments with STEMMUSUEB to investigate the effect of snowpack on the underlying soil mass and energy transfer with different complexities of soil models. The description of the coupled soil- 
snow modeling framework STEMMUS-UEB and the model setup for this study are presented in Section 5.2. Section 5.3 verifies the proposed model and identifies the effect of snowpack on soil liquid-vapor fluxes. The uncertainties and limitations of this study and the applicability of the proposed model are discussed in Section 5.4.

Table 5.1. Brief overview of current soil-snow modeling efforts.

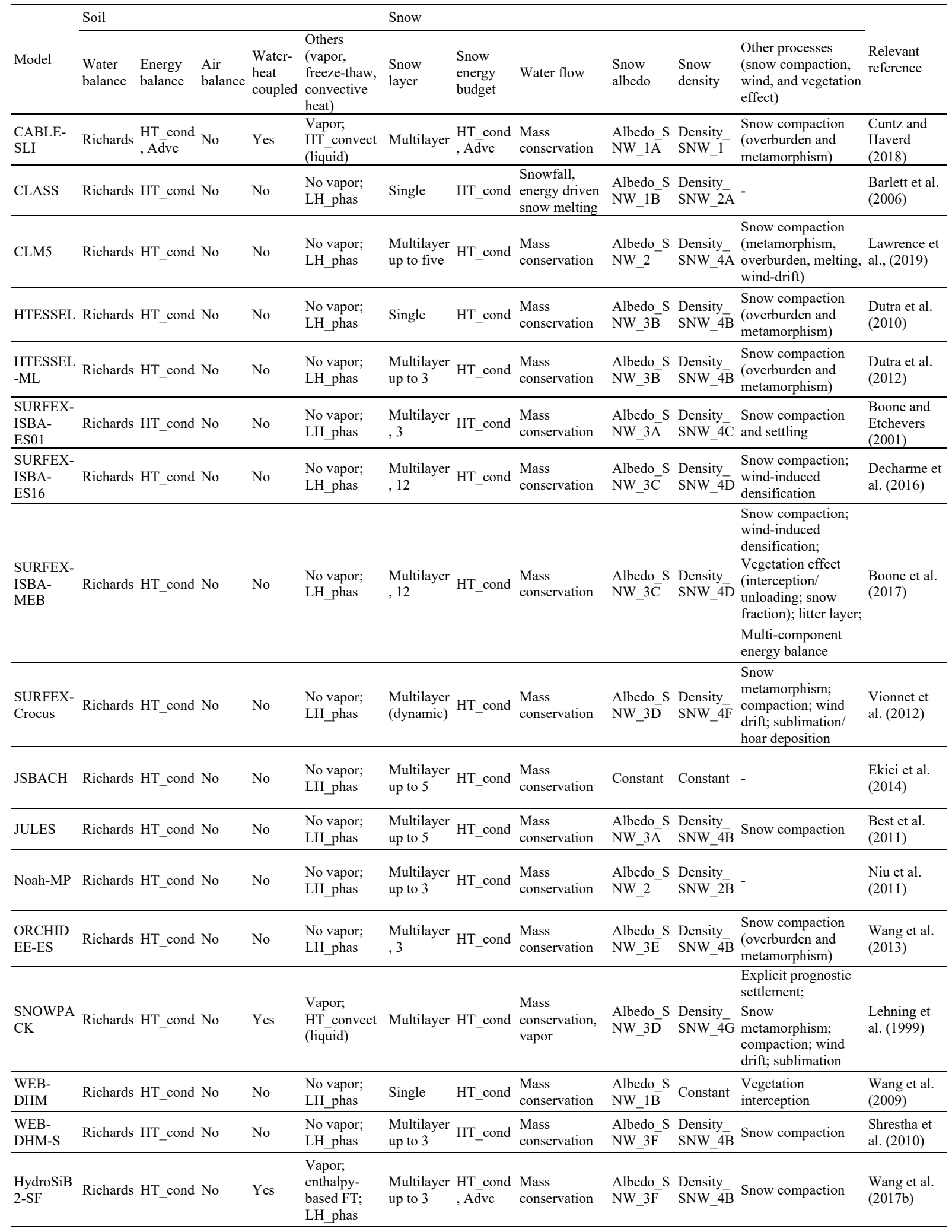


Table 5.1. Continued.

\begin{tabular}{|c|c|c|c|c|c|c|c|c|c|c|c|c|}
\hline \multirow[b]{2}{*}{ Model } & \multicolumn{5}{|l|}{ Soil } & \multicolumn{6}{|l|}{ Snow } & \multirow[b]{2}{*}{$\begin{array}{l}\text { Relevant } \\
\text { reference }\end{array}$} \\
\hline & $\begin{array}{l}\text { Water } \\
\text { balance }\end{array}$ & $\begin{array}{l}\text { Energy } \\
\text { balance }\end{array}$ & $\begin{array}{l}\text { Air } \\
\text { balance }\end{array}$ & $\begin{array}{l}\text { Water- } \\
\text { heat } \\
\text { coupled }\end{array}$ & $\begin{array}{l}\text { Others } \\
\text { (vapor, } \\
\text { freeze-thaw, } \\
\text { convective } \\
\text { heat) }\end{array}$ & $\begin{array}{l}\text { Snow } \\
\text { layer }\end{array}$ & $\begin{array}{l}\text { Snow } \\
\text { energy } \\
\text { budget }\end{array}$ & Water flow & $\begin{array}{l}\text { Snow } \\
\text { albedo }\end{array}$ & $\begin{array}{l}\text { Snow } \\
\text { density }\end{array}$ & $\begin{array}{l}\text { Other processes } \\
\text { (snow compaction, } \\
\text { wind, and vegetation } \\
\text { effect) }\end{array}$ & \\
\hline WEB-GM & - & - & - & - & - & $\begin{array}{l}\text { Multilayer } \\
\text {, vary } \\
\text { with snow } \\
\text { depth }\end{array}$ & $\begin{array}{l}\text { Enthalpy } \\
\text { based } \\
\text { heat } \\
\text { transfer }\end{array}$ & $\begin{array}{l}\text { Mass } \\
\text { conservation }\end{array}$ & $\begin{array}{l}\text { Albedo_S } \\
\text { NW_4 }\end{array}$ & $\begin{array}{l}\text { Density_- } \\
\text { SNW_3 }\end{array}$ & $\begin{array}{l}\text { Snow compaction } \\
\text { (metamorphism, } \\
\text { snow densification, } \\
\text { melting); }\end{array}$ & $\begin{array}{l}\text { Ding et al. } \\
\text { (2017) }\end{array}$ \\
\hline SWAP & Richards & HT_cond & No & No & $\begin{array}{l}\text { No vapor; } \\
\text { LH_phas }\end{array}$ & Single & - & $\begin{array}{l}\text { Mass } \\
\text { conservation }\end{array}$ & Constant & $\begin{array}{l}\text { Density_} \\
\text { SNW_4H }\end{array}$ & $\begin{array}{l}\text { Vegetation } \\
\text { interception }\end{array}$ & $\begin{array}{l}\text { Gusev and } \\
\text { Nasonova } \\
(2003)\end{array}$ \\
\hline COUP & Richards & $\begin{array}{l}\text { HT_cond } \\
\text {, Adve }\end{array}$ & No & Yes & $\begin{array}{l}\text { Vapor; } \\
\text { HT_convect } \\
\text { (liquid) }\end{array}$ & Single & HT_cond & $\begin{array}{l}\text { Mass } \\
\text { conservation }\end{array}$ & $\begin{array}{l}\text { Albedo_S } \\
\text { NW_1A }\end{array}$ & $\begin{array}{l}\text { Density_ } \\
\text { SNW_2C }\end{array}$ & Snow compaction & $\begin{array}{l}\text { Jansson } \\
\text { (2012) }\end{array}$ \\
\hline SHAW & Richards & $\begin{array}{l}\text { HT_cond } \\
\text {, Advc }\end{array}$ & No & Yes & $\begin{array}{l}\text { Vapor; } \\
\text { HT_convect } \\
\text { (liquid, } \\
\text { vapor) }\end{array}$ & Multilayer & $\begin{array}{l}\text { HT_cond } \\
\text {, Adve }\end{array}$ & $\begin{array}{l}\text { Mass } \\
\text { conservation, } \\
\text { vapor }\end{array}$ & $\begin{array}{l}\text { Albedo_S } \\
\text { NW_1C }\end{array}$ & $\begin{array}{l}\text { Density } \\
\text { SNW_4E }\end{array}$ & $\begin{array}{l}\text { Snow compaction, } \\
\text { settling }\end{array}$ & $\begin{array}{l}\text { Flerchinger } \\
\text { and Saxton } \\
(1989) ; \\
\text { Flerchinger } \\
(2017)\end{array}$ \\
\hline HYDRUS & Richards & $\begin{array}{l}\text { HT_cond } \\
\text {, Adve }\end{array}$ & No & Yes & $\begin{array}{l}\text { Vapor; } \\
\text { HT_convect } \\
\text { (liquid, } \\
\text { vapor) }\end{array}$ & - & - & - & - & - & - & $\begin{array}{l}\text { Hansson et } \\
\text { al. (2004); } \\
\text { Šmůnek et } \\
\text { al. (2008) }\end{array}$ \\
\hline $\begin{array}{l}\text { STEMMU } \\
\text { S-UEB }\end{array}$ & Richards & $\begin{array}{l}\text { HT_cond } \\
\text {, Advc }\end{array}$ & Yes & Yes & $\begin{array}{l}\text { Vapor; } \\
\text { LH_phas; } \\
\text { HT_convect } \\
\text { (liquid, } \\
\text { vapor, dry } \\
\text { air); Various } \\
\text { complexity } \\
\text { of SHP }\end{array}$ & Single & $\begin{array}{l}\text { HT_cond } \\
\text {, Adve }\end{array}$ & $\begin{array}{l}\text { Mass } \\
\text { conservation }\end{array}$ & $\begin{array}{l}\text { Albedo_S } \\
\text { NW_3F }\end{array}$ & Constant & $\begin{array}{l}\text { Empirical wind drift } \\
\text { and vegetation } \\
\text { interception }\end{array}$ & This study \\
\hline
\end{tabular}

Note: HT_cond, Heat conduction; Advc, Advection; LH_phas, Latent heat due to phase change;

HT_Convect, Convective heat due to liquid; SHP, soil physical process;

Albedo_SNW_1A, Snow albedo 1A, Function of snow age;

Albedo_SNW_1B, Snow albedo 1B, Empirical function, considering dry/wet states;

Albedo_SNW_1C, Snow albedo 1C, Function of extinction coefficient, grain-size, and solar zenith angle;

Albedo_SNW_2, Snow albedo 2, Two-stream radiative transfer solution, considering snow aging, solar zenith

angle, optical parameters, and impurity;

Albedo_SNW_3A, Snow albedo 3A, Prognostic snow albedo, considering aging effect;

Albedo_SNW_3B, Snow albedo 3B, Prognostic snow albedo, considering aging effect and vegetation type

dependent;

Albedo_SNW_3C, Snow albedo 3C, Prognostic snow albedo, considering aging and optical diameter;

Albedo_SNW_3D, Snow albedo 3D, Prognostic snow albedo, considering age and microstructure;

Albedo_SNW_3E, Snow albedo 3E, Prognostic snow albedo, considering aging effect and dry/wet states;

Albedo_SNW_3F, Snow albedo 3F, Prognostic snow albedo considering aging effect, solar zenith angle;

Albedo_SNW_4, Snow albedo 4, Diagnostic snow albedo, considering snow aging, sleet/snowfall fraction, grain diameter, cloud fraction, and solar elevation effect;

Density_SNW_1, Snow density 1, relying on in situ measurements;

Density_SNW_2A, Snow density 2A, function of air temperature;

Density_SNW_2B, Snow density 2B, Function of extinction coefficient and grain-size;

Density_SNW_2C, Snow density 2C, Function of old (densification), new-fallen (air temperature) snow pack

density, and snow depth;

Density_SNW_3, Snow density 3, Diagnostic density, considering wet-bulb temperature;

Density_SNW_4A, Snow density 4A, Prognostic density, considering temperature, wind effect, snow compaction, water/ice states;

Density_SNW_4B, Snow density 4B, Prognostic density, considering overburden and thermal metamorphisms; Density_SNW_4C, Snow density 4C, Prognostic snow density, considering snow compaction and settling;

Density_SNW_4D, Snow density 4D, Prognostic snow density, considering snow compaction and wind-induced densification;

Density_SNW_4E, Snow density 4E, Prognostic snow density, considering snow compaction, settling, and vapor transfer;

Density_SNW_4F, Snow density 4F, Prognostic density, function of wind speed and air temperature;

Density_SNW_4G, Snow density 4G, Prognostic density, function of stress state and microstructure;

Density_SNW_4H, Snow density 4H, Prognostic density, considering snow temperature. 


\subsection{Description of coupled soil-snow modeling framework and model setup}

This section first presents the coupling procedure of STEMMUS-FT and UEB model, followed by the detailed description of the two models and their successful applications. Then the used model configurations and two tested experimental sites in the Tibetan Plateau were elaborated. The Maqu case is for investigating the effect of snowpack on the underlying soil hydrothermal regimes. The Yakou case is for demonstrating the validity of the developed STEMMUS-UEB model in reproducing the snowpack dynamics (results were presented in Appendix A5). In addition, the relationship between the snow cover properties and albedo was presented in Appendix A5.4, which confirmed the validity of using the albedo to identify the presence of snowpack and its lasting time.

\subsubsection{Coupling procedure}

The coupled process between the snowpack model (UEB) and the soil water model (STEMMUS-FT) was illustrated in Figure 5.1. The sequential coupling is employed to couple the soil model with the current snowpack model. The role of the snowpack is explicitly considered by altering the water and heat flow of the underlying soil. The snowpack model takes the atmospheric forcing as the input (precipitation, air temperature, wind speed and direction, relative humidity, shortwave and longwave radiation) and solves the snowpack energy and mass balance (Eq. A3.1 \& A3.2, subroutines: ALBEDO, PARTSNOW, PREDICORR), which provides the melt water flux and heat flux as the surface boundary conditions for the soil model STEMMUSFT (subroutines: $h \_s u b$ and Enrgy_sub for the advanced coupled models and Diff_Moisture_Heat for the basic coupled model). The soil-snow coupling variables are the snowmelt water flux $M_{\mathrm{r}}$, the convective heat flux due to snowmelt water $Q_{\mathrm{m}}$, and the heat conduction flux $Q_{\mathrm{g}}$. STEMMUS-FT then solves the energy and mass balance equations of soil layers in one time step. To highlight the effect of the snowpack on the soil water and vapor transfer process, in this study, we constrained the soil surface energy boundary as the Dirichlet-type condition (take the specific soil temperature as the surface boundary condition). Surface soil temperature was derived from the soil profile measurements and was not permitted to be higher than zero when there is snowpack. In such way, the reliability of the soil surface energy boundary condition is maintained and the snow thermal effect is implicitly considered. The snowmelt water flux, in addition to the rainfall, was added to the topsoil boundary for solving soil water transfer. To ensure numerical convergence, the adapted time step strategy was used. Half-hourly meteorological forcing measurements were linearly interpolated to the running time steps (subroutine Forcing_PARM). The precipitation rate (validated at 3-hour time intervals) was regarded uniformly within the 3-hour duration (refer to Table A6.1 for details). The general description of the primary 
subroutines in STEMMUS-UEB was presented in Table 5.2. It includes the main functions, input and output, and their connection with other subroutines (linked with Table A6.1 and A6.2 for the description of model input parameters and outputs for this study, see the detailed description in Tarboton and Luce, 1996; Zeng and Su, 2013; Yu et al., 2018).

Table 5.2. Main subroutines in STEMMUS-UEB

\begin{tabular}{|c|c|c|c|c|}
\hline $\begin{array}{l}\text { Model } \\
\text { Subroutines } \\
\end{array}$ & Main functions & Main inputs & Main outputs & Subroutine-Connections \\
\hline \multicolumn{5}{|l|}{ Soil module } \\
\hline Air_sub & $\begin{array}{l}\text { Solves soil dry air balance } \\
\text { equation }\end{array}$ & $\begin{array}{l}\text { Water vapor density, diffusivity, } \\
\text { dispersion coefficient, dry air density, } \\
\text { gas conductivity, flux, liquid water flux, } \\
\text { top and bottom boundary conditions }\end{array}$ & Soil air pressure profile & $\begin{array}{l}\text { CondV_DVg, CondL_h, } \\
\text { Condg_k_g, Density_V, } \\
\text { h_sub --->; } \\
\text {--> Enrgy_sub, }\end{array}$ \\
\hline CondL_h & $\begin{array}{l}\text { Calculates soil hydraulic } \\
\text { conductivity }\end{array}$ & $\begin{array}{l}\text { Soil hydraulic parameters, soil matric } \\
\text { potential, soil temperature }\end{array}$ & $\begin{array}{l}\text { Soil hydraulic } \\
\text { conductivity, soil water } \\
\text { content }\end{array}$ & $\begin{array}{l}\text { Startlnit --->; } \\
\text {--> h_sub, Air_sub, } \\
\text { Enrgy_sub, }\end{array}$ \\
\hline CondT_coeff & $\begin{array}{l}\text { Calculates soil thermal } \\
\text { capacity and conductivity }\end{array}$ & $\begin{array}{l}\text { Thermal properties of soil constituents, } \\
\text { soil texture, soil water content, } \\
\text { volumetric fraction of dry air, dry air } \\
\text { density, vapor density }\end{array}$ & $\begin{array}{l}\text { Soil thermal capacity and } \\
\text { conductivity }\end{array}$ & $\begin{array}{l}\text { StartInit, CondL_h, } \\
\text { Density_V, Density_DA, } \\
\text { EfeCapCond --->; } \\
\text {--> Enrgy_sub, }\end{array}$ \\
\hline CondV_DVg & $\begin{array}{l}\text { Calculates flux of dry air } \\
\text { and vapor dispersity }\end{array}$ & $\begin{array}{l}\text { Gas conductivity, dry air pressure, } \\
\text { volumetric fraction of dry air, saturated } \\
\text { soil water content }\end{array}$ & $\begin{array}{l}\text { Dry air flux and vapor } \\
\text { dispersion coefficient }\end{array}$ & $\begin{array}{l}\text { Startlnit, CondL_h, } \\
\text { Condg_k_g --->; } \\
\text {--> h_sub, Air_sub, } \\
\text { Enrgy_sub, }\end{array}$ \\
\hline CondL_Tdisp & $\begin{array}{l}\text { Calculates transport } \\
\text { coefficient for adsorbed } \\
\text { liquid flow }\end{array}$ & $\begin{array}{l}\text { Soil porosity, soil water content, } \\
\text { temperature, matric potential, volumetric } \\
\text { fraction of dry air }\end{array}$ & $\begin{array}{l}\text { Transport coefficient for } \\
\text { adsorbed liquid flow and } \\
\text { the heat of wetting }\end{array}$ & $\begin{array}{l}\text { Startlnit, CondL_h, } \\
\text { Condg_k_g --->; } \\
-->\text { h_sub, Enrgy_sub, }\end{array}$ \\
\hline Condg_k_g & $\begin{array}{l}\text { Calculates gas } \\
\text { conductivity }\end{array}$ & $\begin{array}{l}\text { Soil porosity, saturated hydraulic } \\
\text { conductivity, volumetric fraction of dry } \\
\text { air }\end{array}$ & Gas conductivity & $\begin{array}{l}\text { StartInit, CondL_h --->; } \\
-->\text { CondV_DVg, }\end{array}$ \\
\hline Density_DA & Calculates dry air density & $\begin{array}{l}\text { Soil temperature, matric potential, dry air } \\
\text { pressure, vapor density and its derivative } \\
\text { with respect to temperature and matric } \\
\text { potential }\end{array}$ & Density of dry air & $\begin{array}{l}\text { StartInit, CondL_h, } \\
\text { Density_V --->; } \\
\text {--> CondT_coeff, } \\
\text { Air_sub, Enrgy_sub, }\end{array}$ \\
\hline Density_V & $\begin{array}{l}\text { Calculates vapor density } \\
\text { and its derivative with } \\
\text { respect to temperature } \\
\text { and matric potential }\end{array}$ & Soil temperature, matric potential & $\begin{array}{l}\text { Vapor density and its } \\
\text { derivative with respect to } \\
\text { temperature and matric } \\
\text { potential }\end{array}$ & $\begin{array}{l}\text { CondL_h --->; } \\
\text {--> Density_DA, } \\
\text { CondT_coeff, h_sub, } \\
\text { Air_sub, Enrgy_sub, }\end{array}$ \\
\hline EfeCapCond & $\begin{array}{l}\text { Calculates soil thermal } \\
\text { capacity and conductivity }\end{array}$ & $\begin{array}{l}\text { Thermal properties of soil constituents, } \\
\text { soil texture, soil water content, } \\
\text { volumetric fraction of dry air, dry air } \\
\text { density, vapor density }\end{array}$ & $\begin{array}{l}\text { Soil heat capacity, thermal } \\
\text { conductivity }\end{array}$ & $\begin{array}{l}\text { StartInit, CondL_h, } \\
\text { Density_V, Density_DA } \\
--->; \\
\text {--> CondT_coeff, }\end{array}$ \\
\hline Enrgy_sub & $\begin{array}{l}\text { Solves soil energy } \\
\text { balance equation }\end{array}$ & $\begin{array}{l}\text { Soil thermal properties, soil hydraulic } \\
\text { conductivity, soil matric potential, soil } \\
\text { water content, soil temperature, soil dry } \\
\text { air pressure, density of dry air, heat of } \\
\text { wetting, vapor density, liquid water flux, } \\
\text { vapor flux, dry air flux, meteorological } \\
\text { forcing, top and bottom boundary } \\
\text { conditions }\end{array}$ & $\begin{array}{l}\text { Soil temperature profile, } \\
\text { liquid water flux, vapor } \\
\text { flux, and dry air flux, } \\
\text { surface and bottom energy } \\
\text { fluxes }\end{array}$ & $\begin{array}{l}\text { Air_sub, h_sub, } \\
\text { CondL_h, CondV_DVg, } \\
\text { CondL_Tdisp, } \\
\text { CondT_coeff, Density_D, } \\
\text { Density_DA, } \\
\text { PREDICORR --->, }\end{array}$ \\
\hline Forcing_PARM & $\begin{array}{l}\text { Disaggregates the } \\
\text { meteorological forcing } \\
\text { into the required time } \\
\text { steps }\end{array}$ & $\begin{array}{l}\text { Observed meteorological forcing at } \\
\text { hourly/daily time scale }\end{array}$ & $\begin{array}{l}\text { Meteorological forcings at } \\
\text { model required time scale }\end{array}$ & $\begin{array}{l}\text { StartInit --->; } \\
-->\text { h_sub, Enrgy_sub, }\end{array}$ \\
\hline h_sub & $\begin{array}{l}\text { Solves soil water balance } \\
\text { equation }\end{array}$ & $\begin{array}{l}\text { Soil temperature, soil water content, } \\
\text { matric potential, soil hydraulic } \\
\text { conductivity, heat of wetting, soil dry air } \\
\text { pressure, vapor density, diffusivity, } \\
\text { dispersity, volumetric fraction of vapor, } \\
\text { meteorological forcing, top and bottom } \\
\text { boundary conditions }\end{array}$ & $\begin{array}{l}\text { Soil matric potential } \\
\text { profile, top and bottom } \\
\text { water fluxes, evaporation }\end{array}$ & $\begin{array}{l}\text { StartInit, CondV_DVg, } \\
\text { CondL_h, CondV_DE, } \\
\text { CondL_Tdisp, } \\
\text { Condg_k_g, Density_V, } \\
\text { Forcing_PARM, } \\
\text { ALBEDO, PARTSNOW, } \\
\text { PREDICORR --->; } \\
\text {--> Air_sub, Enrgy_sub, }\end{array}$ \\
\hline StartInit & Initializes model setup & $\begin{array}{l}\text { Soil texture, thermal properties of soil } \\
\text { constituents, initial soil water content } \\
\text { and temperature, top and bottom } \\
\text { boundary condition settings }\end{array}$ & - & $\begin{array}{l}\text {--> CondV_DVg, } \\
\text { CondL_h, CondV_DE, } \\
\text { CondL_Tdisp, } \\
\text { Condg_k_g, Density_DA, } \\
\text { EfeCapCond, } \\
\text { Forcing_PARM, h_sub, }\end{array}$ \\
\hline
\end{tabular}


Table 5.2. Continued.

\begin{tabular}{|c|c|c|c|c|}
\hline $\begin{array}{l}\text { Model } \\
\text { Subroutines } \\
\end{array}$ & Main functions & Main inputs & Main outputs & Subroutine-Connections \\
\hline $\begin{array}{l}\text { Diff_Moisture_ } \\
\text { Heat }\end{array}$ & $\begin{array}{l}\text { Solves soil water and } \\
\text { energy balance equations } \\
\text { independently }\end{array}$ & $\begin{array}{l}\text { Soil thermal properties, soil hydraulic } \\
\text { conductivity, soil matric potential, soil } \\
\text { water content, soil temperature, } \\
\text { meteorological forcing, top and bottom } \\
\text { boundary conditions }\end{array}$ & $\begin{array}{l}\text { Soil water content and } \\
\text { temperature profile, liquid } \\
\text { water flux, surface and } \\
\text { bottom water and energy } \\
\text { fluxes }\end{array}$ & $\begin{array}{l}\text { Startlnit, CondT_coeff, } \\
\text { Forcing_PARM, } \\
\text { ALBEDO, PARTSNOW, } \\
\text { PREDICORR --->, }\end{array}$ \\
\hline \multicolumn{5}{|l|}{$\begin{array}{l}\text { Snowpack } \\
\text { module }\end{array}$} \\
\hline agesn & Calculates snow age & Snow surface temperature, snowfall & Updated snow age & $\begin{array}{l}\text { PARTSNOW, } \\
\text { PREDICORR --->; } \\
\text {--> ALBEDO, } \\
\end{array}$ \\
\hline ALBEDO & Calculates snow albedo & $\begin{array}{l}\text { Fresh snow reflectance at visible and } \\
\text { near infrared bands, snow age, bare } \\
\text { ground albedo, albedo extinction } \\
\text { parameter, snow water equivalent }\end{array}$ & Snow albedo & $\begin{array}{l}\text { agesn --->; } \\
\text {--> PREDICORR, }\end{array}$ \\
\hline PARTSNOW & $\begin{array}{l}\text { Partitions precipitation } \\
\text { into rainfall and snowfall }\end{array}$ & $\begin{array}{l}\text { Precipitation, air temperature, } \\
\text { temperature thresholds for } \\
\text { rainfall/snowfall }\end{array}$ & Rainfall, snowfall & $\begin{array}{l}\text { Forcing_PARM --->; } \\
\text {--> PREDICORR, }\end{array}$ \\
\hline PREDICORR & $\begin{array}{l}\text { Solves the snow mass and } \\
\text { energy balance equations } \\
\text { and updates state } \\
\text { variables SWE and U }\end{array}$ & $\begin{array}{l}\text { Air temperature, snow albedo, wind } \\
\text { speed, relative humidity, } \\
\text { rainfall/snowfall, shortwave/longwave } \\
\text { radiation, site parameters }\end{array}$ & $\begin{array}{l}\text { Snow energy content, } \\
\text { water equivalent, snow } \\
\text { albedo, snow surface } \\
\text { temperature, meltwater } \\
\text { outflow rate, snow } \\
\text { sublimation, } \\
\text { snowfall/rainfall }\end{array}$ & $\begin{array}{l}\text { Forcing_PARM --->; } \\
-->\text { agesn², ALBEDO². }\end{array}$ \\
\hline
\end{tabular}

Note:

---> means the relevant subroutines which are incoming to the current one, and --> means the relevant subroutines for which the current subroutine is output to.

agesn $^{2}$ and ALBEDO $^{2}$, means the use of subroutines agesn and ALBEDO after solving the snowpack energy and mass conservation equations to update the snow age and albedo, respectively. 

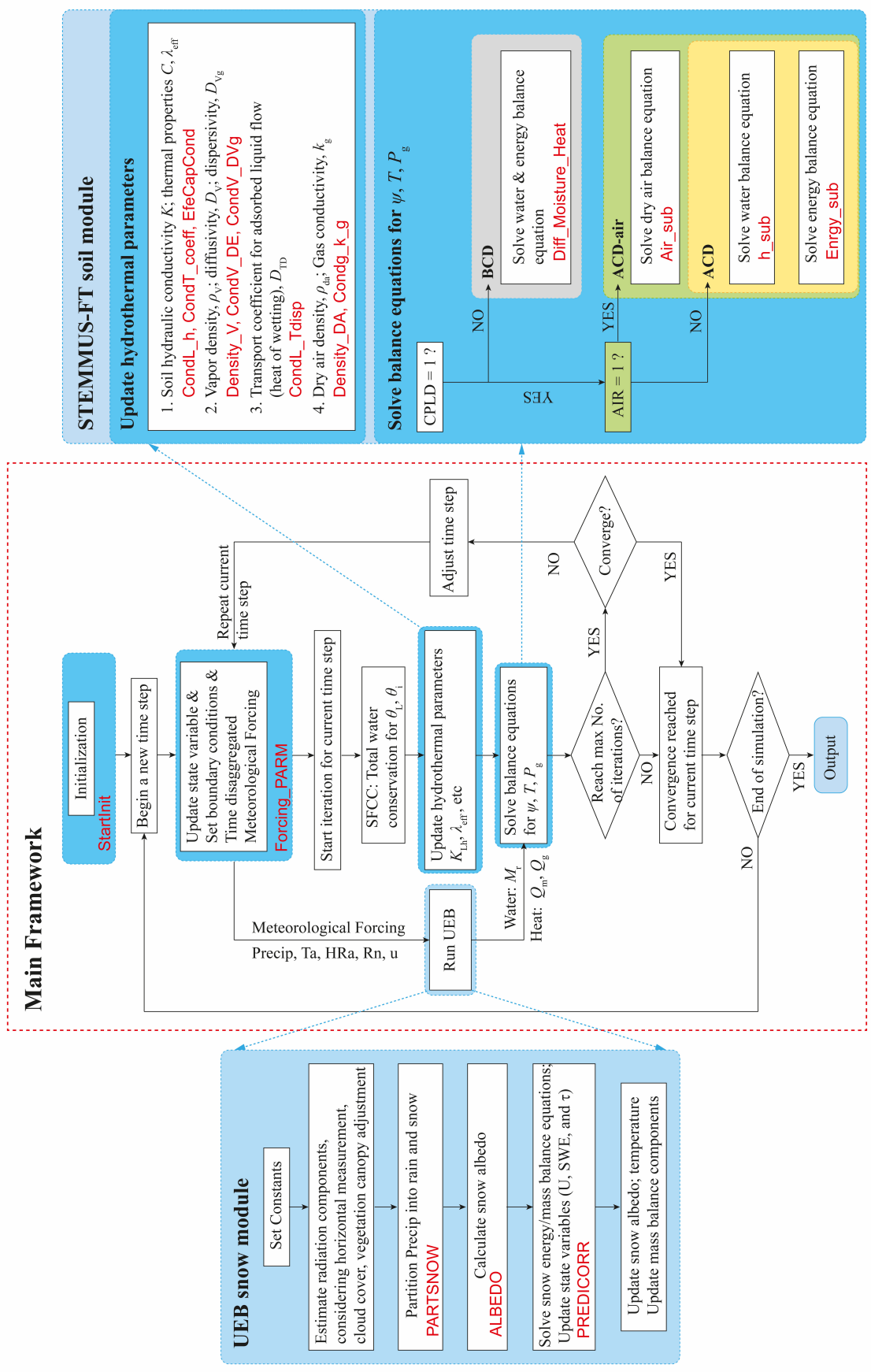

Figure 5.1. The overview of the coupled STEMMUS-FT and UEB model framework and model structure. SFCC is soil freezing characteristic curve, $\theta_{L}$ and $\theta_{i}$ are soil liquid water and ice content; $K_{L h}$ is soil hydraulic conductivity, and $\lambda_{e f f}$ is thermal conductivity. $\psi, T, P_{g}$ are the state variables for soil module STEMMUS-FT (matric potential, temperature, and air pressure, respectively). U, SWE, and $\tau$ are the state variables for snow module UEB (snow energy content, snow water equivalent, and snow age, respectively). UEB is the Utah Energy Balance module. Precip, Ta, HRa, $\mathrm{Rn}$, and $\mathrm{u}$ are the meteorological inputs (precipitation, air temperature, relative humidity, radiation, and wind speed, respectively). $M_{\mathrm{r}}$ is the snowmelt water flux, $Q_{\mathrm{m}}$ is the convective heat flux due to snowmelt water, and $Q_{\mathrm{g}}$ is the heat conduction flux. Model subroutines are in red. 


\subsubsection{Soil mass and heat transfer model}

The detailed physically based two-phase flow soil model (STEMMUS) was first developed to investigate the underlying physics of soil water, vapor, and dry air transfer mechanisms and their interaction with the atmosphere (Zeng et al., 2011b; a; Zeng \& $\mathrm{Su}, 2013)$. It is achieved by simultaneously solving the balance equations of soil mass, energy, and dry air in a fully coupled way. The mediation effect of vegetation on such interactions was recently incorporated via the root water uptake sub-module (Yu et al., 2016) and by coupling with the detailed soil and vegetation biogeochemical process (Yu et al., 2020a; Wang et al., 2021b). It facilitates our understanding of the hydrothermal dynamics of respective components in the frozen soil medium (i.e., soil liquid water, water vapor, dry air, and ice) by implementing the freeze-thaw process (hereafter STEMMUS-FT, for applications in cold regions, Yu et al., 2018; Yu et al., 2020b).

The frozen soil physics considered in STEMMUS-FT includes three parts: (i) the ice blocking effect on soil hydraulic conductivities (see Appendix A1.2), (ii) the inclusion of ice effect in the calculation of soil thermal capacity and conductivity (see Appendix A1.3), and (iii) the exchange of latent heat flux during phase change periods. With the aid of Clausius-Clapeyron relation, which characterizes the phase transition between liquid and solid phase in the thermal equilibrium system, the soil water characteristic curve (e.g., van Genuchten, 1980) is then extended to consider the freezing temperature dependence, i.e., soil freezing characteristic curve (Hansson et al., 2004; Dall'Amico et al., 2011). The fraction of soil liquid-solid water at a given temperature was then calculated prognostically with the soil freezing characteristic curve. Soil hydraulic parameters were further used in the Mualem (1976) model to compute the soil hydraulic conductivity. The ice effect is considered by reducing the soil saturated hydraulic conductivity as a function of ice content (Yu et al., 2018).

In response to minimize the potential model-comparison uncertainties from various model structures (Clark et al., 2015) and to figure out which process matters, three levels of complexity of mass and heat transfer physics are made available in the current STEMMUS-FT modeling framework (Yu et al., 2020b). First, the 1D Richards equation and heat conduction were deployed in STEMMUS-FT to describe the isothermal water flow and heat flow (termed BCD). The BCD model considers the interaction of soil water and heat transfer implicitly via the parameterization of heat capacity, thermal conductivity, and the water phase change effect. The water flow is fully affected by soil temperature regimes in the advanced coupled water and heat transfer model (termed ACD model). The movement of water vapor, as the primary linkage between soil water and heat flow, is explicitly characterized. STEMMUS-FT further enables the simulation of temporal dynamics of three water phases (liquid, vapor, 
and ice), together with the soil dry air component (termed ACD-air model). The governing equations of liquid water flow, vapor flow, airflow, and heat flow were listed in Table 4.1 (see the more detailed model description in Zeng et al., 2011b; a; Zeng \& Su, 2013; Yu et al., 2018; Yu et al., 2020b).

\subsubsection{Snowpack module UEB}

The Utah energy balance snowpack model (UEB; Tarboton \& Luce, 1996) is a singlelayer physically based snow accumulation and melt model. Two precipitation types, i.e., rainfall and snowfall, are discriminated by their dependence on air temperature. The snowpack is characterized using two primary state variables, snow water equivalent $(S W E)$, and the internal energy $U$. Snowpack temperature is expressed diagnostically as the function of $S W E$ and $U$ together with the states of the snowpack (i.e., solid, solid and liquid mixture, and liquid). Given the insulation effect of the snowpack, snow surface temperature differs from the snowpack bulk temperature, which is mathematically considered using the equilibrium method (i.e., balances energy fluxes at the snow surface). The age of the snow surface, as the auxiliary state variable, is utilized to calculate the snow albedo (see Appendix A3.2.4). When the snowpack is shallow, the albedo is the weighting function of the snow albedo and the bare-ground albedo. The solar radiation penetration in the shallow snowpack is exponentially attenuated and expressed in the weighting factor. The melt outflow is calculated using Darcy's law with the liquid fraction as inputs. The conservation of mass and energy forms the physical basis of UEB (Tarboton and Luce, 1996, as presented in Appendix A3).

UEB is recognized as one simple yet physically based snowmelt model. It captures the snow process well (e.g., diurnal variation of meltwater outflow rate, snow accumulation, and ablation, see the general overview of UEB model development and applications in Table A6.3). It requires little effort in parameter calibration and can be easily transferable and applicable to various locations (e.g., Gardiner et al., 1998; Schulz \& de Jong, 2004; Watson et al., 2006; Sultana et al., 2014; Pimentel et al., 2015; Gichamo \& Tarboton, 2019), especially for data-scarce regions like the Tibetan Plateau. We thus selected the original parsimonious UEB (Tarboton and Luce, 1996) as the snow module to be coupled with the soil module (STEMMUS-FT).

\subsubsection{Configurations of numerical experiments}

On the basis of the aforementioned STEMMUS-UEB coupling framework, the various complexities of vadose zone physics were further implemented as three alternative model versions. First, the soil ice effect on soil hydraulic and thermal properties, and the heat flow due to the water phase change were taken into account, while the water and heat transfer is not coupled in STEMMUS-FT and is termed the BCD model. Second, the STEMMUS-FT with the fully coupled water and heat transfer physics (i.e., 
water vapor flow and thermal effect on water flow) was applied and termed the ACD model. Lastly, on top of the ACD model, the air pressure was independently considered as a state variable (therefore, the airflow) and termed the ACD-air model. With the abovementioned model versions (STEMMUS-FT_Snow), taking into account the nosnow scenarios (STEMMUS-FT_No-Snow), Table 5.3 lists the configurations of all six designed numerical experiments. The model parameters used for all simulations for the tested experimental site are listed in Table A6.2.

Table 5.3. Numerical experiments with various mass and energy transfer schemes with/without explicit consideration of snow cover (Eqs. 4.1-4.7 are listed in Table 4.1; Eqs. A3.1-A3.2 are listed in Appendix A3.1).

\begin{tabular}{|c|c|c|c|}
\hline \multicolumn{2}{|l|}{ Processes } & \multirow{2}{*}{ Experiments } & \\
\hline Snowpack (SNW) & Mass and energy transfer in soils (SMETr) & & \\
\hline \multirow{3}{*}{$\begin{array}{l}\text { SNW =1: } \\
\text { UEB (Eqs. A3.1 \& } \\
\text { A3.2) }\end{array}$} & SMETr=1: basic coupled water-heat transfer (Eqs. $4.1 \& 4.2$ ) & BCD-Snow & \multirow{3}{*}{$\begin{array}{l}\text { STEMMUS- } \\
\text { FT_Snow }\end{array}$} \\
\hline & $\begin{array}{l}\text { SMETr=2: advanced coupled water-heat transfer without airflow } \\
\text { (Eqs. } 4.3 \& 4.4 \text { ) }\end{array}$ & ACD-Snow & \\
\hline & $\begin{array}{l}\text { SMETr=3: advanced coupled water-heat transfer with airflow } \\
\text { (Eqs. } 4.5,4.6 \& 4.7)\end{array}$ & ACD-air-Snow & \\
\hline \multirow{3}{*}{$\begin{array}{l}\mathrm{SNW}=0 \text { : } \\
\text { No discrimination of } \\
\text { snow and rainfall }\end{array}$} & SMETr=1: basic coupled water-heat transfer (Eqs. $4.1 \& 4.2)$ & BCD-No-Snow & \multirow{3}{*}{$\begin{array}{l}\text { STEMMUS-FT_No- } \\
\text { snow }\end{array}$} \\
\hline & $\begin{array}{l}\text { SMETr=2: advanced coupled water-heat transfer without airflow } \\
\text { (Eqs. } 4.3 \& 4.4 \text { ) }\end{array}$ & ACD-No-Snow & \\
\hline & $\begin{array}{l}\text { SMETr=3: advanced coupled water-heat transfer with airflow } \\
\text { (Eqs. } 4.5,4.6 \& 4.7)\end{array}$ & ACD-air-No-Snow & \\
\hline
\end{tabular}

\subsubsection{Description of the tested experimental sites}

Maqu station, equipped with a catchment-scale soil moisture and soil temperature (SMST) monitoring network and micro-meteorological observing system, is situated on the northeastern edge of the Tibetan Plateau (Su et al., 2011; Dente et al., 2012; Zeng et al., 2016). According to the updated Köppen-Geiger climate classification system, it can be characterized as a cold climate with dry winter and warm summer. The annual mean precipitation is about $620 \mathrm{~mm}$, and the annual average potential evaporation is about $1353.4 \mathrm{~mm}$. Precipitation in Maqu is uneven over the year with most of the precipitation events occurring from May to October and little precipitation or snowfall during the wintertime. The average annual air temperature is $1.2^{\circ} \mathrm{C}$, and the mean air temperatures of the coldest month (January) and the warmest month (July) are about $10.0^{\circ} \mathrm{C}$ and $11.7^{\circ} \mathrm{C}$, respectively. Alpine meadows (e.g., Cyperaceae and Gramineae), with a height varying from $5 \mathrm{~cm}$ to $15 \mathrm{~cm}$ throughout the growing season, are the dominant land cover in this region. This site is seasonally snow covered, with temporal snow in the non-growing season, which is due to the intermittent snowfall and the rapid snow melting and sublimation caused by the high air temperature and strong solar radiation in the daytime. The general soil types are sandy loam, silt loam and organic soil for the upper soil layers (Dente et al., 2012; Zheng et al., 2015a; Zhao et al., 2018). The soil texture and hydraulic properties were listed in Table A6.2, and how these were used in STEMMUS-UEB is illustrated in Figure 5.1 and Table 5.2. 
The Maqu SMST monitoring network spans an area of approximately $40 \mathrm{~km} \times 80 \mathrm{~km}$ with an elevation ranging from $3200 \mathrm{~m}$ to $4200 \mathrm{~m}$ a.s.1. $\left(33^{\circ} 30^{\prime}-34^{\circ} 15^{\prime} \mathrm{N}, 101^{\circ} 38^{\prime}-\right.$ $\left.102^{\circ} 45^{\prime} \mathrm{E}\right)$. SMST profiles are automatically measured by $5 \mathrm{TM} \mathrm{ECH}_{2} \mathrm{O}$ probes (METER Group, Inc., USA) installed at different soil depths, i.e., $5 \mathrm{~cm}, 10 \mathrm{~cm}, 20 \mathrm{~cm}$, $40 \mathrm{~cm}$, and $80 \mathrm{~cm}$. The micro-meteorological observing system consists of a $20 \mathrm{~m}$ planetary boundary layer (PBL) tower providing the meteorological measurements at five heights above ground (i.e., wind speed and direction, air temperature and relative humidity), and an eddy covariance system (EC150, Campbell Scientific, Inc., USA) equipped for measuring the turbulent sensible and latent heat fluxes and carbon fluxes. The equipment for four-component downwelling and upwelling solar and thermal radiation (NR01-L, Campbell Scientific, Inc., USA), and liquid precipitation (T200B, Geonor, Inc., USA) are also deployed. A dataset from 1 December 2015 to 15 March 2016 was utilized in this study. Independent precipitation data (3-hour time interval) during the same testing period from an adjacent meteorological station were used as the mutual validation data.

Yakou super snow station $\left(38^{\circ} 00^{\prime} 36^{\prime \prime} \mathrm{N}, 100^{\circ} 14^{\prime} 24^{\prime \prime} \mathrm{E}, 4145 \mathrm{~m}\right)$ is located in the upstream Heihe basin in the northeastern of Tibetan Plateau. It is a high-elevation snowcovered site with the wet summers and dry winters. The dominant land type is tundra with frozen ground below. There is a unique seasonal variation of snow depth with the maximum snow depth usually being in the springtime $(32 \mathrm{~cm}$ during the period 20142017). Loam is the main soil type with the silt loam near the surface and sandy soil for the deeper soil layers.

The integrated hydrometeorological, snow cover and frozen ground data were published and available from the Cold and Arid Regions Science Data Center at Lanzhou (Che et al., 2019; Li et al., 2019; Li, 2019). The meteorological data (air temperature, wind speed, precipitation, downward shortwave and longwave radiation, and relative humidity) were recorded by the automatic meteorological station (AMS). In situ measurements of snow cover properties (snow depth and snow water equivalent) were obtained using the state-of -the-art instruments (SR50A and GammaMONitor, Campbell Scientific, USA). Soil moisture profiled at 4, 10, 20, 40, 80, 120, and $160 \mathrm{~cm}$ soil depth was measured using ECH2O-5 probes (METER Group, Inc., USA). In addition to the seven soil depths, the surface soil temperature $(0 \mathrm{~cm})$ was also recorded using the Avalon AV-10T sensors (Avalon Scientific, Inc., USA). The eddy covariance system was equipped at the Yakou site for measuring land surface turbulent fluxes. The dataset from 1 September 2016 to 31 December 2016 was used to validate the model performance in mimicking the dynamics of snow water equivalent, soil hydrothermal regimes and land surface evaporation. The calibrated soil hydraulic and snow cover properties were listed in the Appendix in Table A6.2. 


\subsection{Results: comparison of simulation results of surface variables with/without snowpack effect}

\subsubsection{Albedo}

The time series of surface albedo, calculated as the ratio of upwelling shortwave radiation to the downwelling shortwave radiation and estimated using $\mathrm{BCD}, \mathrm{ACD}$ and ACD-air models, is shown in Figure 5.2 together with precipitation.

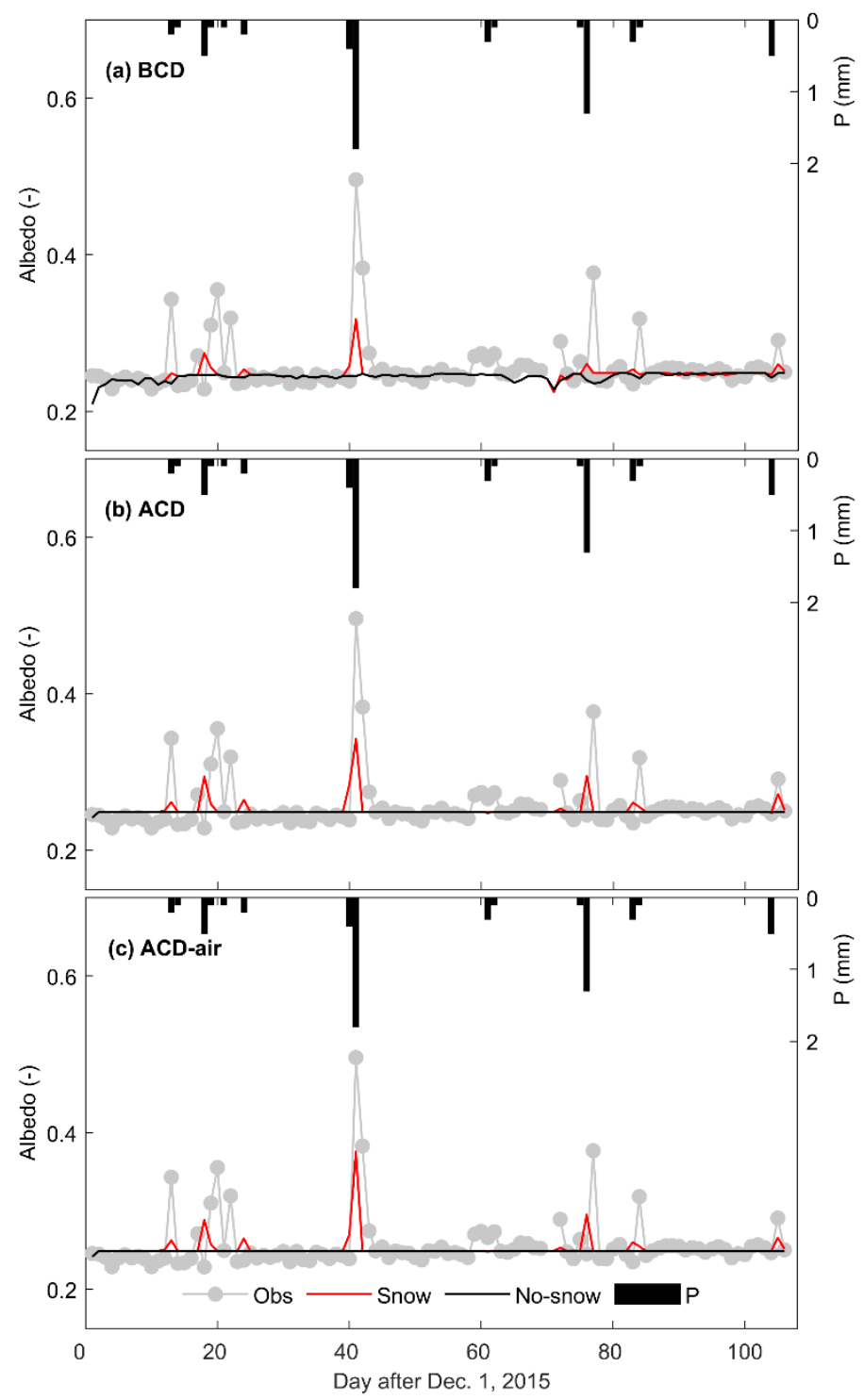

Figure 5.2. Time series of observed and model simulated daily average albedo using (a) BCD, (b) ACD, and (c) ACD-air soil models with and without consideration of the snow module (including precipitation).

As the snowpack has a higher albedo than the underlying surface (e.g., soil, vegetation), compared to the observations, models without snow module presented a relatively flat variation of daily average surface albedo, and lacked the response to the winter precipitation events (Figure 5.2, Table 5.4). With the snow module, STEMMUS-UEB 
models can mostly capture the abrupt increase of surface albedo after winter precipitation events. The mismatches in terms of the magnitude or absence of increased albedo after precipitation events indicated that the model tended to underestimate the albedo dynamics. The shallow snowfall events might be not well captured by the model (see Sect. 5.4.1). Three model versions (BCD-Snow, ACD-Snow, and ACD-air-Snow) produced similar fluctuations regarding the presence of snow cover with slight differences in terms of the magnitude of albedo.

\subsubsection{Soil temperature and moisture dynamics}

The observed spatial and temporal dynamics of soil temperature from five soil layers were used to verify the performance of different models (Fig. 5.3). The initial soil temperature state can be characterized as the warm bottom and cool surface soil layers (based on in-situ observations). The freezing front (indicated by the zero-degree isothermal line, ZDIL) developed downwards rapidly until the $70^{\text {th }}$ day after December 1, 2015, when it reached its maximum depth. Following this, the freezing front stabilized as an offset effect of latent heat release (termed the zero-curtain effect). Such influence can be sustained until all the available water to that layer is frozen, at which point the latent heat effect is negligible compared to the heat conduction. At shallower layers, the atmospheric forcing dominates the fluctuation of thermal states. The isothermal lines (e.g., $-2{ }^{\circ} \mathrm{C}$ ) had a larger variation than that of ZDIL. At deeper soil layers, the temporal dynamics of isothermal lines were smoother than that of ZDIL, indicating that the effect of fluctuated atmospheric force on soil temperature was damped with the increase of soil depth. Compared to the observations, BCD-Snow model presented an earlier development of the freezing front and arrival of the maximum freezing depth $\left(60^{\text {th }}\right.$ day after December 1,2015$)$. The deeper and more fluctuated freezing front indicates that a stronger control of atmospheric forcing on soil thermal states was produced by BCD-Snow model. The ACD models can capture the propagation characteristic of the freezing front well in terms of the variation magnitude and maximum freezing depth. There is no significant difference in soil thermal dynamics between the model with and without the snow module, except at the surface soil layers (Table 5.4).

Figure 5.4 shows the spatial and temporal dynamics of observed and simulated soil water content in the liquid phase (SWCL). The SWCL of active layers depends to a large extent on the soil freezing and thawing status. Soil is relatively wet at soil layers of 10-60 $\mathrm{cm}$ for the starting period. Its temporal development was disrupted by the presence of soil ice and tended to increase wetness during the thawing period. A relatively dry zone $\left(\theta_{L}<0.06 \mathrm{~m}^{3} \mathrm{~m}^{-3}\right)$ above the freezing front was found, indicating the nearly completely frozen soil during the stabilization stage. The initial wet zone of soil moisture was narrowed down and the rewetting zone tended to enlarge from BCDSnow simulation due to its early freezing and thawing of soil (Fig. 5.4b). The position 
of the dry zone occurred earlier due to the early reaching of the stabilization period in the BCD-Snow model (Fig. 5.3b). For the ACD models, the position and development of initial wet zone, rewetting zone, and the dry zone are similar to those from the observations, indicating the soil moisture dynamics can be captured well by the ACD models. Compared to the STEMMUS-FT_Snow model, there was no observable difference in the SWCL dynamics at deeper soil layers from STEMMUS-FT_No-Snow simulations. The surface SWCL was found affected from STEMMUS-FT_Snow simulations (Table 5.4). 


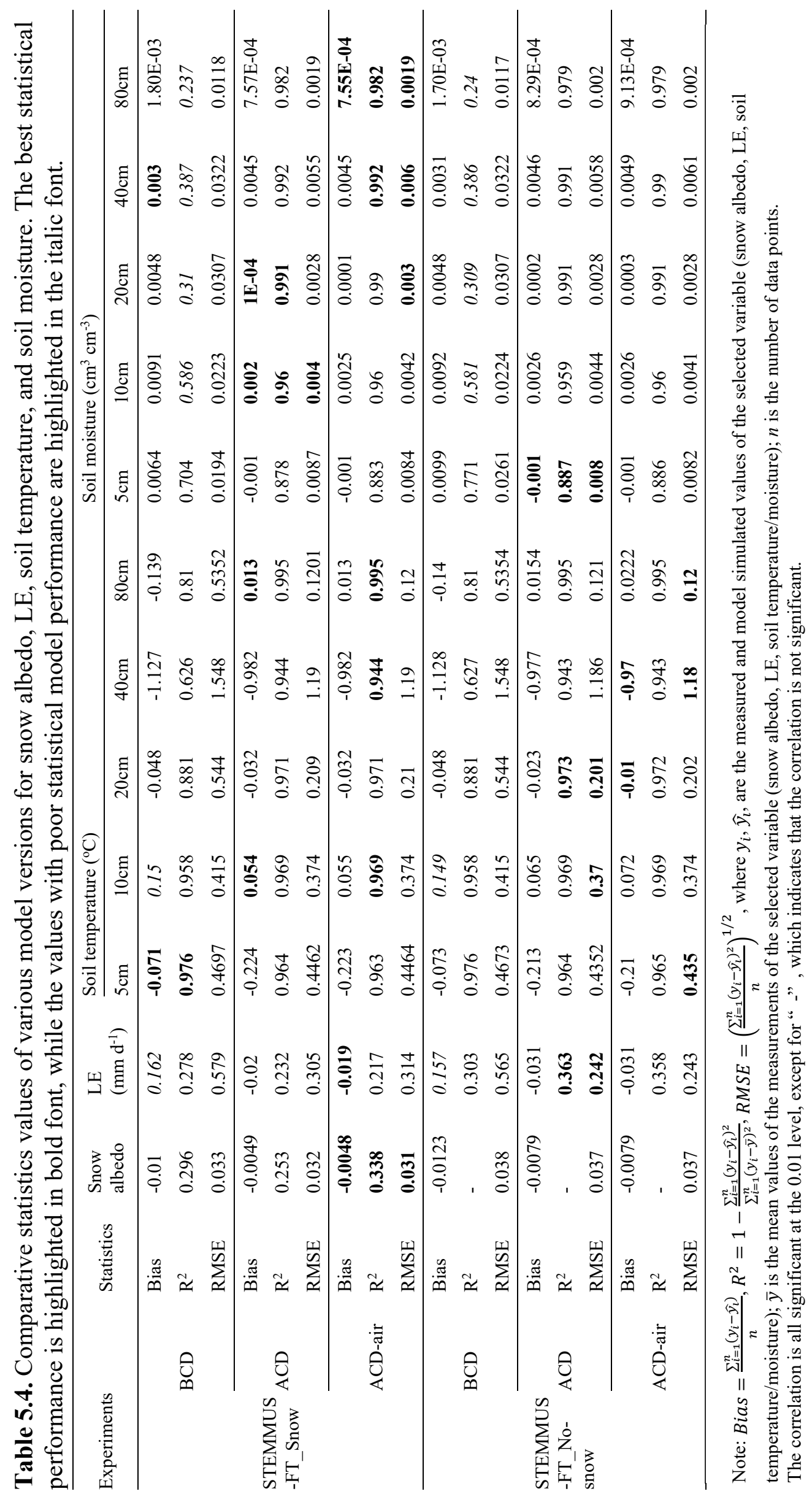



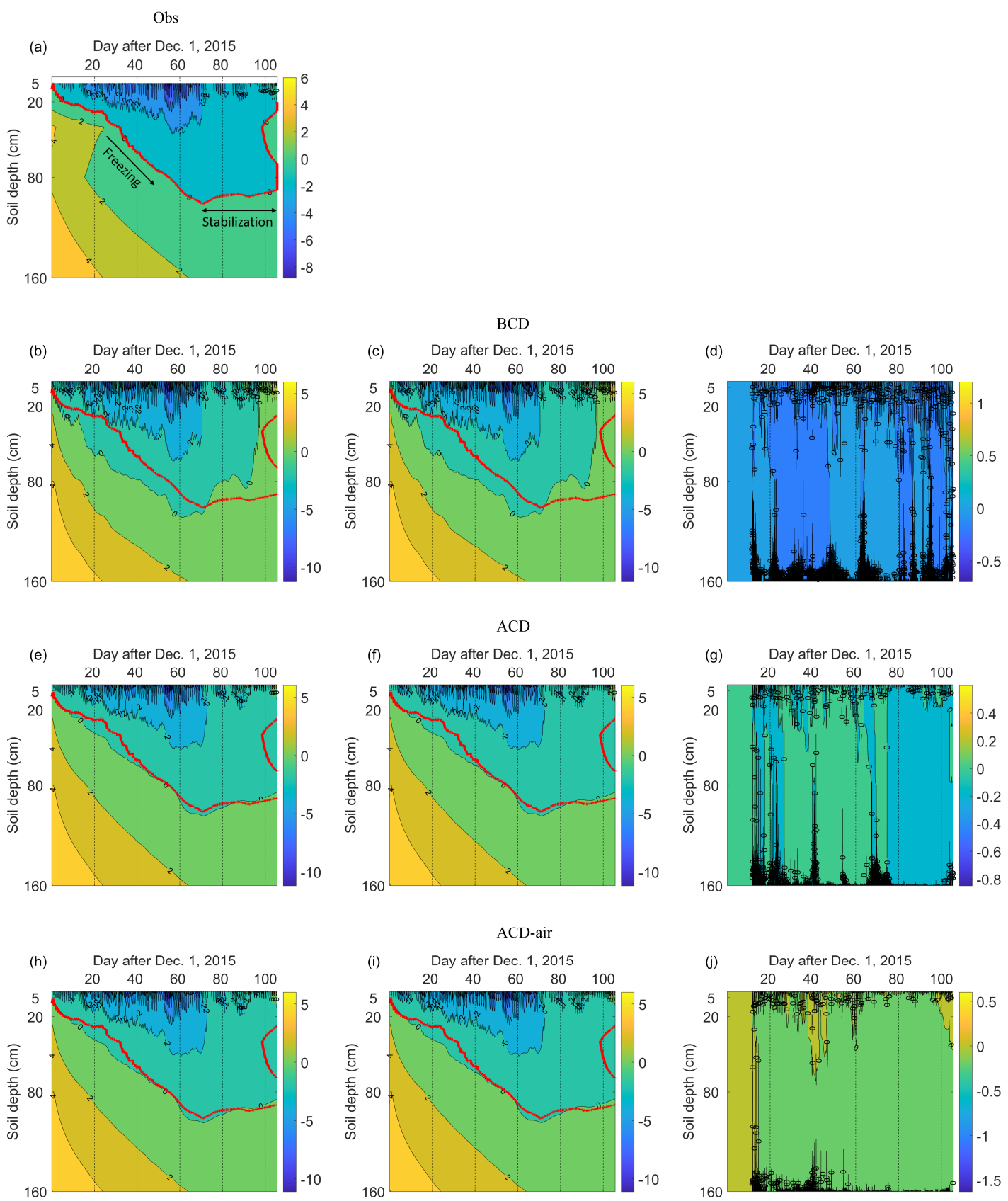

Figure 5.3. The spatial and temporal dynamics of observed (a) and simulated soil temperature using BCD, ACD, and ACD-air soil models both with and without consideration of the snow module (snow: $b, e, h$ and no snow: $c, f, i$ ) and the difference between them $(d, g, j)$ (simulations with snow minus simulations without snow). The red line indicates the zero-degree isothermal line (ZDIL) from the measured soil temperature. The observed soil freezing stage and stabilization stage is marked in Fig. 5.3a. 
Obs
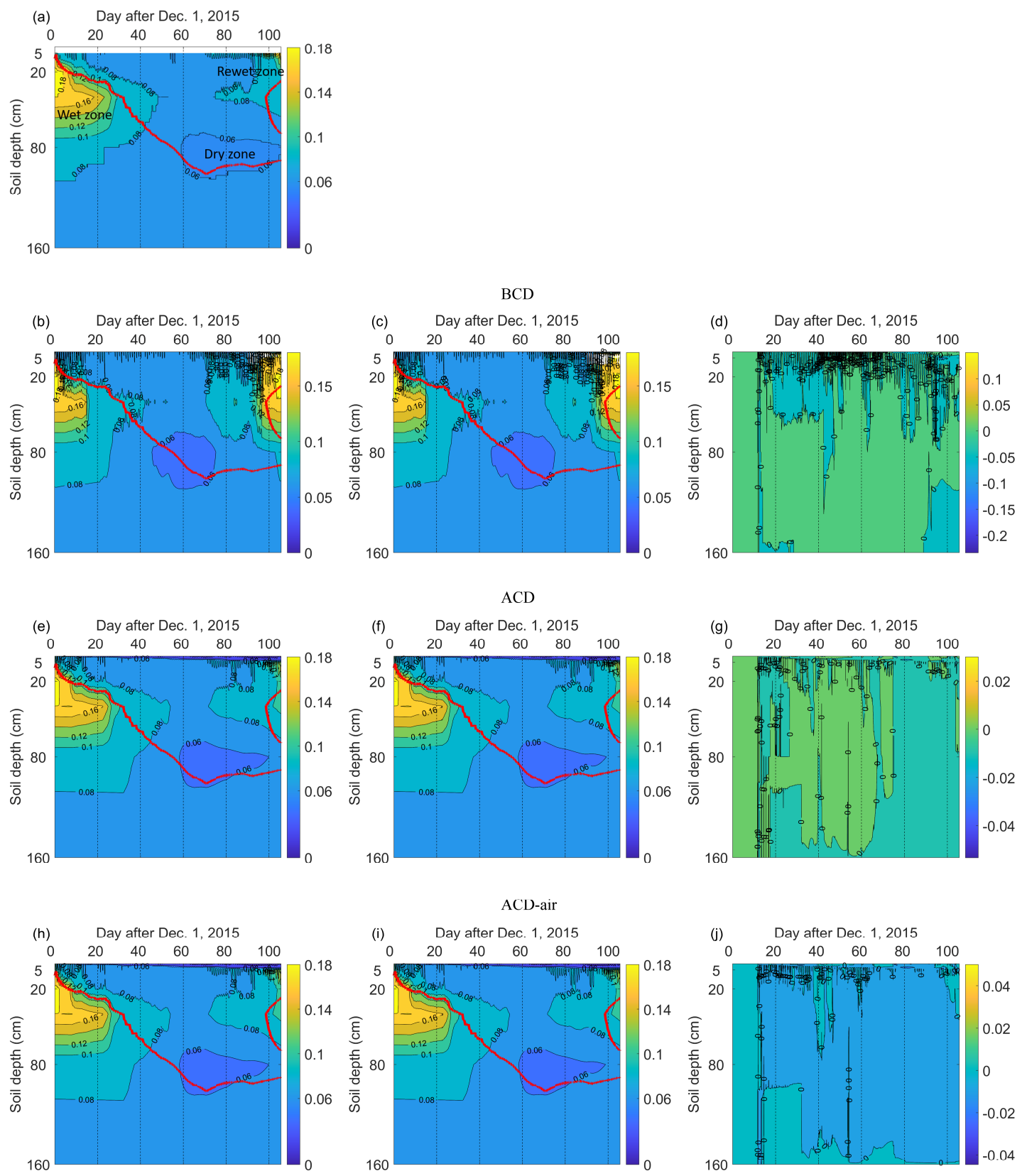

Figure 5.4. The spatial and temporal dynamics of observed (a) and simulated soil volumetric water content using BCD, ACD, and ACD-air soil models both with and without consideration of the snow module (snow: $b, e, h$ and no snow: $c, f, i$ ) and the difference between them $(\mathrm{d}, \mathrm{g}, \mathrm{j})$ (simulations with snow minus simulations without snow). The red line indicates the ZDIL from the measured soil temperature. The observed wet zone, dry zone and rewet zone of soil moisture is indicated in Fig. 5.4a. 


\subsubsection{Surface latent heat flux}

Figure 5.5 shows the comparison of time series of observed and model-simulated surface cumulative latent heat flux using three models with and without consideration of the snow module. Considerable overestimation of latent heat flux was produced by the BCD-Snow model: $121.79 \%$ more than was observed. Such overestimations were largely reduced by ACD and ACD-air models. There is a slight underestimation of cumulative latent heat flux in the ACD-Snow and ACD-air-Snow models, with values of $-8.33 \%$ and $-7.05 \%$, respectively. Compared with STEMMUS-FT_Snow simulations, there is less latent heat flux produced by the STEMMUS-FT_No-snow simulations. This is mainly due to the sublimation of snow cover, which cannot be simulated by the STEMMUS-FT_No-snow models. The difference in cumulative latent heat flux between STEMMUS-FT with and without snow module increases from BCD to ACDair schemes, with the values of $2.02 \%, 7.69 \%$, and $8.97 \%$ for BCD, ACD and ACD-air schemes, respectively.
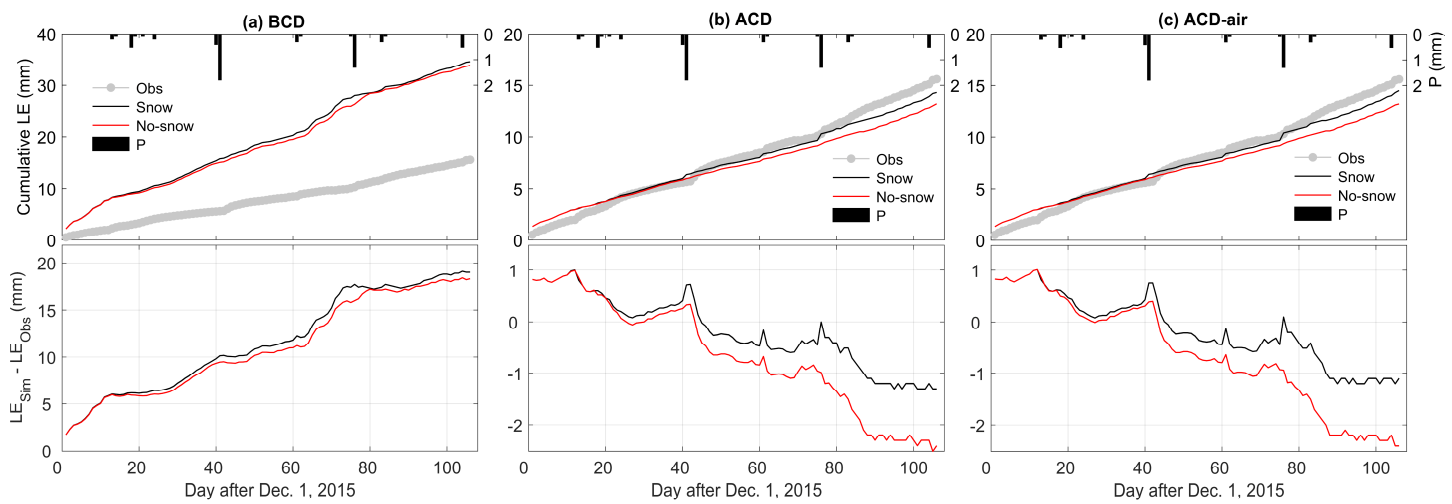

Figure 5.5. Time series of observed and model simulated surface cumulative latent heat flux (LE) using (a) BCD, (b) ACD, and (c) ACD-air soil models with and without consideration of the snow module (including precipitation). The top row shows the comparisons, and the bottom row shows the model bias of the cumulative surface LE.

\subsubsection{Liquid and vapor fluxes}

To further elaborate the effect of snowpack on LE, we presented the diurnal variations of LE and its components at two typical episodes with precipitation events (freezing and thawing period, respectively). The relative contribution of liquid and vapor flow to the total mass transfer after precipitation events was separately presented in Figure 5.8 $\& 5.9$, i.e., the liquid water flux driven by the gradients of temperature $q_{L T}$, matric potential $q_{L h}$ and air pressure $q_{L a}$, water vapor flux driven by the gradients of temperature $q_{V T}$, matric potential $q_{V h}$ and air pressure $q_{V a}$. 


\section{1) $\mathbf{L E}$}

Diurnal dynamics of the observed and simulated latent heat flux during the rapid freezing period with the occurrence of precipitation events, from $10^{\text {th }}$ to $14^{\text {th }}$ days after Dec. 1.2015, are shown as Fig. 5.6a, b, and c. Compared to the observations, the diurnal variations of latent heat flux were captured by the proposed model with various levels of complexities. Performance of BCD, ACD, and ACD-air models in simulating LE differed mainly regarding the magnitude and response to precipitation events. For the BCD-Snow model, the overestimation of LE was found at the $10^{\text {th }}$ and $11^{\text {th }}$ day after December 1 due to relatively high surface soil moisture simulation (Fig. A6.1b). A certain amount of enhanced surface evaporation was produced shortly after precipitation, which is most probably due to the snow sublimation. Snow sublimation does not appear to intuitively match with observations. The mismatch in the LE enhancement after precipitation events can be attributed to the fact that the partition process of precipitation into various components (rainfall, snowfall, canopy interception) might not be captured by the model well. Such a response to the winter precipitation events was absent from the BCD-No-Snow simulations.

The overestimation of LE was reduced by ACD and ACD-air models (Fig. 5.6b \& c). Compared to the ACD-Snow model simulations, the ACD-No-snow model produced a stronger diurnal variation of LE after the precipitation and is approaching the measured LE. Lower diurnal variation of LE for the ACD-Snow model can be ascribed to the lower surface SWCL (see Fig. A6.1d \& g). For the ACD-Snow model, precipitation was partitioned into rainfall and snowfall, part of which was directly evaporated as sublimation. The sum of rainfall and the melting part of snowfall reached the soil surface as the incoming water flux, which is less than that for the ACD-No-snow model (taking all the precipitation as the incoming water flux). There is no significant difference in the dynamics of LE between simulations by ACD models and ACD-air models.

During the thawing period, the diurnal variations of LE were simulated well by the models (Figure 5.7). There are some discrepancies regarding the peak values of LE. For the BCD-Snow model, overestimations were found in $100^{\text {th }}, 101^{\text {st }}$, and $102^{\text {nd }}$ day after December 1,2015 . The high LE values on $100^{\text {th }}$ and $101^{\text {st }}$ day are probably due to the high surface soil moisture by the thawing water (Fig. A6.2b), whereas on the $102^{\text {nd }}$ day, it is due to the snow sublimation (Fig. 5.7a). The peak values were reproduced but shifted by BCD-No-Snow simulation, which occurred on $100^{\text {th }}$ day and at the end of $102^{\text {nd }}$ day, indicating the shift of surface soil moisture states (Fig. A6.2b). 


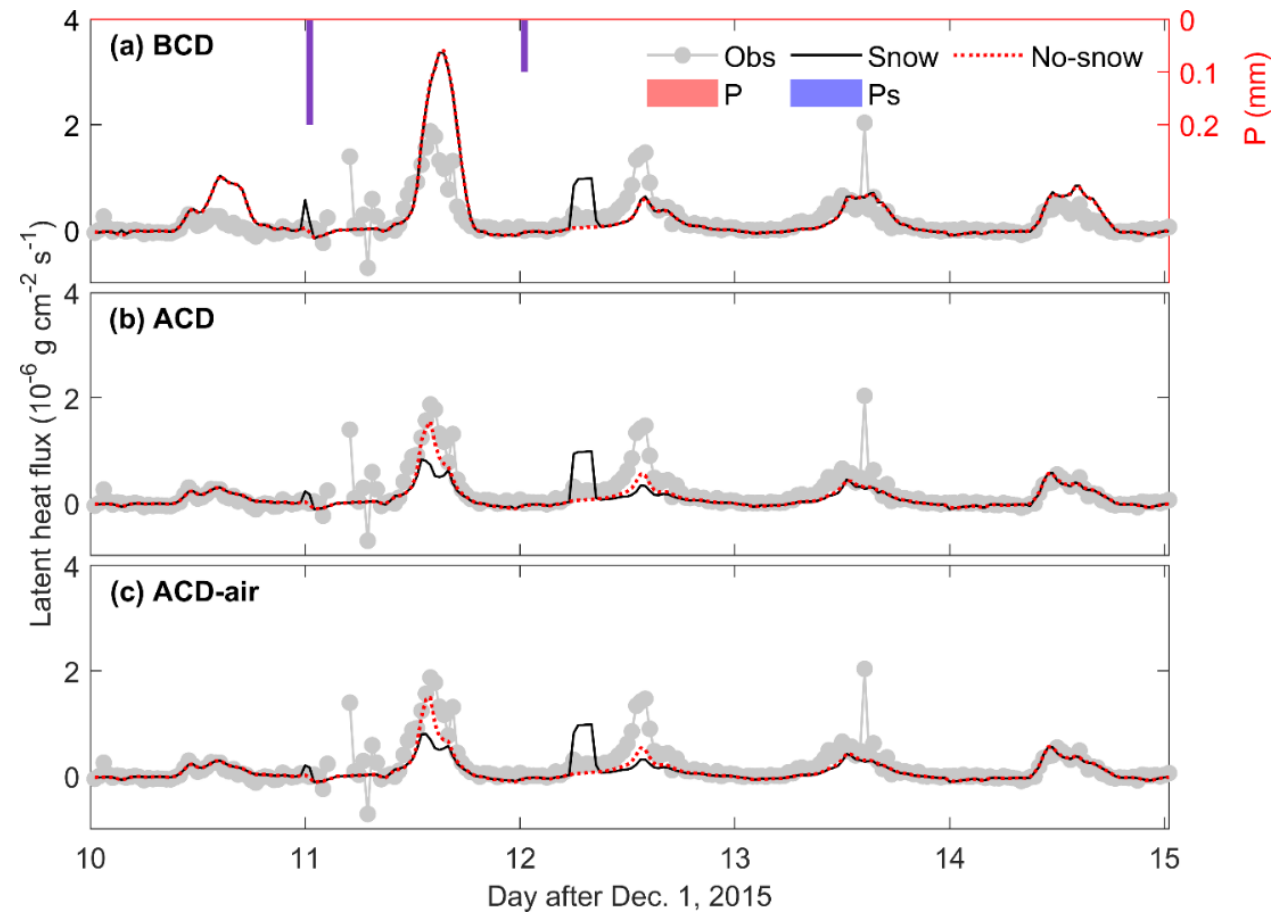

Figure 5.6. Observed and model simulated latent heat flux, using (a) BCD, (b) ACD, and (c) ACD-air soil models with and without the snow module, of a typical $5 \mathrm{~d}$ freezing period (from the $10^{\text {th }}$ to $14^{\text {th }}$ day after 1 December 2015). P is the precipitation and Ps is the snowfall. All precipitation is in the form of snowfall.

For the ACD model, the difference in latent heat flux between snow and no-snow simulations was noticeable $2 \mathrm{~d}$ after precipitation. The larger values of LE from the ACD-No-snow model occurred earlier than those from the ACD-Snow model due to the earlier response of surface soil moisture to the precipitation event (Fig. A6.2). Compared to the observations, the enhancement of LE advanced from the ACD-Snow simulations (Fig. 5.7b). This enhanced evaporation can be attributed to the snow sublimation and increased surface soil moisture content. Similar lag behavior of precipitation-enhanced evaporation was produced by the ACD-air-Snow models (Figure 5.7c). There are mismatches in the time and magnitude of LE enhancement between ACD-Snow model simulations and observations (Fig. 5.7b). This discrepancy lies in the uncertainties of snowpack simulations, which can be attributed to either the inaccurate precipitation measurements (Barrere et al., 2017; Günther et al., 2019) or to the fact that the precipitation partition process is not described well by the model (Harder \& Pomeroy, 2014; Ding et al., 2017). 


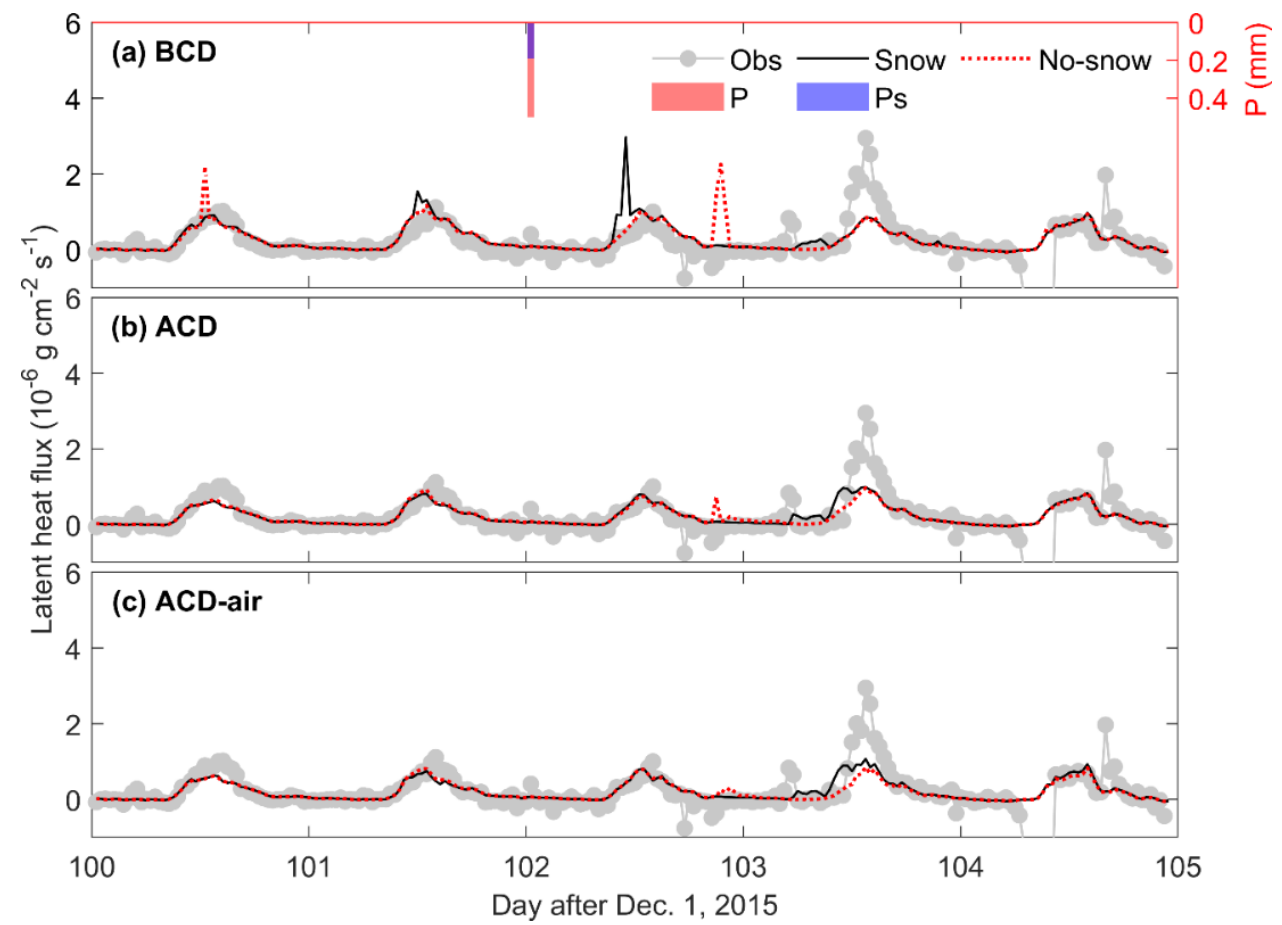

Figure 5.7. Observed and model simulated latent heat flux, using (a) BCD, (b) ACD, and (c) ACD-air soil models with and without the snow module of a typical $5 \mathrm{~d}$ thawing period (from the $100^{\text {th }}$ to $104^{\text {th }}$ days after 1 December 2015). $\mathrm{P}$ is the precipitation and Ps is the snowfall.

\section{2) LE and decomposition of surface mass transfer}

During the freezing period, the soil water vapor rather than the liquid water flux dominated the surface mass transfer process. Missing the description of the vapor diffusion process hindered the BCD model's ability to realistically depict the decomposition of surface mass transfer dynamics (Fig. 5.8a \&b). 


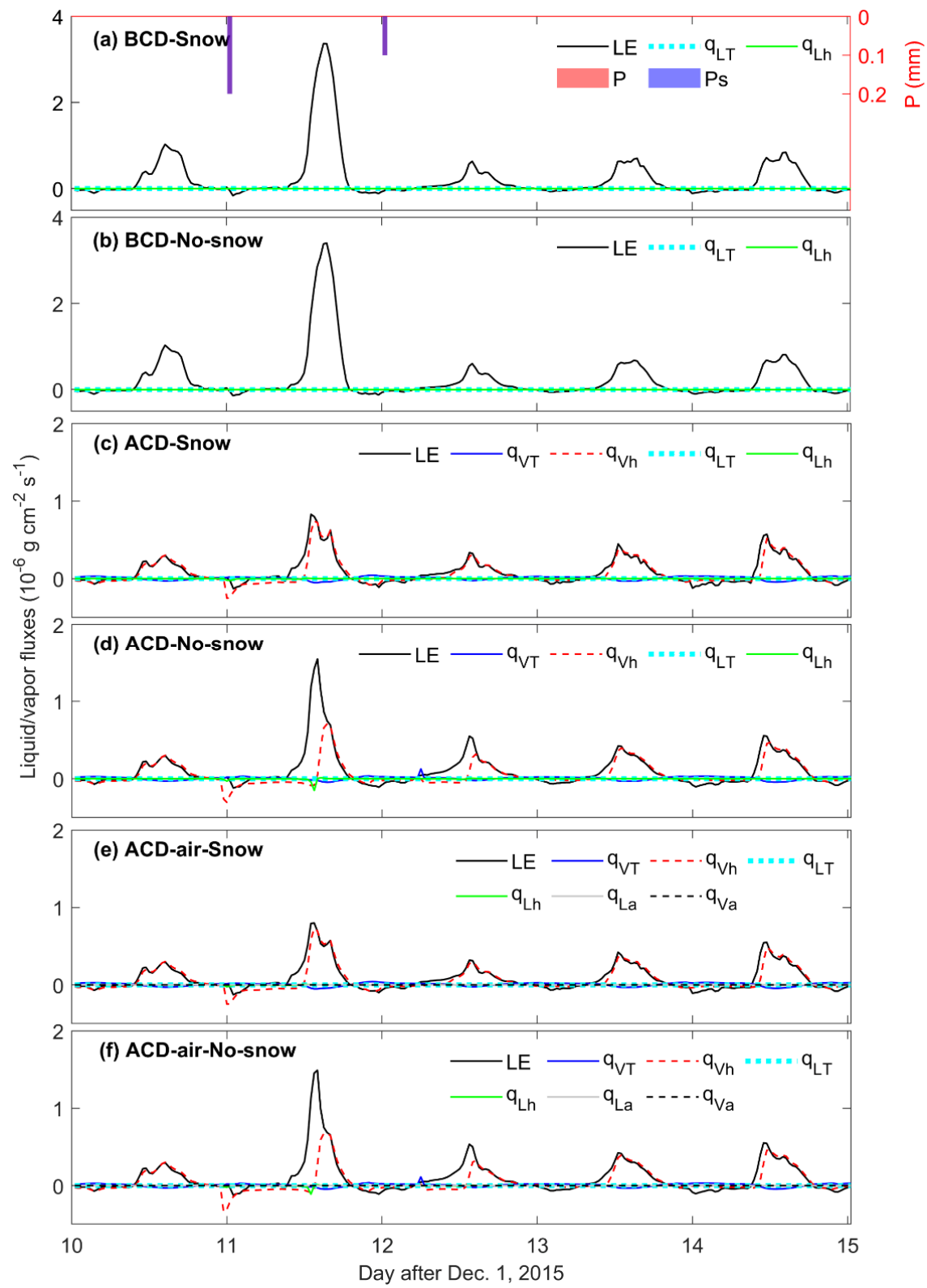

Figure 5.8. Model-simulated latent heat flux and surface soil $(0.1 \mathrm{~cm})$ thermal and isothermal liquid water and vapor fluxes (LE, qvT, qvh, qLT, qLh, qLa, qva) with and without the snow module of a typical $5 \mathrm{~d}$ freezing period (from the $10^{\text {th }}$ to $14^{\text {th }}$ day after Dec. 1. 2015). Panels (a), (c), and (e) are the surface soil thermal and isothermal liquid water and vapor fluxes simulated by the BCD-Snow, ACD-Snow, and ACD-air-Snow models, respectively. Panels (b), (d), and (f) are the surface soil thermal and isothermal liquid water and vapor fluxes simulated by the BCD-No-Snow, ACD-No-Snow, and ACD-air-No-Snow models, respectively. LE is the latent heat flux, qvi and qvh are the water vapor fluxes driven by temperature and matric potential gradients, respectively, $\mathrm{q}_{\mathrm{LT}}$ and $\mathrm{q}_{\mathrm{Lh}}$ are the liquid water fluxes driven by temperature and matric potential gradients, respectively, qLa and qva are the liquid and vapor water fluxes driven by air pressure gradients, respectively. Positive and negative values indicate upward and downward fluxes, respectively. Note that the surface LE fluxes without snow sublimation are presented here. $\mathrm{P}$ is the precipitation, and Ps is the snowfall. All precipitation is in the form of snowfall. 


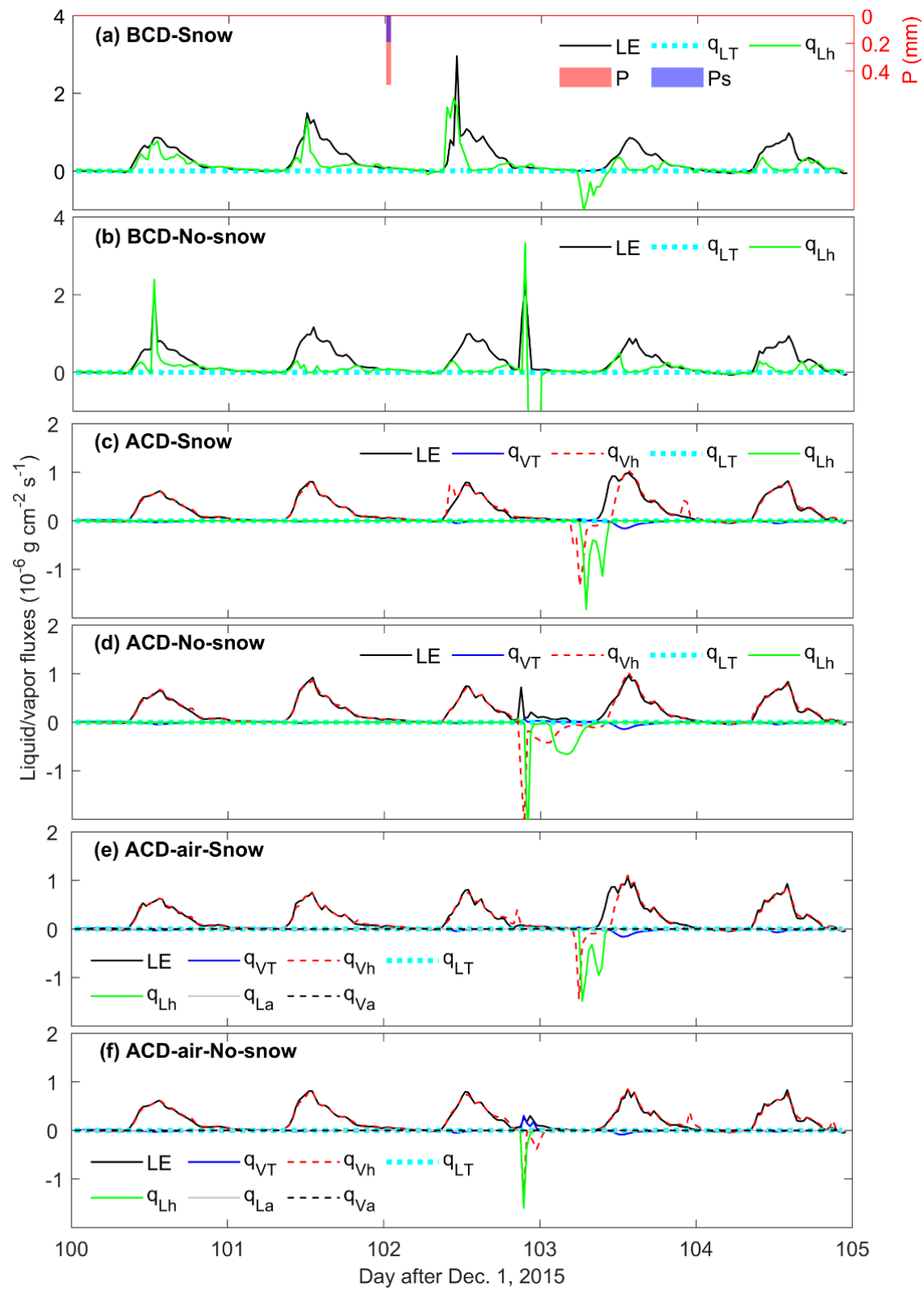

Figure 5.9. Model-simulated latent heat flux and surface soil $(0.1 \mathrm{~cm})$ thermal and isothermal liquid water and vapor fluxes (LE, qvT, qvh, qLT, qLh, qLa, qva) using BCD $(a, b), \operatorname{ACD}(c, d)$, and ACD-air (e, f) simulations with and without the snow module, respectively, during the typical 5-day thawing periods (from the $100^{\text {th }}$ to $104^{\text {th }}$ day after Dec. 1. 2015). Panel (a), (c), and (e) are the surface soil thermal and isothermal liquid water and vapor fluxes simulated by BCD-Snow, ACD-Snow, and ACD-air-Snow model, respectively. Panels (b), (d), and (f) are the surface soil thermal and isothermal liquid water and vapor fluxes simulated by BCD-No-Snow, ACD-No-Snow, and ACDair-No-Snow model, respectively. LE is the latent heat flux, qvi and qvi are the water vapor fluxes driven by temperature and matric potential gradients, respectively, qLT and qLh are the liquid water fluxes driven by temperature and matric potential gradients, respectively, $\mathrm{qLa}_{\mathrm{La}}$ and qVa are the liquid and vapor water fluxes driven by air pressure gradients, respectively. Positive and negative values indicate upward and downward fluxes, respectively. Note that the surface LE fluxes without snow sublimation are presented here. $\mathrm{P}$ is the precipitation, and Ps is the snowfall. 
There is a visible diurnal variation of thermal vapor flux $q_{V T}$ from the ACD model simulation (Fig. $5.8 \mathrm{c} \& \mathrm{~d}$ ). The isothermal vapor flux $q_{V h}$ contributed to most of the mass transfer during the freezing period. It should be noted that the sum of water-vapor fluxes at $0.1 \mathrm{~cm}$ soil layer cannot balance the surface evaporation, especially after the precipitation events (Fig. 5.8c). We assumed this premise and attributed it to the surface ice sublimation process. Precipitation water was frozen on the soil surface, and only vapor fluxes are active in the topsoil layers. Sublimation of surface ice may contribute to the gaps between liquid-vapor fluxes and LE (Yu et al., 2018). As more precipitation water was frozen on the soil surface from the ACD-No-Snow model (Fig. 5.8d), the difference between the sum of water/vapor fluxes at the top $0.1 \mathrm{~cm}$ soil layer and the surface evaporative water enlarged compared to ACD-Snow simulations. Thermal liquid water flux $q_{L T}$ appears negligible to the total mass flux during the whole simulation period. There is no significant difference recognized in the mass transfer between the ACD-air and ACD during the freezing period.

During the thawing period, a certain amount of upward liquid water flux was produced by the BCD model, supplying the water to the topsoil and evaporate into the atmosphere (Fig. 5.9a \&b). Compared to the isothermal liquid flux $q_{L h}$, the thermal liquid flux $q_{L T}$ was negligible to the total mass flux.

For the ACD model, the diurnal variation of thermal vapor flux $q_{V T}$ was enhanced after precipitation, producing a larger amount of upward and downward vapor flux during the nighttime and daytime, respectively (e.g., Fig. 5.9c). As the surface soil is relatively dry, the isothermal vapor flux $q_{V h}$ contributes nearly all of the mass flux during the selected thawing period. Driven by the matric potential gradient, a large amount of isothermal water vapor flux $q v h$, accompanied by downward liquid water flux $q_{L h}$, can be found after the nighttime precipitation event (Fig. 5.9c, d, e, f). These precipitationinduced isothermal liquid-vapor fluxes were lagged and less intense from the ACDSnow model than that from the ACD-No-Snow model simulation (e.g., Fig. 5.9c vs. Fig. 5.9d). The snowpack reduces the instant precipitation infiltration process and enables the snowmelt afterwards, which led to the lagged and weaker response of surface SWCL to the precipitation (Fig. A6.2). This breaks the balance between isothermal vapor flux and evaporative LE (around the 103rd day after 1 December 2015). Compared to the ACD-No-Snow model, the imbalance was enlarged for the ACD-Snow model during the thawing period (Fig. 5.9c \&d).

Compared to the ACD-No-Snow simulations, the upward thermal vapor flux $q_{V T}$ was enhanced after precipitation for the ACD-air-No-Snow model (Fig. 5.9f). This enhanced upward vapor flux reduced the soil liquid water content at $0.1 \mathrm{~cm}$ (Fig. A6.2f) and decreased the soil hydraulic conductivity and then the downward isothermal liquidvapor flux $\left(q_{L h}, q_{V h}\right)$. Other than that there is no significant difference between the ACDair model and the ACD model during the thawing period. 


\subsection{Discussion}

\subsubsection{Uncertainties in simulations of surface albedo and limitations}

After a winter precipitation event, land surface albedo increases considerably (Fig. 5.2), indicating the presence of the snowpack. However, such snowfall events were episodic with small magnitudes (similar to those in Li et al., 2017), which means that they are difficult to capture well. Such difficulties can be partially attributed to the inherent uncertainties in precipitation measurements (both the precipitation amount and types). Due to the spatial variability of precipitation, the accurate observation of winter precipitation has proven to be a challenge, especially during windy winters (Barrere et al., 2017; Pan et al., 2017). It is necessary to have more snowpack-relevant measurements (e.g., the high-resolution measurements of the spatiotemporal field of wind speed, precipitation, and snowpack variations) to understand the dynamics of snowpack and its effect on energy and water fluxes. Furthermore, the temporal resolution of precipitation measurements adopted in this study is relatively coarse $(3 \mathrm{~h})$. In the current precipitation partition parameterization, the amount of snowfall was determined as a function of precipitation and air temperature thresholds. Given the coarse temporal resolution of precipitation measurements, the model may produce a time shift of snowfall events or even the misidentification of snowfall. The simple relation between the air temperature and precipitation types may be not suitable for this region because air temperature is not the best indicator of precipitation types, as argued by Ding et al. (2014). Other factors, i.e., relative humidity, surface elevation, and wetbulb temperature, are also very relevant and should be taken into account for the discrimination of precipitation types. The other uncertainty lies in the representation of the snow process. For example, the wind blow effect and canopy snow interception, which have been recognized as important to the accurate simulation of snowpack dynamics (Mahat \& Tarboton, 2014), are not taken into account in detail. Last but not least, the interpretation of surface albedo dynamics needs to be adapted to the specific site, especially regarding the shallow snow situations (Ueno et al., 2007; Ueno et al., 2012; Ding et al., 2017; Wang et al., 2017b). The albedo of the underlying surface should also be properly accommodated to this Tibetan meadow system. Regardless of the aforementioned uncertainties, our proposed model was capable of capturing the surface albedo variations with precipitation (Fig. 5.2) and can be seen as acceptable for analyzing snow cover effects in such a harsh environment.

\subsubsection{Snow-cover-induced evaporation enhancement}

In contrast to precipitation from rainfall, precipitation water from snowfall enters the soil considerably lagged in time due to the water storage by snow cover (You et al., 2019). With the snow module, precipitation was partitioned into rainfall and snowfall. Part of the snowfall evaporated into the atmosphere as sublimation and the other part 
together with the rainfall infiltrated into the underlying soil. It resulted in the delay of incoming water to the soil with a lower amount compared to that without consideration of the snow module. This amount of incoming water increased the evaporation after precipitation (Fig. $5.6 \& 5.7$ ). The other source for the enhanced evaporation flux after precipitation is snow sublimation, which is absent from the model without the snow module. Sublimation occurs readily under certain weather conditions (e.g., with freezing temperatures, enough energy). It can be more active in regions with low relative humidity, low air pressure, and dry winds. Such an amount of sublimation has been reported as being important from the perspective of climate and hydrology (e.g., Strasser et al., 2008; Jambon-Puillet et al., 2018), especially in high-altitude regions with low air pressure. During the freezing period, the evaporation enhancement can be also sourced from the sublimation of surface ice. The amount of the ice sublimation appeared to decrease during the freezing period in the presence of a transient snowpack (e.g., Fig. 5.8c vs. 5.8d). This is consistent with the results of Hagedorn et al. (2007), who investigated the effect of snow cover on the mass balance of ground ice with an artificially continuous annual snow cover. According to their results, the snow cover enhanced the vapor transfer into the soil and thus reduced the long-term ice sublimation. The relative contribution of increased surface soil moisture, snow sublimation, and surface ice sublimation to the enhanced evaporation is dependent on the preprecipitation soil moisture and temperature states, air temperature, and the time and magnitude of precipitation events. Under the conditions of the low pre-precipitation SWCL with a freezing soil temperature (e.g., Fig. 5.8e, 11th vs. 12th day after 1 December), the precipitation falls on the surface as snowfall and rainfall (most freezes as ice). The sublimation from surface ice can contribute to most of the total mass transfer (e.g., Fig. 5.8e, 11th day after 1 December). If the soil temperature rises above the freezing temperature, there will be no sublimation of surface ice, in terms of contributing to the enhanced evaporation (e.g., Fig. 5.9e, 102nd day after 1 December).

\subsubsection{Snow cover impacts with different soil model complexities}

The model with different complexities of soil mass and energy transfer physics behaves differently in response to the winter precipitation events. During the freezing period, there is no significant difference in the soil moisture simulated using the BCD model with and without the snow module. The precipitation water freezes at the soil surface, which cannot be transferred downwards with the BCD model physics. The sublimation, from either the snow or the surface ice, contributes to the precipitation-enhanced evaporation for the BCD model. As with vapor flow, the surface ice increases the soil moisture at lower layers via the downward isothermal vapor flux (Fig. 5.8). The surface ice sublimation and increased moisture-induced soil evaporation enhancement can be identified from the ACD model simulation. The role of airflow was negligible for the mass transfer during the freezing period. 
When it comes to the thawing period, the BCD model produced a certain amount of liquid water flow, contributing considerably to the mass transfer. The obvious fluctuation of SWCL was noticed due to the thawing water and precipitation event. The main source for the increased evaporation was interpreted as isothermal liquid water flow, while for the ACD model the situation becomes more complex. Thawing surface ice and snowmelt water may coexist at the soil surface, resulting in different soil moisture response to precipitation events. The ice sublimation, snow sublimation, and increased soil moisture contribute to the evaporation enhancement after precipitation. When considering airflow, dry air interacts with soil ice and liquid and vapor water in soil pores (Yu et al., 2018) and alters the soil moisture state. It thus considerably changes the relative contribution of each component to the mass transfer (Fig. 5.9).

\subsection{Conclusions}

With the aim to investigate the hydrothermal effect of the snowpack on the underlying soil system, we developed the integrated process-based soil-snow-atmosphere model, STEMMUS-UEB v1.0.0, which is based on the easily transferable and physically based description of the snowpack process and the detailed interpretation of the soil physical process with various complexities. From STEMMUS-UEB simulations, snowpack affects not only the soil surface conditions (surface ice and SWCL) and energy-related states (albedo, latent heat flux) but also the transfer patterns of subsurface soil liquid and vapor flow. STEMMUS-FT model can mostly capture the abrupt increase of surface albedo after winter precipitation events with consideration of the snow module. There is a significant overestimation of cumulative surface latent heat flux by the BCD model. The ACD and ACD-air models produce a slight underestimation of cumulative LE compared to the observations. Without sublimation from snowpack, there is less latent heat flux produced by STEMMUS-FT_No-snow simulations compared with snow simulations. The presence of snowpack alters the partition process of precipitation and thus the surface SWCL. BCD models with and without snowpack produced similar surface SWCL during the freezing period while resulting in an abrupt increase of soil moisture in response to the precipitation during the thawing period. The ACD-Snow model simulated a less intensive and lagged soil moisture variation in response to precipitation compared to the ACD-No-Snow model during both the freezing and thawing period, respectively. The ACD-air model affected the intensity of increased surface soil moisture, especially during the thawing period.

Three mechanisms, surface ice sublimation, snow sublimation and increased soil moisture, can contribute to the enhanced latent heat flux after winter precipitation events. The relative role of each mechanism in the total mass transfer can be affected by the time and magnitude of precipitation and pre-precipitation soil moisture and temperature states (see Sect. 5.4.3). The simple BCD model cannot provide a realistic partitioning of mass transfer. The ACD model, which takes into account vapor diffusion 
and thermal effect on water flow and snowpack, can produce a reasonable analysis of the relative contributions of different water flux components. When considering the airflow, the relative contribution of each component to the mass transfer was substantially altered during the thawing period. Further work will take into account the thermal interactive effects between snowpack and the underlying soil, which explicitly considers the convective and conductive heat fluxes and the solar radiation attenuation due to the snowpack. Such work will inevitably enhance our confidence in interpreting the underlying mechanisms and physically elaborating on the role of snowpack in cold regions. 

Chapter 6 Integrating soil water and groundwater flow processes 


\section{Abstract}

How to efficiently and physically integrate the soil water dynamics with groundwater flow processes has drawn much attention. This chapter presents a coupled soil watergroundwater model, considering the two-way feedback coupling scheme, and verified its performance using two synthetic cases (using the fully 3D variably saturated flow (VSF) model simulations as the 'reference') and one real catchment case (using the groundwater table depth and soil moisture profile measurements). By the cross validation between the observations and various model simulations, the two-way coupling approach is proven physically accurate and is applicable for large scale groundwater flow problems. Compared to the simulation by groundwater model alone (i.e., only MODFLOW), the coupling of MODFLOW with one soil column reduced the overestimation of groundwater table simulation (taken the VSF model simulations as the reference, case 2D). The results were further improved as more soil columns were used to represent the heterogeneous soil water-groundwater interactions. Compared to the HYDRUS-MODFLOW, the two-way coupling approach produces a similar spatial distribution of hydraulic heads while better performs in mimicking the temporal dynamics of groundwater table depth and soil moisture profiles. We attribute the better performance to the different coupling strategies across the soil-water and groundwater interface. It is thus suggested to adopt the two-way feedback coupling scheme, together with the moving phreatic boundary and multi-scale water balance analysis, to maintain the physical consistency and reduce the coupling errors. The realistic implementation of the vadose zone processes (with STEMMUS), coupling approach, and spatiotemporal heterogeneity of soil water-groundwater interactions was demonstrated critical to accurately represent an integrated soil water-groundwater system. The developed STEMMUS-MODFLOW model can be further equipped with different complexities of soil physics (e.g., coupled soil water and heat transfer, freeze-thaw, airflow processes), surface hydrology (snowfall, runoff), soil and plant biogeochemical processes, towards an integrated "from bedrock to atmosphere" modelling framework. 


\subsection{Introduction}

Vadose zone water flow and groundwater flow interact by exchanging water and energy fluxes, making the process of these two subzones closely coupled. Current earth system models (ESMs), land surface models (LSMs), or soil water models (SWMs), devote many efforts in representing soil water and heat dynamics, while the detailed groundwater flow processes, for instance the lateral groundwater flow, is often ignored (Famiglietti \& Wood, 1994; Liang et al., 2003; Best, 2011; Niu et al., 2011; Brunner \& Simmons, 2012; Milly et al., 2014; Vergnes et al., 2014; de Graaf et al., 2017; Lawrence et al., 2019).

The integrated soil water-groundwater (SW-GW) modelling facilitates the process understanding of the hydrological/ecological system and how it will respond to the future climate changes (Kurylyk et al., 2014a; Kurylyk et al., 2014b; Barthel \& Banzhaf, 2016; Zipper et al., 2017). It is particularly important for the integrated water resource management at the regional scale $\left(10^{2}\right.$ to $\left.10^{5} \mathrm{~km}^{2}\right)$ (Barthel \& Banzhaf, 2016). Furthermore, the integrated SW-GW modelling can be employed to assess the sustainability of the regional ecosystem service and its resilience to climate extremes (Booth et al., 2016; Qiu et al., 2018a; Qiu et al., 2018b; Qiu et al., 2019; Brelsford et al., 2020).

There are quite a number of SW-GW coupling research conducted in recent years (Maxwell \& Miller, 2005; Twarakavi et al., 2008; Niu et al., 2011; Tian et al., 2012; Niu et al., 2014; Bisht et al., 2017). Several approaches have been proposed to integrate the vadose zone processes with the groundwater system, including the conceptual water budget approach with empirical parameterizations (Harbaugh et al., 2000; Scanlon et al., 2002), simplification of vadose zone processes (e.g., the UZF package for MODFLOW, Niswonger et al., 2006), fully 3D Richards solution (Thoms et al., 2006; Maxwell et al., 2017), and quasi-3D unsaturated-saturated coupling scheme (Seo et al., 2007; Zhu et al., 2012; Mao et al., 2019; Zeng et al., 2019).

Fully 3D Richards solution is physically accurate in describing variably saturated water flow process with a solid theoretical foundation. However, it is computationally expensive and not easy to achieve the numerical convergency for large scale modeling under complex meteorological and hydro-geophysical conditions (Twarakavi et al., 2008). The water budget approach, in contrast, requires little computational effort to obtain a converged simulation as it simply considers the vadose zone effect as a certain amount of water flux recharging/discharging the groundwater system (Harbaugh et al., 2000; Scanlon et al., 2002; Twarakavi et al., 2008). This method has been successfully applied in many large-scale groundwater simulations, while additional calibration efforts are necessary as it oversimplifies the vadose zone process. The kinematic wave equation has been used as an alternative to characterize the vadose zone process (Smith, 
1983; Smith \& Hebbert, 1983). It well captures the gravity-induced water flow while neglects the capillary pressure-induced water flow. In such way, the application of this simple method is case dependent (most applicable in regions with deep water tables and less suitable for aquifers with shallow water tables). For the quasi-3D unsaturatedsaturated coupling approach, water flow in the unsaturated zone is assumed only in vertical direction with no lateral flux. The regional scale vadose zone is characterized by multiple soil columns solving Richards equation independently. The saturated zone is solved by the $2 \mathrm{D} / 3 \mathrm{D}$ groundwater flow equations. The $1 \mathrm{D}$ vadose zone model and 2D/3D groundwater model exchange the boundary information as an integrated model (Seo et al., 2007; Zhu et al., 2011; Mao et al., 2019; Zeng et al., 2019). This quasi-3D coupling scheme simultaneously considers near-surface meteorological conditions, surface hydrological conditions, water table fluctuations, and the hydrothermal properties of vadose zone. It sustains the physical reality of the unsaturated-saturated zone processes and improves the numerical stability and computational efficiency (Twarakavi et al., 2008; Zeng et al., 2019).

Proved to be a promising way balancing the computational cost and physical accuracy, the quasi-3D coupling method has drawn much attention and efforts from soil water and groundwater modelers (Havard et al., 1995; Seo et al., 2007; Mao et al., 2019; Zeng et al., 2019). Generally, quasi-3D coupling scheme can be realized by exchanging the groundwater recharge and water table levels across the soil water-groundwater (SWGW) interface. According to Furman (2008), such SW-GW coupling is classified into three categories: i) weakly coupled or one-way coupled, which directly adds the soil water flow solutions onto the groundwater models (e.g., SVAT-MODFLOW, Facchi et al., 2004; UZF-MODFLOW, Niswonger et al., 2006; HYDRUS-MODFLOW, Seo et al., 2007; SWAP-MODFLOW, Xu et al., 2012). Although this scheme is easy to implement, it can be problematic due to its failure in capturing the SW-GW interactions (Beegum et al., 2018; Mao et al., 2019; Zeng et al., 2019; Brandhorst et al., 2021). ii) the fully coupling scheme, which simultaneously solves the soil-water and groundwater flows by building the nodal hydraulic connections and matrices across the interface. It is mathematically rigorous but computationally expensive, thus limits its application in large regional scale problems. iii) two-way feedback coupling scheme, which exchanges water flux or water table levels at the interface nodes. The feedback coupling scheme maintains the consistency of exchanging quantities in space and time, thus effectively avoids the mass balance error accumulation, with moderate computational effort. Nevertheless, the feedback coupling scheme may face the scale-mismatch problem (the parameterization of the water release at the phreatic surface/shared nodes differs from soil water and groundwater models). This problem can result in numerical instabilities and coupling errors (Zeng et al., 2019; Brandhorst et al., 2021). Multi-scale water balance analysis appears to be a promising way to link the soil water and groundwater quantities at the phreatic surface (Zeng et al., 2019). 
Under certain conditions (e.g., high topographic gradient), the lateral water fluxes between saturated regions of soil columns cannot be neglected (illustrated in Figure 6.1). The moving-boundary strategy, using the adaptive soil column bottom boundary instead of the fixed one in response to the fluctuating groundwater table depth, has been reported to overcome the numerical difficulty caused by such saturated lateral water flow and thus reduce the coupling errors (Zeng et al., 2019).

In this chapter, we coupled the soil water model (STEMMUS) with the groundwater model (MODFLOW) in a two-way feedback manner. The iterative feedback scheme, multi-scale water balance analysis, and moving boundary approach were all incorporated in the coupling framework. Two test cases and one real-world catchment scale validation were conducted to testify the developed SW-GW coupling model STEMMUS-MODFLOW. In the following sections, the governing equations, coupling procedure of STEMMUS-MODFLOW, the model setup of two test cases and one catchment scale case are described in Section 6.2. Section 6.3 presents the validation results, followed by the discussion in Section 6.4. This work is summarized in Section 6.5 .
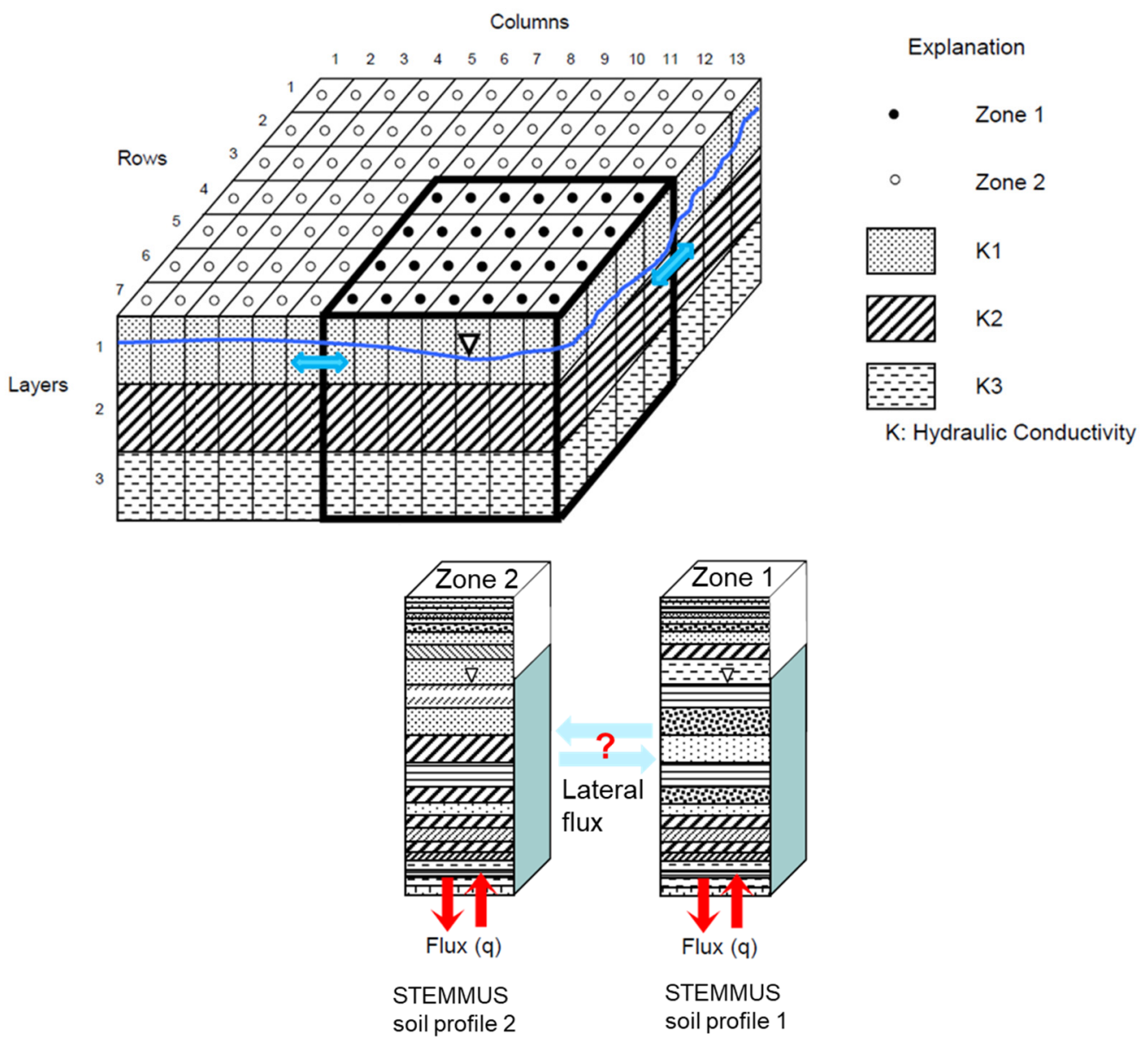

Figure 6.1. Problem illustration using the current SW-GW coupling method, the lateral water fluxes between saturated regions of soil columns is often neglected. Adapted from Seo et al. (2007). 


\subsection{Methodology}

\subsubsection{Governing equations}

MODFLOW assumes that the ground water is with constant density and the porous medium is noncompressible, the 3-D groundwater flow is described by the following partial-differential equation and solved using a block-centered finite-difference method (Harbaugh, 2005).

$$
\frac{\partial}{\partial x}\left(K_{x x} \frac{\partial H}{\partial x}\right)+\frac{\partial}{\partial y}\left(K_{y y} \frac{\partial H}{\partial y}\right)+\frac{\partial}{\partial y}\left(K_{z z} \frac{\partial H}{\partial y}\right)+W=S_{S} \frac{\partial H}{\partial t}
$$

where $K \mathrm{xx}, K y \mathrm{y}$, and $K z z$ are the hydraulic conductivity along the $x, y$, and $z$ coordinate axes; $H$ is the hydraulic head; $W$ is the volumetric flux per unit volume representing sources and/or sinks of water; $S s$ is the specific storage of the porous material; $t$ is time.

The vadose zone water flow is mainly driven by both the gravity and capillary force, the vapor transport mechanisms, i.e., diffusion, advection, and dispersion are included here. In addition, the freezing-thawing process is also explicitly taken into account. The governing equation can be mathematically described using the modified Richards equation (Milly, 1982; Zeng et al., 2011a).

STEMMUS takes into account different heat transfer mechanisms, including heat conduction $\left(\lambda_{e f f} \frac{\partial T}{\partial z}\right)$, convective heat transferred by liquid and vapor flow, the latent heat of vaporization $\left(\rho_{V} \theta_{V} L_{0}\right)$, the latent heat of freezing/thawing $\left(-\rho_{i c e} \theta_{i c e} L_{f}\right)$ and a source term associated with the exothermic process of wetting of a porous medium (integral heat of wetting) $\left(-\rho_{L} W \frac{\partial \theta_{L}}{\partial t}\right)$.

The governing equations were presented in Section 3.2.1. Additional details on the constitutive equations for solving the coupled water and heat equations can be found in Zeng et al. (2011a; b), Zeng \& Su (2013) and Yu et al. (2018).

\subsubsection{Coupling procedure}

\subsubsection{General framework of STEMMUS-MODFLOW}

The current coupling method is through exchanging the boundary information between soil water model STEMMUS and groundwater model MODFLOW (Figure 6.2). Both STEMMUS and MODFLOW model are run separately. First, they run the preparation and initialization part independently. Once MODFLOW starts a new time step simulation, MODFLOW will inform STEMMUS with the time information (absolute time, time step) and the updated water pressure. Then STEMMUS model is told to start the simulation within a given time step. The received water pressure are set as the bottom boundary conditions for the STEMMUS model. After a certain number of 
iterations, STEMMUS model will converge to successfully update the state variables and boundary fluxes. The updated bottom boundary flux is sent back to MODFLOW model as its groundwater recharge. MODFLOW will formulate the matrix equations and iteratively solve for state variables HNEW for the current time step. Such loop will continue till the end of simulation period.

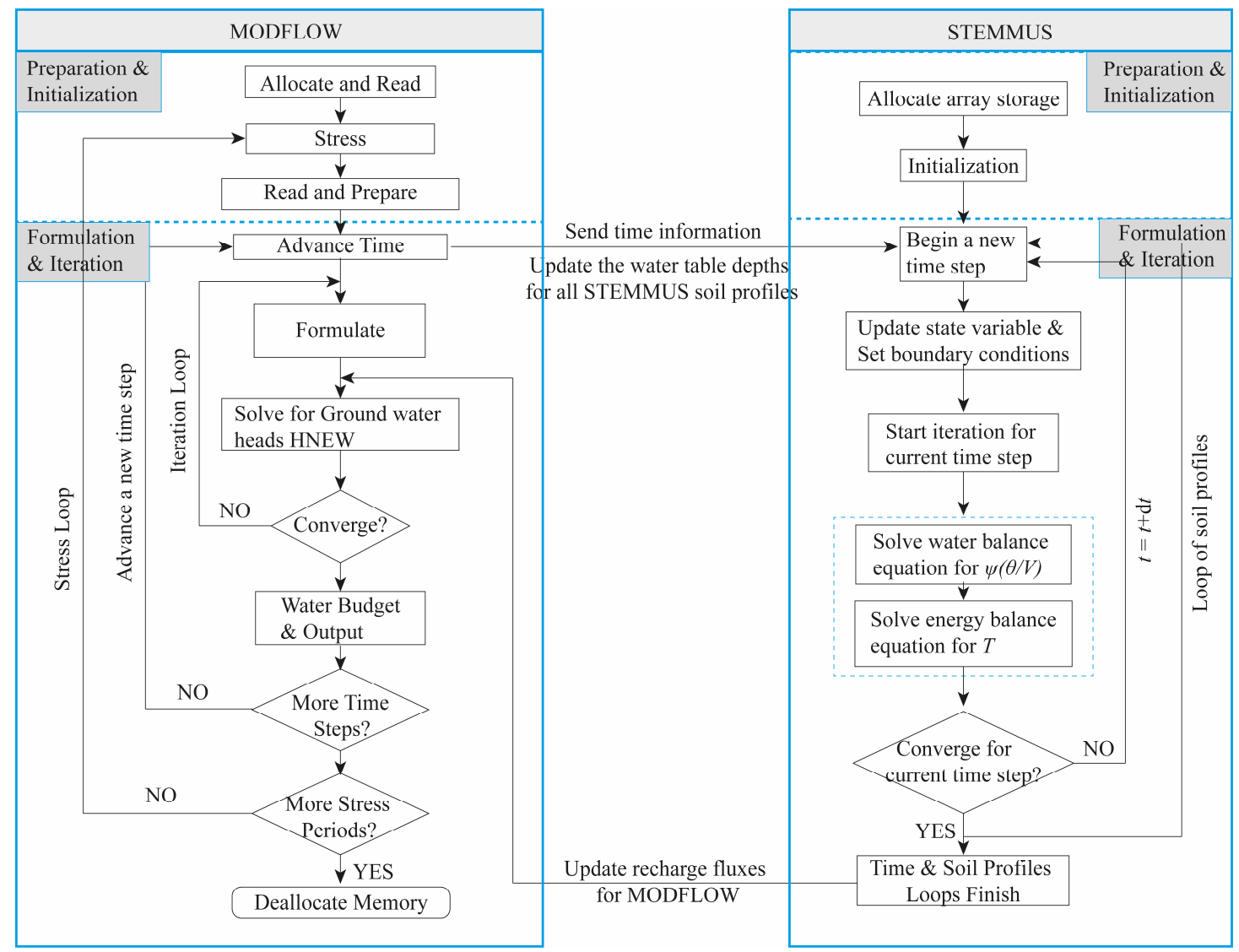

Figure 6.2. The schematic diagram for the coupling procedure of soil water model STEMMUS and groundwater model MODFLOW. HNEW is the updated ground water head. $\psi$ is the soil matric potential, $T$ is the soil temperature, and $\theta$ is the soil water content.

\subsubsection{Spatial coupling}

Generally, the user can divide the study area by making as many unsaturated profiles as he likes. In the following example (Figure 6.3a), two kind of soil profiles were employed to represent the hydraulic and thermal process of the vadose zone of the study area (i.e., STEMMUS soil profile 1 and 2). Each soil profile was assigned a group of MODFLOW cells. The depth to groundwater in each cell of the zone is averaged to determine the hydraulic head at the bottom of the corresponding soil profile. The flux from the bottom of soil profile is then applied to each cell of the zone as the groundwater recharge for the time step. The iterative feedback coupling scheme is utilized to have both the soil water and groundwater models converged at the coupling interface (see Appendix A4). To overcome the issue of the lateral flux in the saturated part of soil 
columns, the moving lower boundary approach for soil water model is adopted here. The soil column size is resized after each MODFLOW time step according to the updated groundwater levels (see Appendix A4).

\subsubsection{Temporal coupling}

Usually, the time step of groundwater models is larger than that of soil water models (Figure 6.3b). MODFLOW is operated with a prescribed time step $\left(10^{3}-10^{6} \mathrm{~s}\right)$. Within the given time step, STEMMUS model will adapt its own time step (variable between $10^{0}-10^{3} \mathrm{~s}$ ) to the converged simulation results. As soon as the accumulative simulation time of STEMMUS reaches that of MODFLOW, STEMMUS will relax and send the bottom boundary information to MODFLOW for the corresponding time step.

\subsubsection{Multi-scale interface water balance analysis}

To minimize the mass error at the interface, the multi-scale water balance analysis is conducted. The space- and time-splitting strategy is used to estimate water budgets of soil water and groundwater models at respective scales. For the soil water zone affected by the fluctuation of groundwater table, specific yield for the small scale (soil water model) is calculated by vertically integrating the soil water storage. Large scale specific yield quantifies the water release of the phreatic aquifer. By scale matching of the water budget components at the interface of respective scales, water balance is conserved and the upper boundary flux for the groundwater flow model can be achieved. In such way, the dynamic changing of specific yield at both scales is physically maintained and linked (see Appendix A4 for detail; Zeng et al., 2019). 
(a) Spatial coupling

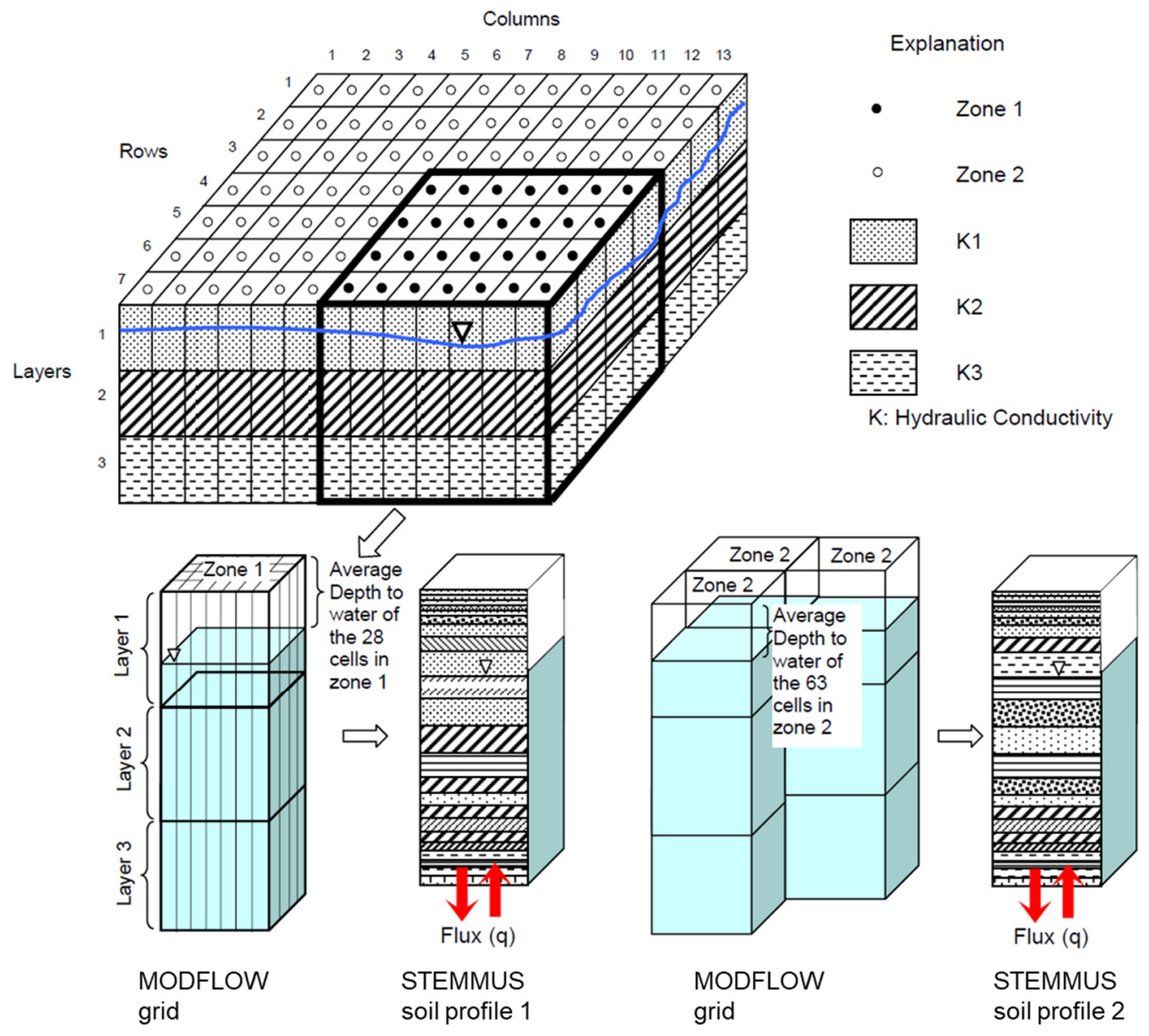

(b) Temporal coupling

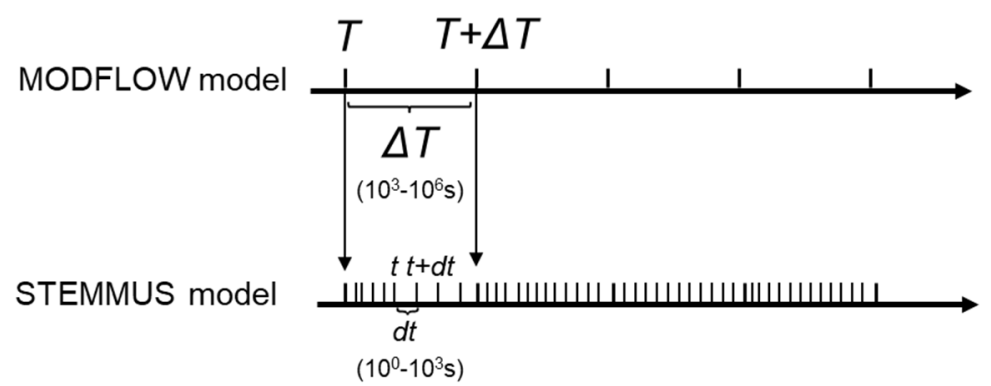

Figure 6.3. The schematic diagram for the (a) spatial coupling and (b) temporal coupling of STEMMUS and MODFLOW, adapted from Seo et al. (2007).

\subsubsection{Two test cases}

Two test cases were used to verify the developed SW-GW coupling model. The true reference was obtained by running the fully 3D variably saturated flow model (VSF). MODFLOW models without and with STEMMUS model were run to evaluate the impact of coupling schemes on SW-GW interactions. 
Case 2D: large groundwater drawdown

This case was used to test the model performance under the condition of large groundwater drawdowns (see the schematic plot of the cross section in Figure 6.4). The $2 \mathrm{D}$ domain dimension is $5000 \mathrm{~cm} \times 1000 \mathrm{~cm}$. The boundary conditions (top, bottom, left, and right) are all set as non-flux boundary. The initial hydrostatic head of the cross section is $700 \mathrm{~cm}$. Two pumping wells are applied as hydraulic stresses to the crosssection field. Well 1 is added at $x=2500 \mathrm{~cm}$ with a pumping rate $\mathrm{Q}_{1}=2 \times 10^{4} \mathrm{~cm}^{2} \mathrm{~d}^{-1}$ per unit width. Well 2 is added at $x=5000 \mathrm{~cm}$ with a pumping rate $\mathrm{Q}_{2}=1 \times 10^{4} \mathrm{~cm}^{2} \mathrm{~d}^{-1}$ per unit width. The pumping screen for both wells are at $z=0-200 \mathrm{~cm}$. Soil type of loam is used, and the hydraulic properties is listed in Table A4.1.

The total simulation period lasts 50 days. As for the spatial discretization, MODFLOW as well as the reference VSF model, uniformly divided the cross section along $x$ direction into 100 columns with the width of $50 \mathrm{~cm}$. The vertical direction is discretized into 91 layers, with the thickness ranging from $5 \mathrm{~cm}$ to $200 \mathrm{~cm}$ (top to bottom). For the $1 \mathrm{D}$ vadose zone model STEMMUS, the cross section along the $z$ direction is discretized evenly into 1000 layers with the thickness of $1 \mathrm{~cm}$. Number of $1 \mathrm{D}$ soil columns is designed as 1,5 , and 11 columns, all evenly distributed along $x$ coordinate.

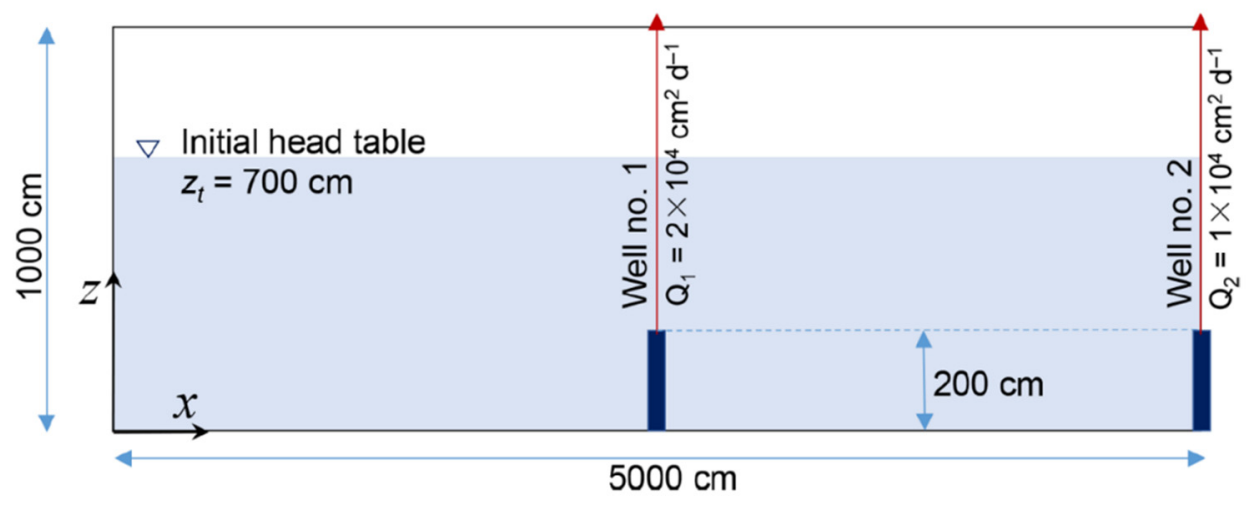

Figure 6.4. Schematic of the cross section for test case 2D. Two pumping wells with screens of $z=0-200 \mathrm{~cm}$ is located at $x=2500$ and $5000 \mathrm{~cm}$. The pumping rates per unit width at well no. 1 and no. 2 are $2 \times 10^{4}$ and $1 \times 10^{4} \mathrm{~cm}^{2} \mathrm{~d}^{-1}$, respectively. Adapted from (Zeng et al., 2019).

Case 3D: pumping and irrigation

More complex conditions with various stresses are equipped in this $3 \mathrm{D}$ case to verify the coupled STEMMUS-MODFLOW model performance. A phreatic aquifer with domain of $1000 \mathrm{~m} \times 1000 \mathrm{~m} \times 20 \mathrm{~m}$ is stressed by constant irrigation and pumping wells (Figure 6.5). The subdomains $(x, y)=(0-440$ and 560-1000 $\mathrm{m})$ are recharged at a rate of $3 \mathrm{~mm} \mathrm{~d}^{-1}$. For subdomains $(x, y)=(560-1000$ and $0-440 \mathrm{~m})$, the infiltration rate is $5 \mathrm{~mm} \mathrm{~d}^{-1}$. Three pumping wells with a constant pumping rate of $30 \mathrm{~m}^{3} \mathrm{~d}^{-1}$ are set up. The screens are located at $(x, y$, and $z)=(220 \mathrm{~m}, 220 \mathrm{~m}$, and 5-10 m), (500 m, 500 
$\mathrm{m}$, and 5-10 m), and (780 m, $780 \mathrm{~m}$, and 5-10 m) for Well no. 1, 2, and 3, respectively. The bottom and lateral boundaries are non-flux. The initial hydrostatic head of the aquifer is $18 \mathrm{~m}$. The used soil parameters are given in Table A4.1.

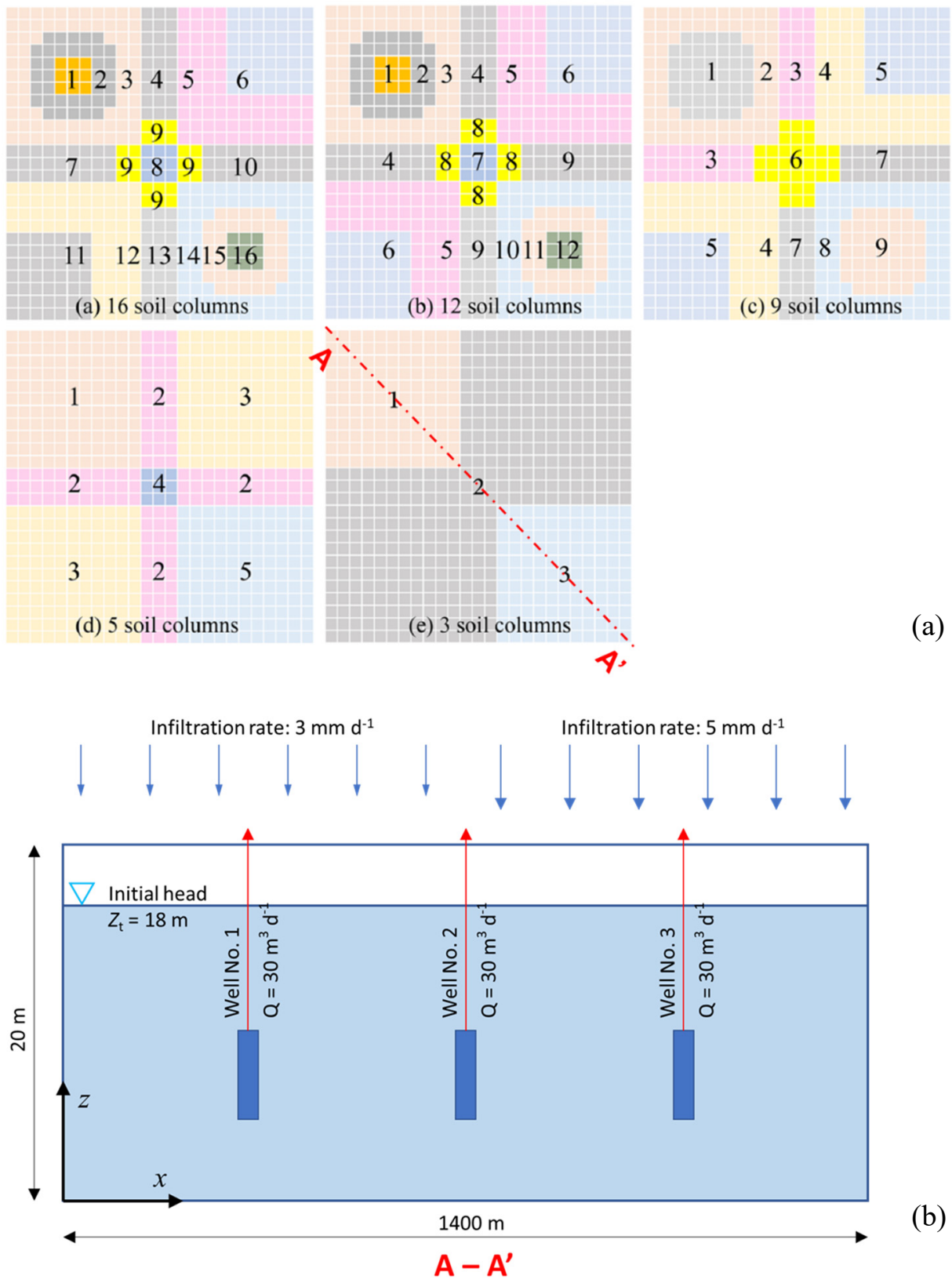

Figure 6.5. Characterization of (a) subzones partitioned for the quasi-3D simulations and (b) cross section $\mathrm{A}-\mathrm{A}^{\prime}$ in case 3D. The vadose zone is partitioned into 16, 12, 9, 5, and 3 subzones. Adapted from Zeng et al. (2019).

The total simulation period lasts 60 days. The aquifer is uniformly discretized into 25 $\times 25$ cells with the width of $40 \times 40 \mathrm{~m}$. The vertical discretization is increasingly finer from bottom to the top with the thickness ranging from $2 \mathrm{~m}$ to $0.1 \mathrm{~m}$. For the 1D soil profile, the discretization is $0.1 \mathrm{~m} \times 30$ and $0.4 \mathrm{~m} \times 5$. The zonation is designed differently in terms of soil column numbers and their locations (Figure 6.5). 


\subsubsection{Catchment scale SW-GW interactions}

\subsubsection{Maqu catchment and model setup}

The STEMMUS-MODFLOW model was used to investigate the SW-GW interactions in Maqu catchment, which is a typical cold climate with dry winter and warm summer. The annual average temperature is about $1.8{ }^{\circ} \mathrm{C}$. The annual precipitation is about 620 $\mathrm{mm}$. The selected Maqu catchment is about $38.86 \mathrm{~km}$ wide from east to west and 26.7 $\mathrm{km}$ long from north to south. The domain size is about $536 \mathrm{~km}^{2}$. Ground surface elevation decreases from $4017 \mathrm{~m}$ to $3367 \mathrm{~m}$ from the northwest to east. Field campaigns were conducted over Maqu in 2017 and 2018, including lithology survey, water table levels, slug test, magnetic resonance sounding (MRS) and time-lapse electrical resistivity tomography (ERT) measurements ( $\mathrm{Li}$ et al., 2021). It provides us with detailed hydro-geophysical information of the study area.

Based on the field experiment, we build up a regional simulation scenario. The related data for such a simulation was collected, including the specific 3D domain dimensions, soil properties, meteorology forcing data, groundwater table depth measurements, hydro-geophysical conditions. According to the field survey and campaign of geomorphology and geology, the selected area can be divided into two parts, the western mountainous area and flat eastern area. The sediments are alluvial deposits with intercalated eolian units in eastern flat area. Soil texture is finer at topsoil layers (sandy loam) and coarse at deep soil layers (sand with gravel). The western mountains are feldspathic quartzose sandstone and sandy slate with soil covered at the top ( $\mathrm{Li}$ et al., 2021). The western boundary, i.e., mountain divide, is the well-defined hydrogeological borders, to which no-flow boundary was applied. Yellow river flows along the eastern boundary, which was set as the head dependent flow boundary (MODFLOW General Head Boundary, GHB for short). The northern and southern segments were assumed as the no-flow boundaries.

Spatial variation of groundwater table depth was collected in August 2018. Long term simulations (1979-2018) were run for approaching the steady state, to calibrate the hydraulic parameters. The precipitation, from the China Meteorological Forcing Dataset (CMFD, He et al., 2020) with spatial resolution of 0.1 degree, was applied to the domain. Precipitation infiltration factors are in the range of $0.05-0.15$, which is lower in the mountainous area with steep terrain and larger in the flat area. Potential evapotranspiration $\mathrm{ET}_{0}$ was from ERA5 dataset (spatial resolution of 0.1 degree). The unconfined aquifer was divided into 5 layers for numerical simulation. The bottom of aquifer was set according to the bedrock depth dataset (Yan et al., 2020). The domain is divided into uniform grids of $500 \mathrm{~m} \times 500 \mathrm{~m}$. The top surface and bedrock elevations are presented in Figure $6.7 \mathrm{a} \& \mathrm{~b}$. 
Based on the pumping test, slug tests, geophysical exploration campaign and knowledge, the horizontal hydraulic conductivity $K_{\mathrm{h}}$ was initially assigned, varied from $0.01 \mathrm{~m} \mathrm{~d}^{-1}$ to $5 \mathrm{~m} \mathrm{~d}^{-1}$. The vertical hydraulic conductivity $K_{\mathrm{v}}$ was assigned as a ratio of $K_{\mathrm{h}}$, i.e., $0.1 * K_{\mathrm{h}}$. The specific yield was assigned uniformly as 0.15 .

River channel network is obtained from the local field survey and verified against the land surface DEM. MODFLOW River package was used to interpret the rivergroundwater interactions.

\subsubsection{Model calibration}

The aim of the calibration process is to obtain the proper initial groundwater head condition and hydraulic parameters. Long-term transient model (REC-ET for MODFLOW) was developed, driven by the annual average precipitation, potential evapotranspiration (from 1 January 1979 to 31 December 2018). The whole simulation period was divided into 40 stress periods, each with 12-time steps. The model was calibrated manually in a forward mode. We started the calibration process by first adjusting the initially assigned hydraulic conductivity value and its zonation (K-zones). The hydraulic conductance of the GHB boundary and riverbed conductance were then slightly changed. The calibration target is to minimize the difference between simulations and observations of groundwater table elevations and at the meantime to be consistent with the hydro-geological conditions as surveyed. It is to note that the observations were mainly collected from the eastern flat area, the calibration process was focused on the eastern part.

\subsubsection{Coupled model simulations}

After the optimization of groundwater flow model, the STEMMUS-MODFLOW model with a finer temporal resolution from 1 January 2016 to 5 August 2018 was run. The meteorological forcing (potential evapotranspiration $\mathrm{ET}_{0}$ and precipitation $\mathrm{P}$ ) was shown in Figure 6.6. The top surface and bedrock elevations are presented in Figure $6.7 \mathrm{a} \& \mathrm{~b}$. The subzones together with the current available measurements of groundwater table depth and soil moisture profile is shown in Figure 6.7c. The whole domain was discretized into 44 subzones for running soil model STEMMUS, with the soil vertical discretization thickness from $2 \mathrm{~m}$ to $0.01 \mathrm{~m}$ (finer on topsoil layers). Nine soil water content profile monitoring points were setup in this region in 2011 (Su et al., 2011; Dente et al., 2012) with 4 currently available on 5 August 2018 (Figure 6.7c). 


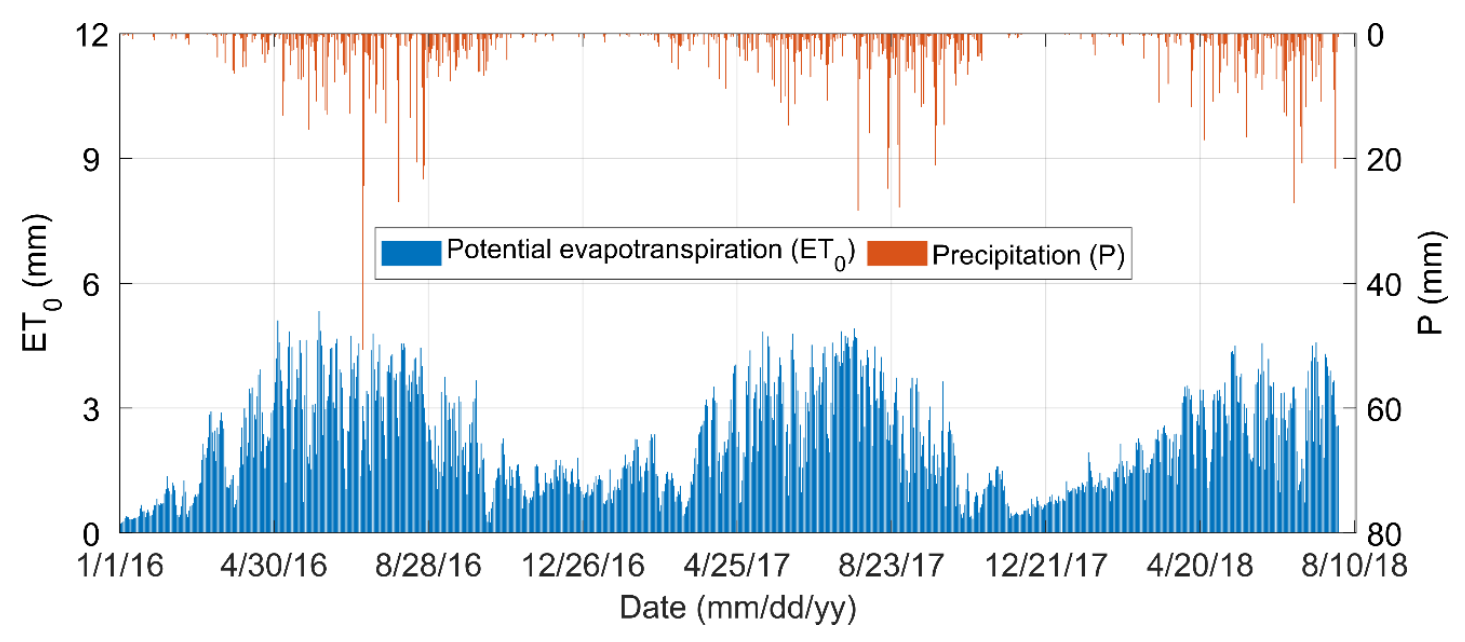

Figure 6.6. Spatial averaged daily meteorological forcing (potential evapotranspiration $\mathrm{ET}_{0}$ and precipitation $\mathrm{P}$ ) in the Maqu catchment.

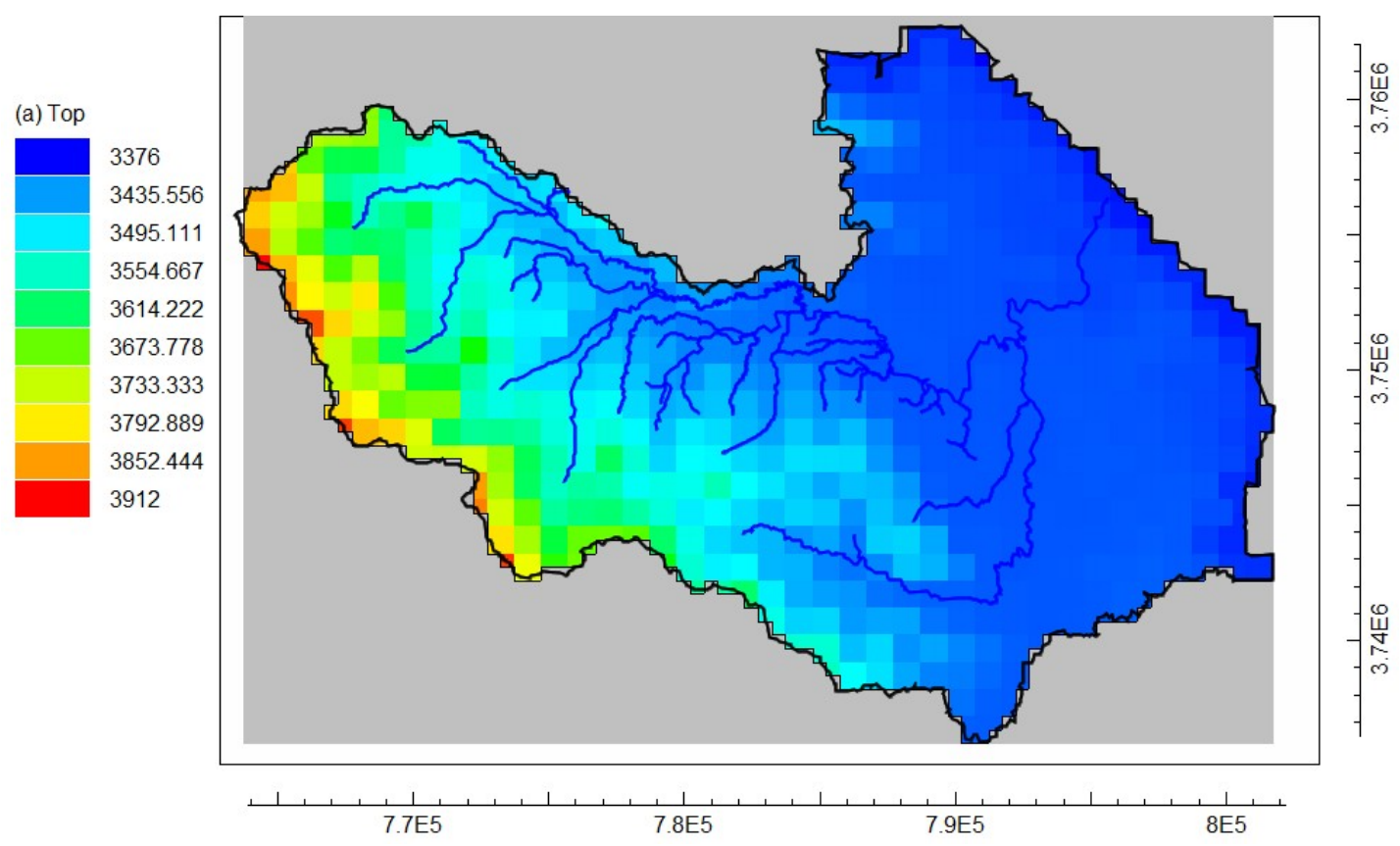



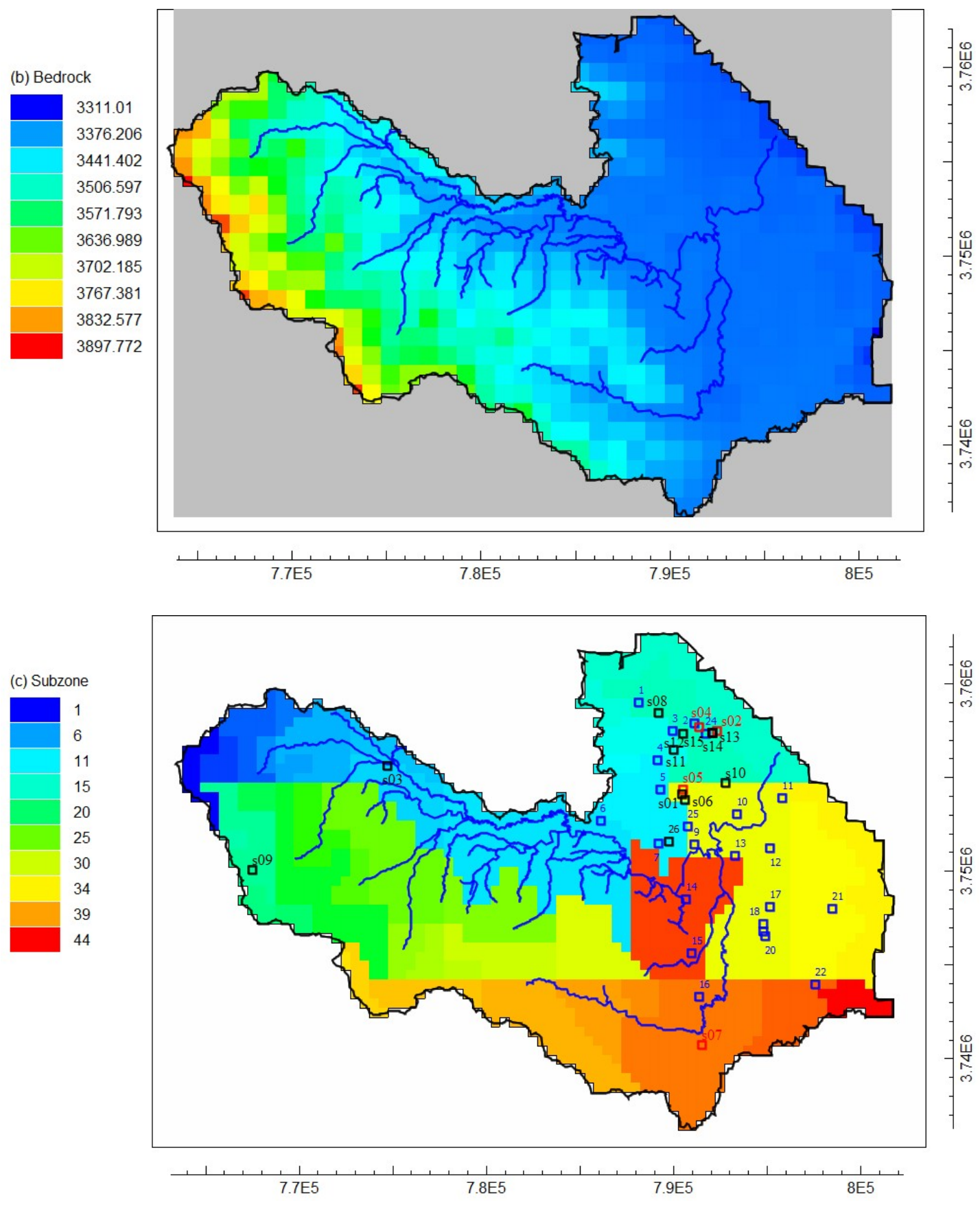

Figure 6.7. (a) Land surface elevation, (b) bedrock elevation of phreatic aquifer, and (c) subzones of soil columns for Maqu catchment problem. Blue line is the river network. Label number with 's' indicates the soil moisture and temperature profile measurements, the red ones are the current available observation points. Blue square dots indicate the position of the groundwater table level measurements on 5 August 2018. Unit is in $\mathrm{m}$.

\subsection{Results}

\subsubsection{Case 2D}

There are two drawdowns corresponding to the pumping well locations (Figure 6.8). Compared with that estimated by VSF model, the STEMMUS-MODFLOW model with 
5 and 11 soil columns well reproduced the amplitude of drawdowns, while underestimated by model with one soil column (Figure $6.8 \mathrm{a} \& \mathrm{~b}$ ). Both the water tables and head solutions were overestimated using MODFLOW alone, indicating the important role of vadose zone process and its interactions with groundwater dynamics (Figure 6.8a \&b).
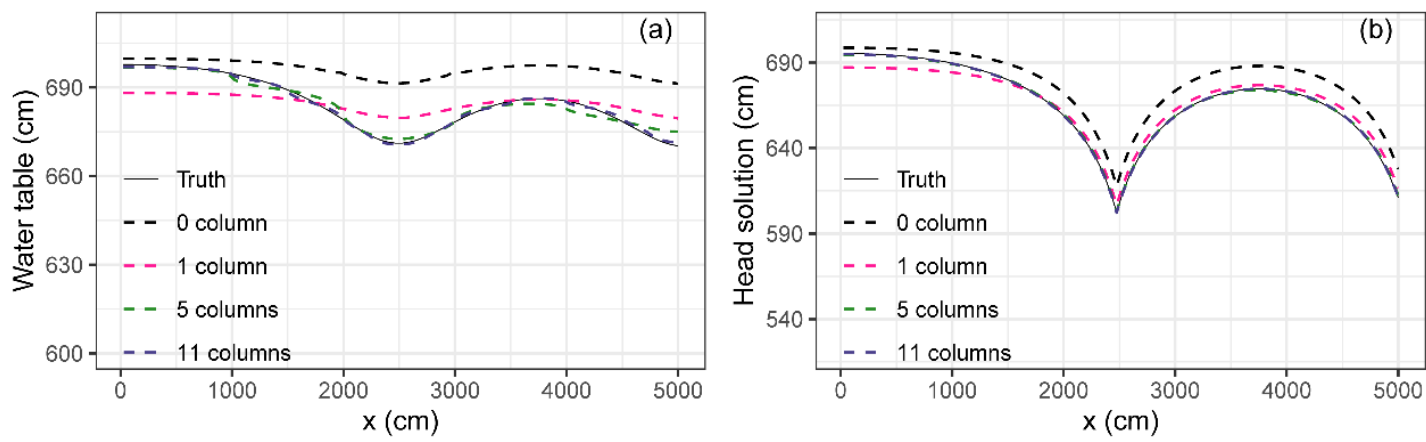

Figure 6.8. Comparison of water table (estimated by fully 3D VSF, MOFLOW only, and STEMMUS-MODFLOW model with 1, 5, 11 soil columns) and head solution $(\mathrm{z}=0)$ (estimated by fully 3D VSF, MOFLOW only, and STEMMUS-MODFLOW model with $1,5,11$ soil columns). Truth is achieved using the fully 3D VSF model. 0 column indicates the MODFLOW only simulations. The moving boundary method is used in the STEMMUS-MODFLOW model in Case 2D.

\subsubsection{Case 3D}

Figure 6.9 shows the simulated water table at A-A' cross section for Case 3D. From the fully $3 \mathrm{D}$ VSF model simulations, three pumping wells with the same pumping rate resulted in three different water table positions, lower water table for low-infiltration zone while higher water table for high-infiltration zone. The STEMMUS-MODFLOW with 9 and 16 subzones produced the similar variation trend. However, MODFLOW alone (without coupled with vadose zone model) produced the higher water table at three pumping well locations.

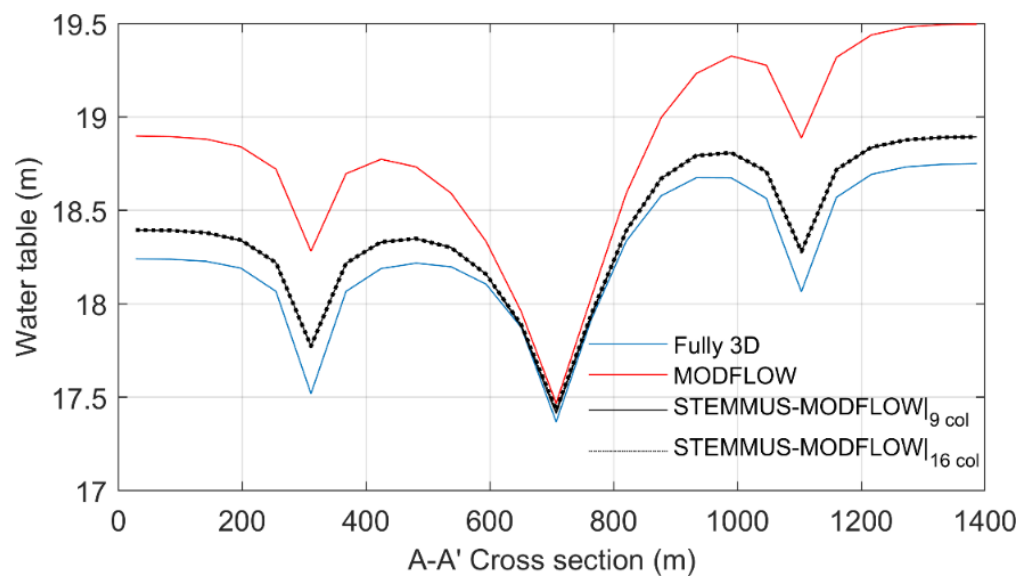

Figure 6.9. Comparison of the phreatic surface at A-A' cross section estimated by the fully 3D Model VSF, MODFLOW only, and the STEMMUS-MODFLOW model with 9 and 16 soil columns, respectively. 
(a) Fully 3D

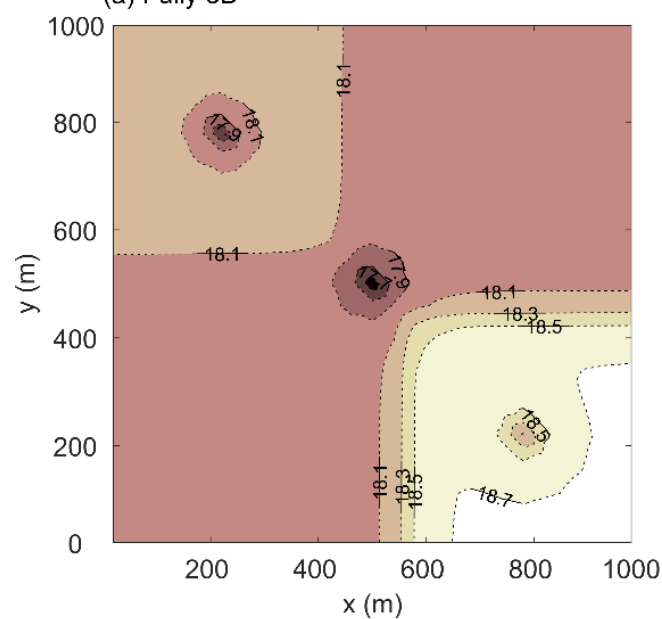

(c) STEMMUS-MODFLOW $\left.\right|_{9 \text { col }}$

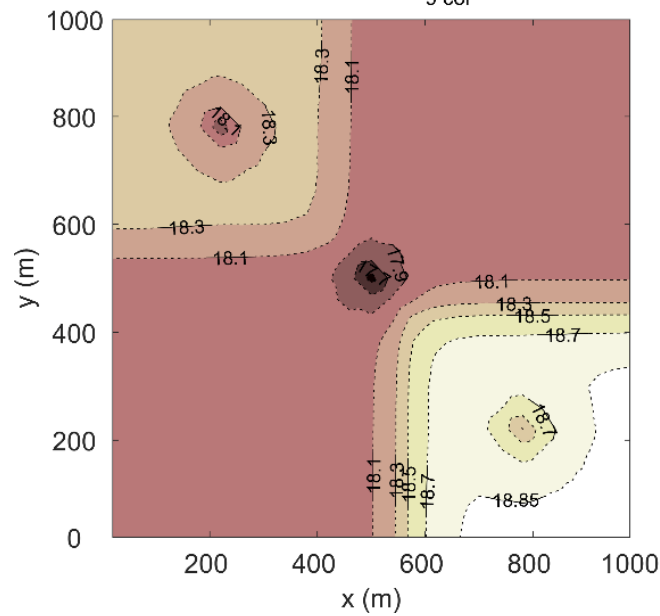

(b) MODFLOW

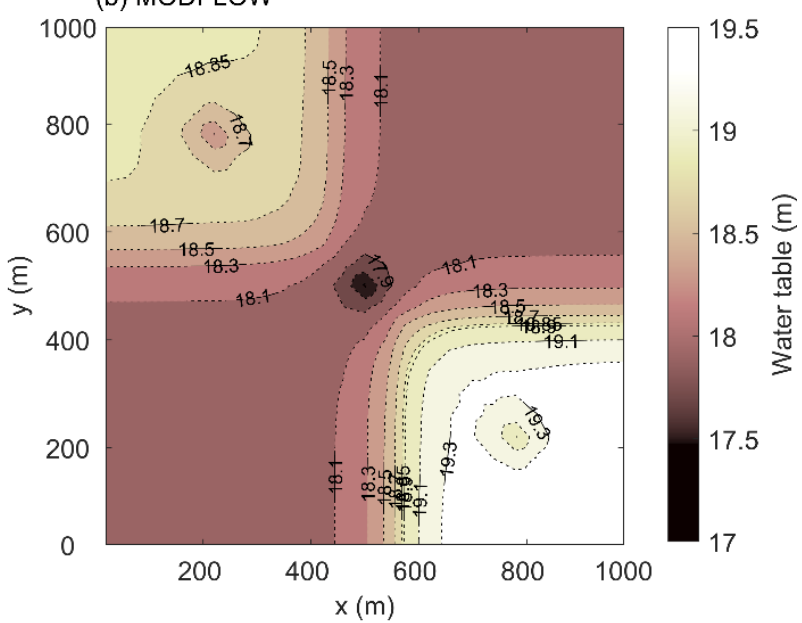

(d) STEMMUS-MODFLOW| $16 \mathrm{col}$

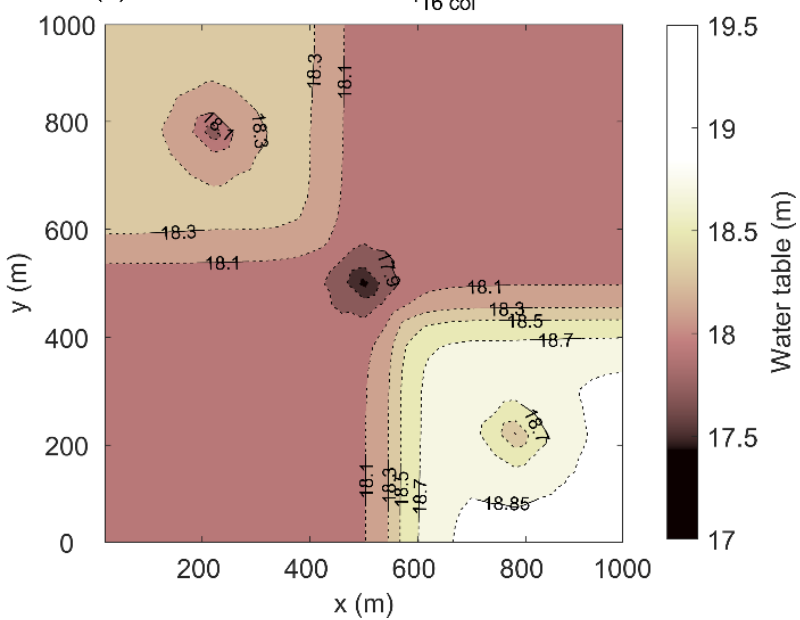

Figure 6.10. Comparison of contours of the phreatic surface solution with (a) the fully 3D VSF model, (b) the MODFLOW only, (c) the STEMMUS-MODFLOW model with 9 soil columns, and (d) the STEMMUS-MODFLOW model with 16 soil columns.

The STEMMUS-MODFLOW-simulated spatial patterns of the phreatic surface solution agreed with that from VSF model simulations (Figure 6.10), although some slight deviations can be seen. MODFLOW alone, however, cannot reproduced the same spatial pattern in the two zones with infiltration and pumping.

\subsubsection{Maqu catchment simulation}

\subsubsection{Calibration results (1979-2018)}

By tuning the hydraulic conductivity zones, values, river conductance, we obtained the acceptable model results as shown in Figure 6.11. The relative errors between the simulated and observed heads are within $0.5 \mathrm{~m}$. MODFLOW-simulated water heads were highly correlated to the observed ones with $\mathrm{R}^{2}$ of 0.9996 and root mean square errors (RMSE) of $0.138 \mathrm{~m}$ (Figure 6.11 and Table 6.1). MODFLOW with the tuned hydraulic parameters well mimicked the spatial distribution of groundwater table depth. 
The calibration results were acceptable and the hydraulic parameters can be further used for the model intercomparison.
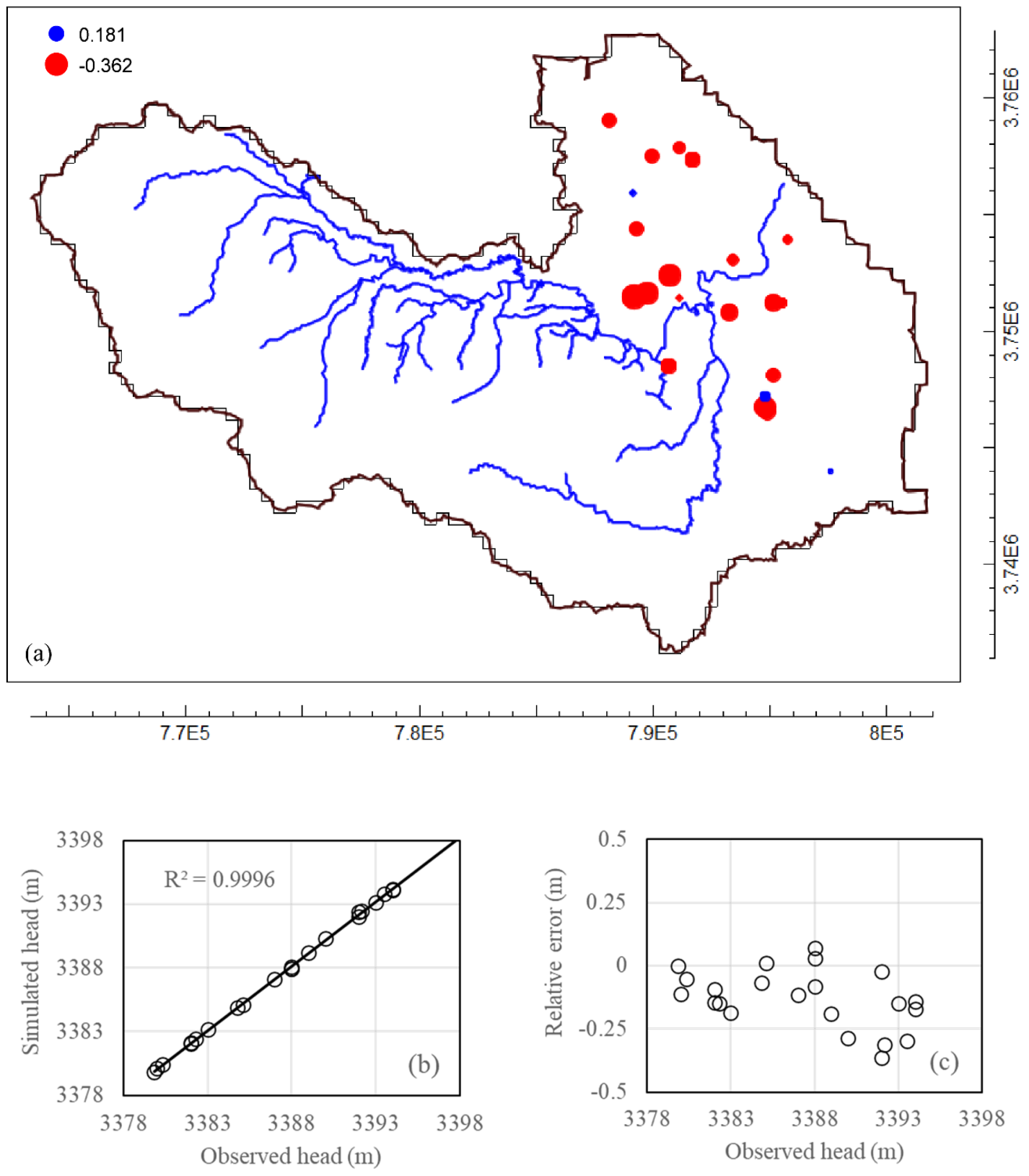

Figure 6.11. Model calibration results using MODFLOW for the long-term period against the water table observations of 5 August 2018: (a) spatial distribution of the relative errors, (b) correlation, and (c) relative bias between the observed and MODFLOW simulated hydraulic head. Unit is in $\mathrm{m}$. 
Table 6.1. Statistical performance of used models in terms of the spatial variation of groundwater table levels.

\begin{tabular}{lllll}
\hline Models & $\mathrm{R}^{2}$ & RMSE $(\mathrm{m})$ & MAE $(\mathrm{m})$ & Remarks \\
\hline MODFLOW & 0.9996 & 0.138 & 0.17 & Calibration (1979-2018) \\
\hline MODFLOW & 0.9987 & 0.203 & 0.15 & \\
HYDRUS-MODFLOW & 0.9811 & 0.946 & 0.754 & Simulation (2016-2018) \\
STEMMUS-MODFLOW & 0.9727 & 0.861 & 0.631 & \\
\hline
\end{tabular}

Note: $R^{2}=1-\frac{\sum_{i=1}^{n}\left(y_{i}-\widehat{y_{l}}\right)^{2}}{\sum_{i=1}^{n}\left(y_{i}-\bar{y}\right)^{2}}, M A E=\frac{\sum_{i=1}^{n}\left|y_{i}-\widehat{y_{l}}\right|}{n}, R M S E=\sqrt{\frac{\sum_{i=1}^{n}\left(y_{i}-\widehat{y_{l}}\right)^{2}}{n}}$, where $y_{i}, \widehat{y_{l}}$, are the measured and model simulated values of the groundwater table levels; $\bar{y}$ is the mean values of the measurements; $n$ is the number of data points.

\subsubsection{Intercomparison results}

\section{1) Spatial variation of groundwater table}

Table 6.1 shows the statistical performance of used models in producing the regional water table elevations. Slightly worse than the calibration results, both models (HYDRUS-MODFLOW and the coupled STEMMUS-MODFLOW) can well simulate the spatial distribution of the water table levels (the coefficient of determination are 0.9811 and 0.9727 , MAEs are 0.754 and $0.631 \mathrm{~m}$, RMSEs are 0.95 and $0.86 \mathrm{~m}$ for HYDRUS-MODFLOW and the STEMMUS-MODFLOW, respectively).

Figure 6.12 presents the spatial variations of water head elevations estimated by HYDRUS-MODFLOW and the STEMMUS-MODFLOW in August 2018. The hydraulic head elevations were simulated higher in the western mountain area, while lower in the eastern region. Water heads became lower approaching the river segments, indicating that groundwater flows toward the river. Two models produced the similar spatial patterns of hydraulic heads. 

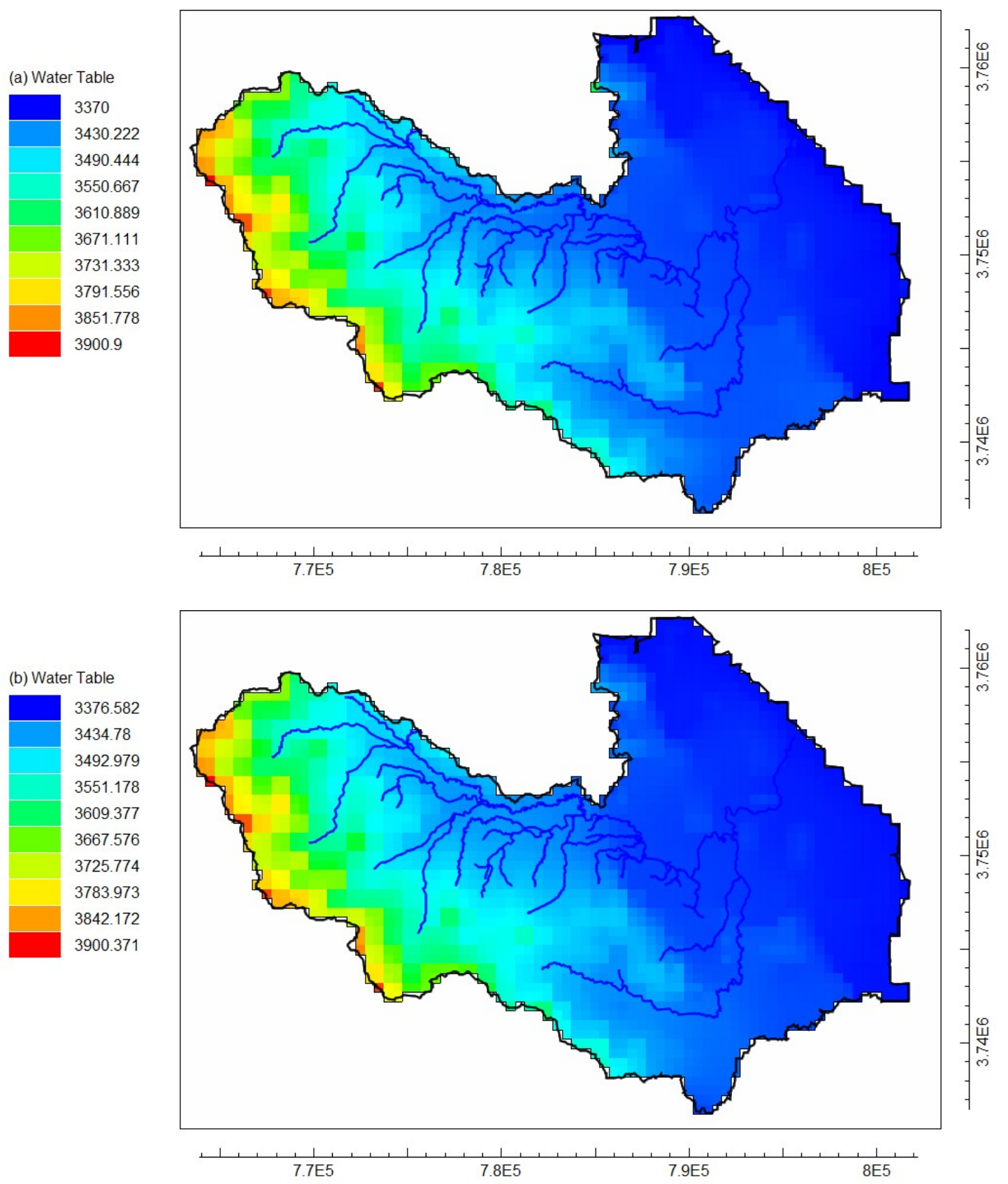

Figure 6.12. Comparison of elevation of water head solutions (the bottom layer) estimated by (a) HYDRUS-MODFLOW and (b) the STEMMUS-MODFLOW. Blue line is the river network.

\section{2) Time series of groundwater table}

One groundwater monitoring well was installed on 19 November 2017. The observed groundwater table levels were used to validate the model performance in reproducing the temporal dynamics of groundwater table depth (Figure 6.13). There is an increasing trend with time in the estimated groundwater table elevations by MODFLOW-Only and STEMMUS-MODFLOW models. The daily MODFLOW simulations show a seasonal fluctuation along the monthly simulation values with the maximums occurring during the September and minimums occurring in May. This corresponds to the seasonal 
patterns of $\mathrm{ET}_{0}$, i.e., larger values in May and smaller values in September. The observed groundwater levels, however, present a delayed maximum value, which may be induced by a pumping test conducted on 19 November 2017. Such water abstraction results in a drawdown of groundwater levels. Groundwater from the vicinity flows towards the pumping well and then recovers after the pumping test. Together with the recharge from precipitation, groundwater levels approach its maximum in February 2018. Groundwater level fluctuations estimated by MODFLOW at daily time scale agreed with the observed ones after May 2018, while there is an overestimation from MODFLOW simulations.

Compared to the MODFLOW estimated groundwater table elevations, STEMMUSMODFLOW produced lower groundwater table levels and lower seasonal fluctuations. It indicates a weaken precipitation recharging effect estimated from the STEMMUSMODFLOW. After May 2018, groundwater levels from the STEMMUS-MODFLOW agreed well with the observations.

The groundwater table elevation simulations from HYDRUS-MODFLOW, however, present a decreasing trend, which indicates that the effect of vadose zone was overestimated.

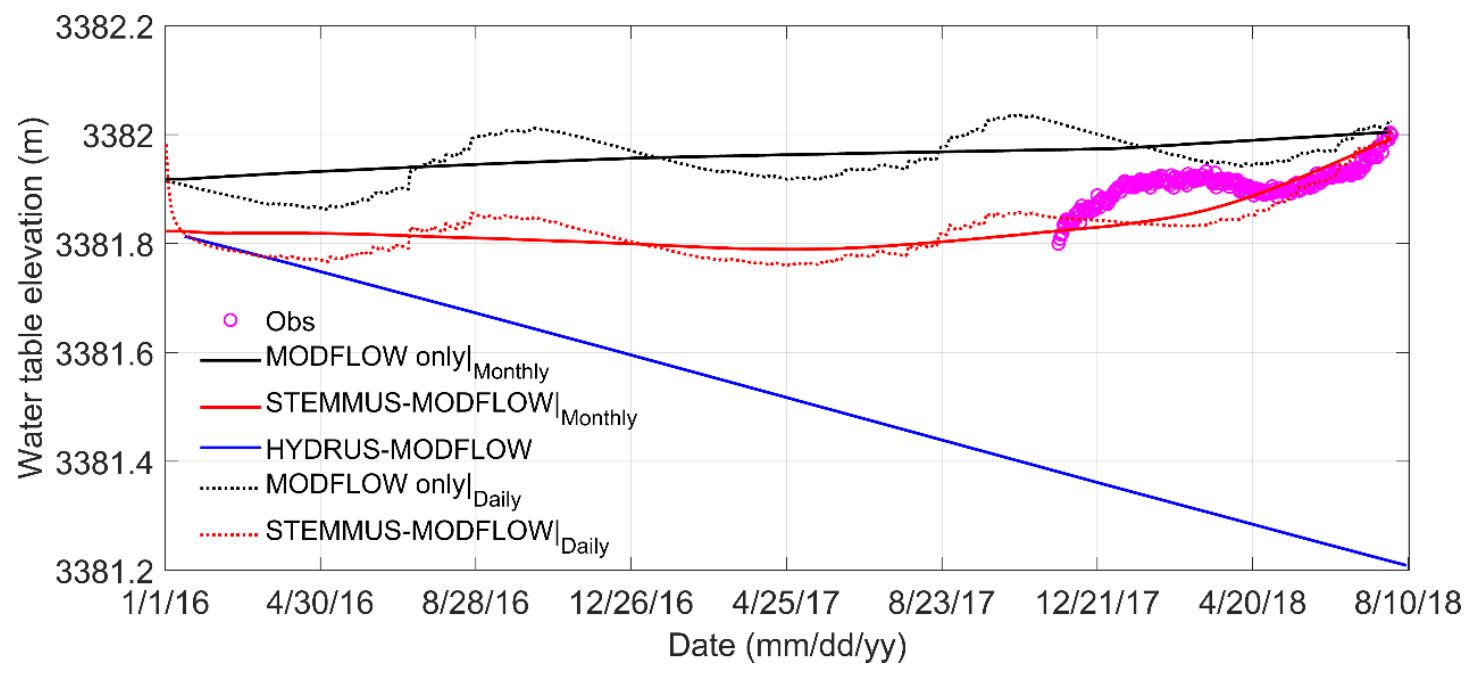

Figure 6.13. Comparison of the observed and model estimated water table elevation dynamics using MODFLOW only, HYDRUS-MODFLOW, and STEMMUSMODFLOW. The observed groundwater table levels are from the installed monitoring well. Note that the daily simulations using HYDRUS-MODFLOW was not shown due to numerical instability.

\section{3) Soil moisture profile}

The development of soil water profile is influenced by both the soil water and groundwater processes (Figure 6.14). The initial soil moisture profile is obtained from the assumed hydrostatic hydraulic head profile. Soil water content was low at the top surface layers, nonlinearly increased till the phreatic surface then remained saturated. 
HYDRUS simulations without MODFLOW were ran for model intercomparison in terms of unsaturated soil moisture profile. The phreatic surface remained unchanged from the HYDRUS simulations with zero bottom water flux $\left(B C=0 \mathrm{~m} \mathrm{~s}^{-1}\right)$. HYDRUS simulated soil moisture profile started to differ from the initial hydrostatic state at the soil depth of about $2 \mathrm{~m}$. Higher than $2 \mathrm{~m}$ in the profile, HYDRUS simulated soil moisture increased till the depth of $0.01 \mathrm{~m}$. This zone is more influenced by the surface meteorological forcing $(\mathrm{P}, \mathrm{ET}$ ) , termed soil water $(\mathrm{SW})$ zone here. It is affected by the surface hydrometeorological conditions, vadose zone soil hydraulic properties. For the HYDRUS simulations with water recharging $\left(B C=1 \mathrm{E}-8 \mathrm{~m} \mathrm{~s}^{-1}\right)$, groundwater table depth moved upwards. In contrast, groundwater level moved downwards given that water is flowing out of the soil bottom boundary $\left(\mathrm{BC}=-1 \mathrm{E}-8 \mathrm{~m} \mathrm{~s}^{-1}\right)$. There is no difference in the simulated unsaturated soil moisture between HYDRUS simulations with and without water recharge $\left(B C=0\right.$ and $\left.B C= \pm 1 E-8 \mathrm{~m} \mathrm{~s}^{-1}\right)$. Soil depth below the groundwater table depth is mainly affected by groundwater flow, termed groundwater (GW) zone here (Figure 6.14e). In-between the SW and GW zones, soil moisture remains unchanged comparing to the initial hydrostatic state, termed deep soil zone (DS) here.

Compared to the position of groundwater table depth at the initial time $(t=0)$, the HYDRUS-MODFLOW and STEMMUS-MODFLOW estimated end-time groundwater table depth was significantly shallow for subzone $1 \#, 7 \#$, and 41\#, while remained relatively steady for subzone $16 \#$, and 32\#. It indicates that soil columns of the subzone $1 \#, 7 \#$, and $41 \#$ are gaining water. Such amount of water increased deep zone soil moisture and even away from the initial hydrostatic conditions as the increase of recharging water (from subzone $1 \#$ to $7 \#$ and 41\#, GW zone increases while DS zone decreases and even disappears). Moving to upper soil layers, the soil moisture profile approaches the HYDRUS simulations as surface meteorological forcing is more dominant. Compared to the HYDRUS simulations, the SW zone becomes shallower as the decrease of groundwater table depth, which means that part of the SW zone is also affected by the groundwater table fluctuations (7\# and 41\#). HYDRUS-MODFLOW presents an increased SW zone for Subzone 1\#. With the decrease of groundwater table depth, the SW zone decreased from HYDRUS-MODFLOW simulations (from Subzone $1 \#$ to $7 \#$ and $41 \#)$.

Compared to the measured soil moisture profiles, HYDRUS model agreed well for Subzone 32\# while overestimated for Subzone 16\#. The STEMMUS-MODFLOW simulated soil moisture profile was mostly in the variation range of soil water content measurements for Subzone 16\# while underestimated for Subzone 32\#. Compared to the HYDRUS only simulations, the SW zone is losing water from the STEMMUSMODFLOW simulations (Figure $6.14 \mathrm{c} \& \mathrm{~d}$ ), which means the groundwater level increase (can be also seen in Figure 6.13). The soil moisture was overestimated by the 
HYDRUS-MODFLOW for Subzone 16\# and 32\#. SW zone from HYDRUSMODFLOW simulations is gaining water from the phreatic aquifer (corresponding to the declining trend of groundwater table elevations in Figure 6.13). These discrepancies can be attributed to that the exchange of information across the SW-GW interface is not realistically delivered by the HYDRUS-MODFLOW (Beegum et al., 2018; Brandhorst et al., 2021).

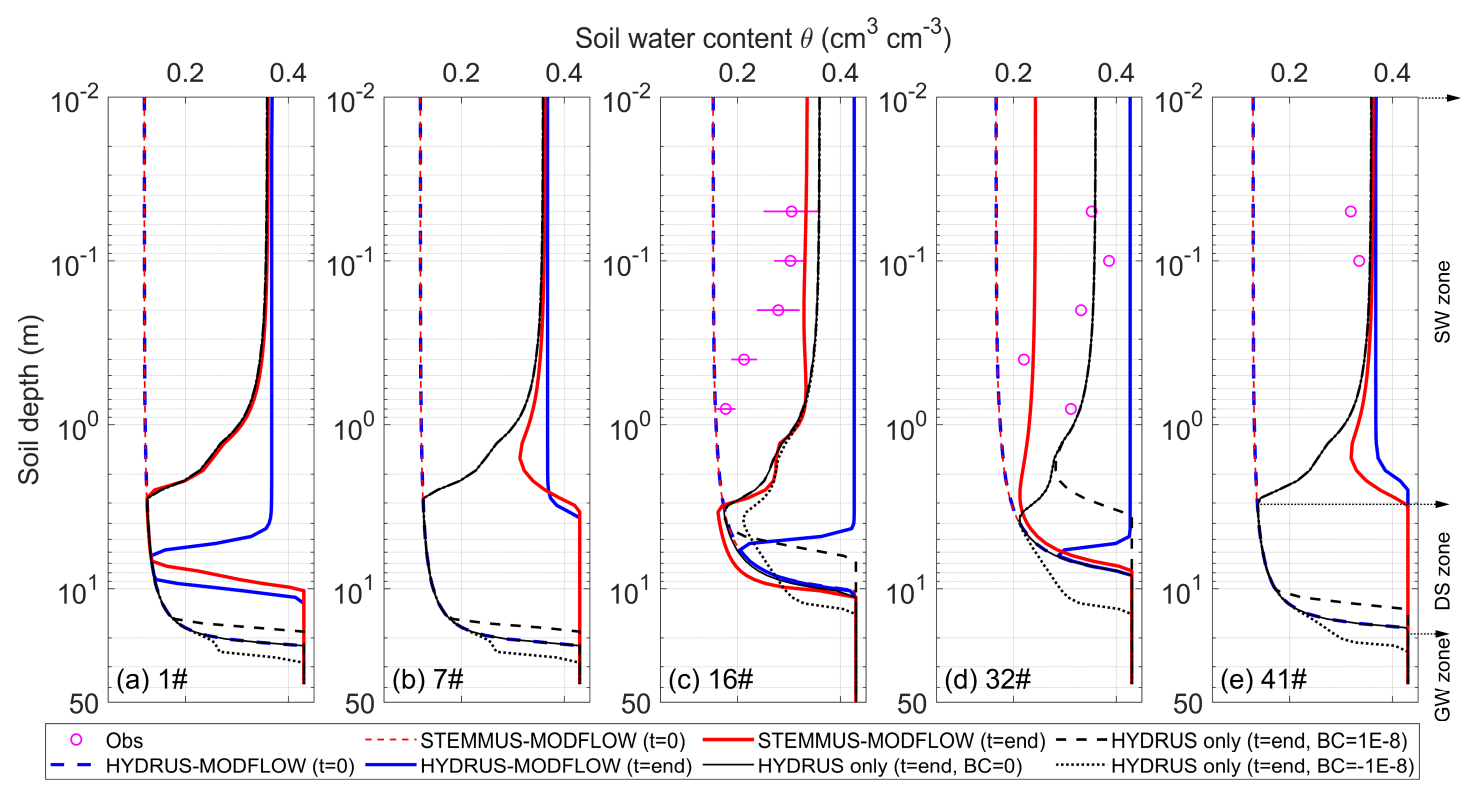

Figure 6.14. Comparison of soil water content profiles, of subzones (a) 1\#, (b) 7\#, (c) 16\#, (d) 32\#, (e) 41\#, from the soil moisture measurements (Obs) and estimated by HYDRUS-MODFLOW and the STEMMUS-MODFLOW at the start and end time. HYDRUS model (without MODFLOW) simulations together with different bottom boundary fluxes $\left(\mathrm{BC}=0,1 \mathrm{E}-8\right.$, and $\left.-1 \mathrm{E}-8 \mathrm{~m} \mathrm{~s}^{-1}\right)$ were used as reference. $\mathrm{GW}$, DS, and $\mathrm{SW}$ zone represents groundwater, deep soil, and soil water zone. The exemplary zone division is based on HYDRUS only simulation $\left(\mathrm{t}=0, \mathrm{BC}=0 \mathrm{~m} \mathrm{~s}^{-1}\right)$.

\subsection{Discussion}

\subsubsection{Role of vadose zone processes}

Given precipitation/snowfall, water flow processes include surface/subsurface runoff, infiltration, root water uptake, and evaporation, and some will eventually drain as groundwater recharge. Considering the spatiotemporal dynamics, the water flow is highly variable depending on the hydrologic, geologic, and soil hydrothermal conditions. Thus, it results in a heterogenous groundwater recharge/discharge, i.e., SWGW interactions. Without considering the vadose zone, groundwater table will be underestimated/overestimated as no groundwater recharge/discharge was simulated (see Figure 6.8). This affects the entire groundwater system with damping influence as depth goes deeper. Such bias can be alleviated by considering the SW-GW interactions homogeneously (i.e., one soil column for STEMMUS-MODFLOW). Only by the proper consideration of the heterogeneous SW-GW interactions, the groundwater table 
can be realistically produced (Figure 6.8). Adding the infiltration process, the situation can be more complex. The soil infiltration water recharges the groundwater system and enhances the SW-GW interactions (Mao et al., 2019). The phreatic surface is the dynamic balance between the infiltration and SW-GW interaction processes. Other than the infiltration process, the heterogeneity of vadose zone flow and SW-GW interaction process were identified and should be well represented to produce the groundwater flow dynamics in space and time (Figure 6.8 \& 6.9). The soil water balance approach (e.g., REC-ET package in MODFLOW), simply assigning the groundwater surface boundary as the resident of water budget equation, cannot reproduce the realistic groundwater table dynamics. It is because that not only the vadose zone process is neglected by water budget approach (i.e., no infiltration, no capillary pressure driven flow, Gee \& Hillel, 1988; Twarakavi et al., 2008) but also the heterogeneity of the vadose zone flow (Mao et al., 2019) and SW-GW interactions is overlooked (Figure $6.8 \& 6.9$ ). For the SWGW coupled modelling development, it is suggested to be verified not only based on its vadose zone flow process, applicability to different spatial and temporal scales and various meteorological and climatic conditions (Twarakavi et al., 2008), but also should take into account the capability in mimicking the dynamic and heterogenous SW-GW interactions.

\subsubsection{The effect of SW-GW coupling approach}

To mathematically implement the SW-GW interaction process, various efforts have been made (Seo et al., 2007; Twarakavi et al., 2008; Zhu et al., 2012; Zeng et al., 2019). In this work, three SW-GW coupling approach, i.e., simple coupling (REC-ET packages for MODFLOW), one way coupling (HYDRUS-MODFLOW), and two-way feedback coupling, were intercompared in a cold region catchment. From current available dataset, three methods can well reproduce the spatial variation of groundwater heads (Table 6.2). For the temporal dynamics, REC-ET packages for MODFLOW overestimated the groundwater table levels (Figure 6.13), indicating that the effect of vadose zone flow process is underestimated. HYDRUS-MODFLOW, in contrast, underestimated the groundwater table elevations. As argued by (Beegum et al., 2018), HYDRUS-MODFLOW suffers from the problem that the exchange quantities of the unsaturated and saturated zone are inconsistent, which can result in the sudden inflow or outflow of the vadose zone and accumulative errors. The other reason can be attributed to the fixed 1D soil column depth, which may produce more lateral groundwater flux into the unsaturated zone model (Seo et al., 2007). The STEMMUSMODFLOW generally matches the groundwater table depth measurements, which is also found consistent with soil moisture profile measurements (Figure 6.14). It demonstrates the validity of the coupling method. The adopted coupling method overcomes the scale-mismatch of exchange quantities and minimize the coupling errors 
due to the nontrivial lateral water flux across the saturated zones of soil columns (Zeng et al., 2019).

\subsubsection{The limitations and outlook}

The current work presented a coupled soil water-groundwater model and verified its performance using two test cases (using the fully 3D VSF model simulations as the truth) and one real world catchment case (taking groundwater table depth and soil moisture profile measurements as the truth). By the cross validation among the observations, and various models, the STEMMUS-MODFLOW is found physically accurate and applicable in regional scale groundwater problems. In addition, the role of vadose zone processes, groundwater flow, coupling approach, and SW-GW interactions was highlighted.

However, regional groundwater simulations in Maqu are with uncertainties and require more effort to confirm the simulation results. More datasets are needed to better constrain and validate this reginal groundwater modelling case, including the reliable meteorological forcing $\left(\mathrm{ET}_{0}, \mathrm{P}\right)$ at desirable time and space scales, time series of groundwater table depth measurements, river flow, soil moisture profile measurement, and subsurface hydraulic property profile information.

On the other hand, soil thermal effect is important not only in the vadose zone but also in the groundwater system under certain conditions. Xie et al. (2021) demonstrated the important role of freezing-induced water migration in shallow groundwater systems under semi-arid climate conditions. Lateral water inflow resulted in the groundwater level rise and further enhanced the freezing-induced groundwater migration. The permafrost dynamics alter the groundwater and surface water exchange and groundwater discharge to the surface was three-fold increased in northern Tibet Plateau under the increasing air temperature scenario, which are mainly temperature driven (Ge et al., 2011; Evans \& Ge, 2017). Moreover, temperature has been identified as a useful tracer for inferring groundwater fluxes (Bense \& Kurylyk, 2017; Bense et al., 2017; Irvine et al., 2017; Kurylyk et al., 2017; Kurylyk \& Irvine, 2019; Bense et al., 2020).

Current SW-GW modelling work hardly considers the thermal effect and lacks realworld applications and verifications (see Appendix Table A4.2). The developed SWGW coupling model in this work facilitates the manipulation of sub-models with different complexity of vadose zone physics (thermal flow, soil water and heat coupling transfer, freeze-thaw, airflow processes), surface hydrology (snowfall, runoff), connection with other relevant processes (soil and plant biogeochemical process), towards an integrated groundwater-soil-plant-atmosphere earth system modelling framework. Given the relevant dataset, the developed SW-GW modelling framework has the potential to answer the following questions: to what extent does the soil thermal 
regimes affect groundwater flow? How and to what extent does the groundwater system affect vadose zone water, heat, and carbon transfer?

\subsection{Conclusion}

The performance of the coupled soil water and groundwater model is verified using two test cases and the Maqu catchment observatory. Vadose zone process and the heterogeneity of soil water-groundwater interactions is demonstrated important in reproducing the water table fluctuation dynamics. Realistic zonation and parameterization of unsaturated soil columns helps to enhance the model performance. Compared to HYDRUS-MODFLOW, the STEMMUS-MODFLOW produces a similar spatial distribution of hydraulic heads. However, better performance was found in mimicking the temporal dynamics of groundwater table depth and soil moisture profiles. This improved performance is due to the different coupling strategies across the soilwater and groundwater interface. It is suggested to adopt the moving phreatic boundary, two-way iterative feedback coupling scheme and multi-scale analysis to maintain the physical rational and reduce the coupling errors. The developed coupling framework has demonstrated its applicability and can be further equipped with different complexity of vadose zone physics (thermal flow, soil water and heat coupling transfer, freezethaw, airflow processes), surface hydrology (snowfall, runoff), soil and plant biogeochemical process, towards an integrated groundwater-soil-plant-atmosphere earth system modelling framework. 


\section{Chapter 7 Effect of vadose zone physics on ecosystem functioning*}

* This chapter is based on: Yu, L., Fatichi, S., Zeng, Y., \& Su, Z. (2020). The role of vadose zone physics in the ecohydrological response of a Tibetan meadow to freezethaw cycles. The Cryosphere, 14(12), 4653-4673. doi:10.5194/tc-14-4653-2020 


\section{Abstract}

The vadose zone is a zone sensitive to environmental changes and exerts a crucial control in ecosystem functioning and even more so in cold regions considering the rapid change in seasonally frozen ground under climate warming. While the way in representing the underlying physical process of the vadose zone differs among models, the effect of such differences on ecosystem functioning and its ecohydrological response to freeze-thaw cycles are seldom reported. Here, the detailed vadose zone process model STEMMUS (Simultaneous Transfer of Energy, Mass and Momentum in Unsaturated Soil) was coupled with the ecohydrological model Tethys-Chloris (T\&C) to investigate the role of influential physical processes during freeze-thaw cycles. The physical representation is increased from using T\&C coupling without STEMMUS enabling the simultaneous mass and energy transfer in the soil system (liquid, vapor, ice) - and with explicit consideration of the impact of soil ice content on energy and water transfer properties - to using T\&C coupling with it. We tested model performance with the aid of a comprehensive observation dataset collected at a typical meadow ecosystem on the Tibetan Plateau. Results indicated that (i) explicitly considering the frozen soil process significantly improved the soil moisture/temperature profile simulations and facilitated our understanding of the water transfer processes within the soil-plant-atmosphere continuum; (ii) the difference among various representations of vadose zone physics have an impact on the vegetation dynamics mainly at the beginning of the growing season; and (iii) models with different vadose zone physics can predict similar interannual vegetation dynamics, as well as energy, water, and carbon exchanges, at the land surface. This research highlights the important role of vadose zone physics for ecosystem functioning in cold regions and can support the development and application of future Earth system models. 


\subsection{Introduction}

Recent climatic changes have accelerated the dynamics of frozen soils in cold regions, as for instance favoring permafrost thawing and degradation (Cheng \& $\mathrm{Wu}, 2007$; Hinzman et al., 2013; Peng et al., 2017; Yao et al., 2019; Zhao et al., 2019). As a consequence of these changes, vegetation cover and phenology, land surface water and energy balances, subsurface soil hydrothermal regimes, and water flow pathways were reported to be affected (Wang et al., 2012; Schuur et al., 2015; Walvoord \& Kurylyk, 2016; Gao et al., 2018; Campbell \& Laudon, 2019). Understanding how an ecosystem interacts with changing environmental conditions is a crucial yet challenging problem of Earth system research for high latitude/altitude regions which deserves further attention.

Land surface models, terrestrial biosphere models, ecohydrology models, and hydrological models have been widely utilized to enhance our knowledge in terms of land surface processes, ecohydrological processes (Fatichi \& Ivanov, 2014; Fatichi et al., 2016a), and freezing and thawing (FT) processes (Ekici et al., 2014; Wang et al., 2017b; Cuntz \& Haverd, 2018; Wang \& Yang, 2018; Druel et al., 2019). By either incorporating a permafrost model into the ecosystem model (Zhuang et al., 2001; Wania et al., 2009; Lyu \& Zhuang, 2018) or equipping the soil model with vegetation dynamics and carbon processes (Zhang et al., 2018), the temporal dynamics of soil temperature, permafrost dynamics and vegetation and carbon dynamics can be simultaneously simulated over cold region ecosystems. Moreover, the incorporation of detailed vadose zone and land surface processes (e.g., soil hydrology and snow cover) usually improves the model performance (Lyu \& Zhuang, 2018) and facilitates model's ability to investigate the ecosystem response to variations in climatic and environmental conditions at various spatial-temporal scales (Zhang et al., 2018). The importance of non-growing-season processes (e.g., freeze-thaw cycle, snow cover) was highlighted when interpreting the carbon budget observations and can significantly alter the carbon cycling and future projection of cold region ecosystems (Zhuang et al., 2001; Wania et al., 2009; Lyu \& Zhuang, 2018; Zhang et al., 2018).

However, in most of the current modelling research in cold region ecosystems, the water and heat transfer process in the vadose zone remains independent and not fully coupled. Such consideration of vadose zone physics might result in unrealistic physical interpretations, especially for soil freezing and thawing processes (Hansson et al., 2004). In this regard, researchers have stressed the necessity to simultaneously couple the water and heat transfer process in dry/cold seasons (Scanlon \& Milly, 1994; Bittelli et al., 2008; Zeng et al., 2009a; Zeng et al., 2009b; Yu et al., 2016; Yu et al., 2018). Concurrently, researchers developed dedicated models, e.g., SHAW (Flerchinger \& Saxton, 1989), HYDRUS (Hansson et al., 2004), MarsFlo (Painter, 2011) and its successor Advanced Terrestrial Simulator (Painter et al., 2016), and Simultaneous 
Transfer of Energy, Mass and Momentum in Unsaturated Soil with Freezing and Thawing (STEMMUS-FT) (Yu et al., 2018; Yu et al., 2020b), implementing the soil water and heat coupling physics for frozen soils (see reviews of the relevant models in Kurylyk and Watanabe, 2013; Grenier et al., 2018; Lamontagne-Halle et al., 2020). Promising simulation results have been reported for the soil hydrothermal regimes. While these efforts mainly focus on understanding the surface and subsurface soil water and heat transfer process (Yu et al., 2018; Yu et al., 2020b) and stress the role of physical representation of freezing/thawing process (Boone et al., 2000; Wang et al., 2017b; Zheng et al., 2017), they rarely take into account the interaction with vegetation and carbon dynamics.

With the largest area of high-altitude permafrost and seasonally frozen ground, Tibetan Plateau is recognized as one of the most sensitive regions for climate change (Liu \& Chen, 2000; Cheng \& Wu, 2007; Yao et al., 2019). Monitoring and projecting the dynamics of hydrothermal and ecohydrological states and their responses to climate change on the Tibetan Plateau are important to help shed light on future ecosystem responses in this region. Considerable land-surface and vegetation changes have been reported in this region, e.g., degradation of permafrost and variations in seasonally frozen ground thickness (Cheng \& Wu, 2007; Yao et al., 2019), advancing vegetation leaf onset dates (Zhang et al., 2013a), and enhanced vegetation activity at the start of growing season (Qin et al., 2016). However, there are divergences with regard to the expected ecosystem changes across the Tibetan Plateau (Cheng \& Wu, 2007; Zhao et al., 2010; Qin et al., 2016; Wang et al., 2018a). In response to climate warming, the degradation of frozen ground can positively affect the vegetation growth in mountainous regions (Qin et al., 2016), but it can also lead to degradation of grasslands (Cheng and $\mathrm{Wu}, 2007$ ), depending on soil hydrothermal regimes and climate conditions (Qin et al., 2016; Wang et al., 2016).

In this chapter, we investigated the consequences of considering coupled water and heat transfer processes on land-surface fluxes and ecosystem dynamics in the extreme environmental conditions of the Tibetan Plateau, relying on land-surface and ecohydrological models confronted with multiple field observations. The inclusion or exclusion of different soil physical processes, i.e., explicitly considering the effect of soil ice content on hydrothermal properties and the tightly coupled water and heat transfer, in such environment frames the scope here. Specifically, the leading questions of the research are as follows. (i) How do different representations of frozen soil and coupled water and heat physics affect the simulated ecohydrological dynamics of a Tibetan Plateau meadow? (ii) How does different vadose zone physics affect our interpretation of mass, energy, and carbon fluxes in the ecosystem? Answering these two questions enables evaluation of the adequacy of models in simulating feedbacks among processes and ecosystem changes across the Tibetan Plateau. 
In order to achieve the aforementioned goals, the detailed soil mass and energy transfer scheme developed in the STEMMUS model (Zeng et al., 2011a, b; Zeng and Su, 2013) was incorporated into the ecohydrology model Tethys-Chloris (T\&C) (Fatichi et al., 2012a, b). The frozen soil physics was explicitly taken into account and soil water and heat transfer were fully coupled to further facilitate the model's capability in dealing with complex vadose zone processes.

\subsection{Experimental site and data}

\subsubsection{General description}

For this research, data from March 2016 to August 2018 collected at the central experimental site $\left(33^{\circ} 54^{\prime} 59^{\prime \prime} \mathrm{N}, 102^{\circ} 09^{\prime} 32^{\prime}\right.$, elevation: $\left.3430 \mathrm{~m}\right)$ were utilized (see Figure 2.1). Seasonally frozen ground is characteristic of this site, with the maximum freezing depth approaching around $0.8 \mathrm{~m}$ under current climate conditions. The dedicated SMST profile (central station, Figure 2.1), with sensors installed at depths of $2.5 \mathrm{~cm}, 5 \mathrm{~cm}, 10$ $\mathrm{cm}, 20 \mathrm{~cm}, 40 \mathrm{~cm}, 60 \mathrm{~cm}$, and $100 \mathrm{~cm}$, was used for validating the model simulations. Note that there are data gaps (25 March-8 June 2016 and 29 March-27 July 2017, extended to 12 August 2018 for $40 \mathrm{~cm}$ ) due to the malfunction of instruments and the difficulty of maintaining the network under such harsh environmental conditions.

\subsubsection{Data}

\subsubsection{Land surface energy and carbon fluxes and vegetation dynamics}

Starting from the raw $N E E$ (net ecosystem exchange) and ancillary meteorological data (friction velocity $u_{*}$, global radiation $R_{g}$, soil temperature $T_{\text {soil }}$, air temperature $T_{\text {air }}$, and vapor pressure deficit $V P D$ ), we employed the REddyProc package (Reichstein et al., 2005; Wutzler et al., 2018) as a postprocessing tool to obtain the time series of NEE, GPP (gross primary production) and ecosystem respiration $R_{\text {eco }}$ dynamics. Three different techniques, $u_{*}$ filtering, gap filling, and flux partitioning, were adopted in REddyProc package. The periods with low turbulent mixing were firstly determined and filtered for quality control ( $u_{*}$ filtering, Papale et al., 2006). Then, considering the covariation of fluxes with meteorological variables and the temporal autocorrelation of fluxes, the marginal distribution sampling algorithm was used as the gap-filling method to replace the missing data (Reichstein et al., 2005). Three cases were identified according to the availability of $R_{g}, T_{\text {air }}$, and $V P D$ : Case $1, R_{g}, T_{\text {air }}$, and $V P D$ data are available; for case 2, only $R_{g}$ data are available; and for case 3, none of the $R_{g}, T_{\text {air }}$, and $V P D$ data are available. A lookup table (LUT) method was used to search for the similar meteorological conditions (i.e., under which $R_{g}, T_{\text {air }}$, and $V P D$ do not deviate by more than $50 \mathrm{~W} \mathrm{~m}^{-2}, 2.5{ }^{\circ} \mathrm{C}$, and $5 \mathrm{hPa}$, respectively, for case 1) within a certain time window. The average value of $N E E$ under these similar meteorological conditions 
was used to replace the missing gaps. The time window size started from $7 \mathrm{~d}$ and extended to $14 \mathrm{~d}$ if no similar meteorological conditions were detected. A similar LUT approach was utilized for case 2, and similar meteorological conditions were determined only by $R_{g}$ within a time window of $7 \mathrm{~d}$. For case 3 , the missing value of $N E E$ was replaced by the average value of adjacent hours (within $1 \mathrm{~h}$ ) on the same day or at the same time of the day, which was derived from the mean diurnal course within $2 \mathrm{~d}$. The aforementioned three steps were repeated with increased window sizes until the missing value could be properly filled. Finally, $N E E$ was separated into GPP and $R_{e c o}$ by nighttime based and daytime-based approaches (Lasslop et al., 2010). Land surface energy fluxes $(L E, H)$ were processed simultaneously using the aforementioned $u_{*}$ filtering and gap filling methods with the REddyProc package.

Furthermore, we downloaded MCD15A3H (Myneni et al., 2015) and MOD17A2H (Running et al., 2015) products for this site as the auxiliary ecosystem carbon and vegetation dynamics data, from the Oak Ridge National Laboratory Distributed Active Archive Center (ORNL DAAC) website. MCD15A3H provides an estimation of $8 \mathrm{~d}$ composites of LAI (leaf area index) and FAPAR (fraction of absorbed photosynthetically active radiation), while MOD17A2H provides an $8 \mathrm{~d}$ composite of $G P P$ (gross primary production). Both MODIS products are at a resolution of $500 \mathrm{~m}$.

\subsubsection{Precipitation, evapotranspiration, and frost front}

The observed surface water conditions over the entire study period, including the precipitation and cumulative evapotranspiration (which is obtained by summing up the hourly latent heat flux measured by eddy covariance system), are shown in Figure 7.1a. Both ET and precipitation are low until the end of the freezing period (see Figure 7.1b), during this early period the daily average ET is $0.15 \mathrm{~mm} \mathrm{~d}^{-1}$. During the growing season, the cumulative precipitation increases and ET follows at a lower rate. The average daily ET for the entire observation period is $1.45 \mathrm{~mm} \mathrm{~d}^{-1}$.

Figure $7.1 \mathrm{~b}$ presents the development of freezing depth with time. Several freezing and thawing cycles frequently occurred at the beginning of the winter, which initializes the freezing and thawing process. The freezing front started to propagate at an average rate of 1.34 and $0.86 \mathrm{~cm} \mathrm{~d}^{-1}$, reaching its maximum depth at around 80 and $70 \mathrm{~cm}$ for the years 2016-2017 and 2017-2018, respectively. Then the thawing process was activated by the atmospheric forcing at the surface and subsurface soil heat flux at the bottom of the soil. 


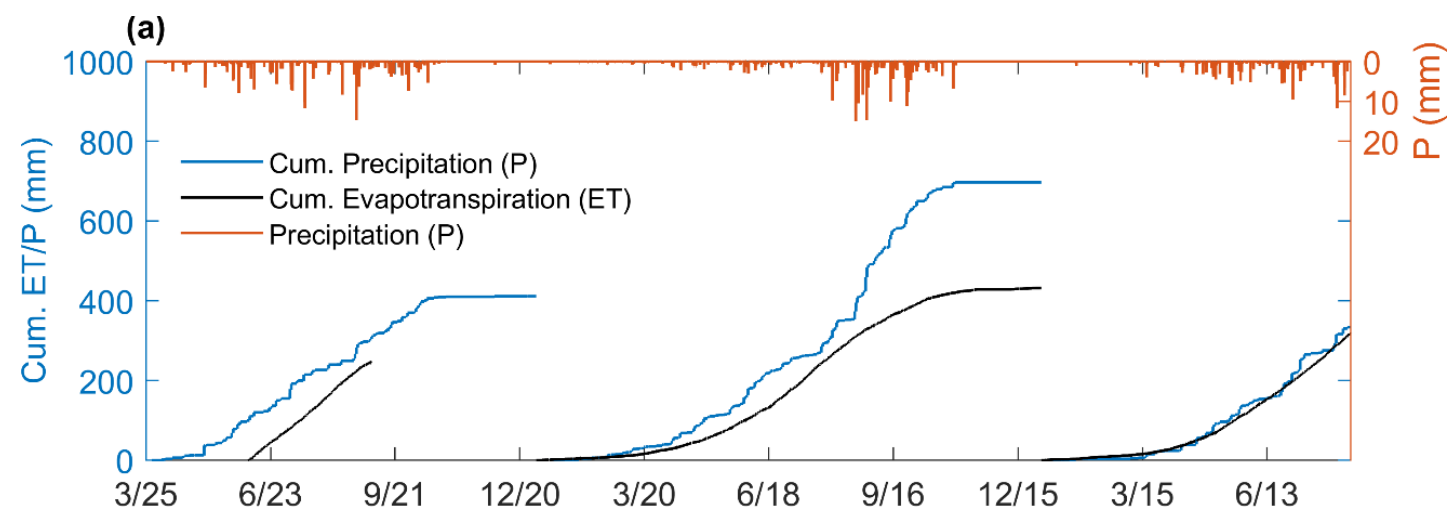

(b)

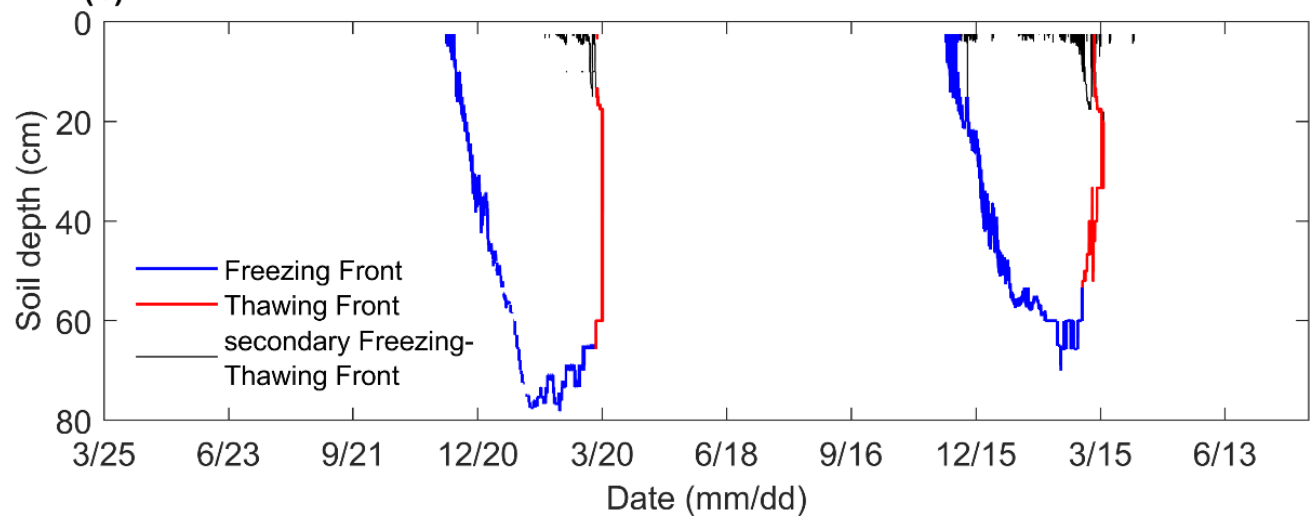

Figure 7.1. (a) Observed cumulative precipitation (P) and evapotranspiration (ET) and (b) observed propagation of the freezing and thawing front, with blue, red, and black colors signifying the primary propagation of freezing front and thawing front (FF and $\mathrm{TF}$ ) and the secondary freezing and thawing front (sFTF) occurring at top soil layers, respectively, for the period 25 March 2016-12 August 2018 at the Maqu site.

\subsection{Modelling the soil-plant-atmosphere continuum}

\subsubsection{T\&C model (unCPLD)}

The Tethys-Chloris model (T\&C) (Fatichi et al., 2012a; b) simulates the dynamics of energy, water, and vegetation and has been successfully applied to a very large spectrum of ecosystems and environmental conditions (Fatichi \& Ivanov, 2014; Fatichi et al., 2016b; Pappas et al., 2016; Fatichi \& Pappas, 2017; Mastrotheodoros et al., 2017). The model simulates the energy, water, and carbon exchanges between the land surface and the atmospheric surface layer accounting for aerodynamic, undercanopy, and leaf boundary layer resistances, as well as for stomatal and soil resistance. The model further describes vegetation physiological processes including photosynthesis, phenology, carbon allocation, and tissue turnover. Dynamics of water content in the soil profile in the plot-scale version are solved using the one-dimensional (1-D) Richards equation. Heat transfer in the soil is solved by means of the heat diffusion equation. Soil heat and water dynamics are uncoupled (however, note that $\mathrm{T} \& \mathrm{C}$ is termed unCPLD to distinguish it later from the coupling with STEMMUS). The detailed model description 
is provided in the above-mentioned references and some key elements applied for this study are explained in the following.

The T\&C model uses the 1-D Richards equation, which describes the water flow under gravity and capillary forces in isothermal conditions for variably saturated soils:

$$
\rho_{L} \frac{\partial \theta}{\partial t}=-\frac{\partial q}{\partial z}-S=\rho_{L} \frac{\partial}{\partial z}\left[K\left(\frac{\partial \psi}{\partial z}+1\right)\right]-S
$$

where $\theta\left(\mathrm{m}^{3} \mathrm{~m}^{-3}\right)$ is the volumetric water content; $q\left(\mathrm{~kg} \mathrm{~m}^{-2} \mathrm{~s}^{-1}\right)$ is the water flux; $z(\mathrm{~m})$ is the vertical direction coordinate; $S\left(\mathrm{~kg} \mathrm{~m}^{-3} \mathrm{~s}^{-1}\right)$ is the sink term for transpiration and evaporation fluxes. $\rho_{L}\left(\mathrm{~kg} \mathrm{~m}^{-3}\right)$ is the liquid water density; $K\left(\mathrm{~m} \mathrm{~s}^{-1}\right)$ is the soil hydraulic conductivity; $\psi(\mathrm{m})$ is the soil water potential; $t(\mathrm{~s})$ is the time. In T\&C, the nonlinear partial differential equation is solved using a finite volume approach with the method of lines (MOL) (Lee et al., 2004). MOL discretizes the spatial domain and reduces the partial differential equation to a system of ordinary differential equations in time, which can be expressed as follows:

$$
d_{z, i} \frac{d \theta_{i}}{d t}=q_{i-1}-q_{i}-T_{v} r_{v, i}-E_{s}-E_{\text {bare }}
$$

where $d_{z, i}(\mathrm{~m})$ is the thickness of layer $i ; q_{i}\left(\mathrm{~m} \mathrm{~s}^{-1}\right)$ is the vertical outflow from a layer $i ; T_{v}\left(\mathrm{~m} \mathrm{~s}^{-1}\right)$ is the transpiration fluxes from the vegetation; $r_{v, i}$ is the fraction of root biomass contained in soil layer $i$; $E_{b a r e}\left(\mathrm{~m} \mathrm{~s}^{-1}\right)$, evaporation from the bare soil; $E_{s}\left(\mathrm{~m} \mathrm{~s}^{-}\right.$ ${ }^{1}$ ), evaporation from soil under the canopy.

The heat conservation equation used in the T\&C neglects the coupling of water and heat transfer physics and only the heat conduction component is considered, which can be expressed as follows:

$$
\rho_{\text {soil }} C_{\text {soil }} \frac{\partial T}{\partial t}=\frac{\partial}{\partial z}\left(\lambda_{\text {eff }} \frac{\partial T}{\partial z}\right)
$$

where $\rho_{\text {soil }}\left(\mathrm{kg} \mathrm{m}^{-3}\right)$ is the bulk soil density; $C_{\text {soil }}\left(\mathrm{J} \mathrm{kg}^{-1} \mathrm{~K}^{-1}\right)$ is the specific heat capacities of bulk soil; $\lambda_{\text {eff }}\left(\mathrm{W} \mathrm{m}^{-1} \mathrm{~K}^{-1}\right)$ is the effective thermal conductivity of the soil. $T(\mathrm{~K})$ is the soil temperature. When soil undergoes freezing and thawing processes, the latent heat flux due to water phase change becomes important, which is not considered in the original T\&C model, but it is in the T\&C-FT (freezing/thawing) model.

\subsubsection{T\&C-FT model (unCPLD-FT)}

To account for frozen soil physics, T\&C-FT model considers ice effect on hydraulic conductivity, thermal conductivity, heat capacity, and subsurface latent heat flux. However, the vapor flow and the thermal effect on water viscosity are not considered in T\&C-FT, and during the non-frozen period, soil water and heat are still independently transferred as in T\&C (this version is named here unCPLD-FT). To explicitly account for freezing and thawing processes, the heat conservation equation is written as follows: 


$$
\rho_{\text {soil }} C_{\text {soil }} \frac{\partial T}{\partial t}-\rho_{\text {ice }} L_{f} \frac{\partial \theta_{\text {ice }}}{\partial t}=\frac{\partial}{\partial z}\left(\lambda_{\text {eff }} \frac{\partial T}{\partial z}\right)
$$

where the latent heat associated with the freezing and thawing processes is explicitly considered and ice water content $\theta_{i c e}$ is a prognostic variable, which is simulated along with liquid water content for each soil layer. Specifically, when Eq. (7.4) is rewritten in terms of an apparent volumetric heat capacity $C_{a p p}$ (Hansson et al., 2004; Gouttevin et al., 2012), it can be solved equivalently to Eq. (7.3):

$$
C_{a p p} \frac{\partial T}{\partial t}=\frac{\partial}{\partial z}\left(\lambda_{e f f} \frac{\partial T}{\partial z}\right)
$$

where $C_{\text {app }}$ can be computed knowing the temperature $T(\mathrm{~K})$, latent heat of fusion $L_{f}$ and the differential (specific) water capacity $\mathrm{d} \theta / \mathrm{d} \psi$ at a given liquid water content $\theta$ (Hansson et al., 2004):

$$
C_{a p p}=\rho_{\text {soil }} C_{\text {soil }}+\rho_{\text {ice }} \frac{L_{f}^{2}}{g T} \frac{d \theta}{d \psi}
$$

The effective thermal conductivity $\lambda_{\text {eff }}\left(\mathrm{W} \mathrm{m}^{-1} \mathrm{~K}^{-1}\right)$ and the specific soil heat capacity $C_{\text {soil }}\left(\mathrm{J} \mathrm{kg}^{-1} \mathrm{~K}^{-1}\right)$ are computed accounting for solid particles, water, and ice content (Johansen, 1975; Farouki, 1981; Lawrence et al., 2018; Yu et al., 2018). The soil freezing characteristic curve providing the liquid water potential in frozen soil is computed following the energy conservative solution proposed by Dall'Amico et al. (2011) and it can be combined with various soil hydraulic parameterizations including van Genuchten (1980) and Saxton and Rawls (2006) to compute the maximum liquid water content at a given temperature and consequently ice and liquid content profiles at any time step (Fuchs et al., 1978; Yu et al., 2018).

Finally, saturated hydraulic conductivity is corrected in the presence of ice content (e.g., Hansson et al., 2004; Yu et al., 2018). Note that beyond latent heat associated with phase change and changes in thermal and hydraulic parameters because of ice presence, all the other soil physics processes described by STEMMUS are not considered here, and heat and water fluxes are still not entirely coupled in T\&C-FT.

\subsubsection{STEMMUS model}

The Simultaneous Transfer of Energy, Mass and Momentum in Unsaturated Soil (STEMMUS) model solves soil water and soil heat balance equations simultaneously in one time step (Zeng et al., 2011a, b; Zeng and Su, 2013). The Richards equation with modifications made by Milly (1982) is utilized to mimic the coupled soil mass and energy transfer process. The vapor diffusion, advection, and dispersion are all taken into account as water vapor transport mechanisms. The root water uptake process is regarded as the sink term of soil water and heat balance equations, building up the linkage between soil and atmosphere ( $\mathrm{Yu}$ et al., 2016). In STEMMUS, temporal dynamics of three phases of water (liquid, vapor and ice) are explicitly presented and simultaneously solved by spatially discretizing the corresponding governing equations 
of liquid water flow and vapor flow (see Section 3.2.1). Additional details on the equations for solving the coupled water and heat equations can be found in Zeng et al. (2011a, b) and Zeng and Su (2013).

\subsubsection{Coupling T\&C and STEMMUS (CPLD)}

As mentioned above (Section 7.3.1-7.3.2), T\&C considers soil water and heat dynamics independently, and T\&C-FT only considers ice effects associated with latent heat, thermal and hydraulic parameters, while all other soil physics processes of STEMMUS are not considered. On the other hand, while STEMMUS model can reproduce well the soil water and heat transfer process in frozen soil, it lacks a detailed description of landsurface processes and of the ecohydrological feedback mechanisms. To take advantage of the strengths of both models, we coupled the STEMMUS model with the landsurface and vegetation components of the T\&C model (termed CPLD) to better describe the soil-plant-atmosphere continuum (SPAC) in cold regions.

The current coupling procedure between the STEMMUS and the T\&C models is based on a sequential coupling via the exchange of mutual information within one time step (see Figure 7.2). The T\&C model and STEMMUS model run sequentially within one time step. First, the preparation and initialization modules are called. Meteorology inputs and constant parameters are set, and the initialization process is performed. After the inputs are prepared, the main iteration process starts. T\&C is in charge of the time control information (starting time, time step, elapsed time) and informs STEMMUS model with these time settings every time step. Meanwhile, the surface boundary conditions obtained by the solution of vegetation and land surface energy dynamics are also sent to drive STEMMUS model. The surface latent heat flux $(L E)$ is partitioned into soil evaporation (used for setting the surface boundary condition of soil water flow) and plant transpiration (further subdivided into layer-specific root water uptakes representing the sink terms of Richards equation).

After convergence is achieved in the soil module (i.e., convergence criteria is set to 0.001 for both soil matric potential, in centimeters, and soil temperature, in kelvin), STEMMUS estimates soil temperature and soil moisture (hereafter ST/SM) profiles, which are utilized to update ST/SM states in T\&C model. The T\&C model then utilizes this updated ST/SM information (rather than its own computed ST/SM profiles) to proceed with the ecohydrological simulations in the following time step. Such iterations continue till the end of the simulation period. 


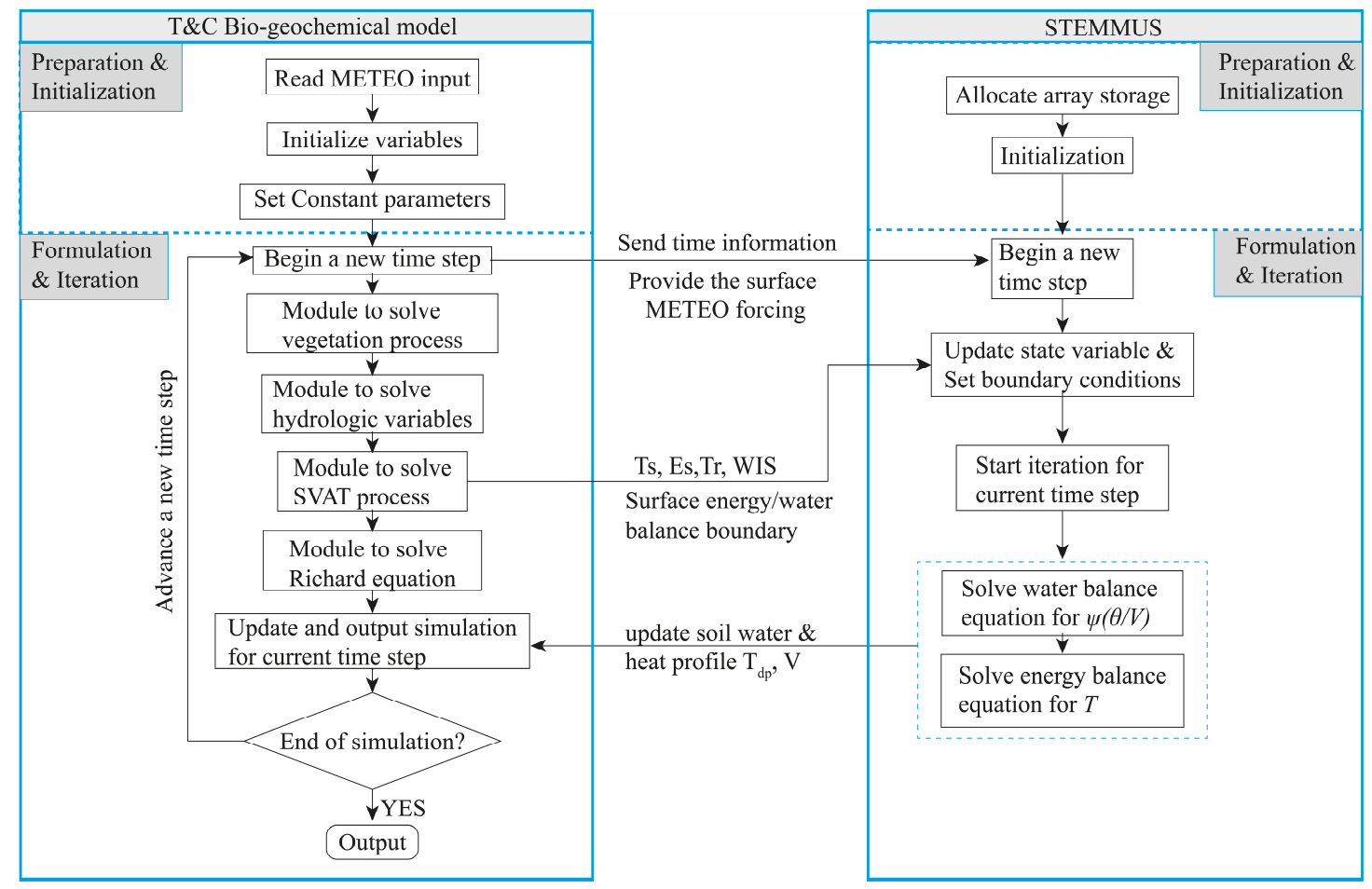

Figure 7.2. Coupling procedure of STEMMUS and T\&C model. METEO is the meteorology forcing, SVAT is acronym for the Soil-Vegetation-Atmosphere mass and heat Transfer. Ts, Es, Tr, WIS are the surface temperature, soil evaporation, plant transpiration, and incoming water flux to the soil, respectively. $\mathrm{T}_{\mathrm{dp}}$ and $\mathrm{V}$ are the soil profiles of temperature in ${ }^{\circ} \mathrm{C}$ and liquid water volume in each layer $(\mathrm{mm})$.

\subsubsection{Numerical experiments}

To investigate the role of increasing complexity of vadose zone physics in ecosystem functioning, three numerical experiments were designed on the basis of the aforementioned modeling framework (Table 7.1). For the first experiment, the T\&C original model was run alone and termed unCPLD simulation. For the unCPLD model, soil water and heat transfer are independent with no explicit consideration of soil ice effect. For the second experiment, the updated T\&C model with explicit consideration of freezing and thawing processes was run as it can estimate the dynamics of soil ice content and the related effect on water and heat transfer (e.g., blocking effect on water flow, heat release/gain due to phase change) but is otherwise exactly equal to the original T\&C model. This second simulation is named the unCPLD-FT simulation, in which the term unCPLD generally refers to the fact that T\&C model and STEMMUS model are not yet coupled. For the third experiment, the STEMMUS model was coupled with the T\&C model to enable not only frozen soil physics but also additional processes and most importantly the tight coupling of water and heat effects. This simulation is named CPLD simulation. In this third scenario, vapor flow, which links the soil water and heat flow, is explicitly considered. In addition to the ice blocking effect as presented in unCPLD-FT, the thermal effect on water flow is also expressed with the temperature dependence of hydraulic conductivity and matric potential. Furthermore, not only the 
latent heat due to phase change, but also the convective heat due to liquid/vapor flow are also simulated.

Table 7.1. Numerical experiments with various mass and energy transfer processes

\begin{tabular}{|c|c|c|c|}
\hline \multirow{2}{*}{ Experiments } & \multicolumn{2}{|c|}{ Soil Physical Processes } & \multirow{2}{*}{$\begin{array}{l}\text { Model } \\
\text { Components }\end{array}$} \\
\hline & Unfrozen period & Frozen period & \\
\hline unCPLD & $\begin{array}{l}\text { Independent water } \\
\text { and heat transfer }\end{array}$ & $\begin{array}{l}\text { Independent water and heat transfer, } \\
\text { No ice effect on soil properties, } \\
\text { No latent heat due to phase change }\end{array}$ & $\begin{array}{l}\mathrm{T} \& \mathrm{C} \text { (Eqs. } 7.1 \& \\
7.3)\end{array}$ \\
\hline unCPLD-FT & $\begin{array}{l}\text { Independent water } \\
\text { and heat transfer }\end{array}$ & $\begin{array}{l}\text { FT induced water and heat transfer } \\
\text { coupling, } \\
\text { Ice effect on soil properties, } \\
\text { Latent heat due to phase change }\end{array}$ & $\begin{array}{l}\text { T\&C-FT (Eqs. } 7.1 \\
\& 7.4)\end{array}$ \\
\hline CPLD & $\begin{array}{l}\text { Tightly coupled } \\
\text { water and heat } \\
\text { transfer }\end{array}$ & $\begin{array}{l}\text { Tightly coupled water and heat transfer, } \\
\text { Ice effect on soil properties, } \\
\text { Latent heat due to phase change, } \\
\text { Convective heat due to liquid/vapor flow. }\end{array}$ & $\begin{array}{l}\text { T\&C-STEMMUS } \\
\text { (Eqs. } 4.3 \& 4.4 \text { ) }\end{array}$ \\
\hline
\end{tabular}

Note:

Independent water and heat transfer: Soil water and heat transfer process is independent.

FT induced water and heat transfer coupling: Soil water and heat transfer process is coupled only during the freezing/thawing (FT) period. Soil water flow is affected by temperature only through the presence of soil ice content (the impedance effect).

Tightly coupled water and heat transfer: Soil water and heat transfer process is tightly coupled; vapor flow, which links the soil water and heat flow, is taken into account; thermal effect on water flow is considered (the hydraulic conductivity and matric potential is dependent on soil temperature; when soil freezes, the hydraulic conductivity is reduced by the presence of soil ice, which is temperature dependent); the convective/advective heat due to liquid/vapor flow can be calculated. Ice effect on soil properties: the explicit simulation of ice content and its effect on the hydraulic/thermal properties.

Hourly meteorological forcing (including downwelling solar and thermal radiation, precipitation, air temperature, relative humidity, wind speed, atmospheric pressure) was utilized to drive the models. For the adaptive time step of STEMMUS simulation, the linear interpolation between two adjacent hourly meteorological measurements was used to generate the required values at every second. The hydrological related initial states, e.g., initial snow water equivalent, soil water and temperature profiles, were taken as close as possible to the observed ones. Since the current initial conditions of the carbon and nutrient pools in the soil are unknown, we spin-up carbon and nutrient pools running only the soil-biogeochemistry module for 1000 years using average climatic conditions and prescribed litter inputs taken from preliminary simulations. Then we used the spun-up pools as initial conditions for the hourly-scale simulation over the period for which hourly observations are available. This last operation is repeated two times, which allows a dynamic equilibrium of nutrient and carbon pools in the soil and vegetation to be reached.

The total depth of the soil column was set to $3 \mathrm{~m}$ and divided into 18 layers with a finer discretization in the upper soil layers $(1-5 \mathrm{~cm})$ than that in the lower soil layers $(10-50$ $\mathrm{cm})$. Soil samples were collected and transported to the laboratory to determine the soil 
hydrothermal properties (see Zhao et al. 2018 for detail). The average soil texture and fitted van Genuchten parameters at three soil layers were listed in Table 3.3. Vegetation parameters were obtained on the basis of literature and expert knowledge (see a summary of the adopted vegetation parameters in Table A6.4). All three numerical experiments shared the same soil and vegetation parameter settings.

\subsection{Results and discussion}

\subsubsection{Surface fluxes simulations}

The $5 \mathrm{~d}$ moving average dynamics of the net incoming radiation $(R n)$, latent heat $(L E)$ and sensible heat $(H)$ fluxes measured and simulated by the unCPLD model, unCPLDFT, and CPLD models for the study period are presented in Figure 7.3. The seasonality and magnitude of surface fluxes can be captured across seasons. A good match between observed and simulated $R n$ and $L E$ was identified during the whole period, with isolated observable discrepancies (Figure 7.3a \& 7.3c and Figure A6.3). Compared to unCPLD and unCPLD-FT simulations, CPLD model simulated similar dynamics of $L E$ while it generally produced a larger overestimation of $R n$, especially during the frozen period. These mismatches of $R n$ can be partly attributed to the uncertainties of observed winter precipitation events and the following snow cover dynamics, which might not be captured well in the models. For the sensible heat flux simulations, all three models can reproduce the seasonal dynamics. However, an overestimation of the $5 \mathrm{~d}$ average values was observed in several periods. Given the good correspondence between observations and simulations of net radiation and latent heat, this discrepancy might be a model shortcoming due to the simplification in considering only one single surface prognostic temperature (i.e., soil surface and vegetation surface temperature were assumed to be the same), but it can be also caused by the lack of energy balance closure in the eddycovariance data (see Sect. 7.4.5). Compared to unCPLD and unCPLD-FT simulations, the overestimation was reduced in the CPLD model simulations and the $H$ dynamics were closer to observations during the growing season.

The correlation between observed and simulated daily average surface heat fluxes with unCPLD, unCPLD-FT, and CPLD models is shown in Figure 7.4 and Figure A6.4 and A6.5. Noticeably all the unCPLD/CPLD model scenarios, with different water and heat transfer physics, exhibited nearly identical statistical performance of surface flux simulations (Figure 7.4). The overall performance of the model in terms of turbulent flux simulations can be regarded as acceptable given the uncertainties in winter precipitation and eddy-covariance observations in such a challenging environment, even though discrepancies exist during certain periods (Figure 7.3). 

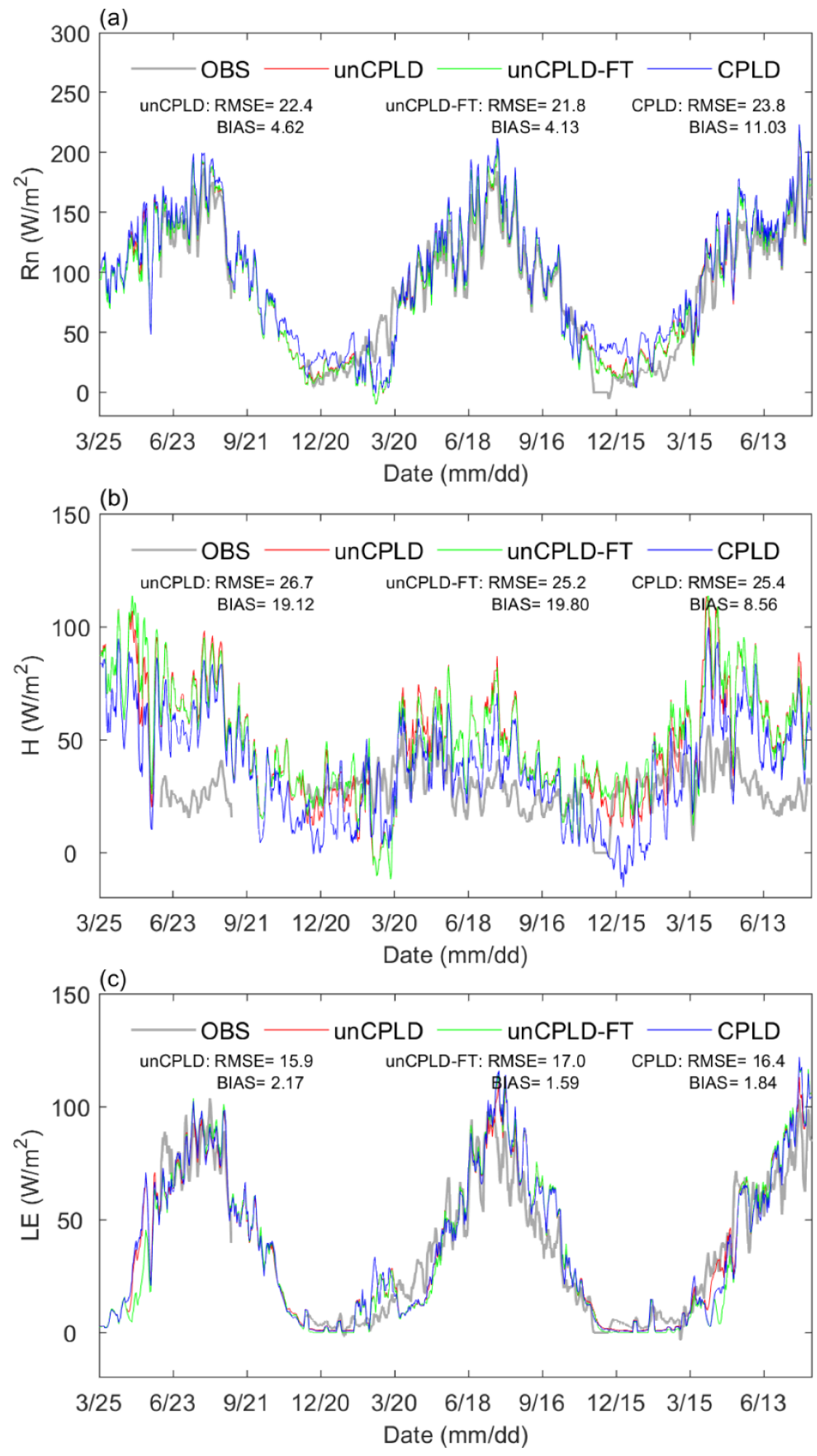

Figure 7.3. Comparison of observed and simulated 5-day moving average dynamics of net radiation $(\mathrm{Rn})$, latent heat flux (LE), and sensible heat flux $(\mathrm{H})$ using the original (uncoupled) $\mathrm{T} \& \mathrm{C}$ (unCPLD), T\&C with consideration of FT process (unCPLD-FT) and coupled T\&C and STEMMUS (CPLD) model. 

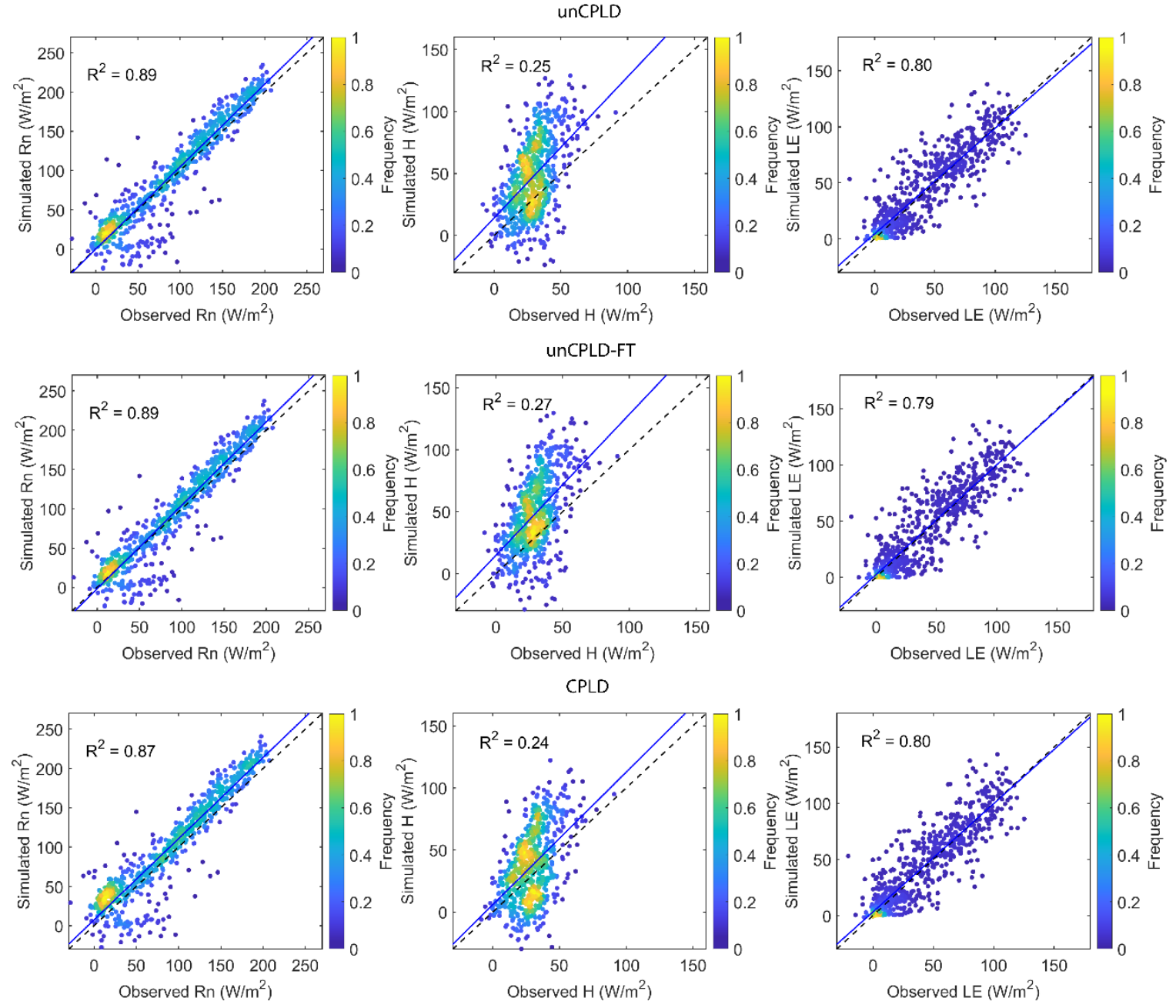

Figure 7.4. Scatter plots of observed and model simulated daily average surface fluxes (net radiation: $\mathrm{Rn}$, latent heat: LE and sensible heat flux: $\mathrm{H}$ ) using the original (uncoupled) $\mathrm{T} \& \mathrm{C}$ (unCPLD), $\mathrm{T} \& \mathrm{C}$ with consideration of FT process (unCPLD-FT) and coupled T\&C and STEMMUS (CPLD) model, with the color indicating the frequency of surface flux values.

\subsubsection{Soil moisture and soil temperature simulations}

The capability of the three models to reproduce the temporal dynamics of soil moisture is illustrated in Figure 7.5. By explicitly considering soil ice content, the unCPLD-FT and CPLD models captured well the response of soil moisture dynamics to the freezethaw cycles, while the unCPLD model lacked such capability and maintained a higher soil water content throughout the winter period, but slightly lower water content in the growing season. For all three models, the consistency between the measured and simulated soil water content at five soil layers was satisfactory during the growing season, indicating the models' capability in portraying the effect of precipitation and root water uptake on the soil moisture conditions. 


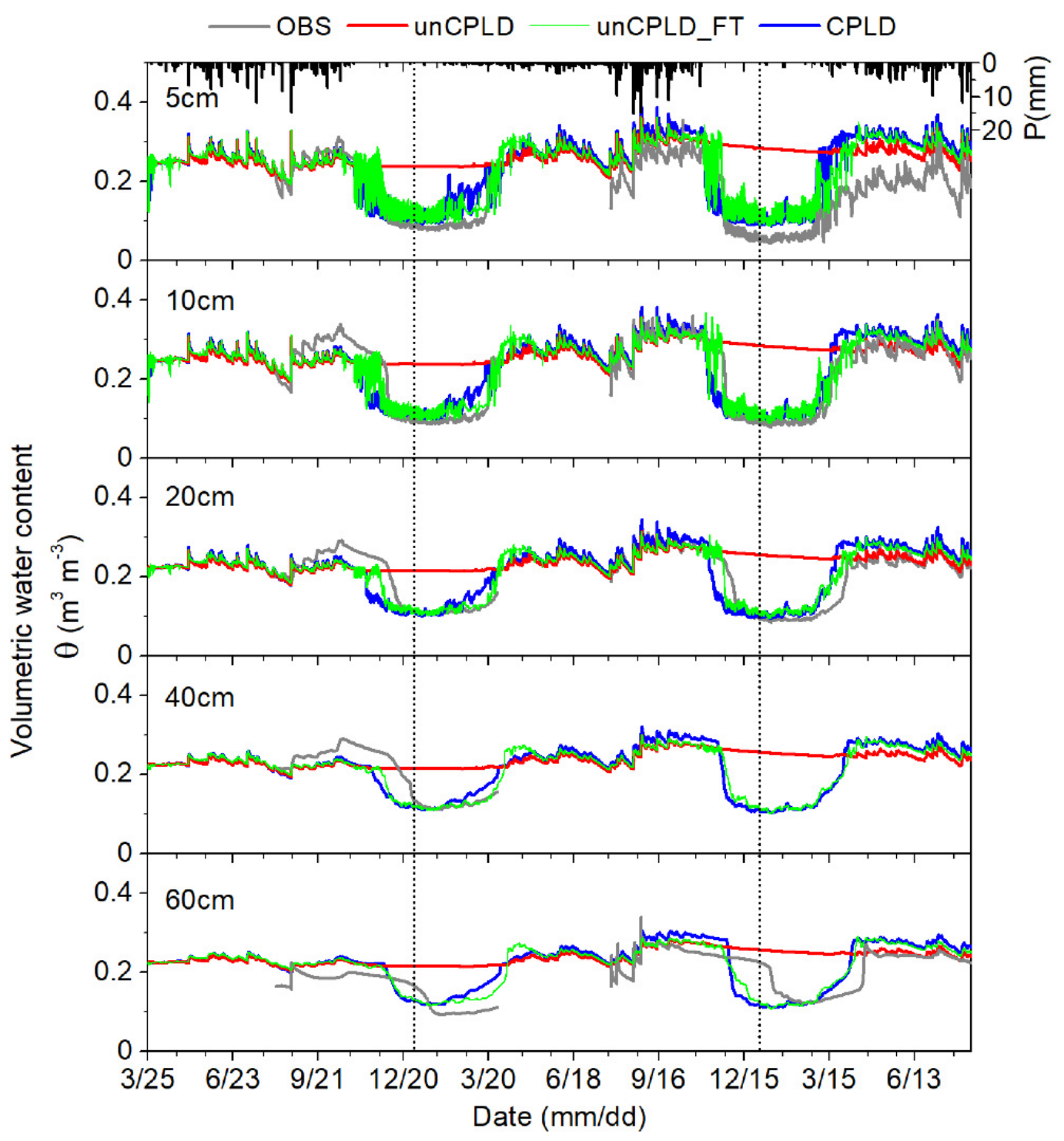

Figure 7.5. Measured and estimated soil moisture at various soil layers using uncoupled $\mathrm{T} \& \mathrm{C}$ (unCPLD), uncoupled $\mathrm{T} \& \mathrm{C}$ with FT process (unCPLD-FT) and coupled T\&C and STEMMUS (CPLD) model. Note that in unCPLD model, soil ice content is not explicitly considered, thus all the water remains in a liquid phase, which leads to a strong overestimation of winter soil water content in frozen soils. 


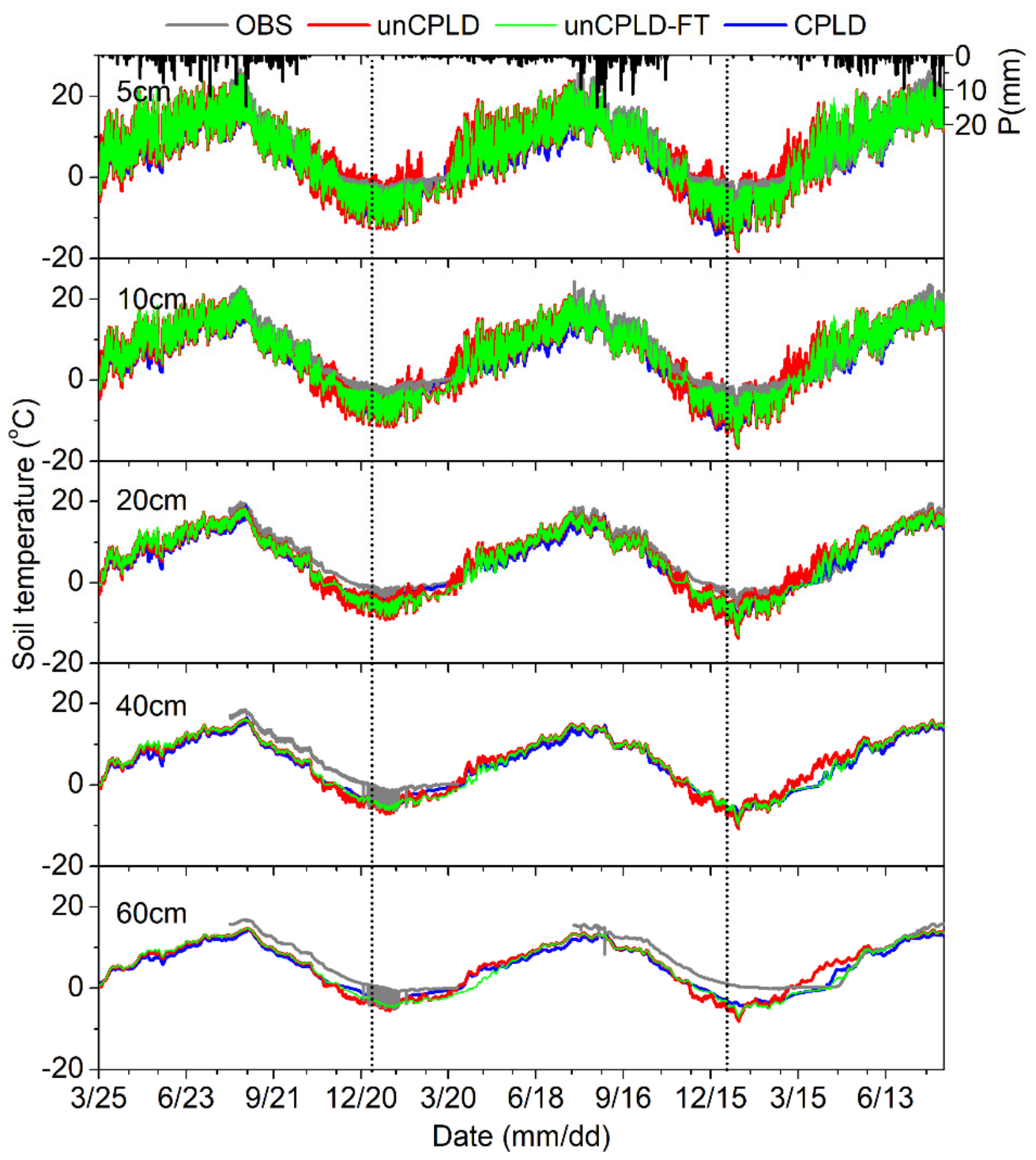

Figure 7.6. Measured and simulated soil temperature at various soil layers using uncoupled T\&C (unCPLD), T\&C with FT process (unCPLD-FT) and coupled T\&C and STEMMUS (CPLD) models.

Five layers of soil temperature measurements were employed to test the performance of the model in reproducing the soil temperature profiles (Figure 7.6). During the growing period, all three models can capture the dynamics of soil temperature well. In this period, there is no significant difference among the three models in the magnitude and temporal dynamics of soil temperature. During the freezing period, a general underestimation of soil temperature and overestimation of its diurnal fluctuations were found at shallower soil layers, which may indicate that there is some thermal buffering effect in reality not fully captured in the models. Compared to the unCPLD-FT and 
CPLD models, the unCPLD model simulations had stronger diurnal fluctuations of soil temperature with an underestimation of temperature at the beginning of the freezing period and a considerable overestimation during the thawing phase. This results in an earlier date passing the $0^{\circ} \mathrm{C}$ threshold than in the unCPLD-FT and CPLD simulations. It should be noted that for the deeper soil layers (e.g., $60 \mathrm{~cm}$ in Figure 7.6), all models tended to simulate the early start of freezing soil temperatures and considerably underestimated the soil temperature during the frozen period. This can be due to the uncertainties in soil organic layer parameters, the not fully captured snow cover effect (Gouttevin et al., 2012), a potentially pronounced heterogeneity in soil hydrothermal properties, or the potential role of solutes on the freezing-point depression (as the presence of solute lowers the freezing soil temperature) (Painter \& Karra, 2014). These mismatches in deep soil temperature degraded the model performance in simulating the dynamics of liquid water (Figure 7.5) and ice content (Figure 7.7) during the frozen period.

\subsubsection{Soil ice content and water flux}

The time-series of soil ice content and water flux from the unCPLD, unCPLD-FT and CPLD model simulations for soil layers below $2 \mathrm{~cm}$ are presented in Figure 7.7. As soil ice content measurements were not available, the freezing front propagation inferred from the soil temperature measurements was employed to qualitatively assess the model performance. The phenomenon that a certain amount of liquid water flux moves upwards along with the freezing front can be clearly noticed for both the unCPLD-FT and CPLD model simulations. As the soil matric potential changes sharply during the water phase change, a certain amount of water fluxes will be forced towards the phase changing region, a phenomenon known as cryosuction. Such a phenomenon has already been demonstrated from theoretical and experimental perspectives by many researchers (Hansson et al., 2004; Watanabe et al., 2011; Yu et al., 2018; Yu et al., 2020b). Cryosuction is much more accentuated in the unCPLD-FT simulation, while it is of course absent in the unCPLD model simulations (Figure 7.7c). Precipitation-induced downward water flux can be observed in all models during summer with very similar patterns. It is of note that compared to the unCPLD-FT model, the CPLD model presented a relatively lower presence of soil ice content, while its temporal dynamics were closer to the observed freezing and thawing front propagation. The difference between the two simulations can be attributed to the constraints imposed by the interdependence of liquid, ice, and vapor in the soil pores which is considered only in the CPLD model. 


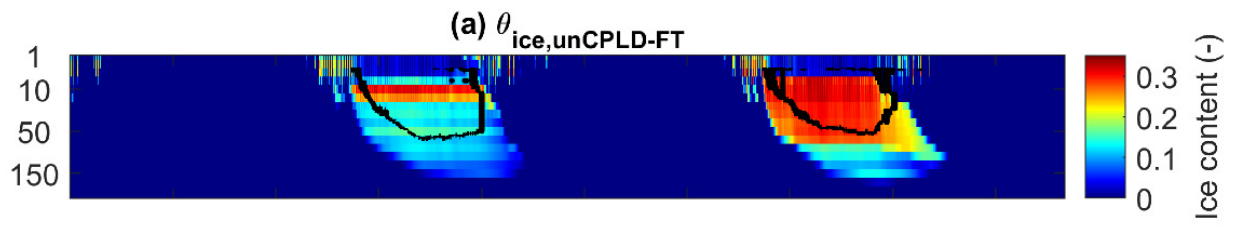

(b) $\theta_{\text {ice, CPLD }}$

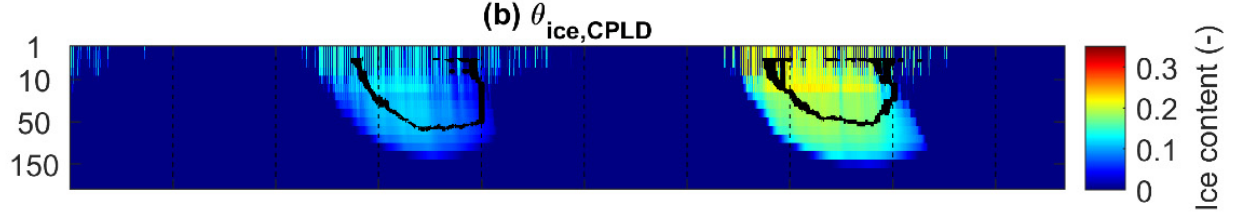

(c) $Q_{\text {unCPLD }}$

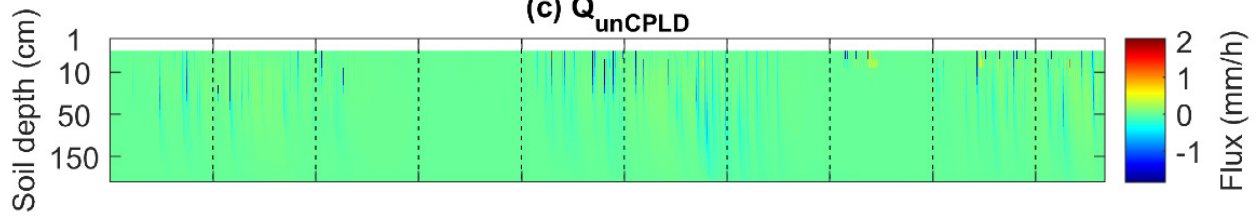

(d) $Q_{\text {unCPLD-FT }}$

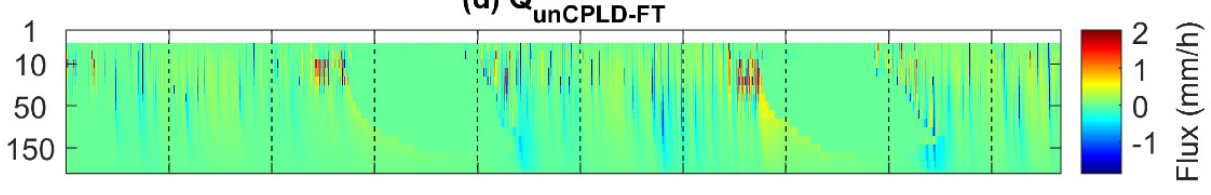

(e) $Q_{\text {CPLD }}$

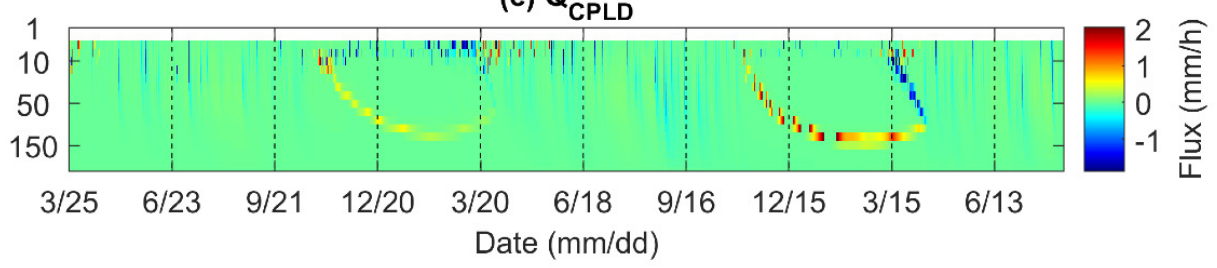

Figure 7.7. Soil ice content from (a) unCPLD-FT and (b) CPLD model simulations with freezing front propagation derived from the measured soil temperature; and vertical water flux (positive value indicates upward water flow) from (c) unCPLD, (d) unCPLD-FT and (e) CPLD model simulations. Note that soil ice content is not represented in the unCPLD model and the fluxes of top $2 \mathrm{~cm}$ soil layers were not reported to highlight fluxes of the lower layers.

\subsubsection{Simulations of land surface carbon fluxes}

The eddy covariance derived vegetation productivity and remote sensing (MODIS) observations of vegetation dynamics are compared with the model simulation in Figure 7.8. When compared with in situ eddy-covariance observations, slightly earlier growth and considerably earlier senescence of grassland with lower photosynthesis were inferred from MODIS GPP product (Figure 7.8a). The mismatch in the phenology is likely a combined issue of $8 \mathrm{~d}$ (or longer if clouds are impeding the view) composites of the MODIS products and challenge of translating vegetation reflectance signals into productivity or leaf area index (LAI) during the grass senescent phase. 
Taking eddy-covariance observations as the reference, the onset date of grassland appears to be captured well by both unCPLD and CPLD model simulations, while there is a delayed onset date in the unCPLD-FT model. Leaf senescence and dormancy phase are a bit delayed in the models when compared with eddy-covariance data and considerably delayed when compared to MODIS-LAI, even though the latter is particularly uncertain as described above. Although there is an observable underestimation of GPP compared to the eddy covariance measurements, the dynamics of $G P P$, which is mainly constrained by the photosynthetic activity and environmental stresses, is reasonably reproduced by all model simulations.

The underestimation of GPP has magnified consequences in terms of reproducing NEE dynamics by the unCPLD and CPLD models. While this might be seen as a model shortcoming, there are a number of reasons that lead to questioning the reliability of the magnitude of carbon flux measurements at this site. By checking other ecosystems' productivity under similar conditions, the annual average GPP for the Tibetan Plateau meadow ecosystem ranges from 300 to $935 \mathrm{~g} \mathrm{C} \mathrm{m}^{-2} \mathrm{yr}^{-1}$, while the annual average NEE ranges from -79 to $-213 \mathrm{~g} \mathrm{C} \mathrm{m}^{-2} \mathrm{yr}^{-1}$ (see the literature summary in Table A6.5; Yu et al., 2020). The EC system used in this experimental site observes an annual GPP and $N E E$ of 1132.52 and $-293.24 \mathrm{~g} \mathrm{C} \mathrm{m}^{-2} \mathrm{yr}^{-1}$. Both the GPP and NEE measured fluxes are significantly larger than existing estimates of the carbon exchange for such an ecosystem type and are unlikely to be correct in absolute magnitude. The ecosystem respiration $\left(R_{e c o}\right)$, indicating the respiration of activity of all living organisms in an ecosystem is shown in Figure 7.8d. The performance of all three model simulations in reproducing $R_{e c o}$ dynamics can be characterized as having an overall good match with regards to the magnitude and seasonal dynamics, which further suggests the discrepancy in observed/simulated GPP is the driver of the disagreement in NEE.

The difference in the soil liquid water and temperature profile simulations between the CPLD and unCPLD models (as shown in Figures 7.5 \& 7.6) resulted in differences in simulated vegetation dynamics, especially concerning the leaf onset date, which is affected by integrated winter soil temperatures. The unCPLD-FT model has a delay in the vegetation onset date when compared to other simulations, due to the significant cryosuction that prolongs freezing conditions and keeps lower soil temperatures. This makes the unCPLD simulation have a slightly shorter vegetation active season compared to the CPLD model simulations. The lower GPP in the unCPLD simulations is instead related to a slightly enhanced water-stress induced by the different soilmoisture dynamics during the winter and summer seasons with a lower root zone moisture produced by the unCPLD model (Figure 7.5), which affects the plant photosynthesis and growth. Differences in soil temperature profiles can also affect root respiration in generating additional small differences in $G P P$. 

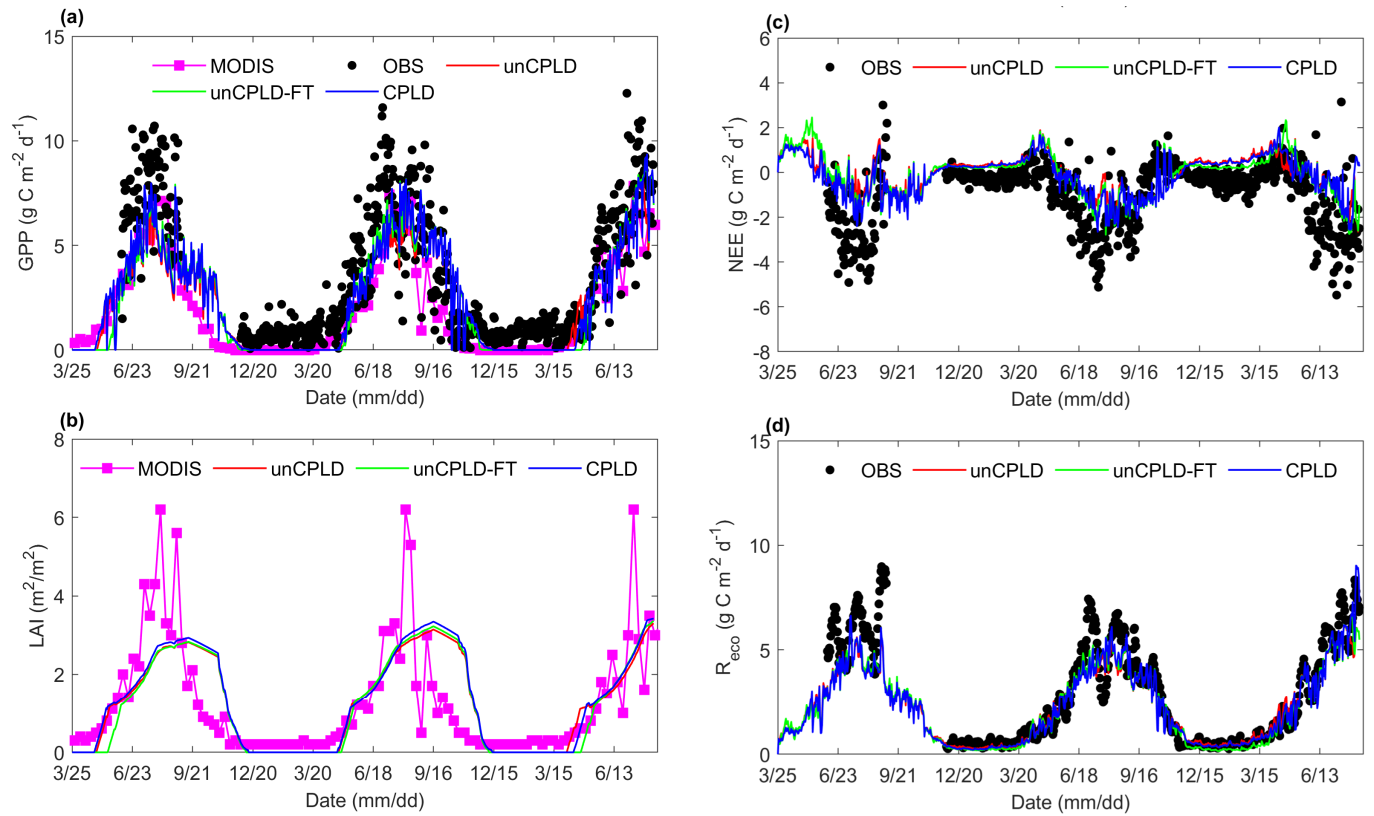

Figure 7.8. Comparison of observations from Eddy Covariance (OBS) or MODIS remote sensing and simulated (a) Gross Primary Production (GPP), (b) Leaf Area Index (LAI), (c) Net Ecosystem Exchange (NEE), and (d) Ecosystem respiration (Reco) using unCPLD, unCPLD-FT, and CPLD model. MODIS refers to the data from MODIS-GPP and MODIS-LAI products.

\subsubsection{Surface energy balance closure}

The energy balance closure problem, usually identified because the sum of latent $(L E)$ and sensible $(H)$ heat fluxes is less than the available energy $\left(R n-G_{0}\right)$, is quite common in eddy covariance measurements ( $\mathrm{Su}, 2002$; Wilson et al., 2002; Leuning et al., 2012). The energy imbalance of EC measurements is particularly significant at sites over the Tibetan Plateau (Tanaka et al., 2003; Yang et al., 2004; Chen et al., 2013; Zheng et al., 2014). Figure 7.9 presents the energy imbalance of hourly $L E$ and $H$ by the eddy covariance measurements, observed $R n$ by the four-component radiation measurements, and the estimated ground heat flux $\left(G_{0}\right)$ by CPLD model. The sum of measured $L E$ and $H$ was significantly less than $R n$, with the slope of $L E+H$ versus $R n$ equal to 0.59 (Figure 7.9a). Usually, the measurements of radiation are reliable (Yang et al., 2004). If we assume that the turbulence flux $(L E, H)$ measurements are accurate, then the rest of energy (around $41 \%$ of $R n$ ) should be theoretically consumed by ground heat flux $G$, which is clearly impossible. When compared to the available energy $(R n-G)$, the slope was increased to 0.70 (Figure 7.9b). Table 7.2 demonstrates that the energy imbalance problem was significant across all seasons. The seasonal variation in energy closure ratio (ECR) can be identified for the case of $L E+H$ versus $R n-G_{0}$, similar to the research of Tanaka et al. (2003), i.e., a good energy closure during the pre-monsoon periods while a degraded one during the summer monsoon periods. 


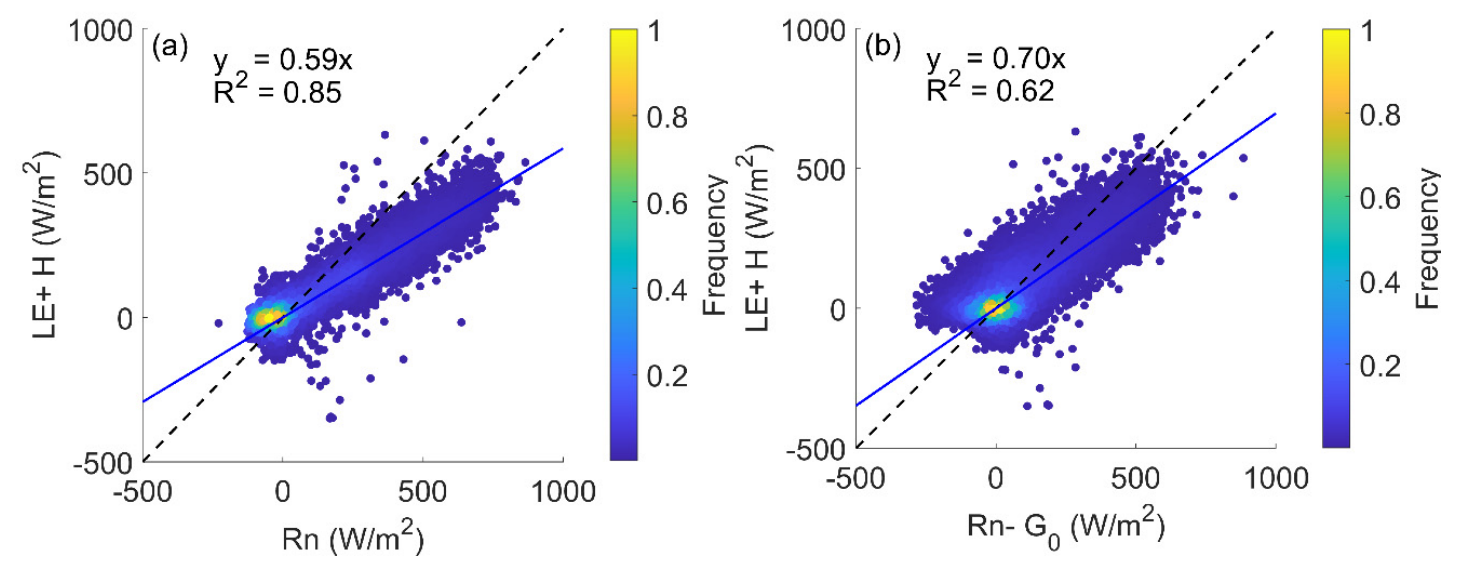

Figure 7.9. Scatter plots of eddy covariance measured hourly values of $\mathrm{LE}+\mathrm{H}$ versus (a) Rn and (b) Rn-G0, with the color indicating the occurrence frequency of surface flux values. $\mathrm{G}_{0}$, the ground heat flux, was estimated by the CPLD model.

Table 7.2. Monthly values of energy closure ratio derived from eddy covariance measured LE $+\mathrm{H}$ versus Rn and Rn-G0, respectively (Dec. 2017-Aug. 2018). G0, the ground heat flux, was estimated by CPLD model.

\begin{tabular}{llllllllll}
\hline Energy closure ratio & Dec & Jan & Feb & Mar & Apr & May & Jun & Jul & Aug \\
\hline$(L E+H)$ vs $R n$ & 0.58 & 0.58 & 0.61 & 0.45 & 0.53 & 0.55 & 0.55 & 0.57 & 0.59 \\
$(L E+H)$ vs $\left(R n-G_{0}\right)$ & 0.98 & 0.90 & 0.90 & 0.51 & 0.62 & 0.68 & 0.64 & 0.63 & 0.67 \\
\hline
\end{tabular}

These problems clearly suggest that care should be taken with the data mutual corroboration issue. Nevertheless, such an issue does not affect the comparison results among models with different vadose zone physics since we did not force any parameter calibration or data-fitting procedure but simply relied on physical constraints, the literature, and expert knowledge to assign model parameters.

\subsubsection{Effects on water budget components}

The effect of different model versions on soil water budget components is illustrated in Figure 7.10. T\&C model can describe in detail different water budget components. Precipitation can be partitioned into vegetation interception, surface runoff, and infiltration. Infiltrated water can then be used for surface evaporation $(E s)$, root water uptake (i.e., transpiration, $T v$ ), and changes in soil water storage $(\Delta V s)$. The other evaporation components, i.e., evaporation from intercepted canopy water $\left(E_{I N}\right)$ and snow cover $\left(E_{S N}\right)$, can be further distinguished by T\&C model. A certain amount of water will drain below the bottom of the $3 \mathrm{~m}$ soil column as deep leakage $\left(L_{K}\right)$. 


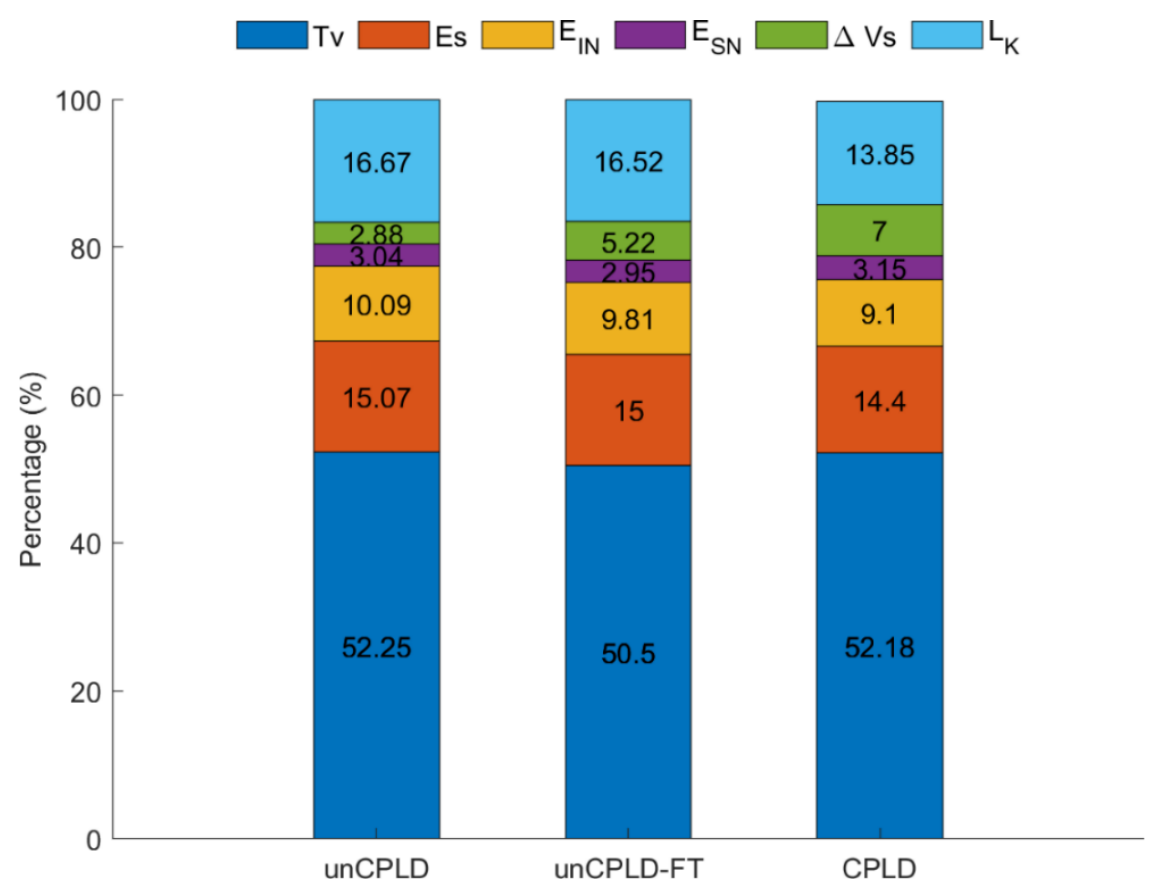

Figure 7.10. Comparison of the relative ratios of different water budget components to precipitation during the whole simulation period produced by different model scenarios. Tv, transpiration; Es, surface evaporation; EIN and ESN, evaporation from intercepted canopy water and snow cover; $\Delta \mathrm{Vs}$, changes in soil water storage; $\mathrm{L}_{\mathrm{K}}$, deep leakage water.

All models demonstrated that most of the precipitation is used by ET. Less water was consumed by ET from unCPLD-FT simulations than that from unCPLD. This is due to the lower amount of vegetation transpiration $(T v)$ and intercepted canopy water evaporation $\left(E_{I N}\right)$ regulated by cooler late winter temperatures and the late beginning of the active vegetation season. The cooler late winter temperatures from unCPLD-FT simulations can be attributed to the retardation of the thawing process due to the phase change-induced heat absorption and the soil ice-induced modification of bulk heat capacity during the freezing-thawing transition period, which dampened the magnitude of temperature variations and delayed the thawing process. With explicit consideration of soil ice, hydraulic conductivity is also reduced, and vertical water flow is retarded during the frozen period (Kurylyk \& Watanabe, 2013). This explains the higher value of $\Delta V S$ in the unCPLD-FT simulation (5.2\%) than that in the unCPLD simulation $(2.8 \%)$. Furthermore, at the end of the freezing period, the unCPLD-FT simulation presents a delayed vegetation onset and thus a decrease in ecosystem water consumption, which favors percolation toward deeper layers and the bottom leakage. Such a positive effect on the bottom leakage flux was slightly weaker than the negative effect (impeded water flow) due to frozen soil throughout the winter season. These results indicate that the presence of seasonally frozen soil can mediate the water storage in the vadose zone via both hydrological and plant physiological controls. 
The effect of coupled water and heat physics (unCPLD vs. CPLD model) on the water budget components can be summarized as follows. (i) The amount of ecosystem water consumption ET was reduced, due to the dampened surface evaporation process (evaporation from the soil surface and intercepted water). (ii) The water storage amount in the vadose zone increased while the bottom leakage decreased. We attribute this to the way ice content is simulated in the CPLD simulation, and also to the temperature dependence of soil hydraulic conductivity (see Table 7.1 and Appendix A1). Specifically, the high accumulation of ice content in the unCPLD-FT simulations indicates a relatively stronger cryosuction effect than in CPLD simulations. This cryosuction effect is mitigated in the fully coupled model because of water vapor transfer and thermal gradients, even though different solutions in the parameterization of bulk soil thermal conductivity and volumetric soil heat capacity could also be responsible for the difference (Yu et al., 2018; Yu et al., 2020b). Overall, taking into account the fully coupled water and heat physics modifies the temporal dynamics of ice formation and thawing in the soil and activates temperature effects on water flow (i.e., low soil temperature will slow down water movement).

\subsubsection{The influence of different mass/heat transfer processes}

Given the same atmospheric forcing and the same model structure to represent landsurface exchanges and vegetation dynamics, different vadose zone physics generate differences in SM and ST vertical profiles. From the perspective of energy fluxes, the convective heat flux and explicit frozen soil physics are taken into account in the CPLD model, while they are not considered in the two unCPLD models. The difference among models in simulating the liquid water flux-induced convective heat flux is mostly relevant to the freezing or thawing process (Kane et al., 2001; Boike et al., 2008; Sjöberg et al., 2016; Chen et al., 2020; Yu et al., 2020b). As it has been observed, a certain amount of liquid water/vapor flux moves toward the freezing front and this effect is different between unCPLD-FT and CPLD while it is absent in unCPLD (Figure 7.7). For the unfrozen period, the total mass fluxes were instead comparable between the two unCPLD and CPLD simulations. For the temperature gradient, there is not much difference between unCPLD and CPLD simulations during both the growing season and freezing-thawing period. The latent heat released by freezing and consumed by the melting processes slows down the freezing and thawing process and decreases the diurnal and seasonal temperature fluctuations (Figure 7.6). Different soil thermal profiles have consequences on the vegetation dynamic process (Figure 7.8), mainly by affecting the beginning of the growing season and the subsequent simulated photosynthesis and growth processes. This is consistent with the decadal observation results of Li et al. (2016), in which they reported the cumulative temperature effect on the carbon dynamics as it breaks the vegetation dormancy, affects the leaf phenology and plant growth dynamics. From the perspective of water fluxes, it is during the frozen 
period that water and heat transfer processes are tightly coupled (Hansson et al., 2004; Yu et al., 2018; Yu et al., 2020b). Both the explicit consideration of soil ice and coupled water and heat physics can affect the vadose zone water flow by altering the hydraulic conductivity and soil water potential gradients. This is testified by the fact that the unCPLD-FT simulation accounting for soil-freezing in a simplified way, in comparison to STEMMUS (e.g., the CPLD simulation), cannot recover the exact dynamics of ice content (Figure 7.7), which impacts leaf onset and to a lesser extent hydrological fluxes. However, in the rest of the year, the simplified solution of vadose zone physics of T\&C leads to very similar results as the coupled one, suggesting that most of the additional physics do not modify substantially the ecohydrological response during unfrozen periods.

\subsection{Conclusion}

The detailed vadose zone process model STEMMUS and the ecohydrological model $\mathrm{T} \& \mathrm{C}$ were coupled to investigate the effect of various model representations in simulating water and energy transfer and seasonal ecohydrological dynamics over a typical Tibetan meadow. The results indicate that the original $\mathrm{T} \& \mathrm{C}$ model tended to overestimate the variability and magnitude of soil temperature during the freezing period and the freezing-thawing transition period. Such mismatches were ameliorated by the inclusion of soil ice content and freezing-thawing processes to the original model, and were further improved with explicit consideration of coupled water and heat physics. For the largest part of the simulated period (i.e., unfrozen), we found that a simplified treatment of vadose zone dynamics is sufficient to reproduce satisfactory energy, water and carbon fluxes - given the uncertainty in the eddy-covariance observations. Additional complexity in vadose zone representation is mostly significant during the freezing and thawing periods as ice content simulations differ among models and the amount of water moving towards the freezing front was differently simulated. These discrepancies have an impact (even though limited to the beginning of the growing season) on vegetation dynamics. The leaf onset is better captured by the unCPLD and CPLD models, while a delayed onset date was reproduced by unCPLDFT model. Nonetheless, overall patterns for the rest of the year do not differ considerably among simulations, which suggests that the difference in vadose zone dynamics, by using a fully coupled water-heat model treatment, is not enough to affect the overall ecosystem response. This also suggests that the additional complexity might be more needed for specific vadose zone studies and investigation of permafrost thawing rather than for ecohydrological applications. Nevertheless, the coupled model can reveal the hidden physically based processes and mechanisms in the vadose zone that cannot be explained by uncoupled models, which can assist the comprehensive physical interpretations of ecosystem responses to subtle climatic changes/trends in high-altitude cold regions. In summary, our investigations using different models of 
vadose zone physics can be helpful in supporting the development and application of earth system models as they suggest that a certain degree of complexity might be necessary for specific analyses. 
Chapter 8 Synthesis 

This thesis contributes to the physical understanding of the water-heat-carbon exchanges across the groundwater-soil-plant-atmosphere interfaces in cold ecosystems, which is achieved through the integrated observation and the advancement of numerical models. In the following, we summarize five perspectives, corresponding to the five research questions asked at the beginning.

\subsection{Summaries of results}

Q1: How to physically understand and interpret the coupled liquid, vapor, dry air, and heat transfer in response to soil freeze-thaw cycles?

We developed the STEMMUS-FT model with the coupled water and heat transfer physics and verified its performance by varying the hydrothermal parameterizations of a typical meadow ecosystem on the Tibetan Plateau. From the intercomparison results of different hydrothermal parameterizations, little difference was found in simulating soil water content, temperature, and freezing depth between two different hydraulic schemes (VG vs. $\mathrm{CH}$ ). The simulation results with four different thermal schemes indicate that de Vries parameterization performed better than others in simulating the soil thermal regime. The simplified de Vries method has the potential to be deployed over the Tibetan plateau.

Given the confirmed STEMMUS-FT model performance, we further investigated the underlying physics and the role of soil ice, vapor, and airflow in frozen soils, in terms of analyzing water and vapor fluxes. The presence of soil ice can block not only the liquid water flow passing through, but also can serve as the source for surface evaporation and the sink for liquid/vapor water fluxes at the freezing front. Together with the water pressure gradient, the soil temperature gradient drives the liquid and vapor transport in frozen soils.

This work also presents the first quantification of the role of vapor flow in frozen soils. Different from current knowledge that only liquid water flux migrates and accumulates to the freezing front, we found that both the liquid and vapor fluxes transfer upward to the freezing front. Vapor flow moving upwards to the freezing front can contribute about $6 \%-13 \%$ to the total water flux for the ice formation. In frozen soil region, it is the vapor flow rather than the liquid flow that contributes most to the total mass flux due to the blocking effect of ice presence in soil pores. The diurnal cycle of soil moisture between the evaporation front and freezing front was found mainly due to the diurnal behavior of thermal vapor flux. The isothermal vapor and liquid water fluxes are the major source for the evaporation into atmosphere. Our results suggest that it is mainly the vapor flow that connects the water/vapor transfer beneath the freezing front (sink) and above the evaporation front (source). 
Moreover, this thesis demonstrated the interactive effect of soil ice and airflow on the spatiotemporal variation of water/vapor transfer. The air pressure-induced liquid/vapor fluxes play a negligible role in the total mass transfer. Nevertheless, the presence of soil ice alters the soil airflow conductance and thus the dry air fluxes. Such air pressureinduced fluxes were found affecting the vapor flow and enhancing its diurnal circulation at the surface evaporation zone.

Q2: How do different representations of soil physical processes (i.e., from the basic coupled to the advanced coupled water and heat transfer processes, and then the explicit consideration of airflow) affect the simulation of soil hydrothermal dynamics in frozen soils?

STEMMUS-FT model was equipped with three complexity levels of soil physical processes, from the basic coupled model (termed BCM) to the advanced coupled heat and mass transfer model (ACM), and, furthermore, to the explicit consideration of airflow (ACM-AIR). The results indicated that compared to in situ observations, the $\mathrm{BCM}$ tended to present earlier freezing and thawing dates with a stronger diurnal variation of soil temperature/liquid water in response to the atmospheric forcing. Such discrepancies were considerably reduced by the model with the advanced coupled water-heat physics. Surface evapotranspiration was overestimated by BCM, mainly due to the mismatches during the initial freezing and freezing-thawing transition period. ACM models, with the coupled constraints from the perspective of water and energy conservation, significantly improve the model performance in mimicking the surface evapotranspiration dynamics during the frozen period.

The analysis of heat budget components and latent heat flux density revealed that the improvement of soil temperature simulations by ACM is ascribed to its physical consideration of vapor flow and thermal effect on water flow, with the former mainly functions at regions above the evaporative front, and the latter dominates below the evaporative front. Our results confirmed that the relative importance of different heat transport processes varied over the time and space. The non-conductive heat processes (liquid/vapor/air-induced heat convection flux) contributed very minimal to the total energy fluxes during the frozen period. The contribution of airflow-induced water and heat flow to the total mass and energy fluxes is negligible. However, given the explicit consideration of airflow, the latent heat flux and its effect on heat transfer were enhanced during the freezing-thawing transition period. This work highlighted the role of considering the vapor flow, thermal effect on water flow, and airflow in portraying the subsurface soil hydrothermal dynamics, especially during freezing-thawing transition periods. To sum up, this study contributes to a better understanding of freezethaw mechanisms of frozen soils, and explains the hydrothermal differences rising from the adopted soil physical processes. 
Q3: How does the snowpack impact subsurface soil water-heat dynamics considering different representations of soil physical processes?

With the aim to investigate the hydrothermal effect of the snowpack on the underlying soil system, we developed the integrated process-based soil-snow-atmosphere model, STEMMUS-UEB v1.0.0, which is based on the easily transferable and physically based description of the snowpack process and the detailed interpretation of the soil physical process with three levels of complexity (basic coupled BCD, advanced coupled ACD, and further with the airflow ACD-air). From STEMMUS-UEB simulations, snowpack affects not only the soil surface conditions (surface ice and soil liquid water content) and energy-related states (albedo, latent heat flux) but also the transfer patterns of subsurface soil liquid/vapor flow. STEMMUS-FT model can capture mostly the abrupt increase of surface albedo after winter precipitation events with consideration of the snow module. Without sublimation from snowpack, there is a less latent heat flux produced by STEMMUS-FT_No-snow simulations compared with snow simulations. The presence of snowpack alters the partitioning process of precipitation and thus the surface soil liquid water content. BCD models with/without snowpack produced similar surface soil liquid water content during the freezing period while resulted in the abrupt increase of soil moisture in response to precipitation during the thawing period. ACDSnow model simulated a less intensive and lagged soil moisture variation in response to precipitation compared to the ACD-No-Snow model during both the freezing and thawing period, respectively. For the ACD-air model, the intensity of the increased surface soil moisture was found affected, especially during the thawing period.

Three mechanisms, surface ice sublimation, snow sublimation and increased soil moisture, can contribute to the enhanced latent heat flux after winter precipitation events. The relative role of each mechanism in the total mass transfer can be affected by the time and magnitude of precipitation and pre-precipitation soil moisture/temperature states. The simple BCD model cannot provide a realistic partitioning of mass transfer. ACD model, with consideration of vapor diffusion and thermal effect on water flow and snowpack, can produce a reasonable analysis of the relative contributions of different water flux components. With the consideration of airflow, the relative contribution of each component to the mass transfer was substantially altered during the thawing period. This work contributes to the understanding of the LE enhancement after winter precipitation events and physically elaborating on the role of snowpack in cold regions.

Q4: How do the soil water-groundwater interactions affect the soil water dynamics?

We developed a coupled soil water-groundwater (SW-GW) model (STEMMUSMODFLOW) and verified its performance using two test cases and the Maqu catchment observatory. By cross validation against observations and the various model 
simulations, the STEMMUS-MODFLOW is demonstrated physically accurate and applicable in large scale groundwater problems. Compared to the HYDRUSMODFLOW simulations in Maqu catchment, the STEMMUS-MODFLOW produces a similar spatial distribution of hydraulic heads while better performance in mimicking the temporal dynamics of groundwater table depth and soil moisture profiles. We attribute this improved performance to the more realistic coupling strategies across the soil-water and groundwater interface. The results suggest that adopting the moving phreatic boundary, two-way feedback coupling scheme, and multi-scale water balance analysis contribute to maintain the physical consistency and reduce the SW-GW coupling errors. The realistic implementation of vadose zone processes, SW-GW coupling approach, and the spatiotemporal heterogeneity of SW-GW interactions was demonstrated critical to accurately represent soil water and groundwater system. The developed STEMMUS-MODFLOW model can be further equipped with different complexity of vadose zone physics (thermal flow, soil water and heat coupling transfer, freeze-thaw, airflow processes), surface hydrology (snowfall, runoff), soil and plant biogeochemical process, towards an integrated groundwater-soil-plant-atmosphere earth system modelling framework.

Q5: What is the importance of vadose zone physics in understanding the ecosystem functioning (water, energy, and carbon exchanges) in cold regions?

The detailed vadose zone process model STEMMUS (Simultaneous Transfer of Energy, Mass and Momentum in Unsaturated Soil) was coupled with the ecohydrological model Tethys-Chloris (T\&C) to investigate the role of influential physical processes during freeze-thaw cycles. Three coupling methods were used, i.e., unCPLD (T\&C coupling without STEMMUS), unCPLD-FT (T\&C coupling without STEMMUS, but with consideration of freeze-thaw process), and CPLD (T\&C coupling with STEMMUS enabling the simultaneous mass and energy transfer in the soil system and the explicit consideration of soil ice). The results suggest that additional complexity in vadose zone representation is mostly significant during the freezing and thawing periods as ice content simulations differ among models and the amount of water moving towards the freezing front was differently simulated. These discrepancies have an impact (even though limited to the beginning of the growing season) on vegetation dynamics. The leaf onset is better captured by the unCPLD and CPLD models, while a delayed onset date was reproduced by unCPLD-FT model. Nonetheless, overall patterns for the rest of the year do not differ considerably among simulations, which suggests that the more detailed description of vadose zone dynamics, by using a fully coupled water-heat model treatment, does not significantly affect the simulation of overall ecosystem response. Nevertheless, the coupled model can reveal the hidden physically based processes and mechanisms in the vadose zone that cannot be explained by uncoupled 
models, which can assist the comprehensive physical interpretations of ecosystem responses to subtle climatic changes and trends over high-altitude cold regions.

In short summary, our investigations using models with different vadose zone physics can be helpful to support the development and application of Earth system models as they suggest that a certain degree of complexity might be necessary for specific analyses.

\subsection{Limitations and outlooks}

Current interpretation of soil freeze-thaw process is largely based on the observation of soil liquid water content and temperature, while lack of precise measurements of soil ice content and soil freezing water characteristic curve. In absence of these observations, the dynamics of soil hydrothermal properties cannot be consistently validated and furthermore the divergence might arise. Direct measurement of soil ice content has been reported using gas dilatometry (Spaans \& Baker, 1996), dielectric spectroscopy (Bittelli et al., 2004) and heat pulse probe (Liu \& Si, 2011) method. However, these methods are either infeasible for specific soil types (silty loam and clay soil, Bittelli et al., 2004) or inevitably overestimated soil ice content, which inherently limit their usage. Recently, Zhou et al. (2014) proposed an indirect method and demonstrated its validity for achieving the dynamics of soil ice content. It is realized at the laboratory scale by the simultaneous measurement of soil total water content and liquid water content using gamma ray attenuation and time domain reflectometry approach, respectively. More efforts on designing the laboratory experiments for different soil types, freezing and thawing conditions are imperative to accurately understand soil freeze-thaw process and validate the frozen soil model physics.

On the other hand, how the plants respond to the water stress is the key process that controls and regulates the water and carbon exchanges between land surface and atmosphere in arid and semi-arid environment, where especially the water stress is projected to increase under future climate change. Researchers have contributed lots of efforts to understanding and interpreting such process from the plant physiology and hydraulic perspective. Traditional Feddes-type root water uptake models have been developed and widely used in current LSMs and crop models (Van Dam, 2000; Jones et al., 2003; Šimůnek et al., 2008), which is also the case for our model (Yu et al., 2016). Many studies have reported that Feddes-type models cannot mimic the response of plant transpiration to water stress even considering the compensation factor (e.g., Cai et al., 2018). Researchers attempted to improve the Feddes-type model by considering the verified compensation parameterization and dynamic root growth. However, such efforts still cannot adequately represent the plant response to water stress, as i) they cannot discriminate the drought induced difference in root density; ii) more importantly, it lacks the physical hydraulic feedbacks from the whole plant level. Recently, Sulis et 
al. (2019) proposed a novel hydraulic architecture-based macroscopic root water uptake approach, in which three parameters were used to describe both the root system and leaf level traits. More inspiringly, the whole plant hydraulics theory has been developed and implemented in the updated LSMs (CLM5, Noah-MP, CoLM, Gou et al., 2018; Kennedy et al., 2019; Li et al., 2021). Root level water acquisition was coincided with the stem-level hydraulic conductance/capacitance, and leaf-level hydraulic capacitance to form the whole plant hydraulic strategy. Such plant hydraulics scheme was demonstrated superior to the previous water stress parameterization and can well explain the root compensatory, hydraulic lift/redistribution phenomenon, the effect of plant water storage, and further the vegetation-climate feedbacks (Gou et al., 2018; Kennedy et al., 2019; Li et al., 2021). The improved representation of whole plant hydraulics will provide further insight into the root water uptake process and soil-plantwater-energy interactions that is of paramount importance to quantify the water-heatcarbon exchanges across the soil-plant-atmosphere interfaces.

Moreover, the current research focused more on the 1D vadose zone processes based on the assumption that the vertical gradients of water, temperature, air pressure, and carbon is more dominant than that for the horizontal gradients. Although such an assumption is mostly valid at certain temporal and spatial scales, it is with limitations from the perspective of process understanding. The lateral water, heat, and carbon fluxes have been demonstrated of paramount importance and should be considered under certain conditions, which is especially true when it is coupled with the surface water-groundwater system (Kurylyk et al., 2016; Sjöberg et al., 2016). For the surface hydrology, the runoff (snowmelt) and routing processes are imperative to be added. All these can contribute to the enhanced understanding of the coupled water-energy-carbon exchanges at the larger scales, with the output that can be validated using the collective point scale measurements and remote sensing products.

Further efforts will focus on collecting the relevant datasets, including the high spatiotemporal resolution of precipitation and wind field for snowpack monitoring, the reliable meteorological forcing at desirable time and space scales, time series of groundwater table depth measurements, river flow, soil moisture profile measurement, and subsurface hydraulic property profile information.

For the applications, it is suggested to test our understanding for various climatic and hydro-geological environments. It has been demonstrated that some mechanisms are important in certain regions where others are not. Moreover, the importance of a specific process among others in the Earth system can change with changing environmental conditions (Kurylyk et al., 2016; Sjöberg et al., 2016; Yu et al., 2020a). For instance, vapor flow has been reported of paramount importance in cold and arid regions while not that important in humid regions (Scanlon \& Milly, 1994; Bittelli et al., 2008; Zeng et al., 2009a; Zeng et al., 2009b; Zeng et al., 2011b; a; Yu et al., 2018; 
Yu et al., 2020b). This asks for extending and validating our understandings from the point scale to the regional or even the global scale, to avoid drawing conclusions based on partial understanding, as a blind man patting an elephant. 

Appendix 


\section{Appendix A1 Frozen soil parameterization}

\section{A1.1 Unfrozen water content}

As the fixed freezing point methods is not physically realistic, the freezing point depression theory was employed in deriving the soil freezing characteristic curve (SFCC) for estimating the unfrozen water content (Koopmans and Miller, 1966; Dall'Amico, 2010). In combination with Clapeyron equation and two soil water retention curve models, two different kinds of SFCC are given below.

Clapeyron + Van Genucthen (Van Genuchten, 1980)

$$
\theta_{t o t}(h)=\left\{\begin{array}{ll}
\theta_{r}+\frac{\theta_{s}-\theta_{r}}{\left[1+|\alpha h|^{n}\right]^{m}}, & h<0 \\
\theta_{s}, & h \geq 0
\end{array},\right.
$$

where $\alpha$ is related to the inverse air-entry pressure. $\theta_{t o t}, \theta_{s}$, and $\theta_{r}$ are the total water content, saturated water content and the residual water content, respectively; $h(\mathrm{~m})$ is the pre-freezing soil water potential; $m$ is the empirical parameter. The parameter $m$ is a measure of the pore-size distribution and can be expressed as $m=1-1 / n$, which in turn can be determined by fitting van Genuchten's analytical model (Van Genuchten, 1980). The unfrozen water content was estimated by employing soil freezing characteristic curve (SFCC) (Dall'Amico, 2010)

$$
\theta_{L}(h, T)=\theta_{r}+\frac{\theta_{S}-\theta_{r}}{\left[1+\left|\alpha\left(h+h_{F r z}\right)\right|^{n}\right]^{m}},
$$

where $\theta_{L}$ is the liquid water content, $L_{f}\left(\mathrm{~J} \mathrm{~kg}^{-1}\right)$ is the latent heat of fusion, $g\left(\mathrm{~m} \mathrm{~s}^{-2}\right)$ is the gravity acceleration, $T_{0}\left(273.15{ }^{\circ} \mathrm{C}\right)$ is the absolute temperature. $h(\mathrm{~m})$ is the prefreezing pressure and $\alpha, n$, and $m$ are the van Genuchten fitting parameters. $h_{F r z}(\mathrm{~m})$ is the soil freezing potential.

$$
h_{F r z}=\frac{L_{f}}{g T_{0}}\left(T-T_{0}\right) \cdot H\left(T-T_{C R I T}\right) \text {, }
$$

where $T\left({ }^{\circ} \mathrm{C}\right)$ is the soil temperature. $H$ is the Heaviside function, whose value is zero for negative argument and one for positive argument, $T_{C R I T}\left({ }^{\circ} \mathrm{C}\right)$ is the soil freezing temperature.

$$
T_{C R I T}=T_{0}+\frac{g h T_{0}}{L_{f}}
$$

Clapeyron + Clapp and Hornberger (Clapp and Hornberger, 1978)

$$
\theta_{L}(h, T)=\theta_{s}\left(\frac{L_{f}}{g \psi_{s}} \frac{T-T_{f}}{T}\right)^{-1 / b},
$$

where $\psi_{s}(\mathrm{~m})$ is the air-entry pore water potential, $b$ is the empirical Clapp and Hornberger parameter.

\section{A1.2 Hydraulic conductivity}

According to the pore-size distribution model (Mualem, 1976), the unsaturated hydraulic conductivity using Clapp and Hornberger, van Genuchten method can be expressed as, 


$$
\begin{aligned}
& K_{L h}=K_{s}\left(\theta / \theta_{s}\right)^{3+2 / \beta}, \\
& K_{L h}=K_{s} S_{e}^{l}\left[1-\left(1-S_{e}^{1 / m}\right)^{m}\right]^{2}, \\
& S_{e}=\frac{\theta-\theta_{r}}{\theta_{s}-\theta_{r}}, \\
& m=1-1 / n,
\end{aligned}
$$

where $K_{L h}$ and $K_{S}\left(\mathrm{~m} \mathrm{~s}^{-1}\right)$ are the hydraulic conductivity and saturated hydraulic conductivity. $\beta(=1 / b)$ is the empirical Clapp and Hornberger parameter. $S_{e}$ is the effective saturation. $l, n$, and $m$ are the van Genuchten fitting parameters.

The block effect of the ice presence in soil pores on the hydraulic conductivity is generally characterized by a correction coefficient, which is a function of ice content (Taylor and Luthin, 1978; Hansson et al., 2004),

$$
\begin{aligned}
& K_{f L h}=10^{-E_{i} Q} K_{L h}, \\
& Q=\left(\rho_{i} \theta_{i} / \rho_{L} \theta_{L}\right),
\end{aligned}
$$

where $K_{f L h}\left(\mathrm{~m} \mathrm{~s}^{-1}\right)$ is the hydraulic conductivity in frozen soils, $K_{L h}\left(\mathrm{~m} \mathrm{~s}^{-1}\right)$ is the hydraulic conductivity in unfrozen soils at the same negative pressure or liquid moisture content, $Q$ is the mass ratio of ice to total water, and $E_{i}$ is the empirical constant that accounts for the reduction in permeability due to the formation of ice (Hansson et al., 2004).

\section{A1.3 Thermal properties}

\section{1) Heat capacity}

The volumetric heat capacity is the average of the soil component capacity weighted by its fraction.

$$
C=\sum_{i=1}^{6} C_{j} \theta_{j}
$$

where $C_{j}$ and $\theta_{j}$ are the volumetric heat capacity and volumetric fraction of the $j$ th soil constituent $\left(\mathrm{J} \mathrm{cm}-3{ }^{\circ} \mathrm{C}-1\right)$. The components are (1) water, (2) air, (3) quartz particles, (4) other minerals, (5) organic matter, and (6) ice (see Table A1.1).

\section{2) Thermal Conductivity}

The method used to calculate the frozen soil heat conductivity can be divided into three categories: i) empirical method (e.g., Campbell method as used in Hansson et al., 2004), ii) Johansen method (Johansen, 1975), and iii) de Vires method (de Vries, 1963). Due to the necessity in the calibration of parameters, the empirical Campbell method is not easy to adapt and rarely employed in LSMs and thus not discussed in the current context. The other variations of Johansen method and de Vries method, in which the parameters are based on soil texture information, i.e., Farouki method (Farouki, 1981) and the simplified de Vries method (Tian et al., 2016), were further incorporated into STEMMUS-FT. 
Johansen method (Johansen, 1975)

The soil thermal conductivity is the weighted function of soil dry and saturated thermal conductivity,

$$
\lambda_{e f f}=K_{e}\left(\lambda_{s a t}-\lambda_{d r y}\right)+\lambda_{d r y}
$$

where the $\lambda_{\text {sat }}\left(\mathrm{W} \mathrm{m}^{-1}{ }^{\circ} \mathrm{C}^{-1}\right)$ is saturated thermal conductivity, $\lambda_{\text {dry }}\left(\mathrm{W} \mathrm{m}^{-1}{ }^{\circ} \mathrm{C}^{-1}\right)$ is the dry thermal conductivity, $K_{e}$ is the Kersten number, which can be expressed as

$$
K_{\mathrm{e}}=\left\{\begin{array}{ll}
\log \left(\theta / \theta_{s}\right)+1.0, & \theta / \theta_{s}>0.05 \\
0.7 \log \left(\frac{\theta}{\theta_{s}}\right)+1.0, & \theta / \theta_{s}>0.1 \\
\theta / \theta_{s}, & \text { frozen soil }
\end{array},\right.
$$

The saturated thermal conductivity $\lambda_{\text {sat }}$ is the weighted value of its components (soil particles $\lambda_{\text {soil }}$ and water $\lambda_{\mathrm{w}}$ ),

$$
\lambda_{\text {sat }}=\lambda_{\text {soil }}^{1-\theta_{s}} \lambda_{w}^{\theta_{s}}
$$

where the solid soil thermal conductivity $\lambda_{\text {soil }}$ can be described as

$$
\lambda_{\text {soil }}=\lambda_{\mathrm{qtz}}^{\mathrm{qtz}} \lambda_{\mathrm{o}}^{1-\mathrm{qtz}}
$$

where the $\lambda_{\mathrm{qtz}}$ and $\lambda_{\mathrm{o}}\left(\mathrm{W} \mathrm{m}^{-1}{ }^{\circ} \mathrm{C}^{-1}\right)$ are the thermal conductivity of the quartz and other soil particles, qtz is the volumetric quartz fraction.

The dry soil thermal conductivity is a function of dry soil density $\rho_{d}$,

$$
\begin{aligned}
& \lambda_{d r y}=\frac{0.135 \rho_{d}+64.7}{2700-0.947 \rho_{d}}, \\
& \rho_{d}=\left(1-\theta_{s}\right) \cdot 2700,
\end{aligned}
$$

Farouki method (Farouki, 1981)

Similar to Johansen method, the weighted method between the saturated and dry thermal conductivities is utilized by Farouki method to estimate soil thermal conductivity. The difference between Farouki method and Johansen method is to express the dry thermal conductivity and solid soil thermal conductivity as the function of soil texture. Equation A1.13 can be replaced with,

$$
\lambda_{\text {soil }}=\frac{8.80 \cdot(\% \text { sand })+2.92 \cdot(\% \text { clay })}{(\% \text { sand })+(\% \text { clay })}
$$

where \%sand, \%clay are the volumetric fraction of sand and clay.

de Vires method (de Vries, 1963)

$$
\lambda_{\text {eff }}=\left(\sum_{j=1}^{6} k_{j} \theta_{j} \lambda_{\mathrm{j}}\right)\left(\sum_{j=1}^{6} k_{j} \theta_{j}\right)^{-1} \text {, }
$$

where $k_{j}$ is the weighting factor for each components; $\theta_{j}$ the volumetric fraction of the $j$ th constituent; $\lambda_{\mathrm{j}}\left(\mathrm{W} \mathrm{m}^{-1}{ }^{\circ} \mathrm{C}^{-1}\right)$ the thermal conductivity of the $j$ th constituent. The six components are: 1 water, 2 air, 3 quartz particles, 4 clay minerals, 5 organic matter, and 6 ice. (see Table A1.1).

$$
k_{j}=\frac{2}{3}\left[1+\left(\frac{\lambda_{\mathrm{j}}}{\lambda_{1}}-1\right) g_{\mathrm{j}}\right]^{-1}+\frac{1}{3}\left[1+\left(\frac{\lambda_{\mathrm{j}}}{\lambda_{1}}-1\right)\left(1-2 g_{\mathrm{j}}\right)\right]^{-1},
$$

where $g_{\mathrm{j}}$ is the shape factor of the $j$ th constituent (see Table A1.1), of which the shape 
factor of the air $g_{2}$ can be determined as follows,

$$
g_{2}=\left\{\begin{array}{ll}
0.013+\left(\frac{0.022}{\theta_{\text {wilting }}}+\frac{0.298}{\theta_{S}}\right) \theta_{L}, & \theta_{L}<\theta_{\text {wilting }} \\
0.035+\frac{0.298}{\theta_{S}} \theta_{L}, & \theta_{L} \geq \theta_{\text {wilting }}
\end{array},\right.
$$

Table A1.1. Properties of soil constituents (de Vries, 1963)

\begin{tabular}{llllll}
\hline Substance & $j$ & $\lambda_{j}\left(\mathrm{mcal} \mathrm{cm}^{-1} \mathrm{~s}^{-1}{ }^{\circ} \mathrm{C}^{-1}\right)$ & $C_{j}\left(\mathrm{mcal} \mathrm{cm}^{-1} \mathrm{~s}^{-1}{ }^{\circ} \mathrm{C}^{-1}\right)$ & $\rho_{j}\left(\mathrm{~g} \mathrm{~cm}^{-3}\right)$ & $g_{j}$ \\
\hline Water & 1 & 1.37 & 1 & 1 & $\ldots$ \\
Air & 2 & 0.06 & 0.0003 & 0.00125 & $\ldots$ \\
Quartz & 3 & 21 & 0.48 & 2.66 & 0.125 \\
Clay minerals & 4 & 7 & 0.48 & 2.65 & 0.125 \\
Organic matter & 5 & 0.6 & 0.6 & 1.3 & 0.5 \\
Ice & 6 & 5.2 & 0.45 & 0.92 & 0.125 \\
\hline
\end{tabular}

Simplified de Vries model (Tian et al., 2016)

Tian et al. (2016) proposed the simplified de Vries method as an alternative method of traditional de Vries method. In this method, the thermal conductivity of soil particles component can be directly estimated based on the relative contribution of measured soil constitutes.

$$
\lambda_{e f f}=\frac{\theta_{w} \lambda_{w}+k_{i} \theta_{i} \lambda_{i}+k_{a} \theta_{a} \lambda_{a}+k_{\min } \theta_{\min } \lambda_{\min }}{\theta_{w}+k_{i} \theta_{i}+k_{a} \theta_{a}+k_{\min } \theta_{\min }}
$$

where $k_{\min }$, can be derived by Eq. A1.18, is the weighting factor of soil minerals, $\theta_{\min }$ is the volumetric fraction of soil minerals, $\lambda_{\min }\left(\mathrm{W} \mathrm{m}^{-1}{ }^{\circ} \mathrm{C}^{-1}\right)$ is the thermal conductivity of soil minerals, can be expressed as the weighted value of its components,

$$
\lambda_{\text {min }}=\lambda_{\text {sand }}^{f_{\text {sand }}} \lambda_{\text {silt }}^{f_{\text {silt }}} \lambda_{\text {clay }}^{f_{\text {clay }}}
$$

where $f_{\text {sand }}, f_{\text {silt }}$, and $f_{\text {clay }}$ are the volumetric fraction of soil sand, silt and clay, respectively. The shape factor of soil minerals is determined as the volumetrically weighted arithmetic mean of the constituent shape factors,

$$
g_{a, \min }=g_{a, \text { sand }} f_{\text {sand }}+g_{a, \text { silt }} f_{\text {silt }}+g_{a, \text { clay }} f_{\text {clay }} \text {, }
$$

where $g_{a, \text { sand }}, g_{a, \text { silt }}, g_{a, \text { clay }}$ are the shape factors of soil sand, silt and clay, their values are $0.182,0.0534$ and 0.00775, respectively (Tarnawski and Wagner, 1992; Tarnawski and Wagner, 1993; Tian et al., 2016).

\section{A1.4 Temperature dependence of matric potential and hydraulic conductivity}

Soil matric potential and hydraulic conductivity are dependent on soil temperature in STEMMUS (Zeng and Su, 2013), which is related to soil water surface tension and viscous flow effects. The temperature dependence of matric potential can be expressed as

$$
h_{\text {Cor }_{-} T}=h e^{-C_{\psi}\left(T-T_{r}\right)}
$$

where, $h_{\text {Cor }_{-} T}$ is the soil matric potential considering temperature effect; $C_{\psi}$ is the 
temperature coefficient, assumed to be constant as $0.0068{ }^{\circ} \mathrm{C}^{-1}$ (Milly, 1982); $T_{r}$ is the reference temperature $\left(20^{\circ} \mathrm{C}\right)$.

Hydraulic conductivity, taken into account the temperature effect, can be written as

$$
K(\theta, T)=K_{S} K_{r}(\theta) K_{T}(T)
$$

where $K_{r}(\theta)$ is the relative hydraulic conductivity, $K_{T}(T)$ is the temperature coefficient of hydraulic conductivity, expressed as

$$
K_{T}(T)=\frac{\mu_{w}\left(T_{r}\right)}{\mu_{w}(T)}
$$

where $\mu_{\mathrm{w}}$ is the viscosity of water. The dynamic viscosity of water can be written as

$$
\mu_{w}(T)=\mu_{w 0} \exp \left[\frac{\mu_{1}}{R(T+133.3)}\right]
$$

where $\mu_{w 0}$ is the water viscosity at reference temperature, $\mu_{1}=4.7428\left(\mathrm{~kJ} \mathrm{~mol}^{-1}\right), R$ $=8.314472\left(\mathrm{~J} \mathrm{~mol}^{-1}{ }^{\circ} \mathrm{C}^{-1}\right), T$ is temperature in ${ }^{\circ} \mathrm{C}$.

\section{A1.5 Gas conductivity}

According to Darcy's law, the gas conductivity can be expressed as

$$
K_{g}=\frac{K_{r g}\left(S_{a}\right) K_{s} \mu_{w}}{\rho_{L} g \mu_{g}}
$$

where $\mu_{g}$ is gas viscosity, and the air viscosity; $K_{r g}$ is the relative gas conductivity, which is a function of effective gas saturation and is defined by Van Genuchten-Mualem model,

$$
K_{r g}=\left(1-S_{a}^{0.5}\right)\left[1-\left(1-\left(1-S_{a}\right)^{\frac{1}{m}}\right)^{m}\right]^{2}
$$

\section{A1.6 Gas phase density}

The gas in the soil pores includes water vapor and dry air. The water vapor density, according to Kelvin's law, is expressed as (Philip and Vries, 1957)

$$
\rho_{V}=\rho_{s V} H_{r}, \quad H_{r}=\exp \left(\frac{h g}{R_{V} T}\right)
$$

where $\rho_{S V}$ is the density of saturated water vapor; $H_{r}$ is the relative humidity; $R_{V}$ (461.5 $\mathrm{J} \mathrm{kg}^{-1} \mathrm{~K}^{-1}$ ) is the specific gas constant for vapor; $g$ is the gravitation acceleration; $T$ is temperature.

The gradient of the water vapor density with respect to $z$ can be expressed as

$$
\frac{\partial \rho_{V}}{\partial z}=\left.\rho_{S V} \frac{\partial H_{r}}{\partial T}\right|_{h}+\left.\rho_{S V} \frac{\partial H_{r}}{\partial h}\right|_{T}+H_{r} \frac{\partial \rho_{V}}{\partial T} \frac{\partial T}{\partial z}
$$

Assuming that the pore-air and pore-vapor could be considered as ideal gas, then soil dry air and vapor density can be given as

$$
\rho_{d a}=\frac{P_{d a}}{R_{d a} T}, \quad \rho_{V}=\frac{P_{V}}{R_{V} T},
$$

where $R_{d a}\left(287.1 \mathrm{~J} \mathrm{~kg}^{-1} \mathrm{~K}^{-1}\right)$ is the specific gas constant for dry air; $P_{d a}$ and $P_{V}(\mathrm{~Pa})$ are 
the dry air pressure and vapor pressure. Following Dalton's law of partial pressure, the mixed soil air pressure is the sum of the dry air pressure and the vapor pressure, i.e. $P_{g}=P_{d a}+P_{V}$. Thus, combining with Eq. A1.31, the soil dry air density can be derived as

$$
\rho_{d a}=\frac{P_{g}}{R_{d a} T}-\frac{\rho_{V} R_{V}}{R_{d a}},
$$

The derivation of dry air density with respect to time and space are

$$
\begin{aligned}
& \frac{\partial \rho_{d a}}{\partial t}=X_{a a} \frac{\partial P_{g}}{\partial t}+X_{a T} \frac{\partial T}{\partial t}+X_{a h} \frac{\partial h}{\partial t}, \\
& \frac{\partial \rho_{d a}}{\partial z}=X_{a a} \frac{\partial P_{g}}{\partial z}+X_{a T} \frac{\partial T}{\partial z}+X_{a h} \frac{\partial h}{\partial z},
\end{aligned}
$$

where

$$
\begin{aligned}
& X_{a a}=\frac{1}{R_{d a} T}, \\
& X_{a T}=\left[\frac{P_{g}}{R_{d a} T^{2}}+\frac{R_{V}}{R_{d a}}\left(H_{r} \frac{\partial \rho_{s V}}{\partial T}+\rho_{s V} \frac{\partial H_{r}}{\partial T}\right)\right], \\
& X_{a h}=-\frac{\partial \rho_{V}}{\partial h},
\end{aligned}
$$

\section{A1.7 Vapor diffusivity}

The isothermal vapor diffusivity is followed the simple theory and expressed as

$$
D_{V_{-} I s o}=D_{V} \frac{\partial \rho_{V}}{\partial h}=D_{a t m} v \tau \theta_{a} \frac{\partial \rho_{V}}{\partial h},
$$

where $v$ is set to $1, \tau=\theta_{a}^{2 / 3}$, and $D_{a t m}=0.229\left(1+\frac{T}{273}\right)^{1.75}\left(\mathrm{~m}^{2} \mathrm{~s}^{-1}\right)$.

The thermal vapor diffusivity is given by considering the enhancement factor as

$$
D_{V_{-} \text {NonIso }}=D_{V} \frac{\partial \rho_{V}}{\partial T}=D_{a t m} \eta \frac{\partial \rho_{V}}{\partial T} \text {, }
$$

where $\eta$ is the thermal enhancement factor.

\section{A1.8 Gas dispersivity}

According to Bear (1972), the gas phase longitudinal dispersivity $D v g$ is expressed as

$$
D_{V g}=\alpha_{L_{-} i} q_{i}, \quad i=\text { gas or liquid, }
$$

where $q_{i}$ is the pore fluid flux in phase $\mathrm{i}$, and $\alpha_{L_{-} i}$ is the longitudinal dispersivity in phase $i$, which can be related to the soil saturation as

$$
\alpha_{L_{-} i}=\alpha_{L_{-} S a t}\left[13.6-16 \times \frac{\theta_{g}}{\epsilon}+3.4 \times\left(\frac{\theta_{g}}{\epsilon}\right)^{5}\right] \text {, }
$$

Following Grifoll's work, the saturation dispersivity can be set to $0.078 \mathrm{~m}$ in case of lacking dispersivity values. 


\section{Appendix A2 Calculation of surface evapotranspiration}

The one step calculation of actual soil evaporation $\left(E_{s}\right)$ and potential transpiration $\left(T_{p}\right)$ is achieved by incorporating canopy minimum surface resistance and actual soil resistance into the Penman-Monteith model (i.e., the $\mathrm{ET}_{\text {dir }}$ method in $\mathrm{Yu}$ et al. 2016). LAI is implicitly used to partition available radiation energy into the radiation reaching the canopy and soil surface.

$$
\begin{aligned}
T_{p}= & \frac{\Delta\left(R_{n}^{c}-G\right)+\rho_{a} c_{p} \frac{\left(e_{s}-e_{a}\right)}{r_{a}^{c}}}{\lambda\left(\Delta+\gamma\left(1+\frac{r_{c, m i n}}{r_{a}^{c}}\right)\right)} \\
E_{s}= & \frac{\Delta\left(R_{n}^{S}-G\right)+\rho_{a} c_{p} \frac{\left(e_{s}-e_{a}\right)}{r_{a}^{S}}}{\lambda\left(\Delta+\gamma\left(1+\frac{r_{s}}{r_{a}^{s}}\right)\right)}
\end{aligned}
$$

where $R_{n}^{c}$ and $R_{n}^{S}\left(\mathrm{MJ} \mathrm{m}^{-2}\right.$ day $\left.^{-1}\right)$ are the net radiation at the canopy surface and soil surface, respectively; $\rho_{a}\left(\mathrm{~kg} \mathrm{~m}^{-3}\right)$ is the air density; $c_{p}\left(\mathrm{~J} \mathrm{~kg}^{-1} \mathrm{~K}^{-1}\right)$ is the specific heat capacity of air; $r_{a}^{c}$ and $r_{a}^{s}\left(\mathrm{~s} \mathrm{~m}^{-1}\right)$ are the aerodynamic resistance for canopy surface and soil surface, respectively; $r_{c, \min }\left(\mathrm{s} \mathrm{m}^{-1}\right)$ is the minimum canopy surface resistance; and $r_{s}\left(\mathrm{~s} \mathrm{~m}^{-1}\right)$ is the soil surface resistance.

The net radiation reaching the soil surface can be calculated using the Beer's law:

$$
R_{n}^{s}=R_{n} \exp (-\tau L A I)
$$

And the net radiation intercepted by the canopy surface is the residual part of total net radiation:

$$
R_{n}^{c}=R_{n}(1-\exp (-\tau L A I))
$$

The minimum canopy surface resistance $r_{c, \min }$ is given by:

$$
r_{c, \min }=r_{l, \min } / L A I_{e f f}
$$

where $r_{l, \min }$ is the minimum leaf stomatal resistance; $L A I_{\text {eff }}$ is the effective leaf area index, which considers that generally the upper and sunlit leaves in the canopy actively contribute to the heat and vapor transfer.

The soil surface resistance can be estimated following van de Griend and Owe (1994),

$$
\begin{array}{ll}
r_{s}=r_{s l} & \theta_{1}>\theta_{\text {min }}, h_{1}>-100000 \mathrm{~cm} \\
r_{s}=r_{s l} e^{a\left(\theta_{\min }-\theta_{1}\right)} & \theta_{1} \leq \theta_{\text {min }}, h_{1}>-100000 \mathrm{~cm} \\
r_{s}=\infty & h_{1} \leq-100000 \mathrm{~cm}
\end{array}
$$

where $r_{s l}\left(10 \mathrm{~s} \mathrm{~m}^{-1}\right)$ is the resistance to molecular diffusion of the water surface; $a$ $(0.3565)$ is the fitted parameter; $\theta_{1}$ is the topsoil water content; $\theta_{\min }$ is the minimum 
water content above which soil is able to deliver vapor at a potential rate.

The root water uptake term described by Feddes et al. (1978) is:

$$
S(h)=\alpha(h) S_{p}
$$

where $\alpha(h)$ (dimensionless) is the reduction coefficient related to soil water potential $h$; and $S_{p}\left(\mathrm{~s}^{-1}\right)$ is the potential water uptake rate.

$$
S_{p}=b(z) T_{p}
$$

where $b(z)$ is the normalized water uptake distribution, which describes the vertical variation of the potential extraction term, $S_{p}$, over the root zone. Here the asymptotic function was used to characterize the root distribution as described in the relevant studies (Gale and Grigal, 1987; Jackson et al., 1996; Yang et al., 2009; Zheng et al., 2015b). $T_{p}$ is the potential transpiration in Equation A2.1. 


\section{Appendix A3 Snowpack module}

\section{A3.1 Snowpack module governing equations}

\section{A3.1.1 Mass balance equation}

The increase or decrease of snow water equivalence with time equals the difference of incoming and outgoing water fluxes:

$$
\frac{d W_{S W E}}{d t}=P_{r}+P_{S}-M_{r}-E
$$

where $W_{S W E}(\mathrm{~m})$ is the snow water equivalent, $P_{r}\left(\mathrm{~m} \mathrm{~s}^{-1}\right)$ is the rainfall rate, $P_{S}\left(\mathrm{~m} \mathrm{~s}^{-1}\right)$ is the snowfall rate, $M_{r}\left(\mathrm{~m} \mathrm{~s}^{-1}\right)$ is the meltwater outflow from the snowpack, and $E$ is the sublimation from the snowpack.

\section{A3.1.2 Energy balance equation}

The energy balance of snowpack can be expressed as follows:

$$
\frac{d U}{d t}=Q_{s n}+Q_{l i}+Q_{p}+Q_{g}-Q_{l e}+Q_{h}+Q_{e}-Q_{m}
$$

where $Q_{s n}\left(\mathrm{~W} \mathrm{~m}^{-2}\right)$ is the net shortwave radiation, $Q_{l i}\left(\mathrm{~W} \mathrm{~m}^{-2}\right)$ is the incoming longwave radiation, $Q_{p}\left(\mathrm{~W} \mathrm{~m}^{-2}\right)$ is the advected heat from precipitation, $Q_{g}\left(\mathrm{~W} \mathrm{~m}^{-2}\right)$ is the ground heat flux, $Q_{l e}\left(\mathrm{~W} \mathrm{~m}^{-2}\right)$ is the outgoing longwave radiation, $Q_{h}\left(\mathrm{~W} \mathrm{~m}^{-2}\right)$ is the sensible heat flux, $Q_{e}\left(\mathrm{~W} \mathrm{~m}^{-2}\right)$ is the latent heat flux due to sublimation and condensation, and $Q_{m}\left(\mathrm{~W} \mathrm{~m}^{-2}\right)$ is the advected heat removed by meltwater.

Equations A3.1 and A3.2 form a coupled set of first-order, nonlinear ordinary differential equations. The Euler predictor-corrector approach was employed in the UEB model to solve the initial value problems of these equations (Tarboton and Luce, 1996).

\section{A3.2 Snowpack module constitutive equations}

\section{A3.2.1 Mass balance}

The observed precipitation rate $P$, can be partitioned into rain $P_{r}$, and snow $P_{S}$, (both in terms of water equivalence depth) based on air temperature $T_{a}$

$$
\begin{array}{ll}
P_{r}=P & T_{a} \geq T_{r} \\
P_{r}=P\left(T_{a}-T_{b}\right) /\left(T_{r}-T_{b}\right) & T_{b}<T_{a}<T_{r} \\
P_{r}=0 & T_{a}<T_{b} \\
P_{s}=F\left(P-P_{r}\right) &
\end{array}
$$


where $T_{r}$ is a threshold air temperature above which all precipitation is rain and $T_{b}$ is a threshold air temperature below which all precipitation is snow. $F$ is employed to account for the wind redistribution effect on the accumulation of snow.

The amount of water sublimate from the snowpack is

$$
E=\rho_{a}\left(q_{s}-q_{a}\right) K_{e}
$$

where $\rho_{a}$ is air density, $q_{s}$ is the surface specific humidity, $q_{a}$ is the air humidity. $K_{e}$ is turbulent transfer conductance for latent heat.

The meltwater outflow from the snowpack can be expressed as

$$
M_{r}=K_{\text {sat }} S^{* 3}
$$

where $K_{\text {sat }}$ is the snow saturated hydraulic conductivity and $S^{*}$ is the relative saturation in excess of water retained by capillary forces. $S^{*}$ is given by:

$$
S^{*}=\frac{\text { liquid water volume }- \text { capillary retention }}{\text { pore volume }- \text { capillary retention }}
$$

\section{A3.2.2 Energy balance}

The net shortwave radiation is calculated from incident shortwave radiation $Q_{s i}$ and albedo $\alpha$, which is a function of snow age and solar illumination angle.

$$
Q_{s n}=(1-\alpha) Q_{s i}
$$

The Stefan-Boltzmann equation is used to estimate the incoming longwave radiation $Q_{l e}$ and outgoing longwave radiation $Q_{l i}$ based on air temperature $T_{a}$ and snow surface temperature $T_{S S}$, respectively.

$$
\begin{aligned}
& Q_{l e}=\varepsilon_{s} \sigma T_{S S}{ }^{4} \\
& Q_{l i}=\varepsilon_{a} \sigma T_{a}{ }^{4}
\end{aligned}
$$

where $\varepsilon_{s}$ is emissivity of snow, $\sigma$ is the Stefan Boltzmann constant. $\varepsilon_{a}$ is the air emissivity, which is based on air vapor pressure, air temperature and cloud cover.

The latent heat flux, $Q_{e}$ and sensible heat flux, $Q_{h}$ are modeled using bulk aerodynamic formulae:

$$
Q_{h}=\rho_{a} C_{p}\left(T_{a}-T_{S S}\right) K_{h}
$$




$$
Q_{e}=\rho_{a} h_{v}\left(q_{s}-q_{a}\right) K_{e}=K_{e} \frac{0.622 h_{v}}{R_{d} T_{a}}\left(e_{a}-e_{s}\left(T_{S S}\right)\right)
$$

$K_{h}$ and $K_{e}$ are turbulent transfer conductance for sensible and latent heat respectively. Under neutral atmospheric conditions $K_{h}$ and $K_{e}$ can be given by

$$
K_{e}=K_{h}=\frac{k_{v}^{2} u}{\left[\ln \left(z_{m} / z_{0}\right]^{2}\right.}
$$

where $z_{\mathrm{m}}$ is the measurement height for wind speed, air temperature, and humidity, $u$ is the wind speed, $k_{\mathrm{v}}$ is von Kármán's constant (0.4), and $z_{0}$ is the aerodynamic roughness.

The heat advected with the snow melt outflow, relative to the solid reference state is:

$$
Q_{m}=\rho_{w} h_{f} M_{r}
$$

The advected heat $Q_{p}$ is the energy required to convert precipitation to the reference state $\left(0{ }^{\circ} \mathrm{C}\right.$ ice phase $)$. The temperature of rain and snow is taken as the greater and lesser of the air temperature and freezing point. With different temperature inherent to snow and rain, this amount of energy can be described as

$$
Q_{p}=\rho_{w} C_{s} P_{s} \cdot \min \left(T_{a}, 0\right)+P_{r}\left[\rho_{w} h_{f}+\rho_{w} C_{w} \cdot \max \left(T_{a}, 0\right)\right]
$$

\section{A3.2.3 Snow temperatures}

\section{1) Snowpack temperature, $T_{S N}$}

Snowpack temperature $T_{S N}$, a quantity important for energy fluxes into the snow, is determined diagnostically from the state variables energy content $U$, and water equivalence $W_{S W E}$, as follows, recalling that energy content $U$ is defined relative to $0^{\circ} \mathrm{C}$ ice phase.

$$
\begin{array}{lcc}
T_{S N}=\frac{U}{\rho_{w} W_{S W E} C_{i}+\rho_{g} D_{e} C_{g}}, & U<0, & \text { all solid phase } \\
T_{S N}=0, & 0<U<\rho_{w} W_{S W E} h_{f}, & \text { solid and liquid mixture } \\
T_{S N}=\frac{U-\rho_{w} W_{S W E} h_{f}}{\rho_{w} W C_{w}+\rho_{g} D_{e} C_{g}}, & U>\rho_{w} W_{S W E} h_{f}, & \text { all liquid phase }
\end{array}
$$

where $\rho_{w} W_{S W E} C_{i}$ is the heat capacity of the snow $\left(\mathrm{kJ}{ }^{\circ} \mathrm{C}^{-1} \mathrm{~m}^{-2}\right), \rho_{w}$ is the density of water $\left(1000 \mathrm{~kg} \mathrm{~m}^{-3}\right)$ and $C_{i}$ is the specific heat of ice $\left(2.09 \mathrm{~kJ} \mathrm{~kg}^{-1}{ }^{\circ} \mathrm{C}^{-1}\right) . \rho_{g} D_{e} C_{g}$ is the heat capacity of the soil layer $\left(\mathrm{kJ}^{\circ} \mathrm{C}^{-1} \mathrm{~m}^{-2}\right), \rho_{g}$ is the soil density and $C_{g}$ the specific heat of soil. $D_{e}$ is the depth of soil that interacts thermally with the snowpack. These together determine snowpack temperature $T_{S N}$ when energy content $U<0$. 
Otherwise, $\rho_{w} W_{S W E} h_{f}$ is the heat required to melt all the snow water equivalence at 0 ${ }^{\circ} \mathrm{C}\left(\mathrm{kJ} \mathrm{m}^{-2}\right), h_{f}$ is the heat of fusion $\left(333.5 \mathrm{~kJ} \mathrm{~kg}^{-1}\right)$ and $\mathrm{U}$ in relation to this determines the solid-liquid phase mixtures. The liquid fraction $L_{f r}=U /\left(\rho_{w} W_{S W E} h_{f}\right)$ quantifies the mass fraction of total snowpack (liquid and ice) that is liquid.

Although in Equation A3.18, $W_{S W E}$ is always 0 as a completely liquid snowpack cannot exist, we present this equation for completeness to keep track of energy content during periods of intermittent snow cover. $\rho_{w} W_{S W E} C_{w}$ is the heat capacity of liquid water, $C_{w}$ is the specific heat of water $\left(4.18 \mathrm{~kJ} \mathrm{~kg}^{-1}{ }^{\circ} \mathrm{C}^{-1}\right)$, is included for numerical consistency during time steps when the snowpack completely melts.

\section{2) Snow Surface Temperature, $T_{\mathrm{ss}}$}

Snow surface temperature $T_{\mathrm{SS}}$ is in general different from snowpack temperature $T_{S N}$ due to the snow insulation effect. We take into account such temperature difference using an equilibrium approach that balances energy fluxes at the snow surface. Heat conduction into the snow is calculated using the temperature gradient and thermal diffusivity of snow, approximated by:

$$
Q_{S N}=\frac{\kappa \rho_{S} C_{S}\left(T_{S S}-T_{S N}\right)}{Z_{e}}=K_{S N} \rho_{S} C_{S}\left(T_{S S}-T_{S N}\right)
$$

where $\kappa$ is snow thermal diffusivity $\left(\mathrm{m}^{2} \mathrm{hr}^{-1}\right)$ and $Z_{e}(\mathrm{~m})$ an effective depth over which this thermal gradient acts. $K_{S N}\left(\kappa / Z_{e}\right)$ is termed snow surface conductance, analogous to the heat and vapor conductance. Here $K_{S N}$ is used as a tuning parameter, with this calculation used to define a reasonable range. Then assuming equilibrium at the surface, the surface energy balance gives:

$$
Q_{S N}=Q_{S n}+Q_{l i}+Q_{h}\left(T_{S S}\right)+Q_{e}\left(T_{S S}\right)+Q_{p}-Q_{l e}\left(T_{S S}\right)
$$

where the dependence of $Q_{\mathrm{h}}, Q_{\mathrm{e}}$, and $Q_{\mathrm{le}}$ on $T_{\mathrm{SS}}$ is through equations A3.11, A3.12 and A3.9 respectively.

Analogous to the derivation of the Penman equation for evaporation the functions of $T_{\mathrm{SS}}$ in this energy balance equation are linearized about a reference temperature $T^{*}$, and the equation is solved for $T_{\mathrm{ss}}$ :.

$$
=\frac{Q_{S n}+Q_{l i}+Q_{p}+K T_{a} \rho_{a} C_{p}-\frac{0.622 K h_{v} \rho_{a}\left(e_{S}\left(T^{*}\right)-e_{a}-T^{*} \Delta\right)}{P_{a}}+3 \varepsilon_{s} \sigma T^{* 4}+K_{S I}}{K_{S N} \rho_{s} C_{s}+K \rho_{a} C_{p}+\frac{0.622 \Delta K h_{v} \rho_{a}}{P_{a}}+4 \varepsilon_{S} \sigma T^{* 3}}
$$

where $\Delta=d e_{s} / d T$ and all temperatures are absolute in $(\mathrm{K})$. This equation is used in an iterative procedure with an initial estimate $T^{*}=T_{\mathrm{a}}$, in each iteration replacing $T^{*}$ by the 
latest $T_{\mathrm{SS}}$. The procedure converges to a final $T_{\mathrm{SS}}$ which, if less than freezing, is used to calculate surface energy fluxes. If the final $T_{\mathrm{SS}}$ is greater than freezing it means that the energy input to the snow surface cannot be balanced by thermal conduction into the snow. Surface melt will occur and the infiltration of meltwater will account for the energy difference and $T_{\mathrm{SS}}$ is then set to $0^{\circ} \mathrm{C}$.

\section{A3.2.4 Albedo calculation}

\section{1) Ground albedo}

Instead of the constant bare soil albedo in the original UEB model, the bare soil albedo is expressed as a decreasing linear function of soil moisture in STEMMUS-UEB.

$$
\begin{aligned}
& \alpha_{g, v}=\alpha_{s a t}+\min \left\{\alpha_{s a t}, \max [(0.11-0.4 \theta), 0]\right\} \\
& \alpha_{g, i r}=2 \alpha_{g, v}
\end{aligned}
$$

where $\alpha_{g, v}$ and $\alpha_{g, i r}$ are the bare soil and ground albedo for the visible and infrared band, respectively. $\alpha_{\text {sat }}$ is the saturated soil albedo, depending on local soil color. $\theta$ is the surface volumetric soil moisture.

\section{2) Vegetation albedo}

The calculation of vegetation albedo is developed to capture the essential features of a two-stream approximation model using an asymptotic equation. It approaches the underlying surface albedo $\alpha_{g, \lambda}$ or the thick canopy albedo $\alpha_{c, \lambda}$ when the $L_{S A I}$ is close to zero or infinity.

$$
\begin{aligned}
& \alpha_{V e g, b, \lambda}=\alpha_{c, \lambda}\left[1-\exp \left(-\frac{\omega_{\lambda} \beta L_{S A I}}{\mu \alpha_{c, \lambda}}\right)\right]+\alpha_{g, \lambda} \exp \left[-\left(1+\frac{0.5}{\mu}\right) L_{S A I}\right] \\
& \alpha_{V e g, d, \lambda}=\alpha_{c, \lambda}\left[1-\exp \left(-\frac{2 \omega_{\lambda} \beta L_{S A I}}{\alpha_{c, \lambda}}\right)\right]+\alpha_{g, \lambda} \exp \left[-2 L_{S A I}\right]
\end{aligned}
$$

where subscripts $V e g, b, d, c, g$ and $\lambda$ represent vegetation, direct beam, diffuse radiation, thick canopy, ground, and spectrum bands of either visible or infrared bands. $\mu$ is the cosine of solar zenith angle, $\omega_{\lambda}$ is the single-scattering albedo, amounting to 0.15 for the visible band and 0.85 for the infrared band, respectively, $\beta$ is assigned as $0.5, L_{S A I}$ is the sum of leaf area index LAI and stem area index SAI, and $\alpha_{c, \lambda}$ is the thick canopy albedo, which is dependent on vegetation type.

The bulk snow-free surface albedo, averaged between bare-ground albedo and vegetation albedo, is written as follows:

$$
\alpha_{\eta, \lambda}=\alpha_{V e g, \lambda} f_{V e g}+\alpha_{g, \lambda}\left(1-f_{V e g}\right)
$$


where $\alpha_{\eta, \lambda}$ is the averaged bulk snow-free surface albedo, $f_{V e g}$ is the fraction of vegetation cover.

\section{3) Snow albedo}

According to Dickinson et al. (1993), snow albedo can be expressed as a function of snow surface age and solar illumination angle. The snow surface age, which is dependent on snow surface temperature and snowfall, is updated with each time step in UEB. Visible and near infrared bands are separately treated when calculating reflectance, which are further averaged as the albedo with modifications of illumination angle and snow age. The reflectance in the visible and near infrared bands can be written as:

$$
\begin{aligned}
& \alpha_{v d}=\left(1-C_{v} S_{a g e}\right) \alpha_{v o} \\
& \alpha_{i r d}=\left(1-C_{i r} S_{a g e}\right) \alpha_{i r o}
\end{aligned}
$$

where $\alpha_{v d}$ and $\alpha_{i r d}$ represent diffuse reflectance in the visible and near-infrared bands, respectively. $C_{v}(=0.2)$ and $C_{i r}(=0.5)$ are parameters that quantify the sensitivity of the visible and infrared band albedo to snow surface aging (grain size growth), and $\alpha_{v o}$ $(=0.85)$ and $\alpha_{\text {iro }}(=0.65)$ are fresh snow reflectance in visible and infrared bands, respectively. $S_{a g e}$ is a function to account for aging of the snow surface, and is given by:

$$
S_{a g e}=\frac{\tau}{1+\tau}
$$

where $\tau$ is the non-dimensional snow surface age that is incremented at each time step by the quantity designed to emulate the effect of the growth of surface grain sizes.

$$
\Delta \tau=\frac{r_{1}+r_{2}+r_{3}}{\tau_{o}} \Delta t
$$

where $\Delta t$ is the time step in seconds with $\tau_{o}=10^{6} \mathrm{~s} . \mathrm{r}_{1}$ is the parameter to represent the effect of grain growth due to vapor diffusion, and is dependent on snow surface temperature:

$$
r_{1}=\exp \left[5000\left(\frac{1}{273.16}-\frac{1}{T_{S}}\right)\right]
$$

$\mathrm{r}_{2}$ describes the additional effect near and at the freezing point due to melt and refreeze:

$$
r_{2}=\min \left(r_{1}^{10}, 1\right)
$$

$r_{3}=0.03(0.01$ in Antarctica) represents the effect of dirt and soot. 
The reflectance of radiation with illumination angle (measured relative to the surface normal) is computed as follows:

$$
\begin{aligned}
& \alpha_{v}=\alpha_{v d}+0.4 f(\varphi)\left(1-\alpha_{v d}\right) \\
& \alpha_{i r}=\alpha_{i r d}+0.4 f(\varphi)\left(1-\alpha_{i r d}\right)
\end{aligned}
$$

where $f(\varphi)=\left\{\begin{array}{cl}\frac{1}{b}\left[\frac{b+1}{1+2 b \cos (\varphi)}-1\right], & \text { for } \cos (\varphi)<0.5 \\ 0, & \text { otherwise }\end{array}\right.$

where $b$ is a parameter set at 2 as in Dickinson et al. (1993).

When the snowpack is shallow (depth $\mathrm{z}<\mathrm{h}=0.01 \mathrm{~m}$ ), the albedo is calculated by interpolating between the snow albedo and bare-ground albedo with the exponential term approximating the exponential extinction of radiation penetration of snow.

$$
A_{v / i r}=r \alpha_{g, v / i r}+(1-r) \alpha_{v / i r}
$$

where $r=\left(1-\frac{z}{h}\right) e^{-z / 2 h}$ 


\section{Appendix A4 STEMMUS-MODFLOW coupling}

\section{A4.1 Multi scale water balance analysis}

Different spatiotemporal scales are operated for soil water and groundwater models. Soil water models are running at $\Delta z=10^{-3}-10^{0} \mathrm{~m}$ and $\Delta t=10^{0}-10^{3} \mathrm{~s}$, while for groundwater models, the domain is usually discretized at $\Delta x / y=10^{0}-10^{3} \mathrm{~m}$ and $\Delta t=10^{3}-10^{6} \mathrm{~s}$.

Within the large-scale time step $\Delta T=T^{J+1}-T^{J}$, and local area of interest $\bar{M}=z_{S}-$ $z_{0}$ (see Figure A4.1), the water storage variation for soil water models, i.e., small scale water yield $\widetilde{S_{y}}$, is given by

$$
\widetilde{S_{y}}=\frac{\left[\omega\left(T^{J+1}\right)-\omega\left(T^{J}\right)+\theta_{s} \cdot \Delta z_{t}\right]}{\Delta z_{t}}+\mu_{s} \cdot \bar{M}
$$

where $\omega$ is the vadose zone water amount in the moving balance domain, see Figure A4.1b, $\omega(t)=\int_{z_{t}(t)}^{z_{s}} \theta(t, z) d z, \Delta z_{t}=\sum_{j=1}^{N} d z_{t}^{j}=z_{t}\left(T^{J+1}\right)-z_{t}\left(T^{J}\right)$ is the total fluctuation of phreatic surface during time period $\Delta T=\sum_{j=1}^{N} d t^{j}=T^{J+1}-T^{J}$, and $\theta_{s}$ is the saturated soil water content. The small-scale water balance in the moving balancing domain at time $t$ is expressed as

$$
\left[q_{t o p}+l \cdot d z_{t} / 2-q_{b o t}\right] \cdot d t=\omega(t)-\omega(t-d t)+\theta_{s} \cdot d z_{t}
$$

where $q_{\text {top }}\left(=K(h) \cdot \partial(h+z) /\left.\partial z\right|_{z=z_{s}}\right)$ and $q_{b o t}\left(=K(h) \cdot \partial(h+z) /\left.\partial z\right|_{z=z_{b}}\right)$ are the nodal fluxes into and out of the moving balancing domain, a fixed top boundary $z_{S}$ and the moving bottom boundary $z_{b}=\min \left(z_{t}(t), z_{t}(t-d t)\right) . d z_{t}=z_{t}(t)-z_{t}(t-$ $d t$ ) is the fluctuation of the phreatic surface during $\mathrm{d} t$, and $l$ is the saturated lateral water flux into the moving domain at time $t$.

Temporally integrating Eq. A4.2 from time $T^{J}$ to $T^{J+1}$, we have the macro-time scale water balance as

$$
R_{\text {top }}+\varepsilon_{l}-R_{\text {bot }}=\omega\left(T^{J+1}\right)-\omega\left(T^{J}\right)+\theta_{s} \cdot \Delta z_{t}
$$

where $R_{\text {top }}$ is the cumulative water flux at $z_{s} . R_{\text {bot }}$ is the cumulative water flux out of the moving domain, and $\varepsilon_{l}$ is the cumulative lateral water flux into the moving balance domain, which can be neglected from the small-scale water balance analysis.

Rephrasing Eq. A4.1 and A4.3, the small-scale specific yield $\widetilde{S_{y}}$ is expressed as

$$
\widetilde{S_{y}}=\left(R_{t o p}+\varepsilon_{l}-R_{b o t}\right) / \Delta z_{t}+\mu_{s} \cdot \bar{M}
$$


Linking with the large-scale specific yield, the upper boundary water flux can be calculated as $F_{\text {top }}=\left[R_{\text {top }}+\left(\overline{S_{y}}-\widetilde{S_{y}}\right) \Delta z_{t}\right] / \Delta T$. In such way, the large-scale properties in the groundwater models are physically maintained.

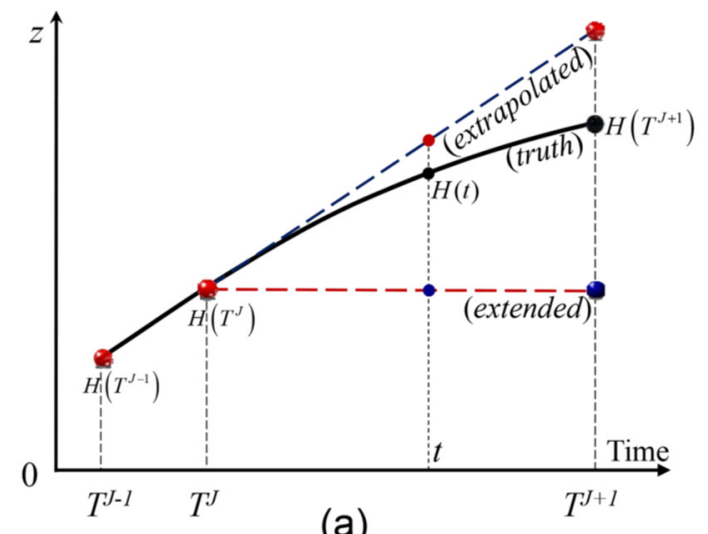

(a)

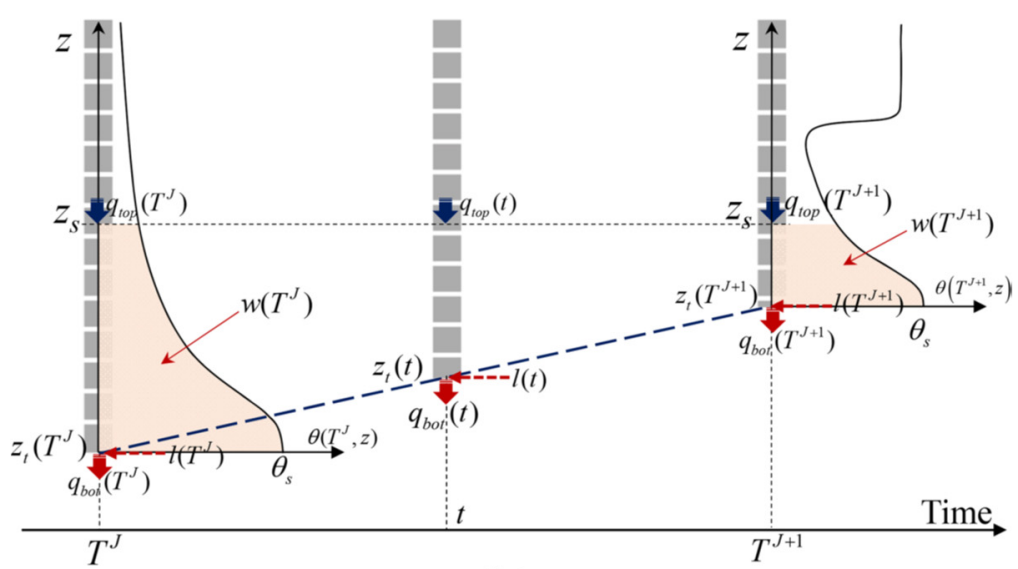

(b)

Figure A4.1. The Dirichlet-Neumann coupling of the soil-water and groundwater flow models at different scales. (a) Linear or stepwise prediction of Dirichlet lower boundary for the soil-water flow model. (b) Water balance analysis based on a balancing domain with moving lower boundary. Blue dashed line is the linearly extrapolated groundwater table as an alternative for prediction of Dirichlet lower boundary. $\mathrm{J}$ (or $\mathrm{j}$ ), $\mathrm{T}$ ( or $\mathrm{t}$ ), and $\Delta \mathrm{T}$ (or dt) are the time level, time, and time-step size at coarse (or fine) scale. At any of the transient states $(\mathrm{t})$, the balancing domain is bounded by a user-specified top elevation $\left(\mathrm{z}_{\mathrm{s}}\right)$ and the moving phreatic surface $\left(\mathrm{zt}_{\mathrm{t}}\right)$. At a transient time $\mathrm{t}\left(\right.$ or $\mathrm{T}^{\mathrm{J}}$ ), the total mass volume in the moving balancing domain is indicated by $\omega(t)$ (or $\left.\omega\left(T^{J}\right)\right)$. The saturated lateral flux of the moving domain is indicated by $l(\mathrm{t})$, while the unsaturated lateral flux is neglected as the assumption of quasi-3D models. The water flux into and out of the balancing domain is indicated by $q_{\text {top }}$ and $q$ bot. Figure adapted from Zeng et al. (2019).

\section{A4.2 The moving Dirichlet lower boundary}

The bottom node of the soil column is adaptively located at the phreatic surface, which is numerically realized as the area averaged moving Dirichlet boundary 


$$
z_{t}\left(T^{J}\right)=\int_{s \in \Pi} H(T) d s / \int_{s \in \Pi} d s
$$

where $z_{t}$ is the elevation of water table, $\prod$ is the influencing domain of a soil column, $H(\mathrm{~T})$ is potentiometric head solution, as well as the elevation of the phreatic surface, and $s$ is the horizontal area.

To estimate the lower boundary head of a soil column, the linear extrapolation is adopted to reduce the coupling errors and speed up the convergence. The small-scale lower boundary head at time $t\left(T^{J}<t \leq T^{J+1}\right)$ is given by

$$
z_{t}(t)=\frac{\left(t-T^{J-1}\right) \cdot z_{t}\left(T^{J}\right)-\left(t-T^{J}\right) \cdot z_{t}\left(T^{J-1}\right)}{T^{J}-T^{J-1}}
$$

\section{A4.3 The Neumann upper boundary}

The governing equation of the activated layer is expressed as

$$
\overline{S_{y}} \frac{\partial H}{\partial t}=\frac{\partial}{\partial x}\left(K \bar{M} \frac{\partial H}{\partial x}\right)+\frac{\partial}{\partial y}\left(K \bar{M} \frac{\partial H}{\partial y}\right)+F_{t o p}-F_{\text {base }}
$$

where $\bar{M}\left(=z_{s}-z_{0}\right)$ is the thickness of the phreatic layer, which is defined as the layer below the vadose zone. $z_{0}$ is the bottom elevation of the top phreatic layer, $z_{0} \ll z_{s}$. $F_{\text {top }}$ is the groundwater recharge into the activated top layer of the phreatic aquifer, $F_{\text {top }}=K \cdot \partial H /\left.\partial z\right|_{z=z_{S}} \cdot F_{\text {base }}$ is the water release into the underlying numerical layer, $F_{\text {base }}=K \cdot \partial H /\left.\partial z\right|_{z=z_{0}}$. The regional-scale specific yield $\overline{S_{y}}$, caused by the fluctuation of the water table, is given by

$$
\overline{S_{y}}=V_{W} /(A \cdot \Delta H)
$$

where $V_{W}$ is the amount of water release by the fluctuation of the phreatic surface $\Delta H$, and $A$ is the area of interest.

Table A4.1. The soil hydraulic parameters used in the test cases.

\begin{tabular}{lllllll}
\hline Cases & Soil type & $\begin{array}{l}\theta_{\mathrm{r}} \\
\left(\mathrm{cm}^{3} \mathrm{~cm}^{-3}\right)\end{array}$ & $\begin{array}{l}\theta_{\mathrm{s}} \\
\left(\mathrm{cm}^{3} \mathrm{~cm}^{-3}\right)\end{array}$ & $\begin{array}{l}\alpha \\
\left(\mathrm{cm}^{-1}\right)\end{array}$ & $n$ & $\begin{array}{l}K \mathrm{~s} \\
\left(\mathrm{~cm} \mathrm{~d}^{-1}\right)\end{array}$ \\
\hline Case 2D & Loam & 0.078 & 0.43 & 0.036 & 1.56 & 24.96 \\
Case 3D & Sandy loam & 0.065 & 0.41 & 0.075 & 1.89 & 106.1 \\
\hline
\end{tabular}




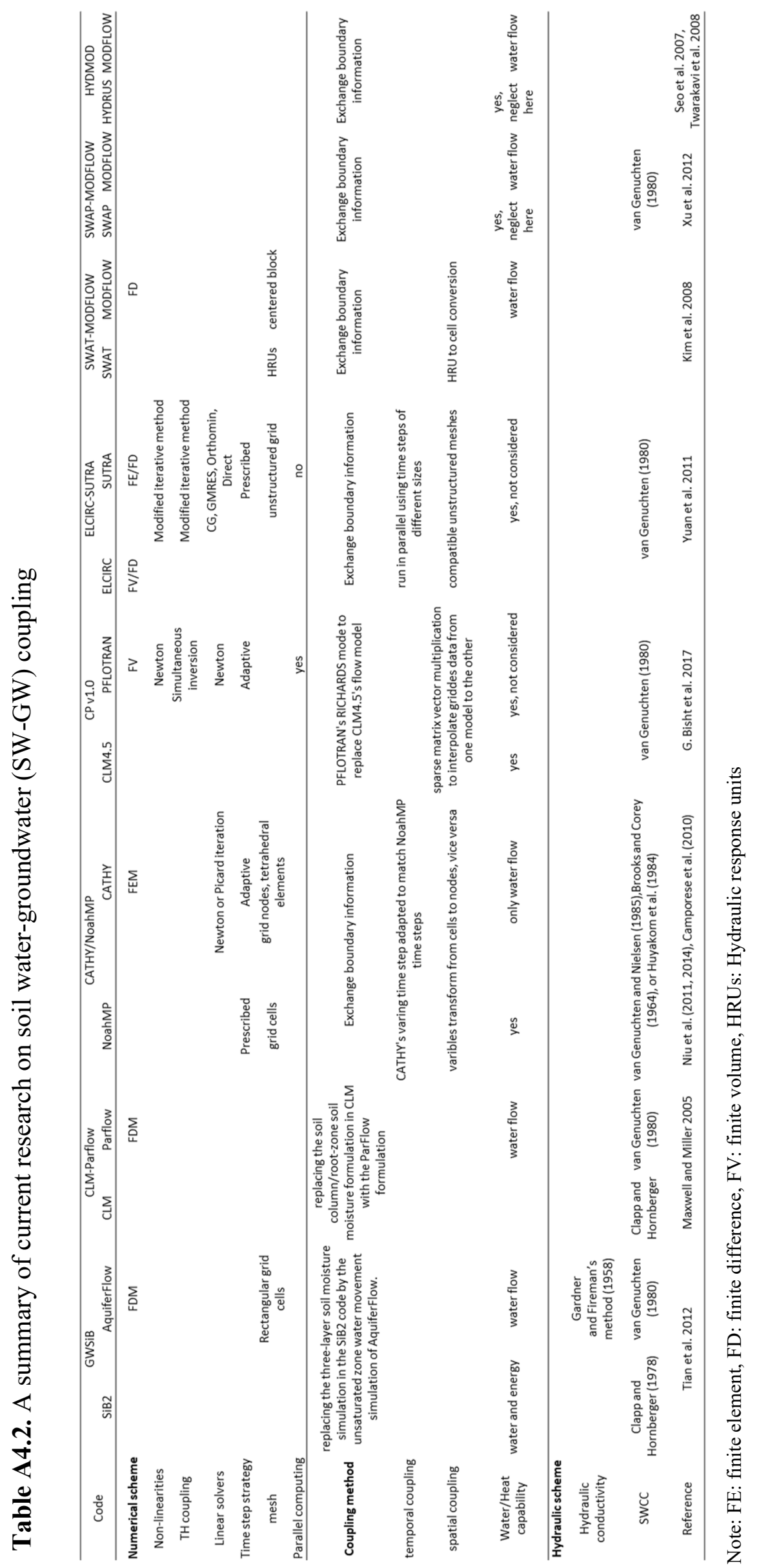




\section{Appendix A5 Results of Yakou site}

\section{A5.1 Snow water equivalent}

STEMMUS-UEB can reproduce the dynamics of snow water equivalent (Figure A5.1). The discrepancies were mainly happened under conditions with lower snow water equivalent. These intermittent shallow snowpack processes are difficult to capture well, due to the drifting snow effect and temporal and complex ground heat conditions, and they require both the high-quality observations and advanced snowpack models.

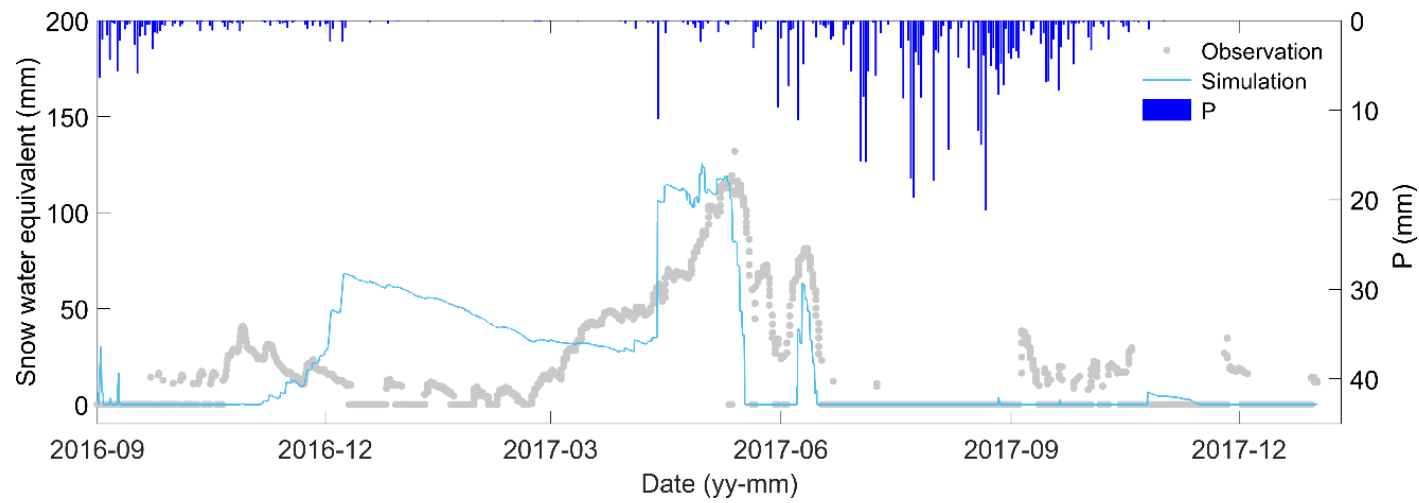

Figure A5.1. Time series of the observed and estimated snow water equivalent using the developed STEMMUS-UEB model.

\section{A5.2 Daily surface evaporation}

Compared to the observations, surface evaporation was underestimated by the model with no snow module during the snowfall periods (Figure A5.2). Models with snow module, however, produced a generally good agreement but with overestimations and underestimations, which corresponds to the mismatches in the snow water equivalent results (Figure A5.1). When the snow water equivalent is overestimated, snowpack sublimation and surface evaporation were overestimated.

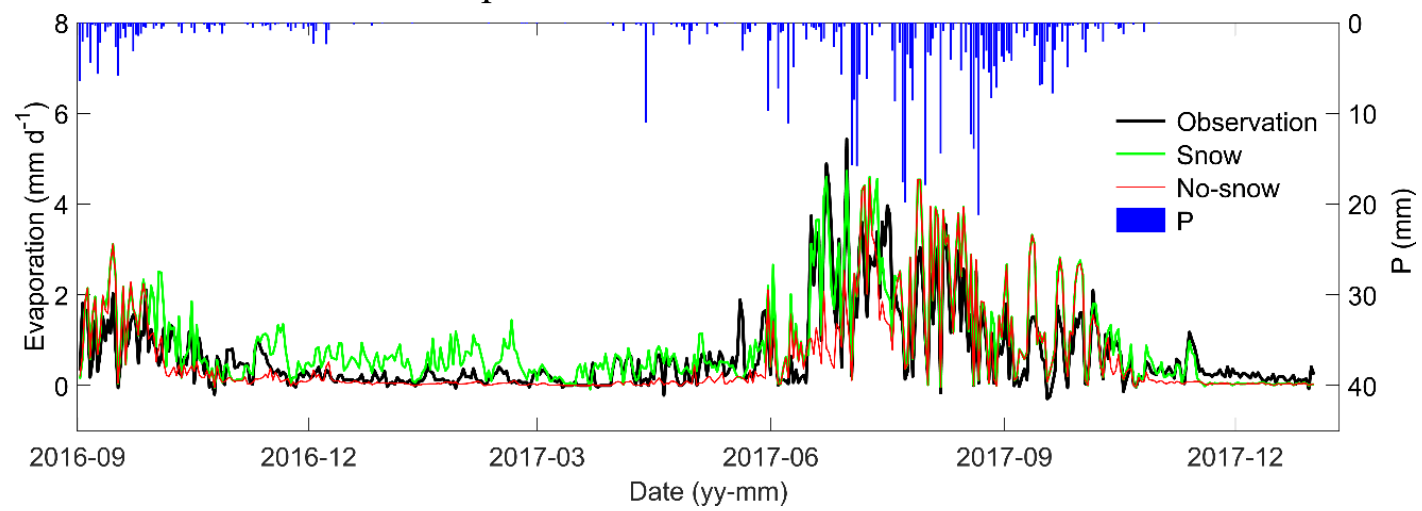

Figure A5.2. Intercomparison of the observed and estimated surface evaporation using the model with and without the snow module.

Compared to the model without the snow module, the model with the snow module produced a better correlation with the measured daily surface evaporation (Figure A5.3). Surface evaporation was underestimated by the model without the snow module and 
slightly overestimated by the model with snow module.
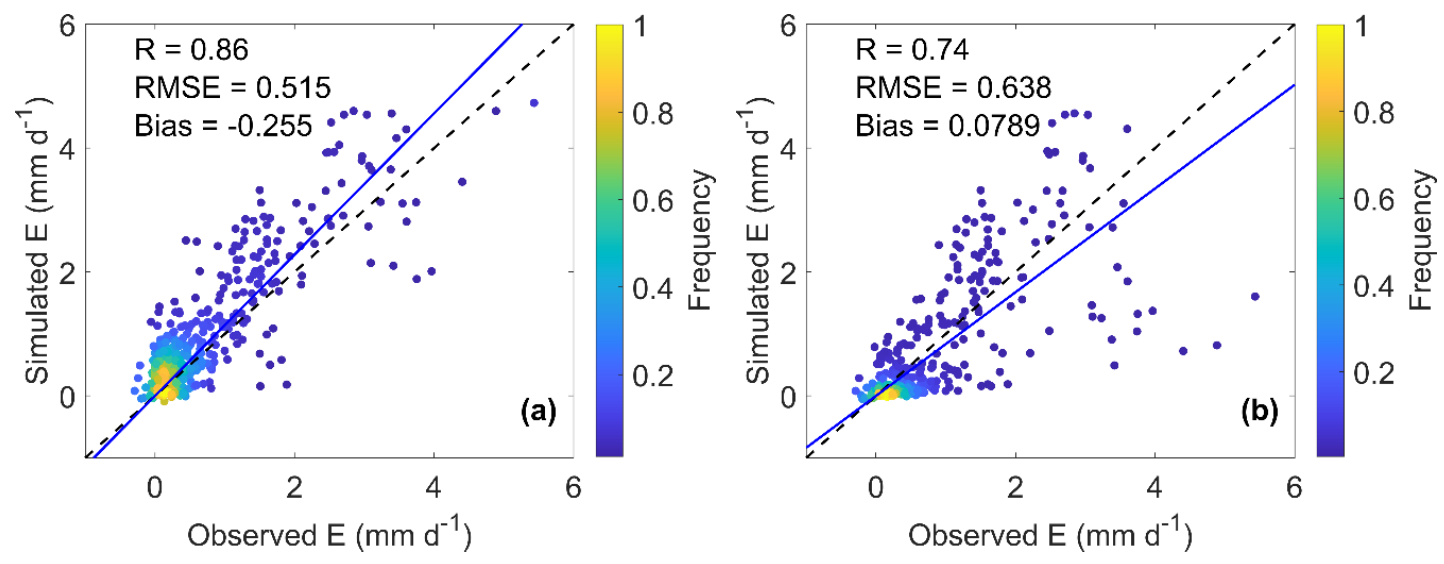

Figure A5.3. Measured and estimated daily surface evaporation using the model with and without snow module ( $\mathrm{a}$ and $\mathrm{b}$, respectively).

\section{A5.3 Soil moisture and temperature}

Models both with and without the snow module can reproduce the soil moisture dynamics in terms of their response to precipitation events (Figure A5.4). Soil moisture was underestimated by the model without the snow module due to the lower amount of incoming water flux. Such underestimation was damped as the soil depth increases. Models with the snow module gain more incoming water (snowmelt water), and thus the underestimation of soil moisture was alleviated.

The dynamics of soil temperature was reproduced well by models both with and without the snow module (Figure A5.5). There is no significant difference between soil temperature simulations of models with and without the snow module. 


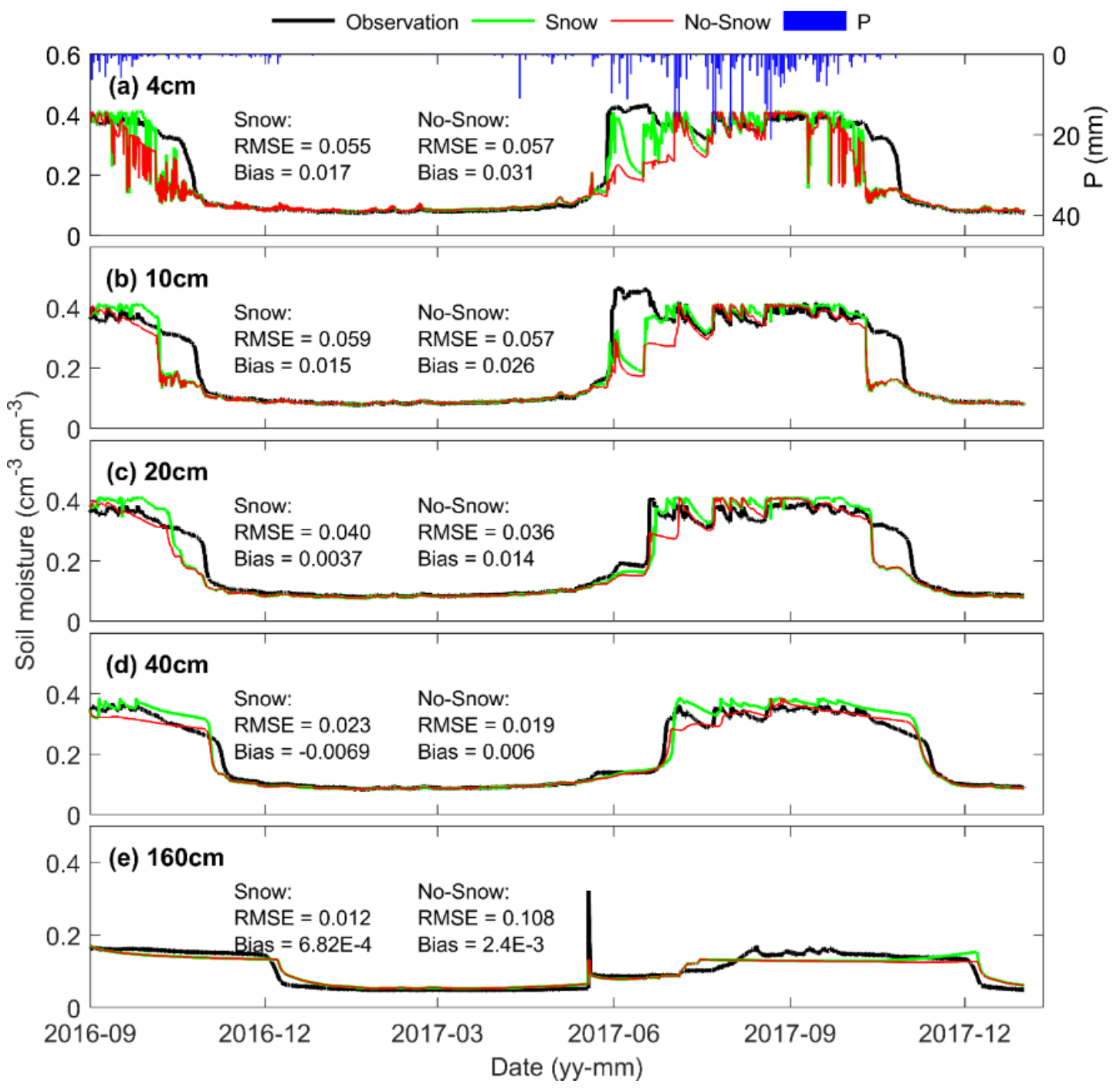

Figure A5.4. Observed and estimated soil moisture at various soil layers using the model with and without the snow module. 


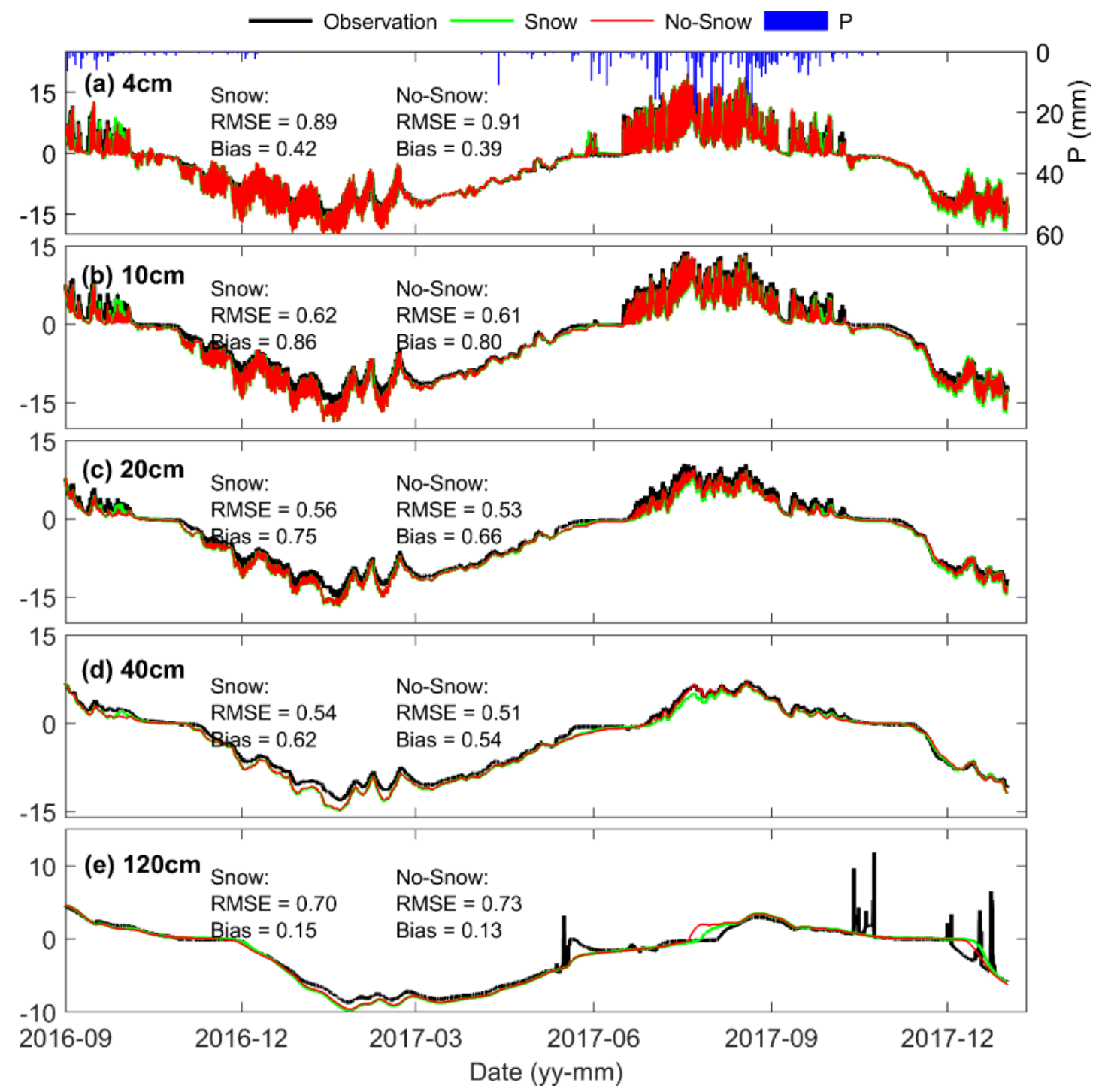

Figure A5.5. Observed and estimated soil temperature at various soil layers using the model with and without the snow module.

\section{A5.4 Snow cover properties and albedo}

There is a good correlation between the snow depth and surface albedo (Figure A5.6). Figure A5.7 shows that surface albedo variations correspond well to the dynamics of the snow cover properties (snow depth and snow water equivalent, SWE). This demonstrated that surface albedo is a reliable indicator to identify the presence of the snowpack and its influencing periods. Three example periods were selected to illustrate the validity of using the indirect method (albedo variation and ancillary meteorological data, i.e., air temperature, and precipitation) to define the presence and lasting time of the snowpack. Results indicated that the snowpack duration was successfully characterized using the indirect method (results were not shown). 


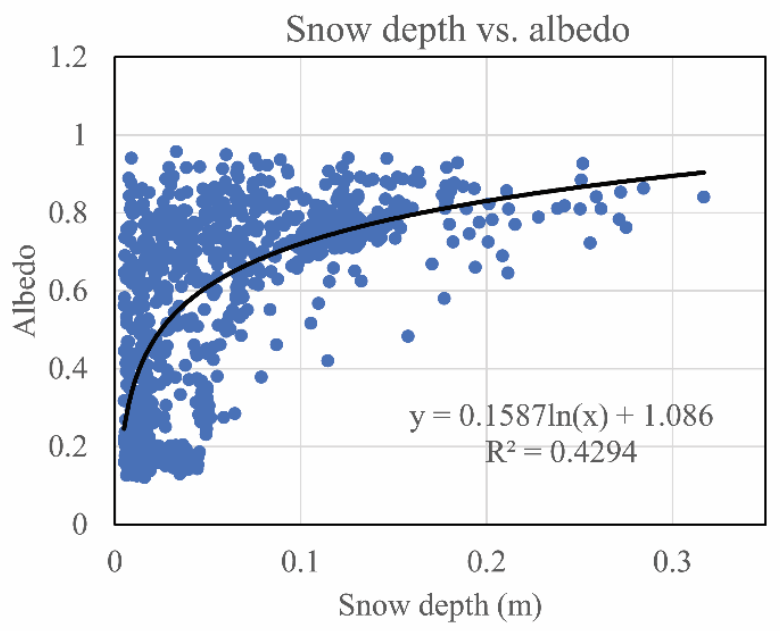

Figure A5.6. Scatter plot of the snow depth and albedo (Yakou station, 2014-2017).

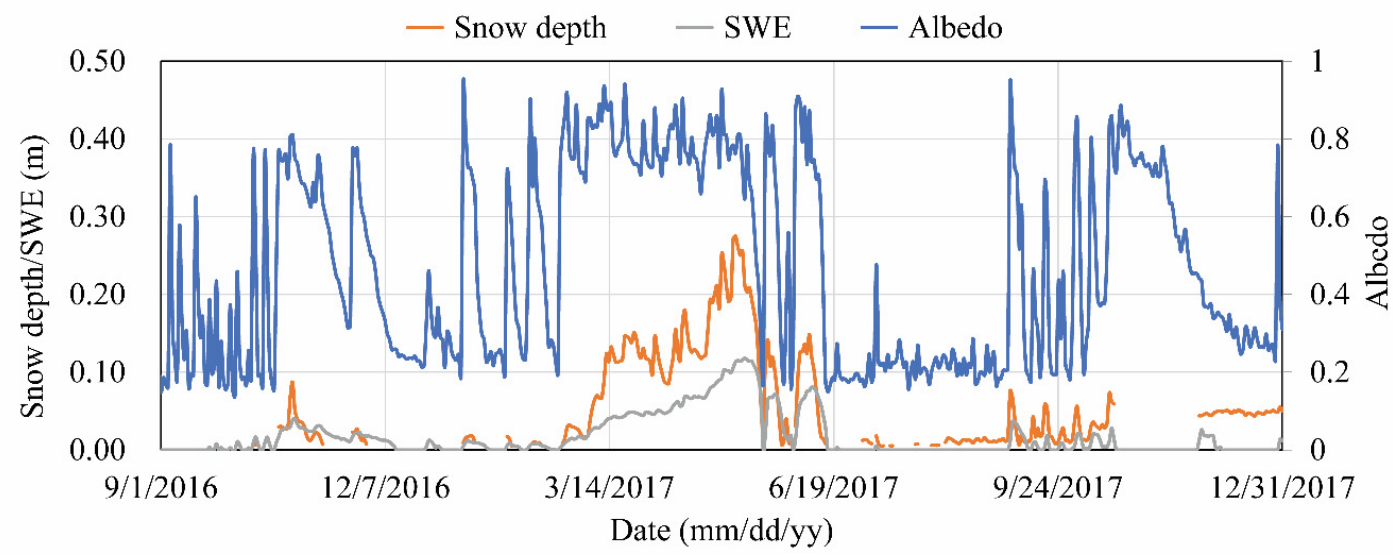

Figure A5.7. Time series of the snow depth, snow water equivalent (SWE), and albedo. 
Appendix A6 Supplemental figures and tables 

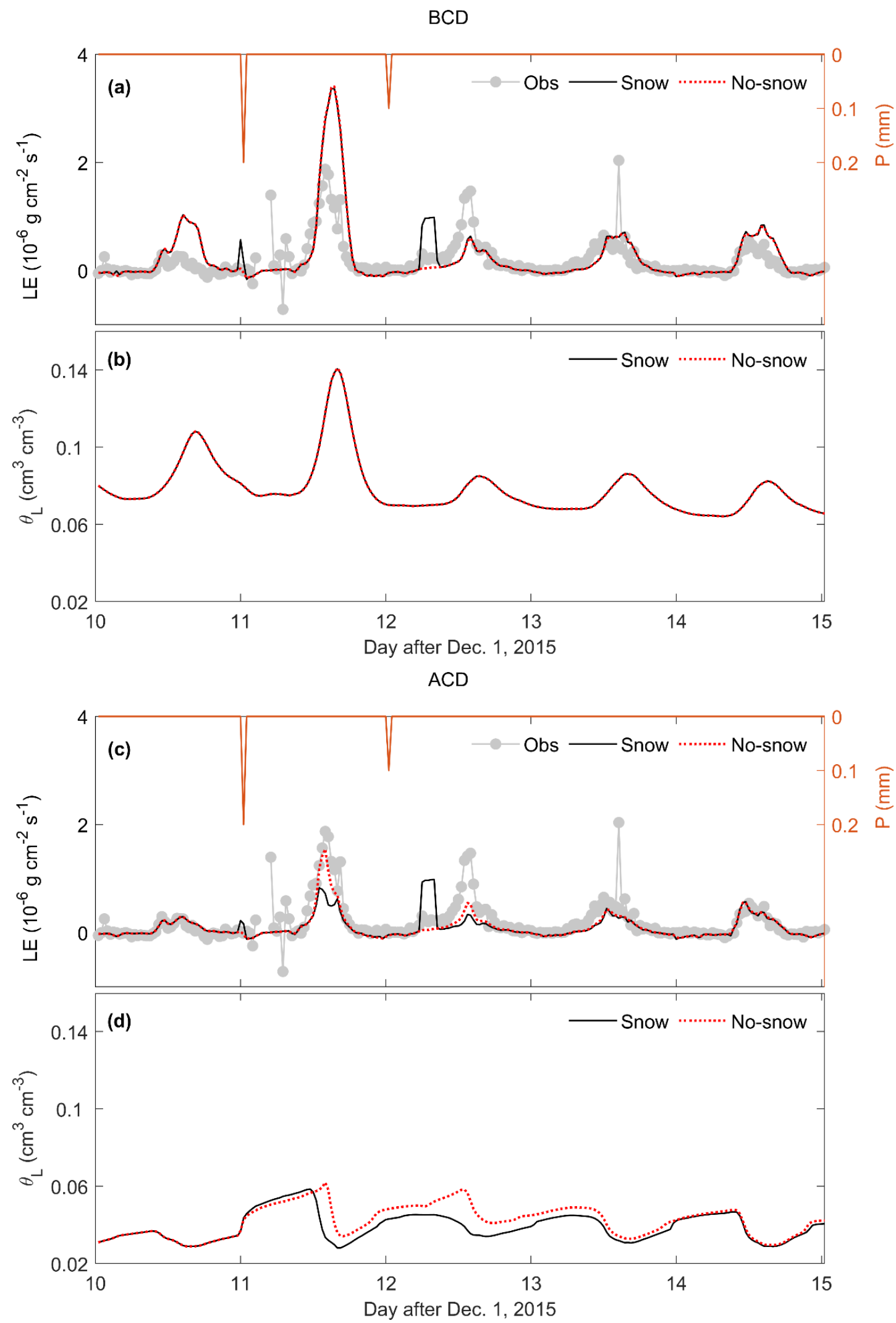


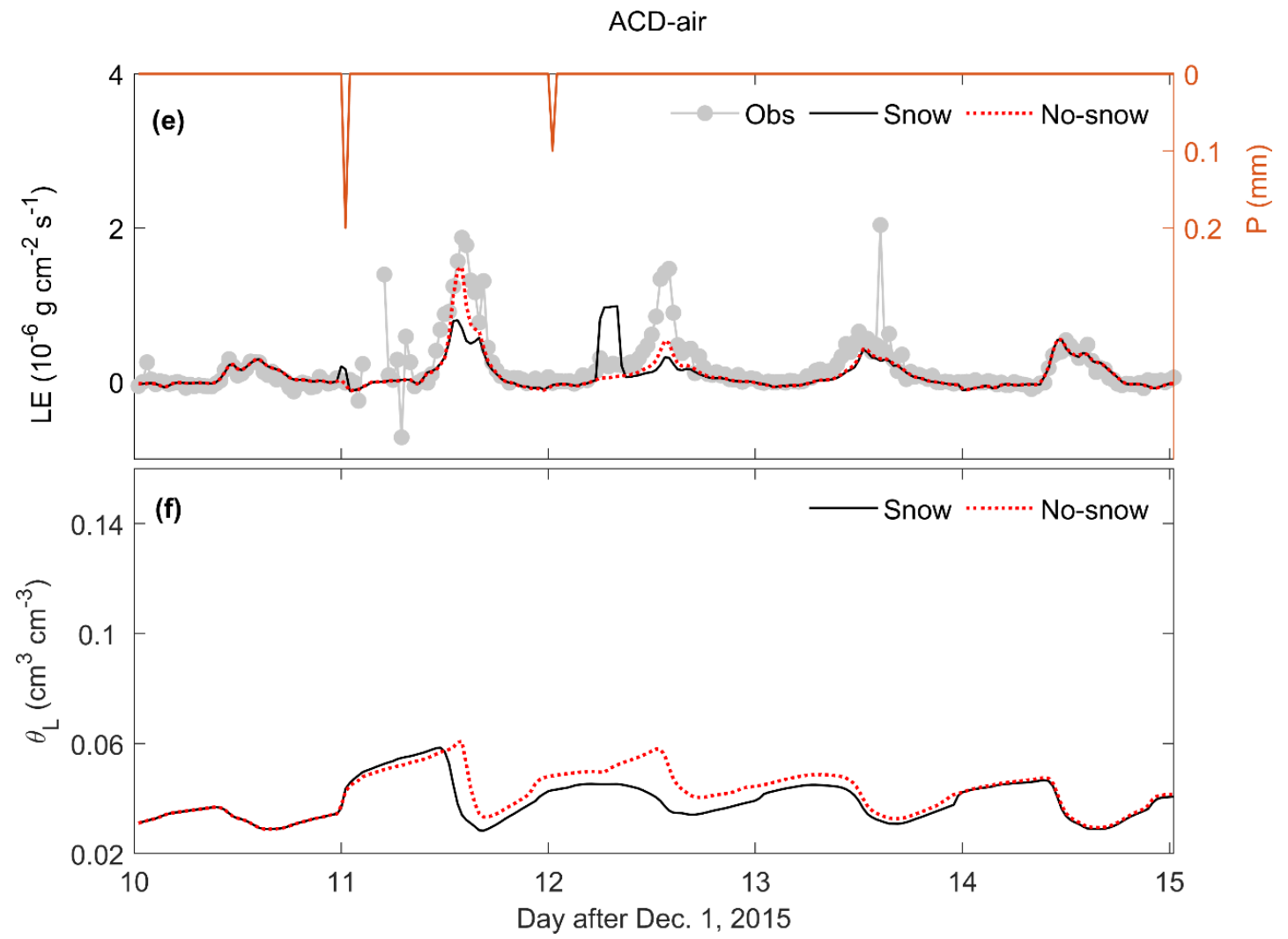

Figure A6.1. Observed latent heat flux and simulated (a, c \&e) latent heat flux and (b, d \&f) surface soil liquid water content $\theta_{L}$ with/without snow module of a typical fiveday freezing period (from 10th to 15th day after December 1.2015) with precipitation. LE is the latent heat flux. 

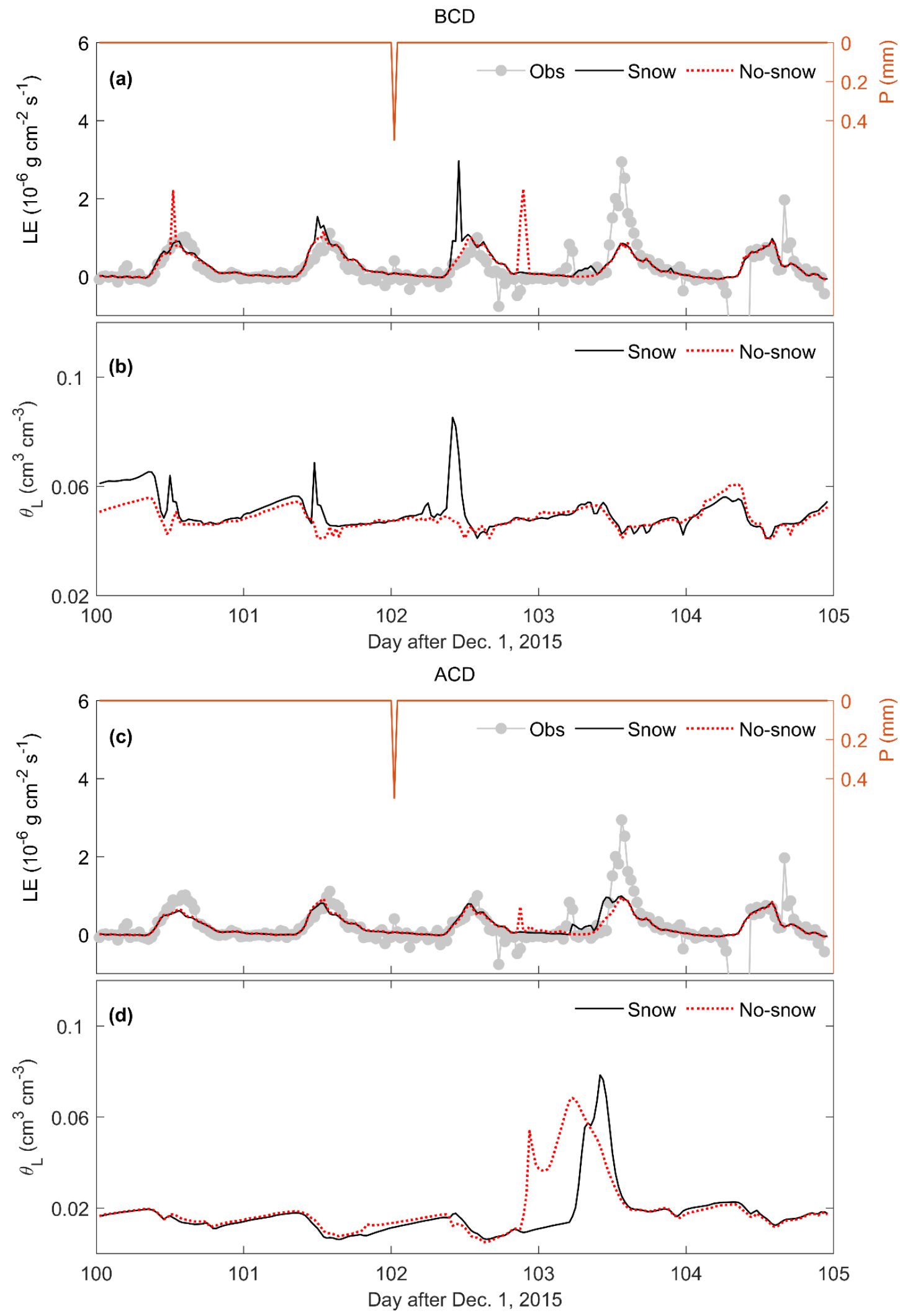


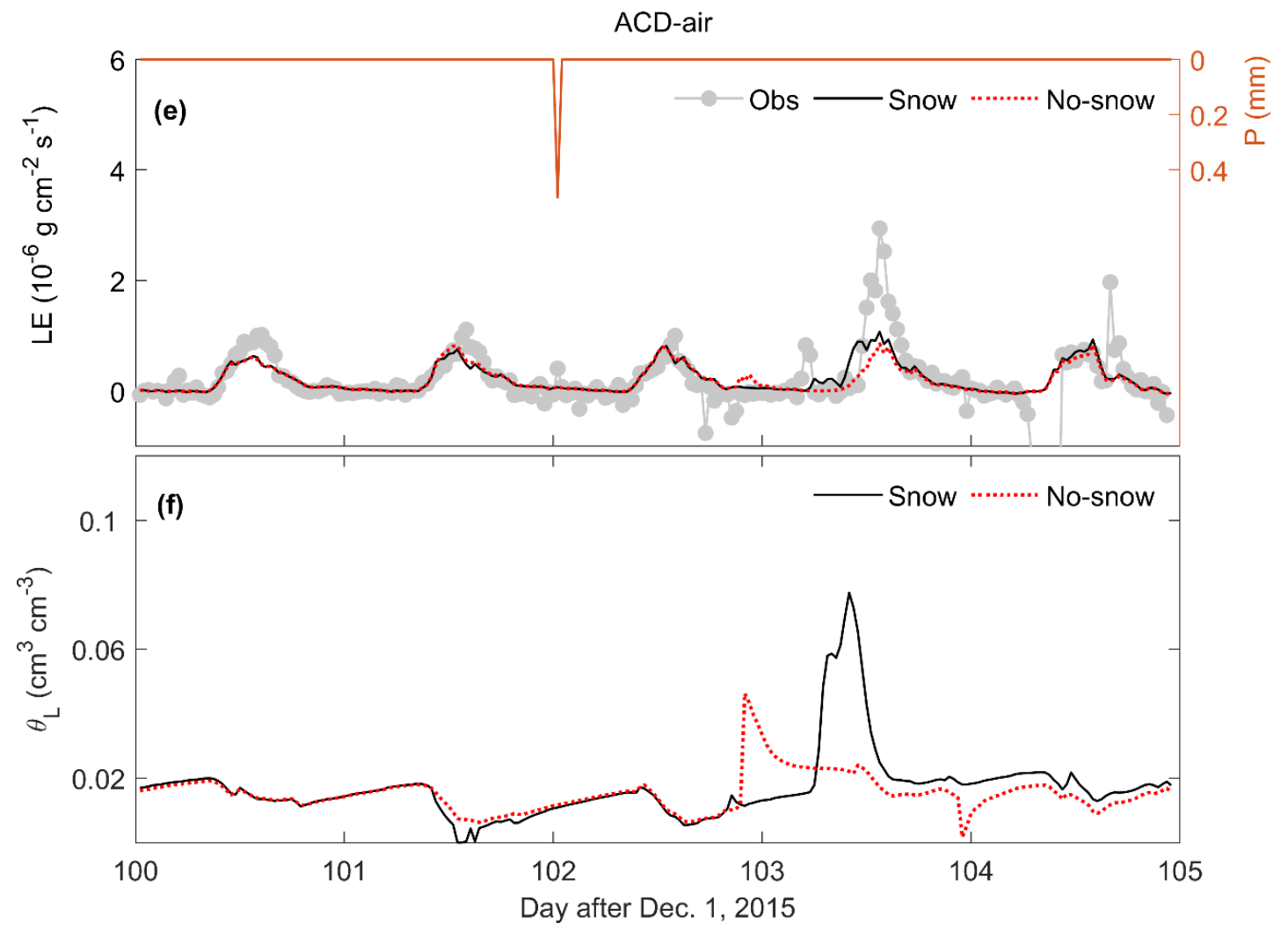

Figure A6.2. Observed latent heat flux and simulated (a, c \&e) latent heat flux and (b, $\mathrm{d} \& \mathrm{f})$ surface soil liquid water content $\theta_{L}$ with/without snow module of a typical fiveday thawing period (from 100th to 105 th day after December 1. 2015) with precipitation. LE is the latent heat flux. 

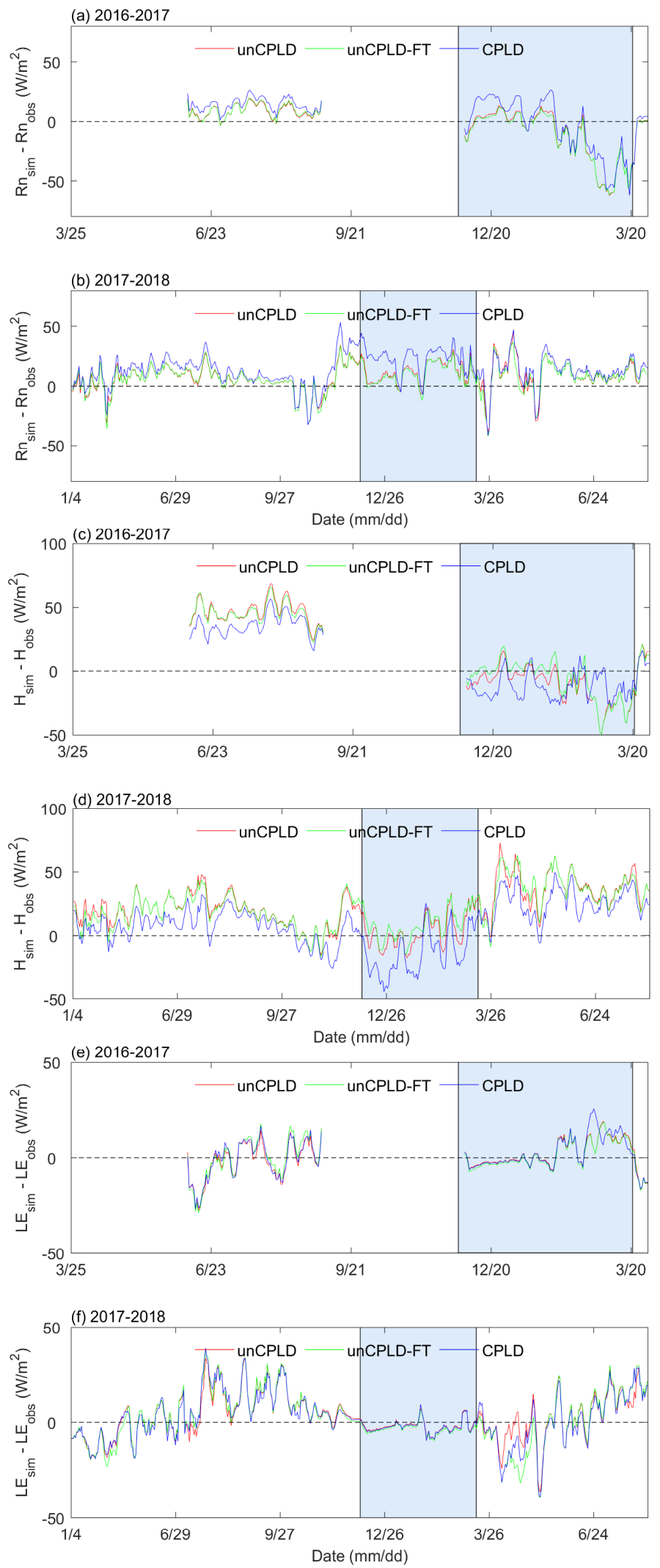

Figure A6.3. Difference between observed and simulated 5-day moving average dynamics of net radiation (Rn), latent heat flux (LE), and sensible heat flux (H) using the original (uncoupled) T\&C (unCPLD), T\&C with consideration of FT process (unCPLD-FT) and coupled T\&C and STEMMUS (CPLD) model. The frozen period, identified from Figure 7.1b, was highlighted by the blue shadow. 

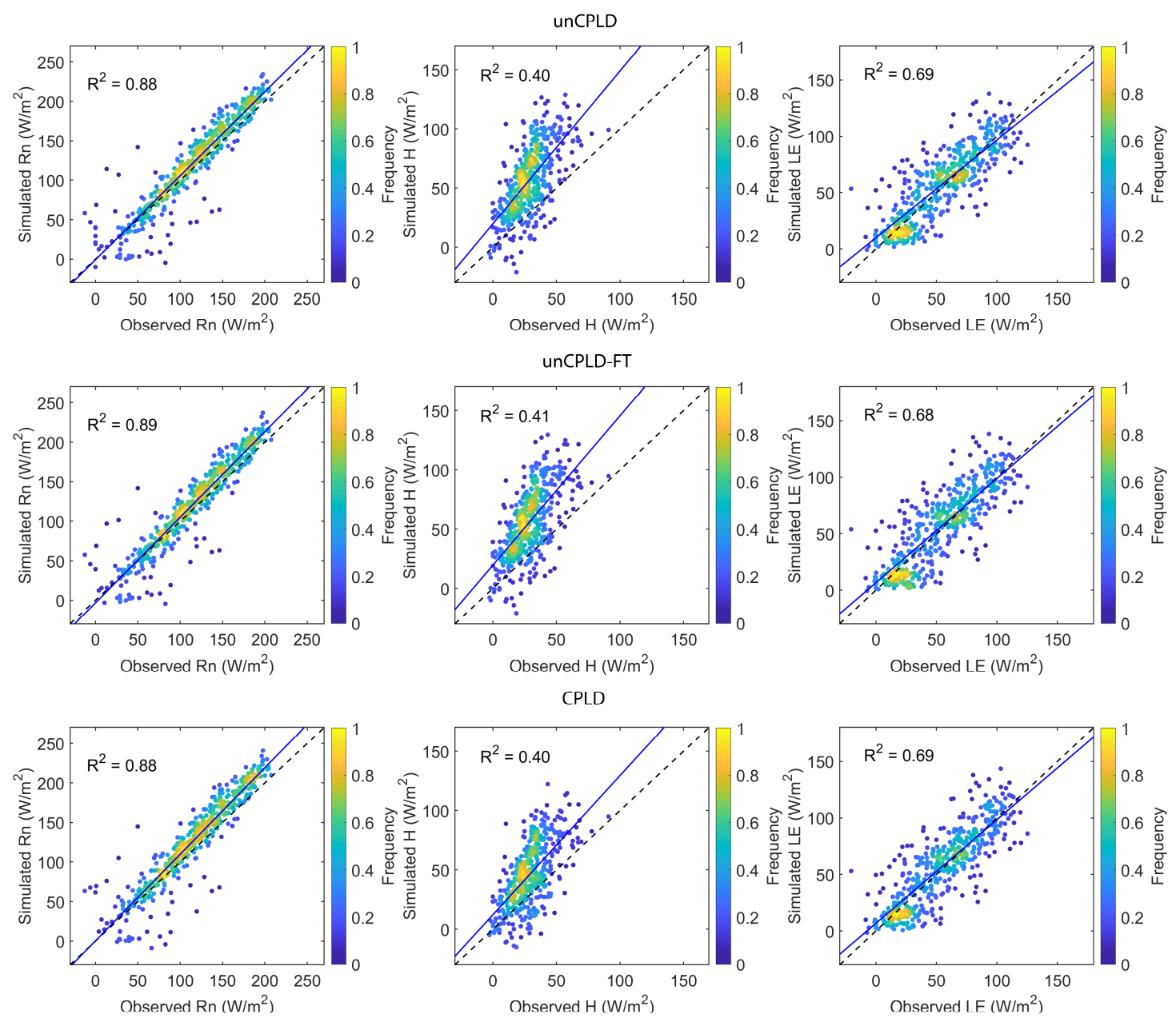

Figure A6.4. Scatter plots of observed and model simulated daily average surface fluxes (net radiation: $\mathrm{Rn}$, latent heat: LE and sensible heat flux: $\mathrm{H}$ ) using the original (uncoupled) $\mathrm{T} \& \mathrm{C}$ (unCPLD), T\&C with consideration of FT process (unCPLD-FT) and coupled T\&C and STEMMUS (CPLD) model during the non-frozen period, with the color indicating the occurrence frequency of surface flux values. 

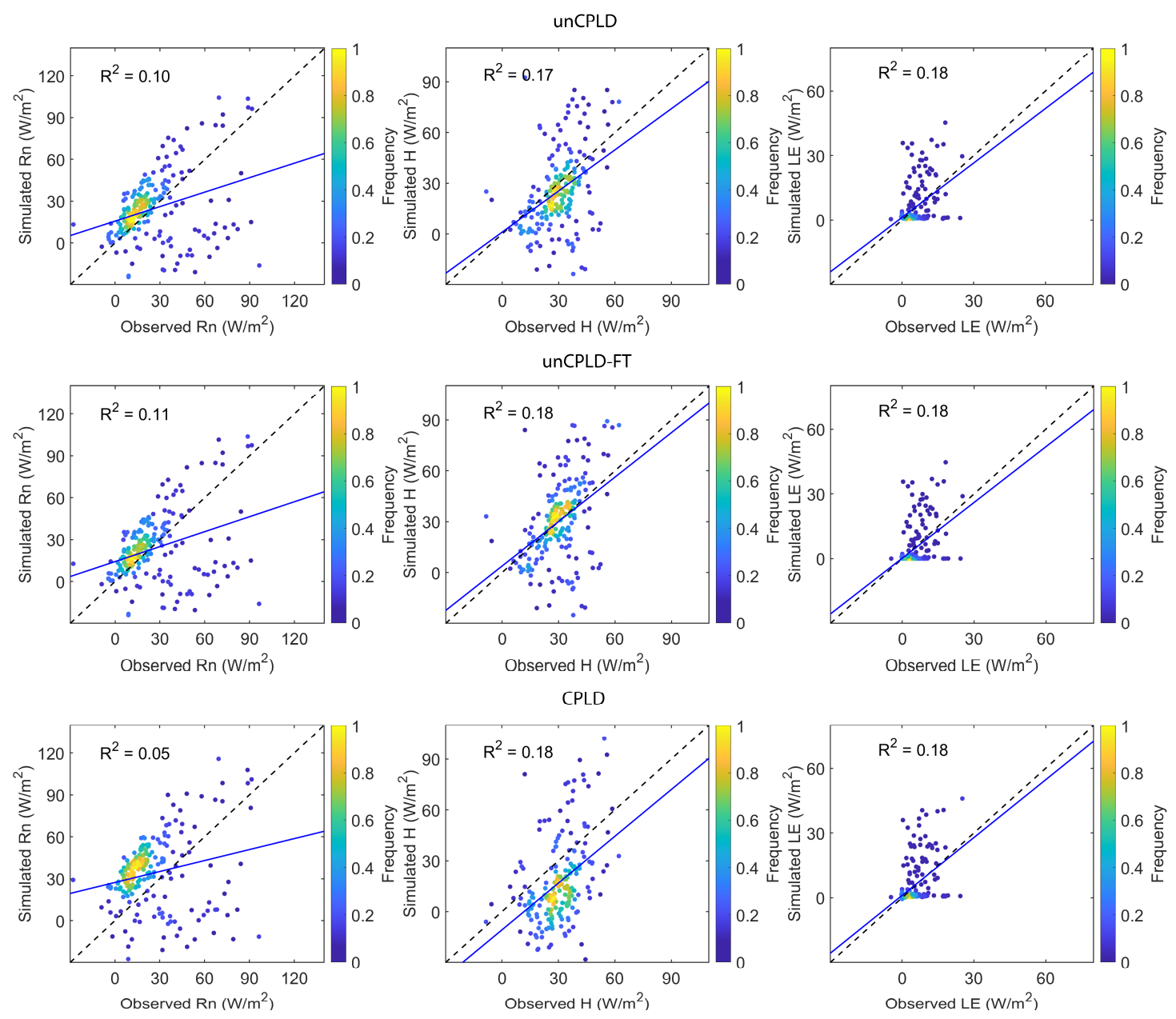

Figure A6.5. Scatter plots of observed and model simulated daily average surface fluxes (net radiation: Rn, latent heat: LE and sensible heat flux: $\mathrm{H}$ ) using the original (uncoupled) T\&C (unCPLD), T\&C with consideration of FT process (unCPLD-FT) and coupled T\&C and STEMMUS (CPLD) model during the frozen period, with the color indicating the occurrence frequency of surface flux values. 
Table A6.1. The description of measurements and its temporal resolution deployed as inputs/outputs of the STEMMUS-UEB model (Maqu case)

\begin{tabular}{|c|c|c|c|c|}
\hline \multicolumn{2}{|c|}{ Model/Measurements } & $\begin{array}{l}\text { Time } \\
\text { Period }\end{array}$ & $\begin{array}{l}\text { Time } \\
\text { Interval }\end{array}$ & Notes \\
\hline \multirow{6}{*}{$\begin{array}{l}\text { Meteor- } \\
\text { ological } \\
\text { Inputs }\end{array}$} & Precipitation & $\begin{array}{l}2015 / 12 / 1- \\
2016 / 3 / 15\end{array}$ & 3 hour & $\begin{array}{l}\text { From weather station, about } 12 \mathrm{~km} \text { away from the } \\
\text { study site. In order to meet the input requirement for } \\
\text { the adaptive time step simulation, the precipitation } \\
\text { was evenly distributed within the three hours. }\end{array}$ \\
\hline & Air Temperature & $\begin{array}{l}2015 / 12 / 1- \\
2016 / 3 / 15\end{array}$ & $30 \mathrm{~min}$ & $\begin{array}{l}\text { From the in situ meteorological station. The time } \\
\text { disaggregated values, to meet the requirement for the } \\
\text { adaptive time step simulation ( } 1 \mathrm{~s}-30 \text { mins), were } \\
\text { obtained by the linear interpolation between the half- } \\
\text { hour measurements. }\end{array}$ \\
\hline & $\begin{array}{l}\text { Air Relative } \\
\text { Humidity }\end{array}$ & $\begin{array}{l}2015 / 12 / 1- \\
2016 / 3 / 15\end{array}$ & $30 \mathrm{~min}$ & $\begin{array}{l}\text { From the in situ meteorological station. The time } \\
\text { disaggregated values, to meet the requirement for the } \\
\text { adaptive time step simulation ( } 1 \mathrm{~s}-30 \text { mins), were } \\
\text { obtained by the linear interpolation between the half- } \\
\text { hour measurements. }\end{array}$ \\
\hline & Wind Speed & $\begin{array}{l}2015 / 12 / 1- \\
2016 / 3 / 15\end{array}$ & $30 \mathrm{~min}$ & $\begin{array}{l}\text { From the in situ meteorological station. The time } \\
\text { disaggregated values, to meet the requirement for the } \\
\text { adaptive time step simulation ( } 1 \mathrm{~s}-30 \text { mins), were } \\
\text { obtained by the linear interpolation between the half- } \\
\text { hour measurements. }\end{array}$ \\
\hline & Air pressure & $\begin{array}{l}2015 / 12 / 1- \\
2016 / 3 / 15\end{array}$ & $30 \mathrm{~min}$ & $\begin{array}{l}\text { From the in situ meteorological station. The time } \\
\text { disaggregated values, to meet the requirement for the } \\
\text { adaptive time step simulation ( } 1 \mathrm{~s}-30 \text { mins), were } \\
\text { obtained by the linear interpolation between the half- } \\
\text { hour measurements. }\end{array}$ \\
\hline & $\begin{array}{l}\text { Four component } \\
\text { downwelling and } \\
\text { upwelling solar } \\
\text { and thermal } \\
\text { radiation }\end{array}$ & $\begin{array}{l}2015 / 12 / 1- \\
2016 / 3 / 15\end{array}$ & $30 \mathrm{~min}$ & $\begin{array}{l}\text { From the in situ meteorological station. The time } \\
\text { disaggregated values, to meet the requirement for the } \\
\text { adaptive time step simulation ( } 1 \mathrm{~s}-30 \text { mins), were } \\
\text { obtained by the linear interpolation between the half- } \\
\text { hour measurements. }\end{array}$ \\
\hline Model & STEMMUS/UEB & $\begin{array}{l}2015 / 12 / 1- \\
2016 / 3 / 15\end{array}$ & $\begin{array}{l}\text { From } 1 \mathrm{~s} \\
\text { to } 30 \\
\text { mins }\end{array}$ & $\begin{array}{l}\text { For all simulations, the adaptive time step was } \\
\text { deployed. }\end{array}$ \\
\hline \multirow{4}{*}{ Outputs } & Soil Moisture & $\begin{array}{l}2015 / 12 / 1- \\
2016 / 3 / 15\end{array}$ & $15 \mathrm{~min}$ & $\begin{array}{l}\text { From the in situ } 5 \mathrm{TM} \text { ECH } 2 \mathrm{O} \text { sensors, installed at } 5 \\
\mathrm{~cm}, 10 \mathrm{~cm}, 20 \mathrm{~cm}, 40 \mathrm{~cm} \text { and } 80 \mathrm{~cm} .\end{array}$ \\
\hline & Soil Temperature & $\begin{array}{l}2015 / 12 / 1- \\
2016 / 3 / 15\end{array}$ & $15 \mathrm{~min}$ & $\begin{array}{l}\text { From the in situ } 5 \mathrm{TM} \text { ECH2O sensors, installed at } 5 \\
\mathrm{~cm}, 10 \mathrm{~cm}, 20 \mathrm{~cm}, 40 \mathrm{~cm} \text { and } 80 \mathrm{~cm} .\end{array}$ \\
\hline & Albedo & $\begin{array}{l}2015 / 12 / 1- \\
2016 / 3 / 15\end{array}$ & $30 \mathrm{~min}$ & $\begin{array}{l}\text { The albedo was derived as the ration of half-hourly } \\
\text { upwelling shortwave radiation to downwelling } \\
\text { shortwave radiation measurements. The data during } \\
\text { the nighttime was filtered out. }\end{array}$ \\
\hline & Latent heat flux & $\begin{array}{l}2015 / 12 / 1- \\
2016 / 3 / 15\end{array}$ & $30 \mathrm{~min}$ & From the installed Eddy Covariance (EC150) system \\
\hline
\end{tabular}


Table A6.2. Model parameters used for all simulations (STEMMUS-UEB)

\begin{tabular}{|c|c|c|c|c|}
\hline \multirow{2}{*}{ Parameter } & \multirow{2}{*}{ Unit } & \multicolumn{2}{|l|}{ Value } & \multirow{2}{*}{ Remarks } \\
\hline & & Maqu case & Yakou case & \\
\hline Soil sand content & $\%$ & $\begin{array}{l}9.00 @ 0-10 \mathrm{~cm} ; \\
10.12 @ 10-40 \\
\mathrm{~cm} ; \\
5.59 @ 40-160 \\
\mathrm{~cm} \\
44.13 @ 0-10 \\
\mathrm{~cm} ; \\
44.27 @ 10-40 \\
\mathrm{~cm} ; \\
65.55 @ 40-160 \\
\mathrm{~cm}\end{array}$ & $\begin{array}{l}9.00 @ 0-10 \mathrm{~cm} ; \\
10.60 @ 10-40 \\
\mathrm{~cm} ; \\
8.30 @ 40-160 \\
\mathrm{~cm} \\
38.80 @ 0-10 \\
\mathrm{~cm} ; \\
44.30 @ 10-40 \\
\mathrm{~cm} ; \\
54.56 @ 40-160 \\
\mathrm{~cm}\end{array}$ & \multirow{5}{*}{$\begin{array}{l}\text { Soil texture, site-specific } \\
\text { (can be obtained from the in- } \\
\text { situ measurements, global soil } \\
\text { texture maps) } \\
\text { Soil hydraulic parameters, } \\
\text { site-specific } \\
\text { (can be obtained from in- } \\
\text { situ/laboratory measurements, } \\
\text { or derived from soil texture } \\
\text { information) }\end{array}$} \\
\hline $\begin{array}{l}\text { Soil saturated } \\
\text { conductivity } \mathrm{K}_{\mathrm{s}}\end{array}$ & $10^{-6} \mathrm{~m} \mathrm{~s}^{-1}$ & $\begin{array}{l}1.45 @ 0-10 \mathrm{~cm} ; \\
0.94 @ 10-40 \\
\mathrm{~cm} ; \\
0.68 @ 40-160 \\
\mathrm{~cm}\end{array}$ & $\begin{array}{l}0.645 @ 0-10 \\
\mathrm{~cm} ; \\
0.303 @ 10-40 \\
\mathrm{~cm} ; \\
0.103 @ 40-160 \\
\mathrm{~cm}\end{array}$ & \\
\hline $\begin{array}{l}\text { Soil saturated } \\
\text { volumetric content } \theta_{\mathrm{s}} \\
\text { Soil residual water } \\
\text { content } \theta_{\mathrm{r}}\end{array}$ & $\begin{array}{l}\mathrm{m}^{3} \mathrm{~m}^{-3} \\
\mathrm{~m}^{3} \mathrm{~m}^{-3}\end{array}$ & 0.035 & 0.010 & \\
\hline Air entry value & $\mathrm{m}^{-1}$ & 0.041 & 0.0041 & \\
\hline VG fitting parameter $n$ & - & 1.332 & 1.365 & \\
\hline Specific heat of water & $\mathrm{KJ} \mathrm{Kg}^{-1} \mathrm{~K}^{-1}$ & 4.18 & 4.18 & \multirow{6}{*}{$\begin{array}{l}\text { Thermal properties of soil } \\
\text { constituents, } \\
\text { Constant }\end{array}$} \\
\hline Specific heat of ice & $\mathrm{KJ} \mathrm{Kg}^{-1} \mathrm{~K}^{-1}$ & 2.09 & 2.09 & \\
\hline Specific heat of air & $\mathrm{KJ} \mathrm{Kg}^{-1} \mathrm{~K}^{-1}$ & 1.005 & 1.005 & \\
\hline $\begin{array}{l}\text { Water heat } \\
\text { conductivity }\end{array}$ & $\mathrm{W} \mathrm{m}^{-1} \mathrm{~K}^{-1}$ & 0.6 & 0.6 & \\
\hline Ice heat conductivity & $\mathrm{W} \mathrm{m}{ }^{-1} \mathrm{~K}^{-1}$ & 2.2 & 2.2 & \\
\hline Air heat conductivity & $\mathrm{W} \mathrm{m}{ }^{-1} \mathrm{~K}^{-1}$ & 0.026 & 0.026 & \\
\hline $\begin{array}{l}\text { Temperature threshold } \\
\text { for rainfall } \\
\text { Temperature threshold } \\
\text { for snowfall }\end{array}$ & ${ }^{\circ} \mathrm{C}$ & 3.5 & 5.0 & $\begin{array}{l}\text { Partition precipitation, } \\
\text { can be adjusted }\end{array}$ \\
\hline Snow density & $\mathrm{Kg} / \mathrm{m}^{3}$ & 450 & 450 & $\begin{array}{l}\text { For the calculation of } \\
\text { meltwater outflow, } \\
\text { default value }\end{array}$ \\
\hline Snow emissivity & - & 0.99 & 0.99 & $\begin{array}{l}\text { Snow energy balance } \\
\text { components, } \\
\text { default value }\end{array}$ \\
\hline $\begin{array}{l}\text { Reflectance for new } \\
\text { snow at visual bands } \\
\text { Reflectance for new } \\
\text { snow at near-infrared } \\
\text { bands }\end{array}$ & - & 0.65 & 0.65 & $\begin{array}{l}\text { For the calculation of snow } \\
\text { albedo, } \\
\text { calibrated locally }\end{array}$ \\
\hline $\begin{array}{l}\text { Snow surface } \\
\text { roughness }\end{array}$ & $\mathrm{m}$ & 0.001 & 0.0001 & $\begin{array}{l}\text { For the calculation of energy } \\
\text { balance components, } \\
\text { calibrated locally }\end{array}$ \\
\hline $\begin{array}{l}\text { Snow saturated } \\
\text { hydraulic conductivity }\end{array}$ & $\mathrm{m} \mathrm{h}^{-1}$ & 160 & 160 & $\begin{array}{l}\text { For the calculation of the } \\
\text { meltwater outflow, } \\
\text { calibrated }\end{array}$ \\
\hline $\begin{array}{l}\text { Snow surface thermal } \\
\text { conductance }\end{array}$ & $\mathrm{m} \mathrm{h}^{-1}$ & 0.02 & 0.02 & $\begin{array}{l}\text { For the calculation of snow } \\
\text { energy balance components, } \\
\text { default value }\end{array}$ \\
\hline
\end{tabular}


Table A6.2. Continued.

\begin{tabular}{lllll}
\hline Parameter & Unit & Value & & Remarks \\
\cline { 3 - 5 } & Maqu case & Yakou case & \\
\hline $\begin{array}{l}\text { Thermally active depth } \\
\text { of soil }\end{array}$ & $\mathrm{m}$ & 0.4 & 0.4 & $\begin{array}{l}\text { For the calculation of snow } \\
\text { energy balance components, } \\
\text { default value }\end{array}$ \\
\hline
\end{tabular}

Table A6.3. A general overview of Utah energy balance (UEB) snowmelt model related research from the perspective of model development and applications

\begin{tabular}{|c|c|c|c|c|}
\hline Study & $\begin{array}{l}\text { Research aim, } \\
\text { modelling/applica } \\
\text { tion perspective }\end{array}$ & Method/Data used & Study region & $\begin{array}{l}\text { Model } \\
\text { capability/utilities/focus/ } \\
\text { highlights }\end{array}$ \\
\hline \multicolumn{5}{|c|}{ UEB model development/extension } \\
\hline $\begin{array}{l}\text { Tarboton } \\
\text { et al. } \\
(1995) ; \\
\text { Tarboton } \\
\text { and Luce } \\
(1996)\end{array}$ & $\begin{array}{l}\text { Developing a } \\
\text { distributed } \\
\text { snowmelt model } \\
\text { UEB }\end{array}$ & $\begin{array}{l}\text { Meteorological } \\
\text { inputs: air } \\
\text { temperature, wind } \\
\text { speed, humidity, } \\
\text { precipitation and total } \\
\text { incoming solar and } \\
\text { longwave radiation; } \\
\text { site information }\end{array}$ & $\begin{array}{l}\text { Central Sierra Snow } \\
\text { Laboratory, } \\
\text { California, USA; } \\
\text { Reynolds Creek } \\
\text { Experimental } \\
\text { Watershed, Boise } \\
\text { Idaho, USA; and the } \\
\text { Utah State University } \\
\text { drainage and } \\
\text { evapotranspiration } \\
\text { research farm, Logan, } \\
\text { Utah, USA }\end{array}$ & $\begin{array}{l}\text { Snow surface } \\
\text { temperature, bulk } \\
\text { temperature, snow water } \\
\text { equivalent, melt outflow; } \\
\text { snow } \\
\text { sublimation/ablation, }\end{array}$ \\
\hline $\begin{array}{l}\text { Hellstrom } \\
(2000)\end{array}$ & $\begin{array}{l}\text { Developing the } \\
\text { forest cover } \\
\text { algorithms in } \\
\text { UEB and test its } \\
\text { performance for } \\
\text { coniferous and } \\
\text { deciduous forest }\end{array}$ & $\begin{array}{l}\text { Meteorological } \\
\text { inputs; canopy } \\
\text { architecture } \\
\text { measurements: } \\
\text { vegetation area index } \\
\text { (VAI), sky view } \\
\text { factor (SVF), forest } \\
\text { canopy closure (FC); } \\
\text { site information }\end{array}$ & $\begin{array}{l}\text { Northern Michigan, } \\
\text { USA }\end{array}$ & $\begin{array}{l}\text { Canopy processes } \\
\text { including attenuation of } \\
\text { solar radiation and wind } \\
\text { speed, the mixed sky and } \\
\text { canopy components of } \\
\text { longwave irradiance, and } \\
\text { precipitation interception } \\
\text { by canopy elements; } \\
\text { more realistic } \\
\text { atmospheric stability } \\
\text { algorithm, }\end{array}$ \\
\hline $\begin{array}{l}\text { Mahat and } \\
\text { Tarboton } \\
(2012)\end{array}$ & $\begin{array}{l}\text { Better estimating } \\
\text { the radiation } \\
\text { energy within and } \\
\text { beneath the forest } \\
\text { canopy in UEB }\end{array}$ & $\begin{array}{l}\text { Meteorological } \\
\text { inputs, vegetation } \\
\text { properties, site } \\
\text { information }\end{array}$ & $\begin{array}{l}\text { Rocky Mountains in } \\
\text { Utah, USA }\end{array}$ & $\begin{array}{l}\text { Two stream radiation } \\
\text { transfer model that } \\
\text { explicitly accounts for } \\
\text { canopy scattering, } \\
\text { absorption and reflection, }\end{array}$ \\
\hline $\begin{array}{l}\text { Mahat and } \\
\text { Tarboton } \\
(2014)\end{array}$ & $\begin{array}{l}\text { Representing the } \\
\text { canopy snow } \\
\text { interception, } \\
\text { unloading and } \\
\text { melt in UEB }\end{array}$ & $\begin{array}{l}\text { Meteorological } \\
\text { inputs, vegetation } \\
\text { properties, site } \\
\text { information }\end{array}$ & $\begin{array}{l}\text { Rocky Mountains in } \\
\text { Utah, USA }\end{array}$ & $\begin{array}{l}\text { New UEB model } \\
\text { algorithms that represent } \\
\text { the processes of canopy } \\
\text { snow interception, } \\
\text { sublimation, mass } \\
\text { unloading and melt, }\end{array}$ \\
\hline $\begin{array}{l}\text { You et al. } \\
(2014)\end{array}$ & $\begin{array}{l}\text { Improve snow } \\
\text { surface } \\
\text { temperature } \\
\text { modelling }\end{array}$ & $\begin{array}{l}\text { Meteorological } \\
\text { inputs; site } \\
\text { information }\end{array}$ & $\begin{array}{l}\text { Central Sierra Snow } \\
\text { Laboratory, CA, Utah } \\
\text { State University } \\
\text { experimental farm, } \\
\text { USA, and subnivean } \\
\text { snow laboratory at } \\
\text { Niwot Ridge, USA }\end{array}$ & $\begin{array}{l}\text { Modified force-restore } \\
\text { approach; adjust effective } \\
\text { conductivity considering } \\
\text { the presence of ground } \\
\text { near to a shallow snow } \\
\text { surface; representing the } \\
\text { penetration of the } \\
\text { refreezing front } \\
\text { following melt, }\end{array}$ \\
\hline
\end{tabular}


Table A6.3. Continued.

\begin{tabular}{|c|c|c|c|c|}
\hline Study & $\begin{array}{l}\text { Research aim, } \\
\text { modelling/applica } \\
\text { tion perspective }\end{array}$ & Method/Data used & Study region & $\begin{array}{l}\text { Model } \\
\text { capability/utilities/focus/ } \\
\text { highlights }\end{array}$ \\
\hline $\begin{array}{l}\text { Sen Gupta } \\
\text { et al. } \\
(2015)\end{array}$ & $\begin{array}{l}\text { Developing a } \\
\text { modelling } \\
\text { framework } \\
\text { facilitating the } \\
\text { integration of } \\
\text { UEB, hydrologic } \\
\text { model BASINS, } \\
\text { and GeoSFM }\end{array}$ & $\begin{array}{l}\text { Gridded } \\
\text { meteorological } \\
\text { forcing, DEM, } \\
\text { vegetation variables, } \\
\text { land cover, glacier } \\
\text { outlines and albedo, } \\
\text { hydrological data }\end{array}$ & $\begin{array}{l}\text { Langtang Khola } \\
\text { watershed (Himalaya), } \\
\text { Nepal }\end{array}$ & $\begin{array}{l}\text { Hydrological model with } \\
\text { topographical effect, } \\
\text { surface water and } \\
\text { streamflow, }\end{array}$ \\
\hline $\begin{array}{l}\text { Gichamo } \\
\text { and } \\
\text { Tarboton } \\
\text { (2019) }\end{array}$ & $\begin{array}{l}\text { Coupling UEB to } \\
\text { hydrologic model } \\
\text { SAC-SMA } \\
\text { together with } \\
\text { assimilation of } \\
\text { snow and } \\
\text { streamflow } \\
\text { observations }\end{array}$ & $\begin{array}{l}\text { Gridded } \\
\text { meteorological } \\
\text { forcing, vegetation } \\
\text { properties, watershed } \\
\text { domain variables } \\
\text { (e.g., slope, aspect), } \\
\text { hydrological data, } \\
\text { and SWE \& } \\
\text { discharge data for } \\
\text { assimilation }\end{array}$ & $\begin{array}{l}\text { Green River } \\
\text { watershed, Salt Lake } \\
\text { City, USA }\end{array}$ & $\begin{array}{l}\text { UEB snowmelt model } \\
\text { with assimilation of SWE } \\
\text { using ensemble Kalman } \\
\text { filter, Sacramento Soil } \\
\text { Moisture Accounting } \\
\text { (SAC-SMA), rutpix7 } \\
\text { stream routing model } \\
\text { with assimilation of } \\
\text { streamflow observation } \\
\text { using particle filter, }\end{array}$ \\
\hline $\begin{array}{l}\text { Gichamo } \\
\text { and } \\
\text { Tarboton } \\
(2020)\end{array}$ & $\begin{array}{l}\text { Developing UEB } \\
\text { parallel for the } \\
\text { simulation of } \\
\text { snow process } \\
\text { using parallel } \\
\text { computing }\end{array}$ & $\begin{array}{l}\text { Gridded } \\
\text { meteorological } \\
\text { forcing, vegetation } \\
\text { properties, watershed } \\
\text { domain variables } \\
\text { (e.g., slope, aspect), } \\
\text { in NetCDF format }\end{array}$ & $\begin{array}{l}\text { Logan River } \\
\text { watershed, Utah, USA }\end{array}$ & $\begin{array}{l}\text { Two parallel versions of } \\
\text { UEB model, one using } \\
\text { the Message Passing } \\
\text { Interface (MPI) and the } \\
\text { other using NVIDIA's } \\
\text { CUDA code on Graphics } \\
\text { Processing Unit (GPU), }\end{array}$ \\
\hline \multicolumn{5}{|c|}{ UEB model applications } \\
\hline $\begin{array}{l}\text { Gardiner et } \\
\text { al., (1998) }\end{array}$ & $\begin{array}{l}\text { Testing UEB in } \\
\text { terms of SWE }\end{array}$ & $\begin{array}{l}\text { Meteorological } \\
\text { inputs, site } \\
\text { information }\end{array}$ & $\begin{array}{l}\text { Paternoster Valley, } \\
\text { Signy Island, South } \\
\text { Orkney Islands, } \\
\text { Antarctic }\end{array}$ & $\begin{array}{l}\text { First application of UEB } \\
\text { in Antarctic, }\end{array}$ \\
\hline $\begin{array}{l}\text { Schulz and } \\
\text { de Jong } \\
(2004)\end{array}$ & $\begin{array}{l}\text { Testing UEB in } \\
\text { terms of } \\
\text { snowmelt and } \\
\text { sublimation }\end{array}$ & $\begin{array}{l}\text { Meteorological } \\
\text { variables, site } \\
\text { information }\end{array}$ & $\begin{array}{l}\text { High Atlas Mountains } \\
\text { of Morocco, Morocco }\end{array}$ & $\begin{array}{l}\text { Snowmelt and } \\
\text { sublimation/ablation, }\end{array}$ \\
\hline $\begin{array}{l}\text { Brown et } \\
\text { al. (2014) }\end{array}$ & $\begin{array}{l}\text { Estimating the } \\
\text { contribution of } \\
\text { glacier and } \\
\text { snowmelt to } \\
\text { stream flow using } \\
\text { integrated } \\
\text { modelling system } \\
\text { (UEB, GeoSFM, } \\
\text { BASINS) }\end{array}$ & $\begin{array}{l}\text { Downscaled NASA } \\
\text { satellite based and } \\
\text { earth system data } \\
\text { products, in-situ } \\
\text { hydrologic data }\end{array}$ & $\begin{array}{l}\text { Langtang Khola } \\
\text { watershed (Himalaya), } \\
\text { Nepal }\end{array}$ & $\begin{array}{l}\text { UEB considering glacier } \\
\text { ice melt over clean and } \\
\text { debris-covered tongues, } \\
\text { Geospatial Stream Flow } \\
\text { Model (GeoSFM), } \\
\text { BASINS model, } \\
\text { streamflow, }\end{array}$ \\
\hline $\begin{array}{l}\text { Sultana et } \\
\text { al. (2014) }\end{array}$ & $\begin{array}{l}\text { Resolve the } \\
\text { underestimation } \\
\text { of SWE by Noah } \\
2.7 .1 \text { by } \\
\text { incorporating } \\
\text { UEB }\end{array}$ & $\begin{array}{l}\text { Meteorological } \\
\text { forcing from } \\
\text { NLDAS-2, site } \\
\text { information }\end{array}$ & $\begin{array}{l}\text { NRCS SNOTEL } \\
\text { stations, California, } \\
\text { USA; T.W. Daniel } \\
\text { Experimental Forest } \\
\text { site, Utah, USA }\end{array}$ & $\begin{array}{l}\text { Snow surface } \\
\text { temperature, snowmelt } \\
\text { event, SWE, }\end{array}$ \\
\hline
\end{tabular}


Table A6.3. Continued.

\begin{tabular}{|c|c|c|c|c|}
\hline Study & $\begin{array}{l}\text { Research aim, } \\
\text { modelling/applica } \\
\text { tion perspective }\end{array}$ & Method/Data used & Study region & $\begin{array}{l}\text { Model } \\
\text { capability/utilities/focus/ } \\
\text { highlights }\end{array}$ \\
\hline $\begin{array}{l}\text { Pimentel et } \\
\text { al. (2015) }\end{array}$ & $\begin{array}{l}\text { Improving snow } \\
\text { cover simulation } \\
\text { over mountainous } \\
\text { regions with } \\
\text { highly irregular } \\
\text { distribution }\end{array}$ & $\begin{array}{l}\text { High-frequency } \\
\text { images were } \\
\text { combined with UEB } \\
\text { model to reproduce } \\
\text { snow evolution at } \\
\text { cell scale }(30 \mathrm{~m} \times 30 \\
\mathrm{m} \text { ) by means of the } \\
\text { assimilation of the } \\
\text { snow cover fraction } \\
\text { observation dataset } \\
\text { obtained from } \\
\text { terrestrial } \\
\text { photography }\end{array}$ & $\begin{array}{l}\text { Sierra Nevada, } \\
\text { southern Spain }\end{array}$ & $\begin{array}{l}\text { Terrestrial photography, } \\
\text { data assimilation of snow } \\
\text { cover observation; Snow } \\
\text { cover and snow depth, }\end{array}$ \\
\hline $\begin{array}{l}\text { Raleigh et } \\
\text { al. (2015) }\end{array}$ & $\begin{array}{l}\text { Diagnosing the } \\
\text { sensitivity/impact } \\
\text { of forcing error } \\
\text { characteristics on } \\
\text { snow simulations }\end{array}$ & $\begin{array}{l}\text { Site information, } \\
\text { meteorological } \\
\text { forcing with various } \\
\text { error characteristics }\end{array}$ & $\begin{array}{l}\text { Imnavait Creek site in } \\
\text { Alaska, USA; the } \\
\text { maritime Col de Porte } \\
\text { site in the Rhône- } \\
\text { Alpes of France, } \\
\text { France; the } \\
\text { intermountain } \\
\text { Reynolds Mountain } \\
\text { East sheltered site in } \\
\text { the Owyhee Range in } \\
\text { Idaho, USA; the } \\
\text { continental Swamp } \\
\text { Angel Study Plot site } \\
\text { in the San Juan } \\
\text { Mountains of } \\
\text { Colorado, USA }\end{array}$ & $\begin{array}{l}\text { Sobol's global sensitivity } \\
\text { analysis, }\end{array}$ \\
\hline $\begin{array}{l}\text { Watson et } \\
\text { al. (2006) }\end{array}$ & $\begin{array}{l}\text { Testing } \\
\text { distributed UEB }\end{array}$ & $\begin{array}{l}\text { Daily precipitation } \\
\text { and temperature data, } \\
\text { and } 28.5-\mathrm{m} \text { maps of } \\
\text { mean annual } \\
\text { precipitation, terrain, } \\
\text { vegetation, and } \\
\text { geothermal heat flux } \\
\text { Meteorological data }\end{array}$ & SNOTEL sites, USA & $\begin{array}{l}\text { Spatial SWE, requires } \\
\text { improvements of snow } \\
\text { interception, and } \\
\text { snowpack thermal } \\
\text { dynamics for tested } \\
\text { regions, }\end{array}$ \\
\hline $\begin{array}{l}\text { Khanduri } \\
\text { and } \\
\text { Thakur } \\
(2020)\end{array}$ & $\begin{array}{l}\text { Testing UEB in } \\
\text { terms of } \\
\text { snowmelt runoff }\end{array}$ & $\begin{array}{l}\text { and remotely sensed } \\
\text { data from Landsat } \\
\text { ETM+, IRS P-6 } \\
\text { LISS-III and MODIS } \\
\text { 8-day snow cover } \\
\text { data product }\end{array}$ & $\begin{array}{l}\text { Himachal Pradesh } \\
\text { state, India }\end{array}$ & Snowmelt runoff, \\
\hline $\begin{array}{l}\text { Liu et al. } \\
(2020)\end{array}$ & $\begin{array}{l}\text { Testing UEB in } \\
\text { terms of glacier- } \\
\text { and snowmelt- } \\
\text { driven } \\
\text { streamflow }\end{array}$ & $\begin{array}{l}\text { Spatial downscaling } \\
\text { of the China } \\
\text { meteorological } \\
\text { forcing dataset } \\
\text { (CMFD) coupled } \\
\text { with other } \\
\text { parameters, the } \\
\text { model simulates the } \\
\text { total surface water } \\
\text { balance using surface } \\
\text { water input from } \\
\text { snowmelt, glacial } \\
\text { melt and rainfall }\end{array}$ & $\begin{array}{l}\text { Middle Tianshan } \\
\text { Mountains, China }\end{array}$ & $\begin{array}{l}\text { A glacier melt model and } \\
\text { snow above/below the } \\
\text { forest ablation algorithm, } \\
\text { streamflow. }\end{array}$ \\
\hline
\end{tabular}


Table A6.4. The used vegetation parameters for a Tibetan meadow ecosystem

\begin{tabular}{lccc}
\hline Parameter & Symbol & Unit & Value \\
\hline Root depth that contains 95\% of fine root biomass & $\mathrm{Z}_{\mathrm{R}, 95}$ & $\mathrm{~m}$ & 0.3 \\
Water use efficiency parameter, which connects the stomatal & $\mathrm{a}_{1}$ & - & 5 \\
aperture and net assimilation & $\mathrm{S}_{\mathrm{LAI}}$ & $\mathrm{m}^{2}$ LAI g C & 0.0225 \\
Specific leaf area & $\mathrm{V}_{\max }$ & - & 60 \\
Maximum rubisco capacity & $\mathrm{T}_{\text {lo }}$ & ${ }^{\circ} \mathrm{C}$ & 0.2 \\
Temperature for leaf onset & $\mathrm{L}_{\text {day_cr }}$ & $\mathrm{h}$ & 11.4 \\
Daylight threshold for senescence & $\mathrm{T}_{\text {cold }}$ & ${ }^{\circ} \mathrm{C}$ & 0 \\
Cold control on leaf shedding & $\psi_{S, 00}$ & $\mathrm{MPa}$ & 0 \\
Water potential at $\%$ loss stomatal conductivity & $\psi_{S, 50}$ & $\mathrm{MPa}$ & -2.8 \\
Water potential at 50\% loss stomatal conductivity & $\mathrm{A}_{\mathrm{cr}}$ & $\mathrm{d}$ & 180 \\
Critical leaf age & $\beta_{R}$ & - & 0.99 \\
Leaf onset water stress & & &
\end{tabular}




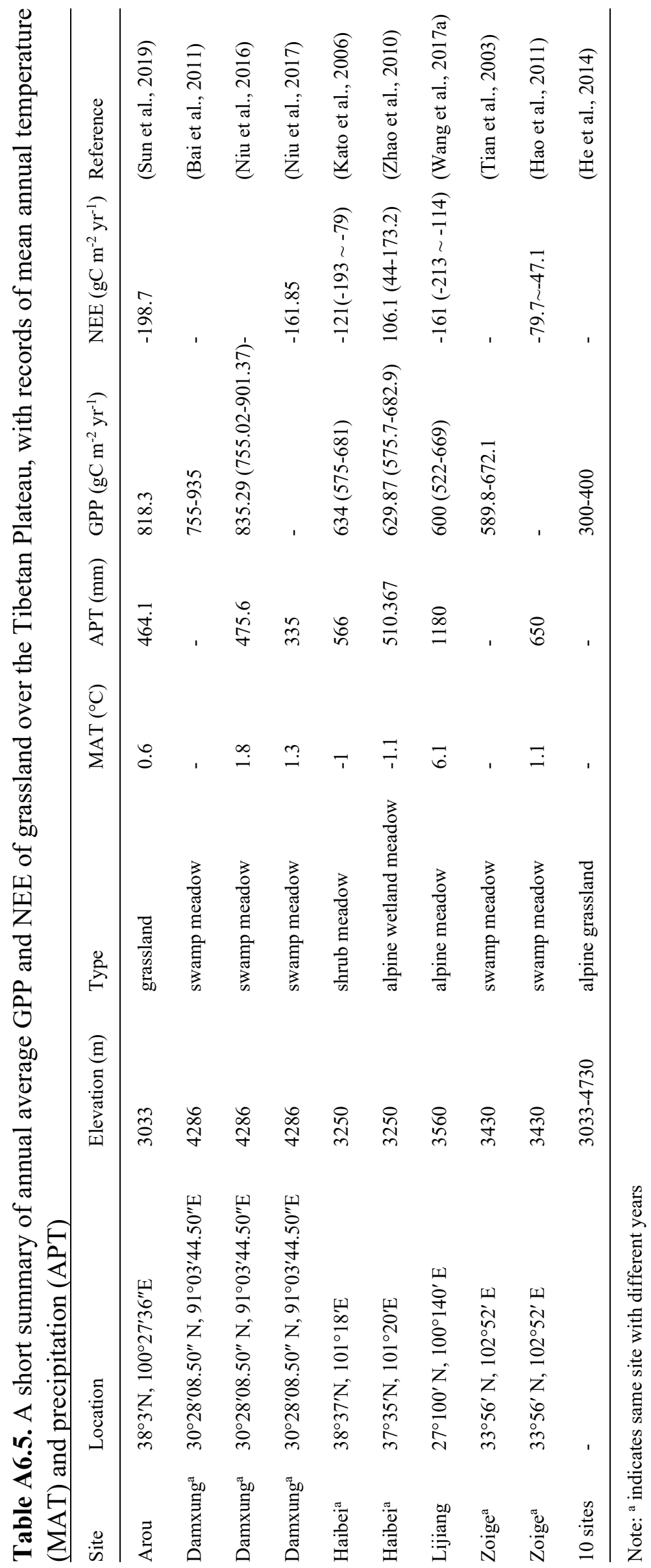




\section{List of symbols}

\begin{tabular}{|c|c|c|c|}
\hline Symbol & Parameter & Unit & Value \\
\hline$a$ & Fitted parameter for soil surface resistance & - & 0.3565 \\
\hline$b(z)$ & Normalized water uptake distribution & $\mathrm{m}^{-1}$ & \\
\hline$C_{a}$ & Specific heat capacity of dry air & $\mathrm{J} \mathrm{kg}^{-1}{ }^{\circ} \mathrm{C}^{-1}$ & 1.005 \\
\hline$C_{a p p}$ & Apparent heat capacity & $\mathrm{J} \mathrm{kg}^{-1}{ }^{\circ} \mathrm{C}^{-1}$ & $\begin{array}{l}=C_{\text {soil }} \\
+\rho_{i} \frac{L_{f}^{2}}{g T} \frac{d \theta_{L}}{d \psi}\end{array}$ \\
\hline$C_{i}$ & Specific heat capacity of ice & $\mathrm{J} \mathrm{kg}^{-1}{ }^{\circ} \mathrm{C}^{-1}$ & 2.0455 \\
\hline$C_{L}$ & Specific heat capacity of liquid & $\mathrm{J} \mathrm{kg}^{-1}{ }^{\circ} \mathrm{C}^{-1}$ & 4.186 \\
\hline$C_{s}$ & Specific heat capacity of soil solids & $\mathrm{J} \mathrm{kg}^{-1}{ }^{\circ} \mathrm{C}^{-1}$ & \\
\hline$C_{\text {soil }}$ & Heat capacity of the bulk soil & $\mathrm{J} \mathrm{kg}^{-1}{ }^{\circ} \mathrm{C}^{-1}$ & \\
\hline$C_{V}$ & Specific heat capacity of water vapor & $\mathrm{J} \mathrm{kg}^{-1}{ }^{\circ} \mathrm{C}^{-1}$ & 1.87 \\
\hline$c_{p}$ & Specific heat capacity of air & $\mathrm{J} \mathrm{kg}^{-1} \mathrm{~K}^{-1}$ & \\
\hline$D_{e}$ & Molecular diffusivity of water vapor in soil & $\mathrm{m}^{2} \mathrm{~s}^{-1}$ & \\
\hline$D_{T D}$ & $\begin{array}{l}\text { Transport coefficient for adsorbed liquid flow } \\
\text { due to temperature gradient }\end{array}$ & $\begin{array}{l}\mathrm{kg} \mathrm{m}^{-1} \mathrm{~s}^{-} \\
{ }^{1}{ }^{\circ} \mathrm{C}^{-1}\end{array}$ & \\
\hline$D_{V a}$ & Advective vapor transfer coefficient & $\mathrm{s}$ & \\
\hline$D_{V g}$ & Gas-phase longitudinal dispersion coefficient & $\mathrm{m}^{2} \mathrm{~s}^{-1}$ & \\
\hline$D_{V h}$ & Isothermal vapor conductivity & $\mathrm{kg} \mathrm{m}^{-2} \mathrm{~s}^{-1}$ & \\
\hline$D_{V T}$ & Thermal vapor diffusion coefficient & $\begin{array}{l}\mathrm{kg} \mathrm{m}^{-1} \mathrm{~s}^{-} \\
{ }^{1}{ }^{\circ} \mathrm{C}^{-1}\end{array}$ & \\
\hline$h$ & Soil matric potential & $\mathrm{m}$ & \\
\hline$H_{c}$ & Henry's constant & - & 0.02 \\
\hline$K$ & Hydraulic conductivity & $\mathrm{m} \mathrm{s}^{-1}$ & \\
\hline$K_{g}$ & Intrinsic air permeability & $\mathrm{m}^{2}$ & \\
\hline$K_{L h}^{\circ}$ & Isothermal hydraulic conductivities & $\mathrm{m} \mathrm{s}^{-1}$ & \\
\hline$K_{L T}$ & Thermal hydraulic conductivities & $\mathrm{m}^{2} \mathrm{~s}^{-1}{ }^{\circ} \mathrm{C}^{-1}$ & \\
\hline$K_{\mathrm{s}}$ & Soil-saturated hydraulic conductivity & $\mathrm{m} \mathrm{s}^{-1}$ & \\
\hline$L_{0}$ & $\begin{array}{l}\text { Latent heat of vaporization of water at the } \\
\text { reference temperature }\end{array}$ & $\mathrm{J} \mathrm{kg}^{-1}$ & \\
\hline$L A I_{e f f}$ & Effective leaf area index & - & \\
\hline$L_{f}$ & Latent heat of fusion & $\mathrm{J} \mathrm{kg}^{-1}$ & $3.34 \mathrm{E} 5$ \\
\hline$n$ & Van Genuchten fitting parameters & - & \\
\hline$P_{g}$ & Mixed pore air pressure & $\mathrm{Pa}$ & \\
\hline$q$ & Water flux & $\mathrm{kg} \mathrm{m}^{-2} \mathrm{~s}^{-1}$ & \\
\hline$q_{a}$ & Dry air flux & $\mathrm{kg} \mathrm{m}^{-2} \mathrm{~s}^{-1}$ & \\
\hline$q_{L}$ & Soil liquid water fluxes (positive upwards) & $\mathrm{kg} \mathrm{m}^{-2} \mathrm{~s}^{-1}$ & \\
\hline$q_{L a}$ & $\begin{array}{l}\text { Liquid water flux driven by the gradient of air } \\
\text { pressure }\end{array}$ & $\mathrm{kg} \mathrm{m}^{-2} \mathrm{~s}^{-1}$ & \\
\hline$q_{L h}$ & $\begin{array}{l}\text { Liquid water flux driven by the gradient of } \\
\text { matric potential }\end{array}$ & $\mathrm{kg} \mathrm{m}^{-2} \mathrm{~s}^{-1}$ & \\
\hline$q_{L T}$ & $\begin{array}{l}\text { Liquid water flux driven by the gradient of } \\
\text { temperature }\end{array}$ & $\mathrm{kg} \mathrm{m}^{-2} \mathrm{~s}^{-1}$ & \\
\hline$q_{V}$ & Soil water vapor fluxes (positive upwards) & $\mathrm{kg} \mathrm{m}^{-2} \mathrm{~s}^{-1}$ & \\
\hline$q_{V a}$ & $\begin{array}{l}\text { Water vapor flux driven by the gradient of air } \\
\text { pressure }\end{array}$ & $\mathrm{kg} \mathrm{m}^{-2} \mathrm{~s}^{-1}$ & \\
\hline
\end{tabular}




\begin{tabular}{|c|c|c|c|}
\hline$q_{V h}$ & $\begin{array}{l}\text { Water vapor flux driven by the gradient of } \\
\text { matric potential }\end{array}$ & $\mathrm{kg} \mathrm{m}^{-2} \mathrm{~s}^{-1}$ & \\
\hline$q_{V T}$ & $\begin{array}{l}\text { Water vapor flux driven by the gradient of } \\
\text { temperature }\end{array}$ & $\mathrm{kg} \mathrm{m}^{-2} \mathrm{~s}^{-1}$ & \\
\hline$r_{a}^{c}$ & Aerodynamic resistance for canopy surface & $\mathrm{s} \mathrm{m}^{-1}$ & \\
\hline$r_{a}^{s}$ & Aerodynamic resistance for bare soil & $\mathrm{s} \mathrm{m}^{-1}$ & \\
\hline$r_{c, \min }$ & Minimum canopy surface resistance & $\mathrm{s} \mathrm{m}^{-1}$ & \\
\hline$r_{l, \min }$ & Minimum leaf stomatal resistance & $\mathrm{s} \mathrm{m}^{-1}$ & \\
\hline$r_{s}$ & Soil surface resistance & $\mathrm{s} \mathrm{m}^{-1}$ & \\
\hline$r_{s l}$ & $\begin{array}{l}\text { Resistance to molecular diffusion of the water } \\
\text { surface }\end{array}$ & $\mathrm{s} \mathrm{m}^{-1}$ & 10 \\
\hline$R_{n}$ & Net radiation & $\begin{array}{l}\mathrm{MJ} \mathrm{m}^{-2} \\
\text { day }^{-1}\end{array}$ & \\
\hline$R_{n}^{c}$ & Net radiation at the canopy surface & $\begin{array}{l}\mathrm{MJ} \mathrm{m}^{-2} \\
\text { day }^{-1}\end{array}$ & \\
\hline$R_{n}^{S}$ & Net radiation at the soil surface & $\begin{array}{l}\mathrm{MJ} \mathrm{m}^{-2} \\
\text { day }^{-1}\end{array}$ & \\
\hline$S$ & Sink term for transpiration & $\mathrm{s}^{-1}$ & \\
\hline$S_{a}$ & Degree of saturation of the soil air & - & $=1-S_{L}$ \\
\hline$S_{L}$ & Degree of saturation in the soil & - & $=\theta_{L} / \varepsilon$ \\
\hline$S_{h}$ & Latent heat flux density & $\mathrm{W} \mathrm{m}{ }^{-3}$ & $=-\rho_{w} L \partial q_{v} / \partial z$ \\
\hline$S_{p}$ & Potential water uptake rate & $\mathrm{s}^{-1}$ & \\
\hline$t$ & Time & $\mathrm{s}$ & \\
\hline$T$ & Soil temperature & ${ }^{\circ} \mathrm{C}$ & \\
\hline$T_{p}$ & Potential transpiration & $\mathrm{m} \mathrm{s}^{-1}$ & \\
\hline$T_{r}$ & Arbitrary reference temperature & ${ }^{\circ} \mathrm{C}$ & 20 \\
\hline$W$ & Differential heat of wetting & $\mathrm{J} \mathrm{kg}^{-1}$ & \\
\hline$z$ & Vertical space coordinate (positive upwards) & $\mathrm{m}$ & \\
\hline$\alpha$ & Air entry value of soil & $\mathrm{m}^{-1}$ & \\
\hline$\alpha(h)$ & $\begin{array}{l}\text { Reduction coefficient related to soil water } \\
\text { potential }\end{array}$ & - & \\
\hline$\varepsilon$ & Porosity & - & \\
\hline$\psi$ & Water potential & $\mathrm{m}$ & \\
\hline$\lambda_{\text {eff }}$ & Effective thermal conductivity of the soil & $\begin{array}{l}\mathrm{W} \\
\mathrm{m}^{-1}{ }^{\circ} \mathrm{C}^{-1}\end{array}$ & \\
\hline$\theta$ & Volumetric water content & $\mathrm{m}^{3} \mathrm{~m}^{-3}$ & \\
\hline$\theta_{i}$ & Soil ice volumetric water content & $\mathrm{m}^{3} \mathrm{~m}^{-3}$ & \\
\hline$\theta_{L}$ & Soil liquid volumetric water content & $\mathrm{m}^{3} \mathrm{~m}^{-3}$ & \\
\hline$\theta_{V}$ & Soil vapor volumetric water content & $\mathrm{m}^{3} \mathrm{~m}^{-3}$ & \\
\hline$\theta_{s}$ & Volumetric fraction of solids in the soil & $\mathrm{m}^{3} \mathrm{~m}^{-3}$ & \\
\hline$\theta_{a}$ & Volumetric fraction of dry air in the soil & $\mathrm{m}^{3} \mathrm{~m}^{-3}$ & $=\theta_{\mathrm{V}}$ \\
\hline$\theta_{\text {sat }}$ & Saturated soil water content & $\mathrm{m}^{3} \mathrm{~m}^{-3}$ & \\
\hline$\theta_{\mathrm{r}}$ & Residual soil water content & $\mathrm{m}^{3} \mathrm{~m}^{-3}$ & \\
\hline$\theta_{1}$ & Topsoil water content & $\mathrm{m}^{3} \mathrm{~m}^{-3}$ & \\
\hline$\theta_{\text {min }}$ & $\begin{array}{l}\text { Minimum water content above which soil is } \\
\text { able to deliver vapor at a potential rate }\end{array}$ & $\mathrm{m}^{3} \mathrm{~m}^{-3}$ & \\
\hline$\rho_{a}$ & Air density & $\mathrm{kg} \mathrm{m}^{-3}$ & \\
\hline$\rho_{d a}$ & Density of dry air & $\mathrm{kg} \mathrm{m}^{-3}$ & \\
\hline$\rho_{i}$ & Density of ice & $\mathrm{kg} \mathrm{m}^{-3}$ & 920 \\
\hline
\end{tabular}




$\begin{array}{clll}\rho_{L} & \text { Density of soil liquid water } & \mathrm{kg} \mathrm{m}^{-3} & 1000 \\ \rho_{s} & \text { Density of solids } & \mathrm{kg} \mathrm{m}^{-3} & \\ \rho_{V} & \text { Density of water vapor } & \mathrm{kg} \mathrm{m}^{-3} & \\ \gamma_{W} & \text { Specific weight of water } & \mathrm{kg} \mathrm{m}^{-2} \mathrm{~s}^{-2} & \\ \mu_{a} & \text { Air viscosity } & \mathrm{kg} \mathrm{m}^{-2} \mathrm{~s}^{-1} & \\ \tau & \text { Light extinction coefficient } & - & \end{array}$




\section{List of abbreviations}

\begin{tabular}{|c|c|}
\hline AWS & Automatic Weather Stations \\
\hline ELBARA-III & ELABARA-III microwave radiometer \\
\hline $\begin{array}{l}\mathrm{BCD} / \mathrm{ACD} / \\
\mathrm{ACD}-\text { air }\end{array}$ & $\begin{array}{l}\text { Basic coupled/advance coupled/advance coupled soil water and heat } \\
\text { transfer processes with airflow }\end{array}$ \\
\hline $\mathrm{BCM} / \mathrm{ACM} /$ & Soil models with the basic coupled/advance coupled/advance coupled \\
\hline ACM-air & soil water and heat transfer processes with airflow \\
\hline $\mathrm{CHF}$ & Conductive Heat Flux \\
\hline CLDAS & China Land Data Assimilation System \\
\hline CLM & Community Land Model \\
\hline CMFD & China Meteorological Forcing Dataset \\
\hline CoLM & Common Land Model \\
\hline DOC & Dissolved Organic Carbon \\
\hline DOY & Day of year \\
\hline EC & Eddy covariance system \\
\hline ECMWF & European Centre for Medium-Range Weather Forecasts \\
\hline ERT & Electrical Resistivity Tomography \\
\hline ESM & Earth System Modeling \\
\hline ESO & Earth System Observation \\
\hline ESS & Earth System Science \\
\hline ET & Evapotranspiration \\
\hline $\mathrm{ET}_{0}$ & Reference crop evapotranspiration \\
\hline FAO & Food and Agriculture Organization of the United Nations \\
\hline FPAR & Fraction of Absorbed Photosynthetically Active Radiation \\
\hline FT & Freeze-Thaw \\
\hline GCOS & Global Climate Observing System \\
\hline GEWEX & Global Energy and Water cycle Experiment \\
\hline GEWEX-Tibet & GEWEX Asian Monsoon Experiment-Tibet \\
\hline GFDL & Geophysical Fluid Dynamics Laboratory \\
\hline GHB & General Head boundary \\
\hline GLDAS & Global Land Data Assimilation System \\
\hline GPP & Gross Primary Production \\
\hline $\mathrm{HC}$ & Heat Content \\
\hline $\mathrm{HFa}$ & Convective heat flux by airflow \\
\hline HFL & Convective heat flux by liquid water \\
\hline HFV & Convective heat flux by water vapor \\
\hline HIRLAM & High resolution limited area model \\
\hline HTESSEL & $\begin{array}{l}\text { Tiled ECMWF Scheme for Surface Exchanges over Land with revised } \\
\text { land surface Hydrology }\end{array}$ \\
\hline HYDRUS & One dimensional variably saturated flow and transport model \\
\hline IFS & Integrated Forecasting System \\
\hline ISBA & Interaction Soil-Biosphere-Atmosphere \\
\hline LAI & Leaf Area Index \\
\hline LDAS & Land Data Assimilation System \\
\hline LE & Latent heat flux \\
\hline LHF & Latent heat of vaporation \\
\hline
\end{tabular}




$\begin{array}{ll}\text { LSMs } & \text { Land Surface Models } \\ \text { MODFLOW } & \text { The USGS Modular Three-Dimensional Finite-Difference } \\ \text { MODIS } & \text { Groundwater Flow Model } \\ \text { MRS } & \text { Moderate Resolution Imaging Spectroradiometer } \\ \text { NEE } & \text { Magnetic Resonance Sounding } \\ \text { NLDAS } & \text { Net Ecosystem Exchange } \\ \text { Noah-MP } & \text { Noah-Multiparameterization land surface model } \\ \text { NWP } & \text { Numerical Weather Prediction } \\ \text { PBL } & \text { Planetary Boundary Layer } \\ \text { PdV57 } & \text { Philip and de Vries 1957 } \\ \text { PM } & \text { Penman-Monteith } \\ \text { RCA } & \text { Rossby Centre regional Atmospheric climate model } \\ \text { REC-ET } & \text { Recharge and Evapotranspiration packages for MODFLOW } \\ \text { SFCC } & \text { Soil freezing characteristic curve } \\ \text { SMST } & \text { Soil Moisture and soil temperature } \\ \text { SnowMIP } & \text { Snow Models intercomparison project } \\ \text { SNTHERM } & \text { Snow Thermal Model } \\ \text { SPAC } & \text { Soil-plant-atmosphere continuum } \\ \text { STEMMUS } & \text { Simultaneous Transfer of Energy, Mass and Momentum in } \\ & \text { Unsaturated Soil } \\ \text { STEMMUS-FT } & \text { Simultaneous Transfer of Energy, Mass and Momentum in } \\ \text { SURFEX } & \text { Unsaturated Soil with Freeze-Thaw } \\ \text { SWCC } & \text { Surface Externalisée, in French } \\ \text { SWRC } & \text { Soil Water Characteristic Curve } \\ \text { T\&C } & \text { Soil Water Retention Curve } \\ \text { UEB } & \text { Tethys-Chloris model } \\ \text { VSF } & \text { Utah Energy Balance model } \\ \text { WBM } & \text { Variably saturated flow model } \\ \text { ZDIL } & \text { Water balance model } \\ & \text { Zero-degree isothermal line } \\ & \end{array}$




\section{Bibliography}

Azmatch, T. F., Sego, D. C., Arenson, L. U., \& Biggar, K. W. (2012). Using soil freezing characteristic curve to estimate the hydraulic conductivity function of partially frozen soils. Cold Regions Sci. Tech., 83-84, 103-109. doi:10.1016/j.coldregions.2012.07.002

Baatz, R., Sullivan, P. L., Li, L., Weintraub, S. R., Loescher, H. W., Mirtl, M., Groffman, P. M., Wall, D. H., Young, M., White, T., Wen, H., Zacharias, S., Kühn, I., Tang, J., Gaillardet, J., Braud, I., Flores, A. N., Kumar, P., Lin, H., Ghezzehei, T., Jones, J., Gholz, H. L., Vereecken, H., \& Van Looy, K. (2018). Steering operational synergies in terrestrial observation networks: opportunity for advancing Earth system dynamics modelling. Earth Syst. Dynam., 9(2), 593609. doi:10.5194/esd-9-593-2018

Bai, J., Xu, X., Song, M., He, Y., Jiang, J., \& Shi, P. (2011). Effects of temperature and added nitrogen on carbon mineralization in alpine soils on the Tibetan Plateau. Ecology and Environmental Sciences(20), 855-859.

Bao, H., Koike, T., Yang, K., Wang, L., Shrestha, M., \& Lawford, P. (2016). Development of an enthalpy-based frozen soil model and its validation in a cold region in China. J. Geophys. Res., 121(10), 5259-5280. doi:10.1002/2015JD024451

Barrere, M., Domine, F., Decharme, B., Morin, S., Vionnet, V., \& Lafaysse, M. (2017). Evaluating the performance of coupled snow-soil models in SURFEXv8 to simulate the permafrost thermal regime at a high Arctic site. Geoscientific Model Development, 10(9), 34613479. doi:10.5194/gmd-10-3461-2017

Barthel, R., \& Banzhaf, S. (2016). Groundwater and Surface Water Interaction at the Regionalscale - A Review with Focus on Regional Integrated Models. Water Resour. Manage., 30(1), 132. doi:10.1007/s11269-015-1163-z

Beegum, S., Šimůnek, J., Szymkiewicz, A., Sudheer, K. P., \& Nambi, I. M. (2018). Updating the Coupling Algorithm between HYDRUS and MODFLOW in the HYDRUS Package for MODFLOW. Vadose Zone J., 17(1), 180034. doi:10.2136/vzj2018.02.0034

Bense, V. F., Ferguson, G., \& Kooi, H. (2009). Evolution of shallow groundwater flow systems in areas of degrading permafrost. Geophys. Res. Lett., 36(22). doi:10.1029/2009GL039225

Bense, V. F., Kooi, H., Ferguson, G., \& Read, T. (2012). Permafrost degradation as a control on hydrogeological regime shifts in a warming climate. Journal of Geophysical Research: Earth Surface, 117(3). doi:10.1029/2011JF002143

Bense, V. F., \& Kurylyk, B. L. (2017). Tracking the Subsurface Signal of Decadal Climate Warming to Quantify Vertical Groundwater Flow Rates. Geophys. Res. Lett., 44(24), 12,244212,253. doi:10.1002/2017GL076015

Bense, V. F., Kurylyk, B. L., de Bruin, J. G. H., \& Visser, P. (2020). Repeated Subsurface Thermal Profiling to Reveal Temporal Variability in Deep Groundwater Flow Conditions. Water Resour. Res., 56(6). doi:10.1029/2019WR026913

Bense, V. F., Kurylyk, B. L., van Daal, J., van der Ploeg, M. J., \& Carey, S. K. (2017). Interpreting Repeated Temperature-Depth Profiles for Groundwater Flow. Water Resour. Res., 53(10), 8639-8647. doi:10.1002/2017WR021496

Bense, V. F., \& Person, M. A. (2008). Transient hydrodynamics within intercratonic sedimentary basins during glacial cycles. Journal of Geophysical Research: Earth Surface, 113(4). doi:10.1029/2007JF000969

Best, M. J. (2011). The Joint UK Land Environment Simulator (JULES), model description Part 1: Energy and water fluxes. Geosci. Model Dev., 4(3), 677-699.

Bisht, G., Huang, M., Zhou, T., Chen, X., Dai, H., Hammond, G. E., Riley, W. J., Downs, J. L., Liu, Y., \& Zachara, J. M. (2017). Coupling a three-dimensional subsurface flow and transport model with a land surface model to simulate stream-aquifer-land interactions (CP v1.0). Geosci. Model Dev., 10(12), 4539-4562. doi:10.5194/gmd-10-4539-2017

Biskaborn, B. K., Smith, S. L., Noetzli, J., Matthes, H., Vieira, G., Streletskiy, D. A., Schoeneich, P., Romanovsky, V. E., Lewkowicz, A. G., Abramov, A., Allard, M., Boike, J., Cable, W. L., Christiansen, H. H., Delaloye, R., Diekmann, B., Drozdov, D., Etzelmüller, B., Grosse, G., Guglielmin, M., Ingeman-Nielsen, T., Isaksen, K., Ishikawa, M., Johansson, M., 
Johannsson, H., Joo, A., Kaverin, D., Kholodov, A., Konstantinov, P., Kröger, T., Lambiel, C., Lanckman, J. P., Luo, D., Malkova, G., Meiklejohn, I., Moskalenko, N., Oliva, M., Phillips, M., Ramos, M., Sannel, A. B. K., Sergeev, D., Seybold, C., Skryabin, P., Vasiliev, A., Wu, Q., Yoshikawa, K., Zheleznyak, M., \& Lantuit, H. (2019). Permafrost is warming at a global scale. Nature Communications, 10(1). doi:10.1038/s41467-018-08240-4

Bittelli, M., Flury, M., \& Roth, K. (2004). Use of dielectric spectroscopy to estimate ice content in frozen porous media. Water Resour. Res., 40(4), W042121-W0421211.

Bittelli, M., Ventura, F., Campbell, G. S., Snyder, R. L., Gallegati, F., \& Pisa, P. R. (2008). Coupling of heat, water vapor, and liquid water fluxes to compute evaporation in bare soils. $J$. Hydrol., 362(3), 191-205. doi:10.1016/j.jhydrol.2008.08.014

Boano, F., Revelli, R., \& Ridolfi, L. (2009). Quantifying the impact of groundwater discharge on the surface-subsurface exchange. Hydrol. Processes, 23(15), 2108-2116. doi:10.1002/hyp.7278

Boike, J., Hagedorn, B., \& Roth, K. (2008). Heat and water transfer processes in permafrostaffected soils: A review of field-and modeling-based studies for the Arctic and Antarctic. Proceeding of the Ninth International Conference on Permafrost(1), 149-154.

Boike, J., Roth, K., \& Overduin, P. P. (1998). Thermal and hydrologic dynamics of the active layer at a continuous permafrost site (Taymyr Peninsula, Siberia). Water Resour. Res., 34(3), 355-363. doi:10.1029/97WR03498

Bojinski, S., Verstraete, M., Peterson, T. C., Richter, C., Simmons, A., \& Zemp, M. (2014). The Concept of Essential Climate Variables in Support of Climate Research, Applications, and Policy. Bull. Am. Meteorol. Soc., 95(9), 1431-1443. doi:10.1175/bams-d-13-00047.1

Bonan, G. B., Patton, E. G., Finnigan, J. J., Baldocchi, D. D., \& Harman, I. N. (2021). Moving beyond the incorrect but useful paradigm: reevaluating big-leaf and multilayer plant canopies to model biosphere-atmosphere fluxes - a review. Agr. Forest Meteorol., 306, 108435. doi:10.1016/j.agrformet.2021.108435

Boone, A., Masson, V., Meyers, T., \& Noilhan, J. (2000). The influence of the inclusion of soil freezing on simulations by a soil-vegetation-atmosphere transfer scheme. J. Appl. Meteorol., 39(9), 1544-1569. doi:10.1175/1520-0450(2000)039<1544:TIOTIO >2.0.CO;2

Boone, A., Samuelsson, P., Gollvik, S., Napoly, A., Jarlan, L., Brun, E., \& Decharme, B. (2017). The interactions between soil-biosphere-atmosphere land surface model with a multi-energy balance (ISBA-MEB) option in SURFEXv8 - Part 1: Model description. Geosci. Model Dev., 10(2), 843-872. doi:10.5194/gmd-10-843-2017

Boone, A. A., \& Etchevers, P. (2001). An intercomparison of three snow schemes of varying complexity coupled to the same land surface model: Local-scale evaluation at an alpine site. $J$. Hydrometeorol., 2(4), 374-394. doi:10.1175/1525-7541(2001)002<0374:AIOTSS $>2.0 . C O ; 2$

Booth, E. G., Zipper, S. C., Loheide, S. P., II, \& Kucharik, C. J. (2016). Is groundwater recharge always serving us well? Water supply provisioning, crop production, and flood attenuation in conflict in Wisconsin, USA. Ecosystem Services, 21, 153-165. doi:10.1016/j.ecoser.2016.08.007

Boulet, G., Braud, I., \& Vauclin, M. (1997). Study of the mechanisms of evaporation under arid conditions using a detailed model of the soil-atmosphere continuum. Application to the EFEDA I experiment. J. Hydrol., 193(1-4), 114-141. doi:10.1016/S0022-1694(96)03148-4

Brandhorst, N., Erdal, D., \& Neuweiler, I. (2021). Coupling saturated and unsaturated flow: comparing the iterative and the non-iterative approach. Hydrol. Earth Syst. Sci., 25(7), 40414059. doi:10.5194/hess-25-4041-2021

Brantley, S. L., McDowell, W. H., Dietrich, W. E., White, T. S., Kumar, P., Anderson, S. P., Chorover, J., Lohse, K. A., Bales, R. C., Richter, D. D., Grant, G., \& Gaillardet, J. (2017). Designing a network of critical zone observatories to explore the living skin of the terrestrial Earth. Earth Surf. Dynam., 5(4), 841-860. doi:10.5194/esurf-5-841-2017

Brelsford, C., Dumas, M., Schlager, E., Dermody, B. J., Aiuvalasit, M., Allen-Dumas, M. R., Beecher, J., Bhatia, U., D'Odorico, P., Garcia, M., Gober, P., Groenfeldt, D., Lansing, S., Madani, K., Méndez-Barrientos, L. E., Mondino, E., Müller, M. F., O'Donnell, F. C., Owuor, P. M., Rising, J., Sanderson, M. R., Souza, F. A. A., \& Zipper, S. C. (2020). Developing a sustainability science approach for water systems. Ecology and Society, 25(2), 1-6. 
doi:10.5751/ES-11515-250223

Brown, M. E., Racoviteanu, A. E., Tarboton, D. G., Gupta, A. S., Nigro, J., Policelli, F., Habib, S., Tokay, M., Shrestha, M. S., Bajracharya, S., Hummel, P., Gray, M., Duda, P., Zaitchik, B., Mahat, V., Artan, G., \& Tokar, S. (2014). An integrated modeling system for estimating glacier and snow melt driven streamflow from remote sensing and earth system data products in the Himalayas. J. Hydrol., 519(PB), 1859-1869. doi:10.1016/j.jhydrol.2014.09.050

Brunner, P., \& Simmons, C. T. (2012). HydroGeoSphere: A Fully Integrated, Physically Based Hydrological Model. Groundwater, 50(2), 170-176. doi:10.1111/j.1745-6584.2011.00882.x

Burke, E. J., Jones, C. D., \& Koven, C. D. (2013). Estimating the permafrost-carbon climate response in the CMIP5 climate models using a simplified approach. J. Clim., 26(14), 48974909. doi:10.1175/JCLI-D-12-00550.1

Cai, G., Vanderborght, J., Langensiepen, M., Schnepf, A., Hüging, H., \& Vereecken, H. (2018). Root growth, water uptake, and sap flow of winter wheat in response to different soil water conditions. Hydrol. Earth Syst. Sci., 22(4), 2449-2470. doi:10.5194/hess-22-2449-2018

Campbell, J. L., \& Laudon, H. (2019). Carbon response to changing winter conditions in northern regions: Current understanding and emerging research needs. Environmental Reviews, 27(4), 545-566. doi:10.1139/er-2018-0097

Che, T., Li, X., Liu, S., Li, H., Xu, Z., Tan, J., Zhang, Y., Ren, Z., Xiao, L., Deng, J., Jin, R., Ma, M., Wang, J., \& Yang, X. (2019). Integrated hydrometeorological, snow and frozen-ground observations in the alpine region of the Heihe River Basin, China. Earth System Science Data, 11(3), 1483-1499. doi:10.5194/essd-11-1483-2019

Chen, L., Fortier, D., McKenzie, J. M., \& Sliger, M. (2020). Impact of heat advection on the thermal regime of roads built on permafrost. Hydrol. Processes, 34(7), 1647-1664. doi:10.1002/hyp.13688

Chen, X., Su, Z., Ma, Y., Yang, K., Wen, J., \& Zhang, Y. (2013). An improvement of roughness height parameterization of the Surface Energy Balance System (SEBS) over the Tibetan plateau. Journal of Applied Meteorology and Climatology, 52(3), 607-622. doi:10.1175/JAMC-D-12056.1

Cheng, G., \& Wu, T. (2007). Responses of permafrost to climate change and their environmental significance, Qinghai-Tibet Plateau. Journal of Geophysical Research: Earth Surface, 112(2). doi:10.1029/2006JF000631

Clapp, R. B., \& Hornberger, G. M. (1978). Empirical equations for some soil hydraulic properties. Water Resour. Res., 14(4), 601-604. doi:10.1029/WR014i004p00601

Clark, M. P., Nijssen, B., Lundquist, J. D., Kavetski, D., Rupp, D. E., Woods, R. A., Freer, J. E., Gutmann, E. D., Wood, A. W., Brekke, L. D., Arnold, J. R., Gochis, D. J., \& Rasmussen, R. M. (2015). A unified approach for process-based hydrologic modeling: 1. Modeling concept. Water Resour. Res., 51(4), 2498-2514. doi:10.1002/2015wr017198

Cuntz, M., \& Haverd, V. (2018). Physically Accurate Soil Freeze-Thaw Processes in a Global Land Surface Scheme. Journal of Advances in Modeling Earth Systems, 10(1), 54-77. doi: $10.1002 / 2017 \mathrm{~ms} 001100$

Dai, Y., Zeng, X., \& Dickinson, R. E. (2001). The Common Land Model (CLM): Technical documentation and user's guide. Rep., 69 pp, School of Earth and Atmospheric Sciences, Georgia Institute of Technology, Atlanta, Georgia, USA.

Dall'Amico, M. (2010). Coupled water and heat transfer in permafrost modeling. (doctoral dissertation), University of Trento.

Dall'Amico, M., Endrizzi, S., Gruber, S., \& Rigon, R. (2011). A robust and energy-conserving model of freezing variably-saturated soil. Cryosphere, 5(2), 469-484. doi:10.5194/tc-5-4692011

Dandar, E., Saaltink, M. W., Carrera, J., \& Nemer, B. (2017). A surface model for water and energy balance in cold regions accounting for vapor diffusion. Hydrol. Earth Syst. Sci. Discuss., $2017,1-25$.

de Graaf, I. E. M., van Beek, R. L. P. H., Gleeson, T., Moosdorf, N., Schmitz, O., Sutanudjaja, E. H., \& Bierkens, M. F. P. (2017). A global-scale two-layer transient groundwater model: Development and application to groundwater depletion. Adv. Water Resour., 102, 53-67. doi:10.1016/j.advwatres.2017.01.011 
De Vries, D. A. (1958). Simultaneous transfer of heat and moisture in porous media. Eos, Transactions American Geophysical Union, 39(5), 909-916. doi:10.1029/TR039i005p00909 De Vries, D. A. (1963). Thermal properties of soils. Physics of Plant Environment, 210-235. De Vries, D. A. (1987). The theory of heat and moisture transfer in porous media revisited. International Journal of Heat and Mass Transfer, 30(7), 1343-1350. doi:10.1016/00179310(87)90166-9

Decharme, B., Brun, E., Boone, A., Delire, C., Le Moigne, P., \& Morin, S. (2016). Impacts of snow and organic soils parameterization on northern Eurasian soil temperature profiles simulated by the ISBA land surface model. Cryosphere, 10(2), 853-877. doi:10.5194/tc-10853-2016

Dente, L., Vekerdy, Z., Wen, J., \& Su, Z. (2012). Maqu network for validation of satellitederived soil moisture products. Int. J. Appl. Earth Obs. Geoinf., 17, 55-65. doi:10.1016/j.jag.2011.11.004

Ding, B., Yang, K., Yang, W., He, X., Chen, Y., Lazhu, Guo, X., Wang, L., Wu, H., \& Yao, T. (2017). Development of a Water and Enthalpy Budget-based Glacier mass balance Model (WEB-GM) and its preliminary validation. Water Resour. Res., 53(4), 3146-3178. doi:10.1002/2016WR018865

Domine, F., Picard, G., Morin, S., Barrere, M., Madore, J.-B., \& Langlois, A. (2019). Major Issues in Simulating Some Arctic Snowpack Properties Using Current Detailed Snow Physics Models: Consequences for the Thermal Regime and Water Budget of Permafrost. Journal of Advances in Modeling Earth Systems, 11(1), 34-44. doi:10.1029/2018ms001445

Douville, H., Royer, J. F., \& Mahfouf, J. F. (1995). A new snow parameterization for the MétéoFrance climate model. Clim. Dyn., 12(1), 21-35. doi:10.1007/BF00208760

Druel, A., Ciais, P., Krinner, G., \& Peylin, P. (2019). Modeling the Vegetation Dynamics of Northern Shrubs and Mosses in the ORCHIDEE Land Surface Model. Journal of Advances in Modeling Earth Systems, 11(7), 2020-2035. doi:10.1029/2018MS001531

Dutra, E., Balsamo, G., Viterbo, P., Miranda, P. M. A., Beljaars, A., Schar, C., \& Elder, K. (2010). An improved snow scheme for the ECMWF land surface model: Description and offline validation. J. Hydrometeorol., 11(4), 899-916. doi:10.1175/2010JHM1249.1

Dutra, E., Viterbo, P., Miranda, P. M. A., \& Balsamo, G. (2012). Complexity of snow schemes in a climate model and its impact on surface energy and hydrology. J. Hydrometeorol., 13(2), 521-538. doi:10.1175/JHM-D-11-072.1

Eigenbrod, K. D., \& Kennepohl, G. J. A. (1996). Moisture accumulation and pore water pressures at base of pavements. in Transportation Research Record. edited, pp. 151-161, doi:10.3141/1546-17.

Ekici, A., Beer, C., Hagemann, S., Boike, J., Langer, M., \& Hauck, C. (2014). Simulating highlatitude permafrost regions by the JSBACH terrestrial ecosystem model. Geosci. Model Dev., 7(2), 631-647. doi:10.5194/gmd-7-631-2014

Endrizzi, S., Gruber, S., Dall'Amico, M., \& Rigon, R. (2014). GEOtop 2.0: Simulating the combined energy and water balance at and below the land surface accounting for soil freezing, snow cover and terrain effects. Geosci. Model Dev., 7(6), 2831-2857. doi:10.5194/gmd-7-28312014

Etchevers, P., Martin, E., Brown, R., Fierz, C., Lejeune, Y., Bazile, E., Boone, A., Dai, Y.-J., Essery, R., Fernandez, A., Gusev, Y., Jordan, R., Koren, V., Kowalczyk, E., Nasonova, N. O., Pyles, R. D., Schlosser, A., Shmakin, A. B., Smirnova, T. G., Strasser, U., Verseghy, D., Yamazaki, T., \& Yang, Z.-L. (2004). Validation of the energy budget of an alpine snowpack simulated by several snow models (SnowMIP project). Ann. Glaciol., 38(1), 150-158. doi:10.3189/172756404781814825

Evans, S. G., Ge, S., \& Liang, S. (2015). Analysis of groundwater flow in mountainous, headwater catchments with permafrost. Water Resour. Res., 51(12), 9564-9576. doi:10.1002/2015WR017732

Evans, S. G., \& Ge, S. M. (2017). Contrasting hydrogeologic responses to warming in permafrost and seasonally frozen ground hillslopes. Geophys. Res. Lett., 44(4), 1803-1813. doi:10.1002/2016g1072009

Facchi, A., Ortuani, B., Maggi, D., \& Gandolfi, C. (2004). Coupled SVAT-groundwater model 
for water resources simulation in irrigated alluvial plains. Environmental Modelling and Software, 19(11), 1053-1063. doi:10.1016/j.envsoft.2003.11.008

Famiglietti, J. S., \& Wood, E. F. (1994). Multiscale modeling of spatially variable water and energy balance processes. Water Resour. Res., 30(11), 3061-3078. doi:10.1029/94WR01498

Farouki, O. T. (1981). The thermal properties of soils in cold regions. Cold Regions Sci. Tech., 5(1), 67-75. doi:10.1016/0165-232X(81)90041-0

Fatichi, S., \& Ivanov, V. Y. (2014). Interannual variability of evapotranspiration and vegetation productivity. Water Resour. Res., 50(4), 3275-3294. doi:10.1002/2013wr015044

Fatichi, S., Ivanov, V. Y., \& Caporali, E. (2012a). A mechanistic ecohydrological model to investigate complex interactions in cold and warm water-controlled environments: 1. Theoretical framework and plot-scale analysis. Journal of Advances in Modeling Earth Systems, 4(5). doi:10.1029/2011MS000086

Fatichi, S., Ivanov, V. Y., \& Caporali, E. (2012b). A mechanistic ecohydrological model to investigate complex interactions in cold and warm water-controlled environments: 2. Spatiotemporal analyses. Journal of Advances in Modeling Earth Systems, 4(5). doi:10.1029/2011MS000087

Fatichi, S., Leuzinger, S., Paschalis, A., Langley, J. A., Donnellan Barraclough, A., \& Hovenden, M. J. (2016a). Partitioning direct and indirect effects reveals the response of water-limited ecosystems to elevated $\mathrm{CO}<\mathrm{sub}>2</$ sub $>$. Proceedings of the National Academy of Sciences, 113(45), 12757-12762. doi:10.1073/pnas.1605036113

Fatichi, S., \& Pappas, C. (2017). Constrained variability of modeled T:ET ratio across biomes. Geophys. Res. Lett., 44(13), 6795-6803. doi:10.1002/2017GL074041

Fatichi, S., Pappas, C., \& Ivanov, V. Y. (2016b). Modeling plant-water interactions: an ecohydrological overview from the cell to the global scale. Wiley Interdisciplinary Reviews: Water, 3(3), 327-368. doi:10.1002/wat2.1125

Flerchinger, G., N. (2017). The Simultaneous Heat and Water (SHAW) Model: Technical Documentation Version 3.0. Technical Rep., 43 pp, Northwest Watershed Research Center, USDA Agricultural Research Service Boise, Idaho

Flerchinger, G. N., \& Saxton, K. E. (1989). Simultaneous heat and water model of a freezing snow-residue-soil system. I. Theory and development. Transactions of the American Society of Agricultural Engineers, 32(2), 565-571.

Fu, B., Li, S., Yu, X., Yang, P., Yu, G., Feng, R., \& Zhuang, X. (2010). Chinese ecosystem research network: Progress and perspectives. Ecological Complexity, 7(2), 225-233. doi:10.1016/j.ecocom.2010.02.007

Fuchs, M., Campbell, G. S., \& Papendick, R. I. (1978). An Analysis of Sensible and Latent Heat Flow in a Partially Frozen Unsaturated Soil. Soil Sci. Soc. Am. J., 42(3), 379-385. doi:10.2136/sssaj1978.03615995004200030001x

Furman, A. (2008). Modeling Coupled Surface-Subsurface Flow Processes: A Review. Vadose Zone J., 7(2), 741-756. doi:10.2136/vzj2007.0065

Gao, B., Yang, D., Qin, Y., Wang, Y., Li, H., Zhang, Y., \& Zhang, T. (2018). Change in frozen soils and its effect on regional hydrology, upper Heihe basin, northeastern Qinghai-Tibetan Plateau. The Cryosphere, 12(2), 657-673. doi:10.5194/tc-12-657-2018

Garcia Gonzalez, R., Verhoef, A., Luigi Vidale, P., \& Braud, I. (2012). Incorporation of water vapor transfer in the JULES land surface model: Implications for key soil variables and land surface fluxes. Water Resour. Res., 48(5). doi:10.1029/2011WR011811

Gardiner, M. J., Ellis-Evans, J. C., Anderson, M. G., \& Tranter, M. (1998). Snowmelt modelling on Signy Island, South Orkney Islands. Ann. Glaciol., 26, 161-166. doi:10.3189/1998aog26-1161-166

Ge, S., McKenzie, J., Voss, C., \& Wu, Q. (2011). Exchange of groundwater and surface-water mediated by permafrost response to seasonal and long term air temperature variation. Geophys. Res. Lett., 38(14). doi:10.1029/2011GL047911

Gee, G. W., \& Hillel, D. (1988). Groundwater recharge in arid regions: Review and critique of estimation methods. Hydrol. Processes, 2(3), 255-266. doi:10.1002/hyp.3360020306

Gichamo, T. Z., \& Tarboton, D. G. (2019). Ensemble Streamflow Forecasting Using an Energy Balance Snowmelt Model Coupled to a Distributed Hydrologic Model with Assimilation of 
Snow and Streamflow Observations. Water Resour. Res., 55(12), 10813-10838. doi:10.1029/2019wr025472

Gichamo, T. Z., \& Tarboton, D. G. (2020). UEB parallel: Distributed snow accumulation and melt modeling using parallel computing. Environ. Model. Software, 125. doi:10.1016/j.envsoft.2019.104614

Gou, S., Miller, G. R., Saville, C., Maxwell, R. M., \& Ferguson, I. M. (2018). Simulating groundwater uptake and hydraulic redistribution by phreatophytes in a high-resolution, coupled subsurface-land surface model. Adv. Water Resour., 121, 245-262. doi:10.1016/j.advwatres.2018.08.008

Gouttevin, I., Krinner, G., Ciais, P., Polcher, J., \& Legout, C. (2012). Multi-scale validation of a new soil freezing scheme for a land-surface model with physically-based hydrology. Cryosphere, 6(2), 407-430. doi:10.5194/tc-6-407-2012

Grenier, C., Anbergen, H., Bense, V., Chanzy, Q., Coon, E., Collier, N., Costard, F., Ferry, M., Frampton, A., Frederick, J., Gonçalvès, J., Holmén, J., Jost, A., Kokh, S., Kurylyk, B., McKenzie, J., Molson, J., Mouche, E., Orgogozo, L., Pannetier, R., Rivière, A., Roux, N., Rühaak, W., Scheidegger, J., Selroos, J. O., Therrien, R., Vidstrand, P., \& Voss, C. (2018). Groundwater flow and heat transport for systems undergoing freeze-thaw: Intercomparison of numerical simulators for 2D test cases. Adv. Water Resour., 114, 196-218. doi:10.1016/j.advwatres.2018.02.001

Grifoll, J., Gastó, J. M., \& Cohen, Y. (2005). Non-isothermal soil water transport and evaporation. Adv. Water Resour., 28(11), 1254-1266. doi:10.1016/j.advwatres.2005.04.008

Groenevelt, P. H., \& Kay, B. D. (1974). On the Interaction of Water and Heat Transport in Frozen and Unfrozen Soils: II. The Liquid Phase. Proc Soil Sci Soc Am, 38(3), 400-404. doi:10.2136/sssaj1974.03615995003800030012x

Günther, D., Marke, T., Essery, R., \& Strasser, U. (2019). Uncertainties in Snowpack Simulations-Assessing the Impact of Model Structure, Parameter Choice, and Forcing Data Error on Point-Scale Energy Balance Snow Model Performance. Water Resour. Res., 55(4), 2779-2800. doi:10.1029/2018wr023403

Gusev, Y. M., \& Nasonova, O. N. (2003). The simulation of heat and water exchange in the boreal spruce forest by the land-surf ace model SWAP. J. Hydrol., 280(1-4), 162-191. doi:10.1016/S0022-1694(03)00221-X

Guymon, G. L., \& Luthin, J. N. (1974). A coupled heat and moisture transport model for Arctic soils. Water Resour. Res., 10(5), 995-1001. doi:10.1029/WR010i005p00995

Hagedorn, B., Sletten, R. S., \& Hallet, B. (2007). Sublimation and ice condensation in hyperarid soils: Modeling results using field data from Victoria Valley, Antarctica. Journal of Geophysical Research: Earth Surface, 112(F3). doi:10.1029/2006jf000580

Hansson, K., Šimůnek, J., Mizoguchi, M., Lundin, L. C., \& van Genuchten, M. T. (2004). Water flow and heat transport in frozen soil: Numerical solution and freeze-thaw applications. Vadose Zone J., 3(2), 693-704.

Hao, Y. B., Cui, X. Y., Wang, Y. F., Mei, X. R., Kang, X. M., Wu, N., Luo, P., \& Zhu, D. (2011). Predominance of Precipitation and Temperature Controls on Ecosystem CO2 Exchange in Zoige Alpine Wetlands of Southwest China. Wetlands, 31(2), 413-422. doi:10.1007/s13157011-0151-1

Harbaugh, A. W. (2005). MODFLOW-2005: the U.S. Geological Survey modular ground-water model--the ground-water flow process. Rep. 6-A16.

Harbaugh, A. W., Banta, E. R., Hill, M. C., \& McDonald, M. G. (2000). MODFLOW-2000, The U.S. Geological Survey Modular Ground-Water Model - User Guide to Modularization Concepts and the Ground-Water Flow Process. Rep. 2000-92.

Harder, P., \& Pomeroy, J. W. (2014). Hydrological model uncertainty due to precipitation-phase partitioning methods. Hydrol. Processes, 28(14), 4311-4327. doi:10.1002/hyp.10214

Harlan, R. L. (1973). Analysis of coupled heat-fluid transport in partially frozen soil. Water Resour. Res., 9(5), 1314-1323. doi:10.1029/WR009i005p01314

Havard, P. L., Prasher, S. O., Bonnell, R. B., \& Madani, A. (1995). LINKFLOW, A Water Flow Computer Model for Water Table Management: Part I. Model Development. Transactions of the ASAE, 38(2), 481-488. doi:10.13031/2013.27856 
He, H., Liu, M., Xiao, X., Ren, X., Zhang, L., Sun, X., Yang, Y., Li, Y., Zhao, L., Shi, P., Du, M., Ma, Y., Ma, M., Zhang, Y., \& Yu, G. (2014). Large-scale estimation and uncertainty analysis of gross primary production in Tibetan alpine grasslands. Journal of Geophysical Research: Biogeosciences, 119(3), 466-486. doi:10.1002/2013jg002449

He, J., Yang, K., Tang, W., Lu, H., Qin, J., Chen, Y., \& Li, X. (2020). The first high-resolution meteorological forcing dataset for land process studies over China. Scientific Data, 7(1), 25. doi:10.1038/s41597-020-0369-y

Hellstrom, R. A. (2000). Forest cover algorithms for estimating meteorological forcing in a numerical snow model. Hydrol. Processes, 14(18), 3239-3256. doi:10.1002/10991085(20001230)14:18<3239::aid-hyp201>3.0.co;2-o

Hinzman, L. D., Bettez, N. D., Bolton, W. R., Chapin, F. S., Dyurgerov, M. B., Fastie, C. L., Griffith, B., Hollister, R. D., Hope, A., Huntington, H. P., Jensen, A. M., Jia, G. J., Jorgenson, T., Kane, D. L., Klein, D. R., Kofinas, G., Lynch, A. H., Lloyd, A. H., McGuire, A. D., Nelson, F. E., Oechel, W. C., Osterkamp, T. E., Racine, C. H., Romanovsky, V. E., Stone, R. S., Stow, D. A., Sturm, M., Tweedie, C. E., Vourlitis, G. L., Walker, M. D., Walker, D. A., Webber, P. J., Welker, J. M., Winker, K. S., \& Yoshikawa, K. (2005). Evidence and implications of recent climate change in Northern Alaska and other Arctic regions. Clim. Change, 72(3), 251-298. doi:10.1007/s10584-005-5352-2

Hinzman, L. D., Deal, C. J., McGuire, A. D., Mernild, S. H., Polyakov, I. V., \& Walsh, J. E. (2013). Trajectory of the Arctic as an integrated system. Ecological Applications, 23(8), 18371868. doi:10.1890/11-1498.1

Hofste, J. G., Van Der Velde, R., Wen, J., Wang, X., Wang, Z., Zheng, D., Van Der Tol, C., \& $\mathrm{Su}, \mathrm{Z}$. (2021). Year-long, broad-band, microwave backscatter observations of an alpine meadow over the Tibetan Plateau with a ground-based scatterometer. Earth System Science Data, 13(6), 2819-2856. doi:10.5194/essd-13-2819-2021

Hrbáček, F., Láska, K., \& Engel, Z. (2016). Effect of snow cover on the active-layer thermal regime-a case study from James Ross island, Antarctic Peninsula. Permafr. Periglac. Proc., 27(3), 307-315.

Iijima, Y., Ohta, T., Kotani, A., Fedorov, A. N., Kodama, Y., \& Maximov, T. C. (2014). Sap flow changes in relation to permafrost degradation under increasing precipitation in an eastern Siberian larch forest. Ecohydrology, 7(2), 177-187. doi:10.1002/eco.1366

Irvine, D. J., Kurylyk, B. L., Cartwright, I., Bonham, M., Post, V. E. A., Banks, E. W., \& Simmons, C. T. (2017). Groundwater flow estimation using temperature-depth profiles in a complex environment and a changing climate. Sci. Tot. Environ., 574, 272-281. doi:10.1016/j.scitotenv.2016.08.212

Isaksen, K., Mühll, D. V., Gubler, H., Kohl, T., \& Sollid, J. L. (2000). Ground surface temperature reconstruction based on data from a deep borehole in permafrost at Janssonhaugen Svalbard. Ann. Glaciol., 31, 287-294.

Ishikawa, T., Tokoro, T., \& Miura, S. (2016). Influence of freeze-thaw action on hydraulic behavior of unsaturated volcanic coarse-grained soils. Soils and Foundations, 56(5), 790-804. doi:10.1016/j.sandf.2016.08.005

Iwata, Y., Hayashi, M., Suzuki, S., Hirota, T., \& Hasegawa, S. (2010). Effects of snow cover on soil freezing, water movement, and snowmelt infiltration: A paired plot experiment. Water Resour. Res., 46(9). doi:10.1029/2009WR008070

Jambon-Puillet, E., Shahidzadeh, N., \& Bonn, D. (2018). Singular sublimation of ice and snow crystals. Nature Communications, 9(1), 4191. doi:10.1038/s41467-018-06689-x

Jansson, P. E. (2012). CoupModel: Model Use, Calibration, and Validation, T. ASABE, 55(4), 1337. doi:10.13031/2013.42245

Johansen, O. (1975). Thermal conductivity of soils, 236 pp, University of Trondheim.

Johansson, E., Gustafsson, L. G., Berglund, S., Lindborg, T., Selroos, J. O., Claesson Liljedahl, L., \& Destouni, G. (2015). Data evaluation and numerical modeling of hydrological interactions between active layer, lake and talik in a permafrost catchment, Western Greenland. J. Hydrol., 527, 688-703. doi:10.1016/j.jhydrol.2015.05.026

Jones, J. W., Hoogenboom, G., Porter, C. H., Boote, K. J., Batchelor, W. D., Hunt, L. A., Wilkens, P. W., Singh, U., Gijsman, A. J., \& Ritchie, J. T. (2003). The DSSAT cropping system 
model. European Journal of Agronomy, 18(3-4), 235-265. doi:10.1016/S1161-0301(02)001077

Jordan, R. (1991). A one-dimensional temperature model for a snow cover: Technical documentation for SNTHERM. 89. Rep., Cold Regions Research and Engineering Lab Hanover $\mathrm{NH}$.

Kane, D. L., Hinkel, K. M., Goering, D. J., Hinzman, L. D., \& Outcalt, S. I. (2001). Nonconductive heat transfer associated with frozen soils. Global Planet. Change, 29(3-4), 275-292. doi:10.1016/S0921-8181(01)00095-9

Karra, S., Painter, S. L., \& Lichtner, P. C. (2014). Three-phase numerical model for subsurface hydrology in permafrost-affected regions (PFLOTRAN-ICE v1.0). Cryosphere, 8(5), 19351950. doi:10.5194/tc-8-1935-2014

Kato, T., Tang, Y., Gu, S., Hirota, M., Du, M., Li, Y., \& Zhao, X. (2006). Temperature and biomass influences on interannual changes in $\mathrm{CO} 2$ exchange in an alpine meadow on the Qinghai-Tibetan Plateau. Global Change Biology, 12(7), 1285-1298. doi:10.1111/j.13652486.2006.01153.x

Kennedy, D., Swenson, S., Oleson, K. W., Lawrence, D. M., Fisher, R., da Costa, A. C. L., \& Gentine, P. (2019). Implementing Plant Hydraulics in the Community Land Model, Version 5. Journal of Advances in Modeling Earth Systems, 11(2), 485-513. doi:10.1029/2018ms001500 Kevin, S., Hugues, L., Vladimir, E. R., Edward, A. G. S., \& Ronald, W. (2014). The impact of the permafrost carbon feedback on global climate. Environmental Research Letters, 9(8), 085003 .

Khanduri, T., \& Thakur, P. K. (2020). Snowmelt Runoff Estimation Using Energy-Balance Approach. in Lecture Notes in Civil Engineering. edited, pp. 193-201, doi:10.1007/978-98113-7067-0_15.

Koopmans, R. W. R., \& Miller, R. D. (1966). Soil freezing and soil water characteristic curves. Soil Sci. Soc. Am. Proc., 30(6), 680-685.

Koren, V., Schaake, J., Mitchell, K., Duan, Q. Y., Chen, F., \& Baker, J. M. (1999). A parameterization of snowpack and frozen ground intended for NCEP weather and climate models. Journal of Geophysical Research Atmospheres, 104(D16), 19569-19585. doi:10.1029/1999JD900232

Koren, V., Smith, M., \& Cui, Z. (2014). Physically-based modifications to the Sacramento Soil Moisture Accounting model. Part A: Modeling the effects of frozen ground on the runoff generation process. J. Hydrol., 519(PD), 3475-3491. doi:10.1016/j.jhydrol.2014.03.004

Kroes, J. G., Van Dam, J. C., Groenendijk, P., Hendriks, R. F. A., \& Jacobs, C. M. J. (2008). SWAP version 3.2. Theory description and user manual. Rep., 266 pp, Alterra, The Netherlands. Kurylyk, B. L., Hayashi, M., Quinton, W. L., McKenzie, J. M., \& Voss, C. I. (2016). Influence of vertical and lateral heat transfer on permafrost thaw, peatland landscape transition, and groundwater flow. Water Resour. Res., 52(2), 1286-1305. doi:10.1002/2015WR018057

Kurylyk, B. L., \& Irvine, D. J. (2019). Heat: An Overlooked Tool in the Practicing Hydrogeologist's Toolbox. Groundwater, 57(4), 517-524. doi:10.1111/gwat.12910

Kurylyk, B. L., Irvine, D. J., Carey, S. K., Briggs, M. A., Werkema, D. D., \& Bonham, M. (2017). Heat as a groundwater tracer in shallow and deep heterogeneous media: Analytical solution, spreadsheet tool, and field applications. Hydrol. Processes, 31(14), 2648-2661. doi:10.1002/hyp.11216

Kurylyk, B. L., \& Macquarrie, K. T. B. (2014). A new analytical solution for assessing climate change impacts on subsurface temperature. Hydrol. Processes, 28(7), 3161-3172. doi:10.1002/hyp.9861

Kurylyk, B. L., MacQuarrie, K. T. B., Caissie, D., \& McKenzie, J. M. (2015). Shallow groundwater thermal sensitivity to climate change and land cover disturbances: Derivation of analytical expressions and implications for stream temperature modeling. Hydrol. Earth Syst. Sci., 19(5), 2469-2489. doi:10.5194/hess-19-2469-2015

Kurylyk, B. L., MacQuarrie, K. T. B., \& McKenzie, J. M. (2014a). Climate change impacts on groundwater and soil temperatures in cold and temperate regions: Implications, mathematical theory, and emerging simulation tools. Earth-Science Reviews, 138, 313-334. doi:10.1016/j.earscirev.2014.06.006 
Kurylyk, B. L., MacQuarrie, K. T. B., \& Voss, C. I. (2014b). Climate change impacts on the temperature and magnitude of groundwater discharge from shallow, unconfined aquifers. Water Resour. Res., 50(4), 3253-3274. doi:10.1002/2013WR014588

Kurylyk, B. L., \& Watanabe, K. (2013). The mathematical representation of freezing and thawing processes in variably-saturated, non-deformable soils. Adv. Water Resour., 60, 160-177. doi:10.1016/j.advwatres.2013.07.016

Lasslop, G., Reichstein, M., Papale, D., Richardson, A., Arneth, A., Barr, A., Stoy, P., \& Wohlfahrt, G. (2010). Separation of net ecosystem exchange into assimilation and respiration using a light response curve approach: Critical issues and global evaluation. Global Change Biology, 16(1), 187-208. doi:10.1111/j.1365-2486.2009.02041.x

Lawrence, D., Fisher, R., Koven, C., Oleson, K., Swenson, S., Vertenstein, M., \& Coauthors (2018). Technical description of version 5.0 of the Community Land Model (CLM). Rep., 337 pp., National Center for Atmospheric Research, Boulder, Colorado, USA

Lawrence, D. M., Fisher, R. A., Koven, C. D., Oleson, K. W., Swenson, S. C., Bonan, G., Collier, N., Ghimire, B., van Kampenhout, L., Kennedy, D., Kluzek, E., Lawrence, P. J., Li, F., Li, H., Lombardozzi, D., Riley, W. J., Sacks, W. J., Shi, M., Vertenstein, M., Wieder, W. R., Xu, C., Ali, A. A., Badger, A. M., Bisht, G., van den Broeke, M., Brunke, M. A., Burns, S. P., Buzan, J., Clark, M., Craig, A., Dahlin, K., Drewniak, B., Fisher, J. B., Flanner, M., Fox, A. M., Gentine, P., Hoffman, F., Keppel-Aleks, G., Knox, R., Kumar, S., Lenaerts, J., Leung, L. R., Lipscomb, W. H., Lu, Y., Pandey, A., Pelletier, J. D., Perket, J., Randerson, J. T., Ricciuto, D. M., Sanderson, B. M., Slater, A., Subin, Z. M., Tang, J., Thomas, R. Q., Val Martin, M., \& Zeng, X. (2019). The Community Land Model Version 5: Description of New Features, Benchmarking, and Impact of Forcing Uncertainty. Journal of Advances in Modeling Earth Systems, 11(12), 42454287. doi:10.1029/2018MS001583

Lee, H. S., Matthews, C. J., Braddock, R. D., Sander, G. C., \& Gandola, F. (2004). A MATLAB method of lines template for transport equations. Environmental Modelling and Software, 19(6), 603-614. doi:10.1016/j.envsoft.2003.08.017

Lehning, M., Bartelt, P., Brown, B., Russi, T., Stöckli, U., \& Zimmerli, M. (1999). snowpack model calculations for avalanche warning based upon a new network of weather and snow stations. Cold Regions Sci. Tech., 30(1), 145-157. doi:10.1016/S0165-232X(99)00022-1

Lemieux, J. M., Sudicky, E. A., Peltier, W. R., \& Tarasov, L. (2008). Simulating the impact of glaciations on continental groundwater flow systems: 1. Relevant processes and model formulation. Journal of Geophysical Research: Earth Surface, 113(3). doi:10.1029/2007JF000928

Leroux, N. R., \& Pomeroy, J. W. (2017). Modelling capillary hysteresis effects on preferential flow through melting and cold layered snowpacks. Adv. Water Resour., 107, 250-264. doi:10.1016/j.advwatres.2017.06.024

Leuning, R., van Gorsel, E., Massman, W. J., \& Isaac, P. R. (2012). Reflections on the surface energy imbalance problem. Agr. Forest Meteorol., 156, 65-74. doi:10.1016/j.agrformet.2011.12.002

Li, H., Li, X., Yang, D., Wang, J., Gao, B., Pan, X., Zhang, Y., \& Hao, X. (2019). Tracing Snowmelt Paths in an Integrated Hydrological Model for Understanding Seasonal Snowmelt Contribution at Basin Scale. Journal of Geophysical Research: Atmospheres, 124(16), 88748895. doi:10.1029/2019JD030760

Li, H., Zhang, F., Li, Y., Wang, J., Zhang, L., Zhao, L., Cao, G., Zhao, X., \& Du, M. (2016). Seasonal and inter-annual variations in $\mathrm{CO} 2$ fluxes over 10 years in an alpine shrubland on the Qinghai-Tibetan Plateau, China. Agr. Forest Meteorol., 228-229, 95-103. doi:10.1016/j.agrformet.2016.06.020

Li, L., Yang, Z. L., Matheny, A. M., Zheng, H., Swenson, S. C., Lawrence, D. M., Barlage, M., Yan, B., McDowell, N. G., \& Leung, L. R. (2021). Representation of Plant Hydraulics in the Noah-MP Land Surface Model: Model Development and Multiscale Evaluation. Journal of Advances in Modeling Earth Systems, 13(4). doi:10.1029/2020MS002214

Li, M., Zeng, Y., Lubczynski, M. W., Roy, J., Yu, L., Qian, H., Li, Z., Chen, J., Han, L., Zheng, H., Veldkamp, T., Schoorl, J. M., Hendricks Franssen, H. J., Hou, K., Zhang, Q., Xu, P., Li, F., Lu, K., Li, Y., \& Su, Z. (2021). A first investigation of hydrogeology and hydrogeophysics of 
the Maqu catchment in the Yellow River source region. Earth Syst. Sci. Data, 13(10), 47274757. doi:10.5194/essd-13-4727-2021

Li, Q., Sun, S., \& Xue, Y. (2010). Analyses and development of a hierarchy of frozen soil models for cold region study. Journal of Geophysical Research Atmospheres, 115(3). doi:10.1029/2009JD012530

$\mathrm{Li}, \mathrm{X}$. (2019). Integrated hydrometeorological - snow - frozen ground observations in the alpine region of the Heihe River Basin, China, Cold and Arid Regions Science Data Center at Lanzhou (CARD), https://doi.org/10.3972/hiwater.001.2019.db.

$\mathrm{Li}, \mathrm{X}$., \& Koike, T. (2003). Frozen soil parameterization in SiB2 and its validation with GAMETibet observations. Cold Regions Sci. Tech., 36(1-3), 165-182. doi:10.1016/S0165232X(03)00009-0

Li, X., \& Vereecken, H. (2020). Observation and Measurement of Ecohydrological Processes. edited, Springer Berlin Heidelberg, Berlin, Heidelberg, doi:10.1007/978-3-662-47871-4.

Liang, X., Xie, Z., \& Huang, M. (2003). A new parameterization for surface and groundwater interactions and its impact on water budgets with the variable infiltration capacity (VIC) land surface model. Journal of Geophysical Research: Atmospheres, 108(D16). doi:10.1029/2002JD003090

Liu, G., \& C. Si, B. (2011). Soil ice content measurement using a heat pulse probe method. Can. J. Soil Sci., 91(2), 235-246. doi:10.4141/cjss09120

Liu, X., \& Chen, B. (2000). Climatic warming in the Tibetan Plateau during recent decades. Int. J. Climatol., 20(14), 1729-1742. doi:10.1002/1097-0088(20001130)20:14<1729::AIDJOC556>3.0.CO;2-Y

Liu, Y., Xu, J. H., Lu, X. Y., \& Nie, L. (2020). Assessment of glacier- and snowmelt-driven streamflow in the arid middle Tianshan Mountains of China. Hydrol. Processes, 34(12), 27502762. doi:10.1002/hyp. 13760

Luo, L., Robock, A., Vinnikov, K. Y., Schlosser, C. A., Slater, A. G., Boone, A., Braden, H., Cox, P., de Rosnay, P., Dickinson, R. E., Dai, Y., Duan, Q., Etchevers, P., Henderson-Sellers, A., Gedney, N., Gusev, Y. M., Habets, F., Kim, J., Kowalczyk, E., Mitchell, K., Nasonova, O. N., Noilhan, J., Pitman, A. J., Schaake, J., Shmakin, A. B., Smirnova, T. G., Wetzel, P., Xue, Y., Yang, Z. L., \& Zeng, Q. C. (2003). Effects of frozen soil on soil temperature, spring infiltration, and runoff: Results from the PILPS 2(d) experiment at Valdai, Russia. J. Hydrometeorol., 4(2), 334-351. doi:10.1175/1525-7541(2003)4<334:EOFSOS >2.0.CO;2

Lv, S. N., Wen, J., Zeng, Y. J., Tian, H., \& Su, Z. B. (2014). An improved two-layer algorithm for estimating effective soil temperature in microwave radiometry using in situ temperature and soil moisture measurements. Remote Sens. Environ., 152, 356-363. doi:10.1016/j.rse.2014.07.007

Lyu, Z., \& Zhuang, Q. (2018). Quantifying the Effects of Snowpack on Soil Thermal and Carbon Dynamics of the Arctic Terrestrial Ecosystems. Journal of Geophysical Research: Biogeosciences, 123(4), 1197-1212. doi:10.1002/2017JG003864

Ma, Y., Hu, Z., Xie, Z., Ma, W., Wang, B., Chen, X., Li, M., Zhong, L., Sun, F., Gu, L., Han, C., Zhang, L., Liu, X., Ding, Z., Sun, G., Wang, S., Wang, Y., \& Wang, Z. (2020). A long-term (2005-2016) dataset of hourly integrated land-atmosphere interaction observations on the Tibetan Plateau. Earth Syst. Sci. Data, 12(4), 2937-2957. doi:10.5194/essd-12-2937-2020

Ma, Y., Kang, S., Zhu, L., Xu, B., Tian, L., \& Yao, T. (2008). TIBETAN OBSERVATION AND RESEARCH PLATFORM: Atmosphere-Land Interaction over a Heterogeneous Landscape. Bull. Am. Meteorol. Soc., 89(10), 1487-1492.

Mahat, V., \& Tarboton, D. G. (2012). Canopy radiation transmission for an energy balance snowmelt model. Water Resour. Res., 48(1). doi:10.1029/2011WR010438

Mahat, V., \& Tarboton, D. G. (2014). Representation of canopy snow interception, unloading and melt in a parsimonious snowmelt model. Hydrol. Processes, 28(26), 6320-6336. doi:10.1002/hyp.10116

Mao, W., Zhu, Y., Dai, H., Ye, M., Yang, J., \& Wu, J. (2019). A comprehensive quasi-3-D model for regional-scale unsaturated-saturated water flow. Hydrol. Earth Syst. Sci., 23(8), 3481-3502. doi:10.5194/hess-23-3481-2019

Mastrotheodoros, T., Pappas, C., Molnar, P., Burlando, P., Keenan, T. F., Gentine, P., Gough, C. 
M., \& Fatichi, S. (2017). Linking plant functional trait plasticity and the large increase in forest water use efficiency. Journal of Geophysical Research: Biogeosciences, 122(9), 2393-2408. doi:10.1002/2017JG003890

Maxwell, R. M., \& Miller, N. L. (2005). Development of a coupled land surface and groundwater model. J. Hydrometeorol., 6(3), 233-247. doi:10.1175/jhm422.1

Maxwell, R. M., Stefan J. Kollet, Steven G. Smith, Carol S. Woodward, Robert D. Falgout, Ian M. Ferguson, Nicholas Engdahl, Laura E. Condon, Basile Hector, Sonya Lopez, James Gilbert, Lindsay Bearup, Jennifer Je_erson, Caitlin Collins, Inge de Graaf, Christine Pribulick, Chuck Baldwin, William J. Bosl, Richard Hornung, Steven Ashby, \& Kulkarni, K. B. (2017). ParFlow user's manual. Rep., 156 pp, International Ground Water Modeling Center, USA.

McKenzie, J. M., Voss, C. I., \& Siegel, D. I. (2007). Groundwater flow with energy transport and water-ice phase change: Numerical simulations, benchmarks, and application to freezing in peat bogs. Adv. Water Resour., 30(4), 966-983. doi:10.1016/j.advwatres.2006.08.008

Milly, P. C. D. (1982). Moisture and heat transport in hysteretic, inhomogeneous porous media: A matric head-based formulation and a numerical model. Water Resour. Res., 18(3), 489-498. doi:10.1029/WR018i003p00489

Milly, P. C. D., Malyshev, S. L., Shevliakova, E., Dunne, K. A., Findell, K. L., Gleeson, T., Liang, Z., Phillipps, P., Stouffer, R. J., \& Swenson, S. (2014). An Enhanced Model of Land Water and Energy for Global Hydrologic and Earth-System Studies. J. Hydrometeorol., 15(5), 1739-1761. doi:10.1175/jhm-d-13-0162.1

Mirtl, M., T. Borer, E., Djukic, I., Forsius, M., Haubold, H., Hugo, W., Jourdan, J., Lindenmayer, D., McDowell, W. H., Muraoka, H., Orenstein, D. E., Pauw, J. C., Peterseil, J., Shibata, H., Wohner, C., Yu, X., \& Haase, P. (2018). Genesis, goals and achievements of Long-Term Ecological Research at the global scale: A critical review of ILTER and future directions. Sci. Tot. Environ., 626, 1439-1462. doi:10.1016/j.scitotenv.2017.12.001

Mu, C. C., Abbott, B. W., Norris, A. J., Mu, M., Fan, C. Y., Chen, X., Jia, L., Yang, R. M., Zhang, T. J., Wang, K., Peng, X. Q., Wu, Q. B., Guggenberger, G., \& Wu, X. D. (2020). The status and stability of permafrost carbon on the Tibetan Plateau. Earth-Science Reviews, 211. doi:10.1016/j.earcirev.2020.103433

Mwangi, S., Zeng, Y., Montzka, C., Yu, L., \& Su, Z. (2020). Assimilation of Cosmic-Ray Neutron Counts for the Estimation of Soil Ice Content on the Eastern Tibetan Plateau. Journal of Geophysical Research: Atmospheres, 125(3), e2019JD031529. doi:10.1029/2019jd031529

Myneni, R., Knyazikhin, Y., \& Park, T. (2015). MCD15A3H MODIS/Terra+Aqua Leaf Area Index/FPAR 4-Day L4 Global 500m SIN Grid V006, NASA EOSDIS Land Processes DAAC, doi:10.5067/MODIS/MCD15A3H.006.

Newman, G. P., \& Wilson, G. W. (1997). Heat and mass transfer in unsaturated soils during freezing. Can. Geotech. J., 34(1), 63-70. doi:10.1139/t96-085

Niswonger, R. G., Prudic, D. E., \& Regan, R. S. (2006). Documentation of the UnsaturatedZone Flow (UZF1) Package for modeling Unsaturated Flow Between the Land Surface and the Water Table with MODFLOW-2005. Rep. 6-A19.

Niu, B., He, Y., Zhang, X., Fu, G., Shi, P., Du, M., Zhang, Y., \& Zong, N. (2016). Tower-Based Validation and Improvement of MODIS Gross Primary Production in an Alpine Swamp Meadow on the Tibetan Plateau. Remote Sensing, 8(7), 592.

Niu, B., Yongtao, H., Xianzhou, Z., Mingyuan, D., Peili, S., Wei, S., \& Leiming, Z. (2017). CO2 Exchange in an Alpine Swamp Meadow on the Central Tibetan Plateau. Wetlands., 37(3), 525-543. doi:10.1007/s13157-017-0888-2

Niu, G.-Y., Paniconi, C., Troch, P. A., Scott, R. L., Durcik, M., Zeng, X., Huxman, T., \& Goodrich, D. C. (2014). An integrated modelling framework of catchment-scale ecohydrological processes: 1 . Model description and tests over an energy-limited watershed. Ecohydrology, 7(2), 427-439. doi:10.1002/eco.1362

Niu, G. Y., Yang, Z. L., Mitchell, K. E., Chen, F., Ek, M. B., Barlage, M., Kumar, A., Manning, K., Niyogi, D., Rosero, E., Tewari, M., \& Xia, Y. (2011). The community Noah land surface model with multiparameterization options (Noah-MP): 1. Model description and evaluation with local-scale measurements. Journal of Geophysical Research Atmospheres, 116(12). doi:10.1029/2010JD015139 
Novak, M. D. (2010). Dynamics of the near-surface evaporation zone and corresponding effects on the surface energy balance of a drying bare soil. Agr. Forest Meteorol., 150(10), 1358-1365. doi:10.1016/j.agrformet.2010.06.005

Oleson, K., Lawrence, D., Bonan, G., Drewniak, B., Huang, M., Koven, C., Levis, S., Li, F., Riley, W., Subin, Z., Swenson, S., Thornton, P., Bozbiyik, A., Rosie, F., Heald, C., Kluzek, E., Lamarque, J.-F., Lawrence, P., Leung, L., \& Yang, Z.-L. (2013). Technical description of version 4.5 of the Community Land Model (CLM), doi:10.5065/D6RR1W7M.

Orgogozo, L., Prokushkin, A. S., Pokrovsky, O. S., Grenier, C., Quintard, M., Viers, J., \& Audry, S. (2019). Water and energy transfer modeling in a permafrost-dominated, forested catchment of Central Siberia: The key role of rooting depth. Permafr. Periglac. Proc., 30(2), 75-89. doi:10.1002/ppp.1995

Paganini, M., Petiteville, I., Ward, S., Dyke, G., Steventon, M., Harry, J., \& Kerblat, F. (2018). Satellite earth observations in support of the sustainable development goals. The CEOS Earth Observation Handbook.

Painter, S. L. (2011). Three-phase numerical model of water migration in partially frozen geological media: Model formulation, validation, and applications. Comput. Geosci., 15(1), 6985. doi:10.1007/s10596-010-9197-z

Painter, S. L., Coon, E. T., Atchley, A. L., Berndt, M., Garimella, R., Moulton, J. D., Svyatskiy, D., \& Wilson, C. J. (2016). Integrated surface/subsurface permafrost thermal hydrology: Model formulation and proof-of-concept simulations. Water Resour. Res., 52(8), 6062-6077. doi:10.1002/2015WR018427

Painter, S. L., \& Karra, S. (2014). Constitutive model for unfrozen water content in subfreezing unsaturated soils. Vadose Zone J., 13(4). doi:10.2136/vzj2013.04.0071

Pan, X., Helgason, W., Ireson, A., \& Wheater, H. (2017). Field-scale water balance closure in seasonally frozen conditions. Hydrol. Earth Syst. Sci., 21(11), 5401-5413. doi:10.5194/hess21-5401-2017

Papale, D., Reichstein, M., Aubinet, M., Canfora, E., Bernhofer, C., Kutsch, W., Longdoz, B., Rambal, S., Valentini, R., Vesala, T., \& Yakir, D. (2006). Towards a standardized processing of Net Ecosystem Exchange measured with eddy covariance technique: algorithms and uncertainty estimation. Biogeosciences, 3(4), 571-583. doi:10.5194/bg-3-571-2006

Pappas, C., Fatichi, S., \& Burlando, P. (2016). Modeling terrestrial carbon and water dynamics across climatic gradients: Does plant trait diversity matter? New Phytologist, 209(1), 137-151. doi:10.1111/nph.13590

Peng, X., Zhang, T., Frauenfeld, O. W., Wang, K., Cao, B., Zhong, X., Su, H., \& Mu, C. (2017). Response of seasonal soil freeze depth to climate change across China. Cryosphere, 11(3), 1059-1073. doi:10.5194/tc-11-1059-2017

Philip, J. R., \& De Vries, D. A. (1957). Moisture movement in porous materials under temperature gradients. Eos, Transactions American Geophysical Union, 38(2), 222-232. doi:10.1029/TR038i002p00222

Pimentel, R., Herrero, J., Zeng, Y., Su, Z., \& Polo, M. J. (2015). Study of Snow Dynamics at Subgrid Scale in Semiarid Environments Combining Terrestrial Photography and Data Assimilation Techniques. J. Hydrometeorol., 16(2), 563-578. doi:10.1175/jhm-d-14-0046.1

Pitman, A. J., Z.-L. Yang, J. G. Cogley, \& Henderson-Sellers, A. (1991). Description of bare essentials of surface transfer for the Bureau of Meteorology Research Centre AGCM. BMRC Res. Rep., 117 pp, Macquarie University, North Ryde, NSW, Australia

Prunty, L., \& Bell, J. (2007). Infiltration rate vs. gas composition and pressure in soil columns. Soil Sci. Soc. Am. J., 71(5), 1473-1475. doi:10.2136/sssaj2007.0072N

Qi, J., Vermeer, P. A., \& Cheng, G. (2006). A review of the influence of freeze-thaw cycles on soil geotechnical properties. Permafr. Periglac. Proc., 17(3), 245-252. doi:10.1002/ppp.559

Qi, J., Wang, L., Zhou, J., Song, L., Li, X., \& Zeng, T. (2019). Coupled Snow and Frozen Ground Physics Improves Cold Region Hydrological Simulations: An Evaluation at the upper Yangtze River Basin (Tibetan Plateau). Journal of Geophysical Research: Atmospheres, 124(23), 12985-13004. doi:10.1029/2019JD031622

Qin, Y., Lei, H., Yang, D., Gao, B., Wang, Y., Cong, Z., \& Fan, W. (2016). Long-term change in the depth of seasonally frozen ground and its ecohydrological impacts in the Qilian 
Mountains, northeastern Tibetan Plateau. J. Hydrol., 542, 204-221. doi:10.1016/j.jhydrol.2016.09.008

Qiu, J., Carpenter, S. R., Booth, E. G., Motew, M., Zipper, S. C., Kucharik, C. J., Chen, X., Loheide, S. P., Seifert, J., \& Turner, M. G. (2018a). Scenarios reveal pathways to sustain future ecosystem services in an agricultural landscape. Ecological Applications, 28(1), 119-134. doi:10.1002/eap.1633

Qiu, J., Carpenter, S. R., Booth, E. G., Motew, M., Zipper, S. C., Kucharik, C. J., Loheide, S. P., II, \& Turner, M. G. (2018b). Understanding relationships among ecosystem services across spatial scales and over time. Environmental Research Letters, 13(5). doi:10.1088/17489326/aabb87

Qiu, J., Zipper, S. C., Motew, M., Booth, E. G., Kucharik, C. J., \& Loheide, S. P. (2019). Nonlinear groundwater influence on biophysical indicators of ecosystem services. Nature Sustainability, 2(6), 475-483. doi:10.1038/s41893-019-0278-2

Raleigh, M. S., Lundquist, J. D., \& Clark, M. P. (2015). Exploring the impact of forcing error characteristics on physically based snow simulations within a global sensitivity analysis framework. Hydrol. Earth Syst. Sci., 19(7), 3153-3179. doi:10.5194/hess-19-3153-2015

Reichstein, M., Falge, E., Baldocchi, D., Papale, D., Aubinet, M., Berbigier, P., Bernhofer, C., Buchmann, N., Gilmanov, T., Granier, A., Grünwald, T., Havránková, K., Ilvesniemi, H., Janous, D., Knohl, A., Laurila, T., Lohila, A., Loustau, D., Matteucci, G., Meyers, T., Miglietta, F., Ourcival, J. M., Pumpanen, J., Rambal, S., Rotenberg, E., Sanz, M., Tenhunen, J., Seufert, G., Vaccari, F., Vesala, T., Yakir, D., \& Valentini, R. (2005). On the separation of net ecosystem exchange into assimilation and ecosystem respiration: Review and improved algorithm. Global Change Biology, 11(9), 1424-1439. doi:10.1111/j.1365-2486.2005.001002.x

Richards, L. A. (1931). Capillary conduction of liquids through porous mediums. Journal of Applied Physics, 1(5), 318-333. doi:10.1063/1.1745010

Romanovsky, V. E., \& Osterkamp, T. E. (2000). Effects of unfrozen water on heat and mass transport processes in the active layer and permafrost. Permafr. Periglac. Proc., 11(3), 219-239. doi:10.1002/1099-1530(200007/09)11:3<219::AID-PPP352>3.0.CO;2-7

Rowland, J. C., Travis, B. J., \& Wilson, C. J. (2011). The role of advective heat transport in talik development beneath lakes and ponds in discontinuous permafrost. Geophys. Res. Lett., 38(17). doi:10.1029/2011GL048497

Running, S., Mu, Q., \& Zhao, M. (2015). MOD17A2H MODIS/Terra Gross Primary Productivity 8-Day L4 Global $500 \mathrm{~m}$ SIN Grid V006. MOD17A3H MODIS/Terra Net Primary Production Yearly L4 Global $500 \mathrm{~m}$ SIN Grid V006.

Rutter, N., Essery, R., Pomeroy, J., Altimir, N., Andreadis, K., Baker, I., Barr, A., Bartlett, P., Boone, A., Deng, H., Douville, H., Dutra, E., Elder, K., Ellis, C., Feng, X., Gelfan, A., Goodbody, A., Gusev, Y., Gustafsson, D., Hellström, R., Hirabayashi, Y., Hirota, T., Jonas, T., Koren, V., Kuragina, A., Lettenmaier, D., Li, W.-P., Luce, C., Martin, E., Nasonova, O., Pumpanen, J., Pyles, R. D., Samuelsson, P., Sandells, M., Schädler, G., Shmakin, A., Smirnova, T. G., Stähli, M., Stöckli, R., Strasser, U., Su, H., Suzuki, K., Takata, K., Tanaka, K., Thompson, E., Vesala, T., Viterbo, P., Wiltshire, A., Xia, K., Xue, Y., \& Yamazaki, T. (2009). Evaluation of forest snow processes models (SnowMIP2). Journal of Geophysical Research: Atmospheres, 114(D6). doi:10.1029/2008JD011063

Saito, H., Šimůnek, J., \& Mohanty, B. P. (2006). Numerical analysis of coupled water, vapor, and heat transport in the vadose zone. Vadose Zone J., 5(2), 784-800. doi:10.2136/vzj2006.0007 Scanlon, B. R., Healy, R. W., \& Cook, P. G. (2002). Choosing appropriate techniques for quantifying groundwater recharge. Hydrogeol. J., 10(1), 18-39. doi:10.1007/s10040-001-01762

Scanlon, B. R., \& Milly, P. C. D. (1994). Water and heat fluxes in desert soils: 2. Numerical simulations. Water Resour. Res., 30(3), 721-733. doi:10.1029/93WR03252

Schaefer, K., Lantuit, H., Romanovsky, V. E., Schuur, E. A. G., \& Witt, R. (2014). The impact of the permafrost carbon feedback on global climate. Environmental Research Letters, 9(8). doi:10.1088/1748-9326/9/8/085003

Schulz, O., \& de Jong, C. (2004). Snowmelt and sublimation: field experiments and modelling in the High Atlas Mountains of Morocco. Hydrol. Earth Syst. Sci., 8(6), 1076-1089. 
doi:10.5194/hess-8-1076-2004

Schuur, E. A. G., McGuire, A. D., Schädel, C., Grosse, G., Harden, J. W., Hayes, D. J., Hugelius, G., Koven, C. D., Kuhry, P., Lawrence, D. M., Natali, S. M., Olefeldt, D., Romanovsky, V. E., Schaefer, K., Turetsky, M. R., Treat, C. C., \& Vonk, J. E. (2015). Climate change and the permafrost carbon feedback. Nature, 520(7546), 171-179. doi:10.1038/nature14338

Sen Gupta, A., Tarboton, D. G., Hummel, P., Brown, M. E., \& Habib, S. (2015). Integration of an energy balance snowmelt model into an open source modeling framework. Environ. Model. Software, 68, 205-218. doi:10.1016/j.envsoft.2015.02.017

Seo, H. S., Simunek, J., \& Poeter, E. P. (2007). Documentation of the HYDRUS Package for MODFLOW-2000, the U.S. Geological Survey Modular Ground-Water Model, Rep., 96 pp, Int. Ground Water Modeling Center, Colorado School of Mines, Golden, CO.

Shrestha, M., Wang, L., Koike, T., Xue, Y., \& Hirabayashi, Y. (2010). Improving the snow physics of WEB-DHM and its point evaluation at the SnowMIP sites. Hydrol. Earth Syst. Sci., 14(12), 2577-2594. doi:10.5194/hess-14-2577-2010

Šimůnek, J., Šejna, M., Saito, H., Sakai, M., \& Van Genuchten, M. (2008). The HYDRUS-1D Software Package for Simulating the One-Dimensional Movement of Water, Heat, and Multiple Solutes in Variably-Saturated Media. Rep., 332 pp, University of California Riverside, Riverside, California, USA.

Sjöberg, Y., Coon, E., K. Sannel, A. B., Pannetier, R., Harp, D., Frampton, A., Painter, S. L., \& Lyon, S. W. (2016). Thermal effects of groundwater flow through subarctic fens: A case study based on field observations and numerical modeling. Water Resour. Res., 52(3), 1591-1606. doi:10.1002/2015WR017571

Slater, A. G., Pitman, A. J., \& Desborough, C. E. (1998). The validation of a snow parameterization designed for use in general circulation models. Int. J. Climatol., 18(6), 595617. doi:10.1002/(sici)1097-0088(199805)18:6<595::aid-joc275>3.0.co;2-o

Smith, R. E. (1983). Approximate soil water movement by kinematic characteristics. Soil Sci. Soc. Am. J., 47(1), 3-8. doi:10.2136/sssaj1983.03615995004700010001x

Smith, R. E., \& Hebbert, R. H. B. (1983). Mathematical simulation of interdependent surface and subsurface hydrologic processes. Water Resour. Res., 19(4), 987-1001. doi:10.1029/WR019i004p00987

Spaans, E. J. A., \& Baker, J. M. (1996). The soil freezing characteristic: Its measurement and similarity to the soil moisture characteristic. Soil Science Society of America Journal, 60(1), 13-19.

Steffen, W., Richardson, K., Rockström, J., Schellnhuber, H. J., Dube, O. P., Dutreuil, S., Lenton, T. M., \& Lubchenco, J. (2020). The emergence and evolution of Earth System Science. Nature Reviews Earth \& Environment, 1(1), 54-63. doi:10.1038/s43017-019-0005-6

Strasser, U., Bernhardt, M., Weber, M., Liston, G. E., \& Mauser, W. (2008). Is snow sublimation important in the alpine water balance? The Cryosphere, 2(1), 53-66. doi:10.5194/tc-2-53-2008 $\mathrm{Su}, \mathrm{Z}$. (2002). The Surface Energy Balance System (SEBS) for estimation of turbulent heat fluxes. Hydrol. Earth Syst. Sci., 6(1), 85-99. doi:10.5194/hess-6-85-2002

Su, Z., De Rosnay, P., Wen, J., Wang, L., \& Zeng, Y. (2013). Evaluation of ECMWF's soil moisture analyses using observations on the Tibetan Plateau. Journal of Geophysical Research Atmospheres, 118(11), 5304-5318. doi:10.1002/jgrd.50468

Su, Z., Timmermans, W., Zeng, Y., Schulz, J., John, V. O., Roebeling, R. A., Poli, P., Tan, D., Kaspar, F., Kaiser-Weiss, A. K., Swinnen, E., Toté, C., Gregow, H., Manninen, T., Riihelä, A., Calvet, J.-C., Ma, Y., \& Wen, J. (2018). An Overview of European Efforts in Generating Climate Data Records. Bull. Am. Meteorol. Soc., 99(2), 349-359. doi:10.1175/bams-d-160074.1

Su, Z., Wen, J., Dente, L., van der Velde, R., Wang, L., Ma, Y., Yang, K., \& Hu, Z. (2011). The Tibetan Plateau observatory of plateau scale soil moisture and soil temperature (Tibet-Obs) for quantifying uncertainties in coarse resolution satellite and model products. Hydrol. Earth Syst. Sci., 15(7), 2303-2316. doi:10.5194/hess-15-2303-2011

Su, Z., Wen, J., Zeng, Y., Zhao, H., Lv, S., van der Velde, R., Zheng, D., Wang, X., Wang, Z., Schwank, M., Kerr, Y., Yueh, S., Colliander, A., Qian, H., Drusch, M., \& Mecklenburg, S. (2020a). Multiyear in-situ L-band microwave radiometry of land surface processes on the 
Tibetan Plateau. figshare.

Su, Z., Zeng, Y., Romano, N., Manfreda, S., Francés, F., Ben Dor, E., Szabó, B., Vico, G., Nasta, P., Zhuang, R., Francos, N., Mészáros, J., Dal Sasso, S. F., Bassiouni, M., Zhang, L., Rwasoka, D. T., Retsios, B., Yu, L., Blatchford, M. L., \& Mannaerts, C. (2020b). An Integrative Information Aqueduct to Close the Gaps between Satellite Observation of Water Cycle and Local Sustainable Management of Water Resources. Water, 12(5), 1495. doi:10.3390/w12051495

Subin, Z. M., Koven, C. D., Riley, W. J., Torn, M. S., Lawrence, D. M., \& Swenson, S. C. (2013). Effects of soil moisture on the responses of soil temperatures to climate change in cold regions. J. Clim., 26(10), 3139-3158. doi:10.1175/JCLI-D-12-00305.1

Sud, Y. C., \& Mocko, D. M. (1999). New Snow-Physics to Complement SSiB Part I: Design and Evaluation with ISLSCP Initiative I Datasets. Journal of the Meteorological Society of Japan. Ser. II, 77(1B), 335-348. doi:10.2151/jmsj1965.77.1B_335

Sulis, M., Couvreur, V., Keune, J., Cai, G., Trebs, I., Junk, J., Shrestha, P., Simmer, C., Kollet, S. J., Vereecken, H., \& Vanderborght, J. (2019). Incorporating a root water uptake model based on the hydraulic architecture approach in terrestrial systems simulations. Agr. Forest Meteorol., 269-270, 28-45. doi:10.1016/j.agrformet.2019.01.034

Sultana, R., Hsu, K. L., Li, J., \& Sorooshian, S. (2014). Evaluating the Utah Energy Balance (UEB) snow model in the Noah land-surface model. Hydrol. Earth Syst. Sci., 18(9), 3553-3570. doi:10.5194/hess-18-3553-2014

Sun, S., Che, T., Li, H., Wang, T., Ma, C., Liu, B., Wu, Y., \& Song, Z. (2019). Water and carbon dioxide exchange of an alpine meadow ecosystem in the northeastern Tibetan Plateau is energylimited. Agr. Forest Meteorol., 275, 283-295. doi:10.1016/j.agrformet.2019.06.003

Sun, S., Jin, J., \& Xue, Y. (1999). A simple snow-atmosphere-soil transfer model. Journal of Geophysical Research: Atmospheres, 104(D16), 19587-19597. doi:10.1029/1999jd900305

Swenson, S. C., Lawrence, D. M., \& Lee, H. (2012). Improved simulation of the terrestrial hydrological cycle in permafrost regions by the Community Land Model. Journal of Advances in Modeling Earth Systems, 4(8). doi:10.1029/2012MS000165

Tanaka, K., Tamagawa, I., Ishikawa, H., Ma, Y., \& Hu, Z. (2003). Surface energy budget and closure of the eastern Tibetan Plateau during the GAME-Tibet IOP 1998. J. Hydrol., 283(1-4), 169-183. doi:10.1016/S0022-1694(03)00243-9

Tarboton, D. G., Chowdhury, T. G., \& Jackson, T. H. (1995). A spatially distributed energy balance snowmelt model. Biogeochemistry of seasonally snow-covered catchments. Proc. symposium, Boulder, 1995, 228, 141-155.

Tarboton, D. G., \& Luce, C. H. (1996). Utah Energy Balance Snow Accumulation and Melt Model (UEB), Computer model technical description and users guide, Rep., Utah Water Research Laboratory and USDA Forest Service Intermountain Research Station, Logan, Utah. Taylor, G. S., \& Luthin, J. N. (1978). A model for coupled heat and moisture transfer during soil freezing. Can. Geotech. J., 15(4), 548-555. doi:10.1139/t78-058

Teng, J., Zhang, S., Leng, W., \& Sheng, D. (2015). Numerical investigation on vapor transfer in unsaturated soil during freezing. paper presented at 6th Japan-China Geotechnical Symposium, SJGS 2015.

Thoms, R. B., Johnson, R. L., \& Healy, R. W. (2006). User's guide to the Variably Saturated Flow (VSF) process to MODFLOW. Rep. 6-A18, $58 \mathrm{pp}$.

Tian, W., Li, X., Cheng, G. D., Wang, X. S., \& Hu, B. X. (2012). Coupling a groundwater model with a land surface model to improve water and energy cycle simulation. Hydrol. Earth Syst. Sci., 16(12), 4707-4723. doi:10.5194/hess-16-4707-2012

Tian, Y., Xiong, M., Xiong, X., \& Song, G. (2003). The organic carbon distribution and flow in wetland soil-plant system in ruoergai plateau. Acta Phytoecologica Sinica(27), 490-495.

Tian, Z., Lu, Y., Horton, R., \& Ren, T. (2016). A simplified de Vries-based model to estimate thermal conductivity of unfrozen and frozen soil. Eur. J. Soil Sci., 67(5), 564-572. doi:10.1111/ejss. 12366

Touma, J., \& Vauclin, M. (1986). Experimental and numerical analysis of two-phase infiltration in a partially saturated soil. Transport in Porous Media, 1(1), 27-55. doi:10.1007/BF01036524 Troch, P. A., Berne, A., Bogaart, P., Harman, C., Hilberts, A. G. J., Lyon, S. W., Paniconi, C., 
Pauwels, V. R. N., Rupp, D. E., Selker, J. S., Teuling, A. J., Uijlenhoet, R., \& Verhoest, N. E. C. (2013). The importance of hydraulic groundwater theory in catchment hydrology: The legacy of Wilfried Brutsaert and Jean-Yves Parlange. Water Resour. Res., 49(9), 5099-5116. doi:10.1002/wrcr.20407

Twarakavi, N. K. C., Simunek, J., \& Seo, S. (2008). Evaluating interactions between groundwater and vadose zone using the HYDRUS-based flow package for MODFLOW. Vadose Zone J., 7(2), 757-768. doi:10.2136/vzj2007.0082

Ueno, K., Sugimoto, S., Tsutsui, H., Taniguchi, K., Hu, Z., \& Wu, S. (2012). Role of patchy snow cover on the planetary boundary layer structure during late winter observed in the central Tibetan Plateau. Journal of the Meteorological Society of Japan. Ser. II, 90, 145-155.

Ueno, K., Tanaka, K., Tsutsui, H., \& Li, M. (2007). Snow Cover Conditions in the Tibetan Plateau Observed during the Winter of 2003/2004. Arctic, Antarctic, and Alpine Research, 39(1), 152-164. doi:10.1657/1523-0430(2007)39[152:SCCITT]2.0.CO;2

Van Dam, J. C. (2000). Field-scale water flow and solute transport. SWAP model concepts, parameter estimation, and case studies, $167 \mathrm{pp}$, Wageningen University, Wageningen, The Netherlands.

van Genuchten, M. T. (1980). A Closed-form Equation for Predicting the Hydraulic Conductivity of Unsaturated Soils. Soil Sci. Soc. Am. J., 44(5), 892-898. doi:10.2136/sssaj1980.03615995004400050002x

Vergnes, J.-P., Decharme, B., \& Habets, F. (2014). Introduction of groundwater capillary rises using subgrid spatial variability of topography into the ISBA land surface model. Journal of Geophysical Research: Atmospheres, 119(19), 11,065-011,086. doi:10.1002/2014JD021573

Verseghy, D. (2009). CLASS the Canadian land surface scheme (version 3.4), climate research division, science and technology branch, Environment Canada.

Verseghy, D. L. (1991). Class-A Canadian land surface scheme for GCMS. I. Soil model. Int. J. Climatol., 11(2), 111-133. doi:10.1002/joc.3370110202

Vionnet, V., Brun, E., Morin, S., Boone, A., Faroux, S., Le Moigne, P., Martin, E., \& Willemet, J. M. (2012). The detailed snowpack scheme Crocus and its implementation in SURFEX v7.2. Geoscientific Model Development, 5(3), 773-791. doi:10.5194/gmd-5-773-2012

Viterbo, P., Beljaars, A., Mahfouf, J. F., \& Teixeira, J. (1999). The representation of soil moisture freezing and its impact on the stable boundary layer. Q. J. Roy. Meteorol. Soc., 125(559), 2401-2426. doi:10.1256/smsqj.55903

Walvoord, M. A., \& Kurylyk, B. L. (2016). Hydrologic impacts of thawing permafrost -a review. Vadose Zone J., 15(6). doi:10.2136/vzj2016.01.0010

Walvoord, M. A., Voss, C. I., \& Wellman, T. P. (2012). Influence of permafrost distribution on groundwater flow in the context of climate-driven permafrost thaw: Example from Yukon Flats Basin, Alaska, United States. Water Resour. Res., 48(7). doi:10.1029/2011WR011595

Wang, C., \& Yang, K. (2018). A New Scheme for Considering Soil Water-Heat Transport Coupling Based on Community Land Model: Model Description and Preliminary Validation. Journal of Advances in Modeling Earth Systems, 10(4), 927-950. doi:10.1002/2017ms001148 Wang, G., Liu, G., Li, C., \& Yang, Y. (2012). The variability of soil thermal and hydrological dynamics with vegetation cover in a permafrost region. Agr. Forest Meteorol., 162-163, 44-57. doi:10.1016/j.agrformet.2012.04.006

Wang, L., Koike, T., Yang, D., \& Yang, K. (2009). Improving the hydrology of the Simple Biosphere model 2 and its evaluation within the framework of a distributed hydrological model. Hydrol. Sci. J., 54(6), 989-1006. doi:10.1623/hysj.54.6.989

Wang, L., Koike, T., Yang, K., Jin, R., \& Li, H. (2010). Frozen soil parameterization in a distributed biosphere hydrological model. Hydrol. Earth Syst. Sci., 14(3), 557-571. doi:10.5194/hess-14-557-2010

Wang, L., Liu, H., Shao, Y., Liu, Y., \& Sun, J. (2018). Water and CO2 fluxes over semiarid alpine steppe and humid alpine meadow ecosystems on the Tibetan Plateau. Theor. Appl. Climatol., 131(1), 547-556. doi:10.1007/s00704-016-1997-1

Wang, L., Liu, H., Sun, J., \& Shao, Y. (2017a). Biophysical effects on the interannual variation in carbon dioxide exchange of an alpine meadow on the Tibetan Plateau. Atmos. Chem. Phys., 17(8), 5119-5129. doi:10.5194/acp-17-5119-2017 
Wang, L., Yao, T. D., Chai, C. H., Cuo, L., Su, F. G., Zhang, F., Yao, Z. J., Zhang, Y. S., Li, X. P., Qi, J., Hu, Z. D., Liu, J. S., \& Wang, Y. W. (2021). TP-River: Monitoring and Quantifying Total River Runoff from the Third Pole. Bull. Am. Meteorol. Soc., 102(5), E948-E965. doi:10.1175/bams-d-20-0207.1

Wang, L., Zhou, J., Qi, J., Sun, L., Yang, K., Tian, L., Lin, Y., Liu, W., Shrestha, M., Xue, Y., Koike, T., Ma, Y., Li, X., Chen, Y., Chen, D., Piao, S., \& Lu, H. (2017b). Development of a land surface model with coupled snow and frozen soil physics. Water Resour. Res., 53(6), 50855103. doi:10.1002/2017WR020451

Wang, Q., van der Velde, R., \& Su, Z. (2018). Use of a discrete electromagnetic model for simulating Aquarius L-band active/passive observations and soil moisture retrieval. Remote Sens. Environ., 205, 434-452. doi:10.1016/j.rse.2017.10.044

Wang, T., Ottlé, C., Boone, A., Ciais, P., Brun, E., Morin, S., Krinner, G., Piao, S., \& Peng, S. (2013). Evaluation of an improved intermediate complexity snow scheme in the ORCHIDEE land surface model. Journal of Geophysical Research Atmospheres, 118(12), 6064-6079. doi:10.1002/jgrd.50395

Wang, Y., Zeng, Y., Yu, L., Yang, P., Van Der Tol, C., Yu, Q., Lü, X., Cai, H., \& Su, Z. (2021). Integrated modeling of canopy photosynthesis, fluorescence, and the transfer of energy, mass, and momentum in the soil-plant-Atmosphere continuum (STEMMUS-SCOPE v1.0.0). Geoscientific Model Development, 14(3), 1379-1407. doi:10.5194/gmd-14-1379-2021

Wania, R., Ross, L., \& Prentice, I. C. (2009). Integrating peatlands and permafrost into a dynamic global vegetation model: 1 . Evaluation and sensitivity of physical land surface processes. Global Biogeochem. Cycles, 23(3). doi:10.1029/2008GB003412

Watanabe, K. (2008). Water and heat flow in a directionally frozen silty soil. paper presented at Proceedings of the third HYDRUS Workshop.

Watanabe, K., Kito, T., Wake, T., \& Sakai, M. (2011). Freezing experiments on unsaturated sand, loam and silt loam. Ann. Glaciol., 52(58), 37-43. doi:10.3189/172756411797252220

Watanabe, K., \& Wake, T. (2008). Hydraulic conductivity in frozen unsaturated soil, 1927-1932. Watson, F. G. R., Newman, W. B., Coughlan, J. C., \& Garrott, R. A. (2006). Testing a distributed snowpack simulation model against spatial observations. J. Hydrol., 328(3-4), 453-466. doi:10.1016/j.jhydrol.2005.12.012

Wicky, J., \& Hauck, C. (2017). Numerical modelling of convective heat transport by air flow in permafrost talus slopes. Cryosphere, 11(3), 1311-1325. doi:10.5194/tc-11-1311-2017

Wilson, K., Goldstein, A., Falge, E., Aubinet, M., Baldocchi, D., Berbigier, P., Bernhofer, C., Ceulemans, R., Dolman, H., Field, C., Grelle, A., Ibrom, A., Law, B. E., Kowalski, A., Meyers, T., Moncrieff, J., Monson, R., Oechel, W., Tenhunen, J., Valentini, R., \& Verma, S. (2002). Energy balance closure at FLUXNET sites. Agr. Forest Meteorol., 113(1-4), 223-243. doi:10.1016/S0168-1923(02)00109-0

Woo, M. (2012). Permafrost Hydrology, 519 pp., Springer-Verlag, Berlin.

Wutzler, T., Lucas-Moffat, A., Migliavacca, M., Knauer, J., Sickel, K., Šigut, L., Menzer, O., \& Reichstein, M. (2018). Basic and extensible post-processing of eddy covariance flux data with REddyProc. Biogeosciences, 15(16), 5015-5030. doi:10.5194/bg-15-5015-2018

Xie, H. Y., Jiang, X. W., Tan, S. C., Wan, L., Wang, X. S., Liang, S. H., \& Zeng, Y. (2021). Interaction of soil water and groundwater during the freezing-thawing cycle: field observations and numerical modeling. Hydrol. Earth Syst. Sci., 25(8), 4243-4257. doi:10.5194/hess-254243-2021

Xu, X., Huang, G., Zhan, H., Qu, Z., \& Huang, Q. (2012). Integration of SWAP and MODFLOW-2000 for modeling groundwater dynamics in shallow water table areas. J. Hydrol., 412-413, 170-181. doi:10.1016/j.jhydrol.2011.07.002

Yan, F., Shangguan, W., Zhang, J., \& Hu, B. (2020). Depth-to-bedrock map of China at a spatial resolution of 100 meters. Scientific Data, 7(1), 2. doi:10.1038/s41597-019-0345-6

Yang, K., Koike, T., Ishikawa, H., \& Ma, Y. (2004). Analysis of the surface energy budget at a site of GAME/Tibet using a single-source model. J. Meteorol. Soc. Jpn., 82(1), 131-153. doi:10.2151/jmsj.82.131

Yang, K., Qin, J., Zhao, L., Chen, Y., Tang, W., Han, M., Zhu, L., Chen, Z., Lv, N., Ding, B., $\mathrm{Wu}, \mathrm{H} .$, \& Lin, C. (2013). A multiscale soil moisture and freeze-thaw monitoring network on 
the third pole. Bull. Am. Meteorol. Soc., 94(12), 1907-1916. doi:10.1175/BAMs-d-12-00203.1 Yang, K., Wu, H., Qin, J., Lin, C., Tang, W., \& Chen, Y. (2014). Recent climate changes over the Tibetan Plateau and their impacts on energy and water cycle: A review. Global Planet. Change, 112, 79-91. doi:10.1016/j.gloplacha.2013.12.001

Yang, Z.-L., Dickinson, R. E., Robock, A., \& Vinnikov, K. Y. (1997). Validation of the Snow Submodel of the Biosphere-Atmosphere Transfer Scheme with Russian Snow Cover and Meteorological Observational Data. J. Clim., 10(2), 353-373. doi:10.1175/15200442(1997)010<0353:votsso >2.0.co;2

Yang, Z. L., and Coauthors (2011). The Community Noah Land Surface Model with MultiParameterization Options (Noah-MP), The University of Texas at Austin, Austin, TX, USA. Yao, T., Thompson, L. G., Mosbrugger, V., Zhang, F., Ma, Y., Luo, T., Xu, B., Yang, X., Joswiak, D. R., Wang, W., Joswiak, M. E., Devkota, L. P., Tayal, S., Jilani, R., \& Fayziev, R. (2012). Third Pole Environment (TPE). Environmental Development, 3, 52-64. doi:10.1016/j.envdev.2012.04.002

Yao, T., Xue, Y., Chen, D., Chen, F., Thompson, L., Cui, P., Koike, T., Lau, W. K. M., Lettenmaier, D., Mosbrugger, V., Zhang, R., Xu, B., Dozier, J., Gillespie, T., Gu, Y., Kang, S., Piao, S., Sugimoto, S., Ueno, K., Wang, L., Wang, W., Zhang, F., Sheng, Y., Guo, W., Ailikun, Yang, X., Ma, Y., Shen, S. S. P., Su, Z., Chen, F., Liang, S., Liu, Y., Singh, V. P., Yang, K., Yang, D., Zhao, X., Qian, Y., Zhang, Y., \& Li, Q. (2019). Recent third pole's rapid warming accompanies cryospheric melt and water cycle intensification and interactions between monsoon and environment: Multidisciplinary approach with observations, modeling, and analysis. Bull. Am. Meteorol. Soc., 100(3), 423-444. doi:10.1175/BAMS-D-17-0057.1

Yi, Y., Kimball, J. S., Rawlins, M. A., Moghaddam, M., \& Euskirchen, E. S. (2015). The role of snow cover affecting boreal-arctic soil freeze-thaw and carbon dynamics. Biogeosciences, 12(19), 5811-5829. doi:10.5194/bg-12-5811-2015

You, J., Tarboton, D. G., \& Luce, C. H. (2014). Modeling the snow surface temperature with a one-layer energy balance snowmelt model. Hydrol. Earth Syst. Sci., 18(12), 5061-5076. doi:10.5194/hess-18-5061-2014

Yu, L., Fatichi, S., Zeng, Y., \& Su, Z. (2020a). The role of vadose zone physics in the ecohydrological response of a Tibetan meadow to freeze-thaw cycles. The Cryosphere, 14(12), 4653-4673. doi: 10.5194/tc-14-4653-2020

Yu, L., Zeng, Y., \& Su, Z. (2020b). Understanding the mass, momentum, and energy transfer in the frozen soil with three levels of model complexities. Hydrol. Earth Syst. Sci., 24(10), 48134830. doi:10.5194/hess-24-4813-2020

Yu, L., Zeng, Y., Su, Z., Cai, H., \& Zheng, Z. (2016). The effect of different evapotranspiration methods on portraying soil water dynamics and ET partitioning in a semi-arid environment in Northwest China. Hydrol. Earth Syst. Sci., 20(3), 975-990. doi:10.5194/hess-20-975-2016

Yu, L., Zeng, Y., Wen, J., \& Su, Z. (2018). Liquid-Vapor-Air Flow in the Frozen Soil. Journal of Geophysical Research: Atmospheres, 123(14), 7393-7415. doi:10.1029/2018JD028502

Zeng, J., Yang, J., Zha, Y., \& Shi, L. (2019). Capturing soil-water and groundwater interactions with an iterative feedback coupling scheme: New HYDRUS package for MODFLOW. Hydrol. Earth Syst. Sci., 23(2), 637-655. doi:10.5194/hess-23-637-2019

Zeng Y. and Su Z. (2016). EC-Earth Development Plan over Tibetan Plateau, the Netherlands EC Earth Meeting, KNMI, De Bilt, Utrecht, the Netherlands, organizer: Bart van der Hurk, Wilco Hazeleger.

Zeng, Y., Su, Z., van der Velde, R., Wang, L., Xu, K., Wang, X., \& Wen, J. (2016). Blending Satellite Observed, Model Simulated, and in Situ Measured Soil Moisture over Tibetan Plateau. Remote Sensing, 8(3), 268. doi:10.3390/rs8030268

Zeng, Y., Su, Z., Wan, L., \& Wen, J. (2011a). Numerical analysis of air-water-heat flow in unsaturated soil: Is it necessary to consider airflow in land surface models? Journal of Geophysical Research: Atmospheres, 116(D20), D20107. doi:10.1029/2011JD015835

Zeng, Y., Su, Z., Wan, L., \& Wen, J. (2011b). A simulation analysis of the advective effect on evaporation using a two-phase heat and mass flow model. Water Resour. Res., 47(10), W10529. doi:10.1029/2011WR010701

Zeng, Y., Su, Z., Wan, L., Yang, Z., Zhang, T., Tian, H., Shi, X., Wang, X., \& Cao, W. (2009a). 
Diurnal pattern of the drying front in desert and its application for determining the effective infiltration. Hydrol. Earth Syst. Sci., 13(6), 703-714. doi:10.5194/hess-13-703-2009

Zeng, Y., Wan, L., Su, Z., Saito, H., Huang, K., \& Wang, X. (2009b). Diurnal soil water dynamics in the shallow vadose zone (field site of China University of Geosciences, China). Environ. Geol., 58(1), 11-23. doi:10.1007/s00254-008-1485-8

Zeng, Y. J., \& Su, Z. B. (2013). STEMMUS : Simultaneous Transfer of Engery, Mass and Momentum in Unsaturated Soil, University of Twente, Faculty of Geo-Information and Earth Observation (ITC), Enschede.

Zhang, G., Zhang, Y., Dong, J., \& Xiao, X. (2013). Green-up dates in the Tibetan Plateau have continuously advanced from 1982 to 2011. Proceedings of the National Academy of Sciences, 110(11), 4309-4314. doi:10.1073/pnas. 1210423110

Zhang, H., Hendricks Franssen, H. J., Han, X., Vrugt, J. A., \& Vereecken, H. (2017). State and parameter estimation of two land surface models using the ensemble Kalman filter and the particle filter. Hydrol. Earth Syst. Sci., 21(9), 4927-4958. doi:10.5194/hess-21-4927-2017

Zhang, M., Wen, Z., Xue, K., Chen, L., \& Li, D. (2016a). A coupled model for liquid water, water vapor and heat transport of saturated-unsaturated soil in cold regions: model formulation and verification. Environmental Earth Sciences, 75(8). doi:10.1007/s12665-016-5499-3

Zhang, P., Zheng, D., van der Velde, R., Wen, J., Zeng, Y., Wang, X., Wang, Z., Chen, J., \& Su, Z. (2021). Status of the Tibetan Plateau observatory (Tibet-Obs) and a 10-year (2009-2019) surface soil moisture dataset. Earth Syst. Sci. Data, 13(6), 3075-3102. doi:10.5194/essd-133075-2021

Zhang, S., Teng, J., He, Z., \& Sheng, D. (2016b). Importance of vapor flow in unsaturated freezing soil: A numerical study. Cold Regions Sci. Tech., 126, 1-9. doi:10.1016/j.coldregions.2016.02.011

Zhang, T. (2005). Influence of the seasonal snow cover on the ground thermal regime: An overview. Rev. Geophys., 43(4). doi:10.1029/2004rg000157

Zhang, W., Jansson, P. E., Schurgers, G., Hollesen, J., Lund, M., Abermann, J., \& Elberling, B. (2018). Process-Oriented Modeling of a High Arctic Tundra Ecosystem: Long-Term Carbon Budget and Ecosystem Responses to Interannual Variations of Climate. Journal of Geophysical Research: Biogeosciences, 123(4), 1178-1196. doi:10.1002/2017JG003956

Zhang, X., Sun, S. F., \& Xue, Y. (2007). Development and testing of a frozen soil parameterization for cold region studies. J. Hydrometeorol., 8(4), 690-701. doi:10.1175/JHM605.1

Zhang, Y., Carey, S. K., Quinton, W. L., Janowicz, J. R., Pomeroy, J. W., \& Flerchinger, G. N. (2010). Comparison of algorithms and parameterisations for infiltration into organic-covered permafrost soils. Hydrol. Earth Syst. Sci., 14(5), 729-750. doi:10.5194/hess-14-729-2010

Zhang, Y., Cheng, G., Li, X., Han, X., Wang, L., Li, H., Chang, X., \& Flerchinger, G. N. (2013). Coupling of a simultaneous heat and water model with a distributed hydrological model and evaluation of the combined model in a cold region watershed. Hydrol. Processes, 27(25), 37623776. doi:10.1002/hyp.9514

Zhao, H., Zeng, Y., Lv, S., \& Su, Z. (2018). Analysis of soil hydraulic and thermal properties for land surface modeling over the Tibetan Plateau. Earth System Science Data, 10(2), 10311061. doi:10.5194/essd-10-1031-2018

Zhao, H., Zeng, Y., Wen, J., Wang, X., Wang, Z., Meng, X., \& Su, Z. (2021). An Air-to-Soil Transition Model for Discrete Scattering-Emission Modelling at L-Band. Journal of Remote Sensing, 2021, 3962350. doi:10.34133/2021/3962350

Zhao, L., Hu, G., Zou, D., Wu, X., Ma, L., Sun, Z., Yuan, L., Zhou, H., \& Liu, S. (2019). Permafrost changes and its effects on hydrological processes on Qinghai-Tibet Plateau. Bulletin of Chinese Academy of Sciences, 34(11), 1233-1246.

Zhao, L., Li, J., Xu, S., Zhou, H., Li, Y., Gu, S., \& Zhao, X. (2010). Seasonal variations in carbon dioxide exchange in an alpine wetland meadow on the Qinghai-Tibetan Plateau. Biogeosciences, 7(4), 1207-1221. doi:10.5194/bg-7-1207-2010

Zhao, Y., Nishimura, T., Hill, R., \& Miyazaki, T. (2013). Determining hydraulic conductivity for air-filled porosity in an unsaturated frozen soil by the multistep outflow method. Vadose Zone J., 12(1). doi:10.2136/vzj2012.0061 
Zheng, D., Van Der Velde, R., Su, Z., Booij, M. J., \& Hoekstra, A. Y. (2014). Assessment of roughness length schemes implemented within the noah land surface model for high-altitude regions. J. Hydrometeorol., 15(3), 921-937. doi:10.1175/JHM-D-13-0102.1

Zheng, D., van der Velde, R., Su, Z., Wang, X., Wen, J., Booij, M. J., Hoekstra, A. Y., \& Chen, Y. (2015a). Augmentations to the Noah model physics for application to the Yellow River source area. Part I: Soil water flow. J. Hydrometeorol., 16(6), 2659-2676. doi:10.1175/JHM-D14-0198.1

Zheng, D., Van Der Velde, R., Su, Z., Wen, J., Booij, M. J., Hoekstra, A. Y., \& Wang, X. (2015b). Under-canopy turbulence and root water uptake of a Tibetan meadow ecosystem modeled by Noah-MP. Water Resour. Res., 51(7), 5735-5755. doi:10.1002/2015WR017115

Zheng, D., van der Velde, R., Su, Z., Wen, J., Wang, X., \& Yang, K. (2017). Evaluation of Noah frozen soil parameterization for application to a Tibetan meadow ecosystem. J. Hydrometeorol., 18(6), 1749-1763. doi:10.1175/JHM-D-16-0199.1

Zhou, X. (2014). Experimental and numerical study of coupled water and heat transport in the freezing ground, University of Zurich.

Zhu, Y., Shi, L., Lin, L., Yang, J., \& Ye, M. (2012). A fully coupled numerical modeling for regional unsaturated-saturated water flow. $J$. Hydrol., 475, 188-203. doi:10.1016/j.jhydrol.2012.09.048

Zhu, Y., Zha, Y. Y., Tong, J. X., \& Yang, J. Z. (2011). Method of coupling 1-D unsaturated flow with 3-D saturated flow on large scale. Water Science and Engineering, 4(4), 357-373. doi:10.3882/j.issn.1674-2370.2011.04.001

Zhuang, Q., Romanovsky, V. E., \& McGuire, A. D. (2001). Incorporation of a permafrost model into a large-scale ecosystem model: Evaluation of temporal and spatial scaling issues in simulating soil thermal dynamics. Journal of Geophysical Research Atmospheres, 106(D24), 33649-33670. doi:10.1029/2001JD900151

Zhuang, R., Zeng, Y., Manfreda, S., \& Su, Z. (2020). Quantifying Long-Term Land Surface and Root Zone Soil Moisture over Tibetan Plateau. Remote Sensing, 12(3), 509.

Zipper, S. C., Soylu, M. E., Kucharik, C. J., \& Loheide Ii, S. P. (2017). Quantifying indirect groundwater-mediated effects of urbanization on agroecosystem productivity using MODFLOW-AgroIBIS (MAGI), a complete critical zone model. Ecological Modelling, 359, 201-219. doi:10.1016/j.ecolmodel.2017.06.002 


\section{Summary}

Recent climate changes have accelerated the coupled water, heat, and carbon exchanges in cold regions, which can further exert the positive feedbacks to future climate changes, leading to the increasingly vulnerable ecosystem, warming climate, and unsustainable Earth system. This thesis is aiming to understand the underlying physics of water, heat, and carbon exchange processes and links it to the surface/subsurface hydrothermal, biogeochemical, ecohydrological regimes, with the focus on the freeze-thaw processes, snowpack associated processes, soil water and groundwater interactions, and cold region ecosystem functioning. This is accomplished by the advancement of integrated observation and numerical models, which are presented in the following chapters.

First, we present the first quantification of the role of vapor flow and airflow, and its interaction with soil ice in frozen soils using the developed STEMMUS-FT model, contributing a better understanding of the freeze-thaw processes (Chapter 3). From the confirmed modeling results against observations, it indicated that other than the liquid water fluxes, vapor flow also moves upward to the freezing front and can contribute about $6 \%-13 \%$ to the total water flux for the ice formation. In frozen soil region, it is the vapor flow rather than the liquid flow that contributes most to the total mass flux as the blocking effect of ice presence in soil pores. The diurnal cycle of soil moisture in the zone between the evaporation front and freezing front was found mainly due to the diurnal behavior of thermal vapor flux. Our results suggest that it is mainly the vapor flow that connects the water/vapor transfer beneath the freezing front (sink) and above the evaporation front (source). The air pressure-induced liquid/vapor advective fluxes make a negligible contribution to the total mass transfer. Nevertheless, the interactive effect of soil ice and air can be found on the spatial and temporal variation in advective fluxes in frozen soils.

Secondly, we translate the difference in soil physical processes into the modelling results of frozen soil hydrothermal regimes, contributing a better understanding of the relative role of different heat transport processes in frozen soils (Chapter 4). The complexity of the STEMMUS-FT varies from the basic coupled model (BCM) to the advanced coupled heat and mass transfer model (ACM), and, furthermore, to the explicit consideration of airflow (ACM-AIR). The physical consideration of vapor flow and thermal effect on water flow improved ACM in soil temperature simulations, with the former mainly functions at regions above the evaporative front, and the latter dominates below the evaporative front. Our results further confirmed that the relative importance of different heat transport processes varied over the time and space. The non-conductive heat processes (liquid/vapor/air-induced heat convection flux) contributed very minimal to the total energy fluxes during the frozen period except the latent heat flux divergence at the topsoil layers. The contribution of the airflow to the 
total mass and energy fluxes is negligible. However, the latent heat flux and its effect on heat transfer were enhanced by the airflow during the freezing-thawing transition period. It is suggested to consider the vapor flow, thermal effect on water flow, and airflow for better portraying the subsurface soil hydrothermal dynamics, especially during freezing-thawing transition periods.

Thirdly, we investigate the effect of snowpack on soil mass transfer considering the coupled soil water-heat-air transfer mechanisms for the first time and indicate the underlying physics for the enhanced LE after-winter precipitation events (Chapter 5). We incorporated the snowpack effect (Utah Energy Balance model, UEB) into a common modeling framework (STEMMUS-FT), that is, STEMMUS-UEB. Three complexity levels of soil physical processes were considered (from the basic coupled, to advanced coupled water and heat transfer, and further to the explicit consideration of airflow, termed $\mathrm{BCD}, \mathrm{ACD}$, and $\mathrm{ACD}-$ air). The $\mathrm{BCD}$ model cannot provide a realistic partition of soil mass transfer as the ACD model does. With the ACD-air model, the relative contribution of each flux component (mainly the isothermal liquid and vapor flow) was significantly altered during the soil thawing period. Compared to the models without considering the snowpack, there is an enhancement of LE observed after winter precipitation events using models considering the snowpack. Such an LE enhancement is sourced from the surface ice sublimation, snow sublimation, and the increased surface soil moisture with the relative contribution depends on the timing and magnitude of precipitation and the pre-precipitation soil hydrothermal regimes. It was found that the snowpack affects not only the soil surface moisture conditions (surface ice and soil liquid water content) and energy-related states (albedo, LE) but also the transfer patterns of subsurface soil liquid and vapor flow.

Fourthly, we built up the soil water-groundwater (SW-GW) coupling framework STEMMUS-MODFLOW, physically considering the heterogeneous water exchange between the SW-GW interface, and demonstrated its application in a cold region environment (Chapter 6). By the cross validation among the observations and various models, the STEMMUS-MODFLOW is demonstrated physically accurate and applicable in large scale groundwater problems. Compared to the HYDRUSMODFLOW, the STEMMUS-MODFLOW produces a similar spatial distribution of hydraulic heads while better performance in mimicking the temporal dynamics of groundwater table depth and soil moisture profiles, which is attributed to the two-way feedback SW-GW coupling scheme. The developed STEMMUS-MODFLOW model can be further equipped with different complexity of vadose zone physics (thermal flow, soil water and heat coupling transfer, freeze-thaw, airflow processes), surface hydrology (snowfall, runoff), soil and plant biogeochemical process, towards an integrated "from bedrock to atmosphere" Earth system modelling framework. 
Furthermore, the linkage between soil hydrothermal regimes and water and carbon cycle was elaborated on a cold region ecosystem (Chapter 7). The detailed vadose zone process model STEMMUS-FT was coupled with the ecohydrological model TethysChloris (T\&C) as an enhanced one. The results show that (i) explicitly considering the frozen soil process significantly improved the soil moisture and temperature profile simulations and facilitated our understanding of the water transfer processes within the soil-plant-atmosphere continuum; (ii) the difference in the soil hydrothermal regimes among various representations of vadose zone physics exert an impact on the vegetation dynamics mainly at the beginning of the growing season; and (iii) models with different vadose zone physics can predict similar interannual vegetation dynamics, as well as energy, water, and carbon exchanges, at the land surface. Our investigations using different models of vadose zone physics can be helpful to support the development and application of Earth system models as they suggest that a certain degree of complexity might be necessary for specific analyses.

This thesis highlights the needs to understand the water, heat, and carbon exchange processes across the different interfaces in an integrated and feedback coupling manner. Both the relevant observation and numerical modelling tools are required to reconcile and advance our understanding of the groundwater-soil-plant-atmosphere system at different temporal and spatial scales under current and future climate conditions. 


\section{Summary in Chinese}

气候变化加速了寒区生态系统水、热、碳交换过程的变化, 进而正反馈于当前 气候, 可能会引起生态系统愈发脆弱, 气候变暖加剧, 地球系统的不可持续发 展。本文旨在从理解寒区生态系统水、热、碳交换过程出发, 进一步联系且阐 释地表/地下水水热、生物化学和生态水文学状态变量发生的变化, 着重于理解 冻融过程, 雪盖相关的过程, 土壤水-地下水相互作用和寒区生态系统功能响应。 本文工作依赖于综合系统观测和数值模型的集成, 将在下面部分进行分别阐述。

首先, 我们利用自主开发的 STEMMUS-FT 模型首次量化了水汽、干空气流及其 与土壤冰的相互作用在冻土水热传输过程中的角色, 旨在更好地理解土壤冻融 过程 (第三章)。利用田间观测, 模型模拟结果得到验证, 进一步分析得知除 了液态水通量, 水汽也会向冻结峰运移并贡献了总水汽通量的 6-13\%。在冻结 区, 由于冰的存在引起的液态水流的阻碍作用, 液态水流对总体质量通量的贡 献显著低于水汽的贡献。在蒸发峰和冻结峰区间内的土壤含水量的日变化主要 是由于温度梯度引起的水汽通量的日变化过程。水汽流连通了从冻结峰（水汽 聚集区) 到蒸发峰 (水汽发散源区) 的水汽传输过程。空气压强引起的对流水 汽通量对总水汽质量传输的贡献很小。然而, 我们发现土壤冰和干空气的相互 作用会影响冻土中对流水汽通量的时空变化规律。

在第四章中, 我们阐述了土壤物理过程的差异是如何反映到冻土水热状态变量 模拟结果的不同的, 能够更好地理解冻土中不同热传输过程的角色。冻土模型 STEMMUS-FT 的复杂度从单一的水热耦合 (BCM), 到复杂紧密的水热耦合 (ACM)，再到明确的考虑了土壤干空气流（ACM-AIR）。ACM 中水汽和热 状态水流动影响的物理考虑明显改进了土壤温度的模拟结果, 前者主要是起作 用于蒸发峰以上区域, 而后者则主要作用于蒸发峰以下的区域。我们的结果证 实了不同热传输过程的相对重要程度是随时间空间而变化的。在冻结时期, 除 了上层土壤的潜热通量, 其它非传导性的热过程（液态水/水汽/干空气引起的热 对流通量）对总的能量通量贡献较小。干空气流对总的质量和能量通量的贡献 很小。然而, 在冻融过渡时期干空气流的存在增强了潜热通量及其对热传输过 程的影响。因而我们建议考虑水汽, 热状态对水流的作用和干空气流, 从而能 够更好地刻画土壤水热动态过程, 尤其是在冻结过渡时期。

在第五章中, 我们首次研究了雪盖对土壤水汽传输过程的影响（考虑土壤水热 和干空气耦合传输机制）并且揭示了冬季降水后地表潜热通量增强效应的机理。 我们将雪盖过程模型 UEB 加入到了通用的模型框架 STEMMUS-FT 中, 即 STEMMUS-UEB。其中土壤物理过程包含了三种不同的复杂度（从简单的水热 
耦合 $\mathrm{BCD}$, 到紧密的水热耦合传输 $\mathrm{ACD}$, 再到明确考虑了干空气流的 $\mathrm{ACD}$ air）。结果表明：BCD 模型不能像 $\mathrm{ACD}$ 和 ACD-air 模型那样合理地刻画土壤质 量传输的分摊过程。在土壤融化时期, 由于干空气流的存在, ACD-air模型中各 通量组分的相对贡献发生了显著的变化。对比未考虑雪盖过程的模型, 考虑了 雪盖过程的模型能够模拟潜热通量在冬季降水后的增强效应。地表潜热通量的 增加主要是由于陆地表面冰的升华, 雪盖的升华以及土壤表面湿度的增加, 这 三方面各自的贡献取决于降水的时间和量级以及降水前的土壤水热状态。研究 表明雪盖不仅会影响土壤表面的湿度条件（地表冰和土壤液态水含量）和能量 相关的状态变量（反射率和地表潜热通量）, 还能显著影响土壤水汽传输过程。

在第六章中, 我们构建了土壤水-地下水耦合模型框架 STEMMUS-MODFLOW, 能够考虑非饱和-饱和交界面水量交换的异质性, 并证实了该模型能够应用于寒 区流域。通过利用观测和不同数值模型的交叉验证, STEMMUS-MODFLOW 模 型证实是物理准确的且能够应用于大尺度地下水问题。相较于 HYDRUSMODFLOW 模型, STEMMUS-MODFLOW 模型可以模拟得到相似的地下水头 的空间分布, 然而能够更好地模拟地下水位的时间变化规律和土壤湿度剖面, 这主要是由于 STEMMUS-MODFLOW 模型采用了双向反馈的土壤水-地下水耦 合机制。STEMMUS-MODFLOW 模型具有很好的可拓展性, 能够添加上不同的 非饱和区土壤物理过程 (包括土壤热状态, 土壤水热耦合运移, 冻融和干空气 流等过程), 陆表水文学过程（雪盖和径流等）, 土壤和植物生物化学过程, 进而形成一个综合的涵盖从基岩到大气水热碳交换过程的地球系统模型框架。

在第七章中, 我们进一步阐释了寒区生态系统中土壤水热状态和水碳循环的联 系。我们将详细的包气带土壤物理过程模型 STEMMUS-FT 和生态水文过程模型 Tethys-Chloris (T\&C) 耦合。结果表明: 明确地考虑土壤冻融过程显著地改进 了土壤温湿度剖面的模拟, 并能有益于我们对土壤-植物-大气连续体中的水汽 传输过程的理解。模型中不同土壤物理过程的表达引起的土壤水热状态的模拟 差异会施加影响于植被的动态变化, 主要是在生长季节开始时期。在年际时间 尺度, 考虑不同土壤物理过程的模型给出了相似的年际植被动态变化和能量水 碳交换规律。总之, 我们需要一定程度的模型复杂度来应对具体问题的分析, 因此考虑不同土壤物理过程复杂度有助于地球系统模型的开发和应用。

本文强调需要以一种整体性且能考虑内部反馈耦合的方式来理解寒区生态系统 的水、热、碳交换过程。需要集合相关的观测和数值模拟工具来解决现有不一 致的认识从而提高我们对不同时间和空间尺度、当前和未来气候条件下的地下 水-土壤-植物-大气系统的刻画能力。 


\section{Samenvatting}

Recente klimaatverandering hebben de gekoppelde uitwisseling van water, warmte en koolstof in koude regio's versneld, wat verder een positieve feedback op toekomstige klimaatverandering kan hebben, en wat zal leiden tot steeds kwetsbaardere ecosystemen, verdere opwarmening van het klimaat en een niet-duurzaam systeem aarde. Dit proefschrift heeft tot doel de onderliggende fysica van water-, warmte- en koolstofuitwisselingsprocessen beter te begrijpen en deze te koppelen aan de oppervlakkige, ondergrondse hydrothermische, biogeochemische enecohydrologische regimes, met focus op vries-dooiprocessen, met sneeuw bedekte land, bodemwater en interacties met grondwater en het functioneren van ecosystemen in koude gebieden. Dit wordt bereikt door het verder onwikkelen en gebruik van geïntegreerde observatie- en numerieke modellen, die in de volgende hoofdstukken worden gepresenteerd en aangewend.

Eerst presenteren we een kwantificatie van de rol van waterdamp en luchttransport in de bodem, en de interactie ervan met bodemijs in bevroren bodems met behulp van het ontwikkelde STEMMUS-FT-model. Dit draagt bij aan een beter begrip van de vriesdooiprocessen (Hoofdstuk 3). Uit de vergelijking van model resultaten met waarnemingen bleek dat behalve de vloeibare waterfluxen, de waterdamp ook omhoog stroomt naar het vriesfront en ongeveer 6\%-13\% kan bijdragen aan de totale waterflux voor de ijsvorming. In gebieden met bevroren bodems is het eerder het damptransport dan de vloeistofbeweging die het meest bijdraagt aan de totale massaflux en als het blokkerende effect van de aanwezigheid van ijs in de bodemporiën. De dagelijkse cyclus van bodemvocht in de zone tussen het verdampingsfront en het vriesfront werd voornamelijk gevonden in het dagelijkse gedrag van thermische dampflux. Onze resultaten suggereren dat het vooral de dampstroom is die de water/damp-overdracht onder het vriesfront (sink) en boven het verdampingsfront (bron) verbindt. De door luchtdruk geïnduceerde advectieve vloeistof/damp fluxen leveren een verwaarloosbare bijdrage aan de totale massaoverdracht. Niettemin kan een interactie van bodemijs en lucht worden beschreven bij analyze van de ruimtelijke en temporele variatie in advectieve fluxen in bevroren bodems.

In tweede instantie hebben we de verschillen in bodemfysische processen vertaald middels het modelleren van hydrothermische regimes in bevroren bodems, wat bijdraagt aan een beter begrip van de relatieve rol van verschillende warmtetransportprocessen in bevroren bodems (Hoofdstuk 4). De complexiteit van het STEMMUS-FT model varieert van het standaard gekoppelde model (BCM) tot het meer geavanceerde gekoppelde warmte- en massaoverdrachtsmodel (ACM), en bovendien met expliciete beschrijving van de luchtstroom (ACM-AIR). De fysieke beschrijving van de dampstroom en het thermisch effect op de waterstroom verbeterde 
ACM in bodemtemperatuursimulaties, waarbij de eerste voornamelijk functioneert in gebieden boven het verdampingsfront, en de laatste domineert onder het verdampingsfront. Onze resultaten bevestigden verder dat het relatieve belang van verschillende warmtetransportprocessen varieerde in tijd en ruimte. De niet-geleidende warmteprocessen (vloeistof/damp/lucht-geïnduceerde warmteconvectieflux) droegen zeer minimaal bij aan de totale energiefluxen tijdens de bevroren periode, behalve de latente warmtefluxdivergentie bij de bovengrondlagen. De bijdrage van de luchtstroom aan de totale massa- en energiefluxen is verwaarloosbaar. De latente warmteflux (LE) en het effect ervan op de warmteoverdracht werden echter versterkt door de luchtstroom tijdens de overgangsperiode van bevriezen naar ontdooien. Er wordt voorgesteld om de dampstroom, het thermische effect op de waterstroom en de luchtstroom in overweging te nemen om de hydrothermische dynamiek van de ondergrond beter in beeld te brengen, vooral tijdens de overgangsperioden van vriezen en ontdooien.

Ten derde onderzochten we voor de eerste keer het effect van een sneeuwlaag op de massaoverdracht in de bodem, rekening houdend met de gekoppelde mechanismen voor overdracht van water-warmte-lucht in de bodem, en leiden we ook de onderliggende fysica af voor de verhoogde LE na neerslag in de winter (Hoofdstuk 5). We hebben het "snowpack-effect" (Utah Energy Balance-model, UEB) opgenomen in een gemeenschappelijk modelleringskader (STEMMUS-FT), dat wil zeggen STEMMUS-UEB. Er werden drie complexiteitsniveaus van bodemfysische processen geimplementeerd (van de basis gekoppelde tot geavanceerde gekoppelde water- en warmteoverdracht, en verder met expliciete beschrijving van de luchtstroom, BCD, ACD en ACD-lucht genoemd). Het BCD-model kan geen realistische verdeling van massaoverdracht in de bodem bieden zoals het ACD-model wel doet. Met het ACDluchtmodel was de relatieve bijdrage van elke fluxcomponent (voornamelijk de isothermische vloeistof- en dampstroom) significant veranderd tijdens de ontdooiperiode van de grond. Vergeleken met de modellen die geen rekening houden met het sneeuwdek, is er een verbetering van LE waargenomen na winterse neerslaggebeurtenissen met behulp van modellen die rekening houden met het sneeuwdek. Een dergelijke LE-verbetering is afkomstig van de sublimatie van oppervlakte-ijs, sublimatie van sneeuw en het verhoogde bodemvocht aan de oppervlakte, waarbij de relatieve bijdrage afhangt van de timing en omvang van de neerslag en de hydrothermische regimes van de bodem voor de precipitatie. Het bleek dat het sneeuwdek niet alleen de vochtcondities van het bodemoppervlak (oppervlakteijs en bodemvloeistofwatergehalte) en energiegerelateerde toestanden (albedo, LE) beïnvloedde, maar ook de overdrachtspatronen van ondergrondse bodemvloeistof- en dampstroom.

Ten vierde hebben we een koppelingsraamwerk voor bodemwater - grondwater (SWGW) STEMMUS-MODFLOW gebouwd, waarbij we de heterogene wateruitwisseling 
in de SW-GW- koppeling fysiek in overweging hebben genomen, en de toepassing ervan in een koude regio hebben gedemonstreerd (Hoofdstuk 6). Door een kruisvalidatie tussen de waarnemingen en verschillende modellen, kon de fysiek nauwkeurigheid van STEMMUS-MODFLOW aangetoond worden en ook de toepasbaarheid voor grootschalige grondwaterproblemen. Vergeleken met de HYDRUS-MODFLOW produceert de STEMMUS-MODFLOW een vergelijkbare ruimtelijke verdeling van hydraulische potentiaal, terwijl het betere prestaties levert bij het nabootsen van de temporele dynamiek van de grondwatertafeldiepte en bodemvochtprofielen. Dit kan worden toegeschreven aan het SW-GWkoppelingsschema met tweerichtingsfeedback. Het ontwikkelde STEMMUSMODFLOW-model kan verder worden uitgerust met verschillende complexiteiten van vadose-zone fysica (thermische stroming, bodemwater- en warmtekoppelingsoverdracht, vries-dooi, luchtstroomprocessen), oppervlaktehydrologie (sneeuwval, afvoer), bodem- en plantbiogeochemische processen, naar een geïntegreerd "van gesteente tot atmosfeer" modelleringskader voor aardse systemen.

Verder werd de koppeling tussen hydrothermale bodemregimes en de water- en koolstofcyclus bestudeerd in een ecosysteem van een koude regio (Hoofdstuk 7). Het gedetailleerde procesmodel voor de vadose zone STEMMUS-FT werd als een verbeterd model gekoppeld aan het ecohydrologische model Tethys-Chloris (T\&C). De resultaten laten zien dat (i) het expliciet beschouwen van bevroren bodemprocessen de simulaties van bodemvocht- en temperatuurprofiel aanzienlijk verbeterde en ons begrip van de wateroverdrachtsprocessen binnen het continuüm bodem-plant-atmosfeer uitbreidde; (ii) het verschil in de hydrothermische regimes van de bodem tussen verschillende representaties van de vadose-zone fysica heeft vooral aan het begin van het groeiseizoen invloed op de vegetatiedynamiek; en (iii) modellen met verschillende vadose-zone fysica kunnen vergelijkbare meerjarige vegetatiedynamieken voorspellen, evenals energie-, water- en koolstofuitwisselingen aan het landoppervlak. Onze onderzoeken met behulp van verschillende modellen van vadose-zone fysica kunnen nuttig zijn om de ontwikkeling en toepassing van "systeem aarde"modellen te ondersteunen, omdat ze suggereren dat een zekere mate van complexiteit noodzakelijkis voor specifieke analyses.

Dit proefschrift benadrukt de noodzaak om de water-, warmte- en koolstofuitwisselingsprocessen en de verschillende koppelingen op een geïntegreerde en inclusief feedback mechanismen beter te begrijpen. Zowel relevante aardobservatie als numerieke modelleringstools zijn nodig om ons begrip van het grondwater-bodemplant-atmosfeersysteem op verschillende temporele en ruimtelijke schalen onder huidige en toekomstige klimaatomstandigheden te bevorderen. 